\title{
As doações Nelson Rockefeller no acervo do Museu de Arte Contemporânea da Universidade de São Paulo
}

\author{
Dissertação apresentada ao Programa de Pós- \\ Graduação Interunidades em Estética e História da \\ Arte da Universidade de São Paulo para obtenção \\ do título de mestre em Estética e História da Arte \\ Linha de Pesquisa: Teoria e Crítica de Arte \\ Orientação: Profa. Dra Ana Gonçalves Magalhães
}

São Paulo

2015 
Autorizo a reprodução e divulgação parcial deste trabalho, por qualquer meio convencional ou eletrônico, para fins de estudo e pesquisa, desde que citada a fonte. As imagens contidas neste trabalho não podem ser reproduzidas sem autorização de seus autores ou arquivos responsáveis por seus direitos autorais.

Toledo, Carolina Rossetti de

As doações Nelson Rockefeller no acervo do Museu de Arte Contemporânea da Universidade de São Paulo / Carolina Rossetti de Toledo: orientadora Ana Gonçalves Magalhães. São Paulo, 2015.

$207 \mathrm{f}$ :il.

Tese (Mestrado) - Universidade de São Paulo, 2015.

1. Doações Nelson Rockefeller. 2. Museu de Arte Moderna de São Paulo. 3. Museu de Arte Contemporânea da Universidade de São Paulo 
Nome: TOLEDO, Carolina Rossetti de

Título: As doações Nelson Rockefeller no acervo do Museu de Arte Contemporânea da Universidade de São Paulo

\author{
Dissertação apresentada ao Programa de \\ Pós-Graduação Interunidades em Estética e \\ História da Arte da Universidade de São \\ Paulo para obtenção do título de mestre em \\ Estética e História da Arte
}

Aprovado em:

\title{
Banca Examinadora
}

Prof. Dr. Tadeu Chiarelli

Julgamento:

Profa. Dra. Helouise Costa

Paulo

Julgamento:
Instituição: Universidade de São Paulo Assinatura:

Instituição: Universidade de São

Assinatura: 
Para Dilce, Peter e Heitor. 


\section{Lista de abreviações}

MAM-SP Museu de Arte Moderna de São Paulo

MAM-RJ Museu de Arte Moderna do Rio de Janeiro

MASP Museu de Arte de São Paulo Assis Chateaubriand

MAC USP Museu de Arte Contemporânea da Universidade de São Paulo

IAB Instituto de Arquitetos do Brasil

MoMA Museu de Arte Moderna, Nova York

CIAA Coordinator of Inter-American Affairs

FAP Federal Art Project

AAA Associated American Artists

AIA Associação Internacional Norte-americana para o Desenvolvimento Econômico e Social SPHAN Serviço do Patrimônio Histórico e Artístico Nacional 


\section{Agradecimentos}

Este trabalho surge da inspiração e generosa orientação de Ana Gonçalves Magalhães, professora e curadora do Museu de Arte Contemporânea da USP, cuja própria pesquisa a respeito das coleções Ciccillo Matarazzo e Yolanda Penteado apontou para a necessidade de um estudo mais aprofundado sobre as doações Nelson Rockefeller no antigo MAM-SP.

Agradeço também aos membros da banca examinadora, professor Tadeu Chiarelli e Helouise Costa, pela dedicação na revisão desta tese.

A pesquisa teria sido impossível não fosse o trabalho de inúmeros arquivistas, curadores e bibliotecários dos acervos consultados. Em particular, gostaria de agradecer o apoio de Fernando Piola e Michelle Alencar, do arquivo do Museu de Arte Contemporânea da USP; Lauci Bortoluci, do serviço de bibliotecas do MAC USP; Amy Fitch, interlocutora constante no Rockefeller Archive Center; Elisabeth Thomas e toda a equipe de assistentes no Arquivo do MoMA em Nova York; James J. Koop, curador associado do Museu de Arte da Universidade de Princeton; Calvin Browne, curador assistente do Departamento de Gravuras e Desenhos do Museu de Arte da Universidade de Princeton; Ana Paula Marques, pesquisadora do Arquivo Wanda Svevo da Fundação Bienal; Margareth Zoller, do serviço de referências do Smithsonian Archives of American Art, pelo envio da documentação de microfilmes ao Brasil.

Gostaria também de agradecer a professora assistente da Universidade de Princeton, Irene Small, que serviu como interlocutora e possibilitou o intercâmbio de pesquisa. E os financiadores da Bolsa Santander de Mobilidade Internacional, apoio financeiro que permitiu o deslocamento até os arquivos norte-americanos e viabilizou a conclusão deste estudo. 


\section{Resumo}

TOLEDO, Carolina Rossetti de. As doações Nelson Rockefeller no acervo do Museu de Arte Contemporânea da Universidade de São Paulo. 2015. 313 p. Tese (Mestrado) - Programa de Pós-Graduação Interunidades em Estética e História da Arte, Universidade de São Paulo.

Esse trabalho investiga a importância das duas doações Nelson Rockefeller (1946 e 1950) na formação do acervo histórico do antigo Museu de Arte Moderna de São Paulo. A pesquisa demonstra como a doação fez parte de uma estratégia mais ampla para aproximar os Estados Unidos e o Brasil no Pós-Guerra por meio de iniciativas no campo das artes. Essa pesquisa traça um panorama do papel de Rockefeller como articulador da política cultural norte-americana e detalha o envolvimento de funcionários do MoMA (René d'Harnoncourt) e seus curadores (Alfred Barr, Dorothy Miller e William Lieberman) na realização das doações. O objetivo central do estudo é tentar dar conta da relevância e singularidade de um conjunto de obras, atualmente no acervo do Museu de Arte Contemporânea da Universidade de São Paulo, que permanece pouco estudado por especialistas e amplamente desconhecido pelo público.

Palavras-chave: Doações Nelson Rockefeller, Museu de Arte Moderna de São Paulo, Museu de Arte Contemporânea da Universidade de São Paulo

\section{Abstract}

TOLEDO, Carolina Rossetti de. The Nelson Rockefeller donations from the collection of the Museum of Contemporary Art of the University of São Paulo. 313p. Thesis (Masters Degree) Interdepartmental Graduate Program in Aesthetics and Art History, University of Sao Paulo.

This research analyzes the role of the Nelson Rockefeller donations (1946 and 1950) in the formation of the first collection of the Museum of Modern Art Sao Paulo. This study demonstrates how the donations were part of a broader strategy to bring United States and Brazil closer together through artistic initiatives during the Post-war period. This research gives a brief overview of the role of Nelson Rockefeller as articulator of the American cultural policy and details the involvement do MoMA employees (René d'Harnoncourt) and curators (Alfred Barr, Dorothy Miller and William Lieberman) in the donations. The main purpose of this work is to shed to light over a unique collection, currently part of Museum of Contemporary Art of the University of Sao Paulo that has remained ignored by specialists and unknown by the public.

Keywords: Nelson Rockefeller art donations, Museum of Modern Art of São Paulo, Museum of Contemporary Art of the University of São Paulo. 


\section{Lista de tabelas}

[Tab. 1] - Gravuras da doação Rockefeller expostas em mostras do MoMA e do Brooklyn Museum.

[Tab. 2] - Galerias de Nova York que intermediaram a venda das obras da doação Rockefeller.

[Tab. 3] - Presença dos artistas das doações Rockefeller nas Bienais de São Paulo (1951-1959).

\section{Lista de mapas}

[Map. 1] - Mapa das galerias de Nova York que intermediaram a venda das obras da doação Rockefeller.

\section{Lista de imagens}

\section{CAPÍTULO 1}

[Fig.1 /Abertura] - Retrato de Nelson Rockefeller em Schiphol, Holanda, 21/08/1959. Dutch National Archives (Open Data Project). Nationaal Archief, Den Haag, Rijksfotoarchief: Fotocollectie Algemeen Nederlands Fotopersbureau (ANEFO), 1945-1989. Fonte: Banco de dados de uso livre Wikimages.

[Fig.2] - Recorte da capa do jornal Folha da Noite, de 16 de novembro de 1946. Fonte: Acervo Grupo Folha.

[Fig.3] - Composição de retratos de Francisco Matarazzo Sobrinho (Fonte: Folhapress); Sérgio Milliet

(Fonte: Folhapress); Eduardo Kneese de Mello (Fonte: Divulgação/ Colégio dos Arquitetos) e Carleton Sprague Smith (Fonte: Divulgação / Biblioteca Pública de Nova York).

[Fig.4] - Exposição da coleção da Seção de Arte da Biblioteca Municipal de São Paulo, s/d. Crédito: Peter Scheier. Fonte: apud NASCIMENTO, 2011, p.78.

[Fig.5] - Fotografia da assinatura do termo de cooperação entre o MAM e o MoMA com Ciccillo Matarazzo, René D’Harnoncourt, Yolanda Penteado e Nelson Rockefeller. Fonte: Folhapress. 
[Fig.6] - Composição de fotos com capa da revista En Guardia publicada pelo CIAA; e cartazes vencedores do prêmio de 3ㅇ lugar na competição One united hemisphere [Um hemisfério unido] do MoMA, em junho de 1942. Da esq. para a dir. obras de John Armory Gibbs (Nova York), Ary Fagundes e Benjamin Araújo Carvalho (Rio de Janeiro). Fonte: Arquivo do Museu de Arte Moderna de Nova York.

[Fig.7] - Capa dos catálogos do MoMA Road to victory [Caminho da vitória] e Objects in wartime [Objetos em tempo de guerra]. Fonte: Arquivo do Museu de Arte Moderna de Nova York.

[Fig. 8 e 9] - Fotografias da série Faces and places of Brazil [Faces e lugares do Brasil], de Genevieve Naylor, em exibição no MoMA em 1943. Fonte: Reznikoff Artististc Partnership / Cortesia de Peter Reznikoff.

[Fig. 10] - Capa do catálogo de Brazil builds. Fonte: Arquivo do Museu de Arte Moderna de Nova York.

[Fig.11] - Reprodução do capítulo sobre o Brasil no catálogo The Latin-American collection of the Museum of Modern Art, 1943. Fonte: Arquivo do Museu de Arte Moderna de Nova York.

[Fig.12] - Alfred Barr (segundo da dir. a esq.) e a primeira equipe do MoMA, 1929. Fonte: Arquivo do Museu de Arte Moderna de Nova York.

[Fig.13] - Fotografia de René d'Harnoncourt (dir.) na I Bienal de São Paulo (1951). Crédito: Peter Scheier. Fonte: Arquivo Histórico Wanda Svevo / Fundação Bienal de São Paulo.

\section{CAPÍTULO 2}

[Fig.14] - Mosaico com obras da doação Nelson Rockefeller de 1946. Fonte: Acervo do Museu de Arte Contemporânea da Universidade de São Paulo. Design gráfico: Renan França.

[Fig. 15] - Foto de Alfred Barr. Fonte: ArtBru Akamedie Austria website/ Wikimages. Foto de Dorothy Miller. Recorte de foto de Louise Nevelson, Alberto Giacometti e Dorothy Miller no Pavilhão ameriano da Bienal de Veneza, onde Miller estava instalando o trabalho de Nevelson em 1962. Crédito: Maryette 
Charlton, 1962. Fonte: Maryette Charlton Papers. Cortesia do Archives of American Art, Smithsonian Institution.

[Fig. 16] - Reprodução da capa do catálogo da exposição Americans 1942 [Americanos 1942]. Fonte: Arquivo do Museu de Arte Moderna de Nova York.

[Fig.17] - Morris Graves. In the night [Na noite] (1943), têmpera sobre papel, 58,5 X 76,4 cm - Doação MAM-SP. Fonte: Acervo do Museu de Arte Contemporânea da Universidade de São Paulo

[Fig.18] - Foto de Morris Graves, 1938. Crédito: Robert Bruce Inverarity. Fonte: Cortesia do Archives of American Art, Smithsonian Institution.

[Fig.19] - Morris Graves. Winter bouquet [Ramalhete de inverno] (1943), óleo sobre eucatex, 122,1 X 67,8 cm - Doação MAMSP. Fonte: Acervo do Museu de Arte Contemporânea da Universidade de São Paulo.

[Fig.20] - Everett Spruce. Antelope mountain [Montanha antílope] (1946), óleo sobre tela, 61,3 X 76,5 cm - Doação MAMSP. Fonte: Acervo do Museu de Arte Contemporânea da Universidade de São Paulo.

[Fig.21] - Caderno de desenhos de Everett Spruce com estudos preparatórios de Antelope Mountain [Montanha antílope] e outras formações rochosas texanas. Fonte: Cortesia da Bywaters Special Collections da Southern Methodist University, Dallas, Texas.

[Fig.22] - Byron Browne. Women of the circus [Mulher de circo] (1946), óleo sobre tela, 127,1 X 101,5 cm - Doação MAMSP. Fonte: Acervo do Museu de Arte Contemporânea da Universidade de São Paulo.

[Fig.23] - Foto de Byron Browne, 1959. Fotógrafo desconhecido. Fonte: Byron Browne Papers. Cortesia do Archives of American Art, Smithsonian Institution.

[Fig.24] - Reprodução de catálogo de Byron Browne da Kootz Gallery. Sam Kootz Papers. Fonte: Archives of American Art, Smithsonian Institution. 
[Fig.25] - Robert Gwathmey. Standard bearer [Porta-estandarte] (1946), óleo sobre tela, 86,5 X 61,6 cm - Doação MAMSP. Fonte: Acervo do Museu de Arte Contemporânea da Universidade de São Paulo.

[Fig.26] - Robert Gwathmey. Desenho preparatório para Standard bearer (Senator) [Porta-estandarte (Senador)], s/d, lápis. Fonte: Stephens, Inc., Investment Bankers, Little Rock, apud KAMMEN, 1999.

[Fig.27] - Robert Gwathmey. Study for Standard bearer (Senator) [Estudo para porta-Estandarte (Senador)], ca. 1946. Grafite sobre papel laminado com cartão $38.7 \times 23.5 \mathrm{~cm}$. Fonte: Museu de Arte da Universidade de Princeton, NJ.

[Fig.28] - Robert Gwathmey. Poll tax country (1945), óleo sobre tela. Fonte: Museu Hirshhorn, Smithsonian Institution, Washington, D.C.

[Fig.29] - Obras de Robert Gwathmey apresentadas na I Bienal de São Paulo: Tobacco farmers [Plantações de fumo], serigrafia, 34,3 X 128, $3 \mathrm{~cm}$ (1947), Topping tobacco [Colhendo fumo], serigrafia, 33,7 X22,2 cm (1947) e Ring around a rosy [Anel à volta da rosa] (1949), serigrafia, 32, 4 X 40 cm. Fonte: Paramour Fine Arts.

[Fig.30] - Jacob Lawrence. Lecture on architecture [Aula de arquitetura] (1946), aquarela sobre papel, 55,4 X 76,4 cm - Doação MAMSP. Fonte: Acervo do Museu de Arte Contemporânea da Universidade de São Paulo.

[Fig.31] - Jacob e Gwen Knight Lawrence entre os artistas e professores do instituto de arte do Black Mountain College no verão de 1946. Fonte: Western Regional Archives/ State Archives of North Carolina.

[Fig.32] - Alexander Calder. Yellow plane [Plano amarelo ou Móbile amarelo, preto, vermelho e branco], sem data, metal pintado, $93 \times 130 \times 125 \mathrm{~cm}$ - Doação MAMSP. Fonte: Acervo do Museu de Arte Contemporânea da Universidade de São Paulo.

[Fig.33] - Bardi exibe a escultura Brazilian fish [Peixe brasileiro] na exposição de Alexander Calder no Masp. Ao fundo, está exposta a escultura Yellow plane [Plano amarelo ou Móbile amarelo, preto, 
vermelho e branco]. Fonte: Biblioteca e Centro de Documentação do Museu de Arte de São Paulo Assis Chateaubriand apud SARAIVA, 2006.

[Fig.34] - Imagem de Yellow plane [Plano amarelo ou Móbile amarelo, preto, vermelho e branco] na exposição inaugural do MAM, Do figurativismo ao abstracionismo. Fonte: Arquivo Histórico Wanda Svevo / Fundação Bienal de São Paulo.

[Fig. 35] - Sala dedicada ao escultor Alexander Calder na II Bienal de São Paulo (1953). Crédito: Autor não identificado. Fonte: Arquivo Histórico Wanda Svevo / Fundação Bienal de São Paulo.

[Fig.36] - Arthur Osver. Forest of chimneys [Floresta de chaminés] (1945), óleo sobre tela. Fonte: Acervo do Museu de Arte Contemporânea da Universidade de São Paulo.

[Fig.37] - Fotografia de Ernestine Vetsburg e Arthur Osver. Imagem retirada de documentário da Lo-fi Saint Louis sobre Ernestive Vetsburg e Arthur Osver. Fonte: http://blip.tv/lofistl/arthur-osver-andernestine-betsberg-2228740

[Fig.38] - Melancholy on a rooftop [Melancolia no telhado] (1942), óleo sobre tela, 121.9 X $61 \mathrm{~cm}$. Fonte: Museum of Modern Art, Nova York.

[Fig.39] - Red ventilator [Ventilador vermelho] (1945), óleo sobre compensado, 73.8 x $60.9 \mathrm{~cm}$. Fonte: The John and Susan Horseman Collection.

[Fig. 40] - Cumuli [Cúmulo] (1991), técnica mista sobre tela, 157,5 X 99 cm. Fonte: Acervo da Philip Slein Gallery, St. Louis.

[Fig.41] - Souvenir [Suvenir](1992), óleo sobre tela, 166,8 X $180 \mathrm{~cm}$. Fonte: Acervo da Philip Slein Gallery, St. Louis.

[Fig.42] - Foto de grupo da exposição Artists in exile [Artistas no exílio] da galeria Pierre Matisse, Nova York. Crédito: George Platt Lynes. Fonte: Arquivo do Museu de Arte Moderna de Nova York. 
[Fig.43] - Marc Chagall. Spring [Primavera] (1938), aquarela e pastel sobre cartolina sobre papelão, 64 X 48,3 cm - Doação MAMSP. Fonte: Acervo do Museu de Arte Contemporânea da Universidade de São Paulo.

[Fig.44] - Capa do terceiro volume da revista Verve (1938), assinada por Pierre Bonnard. Fonte: Biblioteca Pública de Nova York.

[Fig.45] - Winter [Inverno] de Paul Klee, obra publicada na revista no terceiro volume da Verve (1938). Fonte: Biblioteca Pública de Nova York.

[Fig.46] - Summer [Verão] de Joan Miró, obra publicada na revista no terceiro volume da Verve (1938). Fonte: Biblioteca Pública de Nova York.

[Fig.47] - Autumn [Outono] de Abraham Rattner, obra publicada na revista no terceiro volume da Verve (1938). Fonte: Biblioteca Pública de Nova York.

[Fig.48] - André Masson. Germination [Germinação] (1942), 51,3 X 66,5 cm - Doação MAMSP. Fonte: Acervo do Museu de Arte Contemporânea da Universidade de São Paulo.

[Fig.49] - André Masson. Meditation upon an oak leaf [Meditação em uma folha de carvalho] (1942). Fonte: Coleção do Museum of Modern Art, Nova York.

[Fig.50] - André Masson. The armor [A armadura] (1935), óleo sobre tela, 80.6 X 54 cm. Fonte: Fundação Solomon R. Guggenheim, Coleção Peggy Guggenheim, Veneza.

[Fig.51] - Max Ernst. Picture for Young People [Quadro para jovens] (1943), óleo sobre tela, 60,2 X 75,5 cm - Doação MAMSP. Fonte: Acervo do Museu de Arte Contemporânea da Universidade de São Paulo.

[Fig.52] - Max Ernst. Vox angelica (1943). Fonte: Website Albertina Museum

[Fig.53] - Max Ernst. Painting for young people [Quadro para jovens] (1943). Fonte: Wikiart. 
[Fig.54] - Max Ernst. Painting for young people [Quadro para jovens] (1943). Coleção Samling Ulla \& Heiner Pietzsch, Berlim. Fonte: Staatliche Museen zu Berli.

[Fig.55] - Max Ernst. Bryce canion translation (1946), óleo sobre tela, 51 X $41 \mathrm{~cm}$. Fonte: Acervo do Museu de Arte de São Paulo Assis Chateaubriand.

[Fig.56] - Max Ernst. The forest [A floresta] (1927-1928), óleo sobre tela, 96.3 X $129.5 \mathrm{~cm}$. Fonte: Fundação Solomon R. Guggenheim, Coleção Peggy Guggenheim, Veneza.

[Fig.57] - Fernand Léger, Composition [Composição] (1938), óleo sobre tela, 60,2 X 75,5 cm. Fonte: Acervo do Museu de Arte Contemporânea da Universidade de São Paulo.

[Fig.58] - Fotografia do apartamento de Nelson Rockefeller com visão do mural de Fernand Léger realizado em 1938 e do retrato Women with a book [Mulher com livro] (1923). Fonte: Website The Art of the Room.

[Fig.59] - Vista oposta do apartamento de Nelson Rockefeller com mural pintado por Henri Matisse. Fonte: Website The Art of the Room.

[Fig.60] - Casa de campo de Nelson Rockefeller projetada por Wally Harrison em Pocantico Hills. Fonte: Website The Art of the Room.

[Fig. 61] - Fernand Léger O vaso azul (1948), óleo sobre tela; 73,3 x 92,4 cm. Fonte: Acervo do Museu de Arte Contemporânea da Universidade de São Paulo.

[Fig.62] - Fernand Léger. Composition [Composição] (1936). Fonte: Acervo do Museu de Arte Contemporânea da Universidade de São Paulo.

[Fig.63] - Fernand Léger. Study for cinematic mural, study III [Estudo para mural cinemático, estudo III] (1938-1939). Fonte: Acervo do Museum of Modern Art, Nova York. 
[Fig. 64] - George Grosz. Bestiality marches on [Bestialidade avança] (1933), aquarela sobre papel, 66,5 X 48,3 cm. Fonte: Acervo do Museu de Arte Contemporânea da Universidade de São Paulo.

[Fig. 65] - George Grosz. Schönheit, dich will ich preisen (1923), aquarela III no livro Ecce Homo. Fonte: Museum Kunstpalast Düsseldorf.

[Fig. 66] - George Grosz. After the questioning [Depois do interrogatório] (1935), aquarela sobre papel, 44.5 X 58,5 cm. Coleção particular. Fonte: apud JUDIN, 2009, p.79.

[Fig. 67] - Lasar Segall. Guerra (1942). Fonte: Acervo do Museu de Arte de São Paulo Assis Chateubriand.

[Fig. 68] George Grosz. A piece of my world II (The last battalion) [Um pedaço do meu mundo II (o último batalhão)] (1938), óleo sobre tela, $100 \times 140,3 \mathrm{~cm}$.

\section{CAPÍTULO 3}

[Fig.69] - Stanley William Hayter. Tarantelle [Tarantela] (1943), verniz mole e buril em cores sobre papel, 55,2 X $33 \mathrm{~cm}$. Fonte: Acervo do Museu de Arte Contemporânea da Universidade de São Paulo.

[Fig.70 e 71] - Imagens da exposição Gravadores Norte-Americanos do MAM, 1951. Fonte: Rockefeller Archive Center.

[Fig.72] - Capa do catálogo da exposição Gravadores norte-americanos do MAM, 1951. Fonte: Rockefeller Archive Center.

[Fig.73] - Vista da exposição Master prints do MoMA, 1949. Fonte: Arquivo do Museu de Arte Moderna de Nova York.

[Fig.74] - Capa do MoMA bulletin 1944. Fonte: Arquivo do Museu de Arte Moderna de Nova York.

[Fig.75] - Imagem do Atelier 17. Fonte: apud HAYTER, 1962. 
[Fig.76] - Stanley William Hayter. Tarantelle [Tarantela] (1943), verniz mole e buril em cores sobre papel, 55,2 X $33 \mathrm{~cm}$. Fonte: Acervo do Museu de Arte Contemporânea da Universidade de São Paulo.

[Fig.77] - Fred Becker. Aerial jungle IV [Floresta aérea IV] (1948), água forte, água-tinta e ponta seca em cores sobre papel, 44,8 X 30,3 cm. Fonte: Acervo do Museu de Arte Contemporânea da Universidade de São Paulo.

[Fig.78] - Gabor Peterdi. Sign of the lobster [Marca da lagosta] (1947-48), verniz mole e água-tinta em cores sobre papel, 50,4 X 37,7 cm. Fonte: Acervo do Museu de Arte Contemporânea da Universidade de São Paulo.

[Fig.79] - Boris Margo. The sea [O mar] (1949), cellocut em cores sobre papel, 42,1 X 42,2 cm. Fonte: Acervo do Museu de Arte Contemporânea da Universidade de São Paulo.

[Fig.80] - Louis Schanker. Carnival [Carnaval] (1945), xilogravura em cores sobre papel, 36,5 X 53,7 cm. Fonte: Acervo do Museu de Arte Contemporânea da Universidade de São Paulo.

[Fig.81] - Anne Ryan. The captive [O cativo] (1946), xilogravura em cores sobre papel, 35,7 X 39,7 cm. Fonte: Acervo do Museu de Arte Contemporânea da Universidade de São Paulo.

[Fig.82] - Adja Yunkers. Dead bird [Pássaro morto] (1947), xilogravura em cores sobre papel, 43,2 X 50,6 cm. Fonte: Acervo do Museu de Arte Contemporânea da Universidade de São Paulo.

[Fig.83] - Armin Landeck. Alleyway [Passagem no beco] (1948), buril e ponta seca sobre papel, 34,9 X17,7 cm. Fonte: Acervo do Museu de Arte Contemporânea da Universidade de São Paulo.

[Fig.84] - Edward Landon. That which we mourn [Aquele a quem pranteamos] (1945), serigrafia em cores sobre papel, 46,7 X 36,7 cm. Fonte: Acervo do Museu de Arte Contemporânea da Universidade de São Paulo.

[Fig.85] - Henry Mark. Eternal wanderer [Eterno errante] (1947), serigrafia em cores sobre papel, 36,8 X 26, $8 \mathrm{~cm}$. Fonte: Acervo do Museu de Arte Contemporânea da Universidade de São Paulo. 
[Fig.86] - Karl Schrag. Rain and Sea [Chuva e mar] (1946), buril, verniz mole e água-tinta sobre papel, 37,9 X 27,8 cm. Fonte: Acervo do Museu de Arte Contemporânea da Universidade de São Paulo.

[Fig.87] - Mar Jean Kettunen. Heavy bird [Pássaro pesado] (1950), buril e ponta seca sobre papel, 45,3 X 49,2 cm. Fonte: Acervo do Museu de Arte Contemporânea da Universidade de São Paulo.

[Fig.88] - James Louis Steg. Self-analysis [Auto-análise] (1947) , buril sobre papel, 60,6 X 33,9 cm. Fonte: Acervo do Museu de Arte Contemporânea da Universidade de São Paulo.

[Fig.89] - Sue Fuller. Hen [Galinha] (1945), verniz mole e água-forte sobre papel, 37,4 X 30,3 cm. Fonte: Acervo do Museu de Arte Contemporânea da Universidade de São Paulo.

[Fig.90] - Seong Moy. Little act on horseback [Pequeno ato a cavalo] (1949), xilogravura em cores sobre papel, 31,5 X $32 \mathrm{~cm}$. Fonte: Acervo do Museu de Arte Contemporânea da Universidade de São Paulo.

[Fig.91] - Kenneth Kilstrom. Attack on Marshall Gilbert [O ataque a Marshall Gilbert] (1948), verniz mole, buril, água-tinta sobre papel, 25,4 X 45,2 cm. Fonte: Acervo do Museu de Arte Contemporânea da Universidade de São Paulo.

[Fig.92] - Minna Citron. Marine [Marinha] (1948), água-tina e verniz mole sobre papel, 15,8 X 22,7 cm. Fonte: Acervo do Museu de Arte Contemporânea da Universidade de São Paulo.

[Fig.93] - Bernard Reder. Fighting cocks [Galos de briga] (1949), monotipia sobre papel, 51,4 X 45,8 cm. Fonte: Acervo do Museu de Arte Contemporânea da Universidade de São Paulo.

[Fig.94] - Max Kahn. Cat walk [Passeio do gato] (1949), litografia em cores sobre papel, 34,6 X 50,3 cm. Fonte: Acervo do Museu de Arte Contemporânea da Universidade de São Paulo.

[Fig.95] - Eleanor Coen. Baby in the high chair [Bebê na cadeira de pés altos] (1950), litografia em cores sobre papel, 40,3 X 27,7 cm. Fonte: Acervo do Museu de Arte Contemporânea da Universidade de São Paulo. 
[Fig.96] - Francis Chapin. Baby in the high chair [Bebê na cadeira de pés altos], s.d, litografia sobre papel, $32 \times 23,8 \mathrm{~cm}$. Fonte: Art Institute of Chicago.

[Fig.97] - Frank Wallace. Pompei I [Pompeia I] (1949), xilogravura em cores sobre papel, 30,2 X 45,6 cm. Fonte: Acervo do Museu de Arte Contemporânea da Universidade de São Paulo.

[Fig.98] - Louise Krueger. The boaters [Os barqueiros] (1949), xilografia em cores sobre papel, 58,7 X 29,3 cm. Fonte: Acervo do Museu de Arte Contemporânea da Universidade de São Paulo.

[Fig.99] - Raymond Jordan. Synthesis [Síntese] (1948), verniz mole e buril sobre papel, 45,4 X 35,2 cm. Fonte: Acervo do Museu de Arte Contemporânea da Universidade de São Paulo.

[Fig.100] - Jim Forsberg, Composition in oval [Composição em oval] (1948), xilogravura em cores sobre papel, 27,6 X14,8 cm. Fonte: Acervo do Museu de Arte Contemporânea da Universidade de São Paulo.

[Fig.101] - Alton Pickens. Pastoral [Pastoral] (1947), água-forte e águatinta sobre papel, 30,2 X 59,9 cm. Fonte: Acervo do Museu de Arte Contemporânea da Universidade de São Paulo. 


\section{Sumário}

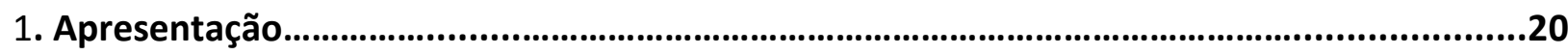

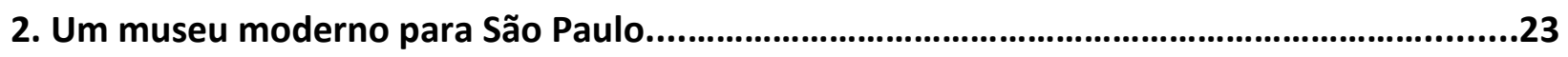

2.1. A política da boa-vizinhança de Nelson Rockefeller.........................................................45

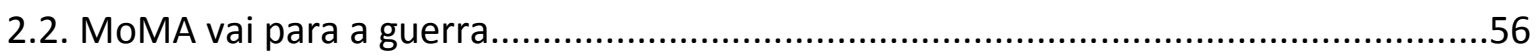

2.3. A demissão de Alfred Barr.........................................................................................70

2.4. A presença de René d'Harnoncourt no Brasil............................................................74

3. A doaação Nelson Rockefeller de 1946 ............................................................................... 81

3.1. Novos artistas norte-americanos................................................................................

In the night, Morris Graves / Antelope mountain, Everett Spruce / Women of the circus, Byron Browne / Standard bearer, Robert Gwathmey / Lecture on architecture, Jacob Lawrence / Yellow plane, Alexander Calder / Forest of chimneys, Arthur Osver

3.2 Europeus no exílio 150

Spring, Marc Chagall / Germination, André Masson / Picture for young people, Max Ernst/ Bestiality marches on, George Grosz /Composition, Fernand Léger

4. Uma coleção de gravuras ...........................................................................................................210

4.1. O departamento de gravura do MoMA.................................................................214

4.2. O papel da gravura na democratização da arte moderna...........................................227

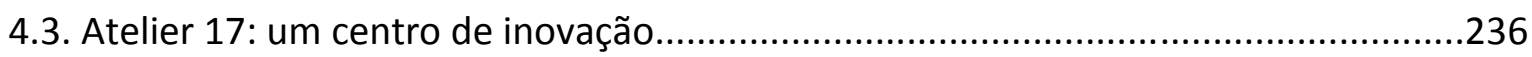

4.4. Gravuras da doação Nelson Rockefeller................................................................245

5. Consideraçø̃es finais ..................................................................................................................274

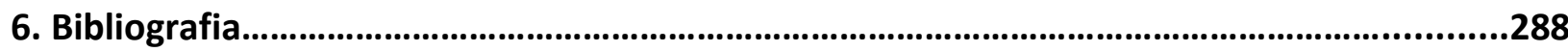




\section{Apresentação}

Às vésperas de completar 70 anos, a doação Rockefeller para o antigo Museu de Arte Moderna de São Paulo permanece, em alguns aspectos, inédita. Pouco estudada por historiadores de arte no Brasil e amplamente desconhecida pelo público geral, as doações Rockefeller, de 1946 e 1950, fazem parte do primeiro acervo museológico de arte moderna no Brasil e são parte fundamental do núcleo histórico do Museu de Arte Contemporânea da Universidade de São Paulo. Apesar de sua importância, foram reduzidas a uma nota de rodapé na historigrafia da arte brasileira e lá permaneceram em segundo plano.

As referências mais comuns na literatura associam as doações Rockefeller ao período inicial de formação dos antigos MAM-SP e MAM-RJ e as ressaltam como um gesto de aproximação do MoMA, na figura do magnata Nelson Rockefeller, com os museus brasileiros. Tendo acesso a uma documentação parcial e incompleta, grande parte da bibliografia comete erros de data, procedência e nomes dos artistas - inconsistências que foram continuamente reproduzidas por outros pesquisadores sem maior apuração. Até agora, não havia sido realizado um estudo focado nas doações. Quase nunca se procurou analisar as próprias obras doadas e entender qual a visão de arte moderna que o conjunto transmitia. Por que esses artistas foram escolhidos? Que propostas estéticas apresentavam? Afinal, que conjunto é esse?

Essa pesquisa procurou sanar tal lacuna e reapresentar as doações Nelson Rockefeller em outra perspectiva. Partindo da documentação original - angariada principalmente nos acervos do MAC USP, MoMA e Rockefeller Archive Center - propusemos investigar as redes de relações pessoais e institucionais que nelas resultaram, traçando uma trajetória desde a produção das obras e a posição de cada artista no sistema das artes da época, passando pelo trabalho dos curadores envolvidos na seleção até a entrega dessas obras ao Brasil.

No primeiro capítulo, busca-se entender o papel de Nelson Rockefeller como articulador privilegiado da política cultural norte-americana no Pós-Guerra e suas relações com o grupo de arquitetos, críticos e empresários envolvidos na formação dos antigos MAM-SP e MAM-RJ. Para isso, foi importante resgatar os anos de sua gestão como Coordenador de Assuntos Interamericanos dos Estados Unidos e entender como as estratégias de fomento das artes na 
América Latina aprendidas na máquina pública do governo Roosevelt serão o ponto de partida para estruturar as doações de 1946 e 1950. O primeiro capítulo explora também a missão institucional do MoMA durante a Segunda Guerra Mundial e mostra como a aproximação cultural foi conquistada, gradativamente, por meio de constantes intercâmbios entre curadores e um crescente interesse por aquisições e exposições de arte latina no MoMA ao longo da década de 1940 a 1950.

O segundo capítulo é dedicado especificamente à primeira doação Rockefeller realizada em 1946. Por meio da documentação disponível nos acervos, descobriu-se que os consultores de Nelson Rockefeller para montar essa coleção foram os curadores do MoMA Alfred Barr e Dorothy Miller. O principal objetivo do capítulo é verificar quais foram os pressupostos estéticos que nortearam o trabalho dos curadores e mostrar como a seleção estava em sintonia com a narrativa de arte moderna do MoMA naquele momento. Dois eixos claros se destacam no conjunto: o grupo de artistas europeus exilados nos Estados Unidos (Max Ernst, George Grosz, Marc Chagall, André Masson, Yves Tanguy e Fernand Léger) e o grupo de novos artistas norte-americanos em ascensão (Alexander Calder, Jacob Lawrence, Everett Spruce, Robert Gwathmey, Byron Browne, Arthur Osver e Morris Graves). Procurou-se mostrar por que esses nomes eram relevantes para o cenário artístico dos Estados Unidos em 1946, ainda que alguns tenham sido esquecidos pela História da Arte.

O terceiro e último capítulo investiga a formação de uma coleção de artes gráficas constituída em decorrência do trabalho pioneiro de Abby Rockefeller, mãe de Nelson e fundadora do MoMA. Sua coleção de mais de 1.600 gravuras fundou o departamento de gravuras e desenhos do museu e abriu novas frentes de investigação e valorização de técnicas experimentais de gravura. O capítulo recupera o processo de estruturação do departamento de gravura do MoMA, chefiado nos seus primeiros anos por William Liebermarn, e descreve qual era o perfil do corpo técnico encarregado de manejar o imenso legado deixado por Abby Rockefeller. Esse trabalho curatorial se viu refletido no conjunto de obras doadas em 1950. Por fim, o capítulo demonstra como a gravura serviu como poderoso elemento de divulgação da internacional da arte norte-americana em meados dos anos 1950 e contextualiza o cenário artístico vinculado às obras e artistas inseridos na segunda doação Rockefeller. 


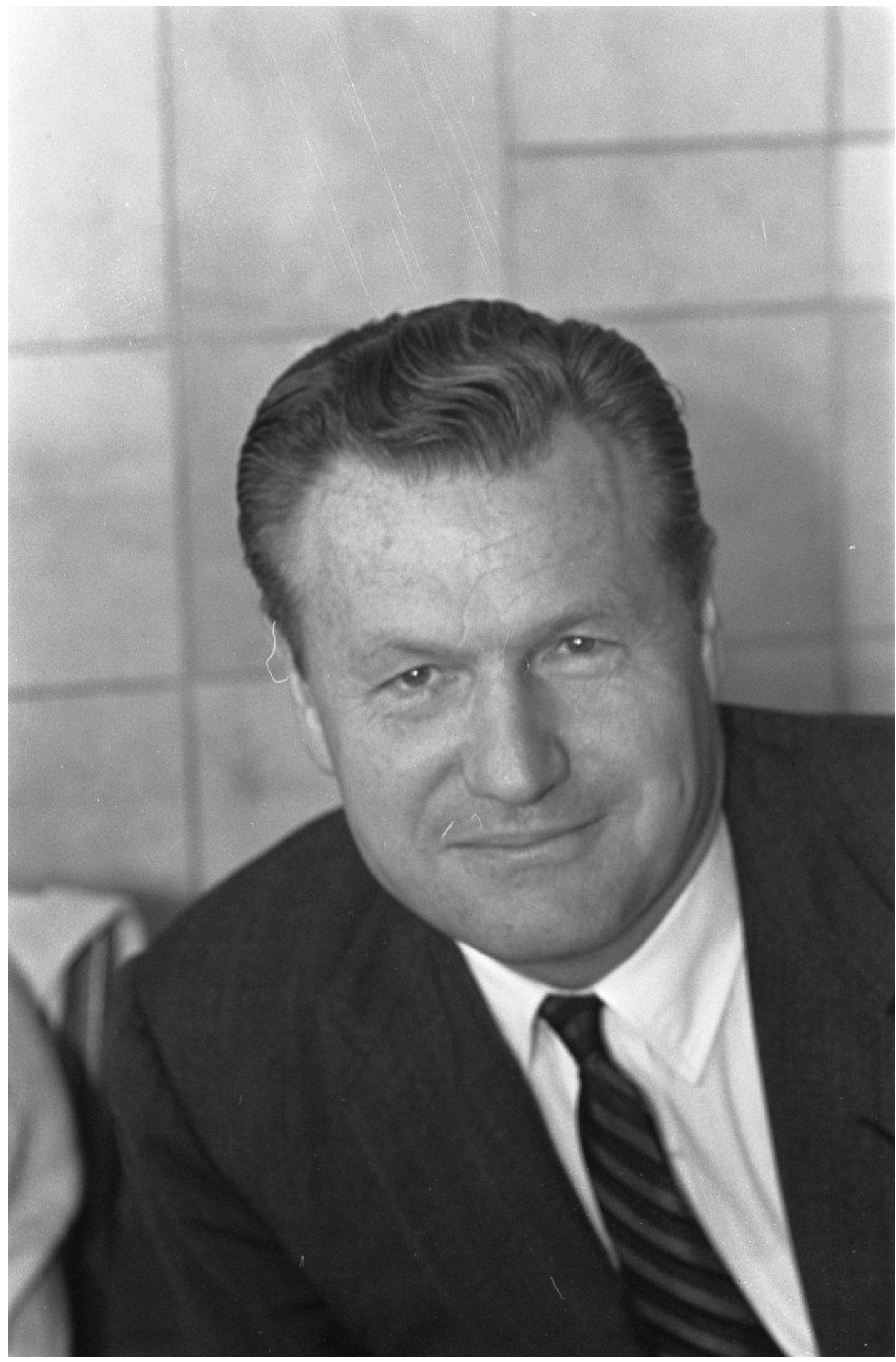

[Fig.1] Nelson Rockefeller 


\section{Um museu moderno para São Paulo}

Em 16 de novembro de 1946, o jornal Folha da Noite anunciava: "Chegou ao Rio o Sr. Nelson Rockefeller". A notícia sobre a viagem do magnata norte-americano ao Brasil, a primeira desde o fim da Segunda Guerra Mundial, foi acompanhada por uma fotografia de Nelson, publicada com destaque na primeira página do diário paulistano. Chegando, não por acaso, no feriado nacional mais patriótico - a Proclamação da República - o discurso de Nelson era de aliança econômica; uma mensagem estratégica nos anos incertos do Pós-Guerra. Em sua primeira entrevista ao jornal, Nelson enalteceu a participação do Brasil no conflito e, com calculado exagero, atribuiu a vitória contra Hitler ao desempenho brasileiro. Acenando para o crescente nacionalismo insuflado por quase uma década de artifícios da ditadura varguista e pela nova Constituinte - aprovada dois meses antes -, Nelson orquestrou com maestria suas primeiras declarações à imprensa:

Todo o povo dos Estados Unidos se sente preso, cada vez mais, ao Brasil. A amizade entre os dois países é secular e esta amizade está mais consolidada depois do papel magnífico desempenhado por vós, durante a guerra. Sem a cooperação integral do Brasil à causa dos aliados, bases materiais, forças armadas e inextendível patriotismo - o resultado do conflito talvez tivesse sido bem outro. Chegando justamente no aniversário da fundação da República brasileira, saúdo o povo e o governo do Brasil, neste dia que é tão grande para os Estados Unidos e, na realidade, para todas as Américas (FOLHA DA NOITE, 1946) ${ }^{1}$.

Durante as duas semanas que passou entre o Rio e São Paulo, o segundo filho de Abby Aldrich e John D. Rockefeller, Jr. fez contato com os homens mais importantes da elite fazendeira e industrial. Nesta viagem, ele estabeleceu o alicerce para o projeto de desenvolvimento agrícola que buscava implementar no interior de São Paulo e Minas Gerais, a

1 Chegou ao Rio o Sr. Nelson Rockefeller, Folha da Noite, São Paulo, 16 nov. 1946. p.1 
fim de garantir a otimização da produção brasileira e o abastecimento ininterrupto de grãos aos Estados Unidos. Nelson Rockefeller tinha fundado meses antes uma organização voltada ao fomento da moradia, educação, saúde e agricultura dos povos latinoamericanos: a Associação Internacional Norte-americana para o Desenvolvimento Econômico e Social (AIA). Sua curiosidade pela região havia amadurecido entre os anos de 1940 e 1945, quando foi apontado pelo presidente Franklin Delano Roosevelt para assumir o cargo de Coordenador para os Assuntos Interamericanos (CIAA). Temporariamente afastado da administração pública em 1946, Nelson deu continuidade a seus interesses na América Latina com a criação da AlA. A associação foi financiada com dinheiro do Fundo dos Irmãos Rockefeller, pequena fortuna do patrimônio de John D. Rockefeller, Jr. destinada às aventuras filantrópicas de seus cinco filhos: Nelson, John D. III., Laurance, Winthrop e David.

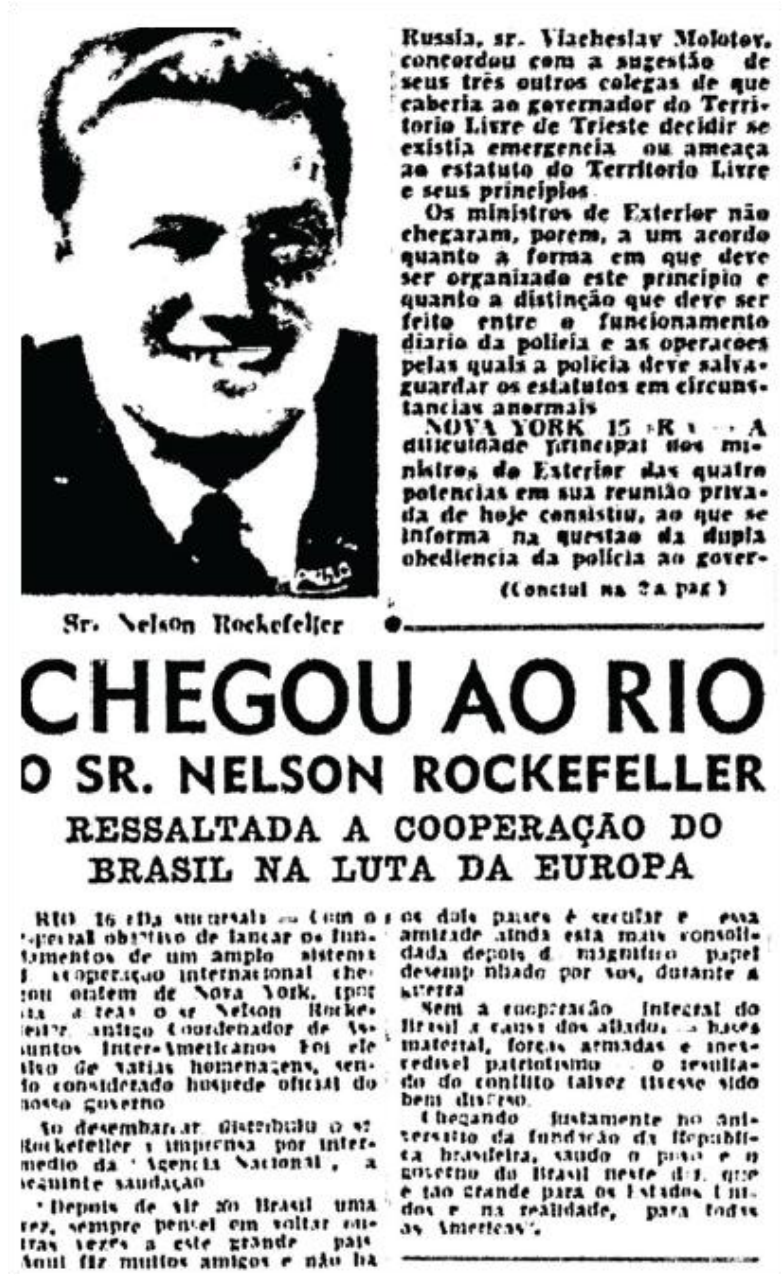

[Fig.2] Reportagem de capa do jornal Folha da Noite de 16 de novembro de 1946. 
O objetivo central da visita de Nelson em 1946 era fazer o lançamento oficial da AIA no Brasil. Porém, sua agenda foi ampliada para acomodar um pot-pourri de encontros com ministros do presidente Eurico Gaspar Dutra, visitas ao Congresso, chás da tarde com damas da alta sociedade e festas organizadas em homenagem a ele e a sua primeira esposa, Mary, quem fielmente o acompanhava na expedição pela América Latina. O casal viajaria em seguida para Caracas. O Brasil e a Venezuela eram os dois países prioritários das ações da AIA e onde Nelson passaria parte do seu tempo na primeira metade da década de 1940 para fazer deslanchar sua nova organização. Em paralelo às iniciativas no campo econômico e político, a visita de Nelson Rockefeller em novembro de 1946 seria um acontecimento histórico de importância seminal para a arte no país. Nelson era ex-presidente do Museu de Arte Moderna de Nova York e sua família tinha uma das mais importantes coleções dos Estados Unidos. Assim, ele não deixou de incluir entre as pautas prioritárias de sua viagem uma ambiciosa iniciativa na área cultural: a formação do primeiro museu de arte moderna do Brasil.

A criação de um MAM no Brasil era um projeto já antigo da geração da Semana de 1922, mas que só se efetivaria no contexto do Pós-Guerra. Para o historiador Serge Guilbaut, a criação de um museu em São Paulo neste período "estava no centro de uma série de discursos que tinham relação com a política internacional e com as lutas nacionais pelo poder" (GUILBAUT, 2011, p.152). A disseminação das noções de "moderno" e "abstrato" se tornariam cruciais para os interesses dos Estados Unidos no xadrez cultural da Guerra Fria. 0 individualismo e a liberdade seriam argumentos importantes para fazer frente ao comunismo e a uma arte atrelada à preocupação do papel social do artista. Neste cenário, o Brasil se destacava como um país de interesse estratégico para os norte-americanos.

Os Estados Unidos concentravam suas atenções especificamente no Brasil para a entrada da cultura moderna porque este era o único país de língua não hispânica, além de ser o único que não estava envolvido em discussões e disputas interamericanas. O Brasil - este potencial gigante da economia se tornou então o principal alvo, o prêmio mais cobiçado de uma disputa cultural no período da reorganização global do Ocidente [...] Desde o fim da guerra, Nelson Rockefeller encorajava o 
Brasil a se abrir aos valores modernos e a desenvolver uma democracia liberal e, para tanto, ele estava preparado a ajudar ativamente aqueles que se lançassem a tal empreendimento (GUILBAUT, 2011, p. 153-155).

"Tive o privilégio de, durante esta viagem, conversar com muitos homens de destaque tanto no Rio como em São Paulo e espero que no futuro nos aproximemos ainda mais a fim de defender a causa do gênio criador contemporâneo" ${ }^{2}$, disse Rockefeller para a imprensa. No mesmo dia, o jornal O Estado de S. Paulo publicou informe sobre a doação de Nelson e a repercussão que sua presença causou entre alguns:

Há muito os artistas plásticos e os intelectuais paulistas vêm trabalhando no sentido de organizar uma sociedade com o fim de estimular o movimento artístico contemporâneo. Dessa campanha nasceu (...) a ideia da Fundação do Museu de Arte Moderna, ideia que teve grande repercussão nos nossos meios artísticos. (...) Aproveitando a presença entre nós do sr. Nelson Rockefeller (...) um grupo de amadores e profissionais de arte promoveu ontem, com a presença daquele ilustre visitante, uma reunião na Biblioteca Municipal, com o intuito de estudar a criação do Museu de Arte Moderna em São Paulo. O professor Carleton Sprague Smith, delegado do Museu de Nova York, que veio com o sr. Rockefeller, expôs os métodos e a técnica de intercâmbio entre os museus norte-americanos, explicando como poderiam ser aplicados aqui aqueles métodos. O sr. Rockefeller trouxe alguns quadros como primeira contribuição e estímulo ao nosso futuro Museu. A comissão encarregada dos trabalhos preliminares dessa obra ficou composta dos srs. Assis Chateaubriand, Sérgio Milliet, Carlos Pinto Alves, Eduardo Kneese de Mello, Quirino da Silva e Rino Levi. ${ }^{3}$

2 Vim ao Brasil com a esperança de contribuir para o bem-estar deste país. Folha da Manhã, São Paulo, 28 nov. 1946, p. 3, grifo nosso.

3 A estada do sr. Nelson Rockefeller em São Paulo. O Estado de s. Paulo, São Paulo, p. 8, 23 nov. 1946. 

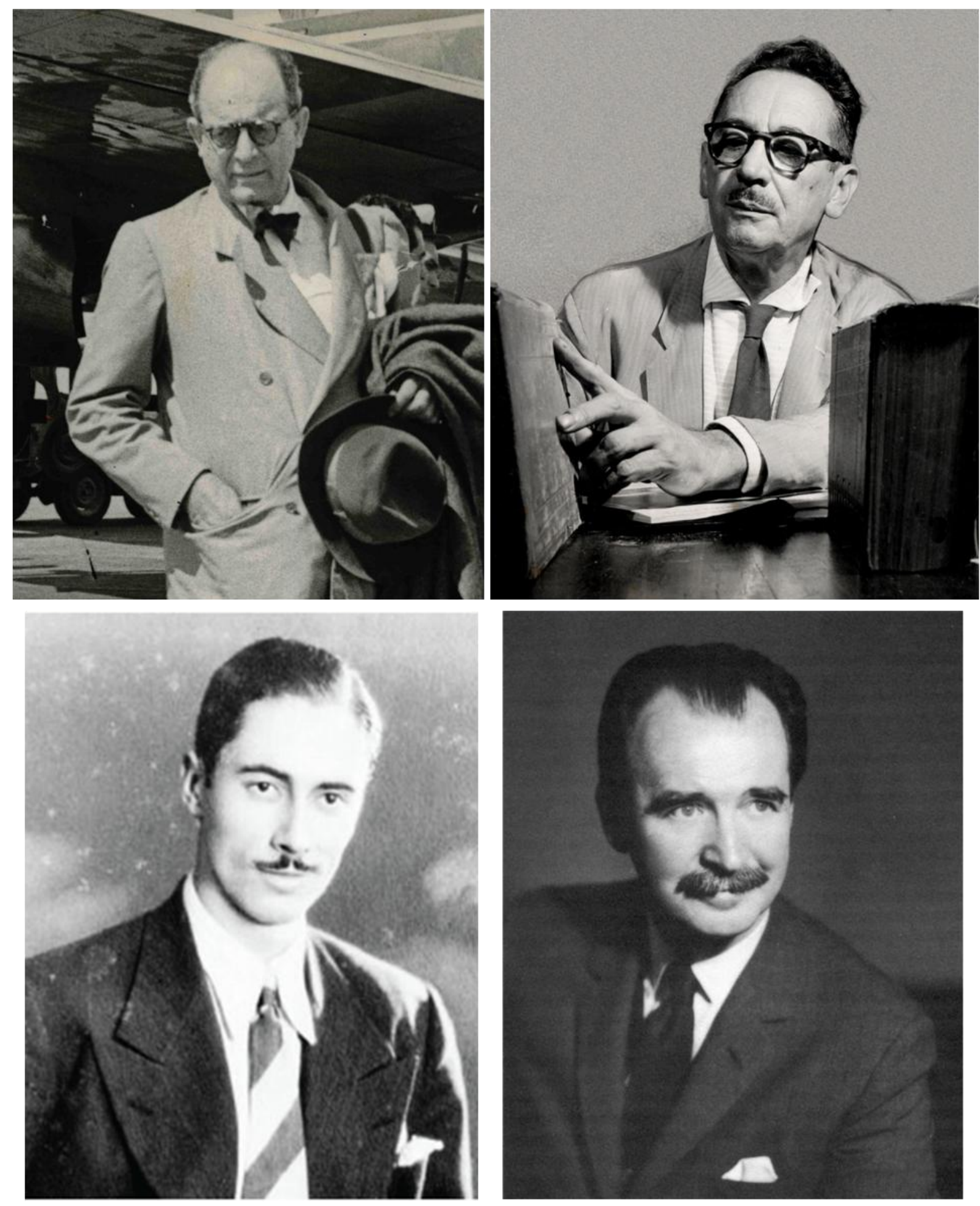

[Fig.3] Os operadores da doação Rockefeller: Francisco Matarazzo Sobrinho, Sérgio Milliet, Eduardo Kneese de Mello e Carleton Sprague Smith (esq. para dir). 
Todas as pessoas cujos nomes são citados no recorte de jornal foram essenciais, cada um a sua maneira, para a consolidação do Museu de Arte Moderna de São Paulo. Contudo, no caso do conjunto Rockefeller, fica evidente pelas correspondências disponíveis a importância maior de quatro homens que atuaram como os operadores da doação: o industrial Francisco Matarazzo Sobrinho, Ciccillo; o crítico de arte Sérgio Milliet, o arquiteto Eduardo Kneese de Mello, e o adido norte-americano Carleton Sprague Smith.

Ciccillo Matarazzo era sobrinho do Conde Francisco Matarazzo, um dos maiores empresários de São Paulo e chefe das poderosas Indústrias Reunidas Matarazzo. O portfólio da empresa variava de oficinas de tecelagem, distribuidoras de óleos, gorduras e refinados, moinhos de processamento de sal, empresa de navegação, importadoras e gráficas. Ciccillo era responsável pela seção da metalúrgica, com a qual fez a própria fortuna. Uma de suas distrações da vida de empresário era seu apreço pela arte. "Eu sempre me interessei por arte. Não sei porque. Nós somos uma família essencialmente de homens de negócios, mas eu sempre tive ligações com a arte (...) Gostava de pintura clássica, de tudo o que parecesse o mais possível comigo. Depois, comecei a ver a evolução da arte" (apud ALMEIDA, 1976, p.31).

Ciccillo casou-se com Yolanda Penteado, de tradicional família quatrocentenária de Campinas, e tornou-se homem refinado, cultivando gostos pela pintura em voga na Europa. Estimulado por amigos e assessores, decidiu criar a Galeria de Arte Moderna, em 1947, instituição que se consolidou na Fundação de Arte Moderna e, finalmente, no Museu de Arte Moderna de São Paulo em 1949.

Carleton Sprague Smith, adido cultural dos Estados Unidos, acompanhou atentamente a formação dos estatutos originais da Galeria de Arte Moderna e sugeriu uma série de mudanças, de forma a tentar tornar a instituição menos centrada na personalidade de Ciccillo. Smith realizou uma análise dos estatutos da galeria e, em julho de 1947, enviou seu parecer para o então diretor Carlos Pinto Alves. Ele demonstrava preocupação com as várias iniciativas culturais simultâneas que estavam em curso em São Paulo: o museu de Álvares Penteado, o Masp de Chateaubriand e a então Galeria de Arte Moderna de Matarazzo. Para o norte- 
americano, a pulverização de esforços era prejudicial para a formação de uma instituição sólida e focada na promoção da arte moderna.

Segundo análise de Regina Teixeira Barros, "as iniciativas de Ciccillo não coincidem com o que os norte-americanos julgam prioritário para um museu em vias de formação" (BARROS, 2002, p. 99). Ciccillo estava dedicado em aumentar seu acervo, aproveitando a queda dos preços na Europa depois da guerra, enquanto os norte-americanos estavam mais preocupados em formar uma boa equipe técnica e nomear um diretor capaz dar solidez institucional ao novo museu. A fim de consolidar uma parceria com o MoMA, Sprague Smith chegou a oferecer treinamentos técnicos sobre gestão de museus e curadoria para os brasileiros (BARROS, 2002, p. 99). Outra sugestão de Smith foi ampliar os nomes do conselho do museu com pessoas fora do campo de ação da família Matarazzo, incluindo alguns dos acadêmicos e críticos envolvidos diretamente na doação Rockefeller, entre eles Sérgio Milliet e Eduardo Kneese de Mello, além outros nomes como Luiz Saia, Francisco Luiz de Almeida Salles e Tarsila do Amaral. As recomendações do norte-americano seriam eventualmente acatadas e os estatutos alterados. Como parte do processo de restruturação, Ciccillo, inclusive, modificou o nome de sua instituição para Fundação de Arte Moderna, antes de mudá-lo definitivamente para Museu de Arte Moderna de São Paulo.

Um dos pontos de divergência entre Ciccillo Matarazzo e os norte-americanos tocava na questão da montagem de um acervo inicial para a instituição que nascia. Enquanto a equipe liderada Sprague Smith entendia que o mais importante no início era garantir a estruturação do museu e sua funcionalidade de gestão, Ciccillo estava obstinamente empenhado em formar sua coleção de arte. Assim, começava a se organizar um importante conjunto de 71 pinturas modernas italianas, hoje parte do acervo do Museu de Arte Contemporânea da Universidade de São Paulo. Essa coleção foi reunida por ajudantes de Ciccillo Matarazzo "comprometidos com o Regime Fascista e sua política pública de divulgação da arte moderna italiana" (MAGALHÃES, 2013, p. 11). É razoável imaginar que os assessores de Rockefeller no CIAA e no MoMA estavam suficientemente informados sobre o sistema das artes da Europa e sobre o movimento de disseminação das tendências do Novecento italiano, lembrando que nos anos 1940 a arte assumia um tom eminentemente político e a doação Rockefeller constrasta 
diretamente com as obras italianas adquiridas por Ciccillo neste período. A coleção de Matarazzo foi composta por pinturas do movimento de "Retorno à Ordem", que resgatam valores da tradição ocidental e se pautam por uma figuração que retoma preceitos clássicos e noções de realismo.

Por outro lado, as obras trazidas por Nelson Rockefeller ao Brasil não se associavam a esse modelo, ainda que de maneira alguma simbolizassem um modernismo coeso. Eram 14 exemplares que justamente representam a diversidade do moderno, podendo passar por exercícios expressionistas de Chagall, o surrealismo de Ernst e Masson, a pintura social negra de Lawrence, o cubismo de Léger ou o abstracionismo geométrico de Calder. O fio condutor desse conjunto não é estético, mas geográfico. Todas as obras doadas são de artistas que em 1946 estavam morando e trabalhando nos Estados Unidos. A doação é reflexo de seu tempo e transmite o discurso de uma arte moderna, libertária e democrática. O conjunto atua, portanto, como uma força contrária à coleção de obras italianas e vai contrapor a arte defendida pelos Aliados às expressões culturais apoiadas por regimes inimigos. No Brasil, ambas as vertentes vão confluir, de maneira singular, para a formação do primeiro acervo do Museu de Arte Moderna de São Paulo.

Novembro de 1946 foi um mês emblemático para a história da arte no Brasil não apenas por causa das doações Rockefeller. Os acontecimentos ocorridos neste curto espaço de tempo seriam fundamentais para o desenvolvimento das primeiras instituições culturais modernas do país e deixariam sua marca para sempre no perfil das principais coleções de artísticas de São Paulo. Além da chegada de Nelson Rockefeller, a segunda semana de novembro de 1946 foi pautada por outra notícia de destaque na imprensa nacional. O casal Pietro Maria e Lina Bo Bardi ganhava os holofotes, em 13 de novembro, com a abertura da primeira exposição de Arte italiana antiga. Organizada por Pietro, a mostra foi exibida no moderno edifício do Ministério da Educação e Saúde, do Rio de Janeiro, que Rockefeller visitaria na semana seguinte. Os Bardi desembarcaram no Rio em outubro, trazendo consigo a coleção do Studio d'Arte Palma, galeria 
fundada por Pietro em Roma. Na abertura da exposição, noticiada como o "primeiro amplo panorama da arte italiana no Brasil", com 50 obras dos séculos XIII ao XVIII, Pietro seria apresentado ao seu futuro empregador, o empresário Francisco de Assis Chateaubriand, cuja fortuna e sentimento de autoimportância viabilizariam o surgimento do Masp.

Uma escolha bastante precisa seria realizada pelo grupo próximo a Nelson de apoiar o museu de Ciccillo, de temperamento mais moderno, ao invés do empreendimento de Chateaubriand, cujo acervo tinha um escopo histórico muito mais distante do projeto do MoMA. Carleton Sprague Smith era crítico ao modo como o Masp estava sendo formado. Ele escreveria para Rockefeller em novembro 1947, criticando a seleção de Chateaubriand na montagem do acervo. "Não foi possível manter o Chateaubriand na linha então o museu no prédio dos Diários Associados é um pot-pourri, ou como os espanhois dizem, uma 'olla podrida' (cozido) de vários estilos". ${ }^{4}$ Ao passo que Carleton minimizava a parceria com Chatô, ele reforçaria sua ligação com o grupo de arquitetos paulistas próximos a Ciccillo. Segundo o pesquisador Zueler Lima, para Sprague Smith "parecia claro que o relacionamento político com Chateaubriand era importante, mas seus planos independentes e associação com Bardi não seriam tão frutíferos quanto [o relacionamento] com os grupos orbitando entorno da ideia de criar museus de arte moderna no Rio e em São Paulo" (LIMA, 2010). ${ }^{5}$

Quando a hora chegou para escolher um dos lados, Rockefeller, orientado por Smith, iria apostar suas fichas nos MAMs em detrimento do Masp. Na avaliação de Smith, "estamos fazendo certo em nos manter próximos ao movimento patrocinado por Carlos Pinto Alves, Rino Levi, E. Kneese de Mello, Almeida Salles e Chichilo [sic] Matarazzo. Eles, assim como o grupo no Rio, estão escrevendo para pedir informações técnicas sobre o Museu [MoMA]". ${ }^{6}$ Ainda assim,

4 "Chateaubriand could not be kept in line so the Museum at the Diários Associados is building a pot-pourri, or as the Spaniards say, an 'olla podrida' [stew] of various styles". SMITH, [Carleton Sprague]. (carta) 06 de novembro de 1947 [para] ROCKEFELLER, [Nelson], Nova York.1f. apud LIMA, 2010, tradução nossa.

5 "It seemed clear that the political relationship with Chateaubriand was important but his independent plans and association with Bardi would not be as fruitful as with the groups orbiting around the idea of creating modern art museums in Rio de Janeiro and in São Paulo". LIMA, 2010, tradução nossa.

6 "We are doing well to stick to the movement sponsored by Carlos Pinto Alves, Rino Levi, E. Kneese de Mello, Almeida Salles and Chichilo [sic] Matarazzo. They, as well as the group in Rio are writing for technical information about the Museum [MoMA] here". SMITH, [Carleton Sprague]. (carta) 06 de novembro de 1946 [para] ROCKEFELLER, [Nelson], Nova York.1f. apud LIMA, 2010. 
Rockefeller sempre manteve uma relação cordial com o Masp, tendo inclusive comparecido e discursado na inauguração do museu.

Porém, em novembro de 1946, Ciccillo e Nelson ainda não se correspondiam. Os principais contatos de Rockefeller na área cultural eram os arquitetos paulistanos ligados ao Instituto de Arquitetos do Brasil, bem como o diretor da Biblioteca Municipal de São Paulo, Sérgio Milliet. Seriam eles os principais interlocutores da comitiva norte-americana para tratar das obras que Rockefeller queria presentear ao Brasil. No Rio de Janeiro, contato havia sido estabelecido com Rodrigo de Mello Franco Andrade, diretor do Serviço do Patrimônio Histórico e Artístico Nacional (SPHAN). Desta forma, no dia 19 de novembro, a coleção de Rockefeller foi entregue primeiro para Andrade, em reunião de críticos e cronistas realizada na sede do Instituto Brasil-Estados Unidos no Rio de Janeiro.

Um jornalista de $O$ Globo presente na cerimônia comentou a importância da doação, ressaltando Nelson como uma das forças propulsoras dos museus norte-americanos e caracterizando a doação de obras como um gesto de amizade que "marca uma era nova na vida artística brasileira" constituindo o "primeiro acervo do primeiro Museu de Arte Moderna do Brasil". Como preconiza a reportagem, o conjunto teve, de fato, uma importância material e simbólica ímpar. Correspondências trocadas entre Nelson e seus assessores caracterizam a doação de 1946 como a "injeção de ânimo" ${ }^{7}$ necessária para tirar os brasileiros da inércia e fazer deslanchar o primeiro museu moderno no país.

Como mostra a documentação coletada nos acervos do Rockefeller Archive Center, a intenção inicial de Nelson era compartilhar igualmente as 14 obras entre os futuros MAMs do Rio e de São Paulo. ${ }^{8}$ As obras trazidas para o Brasil foram: Women of the circus [Mulher de circo] (1946) de Byron Browne, Yellow plane [Plano amarelo ou Móbile amarelo, preto, vermelho e branco], sem data, de Alexander Calder, Bestiality marches on [Bestialidade avança] (1933) de George Grosz, In the night [Na noite] (1943) de Morris Graves, duas Composition [Composição] (1938) de Fernand Léger, Germination [Germinação] (1942) de André Masson, Spring [Primavera] (1938) de Marc Chagall, Antelope mountain [Montanha antílope] (1946) de

7 "Brazilians always liked injections and your 'shot in the arm' in November 1946 started something". Carta de Carleton Sprague Smith para Nelson Rockefeller, 01.03.1948. apud LIMA, 2010.

8 Carta não assinada, 13 de novembro de 1946, Nova York [para] ROCKEFELLER, [Nelson], Nova York. $15 f$. 
Everett Spruce, Standard bearer [Porta-estandarte] (1946) de Robert Gwathmey, Lecture on architecture [Aula de arquitetura] (1946) de Jacob Lawrence, Forest of chimneys [Floresta de chaminés] (1945) de Arthur Osver, Ocean for birds [Oceano para pássaros] (1945) de Yves Tanguy e Picture for young people [Quadro para jovens] (1943) de Max Ernst ${ }^{9}$.

Porém, como se sabe, parte da coleção jamais chegou definitivamente à instituição carioca. A primeira entrega das obras ocorreu no Instituto Brasil-Estados Unidos no Rio de Janeiro e foi parte de um mis-en-scène. Três dias depois, Rockefeller realizou uma segunda cerimônia de entrega em São Paulo, na sede da Biblioteca Municipal, onde a coleção ficou guardada sob a curadoria de Sérgio Milliet até a fundação do antigo MAM, sendo finalmente transferida em 1963 para o MAC USP, onde permanece até hoje.

A Seção de Arte da Biblioteca Municipal foi a primeira morada das doações Rockefeller. Sérgio Milliet aparece como um interlocutor privilegiado de Nelson, para quem foi apresentado por meio de Carleton Sprague Smith. Milliet e Sprague Smith eram professores do Departamento de Sociologia e Política da Universidade de São Paulo. Carleton exerceu esse cargo de maneira temporária entre 1943 e 1946. Ele atuava também como adido de relações culturais no Consulado Norte-americano de São Paulo, além de manter o cargo de chefe da divisão de música da Biblioteca Pública de Nova York, de 1931 a 1959. Musicólogo e talentoso flautista, Sprague Smith nutria grande interesse pelos ritmos brasileiros e aqui fez muitos amigos entre os artistas, músicos e intelectuais.

Em 1940, patrocinado pela seção de Relações Culturais do Departamento de Estado Norte-americano, Carleton realizou um tour de quatro meses pela América Latina para identificar e descrever as expressões musicais regionais e encontrar estratégias para promover a música como elemento de aproximação entre os Estados Unidos e a América Latina. Com

\footnotetext{
${ }^{9}$ Nota sobre tradução de obras: Todas as obras de arte mencionadas nessa pesquisa serão escritas em inglês, seguindo a documentação original da doação, seguidas por sua tradução para o português, tomando por base o catálogo geral de obras do Museu de Arte Contemporânea da Universidade de São Paulo (1973). No caso de obras que não fazem parte da doação, será mantido também o título em inglês ou francês com a tradução para o português apenas quando disponível na bibliografia consultada.
} 
Gilberto Freyre dançou em uma festa de São João em Recife e Heitor Villa-Lobos Ihe dedicaria a composição Assobio a jato, um dueto entre a flauta e o violoncelo. Carleton era defensor de uma diplomacia aberta que possibilitasse um entendimento mútuo entre os povos. "Acho que não devemos tentar disfarçar para os latino-americanos que temos certos hábitos peculiares. Acho que vamos descobrir que as relações culturais estão muito melhores se não tentarmos fingir que somos europeus sofisticados ${ }^{10}$, disse Smith certa vez em uma conferência organizada pelo Departamento de Estado Norte-americano (SHEPARD, 2006, p. 637). De volta aos Estados Unidos, Carleton fundou, em 1958, o Instituto Brasileiro na Universidade de Nova York, centro que estimularia a pesquisa sobre literatura, cultura, economia e história nacional. Sprague Smith era um apaixonado pela arte brasileira em todas suas expressões e, nessas circunstâncias, conheceu Sérgio Milliet, por quem tinha grande admiração. Milliet, por sua vez, já tinha grande proximidade com a cultura norte-americana. Em 1943, depois de uma temporada de pesquisa em Nova York, ele publicou o livro A pintura norte-americana, em que tentava dar conta da produção artística dos Estados Unidos do século XVIII ao XX.

Em 1946, Smith detinha, portanto, um conhecimento acumulado e uma extensa lista de relacionamentos importantes no Brasil, tanto que que Nelson escreve para o chefe da Biblioteca Pública de Nova York, pedindo que a Carleton fosse concedida uma licença, a fim de que ele o acompanhasse na visita ao Brasil ${ }^{11}$. Carleton seria responsável por dar seguimento a todo o processo da doação, assim como acompanhar os bastidores da formação do MAM e do Masp, mantendo Nelson atualizado sobre os avanços nessa frente.

Portanto, quando Nelson Rockefeller confere a Sérgio Milliet a responsabilidade de guardar as obras doadas, ele está muito bem informado sobre as qualidades e feitos do brasileiro, de quem ouvira elogios de Carleton. Uma das primeiras cartas encontradas nos acervos brasileiros sobre a doação é justamente uma correspondência de Nelson Rockefeller

\footnotetext{
10 "I think we shouldn't try to disguise to the Latin Americans that we have certain peculiar habits. I think we will find cultural relations are much better that way than if we try to pretend we are sophisticated Europeans". SHEPARD, 2006, p. 637, tradução nossa.

11 "Dear Mr. Beale, As Dr. Carleton Sprague Smith has told you, the Museum of Modern Art is anxious to develop closer contacts with similar institutions in Brazil. I am leaving this week for Brazil, to be there until the end of November. Because of his unusual experience and intimate knowledge of the people pf Brazil, it was felt that Dr. Smith could make and important contribution to the success of the trip". ROCKEFELLER, [Nelson A.]. (carta) 11 de novembro de 1946, Nova York [para] BEALS, [Ralph], Nova York, tradução nossa.
} 
para Sérgio Milliet, de 25 de novembro de 1946. Na carta, Nelson é compreensivo, diz entender a dimensão dos obstáculos enfrentados para "coordenar diferentes interesses" e "lidar com susceptibilidades". Ele busca animar o colega brasileiro para que não desista do objetivo de fundar um museu em São Paulo, compartilhando sua experiência com o MoMA. "Em Nova York também tivemos dificuldades que, felizmente, se resolveram com o tempo" ${ }^{12}$

Sérgio Milliet foi um personagem central para a institucionalização da arte moderna no Brasil. Antes mesmo de existir as condições necessárias para a concretização do sonho de se formar o museu, Milliet provocou uma inovação no Departamento de Cultura e criou, dentro da Biblioteca Municipal, uma Seção de Arte. Inaugurada oficialmente em 25 de janeiro de 1945, a Seção de Arte foi o primeiro local público de São Paulo dedicado à apreciação e discussão de arte moderna.

O espaço teve um papel importante na formação dos artistas em São Paulo, permitindo o acesso a livros especializados, além de adquirir e expor obras originais de pintores e gravuristas brasileiros modernos. A Seção de Arte também patrocinava mostras educativas. Exposições deste tipo incluíram What is modern painting? [O que é pintura moderna?] ${ }^{13}$, a famosa exposição didática organizada pelo curador do MoMA Alfred Barr Jr., e Creative photography [Fotografia artística], essa última realizada na Biblioteca Municipal em 1947, com reproduções preparadas também pelo MoMA e impressas em painéis com obras de Ansel Adams, Henri Cartier-Bresson e outros. ${ }^{14}$

Havia ainda a preocupação de expor a produção de jovens artistas locais e dar continuidade às mostras didáticas de reproduções de obras estrangeiras. As

12 ROCKEFELLER, [Nelson]. (carta) 25 de novembro de 1946, São Paulo [para] MILLIET, [Sérgio], Nova York. 1 f. apud AMARAL, 1990, p.13.

${ }^{13}$ Nota sobre tradução de tíltulo de exposições: Todas as mostras citadas nessa pesquisa serão escritas em sua língua original acompanhada da tradução do português, quando esta estiver disponível na bibliografia consultada ou em catálogos de exposição. Quando a exposição for mencionada diversas vezes ao longo de uma mesma página, será inserida a tradução para o português apenas na primeira menção.

14 COSTA, Helouise. A exposição como múltiplo: lições de uma mostra norte-americana em São Paulo, 1947. Anais do Museu Paulista. São Paulo. N. sér. V. 22. N. 1. P.107-132. Jan-jun. 2014. O artigo recupera o contexto dessa exposição de fotografias à luz das atividades culturais realizadas pela Biblioteca Municipal de São Paulo, situando a mostra e as técnicas de reprodutibilidade da fotografia no contexto das relações culturais norte-americanas e brasileiras da época. 
atividades da Seção resultaram na constituição de um acervo de arte moderna brasileira que viria a ser o primeiro acervo público dessa natureza no país. (...) A Seção de Arte da Biblioteca Municipal contribuiu de maneira significativa para a atualização de artistas, bem como para a educação do público interessado em arte em geral. Como bem aponta Annateresa Fabris, a Seção de Arte funcionou como "um embrião do tão sonhado museu de arte moderna" (COSTA, 109) ${ }^{15}$.

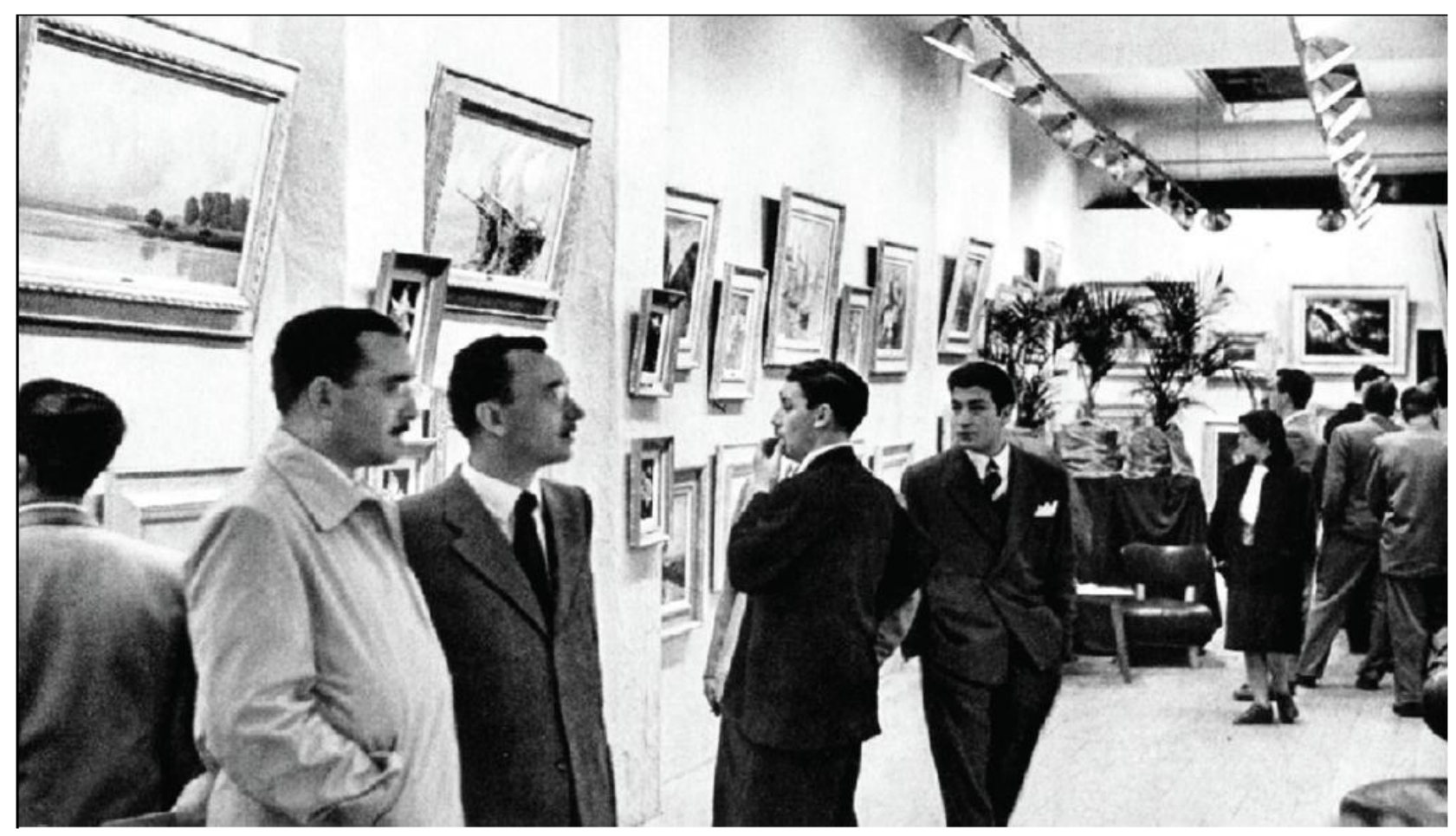

[Fig.4] Exposição do acervo da Seção de Arte da Biblioteca Municipal de São Paulo.

Milliet foi uma das vozes pioneiras na esfera pública paulista em defesa da formação de um museu de arte moderna em São Paulo. Em um artigo no jornal O Estado de São Paulo, em 10 de abril de 1946, ele pede que os artistas, críticos e estudiosos de arte se unam em prol de uma grande campanha organizada para exigir do poder público a instalação de um museu. A união de intelectuais entorno da criação de um projeto único de museu era uma questão

${ }^{15}$ COSTA, Helouise. A exposição como múltiplo: lições de uma mostra norte-americana em São Paulo, 1947, p. 109. 
importante para Milliet, que temia que os interesses egocêntricos e disputas de Chateaubriand e Matarazzo acabassem por trabalhar contra a consolidação do empreendimento.

Há planos e tentativas no ar. O pior, entretanto, é que há planos e tentativas demais. Se cada um, ao invés de pensar num museu para si apenas, como numa sinecurazinha muito cômoda e agradável, quisesse realmente um museu, trataria de não dispensar esforços (...) O museu deve ser criado para todos e dirigido por um grupo de artistas e críticos, uma comissão que impeça a possibilidade de orientações personalistas. ${ }^{16}$

Depois dessa coluna de Milliet, uma série de outros textos apareceu em jornais paulistanos, tanto em defesa quanto contra o surgimento de um museu. ${ }^{17}$ A questão ganhava holofotes e começava a mobilizar a alta elite. Uma das vozes contrárias seria justamente a do prefeito Abrahão Ribeiro:

Jamais cogitaria de criar um Museu de Arte Moderna em São Paulo ou alhures. (...) E por que?! - indagará v.s. escandalizado. Não é que seja contra a arte moderna. Eu não poderia ser contra aquilo que não entendo. É que a noção que eu tenho de museu e das suas finalidades não se coaduna com a pretensão de artistas modernos, cujos trabalhos ainda não se acham definitivamente consagrados pela opinião pública, de modo a se justificar a sua guarda em um museu para gozo e instrução de gerações vindouras. ${ }^{18}$

Outro notório crítico ao projeto foi o escritor Monteiro Lobato:

Esse divórcio entre o Comando (de críticos modernistas) e o Público acabou dando lugar a uma curiosa embolia, ou abarrotamento dos ateliers

16 MILLIET, Sérgio. Coluna Artes e Artistas. O Estado de S. Paulo, 10 abr. 1946.

17 Um mapeamento detalhado sobre a briga que se instalou na imprensa paulista entre os meses de abril e maio de 1946 por causa do museu de arte moderna foi realizado por Regina Teixeira Barros em sua tese de mestrado. 18 RIBEIRO, Abrahão. Carta assinada ao artista Luís Martins, Diário de S. Paulo, 26 de abril de 1946 apud BARROS, 2002, p. 72. 
modernistas com uma prodigiosa quantidade de telas invendáveis, ensaíveis nem de graça. E como esse problema se agravasse com o aumento de preço do espaço urbano, consequentemente à alta dos aluguéis de casa, surgiu a engenhosa ideia do Museu de Arte Moderna. O que eles de fato queriam não era museu nenhum e sim, apenas, um depósito Municipal onde fosse guardada a enorme produção encalhada. Mas como ficava feio pedir à Prefeitura um depósito pediram um museu. ${ }^{19}$

Era nesses termos em que se discutia na imprensa a formação de um museu moderno em São Paulo. Não havia, de maneira alguma, consenso sobre a validade e importância de ter uma instituição aberta ao público para promover a apreciação das novas tendências artísticas. Segundo Regina Teixeira Barros, foi esse momento de grande debate que catalisou os esforços entorno do novo museu.

A proliferação de artigos na imprensa - com inúmeros intelectuais se posicionando contra ou a favor do empreendimento - mostrou que a ideia da criação de um museu era um assunto deveras controverso. Houve momentos de ironia, ou mesmo sarcasmo, momentos de humor e de rancor. Muitas foram as preleções sobre arte, moderna e de todos os tempos. Mas o fato é que a ressonâncias deste debate, veiculado pela imprensa no primeiro semestre de 1946, foi enorme e é muito provável que essa polêmica tenha mobilizado a opinião pública e dado um importante impulso para que intelectuais e amantes das artes se reunissem com o objetivo de concretizar uma vontade que se mostrou comum a muitos (BARROS, 2002, p. 84).

A doação Rockefeller aconteceu alguns meses depois dessa grande campanha pública. 0 momento em que Nelson decidiu agir foi, portanto, muito oportuno e se deu na hora exata para se tornar relevante para a efetiva concretização do projeto. A doação foi, antes de mais nada, uma ação de relações públicas bem orquestrada, da qual Nelson se utilizou para se

19 LOBATO, Monteiro. Carta ao prefeito de São Paulo, Diário de S. Paulo, 30 de abril de 1946 apud BARROS, 2002, p. 73. 
aproximar da elite brasileira durante sua viagem. Rockefeller disse que seu intento ao doar as 14 obras de arte era chamar atenção para os esforços de Milliet e servir como um veículo de divulgação da campanha por um museu de arte moderna no Brasil. "Minha ideia, oferecendo alguns objetos de arte ao Brasil, não é fundar uma coleção nem enriquecer uma coleção já existente, mas acelerar um momentum latente" ${ }^{20}$ Esse comentário demonstra uma sabedoria política adquirida por Rockefeller durante sua gestão no Escritório do Coordenador para Assuntos Interamericanos (CIAA). Essa preocupação reaparece em carta, de 28 de novembro de 1946, escrita por Carleton Sprague Smith para Eduardo Knesse de Mello:

Devo mencionar que os quadros não devem ser considerados demasiado como pedras de lançamento para coleções futuras, mas, sobretudo, estímulos à arte contemporânea - e sugiro que sejam usados efetivamente para promover o estabelecimento de sociedades de museu, não só no Rio e em São Paulo, como talvez também em Belo Horizonte, Porto Alegre, etc. ${ }^{21}$

Depois de inúmeras iniciativas culturais mal-sucedidas à frente do CIAA, Rockefeller aprenderia que a melhor forma de presentear, sem insultar, a elite latino-americana era oferecer um gesto grande o suficiente para fazer algum barulho, mas pequeno o bastante para não parecer estratagema de colonizador ianque. Sua generosidade precisava ser calculada para não incitar críticas.

O presente foi finalmente oficializado na carta de Carleton Sprague Smith para o arquiteto Eduardo Knesse de Mello. "Tenho muito prazer em passar-Ihe às mãos, em nome do sr. Rockefeller, treze gouaches, aquarelas e pinturas a oleo, bem como uma escultura móvel de arame com lâminas de aço", escreveu Carleton Sprague Smith para o presidente do Instituto de

20 ROCKEFELLER, [Nelson] (carta) 25 de novembro de 1946, São Paulo [para] MILLIET, [Sérgio], Nova York, apud AMARAL (1990).

21 SMITH, [Carleton Sprague]. (carta) 28 de novembro de 1946, São Paulo [para] MELLO, [Eduardo Kneese], São Paulo. $2 f$. 
Arquitetos do Brasil. O IAB foi escolhido como o guardião legal para as obras, pois era uma organização que preenchia os "requisitos de neutralidade e responsabilidade".$^{22} \mathrm{O}$ Instituto de Arquitetos do Brasil, fundado em 1921, era uma das entidades mais bem organizadas da categoria e contava com o apoio de alguns dos principais nomes da cultura e do modernismo brasileiros. Vários de seus afiliados estariam envolvidos na formação dos museus, como Rino Levi, Eduardo Kneese de Melo, Villanova Artigas, entre outros. Nessa época, o IAB tinha estatura internacional e havia sido o principal interlocutor com o MoMA para a organização da exposição Brazil builds em 1943, momento em que ambas as instituições começam a se aproximar.

Carleton Sprague Smith insistia na questão de que as obras não deveriam ser entendidas como parte do patrimônio do IAB. Tão logo fosse possível, ele gostaria que fossem encaminhadas para os novos museus. O mais importante não eram as obras e, sim, o impulso que elas poderiam dar para a montagem de equipamentos culturais no Brasil nos moldes do MoMA.

Em carta para Sérgio Milliet, Carleton diz:

Como foi mencionado em diversas ocasiões, estas obras de arte contemporânea deverão ser doadas mais tarde ao Museu de Arte Moderna do Rio de Janeiro e ao Museu de Arte Moderna de São Paulo. O momento mais apropriado para a doação formal destes trabalhos dependerá da rapidez com que os dois comitês formarem organizações estáveis, com planos concretos para a realização de exposições, seções cinematográficas, quadro de membros, etc. (...) Como poderá verificar, esta situação é temporária, e esperamos que seus planos sejam elaborados rapidamente para que um programa ativo possa ser posto em prática e os quadros possam ser doados como foi estabelecido. (...) Foi um prazer encontrar com seu grupo e parece-me que este foi um

22 SMITH, [Carleton Sprague]. (carta) 30 de novembro de 1946, São Paulo [para] MILLIET, [Sérgio], São Paulo. 1f. 
ótimo começo, fundando uma organização que poderá ser de suma importância para o desenvolvimento cultural do hemisfério. ${ }^{23}$

A resposta de Knesse de Mello, confirmando o recebimento das obras demorou dois meses para chegar, pois a sede do IAB mudou de endereço e a correspondência se desviou. "Peço comunicar ao Sr. Rockefeller que (...) aceito com muito gosto e honra ser depositário dos quadros". ${ }^{24}$ Segundo o arquiteto, a doação foi vista como um incentivo aos paulistas e cariocas e o gesto "acolhido com grande simpatia". A comissão nomeada na cerimônia de entrega das obras na Biblioteca Municipal estava "trabalhando ativamente e logo serão conhecidos os estatutos" do novo museu. "Devo-Ihe dizer que a ideia da criação do Museu de Arte Moderna de São Paulo vem tomando vulto e acredito que sua concretização será breve" ${ }^{25}$. Palpite infeliz o de Knesse de Mello, pois um hiato de mais de dois anos separaria a viagem de Rockefeller e a efetiva criação dos MAMs de São Paulo e do Rio de Janeiro.

Já ciente da possível morosidade na organização dos museus, Carleton Sprague Smith sugeriu que as obras fossem apresentadas para a sociedade numa exposição intitulada What is modern painting? [O que é a pintura moderna?]. O título da exposição remete ao livro de mesmo nome escrito por Alfred Barr em 1943. Barr trabalhou neste manuscrito para ser uma ferramenta didática de aproximação com a arte moderna e a abstração. Seu intuito era traduzir alguns códigos básicos da vanguarda para um público geral. O livro foi reeditado três vezes e vendeu 45 mil cópias apenas entre 1946 e 1949 (MALCOM, 1993, p.153). Ao sugerir essa exposição, Smith está se remetendo à tradição do moderno construída pelo MoMA desde 1929 e que vinha sendo exportada de maneira eficaz.

Se, como é provável, as coisas se prolonguem por alguns meses, talvez fosse boa ideia organizar-se uma exposição, a ser intitulada: “O que é a pintura moderna?", apresentando as obras originais chegadas dos Estados Unidos, as quais seriam acrescentada reproduções

23 SMITH, [Carleton Sprague]. (carta) 30 de novembro de 1946, São Paulo [para] MILLIET, [Sérgio], São Paulo.

24 MELLO, [Eduardo Kneese]. (carta) 26 de dezembro de 1946, São Paulo [para] SMITH, [Carleton Sprague], Nova York. 1f.

${ }^{25}$ Op. cit. 
cuidadosamente escolhidas. Também estamos de acordo com o plano atual, de expor as obras na Biblioteca Municipal de São Paulo por algumas semanas, enviando-as em seguida para exposição no Rio. ${ }^{26}$

Há registro de que, talvez, as obras tenham sido expostas na Seção de Arte da Biblioteca Municipal. ${ }^{27}$ Contudo, não foi encontrada nenhuma repercussão maior na imprensa sobre esta mostra. Caso tenham sido de fato apresentadas na biblioteca, essa terá sido uma da poucas vezes em que as 14 obras de arte doadas por Rockefeller foram expostas em conjunto. A segunda ocasião foi apenas em 1955, durante uma exposição do acervo do antigo MAM-SP organizada por Wolfgang A.Pfeiffer (AMARAL, 1983, p.26). Sobre a circulação dessas obras, sabe-se que, possivelmente, a escultura de Alexander Calder Yellow Plane [Plano Amarelo ou Mobile amarelo, preto, vermelho e branco] "ficou durante muito tempo instalada na sede do IAB em São Paulo" (SPINELLI, 2014, p. 54). Há ainda muitas lacunas sobre a efetiva trajetória destas obras do momento em que sairam das mãos de Rockefeller até o atual repositório, o Museu de Arte Contemporânea da Universidade de São Paulo. Houve, inclusive, algumas perdas no caminho.

Uma carta não assinada pelo Museu de Arte Moderna de São Paulo para a Biblioteca Municipal Mário de Andrade, de 23 de setembro de 1949, indica que apenas três obras foram enviadas ao antigo MAM-RJ. “Estamos informados de que um Léger, um Tanguy e um Chagall já foram enviados ao Rio de Janeiro por intermédio do Instituto de Arquitetos de São Paulo. Comprometemo-nos a prevenir o Museu de Arte Moderna do Rio de Janeiro que as outras telas a ele destinadas acham-se em depósito no nosso Museu, a partir desta data". ${ }^{28}$ As três obras mencionadas foram enviadas para a mostra inaugural do antigo MAM-RJ. Dessas, apenas o Chagall retornou para São Paulo. As outras pinturas permaneceram no acervo do Rio de Janeiro, conforme previa a doação, e foram destruídas no incêndio que consumiu o museu em 1978. Não se sabe por que as demais obras endereçadas ao antigo MAM-RJ não chegaram a ser

26 Op. cit.

27 Depoimento de Marcelo Grassmann ao pesquisador João Spinelli, da ECA-USP, apud SPINELLI, 2005, p. 16. 28 MUSEU DE ARTE MODERNA DE SÃO PAULO. (carta) 23 de setembro de 1949, São Paulo [para] BIBLIOTECA MUNICIPAL DE SÃO PAULO, São Paulo. 
enviadas ao museu carioca, contudo, essa omissão acabou por salvar o conjunto, pois possivelmente uma parte maior do conjunto teria sido perdida no fogo que consumiu $90 \%$ do acervo do museu.

Uma das primeiras correspondências pedindo o envio das obras ao Rio de Janeiro data de antes da formação do antigo MAM-RJ. A esse respeito, Rodrigo Mello Andrade, diretor do Serviço de Patrimônio Histórico e Artístico Nacional, escreve para Carleton Sprague Smith em 4 de janeiro de 1947. Andrade agradece a doação de obras ao Brasil e concorda com a decisão de manter o IAB como guardião legal da coleção até sua transferência para os museus brasileiros. "Houve apenas quem sentisse pesar do Chagall não ter tocado o Rio de Janeiro, mas ninguém duvidou do acerto e da equidade do critério com que foi feita a divisão das valiosas pinturas entre as instituições do Rio e de São Paulo", ${ }^{29}$ escreve. Ele completa o relato, certificando que a comunidade cultural do Rio também se movimentava a todo vapor para iniciar a montagem de seu MAM, a fim de receber as obras que Ihes eram destinadas.

A menção do envio das obras reaparece apenas em uma carta de dezembro de 1949, quando Knesse de Mello explica para Rockefeller que o motivo do atraso na entrega da arte para o MAM de São Paulo se deve "em virtude de que alguns dos quadros doados estavam sendo apresentados no Rio de Janeiro (de acordo com instruções anteriores) e só agora voltaram para São Paulo". ${ }^{30}$ Nesta mesma correspondência, Mello admite que as obras destinadas ao Rio de Janeiro permanecem com ele e pergunta como deve proceder. "Estando aquele museu também em funcionamento, você não acha que seria um momento oportuno para enviar a eles as obras que você doou? Aguardo suas ordens a esse respeito". ${ }^{31}$ Nada mais se falou sobre o assunto. Ou caso alguma tratativa neste sentido tenha se dado não há registro do envio de obras para o MAM RJ nos arquivos consultados. Sabe-se, contudo, que aos paulistas coube o espólio total.

29 ANDRADE, [Rodrigo]. (carta) 4 de janeiro de 1947, Rio de Janeiro [para] SMITH, [Carleton S.], Nova York. 2 f.

30 "It was only possible to deliver these paintings at this time because some of them were being shown in Rio de Janeiro (in accordance with your instructions) and only know did thet return to São Paulo. MELLO, [Eduardo Kneese]. (carta) 26 de dezembro de 1949, São Paulo [para] ROCKEFELLER, [Nelson], Nova York. $1 f$.

31 "I am still holding the paintings that you plan to donate to the Museum of Modern Art in Rio de Janeiro. Since that Museum is functioning at present, don't you think this is also an opportune time to send them the paintings you donated? Please instruct me with regard to this matter". MELLO, [Eduardo Kneese]. (carta) 26 de dezembro de 1949, São Paulo [para] ROCKEFELLER, [Nelson], Nova York. 1f. 
Após uma longa trajetória de três anos correspondências trocadas sobre o destino das doações, Ciccillo Matarazzo escreve para Nelson Rockefeller, em 7 de dezembro de 1949, para oficializar o recebimento das obras pelo antigo MAM-SP. O tom pessoal sinaliza o início de uma contínua aproximação entre as instituições de São Paulo e Nova York, parceria que se intensificará, definitivamente, com a montagem da I Bienal de 1951.

\section{Caro amigo,}

Muito embora, com esta carta, só deva satisfazer uma formalidade, acusando a entrega definitiva de sua doação de obras de arte ao Museu de Arte Moderna de São Paulo, quero assinalar que, longe de cumprir um simples dever, sinto a maior alegria em poder escrever-Ihe. Bem certo, a doação Nelson Rockefeller de há muito chegara às mãos do Museu, pois a consideramos nossa desde aquela entrega simbólica, quando ainda aquecia no espírito de alguns paulistas o desígnio de dar a esta cidade um instituto destinado ao cultivo e à expansão das generosas e variadas formas de arte de hoje. Não obstante, com a entrega definitiva das obras, temos a grata oportunidade de novamente assinalar que a bondosa confiança de nosso prezado amigo já se manifestara antes mesmo de concretizar-se, em definitivo, a criação do Museu. $^{32}$

Percebe-se que a primeira doação Rockefeller foi articulada no momento estratégico quando a elite paulista debatia nas páginas dos jornais viabilidade da formação de um museu. Ao ser realizada nesse período oportuno, a doação chamou a atenção da imprensa e ganhou relevância, tendo mobilizado esforços de alguns dos principais atores culturais de São Paulo. Mas é importante notar que a doação não parte de um ato isolado e sua realização tem muito a ver com a formação de um programa para as artes no Escritório de Coordenador de Assuntos Interamericanos. Esse aspecto sobre antecedentes da doação e a construção de um modus operandi das ações culturais dos Estados Unidos no Brasil será detalhado a seguir.

32 SOBRINHO, [Francisco M.]. (carta) 07 de dezembro 1949, São Paulo [para] ROCKEFELER, [Nelson], Nova York. 1 f. 


\section{A política da boa-vizinhança de Nelson Rockefeller}

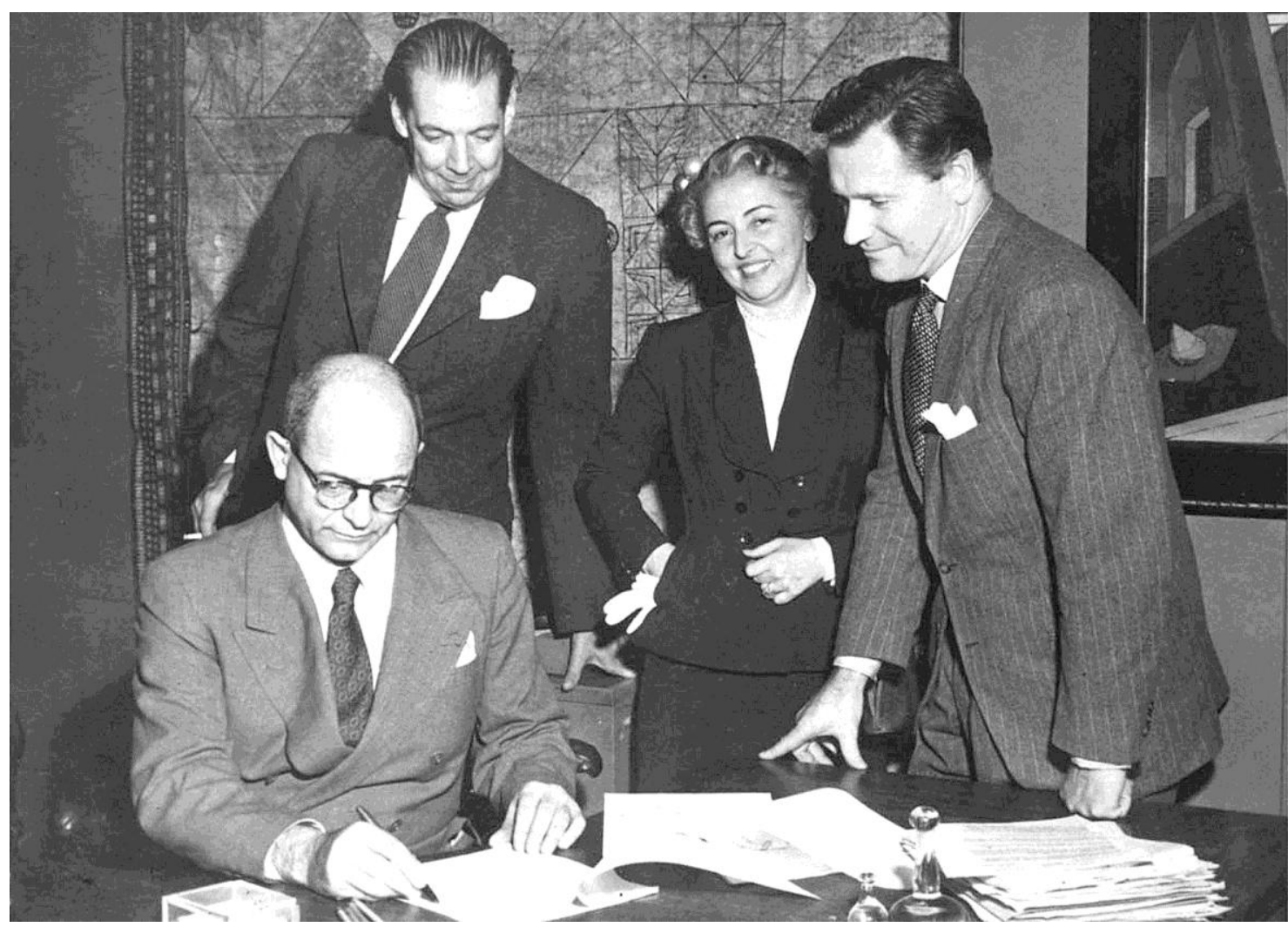

[Fig. 5] Nasce uma parceria. Ciccillo Matarazzo (sentado), Nelson Rockefeller, Yolanda Penteado e René d'Harnoncourt (dir. para esq.) na assinature do termo de cooperação entre o MoMA e o MAM-SP.

Nelson Rockefeller era dotado de um imenso carisma pessoal e facilidade para fazer amigos novos em tempos difíceis. Do pai empresário, herdava o pensamento pragmático, ao que somava certa dose de flexibilidade ideológica que lhe foram cruciais nos anos incertos do Pós-Guerra. Com a mesma naturalidade com que escrevia para Getúlio Vargas em $1945^{33}$, elogiando o governo do recém-deposto ditador brasileiro e desejando-Ihe Feliz Natal; transitava

33 Veja a carta na íntegra: "Sua Excelência, Getúlio Vargas, Esse Natal tem significado pessoal e traz com ele uma enchente de memórias no final de um dos anos mais difíceis que o mundo já conheceu. Eu não posso deixar esse dia passar sem enviar para você e sua família saudações pessoais e renovadas expressões de gratidão pela sua magnífica liderança e inabalável cooperação com o falecido presidente Roosevelt ao longo dos trágicos dias de guerra. Você carregou a novas alturas a tradição de união e compreensão que caracteriza a relação de nossos dois países no último século. Que o futuro possa trazer a paz e felicidade ao redor do mundo para os quais tantos deram suas vidas. Com todos os bons desejos para o Ano Novo. Nelson A. Rockefeller". ROCKEFELLER, [Nelson A.]. (carta) 24 de dezembro de 1945, Nova York [para] VARGAS, [Getúlio], Rio de Janeiro. 1f. 
entre os intelectuais e artistas de esquerda latino-americanos com facilidade. Essas características Ihe foram fundamentais quando assumiu Escritório do Coordenador de Assuntos Interamericanos. Neste cargo, tinha como função conduzir na América Latina a Política da Boa Vizinhança do governo Roosevelt.

Em 30 de julho de 1941, Franklin D. Roosevelt emitiu uma ordem executiva, criando um novo departamento em seu governo, a fim de buscar maior aproximação com a América do Sul em tempos de guerra. Nelson foi o primeiro diretor do Escritório do Coordenador de Assustos Interamericanos (CIAA, sigla em inglês). Seu objetivo era "desenvolver relações comerciais e culturais entre as repúblicas americanas", ampliar a simpatia pelos valores do Ocidente e "o espírito de cooperação entre as Américas no interesse da defesa do hemisfério" ${ }^{34}$ As ações desenvolvidas por essa agência são importantes para entender as doações Rockefeller. Vários funcionários do CIAA vão trabalhar diretamente com o MoMA no planejamento de exposições itinerantes na América Latina, alguns sendo transferidos definidamente para o museu, como o curador René d' Harnoncourt, figura crucial para as doações.

O CIAA era um departamento inédito e Nelson tinha o difícil encargo de construir uma nova estrutura diplomática dentro do governo Roosevelt. A essa altura, ele já tinha superado sua parcela de desafios. Enquanto administrador do mais ambicioso empreendimento imobiliário do Ocidente, o Rockefeller Center, Nelson havia posto à prova sua capacidade de solucionar problemas. O Rockefeller Center, uma construção mastodôntica aparentemente fadada ao fracasso durante os anos da Grande Depressão, já era uma realidade concreta no horizonte de Nova York. Durante os anos no CIAA, Nelson transferiu as técnicas de gestão e criatividade adquiridas na administração do Rockefeller Center para lidar com a burocracia de Washington.

As funções comerciais do CIAA foram, aos poucos, sendo tomadas por outras agências de fomento do governo, tornando o departamento mais conhecido pela sua atuação cultural e

34 "To provide for the development of commercial and cultural relations between the American Republics and thereby increasing the solidarity of this hemisphere and furthering the spirit of cooperation between the Americas in the interest of hemisphere defense". Franklin D. Roosevelt: "Executive Order 8840 Establishing the Office of Coordinator of Interamerican Affairs" July 30, 1941, tradução nossa. Fonte: Gerhard Peters e John T. Woolley, the American Presidency Project. Disponível em: http://www.presidency.ucsb.edu/ws/?pid=16152. 
midiática. Nos primeiros anos, o CIAA financiou a produção de filmes, programas de rádio, aquisições de livros, publicações de revistas, exposições de arte e expedições arqueológicas. Algumas iniciativas populares envolveram os estúdios de Hollywood. Com a intenção de promover imagens mais positivas do México e Brasil, Nelson Rockefeller entrou em contato com Walt Disney e financiou, por meio do CIAA, as animações Saludos Amigos, em que o personagem Zé Carioca faz sua primeira aparição em 1942, assim como The Three Caballeros de 1944 (em português traduzido como Você já foi à Bahia?).

Um projeto de particular interesse é o Programa para as Artes do CIAA, que funcionou de fevereiro de 1941 a junho de 1943. Ele fornece uma visão clara da política cultural dos Estados Unidos nos anos de guerra e do envolvimento do MoMA em atividades governamentais. A natureza experimental do programa fica evidente diante da miríade de atividades variadas encabeçadas pelo órgão. Algumas das ações incluíram, por exemplo, a encomenda de 11 bustos de presidentes latino-americanos para adornar embaixadas, a publicação de uma revista inspirada na Life com o título Em Guarda - para a defesa das Américas, além de concessões de bolsas de estudos para artistas, entre os quais os brasileiros Teresa d'Amico e Henrique Mindlin. Por meio do trabalho da equipe de funcionários do Departamento de Design do MoMA, o CIAA promoveu ainda competições de design de interiores e cartazes de guerra. Ao todo, 855 trabalhos enviados exploraram slogans préestabelecidos pelo museu, como "Vivam as Américas Unidas", "Contra um inimigo comum" ou "Tirem as mãos da América". Dessa forma sedimentava-se o discurso de aliança cultural entre os países do continente. 


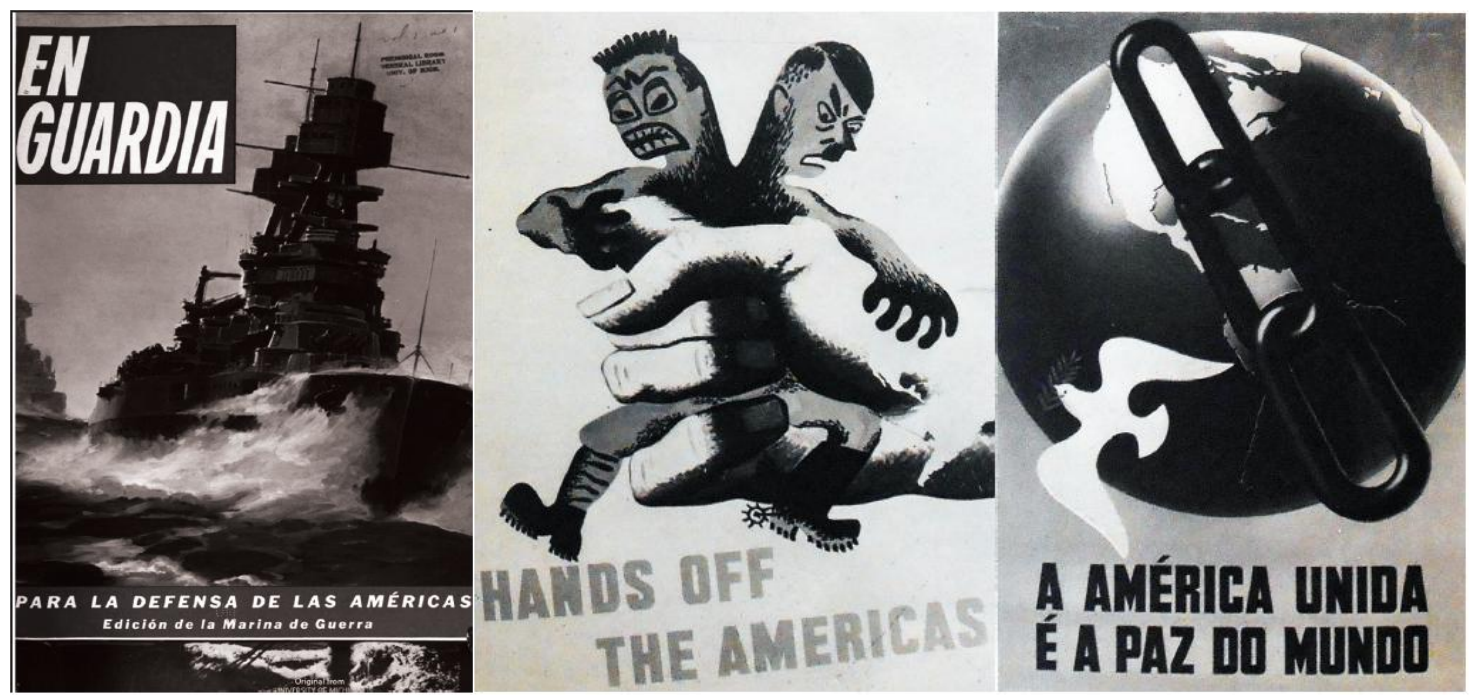

[Fig. 6] Iconografia de guerra. Capa da edição da revista Em Guarda publicada pelo CIAA (esq). Cartazes vencedores do prêmio de $3^{\circ}$ lugar na competição Um hemisfério unido do MoMA em junho de 1942 . No meio, cartaz de John Armory Gibbs (Nova York), e à direita, Ary Fagundes e Benjamin de Araújo Carvalho (Rio de Janeiro).

A primeira grande ação do Programa para as Artes foi fazer circular uma exposição intitulada Contemporary painting of North America [Pintura contemporânea norte-americana]. A exposição percorreu dez países, inclusive o Brasil, de maio a dezembro de 1941, e ganhou catálogo em cores com tiragem de 30 mil volumes em espanhol e português. A comissão organizadora incluiu Alfred Barr, o primeiro diretor do MoMA, e Dorothy Miller, ambos responsáveis pela seleção das obras doadas ao Brasil em 1946. Curadores e funcionários do Metropolitan Museum of Art, Whitney Museum, Brooklyn Museum e antropólogos do Museu de História Natural de Nova York também auxiliaram na organização.

A exposição de 1941 é a primeira tentativa sistematizada de traçar um panorama da arte norte-americana para um público estrangeiro durante a Segunda Guerra Mundial. É importante retomar sua história, pois ela mostra as primeiras ações culturais da equipe de assessores de Nelson Rockefeller no Brasil. Apesar de contabilizar uma visitação total de 218 mil pessoas em todo o continente, um dos resultados mais importantes do projeto pouco teve a ver com a mostra em si, mas consistiu no acúmulo de informações em primeira mão por parte dos funcionários do governo sobre o estado da arte em cada um dos países incluídos no itinerário da mostra. Listas com endereços dos principais nomes da cultura latino-americana seriam distribuídas pelo CIAA para outros departamentos da gestão pública. "Informação deste 
tipo era, até o momento, indisponível, pois só pode ser reunida por meio de contatos pessoais constantes" ${ }^{\prime 35}$, descreveu a comissão organizadora de Contemporary painting of North America [Pintura contemporânea norte-americana] chefiada por John Abbot, futuro presidente do MoMA.

MoMA foi a instituição escolhida para fazer a operação funcionar devido a sua experiência na montagem de exposições itinerantes. Um avanço articulado por Alfred Barr já nos primeiros anos de existência do museu foi a criação do Departamento de Circulação de Exposições, voltado para a ampliação do público interessado em arte. Com o crescimento das preocupações internacionais, esse departamento passou a atuar como o principal braço do CIAA no MoMA, organizando inúmeras exposições enviadas ao exterior.

Para cobrir o máximo de chão em pouco tempo, a coleção foi divida em três partes e enviada, simultaneamente, para regiões diferentes da América Latina. Os 71 doadores privados, museus e galerias, que concordaram em emprestar 267 obras não queriam se ver apartados de suas peças um dia a mais que o necessário, especialmente com uma guerra em curso do outro lado do mundo e submarinos alemães patrulhando os mares. Um projeto deste porte só pôde deslanchar em um período tão sensível da política internacional, pois era liderado por um homem para quem ninguém no mercado da arte de Nova York ousava dizer não: Nelson Rockefeller.

Muitas das galerias convencidas a participar da empreitada tinham como seus melhores clientes a família Rockefeller. As galerias Downtown, Kraushaar, Buchholz, Pierre Matisse, Weyhe e Valentin talvez nem estivessem abertas no início dos anos 1940 não fossem as injeções de dinheiro constantemente proporcionadas pela família mesmo nos anos magros da Grande Depressão. Além disso, parte das obras cedidas para a exposição vinha de doadores anônimos. Esses patronos benevolentes eram ninguém menos do que o próprio Nelson e sua mãe, Abby, cujas coleções particulares sempre estavam a serviço das investidas de Nelson no mundo da arte e da política.

35 "Information of this type was heretofore unavailable because it can only be gathered through constant personal contacts". Relatório sobre a exposição de Pintura contemporânea norte-americana, 1941. Documento do Escritório do Coordenador de Assuntos Interamericanos (CIAA), tradução nossa. Arquivo do MoMA. 
Apesar de haver uma considerável sobreposição entre as galerias envolvidas na mostra de pintura norte-americana de 1941 e as doações Rockefeller de 1946 e 1950, os artistas selecionados são completamente diferentes. A comissão organizadora optou por incluir 76 dos mais conhecidos e prestigiados artistas nos Estados Unidos naquele momento. Curiosamente, nenhum deles foi contemplado na doação Rockefeller de 1946. O motivo disso será aprofundado nos capítulos a seguir e evidencia como os artistas presentes na doação de 1946 fazem parte de um contexto bastante específico que traduz o cenário artístico de Nova York no imediado Pós-Guerra.

Em 1941, contudo, os artistas escolhidos estavam ligados ao grupo da Aschan School e ao reduto de Alfred Stieglitz. Duas a três pinturas de cada artista foram escolhidas de modo a não ressaltar um em detrimento dos demais. A mostra contou com Thomas Hart Benton, George Bellows, Gifford Beal, Arnold Blanch, Charles Burchfield, Joan Sloan, Ben Shahn e Edward Hopper. Os mais abstratos eram Stuart Davis, Arshile Gorky e Georgia O’Keeffe. A arte exportada pelos Estados Unidos em 1941 era mais próxima ao Realismo Social do que ao Expressionismo Abstrato, estilo que viria a se tornar o grande pulo estético dos pintores norteamericanos na década seguinte. Pollock, Rothko, Motherwell e Gottlieb estavam fora do radar do CIAA e do MoMA neste momento.

A seção da exposição de pintura norte-americana chegou ao Rio de Janeiro em novembro de 1941. Ela foi inserida no roteiro de Buenos Aires e Montevidéu e constituia em 68 pinturas e 55 aquarelas. A decisão de mandar apenas um fragmento da coleção para cada país da América Latina causou certo mal-estar, segundo relato da comissão:

Como o orçamento para a exposição não permitiu a impressão de catálogos para cada seção, um catálogo que incluiu pinturas de todas as três seções foi impresso. Isso foi, com frequência, ocasião para confusão (...), uma vez que várias pinturas reproduzidas no catálogo não eram encontradas nas galerias. As autoridades de cada república teriam gostado de acreditar que a exposição foi preparada especialmente para 
seu país e se ressentiram com a implicação de que lhes foi dado apenas uma parte do tour geral. ${ }^{36}$

Constantes reclamações ouvidas por funcionários do CIAA resultaram num ajuste de direcionamento para as futuras ações do órgão. A partir de 1941, foram realizados projetos curatoriais sob medida, procurando valorizar a individualidade artística de cada país e sem cometer o erro de tratar América Latina como um bloco cultural homogêneo. Por exemplo, organizaram-se as exposições Chilean contemporary painting [Pintura contemporânea chilena] (1941-1943), American exhibition in the Guatemala national fair [Exposição norte-americana na feira nacional da Guatemala] (1941) e Brazil builds (1943). Essas iniciativas customizadas para obtiveram sucesso maior do que a exposição Contemporary painting of North America [Pintura contemporânea norte-americana], em parte porque procuravam trabalhar com as elites culturais locais na montagem e seleção das obras apresentadas. A doação Rockefeller de 1946 também reflete esse aprendizado diplomático e é fruto das experiências adquiridas pelo CIAA.

A mostra foi inaugurada no Museu de Belas Artes do Rio de Janeiro, às 15h, de 8 de novembro de 1941. Teve duração exata de um mês. Segundo relato de Caroline Durrieux, gravurista responsável por organizar a exposição no Brasil, a abertura foi um sucesso. "Todos os pintores do Rio e outros intelectuais importantes estavam lá" e "a imprensa apareceu em peso, com inúmeros fotógrafos" ${ }^{37}$. Getúlio Vargas foi um dos poucos presidentes latino-americanos a não comparecer à abertura da exposição em seu país. Contudo, ele enviou o comandante Isaac Cunha para representá-lo, assim como o ministro da Educação, Gustavo Capanema. "Os artistas estavam todos muito curiosos para ver arte moderna norte-americana", descreveu Durrieux. "Eles se dividiram em dois grupos. Um grupo sentia que a exposição era moderna demais e para

36 "As the budget for the exhibition did not permit the printing of a catalogue for each section, one catalogue which included the pictures from all three sections was printed. This was frequently an occasion for confusion in the larger republics since many paintings reproduced in the catalogue could not be found in the galleries. The officials of each republic would also have liked to think that the exhibition was prepared especially for their country and they resented the implication that they were dealt with only as a part of a general tour. Relatório sobre a Exposição de Pintura Contemporânea Norte-americana, p.4, 1941. Arquivo MoMA, tradução nossa.

37 "All painters of Rio and other importante intellectuals were there". Relatório sobre a Exposição de Pintura Contemporânea Norte-americana, p.42, 1941. Arquivo MoMA, tradução nossa. 
o outro não era moderna o suficiente. Ambos os grupos, contudo, estavam interessados no caráter nacional dos trabalhos e na ruptura em relação às influências europeias". ${ }^{38}$

Manuel Bandeira escreveu sobre a exposição no jornal $A$ Manhã, em 11 de novembro. Ele a caracterizou como uma rica coleção de pinturas norte-americanas contemporâneas, "a primeira de uma série de exposições que serão mostradas nas capitais das repúblicas americanas com o propósito de revelar a vida e pensamento dos Estados Unidos refletida pelo trabalho de seus pintores. E ao mesmo tempo, para criar uma atmosfera de compreensão mútua, tão importante para todos os países americanos". No dia seguinte, José Lins do Rego, no mesmo jornal, foi um pouco mais além ao chamar a exposição de "uma valiosa lição" para nossos artistas. "Depois da arte francesa, depois da inundação de lirismo dos jovens ingleses, isso expressa o realismo de um povo que não é apenas mestre da produção em massa, mas grande por sua sensibilidade e por seu esforço para se expressar como criadores autênticos" ${ }^{39}$

Os comentários dos críticos brasileiros revelam que, em um aspecto, a exposição atingiu seu objetivo de incentivar o discurso de aproximação entre as nações por meio da arte. Apesar dos elogios da imprensa cultural carioca, a exposição foi um fracasso. O público brasileiro foi o menor de todos, com 6,5 mil visitantes. A título de comparação, Havana, uma cidade muito menor, teve um público dez vezes maior que o Rio de Janeiro. Caroline Durrieux atribuiu o insucesso à falta de cooperação com as autoridades brasileiras e ao cenário cultural contaminado pela briga entre os pintores acadêmicos e os grupos modernistas.

Na frente social e política, nós falhamos porque nos faltou apoio oficial. Artisticamente, a exposição, sendo um panorama da arte contemporânea nos Estados Unidos, fracassou em criar um real entusiasmo tanto entre os artistas conservadores quanto os

38 "The artists were all very curious to see modern American painting. They divided themselves into two groups. One group felt that the show was too modern and the other that the show was not modern enough. Both groups, however, were interested in the national character of the work and the breaking away from European influences". Relatório da CIAA sobre a Exposição de Pintura Contemporânea Norte-americana, 1941, p. 44, tradução nossa. Arquivo do MoMA.

39 Relatório da CIAA sobre a Exposição de Pintura Contemporânea Norte-americana, 1941, p.44, tradução nossa. Arquivo do MoMA. 
progressistas, que só se deixam interessar por trabalhos puramente acadêmicos ou extremamente avançados. ${ }^{40}$

Prestando contas para seus chefes no CIAA, Caroline Durrieux fez um balanço do cenário artístico no Brasil. Ela lamentou que todas as iniciativas nas artes plásticas no Rio estivessem sob o completo controle do governo. Ela caracterizou a produção artística carioca como "muito conservadora" e descreveu o curso da Escola Nacional de Belas Artes como se saísse direto de um currículo do século XVIII: "começam com pinturas em carvão a partir de moldes de gesso e terminam com o estudo do nu e natureza-morta" ${ }^{41}$. A curadora informou que o Museu Nacional de Belas Artes, a Escola de Belas Artes, as escolas de arte industriais e o ensino de arte nas escolas públicas operavam sob o domínio do Ministério de Educação, havendo poucas iniciativas independentes de apoio e divulgação de novas formas artísticas no Rio de Janeiro. Ainda assim, ela chama atenção para a figura de Gustavo Capanema: “O ministro de Educação e Saúde Pública gosta e apóia arte moderna, especialmente Portinari” ${ }^{42}$. Não por acaso, Cândido Portinari tinha sido o único brasileiro a ganhar uma exposição solo no MoMA até 1940. Neste ano, o governo encomendou a Portinari três grandes murais para o pavilhão brasileiro na Feira Mundial de Nova York de 1939-40. Festa de São João (1939) foi dado de presente pelo Brasil para o MoMA e destruído no incêndio de 1958.

Atenta para o ritmo diferente de São Paulo, Carolina Durrieux conclui seus comentários: "A vida artística não é tão importante no Rio como em São Paulo, onde existem mais artistas modernos e onde, me dizem, um público mais avançado efetivamente compra

\footnotetext{
40 "The reasons for this are: On the politico-social front, we failed because we lacked official support. Artistically, the exhibition, being a cross section of contemporary art in the United States, failed to create real enthusiasm among either the conservative or the progressive artists who can only be interested in purely academic or extremely advanced work". Relatório da CIAA sobre a Exposição de Pintura Contemporânea Norte-americana, p.40, 1941, tradução nossa.

${ }^{41}$ The National School of Fine Arts (...) is very conservative. The curriculum begins with paintings in charcoal from plaster casts and ends in the study of the nude and still life". Relatório da CIAA sobre a Exposição de Pintura Contemporânea Norte-americana, p.45, 1941, tradução nossa.

42 "Sr. Gustavo Capanema, Minister of Education and Public Health, likes and supports modern art", Relatório da CIAA sobre a Exposição de Pintura Contemporânea Norte-americana, p.45, 1941, tradução nossa.
} 
pinturas em exposições". ${ }^{43}$ Gradativamente, o núcleo artístico de São Paulo passaria a chamar maior atenção do CIAA e de Nelson Rockefeller nos anos seguintes.

A partir do relatório CIAA, sabe-se que o principal objetivo do Programa para as Artes era promover exposições itinerantes de arte latino-americana nos Estados Unidos e de artistas norte-americanos nas repúblicas ao Sul, assim gerando um entendimento mútuo das várias culturas no modo mais direto possível. Porém, o envio constante de obras se tornou difícil devido aos altos custos para garantir telas e esculturas em tempos de guerra. A insegurança internacional tornava qualquer deslocamento um esforço épico. ${ }^{44}$

Depois de Pearl Harbor, as fronteiras estavam impenetráveis. Por isso, o escritório de Nelson Rockefeller decidiu montar uma exposição de arte pré-colombiana, colonial e contemporânea apenas com peças que já se encontravam nos EUA. Essa exposição, acompanhada de um catálogo em cores, percorreu instituições norte-americanas por 18 meses, sendo encerrada em 1943. Para contornar as dificuldades logísticas, o governo dos Estados Unidos privilegiou a montagem de exposições educativas com base nas reproduções de originais, assim como mostras de fotografias e gravuras, que tinham um custo de transporte e seguro consideravelmente menores que pinturas e esculturas.

A transferência da seção de arte do CIAA de Nova York para Washington em 1942 e o estabelecimento de um projeto de duração de um ano chamado Creative Achievements Project deu unidade e foco para os funcionários do departamento até então envolvidos com uma série de ações culturais fragmentadas. Aos poucos, esse se tornou o centro das iniciativas culturais do CIAA. Três exposições voltadas para "contra-atacar a propaganda nazista que retrata os Estados Unidos como uma nação puramente materialista" ${ }^{45}$ foram desenvolvidas entre 1942 e

43 "Artistic life is not as important in Rio as in Sao Paulo, where there are more modern artists and where, I am told, a more advanced public actually buys pictures at exhibitions". Relatório da CIAA sobre a Exposição de Pintura Contemporânea Norte-americana, p.46. 1941, tradução nossa.

44 "In the beginning it had been hope that exhibition of major importance could be exchanged between each of the other American Republics and the United States, thus bringing about a mutual understanding of the various cultures in the most direct method possible. War conditions made it necessary to limit and to modify these plans". Relatório do Programa das Artes do CIAA, p. 5, 1943. Arquivo MoMA, tradução nossa.

45 "[These exhibitions] are intended to counteract that Nazi propaganda which portrays the United States as a purely materialistic nation". Relatório do Programa das Artes do CIAA, sem página numerada, 1943, tradução nossa. 
1943. Elas se chamaram Man and the land [Homem e a terra], Art for the people [Arte para o povo] e Towards a new world [Em direção a um novo mundo]. Consistiam em jogos de 100 painéis com fotografias e informações sobre a história do desenvolvimento da cultura e ideais democráticos norte-americanos. Mais interessantes, contudo, são duas outras exposições realizadas sob a égide do Creative Achievement Project, mas idealizadas e executadas pelos curadores do MoMA: Brazil builds e Road to victory foram enormes sucesso de público e entraram para a história do museu como ações emblemáticas da política curatorial do MoMA durante a Segunda Guerra Mundial.

Nelson foi exonerado da direção do CIAA em dezembro de 1944. O órgão foi reformulado em março de 1945 e passou a se chamar Office of Inter-American Affairs, com direção do arquiteto Wallace Harrison. Nessa nova formulação, o escritório perdia muitos de seus atritutos iniciais e, em abril de 1946, foi definitavamente extinto e as atividades culturais assumidas pelo Departamento de Estado Americano. Para dar continuidade ao programa cultural do CIAA, o Departamento de Estado criou, dentro da Galeria Nacional de Arte, uma autarquia intitulada Inter-American Office, que tinha como objetivo promover intercâmbio entre os Estados Unidos e a América Latina, por meio de exposições itinerantes, e a publicação de catálogos e livros. Foi esse órgão que viabilizou o envio das exposições organizadas pela curadoria do MoMA, como a já mencionada Creative photography [Fotografia Artística], apresentada na Seção de Arte da Biblioteca Municipal de São Paulo, e New directions in gravure: Hayter and studio 17 [Novas direções da gravura: Hayter e Atelier 17]. Essa última exposição esteve diretamente relacionada ao conjunto de gravuras da segunda doação de Nelson Rockefeller ao antifo MAM-SP, como será mostrado no último capítulo dessa pesquisa. 


\section{MoMA vai para a guerra}

Nos anos 1940, o MoMA acordou para a América Latina. O museu, até então dedicado à apreciação das vanguardas europeias e à prática artística nacional, descobriu na arte latinoamericana um novo tema. Até a Segunda Guerra Mundial, apenas um artista mexicano tinha conquistado as paredes do museu. Os murais de Diego Rivera eram muito apreciados por Abby Rockefeller, tornando-o o único latino-americano a ter duas exposições solo no MoMA, a primeira em 1932. As mostras Portinari of Brazil [Portinari do Brasil] e Two centuries of Mexican art [Dois séculos de arte mexicana] em 1940 marcam uma mudança de paradigma da curadoria. É interessante observar como a descoberta da arte latino-americana pelo MoMA andou, lado a lado, com a nova diplomacia do governo e com o interesse particular de Nelson Rockefeller à frente da coordenação de Assuntos Interamericanos.

\section{ROAD TO VICTORY \\ A PROCESSION OF PHOTOGRAPHS OF THE NATION AT WAR DIRECTED BY LT. COMOR. SDWARO STEICHEN, U.S.N.R, TEXY BY CART SANBQUNO}

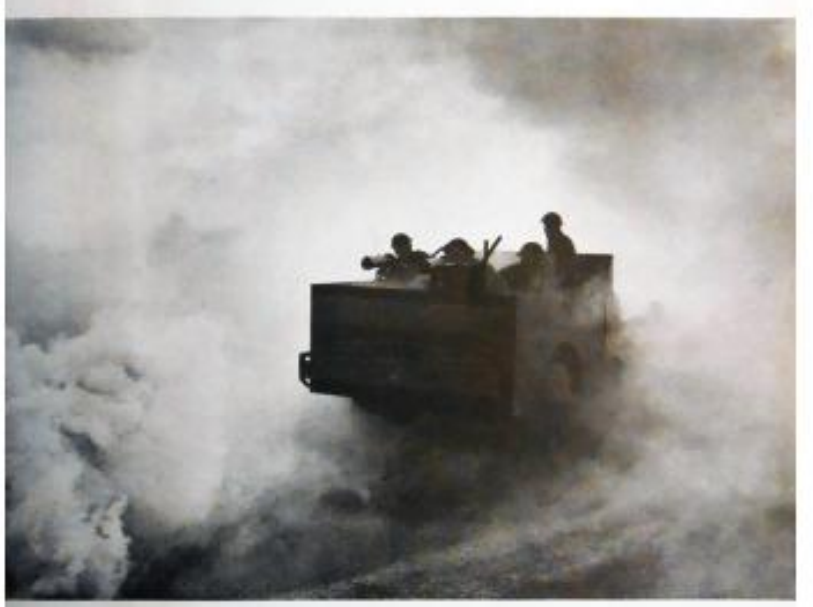

USEFUL OBJECTS IN WARTIME

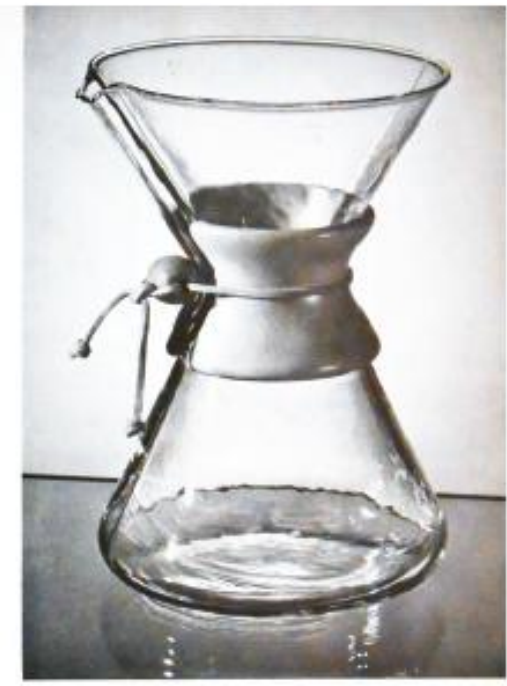

The Diwltilin of the MUSEUM OF MODERN ART The . Birrlelin of 5-6 VOLUME IX JUNE 1942

[Fig. 7] Catálogos do MoMA, Road to victory e Useful objects in wartime. 
Movido pelo clima político nacional, o museu também serviu como repositório de iniciativas cívicas. Especialmente a partir da entrada dos norte-americanos no conflito, o museu passou a intercalar, mais frequentemente, individuais de Picasso, Miró, Dali e Klee, com fotografias de guerra, ilustrações de soldados, cartazes, mostras de roupas de camuflagem e exposições voltadas à arrecadação de dinheiro para a Defesa Nacional. No início da década de 1940, o MoMA, uma instituição relativamente jovem, procurava se tornar mais presente e relevante na sociedade norte-americana. Com a guerra, o museu teve a oportunidade de avançar seu papel no diálogo nacional e conquistar, gradativamente, a atenção do cidadão comum preocupado com os rumos da Europa, mas talvez ainda um tanto indiferente à arte moderna.

De 1939 a 1945, o MoMA organizou oito exposições com trabalhos de artistas da América Latina. No mesmo período, ao menos 40 foram montadas tendo a guerra como temática principal. ${ }^{46}$ A preocupação do museu com o cenário internacional era evidente. Vale destacar as exposições organizadas em parceria do MoMA com o escritório de Nelson Rockefeller e as que tiveram o Brasil como objeto de investigação. Brazil builds, Faces and places in Brazil [Faces e lugares no Brasil] e The latin-american collection of the Museum of Modern Art [A coleção latino-americana no Museu de Arte Moderna], montadas entre janeiro e junho de 1943, são testemunhos da tentativa de aproximação cultural com os brasileiros e fornecem um pano de fundo iluminador para compreender as doações Rockefeller que se concretizariam nos anos seguintes.

Para a maioria dos norte-americanos, o Brasil era um enigma. A imagem fornecida pelo cinema era a de um país folclórico, pobre, ensolarado e exótico. Os esforços de Hollywood haviam produzido pérolas tais como Uma noite no Rio (1941) e Minha secretária brasileira (1942) com Carmen Miranda e todo seu esplendor tropical. Além de patrocinar o surgimento de outra estrela popular, o malandro Zé Carioca, Nelson Rockefeller designou um departamento do CIAA para produção de filmes educativos sobre a América Latina. Para chefiar a nova seção cinematográfica, Nelson nomeou John Hay Whitney, produtor de $E$ o vento levou, vice-

46 Lista de exposições do MoMA. Disponível:

http://www.moma.org/learn/resources/archives/archives exhibition history list\#1940

Acessado em 07.11.2013. 
presidente do MoMA e herdeiro de outra família central para a arte em Nova York. Whitney comandaria a produção de 288 curtas e longas-metragens sobre as virtudes dos povos latinoamericanos. Quando Getúlio Vargas anunciou a cooperação brasileira na guerra ao lado dos Aliados em agosto de 1942, o CIAA divulgou o clipe Brazil at war [Brasil em guerra], mostrando o país como um aliado estratégico e rico fornecedor de minério de ferro, borracha e soldados para engrossar os esforços militares dos Estados Unidos.

A fim de obter imagens e informações estratégicas sobre os costumes e modo de vida brasileiros, o CIAA enviou a fotógrafa Genevieve Naylor para uma viagem do leito do rio São Francisco ao calçadão de Copacabana, que durou de outubro de 1940 a agosto de 1942. Como resultado, Faces and places in Brazil [Faces e lugares no Brasil] foi inaugurada simultaneamente a Brazil builds. Ambas as exposições eram complementares, tinham o objetivo de avançar as relações com o Brasil e foram financiadas pelo Escritório do Coordenador de Assuntos Interamericanos.

Cinquenta fotografias de Genevieve Naylor foram apresentadas no MoMA, em 27 de janeiro de 1943. Divididas em sete séries temáticas, elas mostravam os "vários tipos e raças" das crianças brasileiras, os vaqueiros e jangadeiros da comunidade do Rio São Francisco, obras de Aleijadinho e festivais religiosos em Minas Gerais, trabalhadores das grandes cidades, especialmente Rio e São Paulo, e o lazer de Copacabana e o Carnaval. ${ }^{47}$

Sobre Genevieve, o poeta Vinícius de Moraes certa vez escreveu:

Americanazinha adorável que se acha aqui no Rio. Genevieve parece ter saído de uma história de Robin-Hood, com seu arzinho de jovem pajem, sua elegância bem colorida, uma pena sempre atrevidamente espetada no chapéu. Nada escapa, no entanto, à maquinazinha dessa enfeitiçada. Perto dela não há momento fotográfico que passe sem cair naquela

47 Apesar da qualidade fotográfica e interesse histórico das imagens de Genevieve, seu trabalho permanece pouco explorado por pesquisadores brasileiros, tendo sido publicado apenas recentemente por uma editora nacional. Ver: ERMAKOFF, 2013. 
arapuca bem armada. Genevieve dá um pulinho e a vida ali ficou batendo asa na sua chapa impressionada. ${ }^{48}$

Antes de ser enviada ao Brasil pelo CIAA, Genevieve tinha adquirido experiência com esse tipo de missão fotográfica exploratória. Em 1937, ela trabalhou para o Works Progress Administration (WPA), instituição governamental criada durante a Grande Depressão para financiar o trabalho de artistas nos Estados Unidos. O WPA, um New Deal para a arte, tentava e usar a arte para levantar a moral norte-americana, e registrar o reerguimento econômico e social de uma nação posta de joelhos pela crise acionária de 1929.

Para a historiadora brasileira Ana Mauad, a fotografia de Naylor se aproxima da linguagem social dos fotógrafos da geração WPA, como Dorothea Lange e Lewis Hine. Ao mesmo tempo em que suas imagens "compõem um mosaico" sobre a diversidade do Brasil, o trabalho de Naylor "dialogava também com a pedagogia do olhar própria a política implementada pelo CIAA" (MAUAD, 2005, p.55). Ela tinha como missão construir uma imagem positiva da polifonia racial e cultural brasileira. Críticas ao trabalho de Naylor foram registradas pelo departamento do CIAA no Rio de Janeiro. "Há muito mais no Brasil que sacolejos de negros, negros no Carnaval, instituições religiosas e bricabraque" ${ }^{49}$, reclamou um diretor do CIAA no Rio de Janeiro para seus superiores em Washington. Ofendido pelo trabalho de Genevieve, o diretor se recusou a mostrar as fotos em uma exposição planejada para o Rio.

\footnotetext{
48 Vinícius de Moraes, "A última catedral", em A Manhã, 19.10.1941, Rio de Janeiro apud MAUAD, Ana Maria. Genevieve Naylor, fotógrafa: impressões de viagem (Brasil, 1941-1942) in Revista Brasileira de História. Vol. 25 no. 49, São Paulo, jan-jun 2005.

49 Memorando da Divisão Brasileira do CIAA para Francis Alstock, Rio de Janeiro, 11.8.1942, Arquivos CIAA, National Archives, Washington, citado em MENDONÇA, A. R. Carmen Miranda foi a Washington, apud MAUAD, op. cit., p.89.
} 


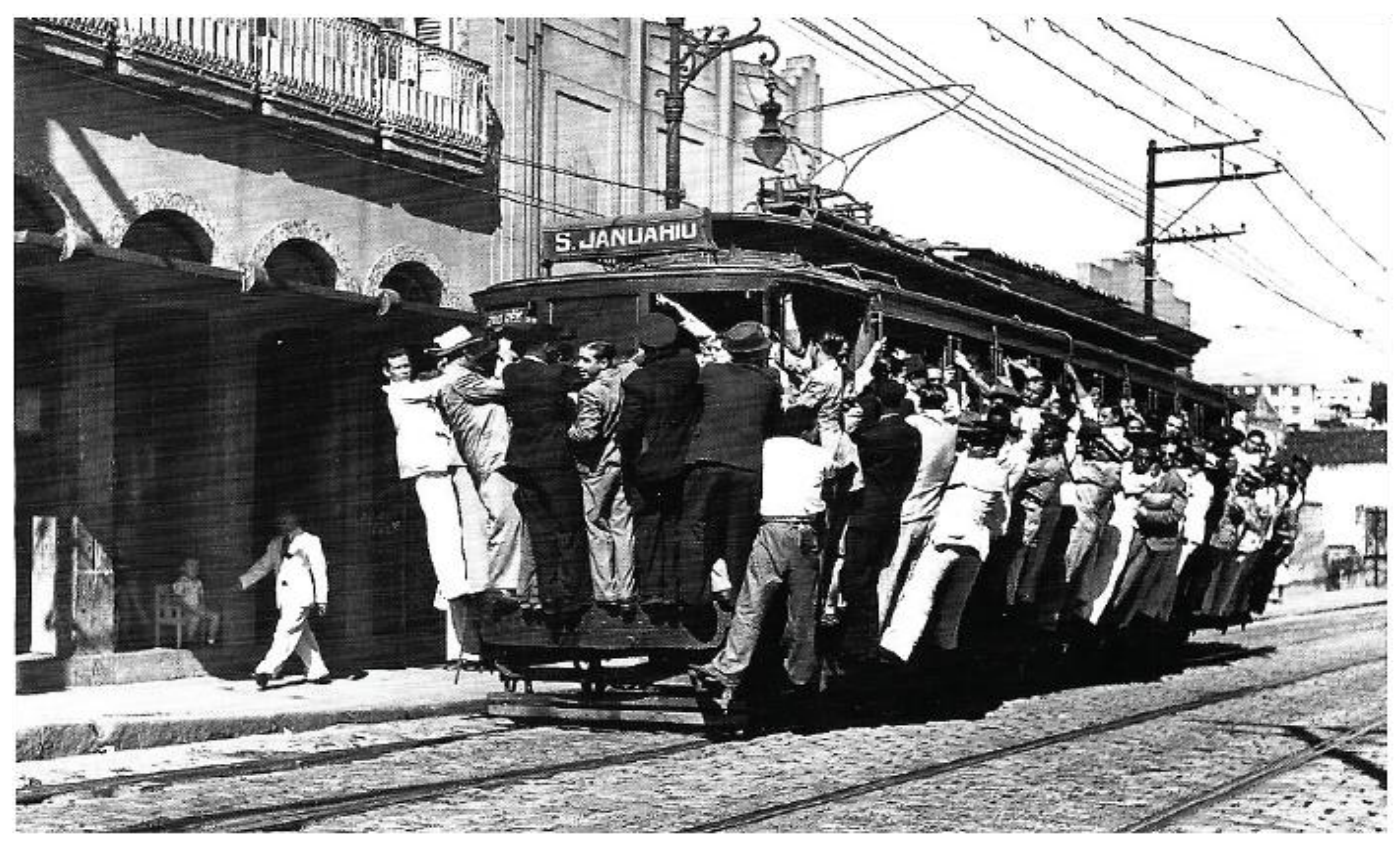

[Fig. 8] Fotografia da série Faces and places of Brazil, em exibição no MoMA em 1943.

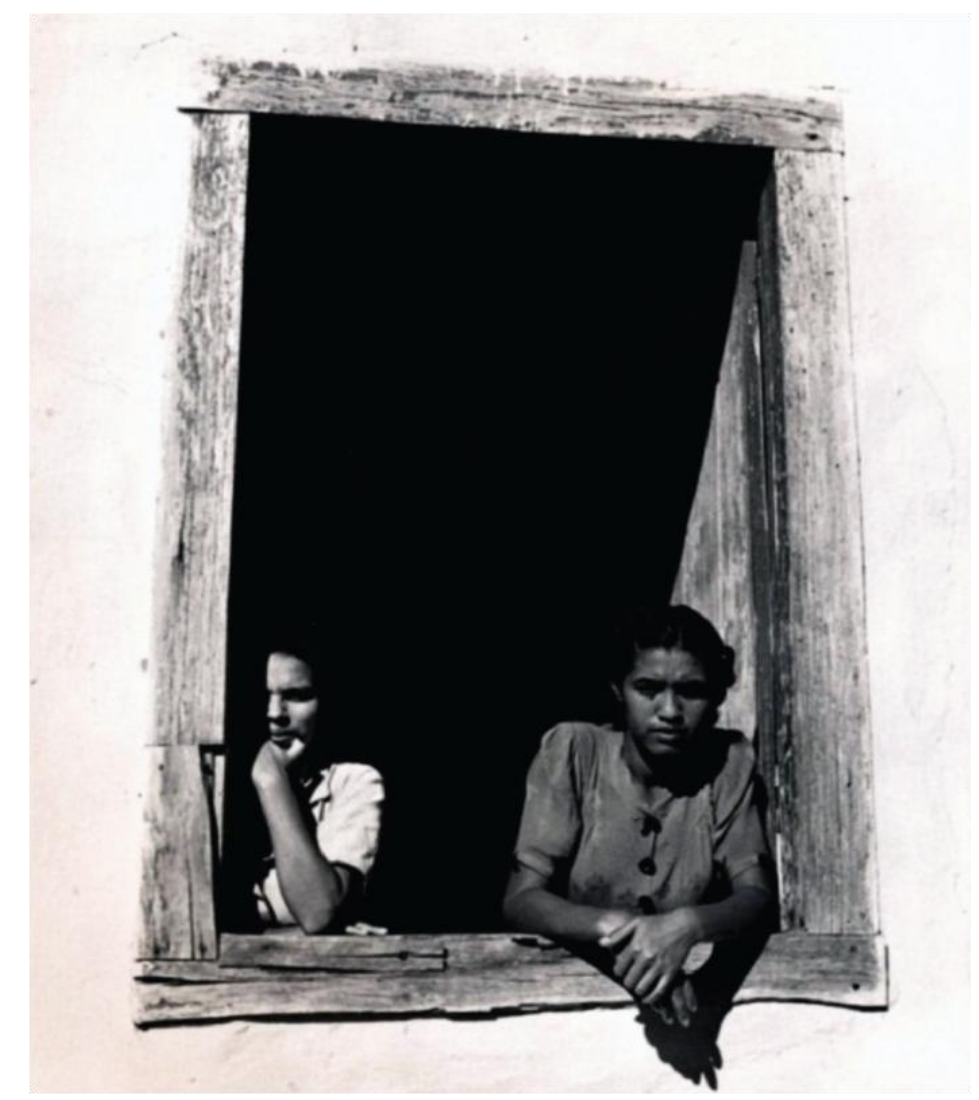

[Fig. 9] Fotografia também parte da mesma série de Genevieve Naylors sobre o Brasil. 
O olhar da fotógrafa norte-americana pode hoje parecer contaminado por uma narrativa estereotipada de Brasil. Contudo, é importante ter em mente que Genevieve Naylor era uma funcionária do governo, trabalhando para um departamento de propaganda e cinema, numa ditadura latino-americana em clima de guerra, com o objetivo específico de apresentar o Brasil para o público estrangeiro. As fotos exibidas na exposição Faces and places in Brazil [Faces e lugares no Brasil] eram condizentes com a narrativa do MoMA em 1943, que procurava valorizar e engrandecer as expressões culturais da América do Sul.

Enquanto as fotografias de Genevieve eram exibidas no corredor do primeiro andar do MoMA, uma segunda exposição sobre o Brasil foi anunciada no salão principal. Ao longo de três meses, todo o térreo do edifício do museu foi tomado por modelos, ampliações fotográficas, desenhos, planos, mapas e uma projeção contínua de 48 slides em cor. O primeiro comunicado à imprensa emitido pelo MoMA em 1943 noticiava a abertura de Brazil builds: "Nova-iorquinos vão ter a oportunidade na quarta-feira, 11 de janeiro, para familiarizar-se com a melhor arquitetura, não só deste hemisfério, mas do mundo, quando o Museu de Arte Moderna abrir a primeira exposição a temporada 1943: Brazil builds". ${ }^{50}$

Philip Goodwin, arquiteto responsável pela concepção museológica da nova sede do MoMA, foi quem assinou o projeto da exposição. Goodwin passou o verão de 1942 em companhia do fotógrafo G.E. Kidder Smith, coletando imagens das jóias da arquitetura brasileira, desde fazendas de café e igrejas coloniais a estruturas modernas dos centros urbanos. O antigo Ministério da Educação no Rio de Janeiro era um dos projetos mais comentados no material de divulgação da exposição. A equipe responsável pela concepção da sede do ministério ganharia o palco internacional e marcaria a história da arquitetura modernista no Brasil: Lúcio Costa, Carlos Leão, Oscar Niemeyer, Affonso Eduardo Reidy, Ernani Vasconcellos e Jorge Machado Moreira.

50 "New Yorkers will have an opportunity on Wednesday, January 13, to become acquainted with some of the finest modern architecture not only in this Hemisphere but in the world when the Museum of Modern Art opens the first exhibition of its 1943 season: Brazil builds". Comunicado do MoMA à imprensa, 10 abril de 1943, tradução nossa. 


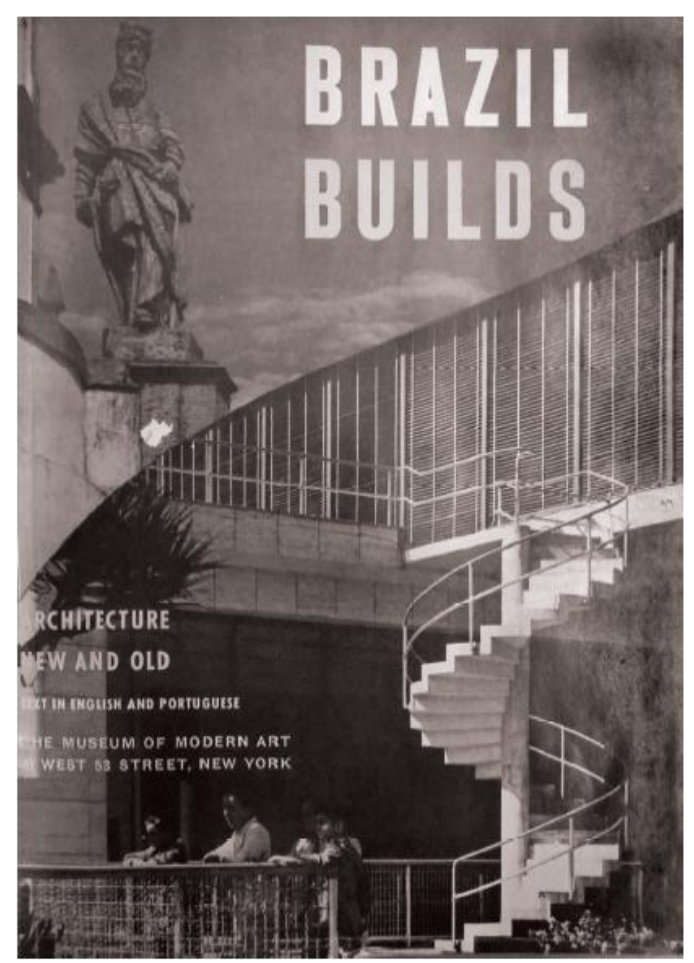

[Fig. 10 ] Capa do catálogo de Brazil builds.

O conteúdo político da exposição Brazil builds é evidente. Goodwin não só elogiava diretamente o empenho do governo de Getúlio Vargas no patrocínio de um "boom imobiliário" no Brasil, como enaltecia o papel do Estado no financiamento do modernismo brasileiro por meio da encomenda de prédios públicos nos moldes do Ministério de Educação. O comunicado à imprensa anunciava: "As capitais do mundo que vão precisar de reconstrução depois da guerra não podem buscar modelo melhor do que os prédios modernistas da capital do Brasil” ${ }^{51}$. No catálogo, Goodwin afirma que o MoMA se achava ansioso já em 1942 por travar relações com o Brasil, "um país que ia ser nosso futuro aliado". Quando Goodwin partiu para o Rio de Janeiro para iniciar o trabalho da exposição, Vargas ainda não tinha se posicionado claramente a favor dos Estados Unidos na guerra, mas na ocasião do coquetel de abertura no MoMA, meses depois, a aliança entre Brasil e os Estados Unidos já estava consolidada.

51 "The capitals of the world that will need rebuilding after the war can look to no finer models than the modern buildings of the capital city of Brazil". Comunicado do MoMA à imprensa "Brazilian government leads Western Hemisphere in encouraging modern architecture", 12 de janeiro de 1943, Arquivo do MoMA, tradução nossa. 
A mostra foi um sucesso. O relatório do Projeto para as Artes do CIAA aponta Brazil builds como a melhor iniciativa realizada pelo escritório em toda a sua gestão. A mostra foi inserida na agenda do Departamento de Circulação de Exposições do MoMA e permaneceu em tour pelos Estados Unidos, México e Brasil durante três meses.

A apreciação entusiástica nos Estados Unidos da arquitetura brasileira e o generoso esforço deste país em se fazer conhecido por meio dessas exposições, não apenas para o público nos Estados Unidos, mas também no México e no Brasil, foi um dos melhores exemplos de uma consistente aderência ao propósito de nosso programa. ${ }^{52}$

O caráter experimental e improvisado das primeiras ações do CIAA foi substituído por iniciativas de grande sucesso. O escritório se viu capaz de criar em poucos anos um método de trabalho eficiente. A crescente contratação e treinamento de profissionais de arte permitiu o surgimento de exposições como Brazil builds. Este foi o ponto de partida para o estabelecimento de contatos duradouros entre os arquitetos modernistas de São Paulo e a curadoria do MoMA. Tais relacionamentos seriam cruciais para as doações Nelson Rockefeller de 1946. É justamente o Instituto de Arquitetos do Brasil, por meio de seu diretor Eduardo Kneese de Mello, que vai se responsabilizar pelas 14 obras doadas ao Brasil. Essa relação só pode ser compreendida se levado em conta o histórico de ações do CIAA e do MoMA na primeira metade da década de 1940.

Em março de 1943, imediatamente após o término de Brazil builds, o MoMA lançou sua mais ambiciosa plataforma para a divulgação da arte da América Latina: a exposição The latinamerican collection of the Museum of Modern Art [A coleção latino-americana do Museu de Arte Moderna]. ${ }^{53}$ Foi uma iniciativa milionária financiada por um doador anônimo. No ano anterior, o museu tinha recebido uma grande remessa de dinheiro para comprar arte latino-

52 "The enthusiastic appreciation in the U.S. of Brazil's accomplishment in Architecture and this country's generous effort to have it become known by means these exhibitions, not only to the public in the U.S. but also in Mexico and Brazil was one of the better examples of consistent adherence to the purpose of our program". Relatório do Programa das Artes do CIAA, 1943, tradução nossa.

53 Uma versão menor da exposição só com pinturas circulou pelos Estados Unidos entre 1943 e 1944. 
americana. O Fundo de Aquisições permitiu ao museu obter, segundo divulgado em 1943, “a maior e mais importante coleção de arte contemporânea latino-americana do mundo" 54 . Maior inclusive do que as coleções nos museus das "repúblicas irmãs ao sul", segundo relata o catálogo da exposição. Falando sobre o surgimento do fundo, Alfred Barr comenta: "Com visão e generosidade, o doador anônimo do Fundo Interamericano estipulou que o dinheiro deveria ser gasto com trabalhos de interesse ou qualidade, de maneira silenciosa e sem envolvimento em complicações e compromissos oficiais". ${ }^{55} \mathrm{O}$ cauteloso milionário era ninguém menos que Nelson Rockefeller.

Como seria de costume de Nelson ao longo da carreira pública, os aspectos pessoais e profissionais de sua vida se misturavam. Quando necessário, injetava dinheiro da fortuna familiar em projetos de interesse da nação e de sua carreira. Neste caso específico, ele usaria o MoMA para alcançar objetivos estabelecidos pelo Escritório do Coordenador de Assuntos Interamericanos. Uma grande exposição de arte latino-americana no museu era a vitrine necessária para fazer avançar a sua aproximação com lideranças políticas regionais. Porém, como bom negociante, Nelson avaliou que seria mais interessante manter as aquisições em segredo. Assim, evitaria o aumento desenfreado dos preços das obras, que ocorreria caso anunciado que um Rockefeller estava determinado a comprar.

Alfred Barr escreve:

Graças à Segunda Guerra Mundial e a certos homens de boa vontade do hemisfério ocidental, estamos derrubando as vendas do entendimento cultural que mantiveram os olhos das repúblicas americanas fixados na Europa, com raros relances uns aos outros no último século e meio. No campo da arte,

\footnotetext{
54 "The largest and most importante collection of latin-american contemporary art of the worls". Catálogo de The Latin-american collection of the MoMA [A coleção latino-americana do MoMA], 1943, tradução nossa.

55 "With vision as well as generosity the anonymous donor of the Inter-American Fund stipulated that the Money should be spent for works of interest or quality, quietly and without involvement in official complication or compromise". Catálogo da exposição The latin-american collection of the MoMA[A coleção latino-americana do MoMA], p. 3-4, 1943, tradução nossa.
} 
estamos começando a olhar uns aos outros na cara com interesse e alguma compreensão. $^{56}$

Para reunir uma nova coleção, Nelson enviou seu amigo Lincoln Kirstein, o diretor da companhia de balé de Nova York, a uma viagem de compras pelo Brasil, Argentina, Uruguai, Bolívia, Chile, Colômbia, Cuba, Equador, Peru e México. Kirstein adquiriu, aproximadamente, 200 obras, a maioria desenhos e gravuras. Três esculturas e vários cartazes completam o conjunto. Na apresentação da coleção, Kirstein explicou que, devido às dificuldades de viagem durante a guerra, vários países não puderam ser visitados. Ainda que impressionante, a coleção do MoMA tinha lacunas graves, segundo ele. Não de todo satisfeito com a sua seleção, Kirstein recomendou ao MoMA que investisse na posterior aquisição de peças do escultor brasileiro Bruno Giorgi, do argentino Fioravanti e do mexicano Ortiz Monasterio, cujas obras não havia conseguido encontrar.

Uma análise atual da coleção revela, de fato, algumas inconsistências. Para se limitar ao caso brasileiro, nomes como Anita Malfatti, Tarsila do Amaral, Di Cavalcanti, Victor Brecheret, Vicente Rego Monteiro, Cícero Dias e Alfredo Volpi foram ignorados por Kirstein. O que hoje é evidente talvez já o fosse para Alfred Barr em 1943. A montagem de exposições a toque de caixa, que veio a caracterizar muitos os esforços de guerra do MoMA - inclusive as doações Rockefeller -, tinha como resultado algumas omissões importantes. Barr, que acompanhou marginalmente esse projeto, não deixou de registrar um mea culpa na abertura do catálogo:

Limitações de tempo, acessibilidade e fundos criaram infelizes omissões tanto de países quanto artistas, mas da forma que está a divisão da América Latina da Coleção do Museu agora possui mais pinturas chilenas que britânicas, mais brasileiras que italianas; e se certos países latino-americanos ainda não estão representados isso é também verdade para importantes países europeus. Contudo, a coleção do

56 "Thanks to the Second World War and to certain men of good will throughout our Western Hemisphere, we are dropping those blinders in cultural understanding which have kept the eyes of all American republics fixed on Europe with scarcely a side glance at each other during the past century and a half". Catálogo da exposição The latin-american collection of the MoMA, [A coleção latino-americana do MoMA] 1943, p.3, tradução nossa. 
museu não é estática, mas dinâmica, mudando continuamente. Erros de omissão serão concertados; erros de inclusão serão eliminados. ${ }^{57}$

Entre as peças de maior destaque abocanhadas por Kirstein em sua viagem, estão Selfportrait [Auto-retrato] (1940) de José Clemente Orozco e a pintura The new rich [Os novos ricos] (1941) de Antonio Ruiz. As principais obras da exposição vinham da coleção particular de Abby e Nelson Rockefeller ou eram presentes de outros doadores. Nessa categoria, se encaixam a escultura Christ [Cristo] (1941) de Maria Martins, Hill [Morro] (1933) e Saint John Party [Festa de São João] (1939) de Candido Portinari, Self-portrait with chopped hair [Autoretrato com cabelo cortado] (1940) de Frida Kahlo, Subway [Metro] (1928) de José Orozco, além da maioria das obras de Diego Rivera - único artista do grupo a ganhar atenção sistemática do museu antes da Segunda Guerra Mudial.

Os “erros de inclusão" aludidos por Barr são mais difíceis de precisar. Só podemos saber a quais artistas Barr se referia quando conduzida uma análise cuidadosa sobre as condições e o momento em que certas obras foram eliminadas da coleção do MoMA. Contudo, da seção brasileira, só permanecem no museu a escultura de Maria Martins e os Portinaris. Já não fazem mais parte do acervo as obras do núcleo de "seguidores de Portinari" adquiridas por Kirstein em 1942, sendo eles dois desenhos de Edith Behring, então aluna de Portinari - Menino negro (1938) e Menino negro, perfil (1939) -, um óleo de José Bernardo Cardoso Júnior Naturezamorta com vista da Baía de Guanabara (1937) e Os amantes (1941) do ilustrador manauara Percy Deane. Artistas que também foram excluídos do acervo incluem: Heitor dos Prazeres, Alberto Veiga Guignard, José Pancetti, Georgette Pinet, Francisco Rebolo, Paulo Rossi Osir e Tomás Santa Rosa Júnior.

\footnotetext{
57 "Limitation of time, accessibility and funds have created certain regrettable omissions both of countries and of artists but as it stands the Latin-American division of the Museum Collection is rather more complete than the European - for the Museum now owns more Chilean painting than British, more Brazilian than Italian; and if certain Latin American countries are not yet represented this is also true of important European countries. However, the Museum Collection is not a static but a dynamic affair, continually changing. Errors of omission will be repaired; errors of inclusion will be eliminated. To the field of friendly competition, to this company of living works of art, the Museum welcomes the new arrivals from the other American republics". Catálogo da exposição The latin-american collection of the MoMA [A coleção latino-americana do MoMA], Nova York: MoMA, 1943, tradução nossa.
} 
Por causa do grande número de visitas a The latin-american collection [A coleção latinoamericana do Museu de Arte Moderna] e da curiosidade despertada nos nova-iorquinos pelos exóticos vizinhos ao sul, a exibição foi prolongada, fechando um mês depois do previsto.

No mesmo ano, outra exposição itinerante centrada no trabalho de Modern painters of Brazil [Pintores modernos do Brasil] foi enviada a oito universidades dos estados de Nova York, Ohio, Delaware, Georgia e Wisconsin. Um comunicado do MoMA à imprensa não se isenta de reconhecer as lacunas desta segunda exposição sobre pintura brasileira. A mostra incluiu nomes como Carlos Scliar, Roberto Burle Marx, Gerson Borsoi, Athos Bulcão, José Pancetti, Alberto da Veiga Guignard e Candido Portinari. O MoMA declarou que "a exposição não é representativa de um panorama geral da arte contemporânea no Brasil” ${ }^{58}$. O museu lamentou, particularmente, a impossibilidade de contar com uma pintura significativa de Portinari, artista representado apenas por pequenos desenhos e estudos. No comunicado à imprensa, Portinari é identificado como o "líder do movimento modernista brasileiro" e o "Diego Rivera do Brasil". A divulgação evidencia a rasa compreensão que o MoMA tinha sobre a prática da arte moderna no Brasil:

Muito pouco tem sido publicado sobre a pintura contemporânea do Brasil e tivemos que depender principalmente de informação de visitantes para compor grande parte do material de divulgação. Até o momento, é impossível determinar quais pintores pertencem ao grupo de São Paulo e quais podem ser reivindicados pelo Rio. O Museu de Arte Moderna muito aprecia qualquer informação factual que os visitantes da exposição possam nos fornecer. ${ }^{59}$

\footnotetext{
${ }^{58}$ Comunicado à imprensa da mostra Modern painters of Brazil [Pintores modernos do Brasil], Arquivo do MoMA. 59 "Very little has been published as yet about contemporary Brazilian painting and we have had to try to rely principally on visitor's information for most of the foregoing material. It is so far impossible to determine exactly which painters belong to the group from S.P. and which are Rio's claim. The Museum of M.A. would appreciate any factual information that visitors to the exhibit may be able to supply". Comunicado à imprensa sobre exposição Modern painters of Brazil [Pintores modernos do Brasil]. Arquivo MoMA, tradução nossa.
} 


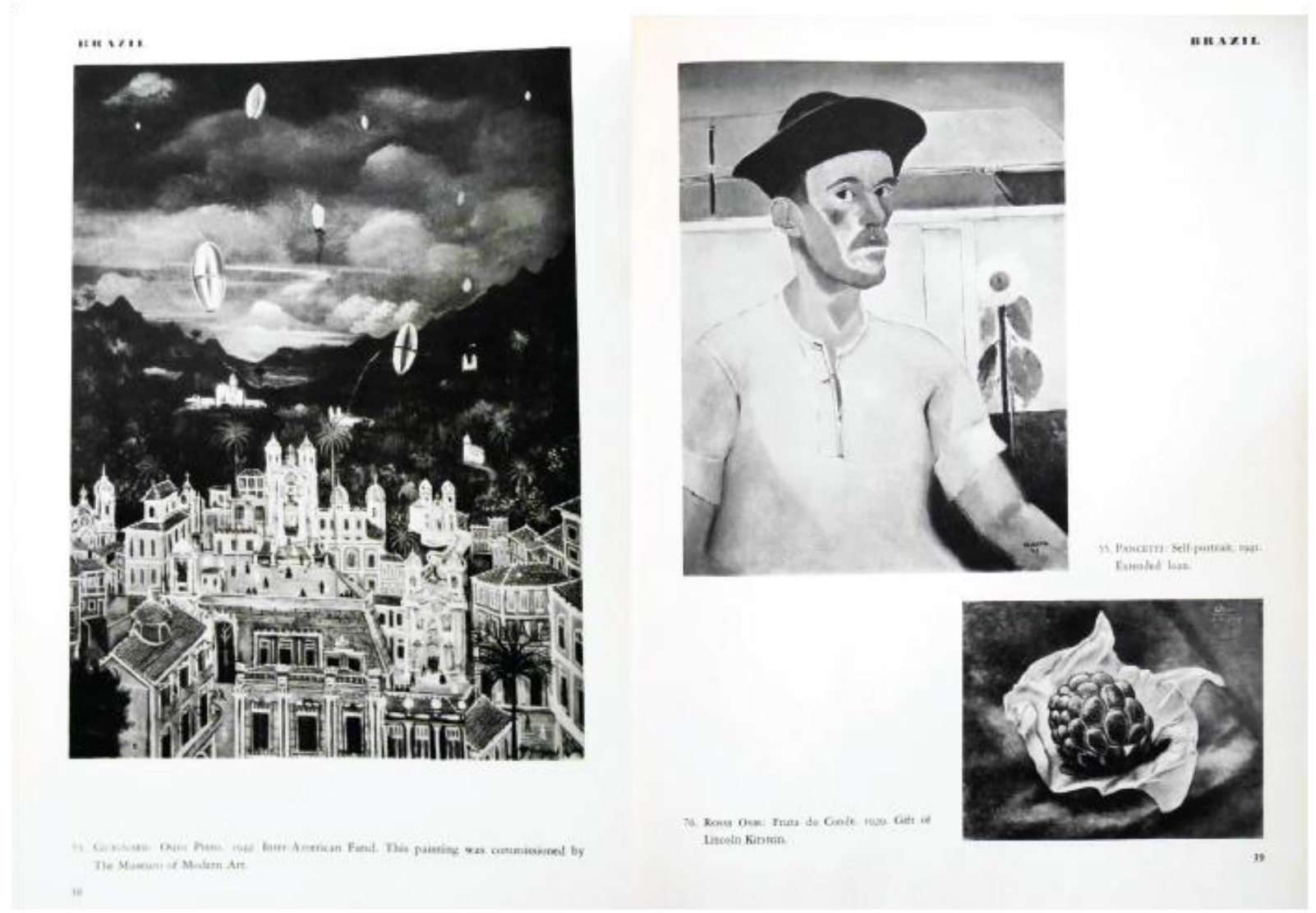

[Fig. 11] Reprodução do capítulo sobre o Brasil no catálogo The latin-american collection of MoMA, 1943.

A tentativa de compreender o cenário artístico brasileiro fazia parte dos esforços de aproximação política dos Estados Unidos. Com o CIAA, Nelson Rockefeller teve sua primeira experiência na coordenação de estratégias culturais e políticas para a América Latina. Para isso, ele usou extensivamente o conhecimento, os recursos e o tempo dos funcionários do MoMA. Algumas ações preferidas envolveram exposições de arte no Brasil, e mostras de pintura e arquitetura brasileira nos Estados Unidos. As parcerias iniciadas nos anos do CIAA seriam essenciais para o sucesso do intercâmbio pretendido com a doação de 1946. A arte era uma plataforma para o diálogo entre nações e seria um canal bem-sucedido para a aproximação política e cultural no Pós-Guerra.

Em 1943, os esforços do MoMA para atrair um número ampliado de frequentadores começavam a gerar frutos. A arrecadação da bilheteria engrossava. Um documento enviado pela administração do MoMA para Abby Rockfeller e membros do conselho, em outubro de 1943, aponta aumento de $18 \%$ no número de visitantes em relação ao mesmo período do ano 
anterior. ${ }^{60} \mathrm{~A}$ arrecadação dos ingressos tinha sido US\$2 mil maior entre os meses de julho e setembro de 1943. Mostras que exploravam o uso da reprodução fotográfica em grandes ampliações e com uma expografia dinâmica, como proposta por Edward Steichen em Road to victory - também financiada pelo escritório de Nelson Rockefeller em Washington - enchiam os olhos de um público crescente e diversificado.

A preocupação de que o museu não fosse visto como um lugar elitista e esnobe estava presente na correspondência entre a diretora da assessoria de imprensa do MoMA, Sarah Newmeyer, e Abby Rockefeller. Em uma das cartas trocadas em 1943 entre as duas senhoras, segue em anexo um recorte da revista This week, o suplemento semanal do jornal Herald Tribune. Na reportagem assinada pelo jornalista Clarence Woodbury e ilustrada por Harry Kane, o MoMA é retratado como um espaço atraente e convidativo para o "motorista de caminhão ao milionário". "O Museu de Art Moderna está fazendo um sucesso, servindo cultura e sanduíches. É o museu onde visitantes não precisam reverenciar a Arte com A maiúscula", dizia a reportagem. Na década de 1940, o MoMA já era uma instituição mais popular. As filas de entrada cresciam. O número de exposições aumentava, assim como seu alcance internacional para um público incipiente na América Latina.

Durante a Segunda Guerra Mundial, o MoMA passou por uma profunda transformação. Muitas de suas exposições passaram a ter como temática questões regionais e a incluir mostras mais populares, com o intuito de ampliar o público do museu. Esse processo de abertura andou lado a lado com o aumento da atenção também por arte latino-americana e brasileira em particular. É nesse momento de transição do museu que foram consolidadas as relações entre os curadores nova-iorquinos e os arquitetos brasileiros que seriam essenciais na articulação dos museus de arte no Brasil e das doações Rockefeller.

60 MoMA's Attendance Report for September 1943. Correspondência de Abby Aldrich Rockefeller. Série I. Rockefeller Archive Center. 


\section{A demissão de Alfred Barr}

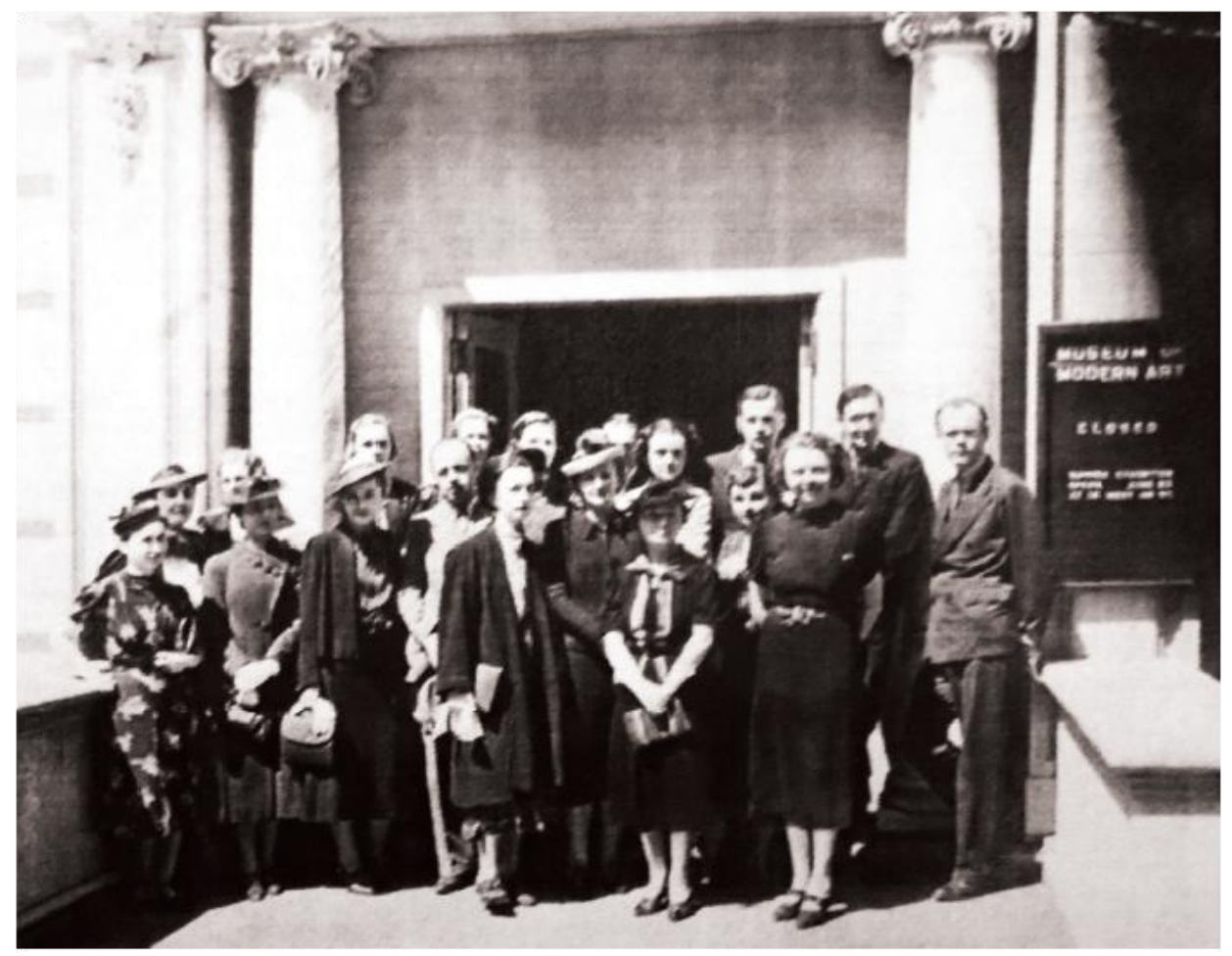

[Fig. 12] A gênese do MoMA. Alfred Barr (segundo da dir. a esq.) e a primeira equipe do museu em 1929.

Em 1943, algo improvável aconteceu no MoMA. A instituição sofreria uma mudança radical com a demissão do seu primeiro diretor, Alfred Barr. Ele tinha um comportamento difícil e a paciência da mesa diretora se esgotou em outubro daquele ano, meses depois da exposição Brazil builds. Nem a simpatia de Abby Rockefeller, que tinha apoiado Barr em várias disputas internas do museu, foi o suficiente para segurá-lo no cargo de diretor. No final, Abby chegaria a se referir ao temperamento de Alfred Barr de maneira impaciente: "Acho que a atitude de Alfred Barr me incomodou tanto quanto a você. Era como tentar conduzir um cavalo que não avançava. Talvez eu devesse dizer que era como tentar montar um cavalo teimoso" ${ }^{61}$, escreveu Abby, em confidência, para Stephen Clark.

61 "I think Alfred Barr's attitude disturbed me almost as much as it did you. It was like trying to drive a horse that wouldn't go ahead, and perhaps I should say it was like trying to drive a balky horse". ROCKEFELLER, [Abby]. (carta) 17 de novembro de 1943, Nova York [para] CLARK, [Stephen], Nova York. 1f. 
Há anos Barr sofria de exaustão e esgotamento mental, atrasando a entrega de artigos para os catálogos do museu e se recusando a cumprir prazos. Seus inimigos o acusavam de comportamento paranóico e falta de jogo de cintura para lidar até com os menores dos problemas administrativos corriqueiros de uma instituição em crescimento como o MoMA. No dia 15 de outubro, Stephen Clark, então diretor do conselho do museu, enviou uma carta para Alfred Barr, anunciando a demissão e descrevendo, minuciosamente, suas falhas enquanto diretor:

Prezado Alfred,

Faz algum tempo que os mais ativos membros do conselho estão preocupados com sua posição do museu. A preocupação deles tem surgido do fato de que muito de seu tempo tem sido gasto com a rotina administrativa e tão pouco no tipo de trabalho que você está particularmente qualificado a fazer.

Mrs. Rockefeller e eu conversamos frequentemente com você a respeito disso. Desde novembro de 1940 estamos incomodados com sua negligência pela produção de textos críticos e com seu fracasso em fazer qualquer progresso com a História da Arte Moderna.

[...]

Por causa disso, nós chegamos infelizmente à conclusão de que é no melhor interesse do museu que você se retire do cargo de diretor e continue suas atividades como diretor assistente, com um salário de $\$ 6,000$ ao ano. Como diretor assistente você não teria nenhuma função administrativa ou obrigação de manter um escritório no museu. Nós, contudo, esperamos contar com o benefício de seu conhecimento e recomendações como membro do conselho e de vários comitês. Nós esperamos também que você produza trabalhos de história da arte e crítica que serão publicados com apoio do museu.

$[\ldots]$

Devo dizer, em conclusão, o quanto lamentamos ter que tomar esse passo. Todos nós temos consciência dos grandes serviços que você prestou ao museu e todos nós mantemos os mais amistosos e carinhosos sentimentos em relação a você. Quando o choque inicial desta decisão passar, talvez você perceba que 
estamos tomando essa medida em seu interesse. Se você continuar a se preocupar com todos os mais triviais detalhes da administração do museu e continuar a gastar a maior parte de seu tempo revisando e editando o trabalho de outras pessoas, logo você vai perder a capacidade de fazer qualquer trabalho próprio original. Você tem grande talento e uma grande reputação no mundo da arte, mas por vários anos tem feito pouco para justificar essa reputação. Você agora terá a oportunidade e o incentivo de dedicar sua total atenção ao tipo de trabalho com real valor para você e para o museu. ${ }^{62}$

Assim, o MoMA perdia o seu mais emblemático diretor, cuja biografia seria para sempre entrelaçada à história do surgimento de um dos primeiros museus modernos. Barr havia treinado uma geração de curadores, criado uma estrutura museológica inovadora - com departamentos específicos para o estudo e pesquisa dos vários suportes artísticos - e escrito textos seminais para a história da arte moderna. Mas tudo isso já era passado. No final de 1943, o museu entrava em uma segunda fase de maturação.

Alfred Barr foi substituído por James Soby, o novo chefe de departamento de Pintura e Escultura e também o organizador dos esforços de guerra do museu. As funções administrativas

62 "Dear Alfred/ For some time past a number of our more active Trustees have been greatly concerned about your position in the Museum. Their concern has arisen from the fact that so much of your time has been spent on administrative routine and so little on the kind of work you are particularly qualifies to do. / Mrs. Rockefeller and I have talked to you frequently about this matter. I find that as far back as November 1940 we were disturbed over your neglect of critical writing and over your failure to make any progress with the History of Modern Art. / Because of that fact, we have regretfully reached the conclusion that in the best interest of the Museum you should retire from the office of Director and assume the position of Advisory Directir, at a salary of $\$ 6,000$ a year. As Advisory Director you would not have any administrative or executive duties or the obligation to maintain an office in the Museum. We would, however, expect to have the benefir of your knowledge and advice as Trustee and as a member of various comittees. We hope, also, that you would produce various Works of art history and criticismo which would be published under the sponsorship of the Museum. / May I say, in conclusion, how greatly we regret the necessity for taking this step. All of us are mindful of the great services you have rendered to the Museum and all o us have the friendliest and kindliest feelings toward you. When the first shock of this decision wears away you may, perhaps, realize that in taking this step we are acting in your own interest. If you go on worrying over petty details of museum management and continue to spend most of your time editing and revising the work of other people you will soon lose the capacity to do any original work of your own. You have great talents and a great reputation in the world of art, but for several years past you have done little to justify that reputation. You will now have the opportunity and incentive to devote your undivided attention to the kind of your that will be of real value to yourself and to the Museum". CLARK, [Stephen]. (carta) 15 de outubro de 1943, Nova York [para] BARR, [Alfred], Nova York. 3f, tradução nossa. 
da diretoria foram compartilhadas por uma comissão. Depois de negociar um novo salário e uma saída honrosa, Alfred Barr permaneceu na instituição, mantendo um escritório dentro do museu e assumindo o cargo de diretor de aquisições. Barr foi afastado com a premissa de que teria mais tempo para se concentrar na escrita sobre a história da arte moderna e terminar um grande livro sobre Henri Matisse.

Barr sempre tinha se mostrado um observador tenaz e, mesmo após sua demissão do MoMA, ele continuaria a assessorar Nelson Rockefeller na escolha de obras para sua coleção particular, além de desempenhar outras atividades pontuais para os Rockefellers. A escolha das obras que seriam doadas ao Brasil seria uma destas atividades. Em um final de semana de novembro de 1946, Alfred Barr, acompanhado de sua pupila Dorothy Miller, visitou as principais galerias de Midtown Manhattan para escolher as 14 obras que Nelson Rockefeller levaria de presente para o Brasil dias depois. 


\section{A presença de René D’Harnoncourt no Brasil}

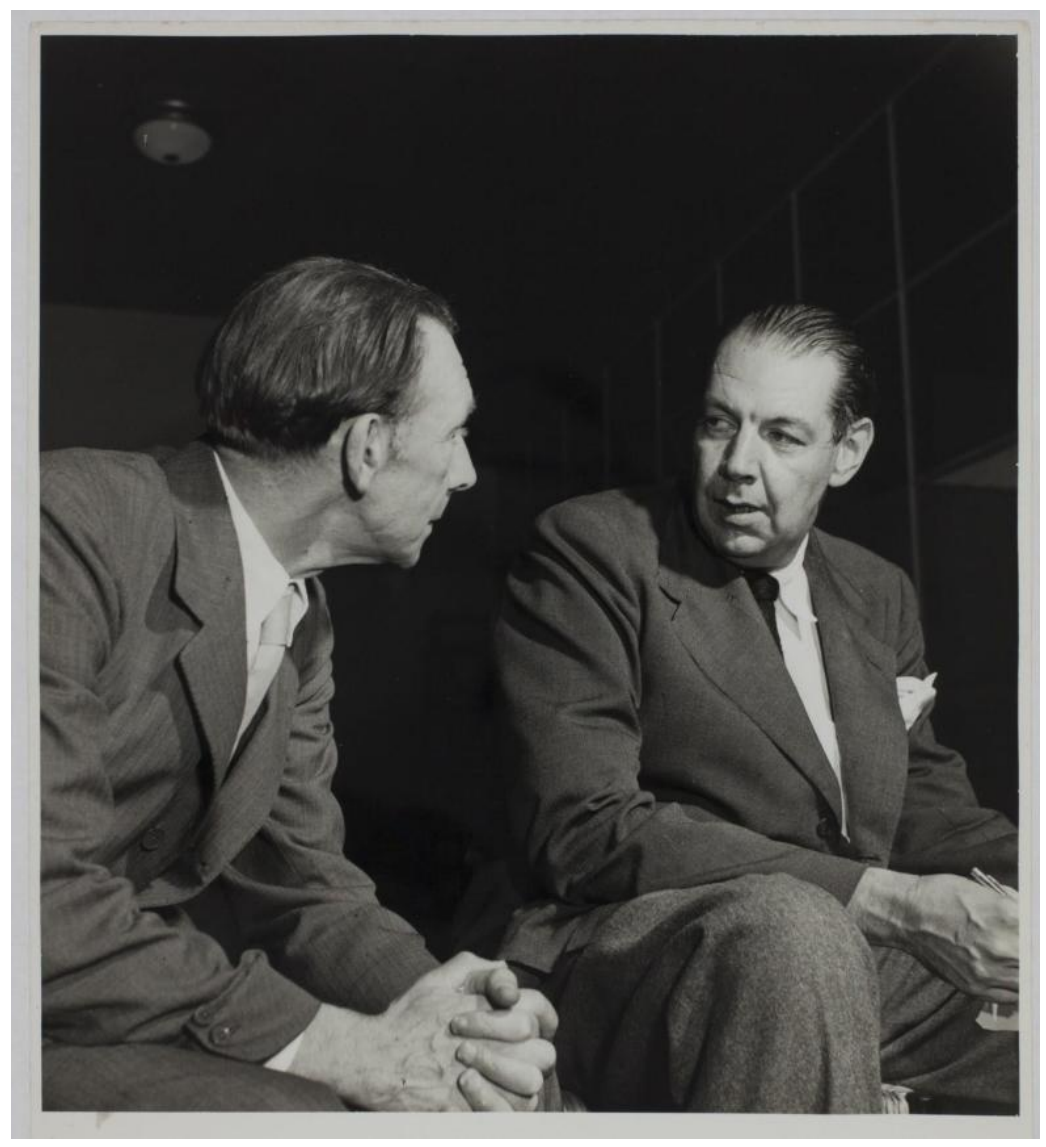

[Fig. 13] René d'Harnoncourt na I Bienal. Ele foi o responsável por supervisionar a instalação das obras da seção norte-americana da I Bienal de São Paulo.

Mesmo sem Alfred Barr no comando, o Museu de Arte Moderna avançava a todo vapor. A equipe de funcionários crescia com novas contratações. Vários dos recém-admitidos eram trazidos do CIAA, como, por exemplo, René d'Harnoncourt, que seria nomeado diretor do MoMA em 1949. Nascido em Viena em 1901, filho de pai franco-austríaco e mãe checa, René foi educado em casa até os 10 anos. Estudou química e filosofia da Universidade de Graz e engenharia na Politécnica de Viena. Pintava nas horas vagas e, com colegas da faculdade, organizou uma exposição de gravuras de Matisse e Picasso em Graz. A cidade abrigava um dos museus mais antigos de arte primitiva da Europa, uma obsessão de René para o resto da vida. A paixão pela arte dos povos não-ocidentais seria um interesse compartilhado por René e Nelson 
Rockefeller, assim como por seu filho Michael. Juntos fundariam, em 1954, o Museu de Arte Primitiva em Nova York, com peças de povos da Oceania, Ásia e Américas. A coleção pertence hoje ao Metropolitan Museum of Art.

René d'Harnoncourt chamou atenção de Nelson Rockefeller em 1938, quando o austríaco naturalizado norte-americano organizou uma exposição de arte indígena para o Departamento de Interior. Em 1943, Nelson contratou René para dirigir a Seção de Arte do Escritório do Coordenador de Assuntos Interamericanos. No ano seguinte, com a extinção do Programa para as Artes do CIAA, René foi absorvido pela equipe do MoMA e nomeado vicepresidente de Atividades Internacionais, cargo que compartilhou com a segunda função de diretor do Departamento de Indústrias Manuais, voltado para a preservação de esculturas, tapeçarias e outras formas artísticas de povos indígenas.

Apesar da temporada curta no CIAA, René d'Harnoncourt daria continuidade no MoMA ao trabalho de aproximação cultural com a América Latina. Essa era a sua especialidade. Ele tinha feito muitos contatos na região, especialmente no México, país onde tinha morado nos anos 1920 e tentado sobreviver como artista. A ação mais importante de sua carreira neste sentido foi uma viagem pelo México, Peru, Chile, Argentina e Brasil como representante do MoMA. Ao longo de três meses, René estabeleceu contatos com diretores de museus e membros da elite cultural. No caso brasileiro, os relacionamentos travados por René, entre dezembro de 1944 e março de 1945, e as conclusões trazidas por ele aos ouvidos de Nelson seriam fundamentais para que Rockefeller buscasse a aproximação com o grupo de intelectuais e arquitetos do IAB.

Em 9 de abril de 1945, René d’Harnoncourt entregou um relatório detalhado sobre sua viagem à América Latina. Tinha feito um mapeamento do cenário cultural de cada um dos países visitados e sugeria estratégias específicas de como ampliar a aproximação com a região. O objetivo oficial da viagem de René era fazer um levantamento de galerias, livrarias e museus que pudessem ser interlocutores e atuar como postos avançados do MoMA, promovendo assinaturas das publicações do museu, venda de livros e exposições. Essas alianças eram essenciais devido às dificuldades da época para o envio de dinheiro ao exterior. Por isso, para que o MoMA pudesse expandir seu alcance internacional, era necessário estabelecer parcerias 
locais. Funcionários norte-americanos nos escritórios regionais do CIAA no Rio de Janeiro e São Paulo serviriam de auxílio para garantir a transferência de recursos gerados com a venda de publicações e reproduções para Nova York.

A entusiástica recepção como representante do Museu em todos os lugares que fui muito excedeu minhas expectativas e não há dúvida de que o Museu é considerado por todos os intelectuais da América Latina uma instituição líder do hemisfério. O desejo de se tornar um membro e participar das atividades do Museu foi manifestado para mim em todos os países e as cartas que recebi desde o meu retorno confirmam a sinceridade dessas manifestações. ${ }^{63}$

Segundo o relatório de d'Harnoncourt, em São Paulo o primeiro contato citado é o do "Sr. Mesquita", cuja livraria é "o ponto de encontro de artistas, arquitetos e pessoas da sociedade ${ }^{\prime 64}$. René d’Harnoncourt se referia à livraria Jaraguá na Rua Marconi, n.54, fundada por Alfredo Mesquita, dramaturgo e idealizador da pioneira revista Clima. Os parceiros locais do MoMA eram agraciados com uma comissão de $25 \%$ sobre a venda de assinaturas, mas o serviço que despertou o maior interesse dos paulistanos foi envio de películas. "As dificuldades com a censura tornam um programa de circulação de filmes impossível até o final da guerra” ${ }^{65}$, lamentou René. Ele teve problemas também para montar o seu relatório final, pois o departamento de censura não Ihe permitiu levar para os Estados Unidos quaisquer notas ou

63 "The enthusiastic reception I received as a representative of the Museum everywhere I went far exceeded my expectations and there is no question that the Museum is considered by all progressive intellectuals of Latin America as the leading institution of the hemisphere. The desire to become a member and to participate in the activities of the Museum was manifested to me in every country and the letter I have received since my return bear out the sincerity of these protestations". Relatório da Viagem para a América Latina Dec. 27, 1944 a 23 de Mar, 1945. Rene d'Harnoncourt to Board of Trustees. René d'Harnoncourt Papers. Series II. Folder 28. Arquivo do MoMA, tradução nossa.

64 "In Sao Paulo the book store of Sr. Mesquita, a meeting-place of artists and architects and society people, has accepted the responsibility to act as our membership agent". D'HARNONCOURT [René]. (carta) 9 de abril de 1945 [para] Board of Trustees. Coleção René d'Harnoncourt. Série II. Pasta 28. Arquivo do MoMA, tradução nossa.

65 "Since censorship difficulties make a circulation program impossible until after the end of the war". D'HARNONCOURT [René]. (carta) 9 de abril de 1945 [para] Board of Trustees. Coleção René d'Harnoncourt. Série II. Pasta 28. Arquivo do MoMA, tradução nossa. 
documentos sobre o Brasil. Suas anotações tiveram de ser remetidas na forma de documentos consulares via as embaixadas e escritórios comerciais norte-americanos no Rio de Janeiro, São Paulo e Belém.

Nesta viagem, René garantiu a parceria do Instituto de Arquitetos do Brasil, organização para a qual Nelson doaria, em caráter temporário, as 14 obras de 1946. “O efeito de Brazil builds nos garante a cooperação, de coração aberto, dos jovens e ativos arquitetos, e eu também fui capaz de garantir o apoio de Portinari em São Paulo", congratulou-se René, em carta para o presidente do conselho do MoMA, Stephen Clark, em abril de $1945 .^{66}$

O documento mais interessante da série sobre a viagem de d'Harnoncourt à América Latina é uma lista de sete tópicos intitulada "Esboço de Coisas Possíveis a Serem Realizadas no Brasil pelo Museu de Arte Moderna". O memorando não é assinado e faz parte de uma discussão interna e estratégica do MoMA. Uma marcação a lápis indica que o texto foi enviado para ciência de Nelson Rockefeller. No documento, é discutida a viabilidade do envio de exposições anuais ao Brasil, com material reunido em cooperação com o Departamento de Estado, a Galeria Nacional ou o Conselho de Interamericano, nos moldes da exposição Brazil builds. Outra iniciativa citada mencionava a organização de mostras de cinema bimestrais com divulgação nos vários cineclubes do país - "o interesse neste campo é grande e muito pode ser feito. Se vários filmes pudessem ser enviados agora, que Nelson possa inaugurar ou apoiar, seria muito popular" ${ }^{\prime 67}$. Um ponto do memorando busca meios de facilitar a presença de artistas brasileiros nos Estados Unidos por meio do Conselho Interamericano. O documento reconhece a dificuldade para um artista brasileiro planejar qualquer tipo de mostra "caso não tenha amigos aqui".

São várias as estratégias pensadas para uma aproximação institucional com o Brasil. Contudo, o item mais relevante para esta pesquisa está no sexto comentário do memorando e

66 "The effect of Brazil builds insures us the wholehearted cooperation of the young and active architects and I have also been able to secure the help of Portinari in São Paulo". D'HARNONCOURT, [René]. (carta) 2 de abril de 1945, Nova York [para] CLARK, [Stephen], Nova York. 3f.

67 "If several films could be mailed now which Nelson could inaugurate or sponsor, it would be very popular". Possible outline of things to do in Brazil for The Museum of Modern Art. Coleção René d'Harnoncourt, Série II, Pasta 28, Arquivo do MoMA, tradução nossa. 
consiste na primeira referência encontrada nos arquivos do MoMA e do Rockefeller Archive Center sobre a doação de 1946:

Nelson falou em dar várias pinturas para o Museu do Rio e para o incipiente Museu de Arte Moderna em São Paulo. Isso será visto de maneira positiva, tenho certeza, mas como é um precedente precisa passar por uma cuidadosa consideração. Deve ser um presente pessoal ou institucional? Qual deve ser a nossa política futura? ${ }^{68}$

Esse questionamento nos fornece uma janela importante para o pano de fundo que norteou a doação. O memorando toca num ponto sensível. Temia-se que o presente de Rockefeller poderia, de alguma forma, ferir as sensibilidades dos brasileiros e mais atrapalhar do que ajudar a causa da aliança política com o país. Havia uma preocupação grande em não estimular críticas anti-imperialistas com a doação e, assim, implodir todo o trabalho de aproximação sendo realizado desde os anos do CIAA. O cuidado cirúrgico no contato com os brasileiros tinha como base outro alerta registrado por d'Harnoncourt no retorno da viagem à América Latina:

Já que a atitude defensiva de muitos latino-americanos em relação aos Estados Unidos é baseada no medo de perder sua identidade cultural sob a pressão da influência dos Estados Unidos, introduzida particularmente pelos filmes e revistas, nosso programa deve enfatizar que nós não consideramos as relações culturais como um veículo de imposição da nossa cultura ou mesmo apresentá-la como um modelo para eles, mas como meio de dar a eles instrumentos para construir suas próprias características culturais. Devemos ressaltar que nós percebemos que, de um ponto de vista egoísta, só podemos ganhar com as realizações culturais latino-americanas se elas não forem cópias

68 "Nelson spoke of giving several pictures to a Museum in Rio and the incipient Museum of Modern Art in Sao Paulo. This would well be thought of I am sure but as a precedent it needs careful consideration. Should the gift be personal or institutional? What is the future policy to be?" Possible outline of things to do in Brazil for The Museum of Modern Art. Coleção René d'Harnoncourt, Série II, Folder 28, Arquivo do MoMA, tradução nossa. 
de nossos próprios esforços, mas contribuirem com algo original para a civilização como um todo. ${ }^{69}$

O direcionamento de René d'Harnoncourt balizou as ações da equipe envolvida na doação de 1946. Tanto as correspondências trocadas por Carleton Sprague Smith com os paulistas quanto as declarações feitas por Nelson à imprensa brasileira descrevem as obras "não como pedras de fundação para coleções futuras", mas tão somente "estímulos" para a promoção de museus modernos no Brasil. A decisão de tratar a doação como obras provenientes do acervo particular de um generoso Rockefeller foi um subterfúgio diplomático.

A documentação existente nos arquivos indica que as pinturas e esculturas doadas nunca fizeram parte da coleção privada de Nelson, exceto os dois Légers. Na realidade, elas foram adquiridas por Alfred Barr e Dorothy Miller com o intuito específico de serem enviadas ao Brasil como a representação da mais contemporânea arte moderna em voga nos Estados Unidos.

A seguir, descreve-se o trabalho da curadoria na seleção dessas obras, mostrando como ela estava em sintonia com o discurso sobre arte moderna promovida pelo MoMA nessa época. Uma narrativa sobre a história da arte morte que era endossada pelo governo norte-americano e utilizada em exposições oficiais para fazer avançar a presença cultural dos Estados Unidos nos anos 1940.

69 "Since the defensive atitude of many Latin Americans toward the United States is based on a fear of losing their cultural identity under the pressure of United States influence, introduced particularly through the movies and magazines, our program should stress the fact that we do not consider cultural relations as a vehicle of imposing our culture or even presenting it as a model to them, bus as a means of giving them the tools for building up their own characteristic cultural forms. We should let them know that we realize the from na egoistic point of view we can only gain from Latin American cultural achievements if they are not copies of our own endeavors but contribute something original to civilization as a whole". Recomendaçoes no campo do intercâmbio cultural. Documento anexo à carta de René d'Harnoncourt para Stephen C. Clark, 2 abr. 1945. René d'Harnoncourt Papers. Series II. Folder 28. Arquivo do MoMA, tradução nossa. 


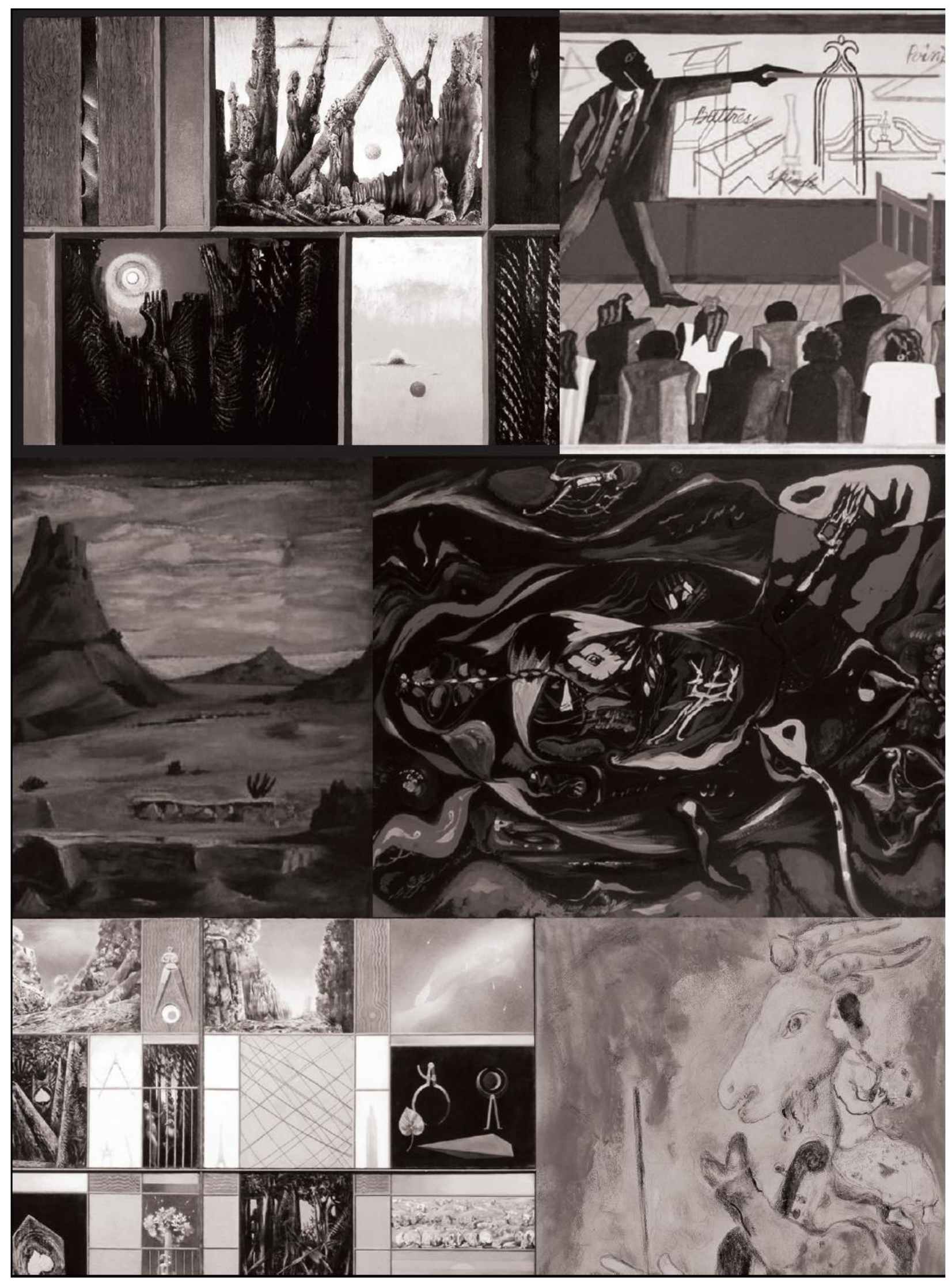




\section{Doação Nelson Rockefeller de 1946}

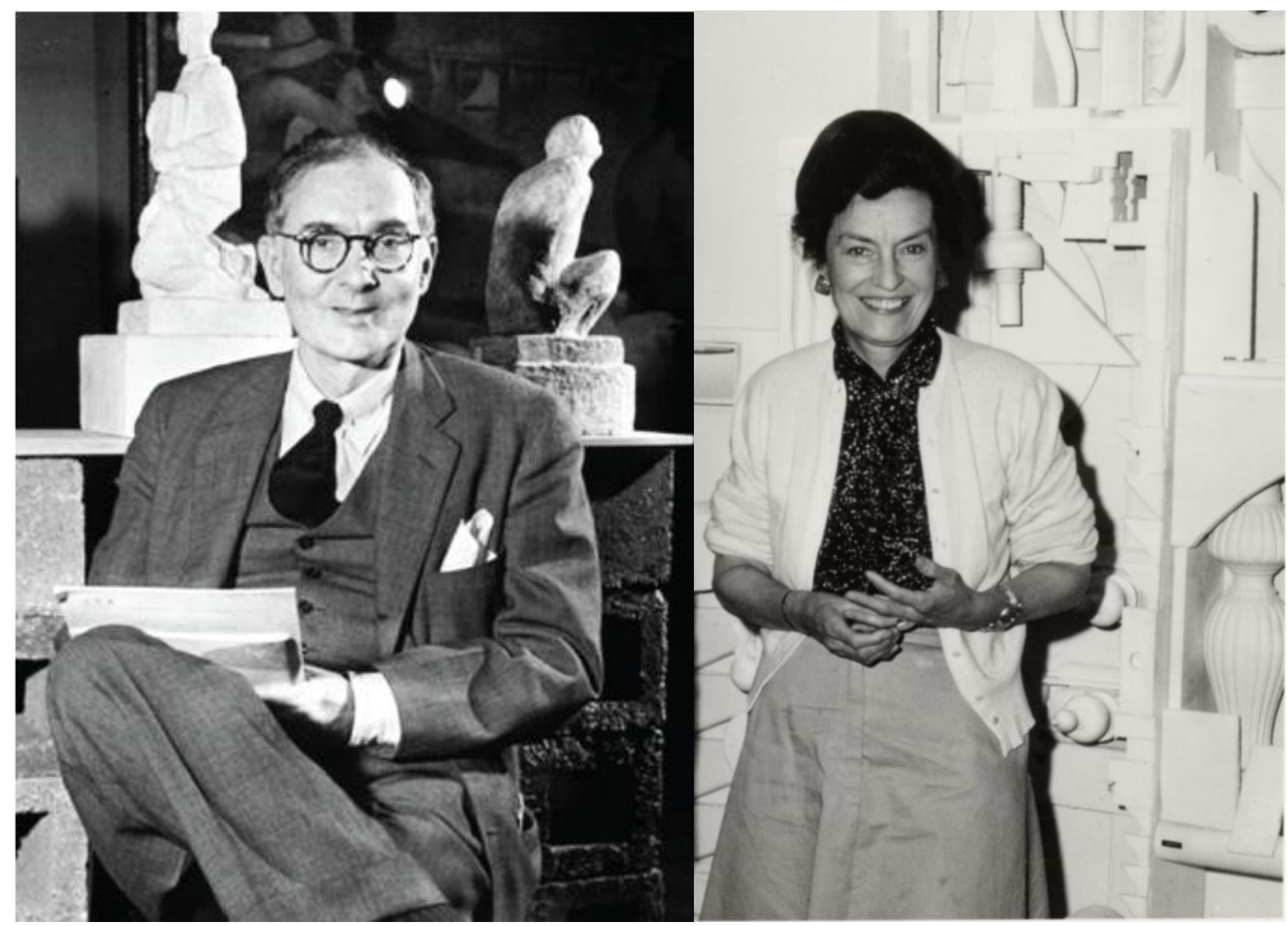

[Fig. 15] Os curadores do MoMA responsáveis pela doação Rockefeller: Alfred Barr e Dorothy Miller.

Em 13 de novembro de 1946, Alfred Barr escreveu uma carta informando Nelson Rockefeller sobre as obras adquiridas para o Brasil. A compra das 13 pinturas e uma escultura foi realizada às pressas, em uma investida de Alfred Barr e Dorothy Miller pelo circuito de galerias de Nova York.

Dorothy Miller era a curadora do MoMA responsável pelas exposições Americans [Americanos], série iniciada em 1942 com o intuito de apresentar novos nomes da arte moderna do país. Miller, que tinha começado a carreira no MoMA como assistente de Barr, havia se tornado um dos principais nomes do museu. Ela tinha profundo conhecimento do estoque disponível nas galerias de Midtown Manhattan e bom relacionamento com os vendedores. Não por acaso, artistas presentes nas suas mostras Americans [Americanos] foram 
inseridos na doação brasileira, entre os quais Everett Spruce, Jacob Lawrence, Arthur Osver e Morris Graves. Em poucos dias, Barr e Miller reuniram a coleção, pinçando os melhores trabalhos disponíveis nos acervos das galerias Downtown, Pierre Matisse, American Artists Association, Art of This Century, todas localizadas em um raio de poucas quadras de distância do MoMA.

“Devo dizer que tanto Dorothy quanto eu gostamos muito de fazer essas compras. Se tivéssemos mais tempo, a seleção poderia ter sido melhor", confessou Barr a Nelson, na carta escrita um dia antes da partida do Rockefeller ao Rio. ${ }^{70}$ Sobre a qualidade da mostra reunida em tão pouco tempo, Barr avalia: “Em minha opinião, todos os trabalhos são de boa qualidade, alguns deles de excepcional qualidade". Anexo à carta, Barr montou um relatório sobre as obras, com lista de preços, fotos, biografias dos artistas e um manual de instruções redigido por d'Harnoncourt de como montar o móbile do Calder. As informações deveriam assessorar a comitiva de Nelson na interlocução com os brasileiros. "Você e Carleton vão resolver no local exatamente como querem usar esse material", disse Barr. Sua sugestão, contudo, era dividir as obras entre o Rio de Janeiro e São Paulo da seguinte maneira:

São Paulo ficaria com Women of the circus [Mulher de circo] (1946) de Byron Browne, Yellow plane [Plano amarelo ou Móbile amarelo, preto, vermelho e branco], sem data, de Alexander Calder, Bestiality marches on [Bestialidade avança] (1933) de George Grosz, In the night [Na noite] (1943) de Morris Graves, uma Composition [Composição] (1938) de Fernand Léger, Germination [Germinação] (1942) de André Masson e Spring [Primavera] (1938) de Marc Chagall. O Rio de Janeiro seria presenteado com Antelope mountain [Montanha antílope] (1946) de Everett Spruce, Standard bearer [O porta-estandarte] (1946) de Robert Gwathmey, Lecture on architecture [Aula de arquitetura] (1946) de Jacob Lawrence, Forest of chimneys

70 "Dear Nelson, (...) The works are, as you wished, all by younger artists ranging in age from Jacob Lawrence who is 29 to the oldest, Calder, who is 48. Most of them are in their 30's. George Grosz, if you include him among the Americans, is older. The works by Europeans living in this country were all done in the United States with the exception of the Chagall. (Your two Legers, I think, were done here in 1938). (...) In my opinion all the works are of good quality, some of them of exceptional quality. You and Carleton will work out on the spot just how you want to use this material. Let me say that both Dorothy and I greatly enjoyed making these purchases. If we had had more time the selection might have been better and certainly the biographies, etc., more complete. Good luck to you". Carta para Nelson Rockefeller, 13 Nov. 1946. Coleção NAR. Grupo: Museus. Série: II 4 L. Caixa: 148. Folder 1964, tradução nossa. 
[Floresta de chaminés] (1945) de Arthur Osver, a segunda Composição (1936) de Léger, Ocean for birds [Oceano para pássaros] (1945) de Yves Tanguy e Picture for young people [Quadro para jovens] (1943) de Max Ernst.

Segundo a carta de Barr para Rockefeller, o princípio norteador da seleção era apresentar os novos modernos. "As obras norte-americanas são, como você queria, todas de 'jovens' artistas, variando da idade de Jacob Lawrence, que tem 29, até o mais velho, Calder, que tem 48. A maioria deles está em seus 30. George Grosz, se você incluí-lo entre os norteamericanos, é o mais velho", escreveu Barr.

Além dos trabalhos da nova geração, os curadores escolheram pinturas de artistas renomados da Europa, mestres como Chagall, Léger, Ernst, Masson e Tanguy. Barr ressalta que - exceto o guache de Chagall - "todas as obras foram realizadas nos Estados Unidos". Só é possível entender a importância desse comentário se levado em conta o contexto histórico.

No ano de 1946 era muito importante consolidar o papel pioneiro dos Estados Unidos na promoção e consagração da arte moderna no mundo Ocidental. Por isso, a doação deveria ressaltar o trabalho dos jovens norte-americanos, assim como de artistas europeus exilados em Nova York. Durante a Segunda Guerra Mundial, o mercado da arte passou por uma revolução com a imigração em massa de intelectuais e artistas da Europa para os Estados Unidos. A ebulição cultural em Nova York transformou a cidade no novo epicentro artístico do mundo.

Neste sentido, a doação Rockefeller de 1946 pode ser dividida em dois grandes grupos principais: "novos americanos" e "europeus no exílio". Esses dois pólos artísticos refletem o momento artístico, mas também as características curatoriais das duas pessoas responsáveis pelas aquisições. Enquanto a carreira de Dorothy Miller era marcada pela promoção de novos nomes na arte norte-americana, Alfred Barr tinha como referência principal a geração anterior das vanguardas da Europa. A elegante mistura dessas duas tendências, e personalidades, resultou em uma coleção ímpar, cujo valor artístico e histórico é imensurável.

A doação Rockefeller de 1946 é de extrema importância, pois além de compor o acervo inicial do primeiro museu de arte moderna do Brasil, é testemunho cristalino da mudança do cenário artístico do Pós-Guerra, cujo centro de gravidade mudou de Paris para Nova York. 


\section{Os novos norte-americanos}

Dorothy Miller trabalhou no MoMA por quase 35 anos. Começou como assistente de Alfred Barr em 1935 e, pacientemente, ascendeu à hierarquia do museu até ser promovida à curadora sênior de coleções, cargo pelo qual se aposentou em 1969. Antes de ser contratada pelo MoMA, Dorothy Miller já tinha alguma experiência. Em 1935, fez o curso de John Corton Dana, fundador do Museu de Arte de Newark e um dos primeiros formalizar práticas modernas de profissionalização da museologia. Dorothy trabalhou em Newark de 1926 a 1930, depois na catalogação de objetos de arte indígena do Museude Arte de Montclair, até ser chamada para colaborar na organização de um catálogo do MoMA em 1932. Quem primeiro despertou o interesse de Dorothy por arte moderna norte-americana foi Holger Cahill, diretor-geral do Federal Art Project e seu futuro marido.

A personalidade e vigor de Dorothy deixariam sua marca para sempre na história do MoMA. Ela é talvez mais lembrada hoje pela destemida persistência com que promoveu o trabalho de novos artistas norte-americanos em exposições pioneiras para seu tempo. Em particular, destaca-se a série de seis exposições intitulada Americans [Americanos], organizadas desde 1942 até 1963. ${ }^{71}$ Diferentemente das grandes coletivas em que artistas são representados por uma ou duas obras, essas exposições priorizavam não mais do que 20 artistas, cada um com uma galeria inteira só para suas obras. Elas serviram como importantes vitrines para o lançamento de novos nomes, entre os quais Alton Pickens, Everett Spruce, Morris Graves, Jacob Lawrence e Arthur Osver, artistas inseridos nas doações Rockefeller, além de personalidades como Jackson Pollock e Mark Rothko nos anos 1950.

No catálogo da primeira edição da série, Americans 1942 - 18 artists from 9 states [Americanos 1942 - 18 artistas de 9 estados], Dorothy Miller define o pilar conceitual desse conjunto de exposições:

71 Americans 1942 - 18 Artists from 9 States [Americanos 1942 - 18 artistas de 9 estados] (1942), Fourteen Americans [Quatorze americanos] (1946-1956), Fifteen Americans [Quinze Americanos] (1952), 12 Americans [12 americanos] (1955-1957), The New American Painting [Nova pintura Americana] (1957-1961) e Sixteen Americans [Dezesseis americanos] (1959-1963). 
Americanos 1942 é a primeira de uma série de exposições que o Museu de Arte Moderna de Nova York está planejando e que vai providenciar um levantamento contínuo das artes nos Estados Unidos durante os anos 1940. (...) O número de artistas desta exposição foi mantido pequeno a fim de que cada um possa ser representado por um grupo suficiente de trabalhos para dar um indicativo do estilo e personalidade. $^{72}$

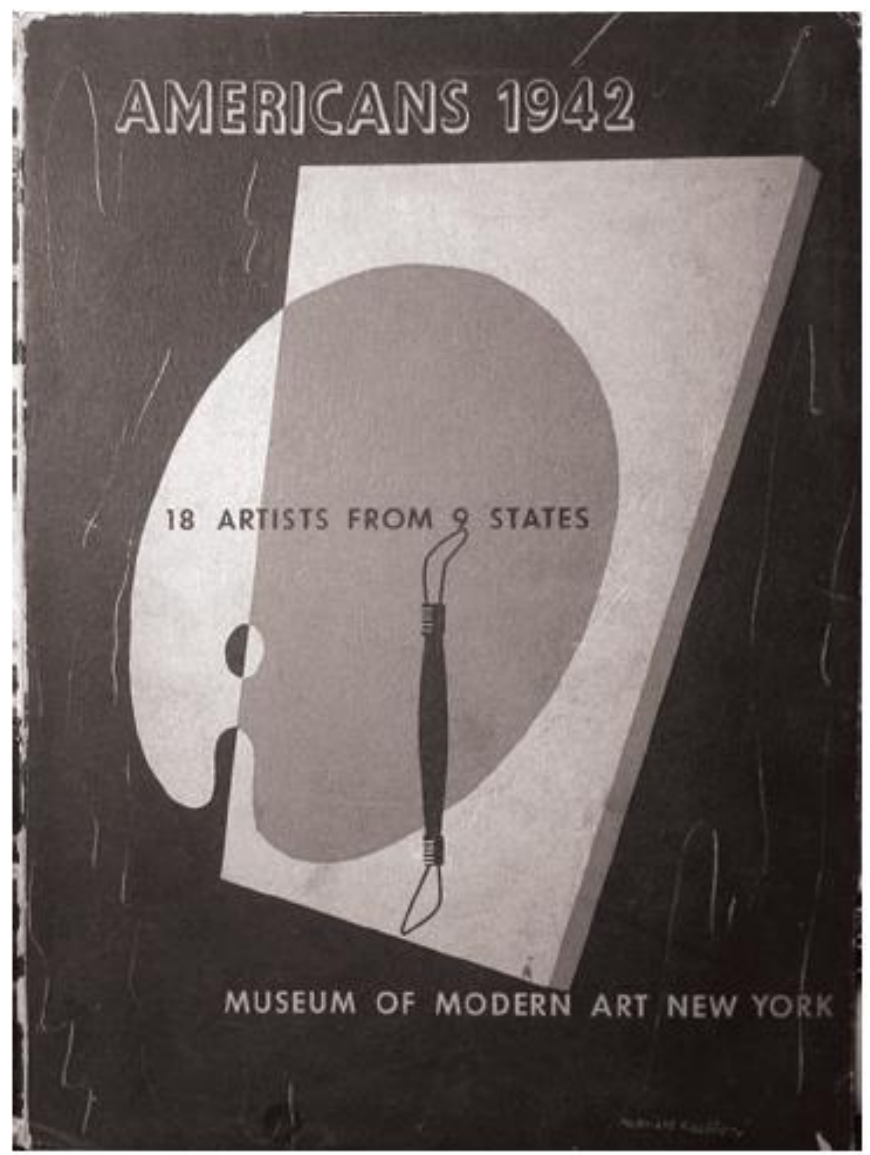

[Fig. 16] Catálogo da exposição do MoMA Americans 1942 [Americanos 1942].

72 "Americans 1942 is the first of a series of exhibitions which the Museum of Modern Art is planning and which will provide a continuing survey of the arts in the United States during the 1940's. (...) The number of the artist in the exhibition has been kept small in order that each might be represented by a group of works sufficient to give an indication of style and personality". Catálogo da exposição Americans 1942, p. 9, 1942, tradução nossa. 
Em relação ao caso específico dessa exposição, um esforço foi feito para apresentar artistas que estavam fora do circuito nova-iorquino. Os pintores vinham do interior do país e trabalhavam para as bases regionais do Federal Art Project (FAP) dirigido por Holger Cahill. A intenção de Dorothy era mostrar o grupo de elite de artistas vinculados ao programa federal liderado, coincidentemente ou não, por seu marido. Por sua vez, Nelson Rockefeller e Alfred Barr tinham publicamente defendido o programa de fomento às artes. E o MoMA, desde os anos 1930, vinha fazendo aquisições pontuais do FAP e inserindo essas obras em exposições panorâmicas de arte moderna.

A proposta de Dorothy era, contudo, muito mais focada e agressiva. Tinha como objetivo criar definitivamente um espaço - e um mercado - para artistas pouco conhecidos em Nova York. O discurso sobre os novos artistas tocava na descoberta da arte regionalista e, como pedia o momento político, passava pela promoção dos ideais democráticos dos Estados Unidos. Sobre os 18 artistas vindos do Texas, Califórnia, Oregon, Washington, Missouri, Michigan, Illinois, Pennsylvania e Massachussetts para a primeira exposição da série, ela comenta:

Americanos 1942 cobre um amplo leque geográfico, mas o alcance do trabalho em si é ainda maior. Termos abrangentes como cena norteamericana, comentário social, neo-romantismo, surrealismo, e abstração podem ser usados para descrevê-lo, mas grande parte não cabe nessas categorias. Alguns dos artistas na exposição reagem de maneira intensamente pessoal ao mundo (...) Outros têm uma complexa e cultivada abordagem para o problema artístico da maestria em seus dois mundos - o mundo interior da emoção e ideia e o mundo externo. Outros ainda expressam uma luta espiritual, um intenso esforço interno para a expressão primária da forma. Tudo isso só é possível diante da liberdade que a nossa democracia fornece ao artista. Nenhuma arregimentação, compulsão ou restrição poderia suscitar expressões tão ricas e diversas do espírito criativo de um povo. ${ }^{73}$

73 "Americans 1942 cover a wide geographical range but the range of the work itself is even wider. Omnibus terms such as American scene, social comment, neoromanticism, surrealism, and abstraction might be used to describe it, but much of it cannot be fitted into these categories. Some of the artists in the exhibition react in a highly 
Entre nomes escolhidos nessa primeira mostra da série Americans [Americanos], dois são particularmente importantes para esta pesquisa: Everett Spruce e Morris Graves. Ambos inseridos na doação Rockefeller, esses artistas faziam parte do poleiro de Dorothy Miller e representavam, cada um a sua maneira, a diversidade da nova arte. Ao passo que Spruce era vinculado ao grupo de paisagistas dedicados à representação do "grande interior americano", Graves investigava a mística do subconsciente humano em composições expressionistas.

personal way to an environment which has been closely observed and keenly felt. Others have a complex and cultivated approach to the artist's problem of mastery in his two worlds - the inner world of emotion and idea and the outer world of fact. Still others express a spiritual wrestling, an intense inner striving for a primary utterance of form. All this is possible only in the liberty which our democracy gives to the artist. No regimentations, no compulsions or restrictions could call forth such richly various expressions of a people's creative spirit". Catálogo da exposição American 1942, p. 9, 1942, tradução nossa. 


\section{In the night, Morris Graves}

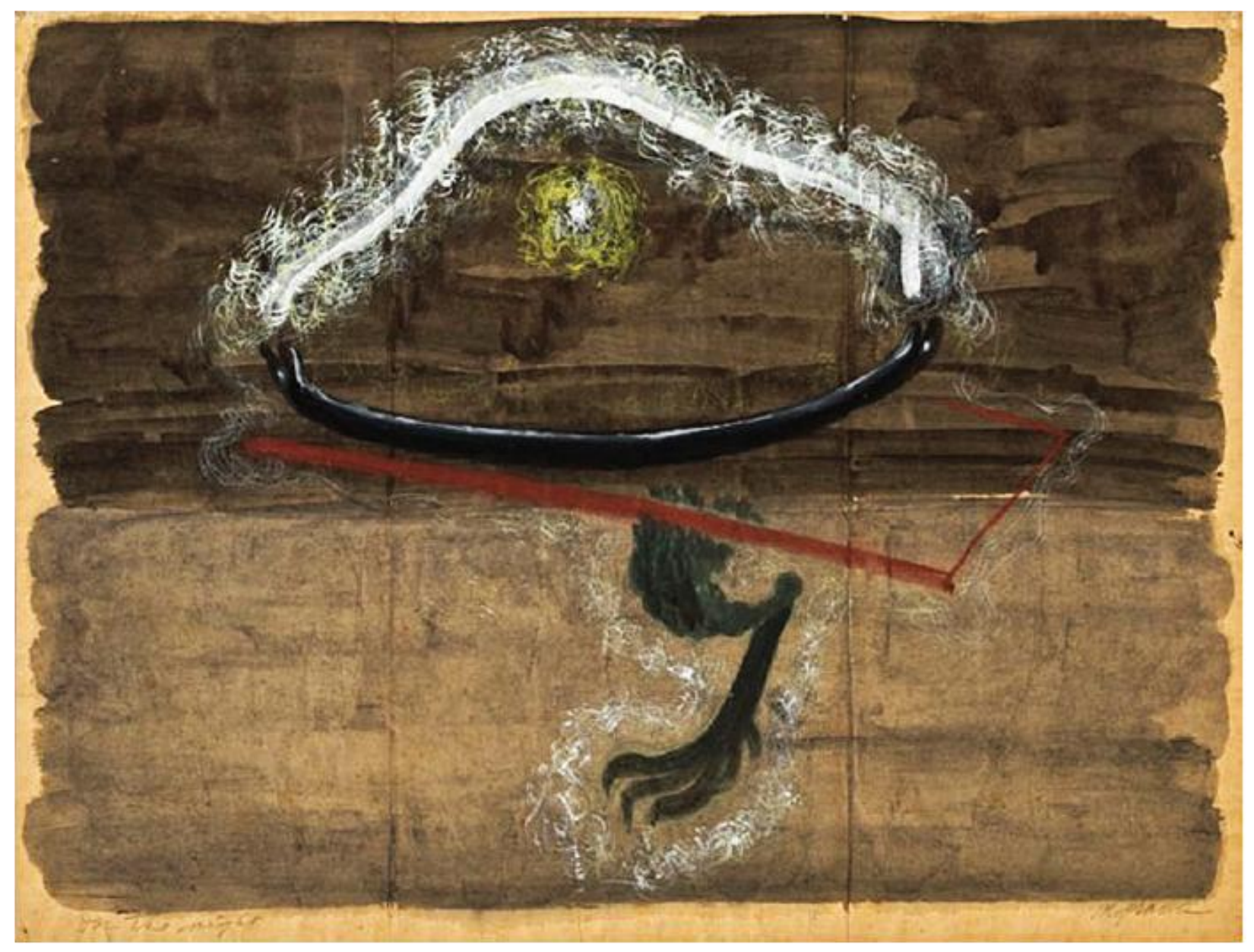

[Fig.17] Morris Graves. In the night [Na noite] (1943), têmpera sobre papel, 58,5 X 76,4 cm.

In the night [Na noite] é uma obra importante de Morris Graves. Ela está vinculada à exposição responsável por catapultá-lo do anonimato aos holofotes do mundo artístico. Americans 1942 [Americanos 1942] foi um divisor de águas na carreira do artista, que até então nunca tinha recebido uma mostra solo em Nova York. Antes do esforço de Dorothy Miller, Graves era praticamente um desconhecido fora da sua terra natal, o Estado de Washington. Um guache também intitulado In the night [ $\mathrm{Na}$ noite] foi pendurado ao lado de mais 29 obras em uma galeria do MoMA dedicada inteiramente ao trabalho de Graves. A têmpera sobre papel presente hoje no MAC USP é de 1943 e faz parte de uma série de obras realizadas imediatamente após a exposição do MoMA. In the night [Na noite] é um exemplo virtuoso da 
linguagem estética de Morris Graves no mais importante período da primeira fase de sua carreira.

Graves baseou seu trabalho na interpretação do espiritual da arte. Sua aproximação com filosofias orientais e a investigação metafísica despertaram um interesse profundo pela contemplação do mundo natural e emocional. São famosas suas representações de pássaros, cobras e pequenos roedores típicos do noroeste dos Estados Unidos, assim como composições orgânicas abstratas em preto, verde e dourado. In the night [Na noite] é um meio caminho entre esses dois traços mais característicos da sua obra. Nela existe a sobreposição de formas animais com um substrato psíquico perturbador. Esta obra é uma jornada do artista em direção ao que ele batizou de "arte do olho interior".

A realização estética de Morris Graves passava sempre pela interrogação espiritual, mas ao contrário da arte cristã e da representação figurativa de Jesus crucificado, a arte religiosa de Graves surge da consciência espiritual despertada por ensinamentos budistas, com os quais ele entrou em contato na adolescência durante sucessivas viagens ao Oriente.

Nascido em uma família protestante instalada em Seattle na década de 1910, Morris Graves detestava o modo de vida austero, regulado e castrador de sua infância. A jardinagem e a pintura foram os únicos consolos de uma infância perturbada por desastres financeiros, um pai ausente e falências respiratórias causadas por infecções pulmonares crônicas. Em 1928, Graves acompanhou o irmão mais velho em sua primeira viagem ao Oriente. Com 17 anos e uma educação incompleta, ele conseguiu um trabalho de 40 dias em um navio mercante com obrigações comerciais em Shanghai, Kobe, Yokohama, Honolulu e São Francisco. Graves fez duas outras viagens ao Japão em 1930.

“Havia nele uma crescente atração pelas atitudes espirituais e filosóficas do Extremo Oriente, uma visão de mundo que apresentava um contraste dramático com o rígido pano de fundo protestante de Seattle", ${ }^{74}$ escreve o crítico de arte Ray Kass, em sua monografia sobre Graves para a exposição da Coleção Philips de Washington D.C. (KASS, 1984, p.22). Kass identifica na filosofia Zen alguns dos princípios estéticos do trabalho de Graves: simplicidade,

74 "There was in him a growing attraction to the philosophical and spiritual attitudes of the Far East, a world view that presented a dramatic contrast to his strict Protestant background in Seattle". KASS, 1984, p.22, tradução nossa. 
naturalidade, quietude, tranquilidade, assimetria e vazio. Graves veio a se associar a um grupo de artistas que compartilhavam destes princípios, entre os quais John Cage, Mark Tobey e Nancy Wilson Ross. Graves e Tobey foram mais tarde identificados pela historiografia como os líderes da Escola do Noroeste Americano, um movimento artístico dos arredores de Seattle que combinava elementos da geografia e fauna da região com influências da estética asiática. Outros nomes vinculados ao grupo de Washington foram Guy Anderson e Kenneth Callahan.

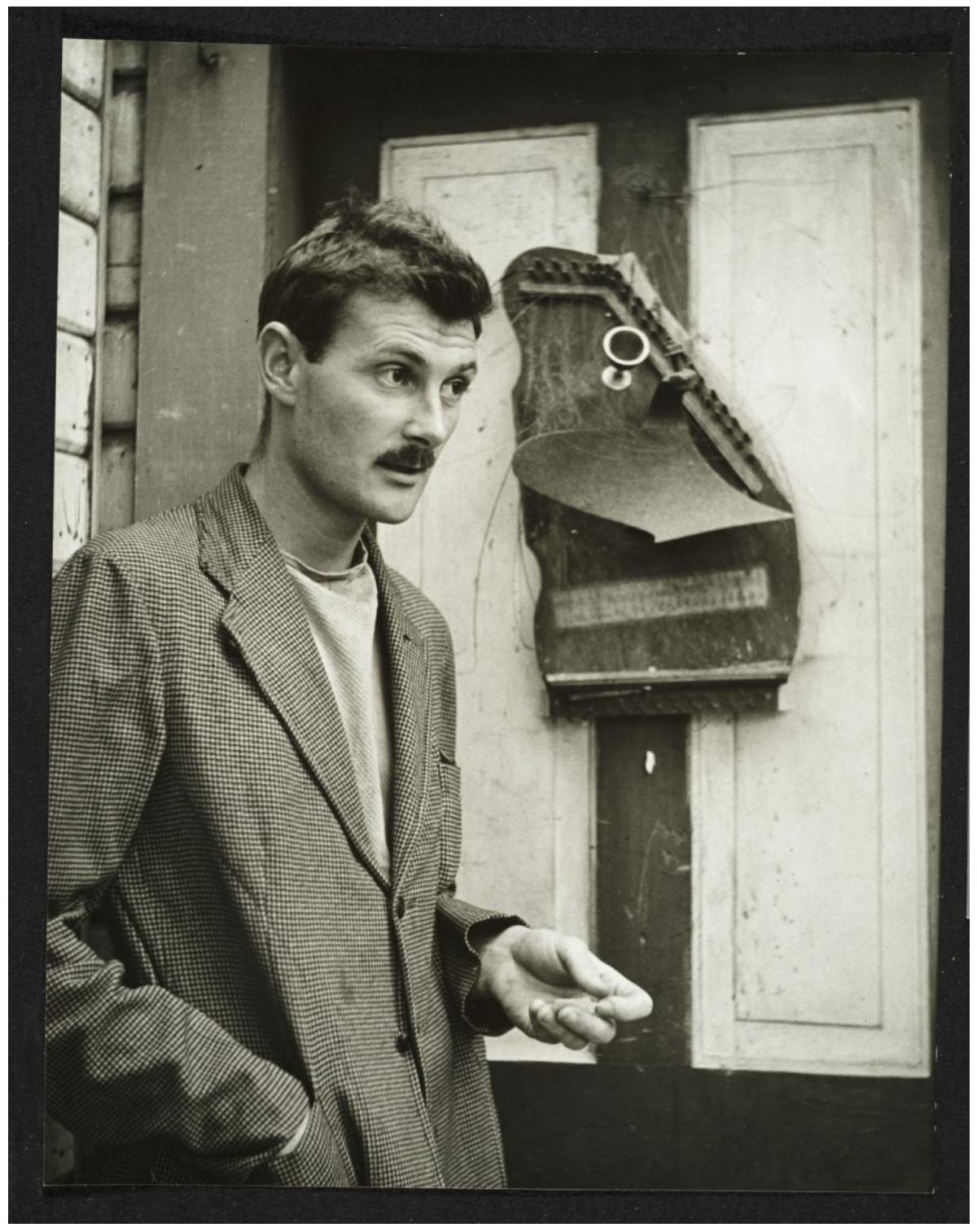

[Fig.18] Morris Graves em 1938. 
Em In the night [Na noite] do MAC USP, Graves utiliza uma técnica herdada do contato com Tobey, um artista mais velho e seu mentor informal. Em meados de 1930, Tobey começou a desenvolver a chamada "escrita branca" inspirada na caligrafia do oriente. Para esses artistas, a escrita branca tinha um significado conceitual. Ela era a realização formal de uma iluminação espiritual. Segundo Ray Kass, as linhas brancas em movimento simbolizariam "a luz como uma ideia unificadora que percorre todos os elementos da vida" ${ }^{\prime 75}$. Para Graves, a caligrafia branca era "a luz interior das visões, que criava um habitat mágico para suas criaturas simbólicas" $(\text { KASS, 1984, p. 30 })^{76}$. Além do subtexto filosófico, a caligrafia branca parece estar presente nos trabalhos destes artistas, pois funciona como uma eficiente solução pictórica. A técnica permite criar unidade e coesão nas composições com relativa simplicidade. No caso específico de In the night [Na noite], os riscos erráticos circundam as formas centrais da composição, sustentando a estética do etéreo e do místico pretendida pelo artista, ao passo que fornece também o ponto de entrada para o olhar do espectador.

Situar o trabalho de Morris Graves no seu contexto regionalista parece importante para entender as raízes culturais, filosóficas e estéticas deste artista. Porém, mais interessante, e talvez iluminador, é o diálogo que Ray Kass estabelece entre Morris Graves e alguns dos maiores nomes da primeira geração do modernismo norte-americano.

Podemos associar o trabalho de Graves com o da geração de abstracionistas inspirados na natureza que imediatamente 0 precederam, i.e., Geórgia O’Keeffe, Marsden Hartley, Arthur Dove, e John Marin. Como Graves, eles encontraram no ambiente natural uma fonte especial de formas de expressão pessoal que em suas obras quase adquire um significado espiritual. Diferentemente deles, contudo, Graves não percebia o mundo do Noroeste através dos olhos de um artista que tinha recebido o primeiro ímpeto do modernismo europeu.

\footnotetext{
75 "White lines in movement symbolized light as a unifying idea which flows through compartmented units of life". KASS, 1984, p. 30, tradução nossa.

76 “For Graves, 'white writting' supported a diferente visual experience - the interior light of visions - which created a magical habitat for his symbolic creatures, a habitat that evoked a real mystery of the natural environment". KASS, 1984, p. 30, tradução nossa.
} 
Ao contrário, as imagens dele são representações de um sentido emblemático - figuras que aparecem na imaginação e cuja similitude impinge provocativamente nosso próprio sentido de identidade (KASS, 1984, p. 20). ${ }^{77}$

O uso da natureza como fonte de inspiração para composições abstracionistas parece, de fato, ser uma aproximação possível entre Graves e os primeiros abstracionistas norteamericanos. Na mesma medida, as penugens de Graves, as pétalas de O’Keeffe e as folhagens de Dove desvendam o abstrato adormecido no orgânico. Talvez tenham sido as semelhanças entre esse artista de Seattle e essa geração anterior que tornaram Graves mais palatável para o público de arte moderna de Nova York. Em diversas ocasiões, Graves foi comparado também a Paul Klee e valorizado pela curadoria do MoMA por sua dupla habilidade de combinar uma linguagem internacional da arte a elementos inspirados pelo Noroeste Americano, criando uma arte inquestionavelmente nacional e moderna.

O primeiro contato de Dorothy Miller com o trabalho de Morris Graves se deu no final dos anos 1930. Nessa oportunidade, ela acompanhou seu marido, Holger Cahill, em uma viagem a Seattle para selecionar obras de artistas das seções regionais do Federal Art Project para uma exposição que seria montada em Washington D.C. Dorothy foi fisgada por uma série de têmperas com cera de Graves intitulada Messages [Mensagens]. Eram abstrações inspiradas em marcações dos índios da reserva Squamish perto da cidade de La Conner, onde ele mantinha um estúdio. As Messages [Mensagens] de Graves foram inseridas na exposição Americans 1942 [Americanos 1942] e seriam eventualmente incorporadas à coleção permanente do Museu de Arte Moderna de Nova York. Impulsionadas pelo favoritismo de Dorothy Miller e Alfred Barr, que também ficou impressionado com o trabalho de Graves, as obras enviadas ao MoMA venderam com facilidade, contabilizando, em média, US\$ 100 cada.

77 "One can associate Graves's work with that of the generation of nature-oriented abstractionists who immediately preceded him, i.e. Georgia O'Keeffe, Marsden Hartley, Arthur Dove, and John Marin. Like Graves, they found the natural environment to be a special source of personally expressive forms that in their works assume an almost spiritual meaning. Unlike them, however, Graves did not perceive his Northwest world through the eyes of an artist who had received a primary impetus from early European modernism. Rather, his images are representational in an emblematic sense - figure that appear before the imagination and whose likenesses provocatively impinge on our own sense of identity". KASS, 1984, p. 20, tradução nossa. 
Depois do seu sucesso em Americans 1942 [Americanos 1942], Morris Graves foi preso. Ele havia se alistado no Exército, mas tentado fugir antes de ser transferido para um campo de treinamento. Recusando ir para a guerra, foi detido como desertor até dezembro de 1942, um dos momentos mais difíceis e psicologicamente desafiadores de sua vida. No ano seguinte, entraria em um período produtivo de trabalho. Em 1943, realizou uma série de têmperas com o tema In the night [Na noite], da qual faz parte a obra do MAC USP.

Todas as principais obras de Morris Graves são composições sobre papel. Inicialmente muito pobre para financiar pinturas a óleo, Graves veio a dominar as técnicas do guache e aquarela. Os anos de 1938 e 1941 marcam um salto produtivo no suporte que seria o mais característico de sua carreira. Neste sentido, In the night [Na noite], uma têmpera sobre papel, é um exemplo da proeza de Graves nesta linguagem. A sua intensa produção nestes anos resultou na série de guaches intitulada "olhar interior" que forma a espinha dorsal da sua presença na exposição do MoMA de 1942. Desta série, fazem parte algumas de suas composições mais conhecidas, como Eagle of the inner eye [Águia do olho interior] (1941) e Owl of the inner eye [Coruja do olho interior] (1941).

A dedicação exclusiva de Morris Graves a obras em papel seria motivo para uma crítica avassaladora de Clement Greenberg. Em fevereiro de 1945, ocasião de uma exposição na galeria Willard, o crítico de The nation desferiu golpes contra sua obra:

Em primeiro lugar, a reverência pela natureza pode fornecer apenas material escasso e irrelevante nesses tempos - quando o principal e inexorável problema é a vida urbana; em segundo lugar, guache e papel fino podem fazer apenas tanta coisa na mão de qualquer artista; em terceiro lugar, a tradição com a qual Graves trabalha - pintura chinesa e Klee - é muito estreita e por demais removida do mainstream. Ela foi grande o suficiente para demonstrar que ele era talentoso e original para começar; mas uma vez que a demonstração foi feita não restou espaço para avançar.

Com o autoritarismo intelectual que Ihe era característico, Greenberg disse ainda: 
A experiência moderna estabelece os parâmetros dentro dos quais a arte moderna deve ser praticada. Esses parâmetros são consideravelmente mais amplos do que aqueles da pintura de Graves, que por mais amplos que possam ser, eles têm, desde a morte de Klee, excluído pássaros, peixes e árvores. Por toda a sua ênfase no interior, o olho de Graves não é introspectivo o suficiente. Se fosse, ele seria um olho positivo capaz de ver através e para além do panteísmo. (GREENBERG, 1986, p.7) ${ }^{78}$.

Outras leituras questionáveis da obra de Graves foram realizadas nos anos sequintes. A próxima exposição organizada por Dorothy Miller depois de Americans 1942 [Amerianos 1942] associou Morris Graves ao neo-romantismo. Essa leitura será mais tarde contestada pela historiografia especializada na obra de Graves. Contudo, a estratégia encontrada pelo MoMA para explicar as obras do "olho interior"- que investigam temas noturnos, inquietações místicas e remetem a um sentimento de solidão e natureza - foi enquadrar Morris Graves como um "romântico moderno".

Romantic Painting in America [Pintura Romântica na América] foi a quinta exposição de uma série idealizada pelo MoMA para explicar os movimentos, tendências e divisões da arte moderna. O conjunto de exposições fazia parte da missão didática do museu. A instituição precisava criar um novo público para arte moderna e, de certa forma, educá-lo. A primeira exposição desta série foi Cubism and Abstract Art [Cubismo e arte abstrata] de 1936, seguida por Fantastic Art, Dada and Surrealism [Arte fantástica, Dadaísmo e Surrealismo], Masters of

78 "It has been feeling that the basis of Morris Graves's art would not be sufficient to carry it beyond its first impulse. In the first place, nature worship can furnish but scanty and rather irrelevant material in these times when the main and inescapable problem is urban life; in the second place gouache on thin paper can do only so much in any one artist's hands; in the thirds place, the tradition in which Graves works - Chinese painting and Klee - is too narrow and too far removed from the mains stream. It was large enough for him to demonstrate that he was talented and original to begin with; but once the demonstration was made there was no place left to go (...) Modern experience sets the bounds within which modern art must be practiced. These bounds are considerably wider than those of Graves's painting, but wide as they may be, relatively, they have, since the death of Klee, excluded birds, fishes, and trees. For all its emphasis in inwardness, Graves's eye is not really inward enough; if it were, it would be a positive eye that saw through and beyond pantheism". GREENBERG, 1986, p.7, tradução nossa. 
popular painting [Mestras da pintura popular] e American realists and magic realists [Realistas americanos e realistas mágicos]. Quando Romantic painting in America [Pintura romântica na América] entrou em cartaz em novembro de 1943, a obra de Morris Graves ganhou uma nova camada de significação, não necessariamente condizente com princípios norteadores de seu trabalho, segundo os historiadores da arte Ray Kass e Theodore Wolff.

Organizada por Dorothy Miller com texto introdutório de James Soby, Romantic painting in America [Pintura romântica na América] encontrava nas cenas noturnas de postos de gasolina, casas solitárias e estradas vazias de Edward Hopper o princípio de um neoromantismo na arte norte-americana. Artistas associados a essa tendência foram Georgia O’ Keeffe, - "dedicada a uma metafísica da natureza-morta" - John Marin, Max Weber, Marsden Hartley - todos "expressionistas românticos", segundo Soby, - e Charles Burchfield - cujas aquarelas seriam a mais "consistente e pura manifestação do romantismo no século XX"79.

Nessa curadoria, Morris Graves foi inserido no grupo de "românticos do subconsciente", ao lado Darrel Austin, Loren Maclver e William Fet. As obras Snake and moon [Cobra e lua] (1938-1939), Blind bird [Pássaro cego] (1940), Owl of the inner eye [Coruja do olho interior] (1941) foram tidas como representativas de uma poética noturna e mística. Soby escreve:

Com Graves, assim como com o falecido Paul Klee, o Romantismo desembarca em uma expressão simbólica interior, inventando uma linguagem de signos e totens para descrever a comunicação íntima entre a imaginação profunda do artista e seu meio. A escrita ectoplasmática com a qual as figuras de Graves assumem forma está relacionada à "escrita branca" de Mark Tobey, utilizada por este último em uma série de trabalhos com intenção deliberadamente mística. Graves reconhece sua dívida com o artista mais velho, mas ele é talvez o mais consistente jovem artista norte-americano expoente do duplamente introspectivo romantismo, cujo precedente pode ser encontrado do século XVI ao XIX, mas que alcançou sua aplicação mais ampla nos últimos vinte anos. Entre os homens mais jovens, como

${ }^{79}$ Catálogo da exposição Romantic painting in America [Pintura romântica na América], 1943, Arquivo do MoMA. 
estelar talento de William Fet, esse tipo de romantismo ainda parece ganhar novos adeptos. Graves fala por si e por todos eles quando declara: 'Eu pinto para descansar do fenômeno do mundo exterior' ${ }^{80}$

O historiador da arte Theodore Wolff critica essa construção de um Graves neoromântico. Segundo ele, Morris Graves não tinha interlocução com o Romantismo europeu. Suas fontes filosóficas estavam na tradição milenar oriental. O espiritual e o divino na arte de Morris Graves "não devem ser lidos a partir do quadro de referência do romântico ou fantástico, muito à margem a suas verdadeiras intenções", diz Wolff. ${ }^{81}$ "Ainda que Graves permanecesse aberto a todos os sistemas e abordagens metafísicas, o Oriente, em um sentido especial e especifico, serviu mais como um guia em sua jornada espiritual/criativa do que o Ocidente" (WOLFF, 1983, p.13-14) $)^{82}$.

Morris Graves era um artista em ascensão nessa época. Sua obra vivenciava um período de apreciação e valorização no circuito de exposições patrocinadas pelo MoMA em meados da década de 1940. A inclusão de seu nome na doação Rockefeller de 1946 está diretamente relacionada, portanto, a esse contexto e pode ser entendida como resultado do trabalho de Dorothy Miller à frente de Americans 1942 [Americanos 1942] e Romantic painting in America [Pintura romântica na América] de 1943.

No Brasil, contudo, Morris Graves permanece pouco conhecido e colecionado. Poucos críticos nacionais se preocuparam em estudar sua obra. Uma das poucas historiadoras

80 "With Graves, as with the late Paul Klee, Romanticism arrives at an interior, symbolic expression, inventing a language of signs and omens to describe and intimate communion between the artist's inner most imaginative and his medium. The ectoplasmic scribble within which Graves' figures take shape is related to Mark Tobey's "white writing", utilized by the latter in a number of his works with deliberately mystic intent. Graves freely acknowledges his debt to the older artist, but he is himself perhaps the most consistent young American exponent of that doubly introspective Romanticism for which precedent may be found from the 16th to the 19th centuries but which has reached its widest application in the past twenty years. Among younger men, such as the startlingly talented William Fet, this kinds of Romanticism still appears to be gaining converts. Graves speaks for himself and for them when he declares: 'I paint to rest from the phenomena of the external world'". Catálogo Romantic painting in America, p.48, 1943, tradução nossa.

81 "To do so would be to deny his work's major frame of reference, and top lace it within a contexto (be it romantic or fantastic) very much at tangent to his true intentions". WOLFF apud KASS, 1983, p.13, tradução nossa.

${ }^{82}$ While Graves remains open to all metaphysical systems and approaches, the East, in a special and specific sense, has served more as a guide to him in his spiritual / creative journey than the West". WOLFF apud KASS, 1983, p.13, tradução nossa. 
brasileiras a mencionar sua obra foi Aracy Amaral: "Morris Graves representa uma vertente onírica das correntes surrealistas norte-americanas, permanentemente caracterizadas pelo realismo mágico por combinar, segundo Barbara Rose, 'o factual com o fantástico'”.

O MAC USP possui apenas uma outra obra dele no acervo, Winter bouquet [Ramalhete de inverno] (1953). Esse quadro foi doado por Sra. e Sr. Henry Ford II, neto do fundador da automobilística Ford Motor Company, em ocasião de sua visita ao antigo MAM-SP. O ato de doação de Winter bouquet [Ramalhete de inverno] mereceu cobertura da imprensa na época, e o jornal O Estado de S. Paulo veiculou uma matéria a respeito em 26 de fevereiro de 1961. Na reportagem, Morris Graves é considerado "um dos maiores destacados pintores contemporâneos dos Estados Unidos". No catálogo geral das obras do MAC USP, de 1988, Aracy descreve:

De fato, a espiritualidade emana desta tela, de silenciosa beleza. Assim, nesta composição aparentemente simples: uma mesa, um vaso com vegetação hibernal sobre um fundo elaborado - tratado à espátula com sobreposições tonais deixando entrever as capas de cor de sua constituição dentro da gama dos ocres suaves - o "tema" da pintura obedece a uma mesma harmonia em sua delicadeza (...) Simbolista, como em outros de seus trabalhos, este artista induz claramente a uma proposta de meditação contemplativa (AMARAL, 1988, p.96).

Em 1955, Morris Graves teve seu maior destaque no cenário artístico brasileiro devido à sua participação na III Bienal de São Paulo. Graves é representado, nesta ocasião, com duas obras: Bird maddened by the sound of machinery in the air [Pássaro enlouquecido pelo som de máquinas no ar] (1944) - pintura que continua na coleção permanente do Museu de Arte Moderna de São Francisco - e Filhote de ganso (1952). Essa edição do pavilhão norteamericano concentrou-se em mostrar artistas de destaque na Costa do Pacífico dos Estados Unidos, vindos dos estados de Oregon, Washington e California. "Em um país tão grande, o desenvolvimento da arte nas suas várias regiões e seus centros mais afastados constitui aspecto importante da atividade artística nacional, atividade que suplementa e completa as funções de 
Nova York como grande centro de exposição e seleção, e como mercado artístico", escreveu a curadora Grace McCann Morley, do Museu de Arte de São Francisco, instituição responsável pela seção norte-americana naquele $a n 0^{83}$. Era a primeira vez que o MoMA cedia seu lugar como organizador do pavilhão da Bienal de São Paulo. Assim como na doação Rockefeller, a representação dos Estados Unidos tinha a preocupação de destacar artistas fora do eixo novaiorquino e Morris Graves aparece, em ambos os casos, como um expoente da arte da região do Noroeste do país.

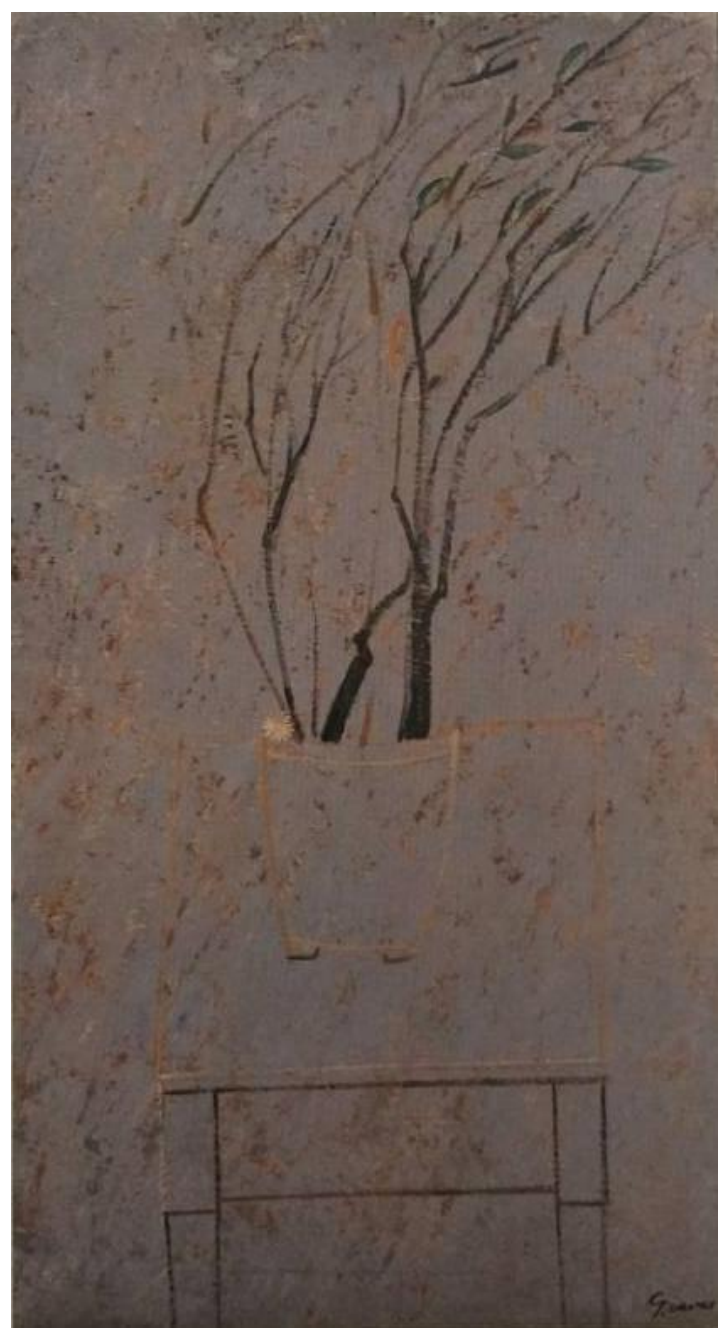

[Fig. 19] Winter bouquet [Ramalhete de Inverno] (1953), Morris Graves

83 Catálogo da III Bienal de São Paulo, 1955, p. 113. Fundação Bienal de São Paulo. 


\section{Antelope mountain, Everett Spruce}

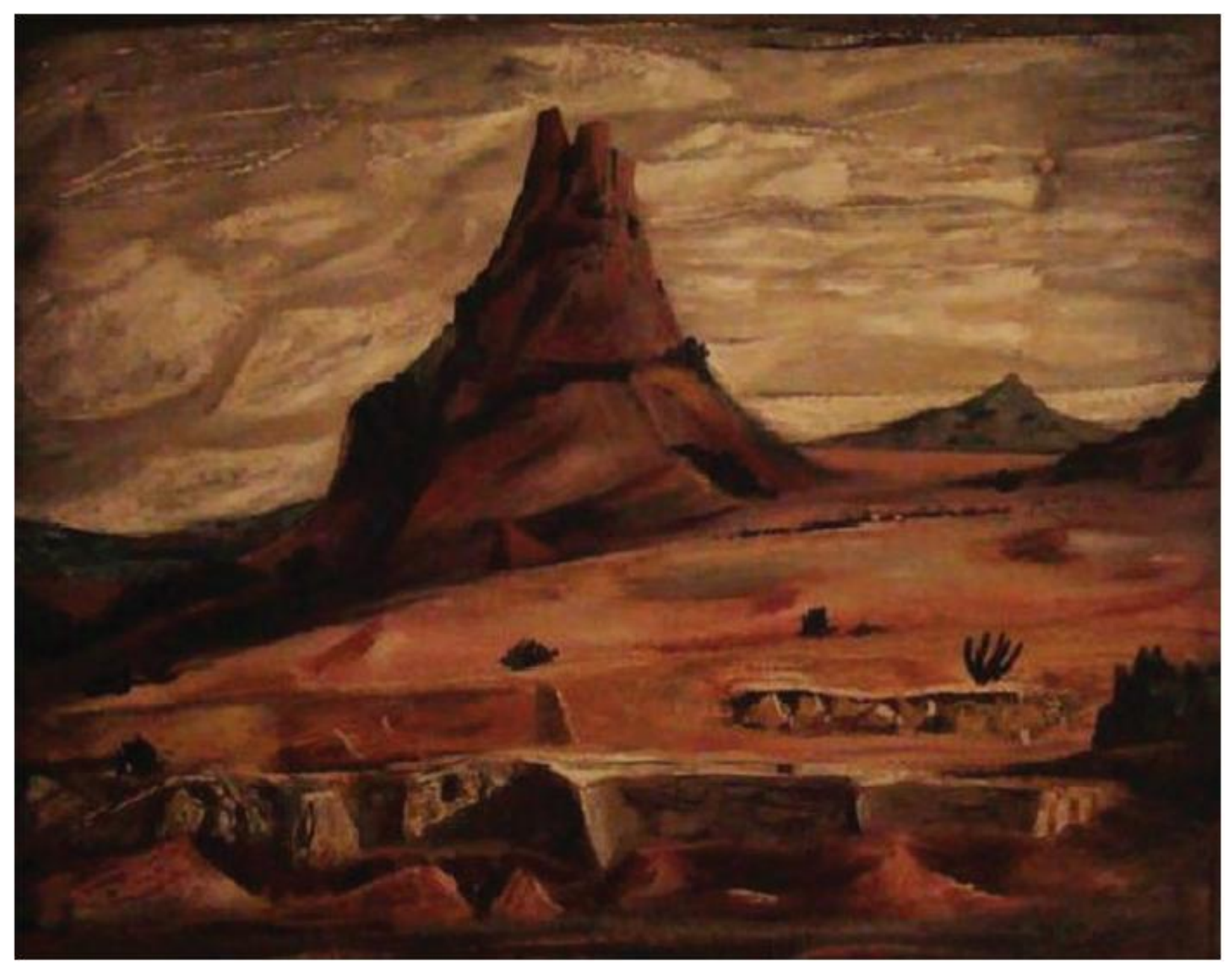

[Fig.20] - Everett Spruce. Antelope mountain [Montanha antílope] (1946), óleo sobre tela, 61,3 X 76,5 cm

Outro pintor inserido nas exposições Romantic painting in America [Pintura romântica na América] e Americans 1942 [Americanos 1942] foi Everett Spruce. Assim como Morris Graves, Spruce estava no radar de Dorothy Miller. Enquanto Graves iria para São Paulo, segundo divisão proposta por Alfred Barr, a pintura de Spruce deveria ter sido enviada ao Rio de Janeiro. A pintura Antelope mountain [Montanha antílope] é de 1946 e, portanto, contemporânea à doação em si. 
Antelope mountain investiga um dos temas clássicos do artista: a região do meio-oeste dos Estados Unidos. ${ }^{84}$ Spruce frequentemente fazia expedições para retratar as paisagens monumentais nos arredores de Dallas. A geografia é desabitada e a formação rochosa alçada ao centro da composição, assumindo uma presença quase escultural. O cenário é abandonado de qualquer presença humana. Nada existe além da terra, da rocha e do ar. Os traços expressionistas de Everett Spruce aparecem com mais vigor no movimento das nuvens. O céu, e todo o resto da paisagem, é coberto por camadas pastéis. A palheta reduzida - laranja, verde, marrom e amarelo envelhecido - traduz o árido dessa terra. O interesse poético e profundo respeito pela vastidão do interior do país fizeram com que Everett Spruce encontrasse nas paisagens desérticas do Texas o objeto de seu modernismo.

Everett Spruce é um artista ligado ao ambiente artístico texano. Nascido na comunidade rural de Conway, Arkansas, ele se mudou para Dallas para estudar arte com de Olin Travis entre 1926 e 1929. Para se sustentar, trabalhava como zelador e depois como auxiliar do Museu de Belas Artes de Dallas e, eventualmente, assistente do diretor. "Toda essa experiência ampliou minha visão, me tornou humilde diante da arte. Com a exceção de três férias de verão, minha pintura se limitava às noites e um dia por semana durante esses dez anos com o museu", 85 lembrou Spruce em depoimento para o catálogo de Americans 1942 [Americanos 1942]. Foi só a partir de 1940, com um novo cargo no Departamento de Arte da Universidade de Texas, que Spruce teve mais tempo para se dedicar intensamente à pintura. Quando estreou a exposição do MoMA em 1942, Spruce tinha tido apenas duas exposições individuais em Nova York, a primeira no Studio Delphic em 1937 e a segunda na galeria Hudson D.Walker em 1938.

Nesta época, Spruce era um artista em busca de identidade. Suas obras assumem estilos variados. A temática é, contudo, quase sempre a geografia e vida do Texas. Por vezes, é possível ver elementos da pintura da Cena Norte-americana, praticada por Thomas Benton e Grant

84 A Universidade Metodista de Dallas mantém no acervo da biblioteca um caderno de desenhos de Everett Spruce com estudos preparatórios do Antelope mountain e outras formações rochosas texanas. Disponível: http://digitalcollections.smu.edu/cdm/compoundobject/collection/tar/id/1935/show/1927/rec/1280. Acessado em 12.11.2013.

85 "All this experience broadened my outlook, made me humble towards art. With the exception of three summers, my painting was limited to nights and one day a week during these ten years with the museum". Catálogo Americans 1942 [Americanos 1942], 1942, p. 121-122, tradução nossa. 
Wood. Spruce foi associado ao grupo de expressionistas românticos ao lado de artistas figurativos como Charles Burchfield e Joseph de Martini. "Todos eram pintores da sensação, suas telas interpretações privadas das forças da natureza ou das implicações metafísicas do mundo" (MECKLENBURG, 1984, p. 47). ${ }^{86}$ As obras de Spruce apresentadas em Americans 1942 [Americanos 1942] lançam um olhar positivo sobre a terra e o trabalhador. Um registro cívico próximo à arte praticada no Federal Art Project.

Everett Spruce ganhou maior notoriedade no cenário artístico de Nova York nas mesmas circunstâncias em que Morris Graves foi projetado para o centro do pódio. Ambos eram artistas fora do eixo nova-iorquino, trabalhando com temas regionais, que foram "descobertos", por assim dizer, por um trabalho liderado por Dorothy Miller e relacionado ao programa federal de incentivo às artes de Holger Cahill. Enquanto Graves desfrutou de maior repercussão ao longo da carreira e depois de sua morte, a crítica de arte não se debruçou o suficiente sobre a obra de Spruce, que viria a ser mais lembrado como professor da Universidade do Texas, onde trabalhou por quase três décadas. Há pouca bibliografia disponível sobre seu trabalho enquanto artista. Ele é praticamente um desconhecido do público de arte e pesquisadores além do Texas. Hoje, grande parte de suas obras se encontra no Museu de Arte de Dallas.

Spruce foi inserido em exposições itinerantes do MoMA e ganharia notoriedade internacional justamente em 1946, quando além da doação Rockefeller, ele foi selecionado para integrar a grande exposição patrocinada pelo Departamento de Estado chamada Advancing American art [Avançando a arte norte-americana]. Em outubro de 1946, o governo organizou uma mostra com 117 exemplos da nova arte norte-americana. O título da exposição traduzia, literalmente, o objetivo político da iniciativa. O conjunto circulou em Paris, Praga, Porto Príncipe e Havana. Organizada por J. Le Roy Davidson, com dinheiro do Escritório de Informação Internacional e Assuntos Culturais, a exposição havia sido planejada para um roteiro muito mais amplo, mas foi cancelada depois de críticas aos ensejos comunistas de alguns artistas e teor estético das obras.

86 "All were painters of mood, their canvases private interpretations of nature's forces or of the metaphysical implications of the world in microcosm". MECKLENBURG, 1984, p.47, tradução nossa. 

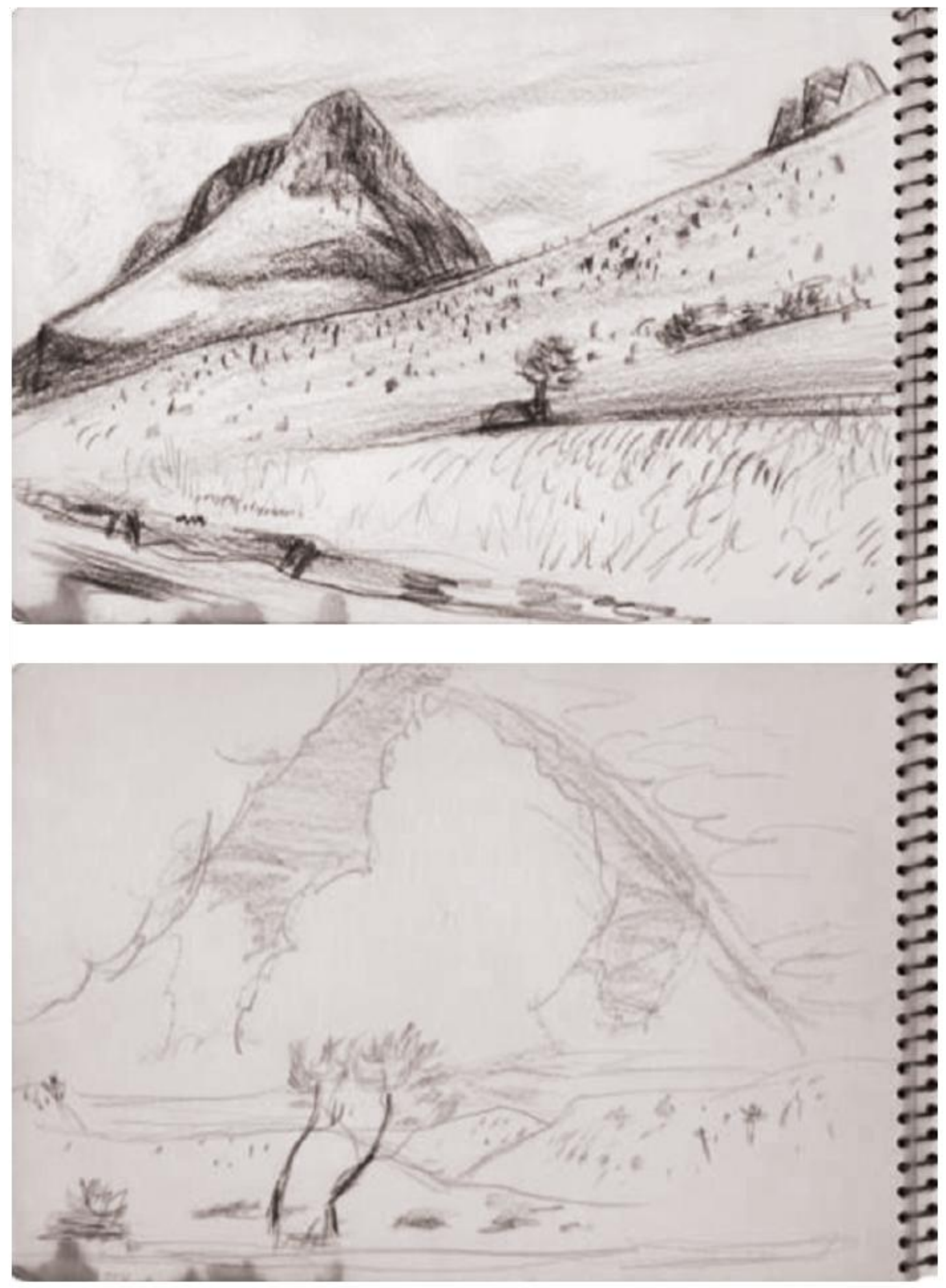

[Fig.21] A Universidade Metodista de Dallas mantém no acervo da biblioteca um caderno de desenhos de Spruce com estudos preparatórios de Antelope mountain [Montanha antílope] e outras formações rochosas texanas. 
As obras foram ridicularizadas em veículos de comunicação de circulação nacional e criticadas por seu suposto substrato comunista. A revista Look, por exemplo, publicou uma reportagem destrutiva de duas páginas com o título "Seu dinheiro pagou por essas obras". Trabalhos de Robert Gwathmey, Ben Shahn e Yashuo Kuniyoshi, entre outros inseridos na exposição, ilustravam a reportagem. Depois do cancelamento da exposição, todas as pinturas foram leiloadas e pulverizadas em várias coleções particulares e universitárias ao redor dos Estados Unidos.

O impacto de Advancing American art [Avançando a arte americana] na formação da identidade dos museus universitários do Oklahoma, Geórgia e Alabama tem sido um instigante tema de pesquisa para teses e dissertações (BURGESS, 2010). Um ponto levantado pela literatura é que a exposição foi um caso exemplar da tentativa do governo em estabelecer uma aproximação política com outros países a partir da imposição de uma "cultura oficial". "Um conceito que parecia intrinsecamente não democrático e suspeitamente remanescente do elitismo artístico europeu" (AUSFIELD, 1984, p. 12) ${ }^{87}$.

Exposições panorâmicas deste tipo já vinham sendo usadas com sucesso há anos por instituições privadas - MoMA, Metropolitan e Whitney Museum - para servir como vitrines da arte norte-americana para públicos estrangeiros. Dentro do governo, iniciativas semelhantes por exemplo, Contemporary painting in North America [Pintura contemporânea norteamericana] (1941) - eram organizadas pelo escritório de Nelson Rockefeller e o Departamento de Informação de Guerra. Porém, com o fim da Segunda Guerra Mundial, esses dois órgãos do governo foram extintos e exposições de itinerância internacional passaram a ser responsabilidade do Departamento de Estado. Essa mudança de hierarquia aumentou significativamente a visibilidade das iniciativas culturais do governo e a maior repercussão acabaria por ser um problema para os organizadores.

Sobre a arte selecionada para a exposição, a historiadora Margareth Lynne Ausfield comenta:

87 "There was a Strong resistance within the State Department to 'official culture', a concept which seemed inherently undemocratic and suspiciously reminiscente of European artistic elitism". AUSFIELD, 1984, p. 12. 
Os norte-americanos geralmente dividiam arte contemporânea em dois campos - o figurativo que era "americano" e o abstrato que era "estrangeiro". Como o público em geral não tinha nenhum entendimento das teorias intelectuais dos movimentos artísticos históricos europeus sobre as quais a abstração era baseada, a pintura mais amplamente aceita (como as tradições do Regionalismo ou Cena Norte-americana) tendia a ser aquela facilmente apreensível e de derivação não-europeia (AUSFIELD, 1984, p. 13). ${ }^{88}$

A decisão do curador J. LeRoy Davidson de inserir obras de arte abstratas irritou e confundiu o público. Até o presidente Harry Truman fez piadas na imprensa sobre as pinturas. A apresentação de uma arte moderna com nomes antes vistos apenas em circuitos seletos galerias nova-iorquinas, coleções privadas e o MoMA - teria sido um dos motivos por trás do fracasso retumbante da mostra. Segundo interpreta Ausfield, o significado de Advancing American art [Avançando a arte americana] se dá mais pela resposta que gerou do que pela seleção de obras em si. "A controvérsia só foi relacionada com arte porque a própria arte tinha se tornado um tópico político nos anos 1930 e 1940, quando artistas, especialmente aqueles da Escola Sócio-Realista, atuaram conspicuamente como críticos sociais" (AUSFIELD, 1984, p.26) ${ }^{89}$.

Três telas de Spruce foram inseridas na exposição: Canyon in the night [Cânion na noite] Turkey [Peru], Owl on the rock [Coruja sobre a rocha]. Todas vendidas pela galeria Mortimer Levitt, possivelmente a mesma que comercializou Antelope mountain [Montanha antílope]. Sua pintura foi criticada por conservadores e a tela Turkey virou alvo de chacota nacional. Como parte da campanha midiática contra Advancing American art [Avançando a arte americana], a pintura de Spruce foi reproduzida por jornais e ridicularizada na arena pública. Não cabe aqui

88 "Americans generally divided contemporary art into two camps - the representational which was 'American' and the abstract that was 'foreign'. Because the general public had no understanding of the intellectual theories of historical European art movements upon which abstraction was based, the most widely accepted painting (such as that of the Regionalist or American Scene traditions) tended to be easily apprehensible and non-European in derivation". AUSFIELD, 1984, p. 13, tradução nossa.

${ }^{89}$ The controversy surrounding it was art related only because art itself was a political topic in the 1930s and 1940s, when artists, especially those of Social Realist School, functioned conspicuosly as social critics". AUSFIELD, 1984, p. 26, tradução nossa. 
entrar em maiores detalhes desta fascinante exposição, mas recuperar sua história é importante para entender o status de Everett Spruce na topografia da arte.

Seu nome estava em nítida ascensão, principalmente por causa do espaço conquistado quatro anos antes nas paredes do MoMA e pela repercussão causada pela exposição itinerante de arte norte-americana. Em 1946, havia um mercado aquecido para as obras de Spruce como nunca mais ocorreria nos próximos anos. 


\section{Woman of the circus, Byron Browne}

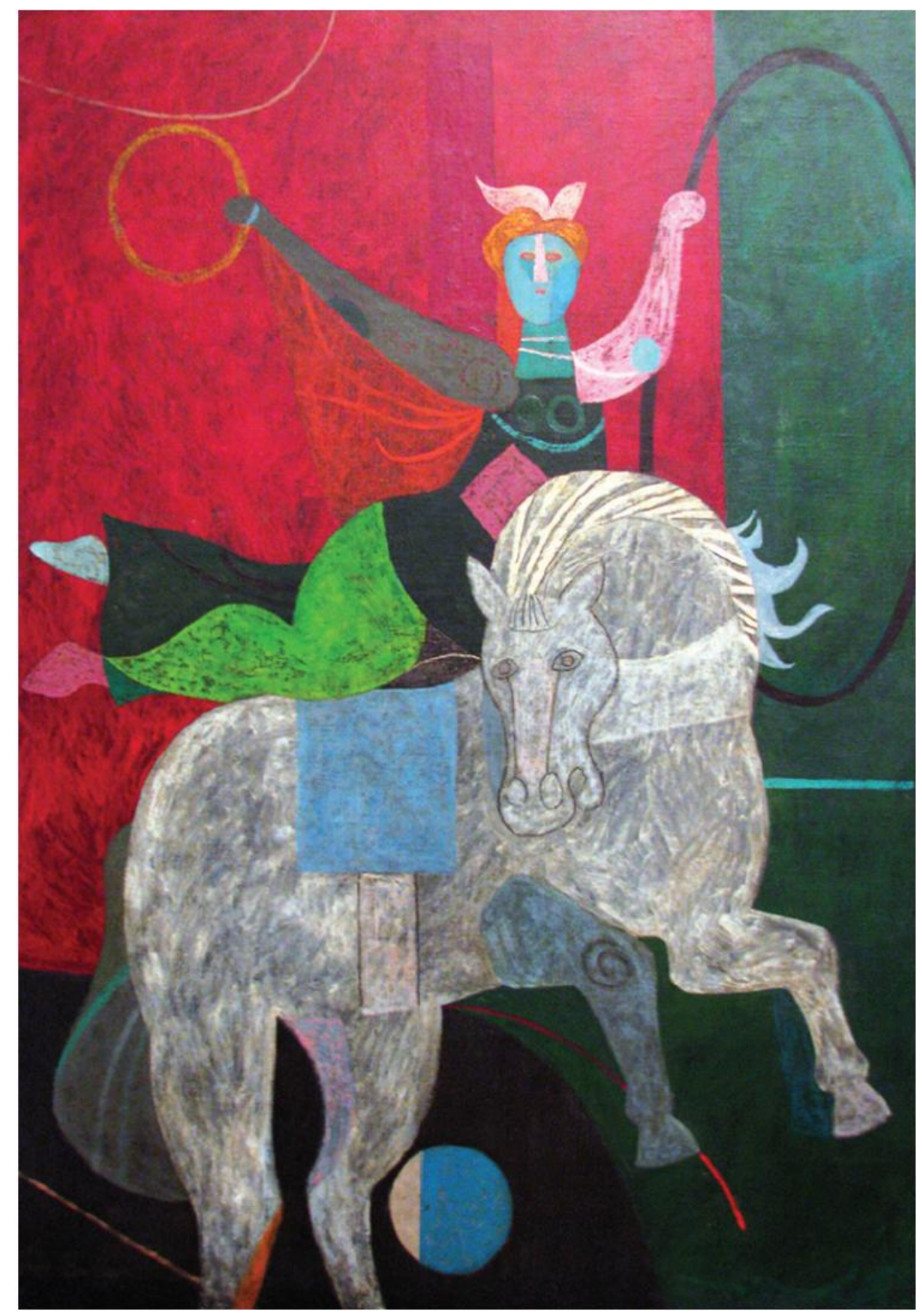

[Fig.22] Byron Browne. Women of the circus [Mulher de circo] (1946), óleo sobre tela, 127,1 X 101,5 cm

Dois outros artistas que fizeram parte da exposição Advancing American art [Avançando a arte americana] - Byron Browne e Robert Gwathmey - estão no conjunto doado por Nelson ao Brasil. A presença de Spruce, Browne e Gwahtmey nessas duas coleções indica a estatura internacional desses artistas em 1946. Reunidos nas mesmas exposições, sua produção era pautada por princípios estéticos e filosóficos diametralmente opostos. Enquanto Spruce se 
aproxima da pintura regionalista norte-americana, Robert Gwathmey era ligado ao sóciorealismo pictórico e à crítica social, ao passo que Byron Browne trabalhava com princípios do Cubismo e da abstração formal. A junção de artistas tão diferentes em coleções pensadas para um público estrangeiro sustentava o discurso da diversidade, livre-expressão e amplitude estética da nova arte norte-americana.

Byron Browne foi um pintor da primeira geração da Escola de Nova York. Inicialmente ligado à Academia Nacional, ele passaria a circular entre a vanguarda. Seu estilo eventualmente se aproximaria da abstração. Assim como outros artistas da coleção Rockefeller, Browne foi inserido no programa do governo federal de apoio à arte na década de 1930. Sua maior comissão para o Federal Art Project foi o mural Abstraction [Abstração] de 1938, realizado para a sede da Estação de Rádio Municipal de Nova York.

Cubismo é o termo mais recorrente para definir a pintura de Browne, mas dificilmente ele pode ser considerado um artista de uma nota só. Ao longo da carreira, o nível de abstração oscilou muito, passando por períodos de completa figuração e mesmo resgate neoclássico. A formação acadêmica de Browne jamais o abandonaria. Essa característica foi, talvez, o maior desafio para o florescimento de uma sólida clientela para as obras de Byron Browne. Seu estilo era considerado por demais errático. Alguns críticos viam nele um artista habilidoso, mas não tão inventivo quanto outros pintores atuantes no cenário nova-iorquino naquele momento.

No período inicial da carreira, Byron Browne foi bastante ativo na organização de associações voltadas à criação de espaços para a apreciação de arte moderna. Em 1937, foi um dos membros fundadores do grupo American Abstract Artists e professor do Art Students League, de 1948 a 1961, tendo como interlocutores os artistas Arshile Gorky, Willem de Kooning, Lee Krasner, Adolph Gottlieb e Hans Hofmann. Contudo, Browne não alcançaria o mesmo estrelato que alguns de seus companheiros. "Embora tenha vivido para ver o amanhecer exaltado de sua geração, Browne nunca desfrutou de celebridade. Ele nunca se tornou tão publicamente proeminente como outros membros da Escola de Nova York", declara o curador de pintura do Smithsonian Institution Harry Rand (RAND, 1987, p.28) ${ }^{90}$.

\footnotetext{
90 "Although he lived to see his generation's dawning exaltation, Browne never himself enjoyed celebrity [...] He never became as publicly prominent as other members of the New York School”. RAND, 1987, p.28, tradução nossa.
} 


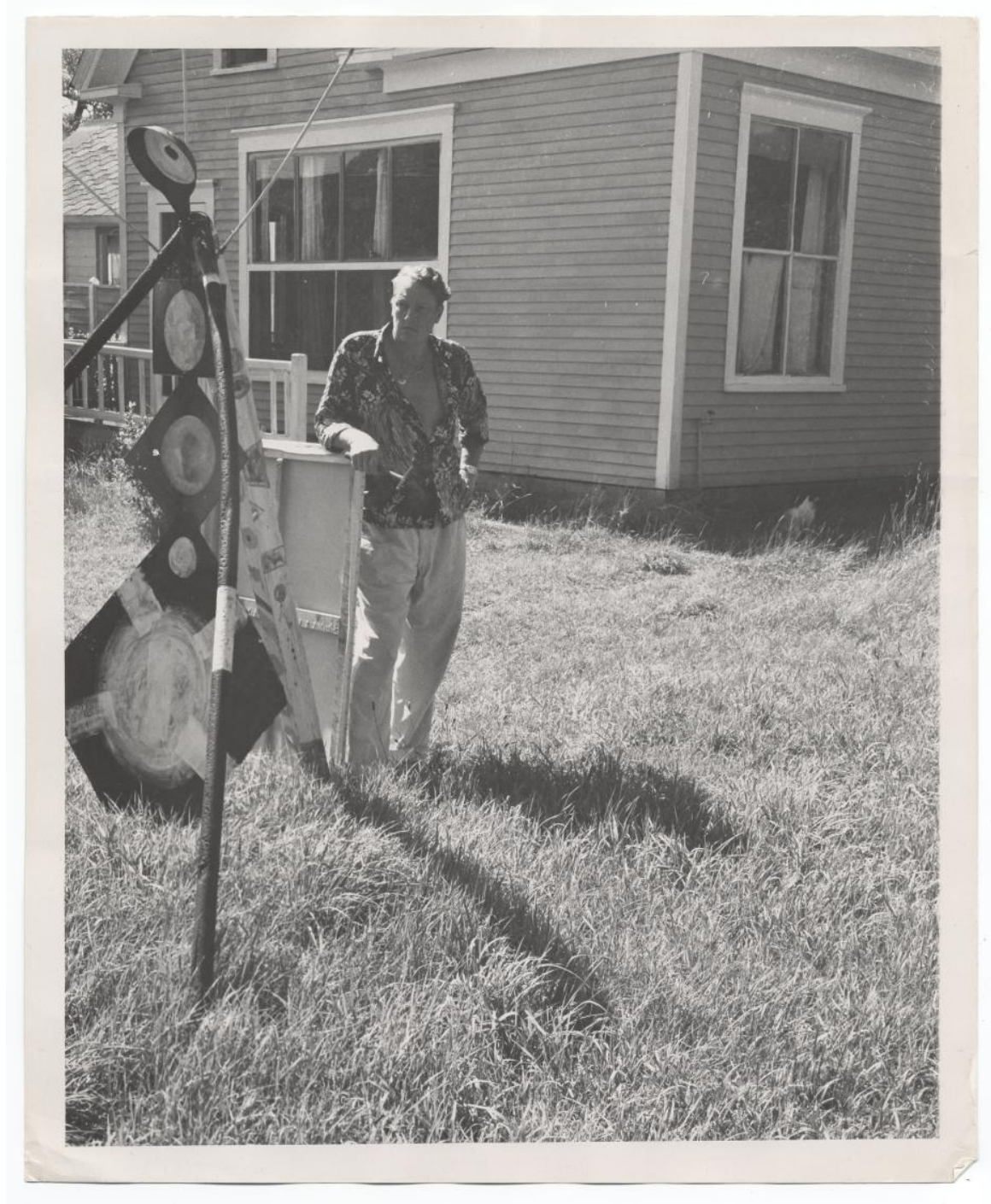

[Fig. 23] O artista Byron Browne em sua casa em Provincetown em 1959.

A primeira vez que Alfred Barr permitiu a entrada de Byron Browne no MoMA foi em 1936. Em conjunto com Holger Cahill, Barr organizou uma exposição sobre o primeiro ano de atividade do Federal Art Project. Os estudos preparatórios de Browne para murais do Williamsburg Federal Housing Project no Brooklyn estão entre as poucas obras abstratas de toda a exposição. Ao longo da década de 1930, o trabalho de Browne foi exposto, principalmente, em eventos organizados pelo American Abstract Artists e outros grupos artísticos, aparecendo também em mostras no Whitney Museum of American Art. A maior 
publicidade da sua arte veio a partir de 1945, quando o empresário Sam Kootz o escolheu para fazer parte do grupo de elite de artistas de sua nova galeria.

Advogado e empresário, Samuel Kootz estreou no mundo artístico como crítico das tendências modernas na arte. Em 1930, publicou um panorama da pintura norte-americana com foco nos artistas do reduto de Alfred Stieglitz: Dove, O’Keeffe e Marin. Em 1943, lançou seu livro de maior repercussão, New frontiers in American painting [Novas fronteiras da pintura norte-americana]. No prefácio, o crítico lamenta o meticuloso descaso das editoras e museus por artistas vivos. Seu texto é quase um manifesto pela nova arte e tem um tom heroico, em defesa da vanguarda de Nova York. No ano seguinte, Kootz fundou sua galeria e, por causa do livro, ganhou a simpatia dos principais homens do modernismo norte-americano. A galeria Kootz protagonizou as carreiras de Robert Motherwell, Adolph Gottlieb, William Baziotes e Hans Hofmann, se tornou notória por ter sido escolhida por Picasso para representar suas obras em Nova York, além de ter sido a primeira casa a organizar uma exibição de Fernand Léger nos Estados Unidos em 1945.

Na visão crítica de Kootz, arte era política. “Essa guerra é uma guerra de ideias - da democracia contra o fascismo (...) uma guerra pela mente dos homens. O que os homens vão pensar, quais serão suas crenças, na era do pós-guerra, determinará o destino da América"91 (KOOTZ, 1943, p.3). A função do artista seria o de moldar as opiniões dos homens e "ativamente participar da revolução".

Artistas não podem decidir guerras, não podem nem influenciar seus cursos. Mas podem auxiliar na criação da sociedade decente pela qual nós agora lutamos e morremos. De suas ideias, imaginação, e atitudes militantes liberais, podem surgir algum guia para o mundo do PósGuerra (KOOTZ, 1943, p.3). ${ }^{92}$

91 "This war is a war of ideas - of democracy against fascism. It had been called a war for men's minds. How those men will think, what their belief will be, in the post-war era, will determine the destiny of America". (KOOTZ, 1943, p.3, tradução nossa).

92 "Artists can't decide wars, they can't even influence their course. But they can assist the creation of the decent society for which we now fight and die. From their ideas, their imagination, their militantly liberal attitudes, can come some guidance for the post-war world". (KOOTZ, 1943, p. 3, tradução nossa). 
Segundo ele, o artista que melhor traduzia os ideais democráticos e a inovação estética que libertaria a alma e mente do homem moderno era Pablo Picasso. Os artistas que compartilhassem da "moralidade" e "consciência de seu tempo" de Picasso seriam os pioneiros do modernismo norte-americano, entre os quais ele incluía Byron Browne. Sua leitura se dá a partir de uma narrativa simplificada que enaltece a Escola de Paris. Sem o contato com as ideias vindas da Europa, a arte norte-americana, segundo ele, seria provinciana, nacionalista e esteticamente castradora. Mais especificamente, estava no Cubismo e não no Surrealismo tido por ele como a "decadência da França" - o adubo para o florescimento das novas fronteiras da pintura. Kootz criticava a "aberração" surrealista, o neo-romantismo "soporífero" e a "vaidade nacionalista" dos pintores da Cena Norte-americana. Para ele, estava apenas no Abstracionismo e no Expressionismo o caminho para o futuro da arte.

Para Kootz, a abstração presente na arte de Stuart Davis, Byron Browne, John Graham e Jan Matulka era uma derivação direta do progresso do Cubismo nos Estados Unidos. Na obra destes artistas, objetos do mundo real são o ponto de partida para a construção formal e rearranjo estético do espaço na composição. Em New frontiers in American painting [Novas fronteiras da pintura norte-americana], duas obras cubistas de Browne são reproduzidas: Painting on black [Pintura em preto] (1939) e Women at a window [Mulher na janela] (1942). Apesar do apoio inicial, Kootz nunca escondeu sua resistência em relação ao artista. A única menção a Browne no livro envolve um elogio seguido de uma reprimenda. Enquanto ele via no trabalho de Browne os princípios de composição cubista de Picasso que tanto admirava, as telas de aspecto neoclássico eram vistas como os pontos fracos que eventualmente poderiam destruir Byron Browne. Kootz tinha uma visão muito específica sobre a direção a ser tomada pela vanguarda e essa faceta do trabalho de Browne não fazia parte de sua ideia de progresso.

Browne espalha suas energias e ideais, pulando de vivas abstrações para o trabalho representacional que não é muito longe do academicismo. Seu trabalho mais recente não oferece espaço para discussão, ao passo que suas invenções abstratas, suas brilhantes harmonias em cor e sua exatidão na divisão espacial são altamente recompensadoras. Eu sinceramente espero que ele se restrinja ao uso 
deste equipamento inventivo como promete um grande número de suas obras (KOOTZ, 1943, p. 49). ${ }^{93}$

Browne assinou um contrato de $\$ 3000$ anuais com Kootz. Em contrapartida, toda a sua produção era destinada à galeria. Em 1946, Byron Browne era um dos principais nomes da galeria. Woman of the circus [Mulher de circo] foi exibida em uma exposição individual realizada de 11 a 30 de novembro de 1946. Dorothy Miller e Alfred Barr visitaram a galeria de Kootz, muito possivelmente, nos primeiros dias da exposição, e escolheram Woman of the circus [Mulher de circo] entre as 18 pinturas expostas, que tinham como eixos temáticos a vida circense e o ambiente boêmio dos músicos de jazz. ${ }^{94}$

Woman of the circus [Mulher de circo] faz parte de uma série de pinturas que investigam o mundo fantástico dos trapezistas e acrobatas. Pequenos territórios de cor e forma se justapõem. Uma acrobata - em segmentos de verde, rosa e laranja - flutua sobre um imenso cavalo branco, enquanto realiza um esquete de argolas. Vermelho e verde-musgo formam o pano de fundo da composição, aludindo a uma lona de circo. O movimento é sugerido pela pose tencionada da mulher, que se equilibra com braços abertos, argola na mão direita, chicote na esquerda, e pelo cavalo que se suspende nas duas patas traseiras, formando o ponto central da composição. Esse tema não havia passado despercebido por Picasso, com a sua série dos saltimbancos, a maior referência para o trabalho de Browne.

93 Browne diffuses his energies and ideas, hoping from lively abstractions to representational work that is not so far removed from academicism. The latter work offers no room for discussion, whereas his abstract inventions, his brilliant color harmonies and his spare rightness in space divisions are highly rewarding. I sincerely hope he confines himself to using that equipment as inventively as a good body of his works promises (KOOTZ, 1943, p. 49, tradução nossa).

94 Catálogo de Exposição de Byron Browne na Galeria Kootz, 11-30 nov. 1946. Kootz Gallery Scrapbook No. 4, 1946-1947. p. 20 - 22. Archives of American Art. Smithsonian Institution, Washington, D.C. Disponível: http://www.aaa.si.edu/collections/viewer/kootz-galleryscrapbook-no-4-13278 


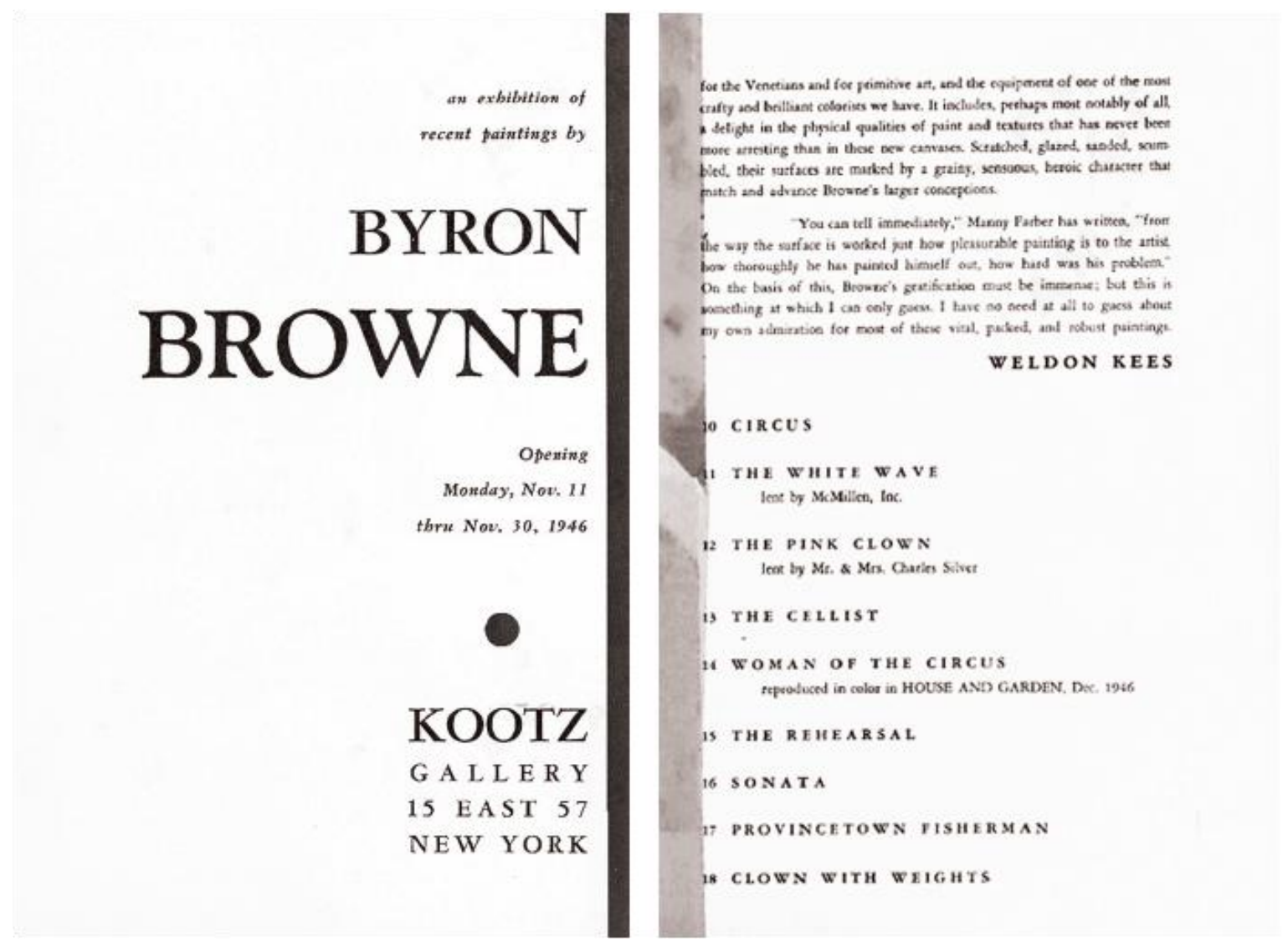

[Fig. 24] Catálogo da mostra de Browne na Kootz Gallery, em que Woman of the circus [Mulher de circo] foi apresentada pela primeira vez.

A obra do MAC USP foi reproduzida na revista House \& Garden ao lado da crítica de Leo Lerman:

Byron Browne está atualmente preocupado com o circo: sua serragem, seus artistas, sua decoração. As cores dele são mais exuberantes que as de Avery ou Lawrence (Jacob), seus padrões mais complicados. Mas ele é, indubitavelmente, um virtuoso da paleta. (...) Suas telas são ricas, agregadoras, bombasticamente vitais. Mulher de circo é simbolicamente Byron Browne. Ela funde seus talentos, concentra suas qualidades. ${ }^{95}$

95 "Byron Browne is currently concerned with the circus; its sawdust, its performers, its décor. His colors are more lush than Avery's or Lawrence's, his patterns more complicated. But he is indisputably a virtuoso of palette. Looking at his paintings, it is immediately obvious that he loves living, that he loves painting. His canvases are rich, gregarious, bombastically vital. Women in the circus (page 123) is symbolically Byron Browne. It fuses his talents, concentrates his gifts. But Browne can also paint a reflective, brooding picture somewhat reminiscent of abstract Picasso, a little owing to Klee, but always Browne". LERMAN, Scrapbook No. 4, - 1946-1947. p. 23. Archives of American Art. Smithsonian Institution, Washington, D.C, tradução nossa. 
A revista Art Digest declarou a exposição como "a prova convincente dos talentos inquestionáveis de Byron Browne". Marion Summers, do Daily Worker, chamou Browne de um dos "mais brilhantes jovens artistas norte-americanos". Para ela, Browne "cresceu da tradição de Picasso, mas desenvolveu uma linguagem própria". Carlyle Burrows, do New York Herald Tribune, considerou a exposição de obras circenses como um grande marco na carreira do artista. "Sua cor e imagens atingiram agora sua mais rica e mais saborosa combinação".

Mas Byron Browne não era unanimidade. Mesmo nas críticas positivas, comentários sobre a limitação do seu alcance artístico estão presentes. Robert M. Coates, do The New Yorker, disse que "como a ideia de Browne sobre a cor parece ser quanto mais luminosa melhor, o objeto está bem adaptado a seus talentos". Um crítico da Art news avaliou que "o objeto, para ele, é uma fonte inesgotável e complexa de formas, que ele arranja e distorce em suas grandes telas para criar, não tanto uma nova visão sobre a natureza, mas uma nova decoração". Outros avaliaram sua arte como uma variação de humores cubistas em voga na Europa há pelo menos três décadas e, portanto, ultrapassada. ${ }^{96}$

O historiador Serge Guilbaut analisa o fim da carreira de Byron Browne como a consequência de uma mudança de gosto no mercado da arte moderna. A tirania do Expressionismo Abstrato acabaria por diminuir seu espaço. A dominação dessa vertente artística exterminou o mercado possível para o cubismo tardio de Browne. "Foi neste momento que Browne (...), sem querer se colocou, fora da corrida, porque seus trabalhos permaneciam muito próximos ao que havia sido feito em Paris". Mais especificamente, para Guilbaut, "o elegante pintor cubista e excelente modernista Byron Browne estava cometendo suicídio ao defender o modernismo parisiense" (GUILBAUT, 1983, p. 178). ${ }^{97}$

Byron Browne e Samuel Kootz romperiam para sempre e de maneira desastrosa. A falência do artista seria atribuída diretamente às ações tomadas pelo galerista no final dos anos 1940. A contínua experimentação de Browne com a figuração e, eventualmente, a inabilidade

96 Recortes de jornais sobre a exposição na Kootz Galllery. Scrapbook No. 4, - 1946-1947. p. 23. Archives of American Art. Smithsonian Institution, Washington, D.C, tradução nossa

97 "It was at this moment that Bearden, Holty, and Browne, unwittingly put themselves out of the running because their work remained too close to what had been done in Paris". GUILBAUT, 1983, p. 178, tradução nossa. 
de sua pintura avançar além de ecos de Picasso fizeram com que Kootz antecipasse o término do contrato. Em 1951, ele tentou se desfazer do acervo de telas em sua posse. Em um movimento humilhante para Browne, Kootz decidiu "queimar o estoque" e destinou dezenas de pinturas para a loja de departamentos Gimbel, que vendeu telas de Browne com etiquetas de $50 \%$ de desconto para o público geral. Esse ato destruiu a carreira de Browne. Museus e colecionadores privados se prontificaram a se desfazer de suas obras, que já não tinham valor comercial. O artista nunca se recuperou totalmente do choque e, no ano seguinte, morreu de ataque cardíaco. 


\section{Standard bearer, Robert Gwathmey}

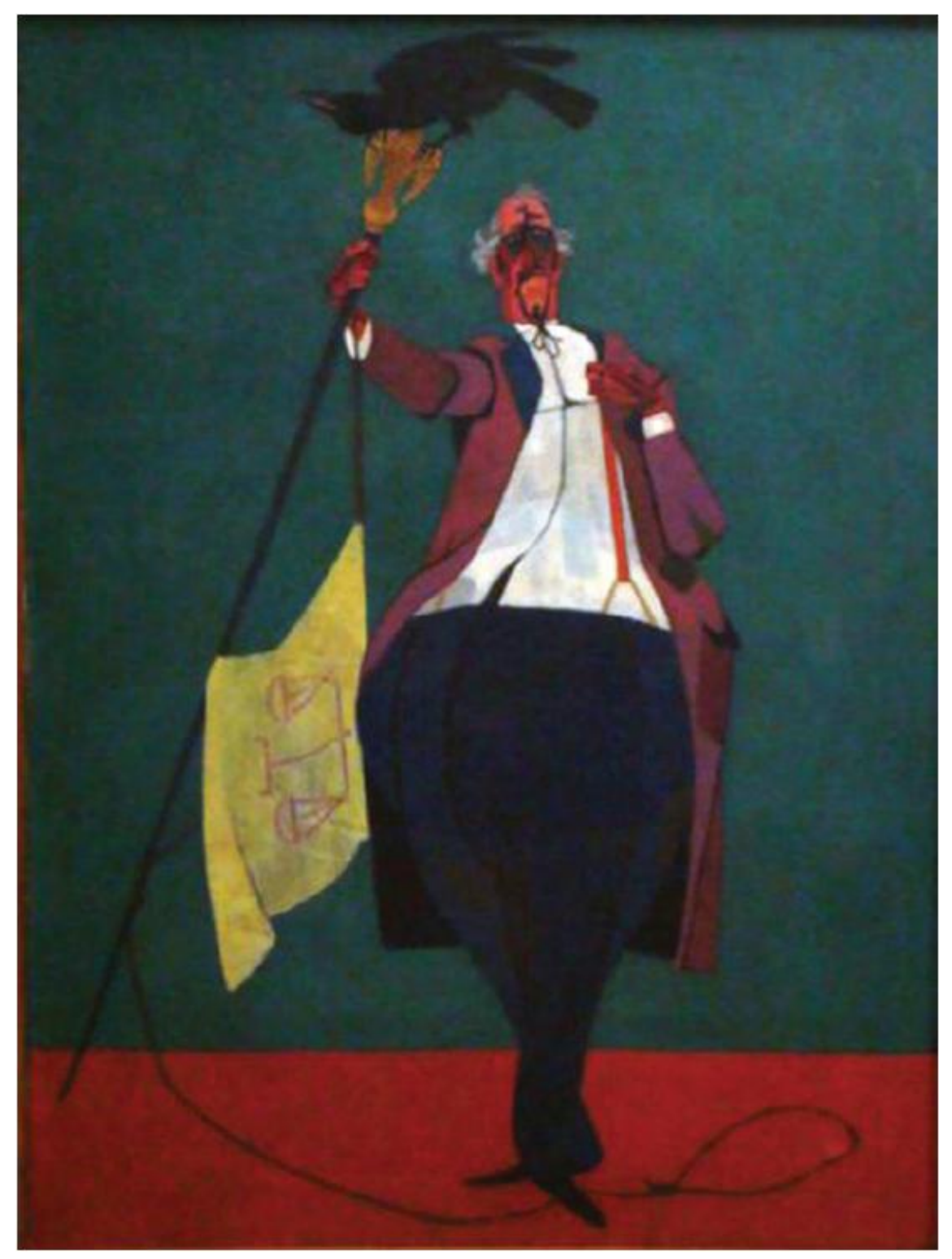

[Fig.25] Robert Gwathmey. Standard bearer [Porta-estandarte] (1946), óleo sobre tela, 86,5 X 61,6 cm.

Robert Gwathmey foi um artista plástico do Estado de Virgínia ligado ao sócio-realismo. Ele ficou conhecido, principalmente, pelas obras em que investiga a condição do negro no sul dos Estados Unidos. Assim como Jacob Lawrence, muitos quadros de Gwathmey retratam o preconceito racial, os linchamentos e a exploração dos trabalhadores nas plantações de 
algodão. A situação dos negros nos Estados Unidos nos anos 1940, especialmente nos estados do sul, era lamentável. Eles não podiam frequentar as mesmas escolas que brancos. Não eram contratados para integrar a força policial e demais postos do serviço público. Eram obrigados, por lei, a se sentar em áreas específicas de restaurantes. Tinham bebedouros e banheiros públicos separados. No ano de 1946, quando Gwathmey produziu Standard bearer [Portaestandarte], a Corte Suprema dos Estados Unidos, em uma decisão pioneira, considerou inconstitucional o código legal do Estado da Virgínia que exigia a separação de brancos e negros em viagens de ônibus interestaduais.

Dois anos antes, o romance de Lillian Smith Strange fruit [Fruta estranha], sobre um relacionamento amoroso interracial, chocou o país. Outro livro que recolocou a questão do preconceito racial na agenda do dia foi An American dilemma: the negro problem and modern democracy [Um dilema americano: o problema do negro e a democracia moderna], influente estudo do economista Gunnar Myrdal que evidencia a disparidade social e econômica da comunidade negra. Os livros de Lilian Smith e Gunnar Myrdal publicados em 1944 se tornaram best-sellers. O estudo de Myrdal evidenciava a exclusão econômica dos negros nos anos 1940 e foi citado no caso Brown v. Board of Education da Corte Suprema Norte-americana que determinou a inconstitucionalidade da segregação racial nas escolas públicas. An American dilemma [Um dilema americano] é considerado um dos primeiros livros a propor estratégias de ações afirmativas como solução para diminuir a desigualdade racial.

Ainda que o preconceito racial começasse a ganhar espaço no debate público, os anos de glória do movimento de direitos civis ainda estavam uma década à frente. As grandes marchas a Washington, o discurso de Martin Luther King e a lei de integração racial das escolas públicas iriam acontecer apenas a partir dos anos 1950 e 1960. Para um artista socialmente engajado como Gwathmey, oriundo de um dos estados mais conservadores e violentos, a questão racial era um tema inescapável. Neste sentido, Standard bearer [Porta-estandarte] é um retrato da política corrupta e racista que contaminava o sul dos Estados Unidos anos 1940.

A obra presente hoje no MAC é uma leitura ácida da condição de supremacia do homem branco. Ela representa uma figura rotunda e quase cômica de um senhorio de corpo avantajado. O homem vestido de fraque e suspensórios segura um estandarte de onde pende 
uma flâmula com o símbolo da Justiça e, a seus pés, uma corda de enforcamento. Imagens de negros enforcados em beiras de estradas e expostos em praças públicas eram manchas frequentes na história daquela região. Outra figura usada por Gwathmey para representar a segregação racial é o corvo preto, presente também no quadro Poll tax country (1945) e em outras composições do artista. O corvo preto é um símbolo frequente na arte de Gwathmey e, segundo o historiador da Universidade de Minnesota Charles Pielh, "pode retratar a disseminação e declínio inevitável do sistema de segregação que os habitantes do sul chamavam de Jim Crow" (PIEHL, 1985, p.57). ${ }^{98}$ As leis Jim Crow estabeleciam a segregação de negros em escolas e locais públicos. ${ }^{99}$ Elas vigoraram nos Estados Unidos de 1876 a 1965 . O corvo preto (crow em inglês) seria, portanto, uma referência de Gwathmey ao sistema legislativo racista do sul.

Robert Gwathmey tinha o hábito de realizar desenhos preparatórios para seus quadros. Um desenho de Standard bearer [Porta-estandarte] mostra como a figura do porta-estandarte fazia parte de uma possível composição maior, que incluia três trabalhadores rurais, sendo dois homens e uma mulher. Um trabalhador segura a enchada, outro colhe uma planta de tabaco, enquanto a figura feminina carrega toras de madeira e um balde para serviços domésticos. Ao fundo, uma casa pegando fogo é outro indicador da violência contra as comunidades negras rurais bastante presente nas obras de Gwathmey deste período. O arranjo formal do desenho ressalta ainda mais a disparidade social dos personagens. Os negros estão em segundo plano e seus corpos vergados pelo trabalho braçal, tornando-os ainda menores e franzinos, ao passo que a pujança anatômica do porta-estandarte se torna ainda mais contrastante. No desenho preparatório, a dominância do homem branco ganha proeminência e materialidade. Contudo, na obra final, Gwathmey optou por eliminar o pano de fundo e se concentrar na figura central.

98 "On the roof of the speaker's platform is a black crow, a frequent symbol in Gwathmey's art that may depict the pervasiveness and inevitable decay of the segregation system that the Southerners called Jim Crow". PIEHL, 1985, p.57, tradução nossa.

990 termo Jim Crow se refere a um esquete popular escrito em 1828 pelo ator Thomas Dartmouth Rice intitulada Jump Jim Crow. Rice escurecia o seu rosto com carvão para interpretar um personagem negro bastante estereotipado, que cantava: Come listen all you galls and boys,/ I'm going to sing a little song,/My name is Jim Crow./Weel about and turn about and do jis so,/Eb'ry time I weel about I jump Jim Crow. 


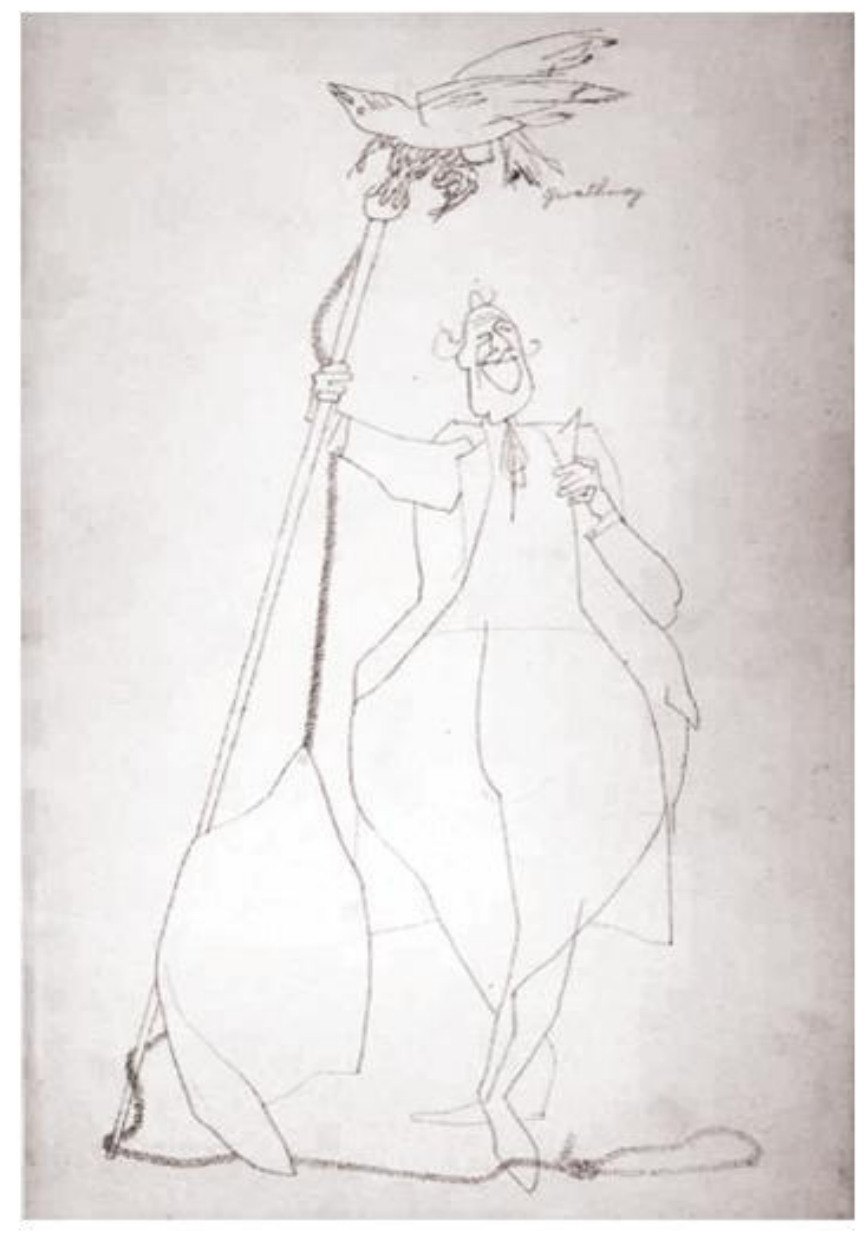

[Fig.26] Study for standard bearer (senator) [Estudo para porta-estandarte (senador)], ca. 1946. Grafite sobre papel laminado com cartão $38.7 \times 23.5 \mathrm{~cm}$.

Outro desenho preparatório está hoje no acervo do museu de arte da Universidade de Princeton. Esta versão do desenho se aproxima mais da composição final a óleo presente no MAC. O título do desenho Study for standard bearer (senator) [Estudo para porta-estandarte (senador)] sugere que o homem é, na realidade, um político local. Possivelmente um legislador do próprio Estado da Virgínia, cuja figura nos lembra um personagem retratado em outra obra de Gwathmey também de cunho político: Poll tax country. 


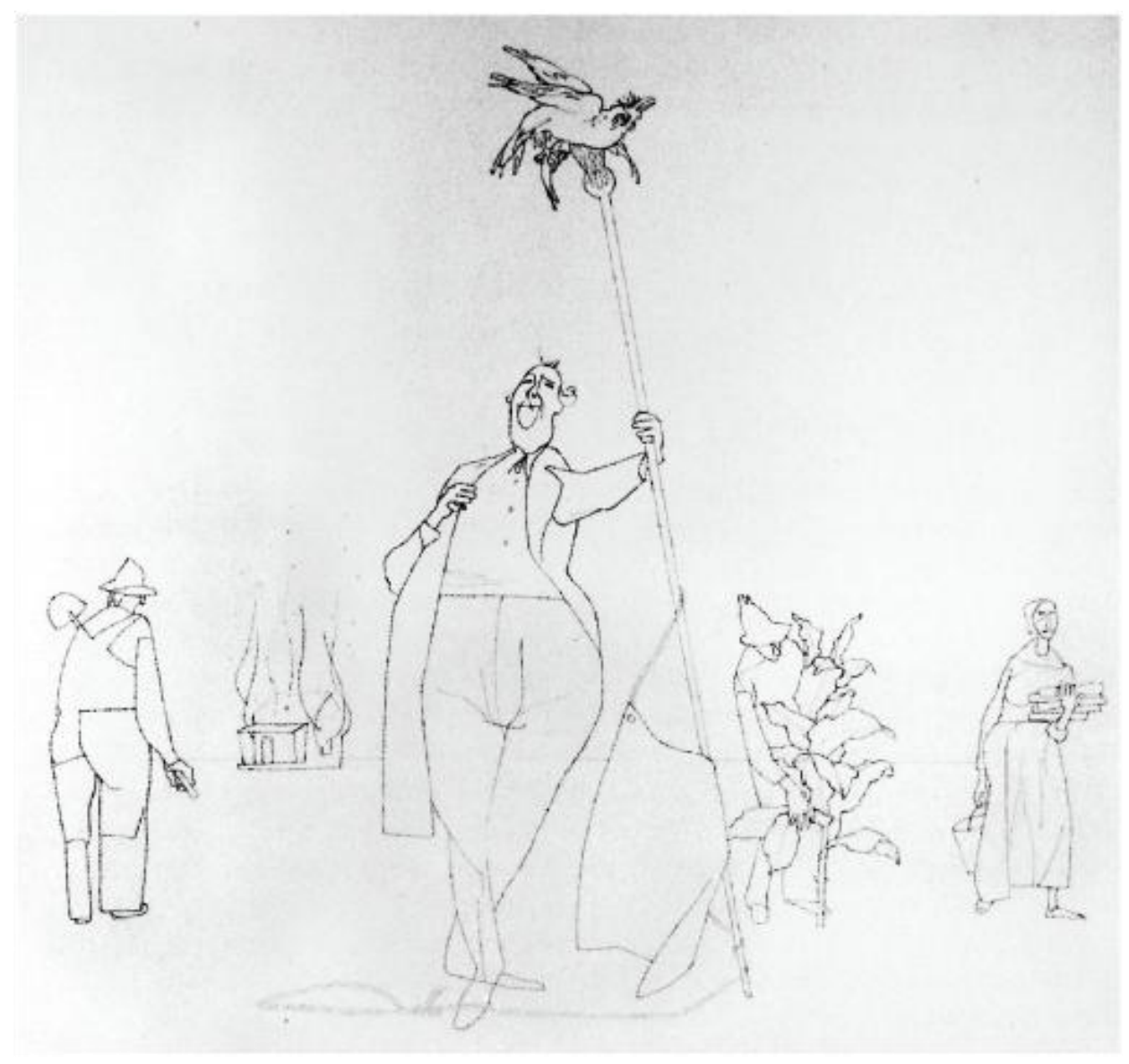

[Fig.27] Desenho preparatório para Standard bearer [Porta-estandarte] (n.d).

Assim como o porta-estandarte, o político em cima do palanque assume ares de uma ridícula soberba. Poll tax country é uma obra de 1945, anterior a Standard bearer [Portaestandarte], e se refere a um polêmico sistema de coleta de impostos que consistia na cobrança de \$1 a \$2 dólares anuais cumulativos por até 24 anos. Por não ser proporcional à renda e ter que ser liquidado antes das eleições, o imposto foi considerado particularmente prejudicial para as comunidades mais pobres. A Carolina do Norte, Flórida e Luisiana aboliram o imposto em 1937, mas os estados mais conservadores como a Virginia deram continuidade à coleta até ela ser considerada inconstitucional pela Corte Suprema em 1964. Poll tax country, assim como Standard bearer [Porta-estandarte], é uma crítica direta à elite política hegemônica do sul por meio da qual o sistema de segragação racial se perpetuava. 


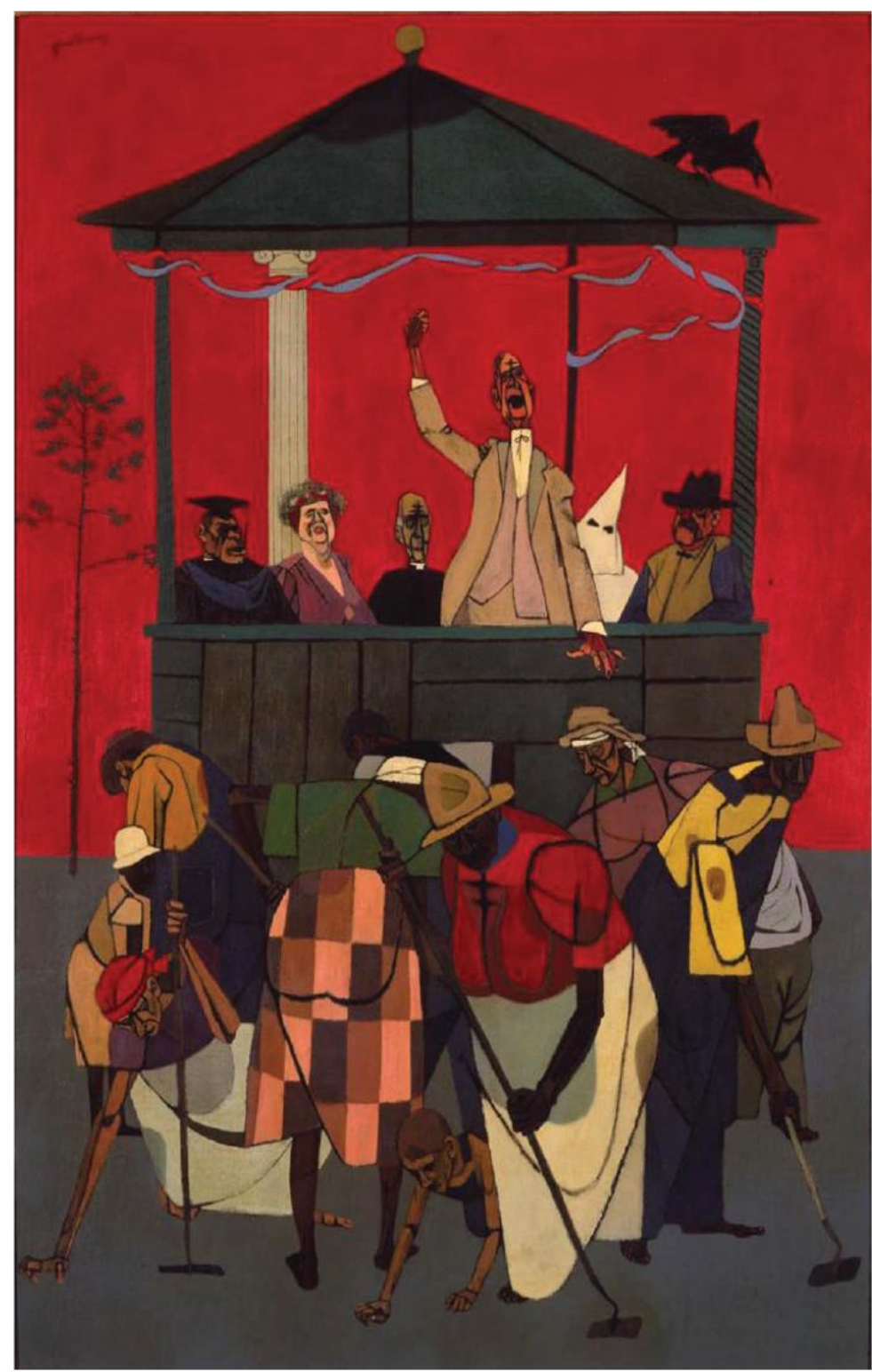

[Fig.28] Poll tax country (1945). Óleo sobre tela, 104,4 X 71,8 cm.

Para Michael Kammen:

Poll tax country é um comentário nada sutil e devastador sobre os brancos demagogos do sul e a cumplicidade do clero, das socialites e dos satisfeitos educadores negros. A presença pública de um homem da Ku Klux Klan e de um corvo preto estridente competindo com o orador se posiciona em nítido contraste com os coloridos 
trabalhadores com suas enxadas em primeiro plano (KAMMEN, 1999, p. 55). ${ }^{100}$

A decisão de Gwathmey de retirar os trabalhadores negros da cena de Standard Bearer e concentrar a composição em uma única figura pública personifica o tom de contestação política. O estandarte que o senador carrega traz a imagem de uma Justiça falida e do estrangulamento racial. Para Gwathmey, o político é o mesmo ator que implementa a segregação racial via as leis Jim Crow e quem, por meio de atos legislativos ou físicos, exerce a violência sistemática contra a população negra. A mensagem de Gwathmey era poderosa e, dado o momento histórico, altamente revolucionária.

Robert Gwathmey era um dos artistas plásticos mais ativos e socialmente engajados do sul dos Estados Unidos nos anos 1940. Sua participação na organização de cooperativas de artistas do Works Progress Administration, em seminários na Livraria Contemporânea em Pittsburgh - um ponto de encontro notório do Partido Comunista local - além de reuniões na Escola de Trabalhadores de Filadélfia, rendeu a Gwathmey a vigilância de agentes secretos do FBI de 1942 a 1969. Relatórios enviados a J. Edgar Hoover, o chefe do serviço secreto, caracterizam Gwathmey como um "sujeito comunista, porém não subversivo" que abraçava a ideia do Comunismo, sobretudo de um "ponto de vista intelectual". ${ }^{101}$

“No início dos anos 1940, se um homem branco demonstrasse um forte interesse e apoio pela cultura negra, ele frequentemente despertava a suspeita de que deveria ser algum tipo de radical" (KAMMEM, 1999, p.53). ${ }^{102}$ Ainda que a arte de Gwathmey tocasse em um tema sensível, o seu discurso contestador e marginal encontrou um espaço de prestígio nas principais instituições de arte moderna dos Estados Unidos.

100 "Poll Tax Country is a devastating, unsubtle commentary on white southern demagogues and the complicity of white clergy, socialites, and self-satisfied black educators. The public presence of a Klansman and a raucous black crow competing with the orator all stand (and sit) in sharp contrast to the colorful toilers with their hoes in the foreground". KAMMEN, 1999, p. 55, tradução nossa.

101 Relatório do FBI, 19. Jan. 1944, no. 100-41001 em KAMMEN, Michael, Robert Gwathmey - The Life and Art of a Passionate Observer, p. 53.

102 "During the early 1940s, if a white man demonstrated a strong interest in and support for black culture, he frequently aroused suspicion that the must be some sort of wild-eyed radical". KAMMEM, 1999, p.53, tradução nossa. 
Em 1946, quando Gwathmey produziu Standard bearer [Porta-estandarte], ele já era um artista renomado e tinha exposto no Whitney, no MoMA, na Coleção Phillips em Washington D.C., na Feira Mundial de Nova York e São Francisco e na New School for Social Research, entre outras instituições de renome. A partir de 1939, deu aulas na Carnegie Institute of Technology em Pittsburgh e, de 1942 a 1968, foi professor de desenho na Cooper Union em Nova York. Segundo Michael Kammen, "em 1946, tanto museus quanto indivíduos privados tinham ansiosamente começado a colecionar e expor obras de Gwathmey. Ele era um sócio-realista com estilo e temática absolutamente distintos" (KAMMEN, 1999, p.58). ${ }^{103}$

Em 1941, Gwathmey passou a ser um dos artistas representados pela galeria de Herman Baron, a American Contemporary Artists em Nova York. A ACA foi fundada por Baron em 1932 e tinha como foco artistas vinculados ao sócio-realismo. Estavam ligados à ACA Philip Evergood, William Groper, Anton Refregier, Joseph Solman, Alton Pickens e Robert Gwathmey - estes dois últimos inseridos na doação ao antigo MAM em 1946 e 1950, respectivamente. Foi desta galeria que Dorothy Miller e Alfred Barr adquiriram Standard bearer [Porta-estandarte] para a primeira doação Rockefeller. De 21 de janeiro a 9 de fevereiro de 1946, Robert Gwathmey ganhou uma exposição solo na ACA em Nova York. Por falta de acesso ao catálogo da ACA, não é possível determinar se Standard bearer [Porta-estandarte] integrou essa exposição. Contudo, sabe-se que em 1946 todas as obras de Gwathmey eram vendidas por Herman Baron em sua galeria em Manhattan (KAMMEN, 1999).

A obra que pertence hoje ao MAC USP fazia parte da produção recente do artista, que vivia uma de suas melhores fases. Assim como Everett Spruce e Byron Browne, Gwathmey participou da polêmica exposição Advancing American art [Avançando a arte americana], com duas obras intermediadas pela galeria ACA: Work song [Canção de trabalho] (1946) e Workers of the land (dirt farmers) [Trabalhadores da terra (fazendeiros da lama)] (1946). Sem dúvida, a produção de Gwathmey era conhecida por Miller e Barr e estaria no radar de ambos os curadores.

103 "By 1946 museums as well as private individuals had eagerly begun to collect and feature works by Gwathmey. He was a Social Realist with an absolutely distinctive style and subject manner, and his art was appealing and unlike any other". KAMMEN, 1999, p.58, tradução nossa. 
Robert Gwathmey seria mais conhecido no Brasil por suas gravuras e não tanto pelas pinturas. Ele ajudou a fundar, ao lado de Edward Landon, a National Serigraph Society, em 1940, uma associação de artistas que promovia a produção e divulgação da serigrafia, até aquele momento considerado um suporte gráfico comercial e não vinculado à prática artística. Gwathmey teve uma grande produção de gravuras que tocavam nos temas da segregação racial e na vida das lavouras do sul. Foi com essa produção que ele estreou na I Bienal de São Paulo, por meio de três gravuras intermediadas pela National Serigraph Society: Tobacco farmers [Plantações de fumo] (1947), Colhendo fumo [Topping tobacco] (1947) e Ring around a rosey [Anel à volta da rosa] (1949).

Por sua temática e mesmo pelo estilo de desenho gráfico e com cores primárias, essas três obras aproximam Gwathmey da produção de Jacob Lawrence. Existe um diálogo evidente entre as obras desses dois artistas no que diz respeito a uma narrativa sobre segregação versus emancipação racial. Não por acaso, a divisão proposta por Alfred Barr previa que as duas obras deveriam permanecer juntas na coleção do MAM-RJ, a fim de ressaltar esse diálogo. Ao passo que Gwathmey se dedicava a retratar a condição do negro rural e da opressão dos homens brancos - como em Standard bearer [Porta-estandarte] -, Lawrence, por sua vez, pintaria a vida dos negros nos grandes centros urbanos do norte do país. 

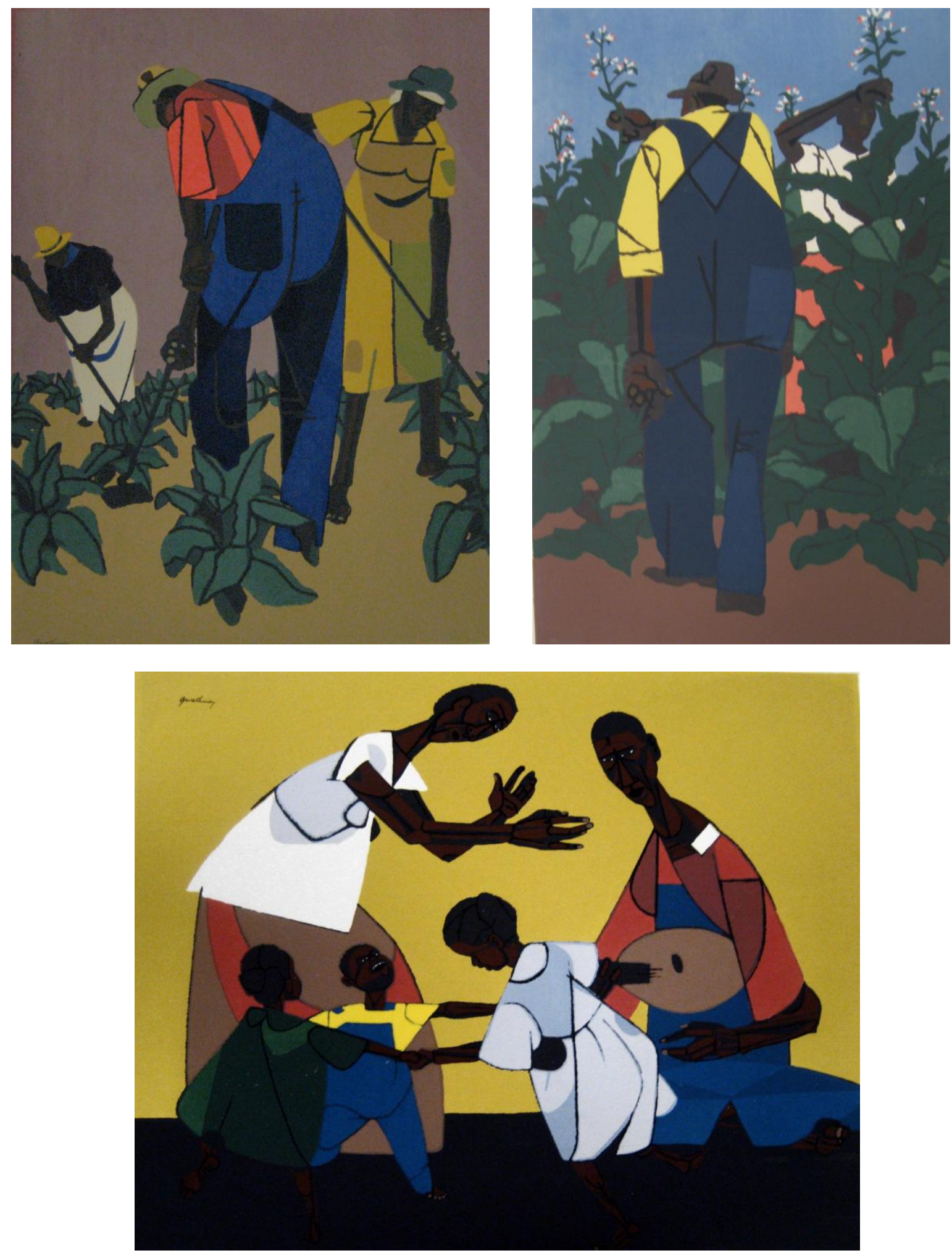

[Fig.29] Tobacco farmers [Plantações de fumo] (1947), Colhendo fumo [Topping tobacco] (1947) e Ring around a rosey [Anel à volta da rosa] (1949). Essas três obras foram exibidas no pavilhão norte-americano da I Bienal (SP). 


\section{Lecture on architecture, Jacob Lawrence}

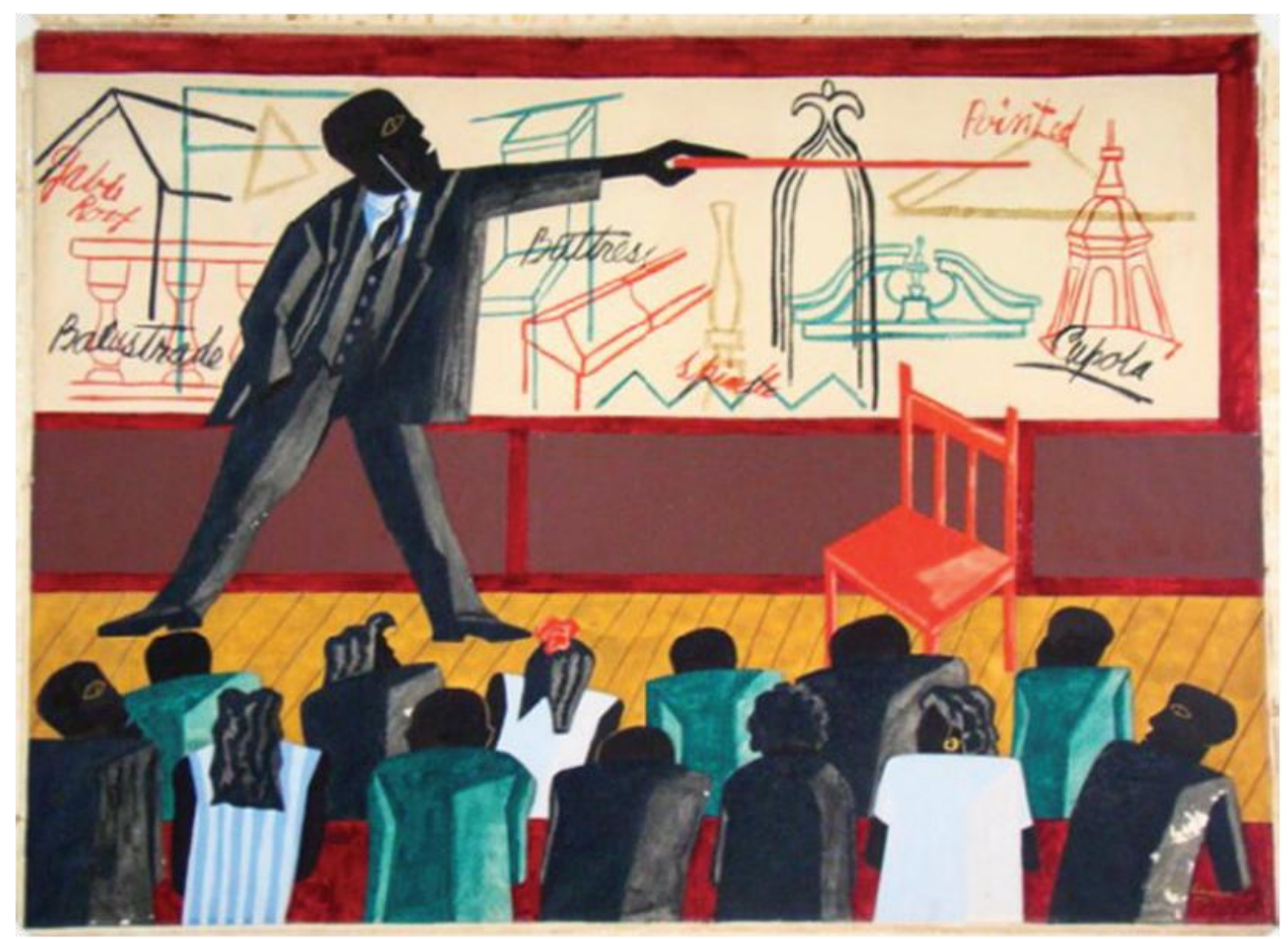

[Fig.30] Jacob Lawrence. Lecture on architecture [Aula de arquitetura] (1946), aquarela sobre papel, 55,4 X 76,4.

Jacob Lawrence é o único artista negro da coleção Rockefeller. A obra de Lawrence, reconhecidamente hoje um dos artistas negros norte-americanos mais importantes da década de 1940, é um destaque das doações. A obra de maior repercussão de Jacob Lawrence continua sendo a série de 60 guaches sobre a diáspora negra, período em que milhares deixaram suas casas nos Estados do Sul dos Estados Unidos em busca de melhores condições de trabalho e moradia no Norte. A epopéia foi registrada por Lawrence na série The migration of the negro [Migração do negro] (1940-1941), que pertence aos acervos do MoMA e da coleção Philips em Washington D.C.

A própria família Lawrence fez parte deste movimento, quando sua mãe se muda da Filadélfia, em 1924, em direção à crescente comunidade do Harlem em Nova York. Lawrence 
chegou ao Harlem com 13 anos e, rapidamente, se envolveu no florescimento cultural da comunidade. Aquele era um espaço de convívio com as tradições ancestrais africanas, por meio da dança, filosofia, religião e arte, ao mesmo tempo em que era também um importante polo difusor de modernidade. Um número crescente de intelectuais e trabalhadores se aglomerava nos blocos de apartamentos superpopulados do Harlem na primeira metade do século XX. Ali conviviam artistas, políticos músicos, escritores e lideranças sociais.

Estudos sobre a produção de Lawrence jamais conseguiram separar sua pintura do forte contexto político e social que pautou a sua vida. Temas frequentes de suas pinturas serão os personagens e trabalhadores braçais com os quais se deparava no bairro. Grande parte de sua produção no ano de 1946, data de Lecture on architecture [Aula de arquitetura], se reporta a personagens encontrados nas casas, nas festas particulares da classe média afro-americana, nos salões de beleza, mercearias e oficinas do Harlem.

Segundo a historiadora Leslie King-Hammond, "ele foi testemunha aos estilos de vida aculturados, inovadores e empobrecidos criados pelas confluências da Grande Migração, da depressão, da era do jazz, e da emergência dos Novos Negros na Renascença do Harlem" (KINGHAMMOND, 2000, p. 69) ${ }^{104}$. Para a historiadora, o que torna Lawrence singular é a consciência do ambiente tão excepcional onde forjou sua identidade.

\begin{abstract}
As ruas de Harlem - seu movimento, as pessoas, as cores e sons locais - tornaram-se uma fonte inesgotável de inspiração visual e espiritual para Lawrence. (...) Ele não se tornaria apenas o contador de histórias visuais do Harlem, mas de fato acabaria sendo o biógrafo de uma comunidade extraordinária e o autobiógrafo do artista que evoluiu a partir dela (KINGHAMMOND, 2000, p.77) ${ }^{105}$.
\end{abstract}

\footnotetext{
104 "Jacob Lawrence was a witness to the acculturates, innovative, and improvised lifestyles created by these confluences of the Great Migration, the depression, the jazz age, and the emergenve of the New Negros of the Harlem Renaissance". KING-HAMMOND in NESBETT, 2000, p.69, tradução nossa.

105 "The streets of Harlem - their movement, the people, the local color, and the sounds - became a bottomless source of visual inspiration for Lawrence [...] Lawrence would not become just the storyteller of Harlem, ut infact he would become the biographer of an extraordinary community and the autobiographer of the artis who evolved from it. KING-HAMMOND in NESBETT, 2000, p.77, tradução nossa.
} 
Jacob Lawrence é, em alguma medida, resultado deste fenômeno singular do Harlem nos anos 1930 e 1940. Sua trajetória profissional é singular. Neste ambiente, ele pôde receber aulas de arte nos centros culturais espalhados pelo bairro. A educação artística era uma oportunidade rara para os negros e Lawrence seria o primeiro grande pintor do século XX tecnicamente treinado e educado dentro da comunidade. Lawrence foi aluno de Charles Alston no centro cultural Utopia Children's House. Ele teve acesso a aulas do Works Progress Administration, entre 1934 e 1937, e a estudos no Harlem Art Workshop e American Artist's School. Auxiliado economicamente por doações da Harmon Foundation e do Fundo Rosenwald, programas de incentivo para a produção artística da comunidade, Jacob Lawrence pôde estabelecer uma carreira como artista profissional. Honrando o bairro que o criou, sua primeira exposição solo foi justamente na sede do YMCA do Harlem em 1938.

O divisor de águas do período jovem da carreira veio a partir do contato com Edith Halpert, dona da galeria Downtown, dedicada à promoção da arte moderna. O relacionamento de Lawrence com Edith se deu por meio do historiador Alain Locke, que havia sido parte da primeira leva de intelectuais e reformistas negros do Harlem. Locke frequentava a galeria de Edith desde o final dos anos 1920, tornando-se um interlocutor próximo da dona da Downtown. Edith havia morado no Harlem quando desembarcou ainda menina nos Estados Unidos, fugindo com a mãe e irmã da represália contra os judeus na sua cidade natal Odessa, em 1906, período em que o bairro ainda era moradia dos imigrantes judeus pobres em Manhattan. Talvez essa ligação tenha contribuído ao interesse despertado em Edith pela estrela ascendente do Harlem.

Em 1941, ela decidiu expor a maior obra de Lawrence, The migration of the negro [Migração do negro] (1940-1941), pela primeira vez no grande circuito da arte de Nova York. O sucesso inicial da carreira de Lawrence muito se deve ao investimento realizado por ela e os esforços de divulgação de sua arte entre colecionadores e curadores importantes. Negociante habilidosa, Edith tinha a preocupação de inserir obras icônicas de seus artistas em grandes museus. Assim, em 1942, ela intermediou a venda dos 60 guaches, em dois conjuntos de 30, para duas grandes instituições: o MoMA e a Coleção Phillips em Washington, D.C. 
Foi Alfred Barr que, a contragosto, selecionou quais obras iriam para o MoMA e quais para a coleção de Duncan e Marjorie Philips. "Barr não era grande fã de Edith Halpert e estava muito mais interessado em gastar seus poucos dólares de aquisição com arte europeia", escreve Lindsay Pollock, biógrafa de Edith ${ }^{106}$. Artistas representados por Edith entrariam para a coleção do MoMA principalmente por meio de doações Abby Rockefeller, uma cliente fiel e amiga próxima. "Edith periodicamente confrontava Barr sobre sua falta de apoio aos talentos locais, os norte-americanos que ela selecionara e cujas obras estavam penduradas a poucas quadras do museu. Neste caso, Edith achava que Barr não podia recusar a série Migração" $\left(\right.$ POLLOCK, 2006, p. 250) ${ }^{107}$. Como o curador não queria pagar pelas obras com dinheiro do fundo de aquisição do museu, Edith orquestrou uma maneira de elas serem doadas ao MoMA através da aquisição por Adele Rosenwald Levy, cuja família mantinha a Rosenwald Foundation, que havia concedido uma bolsa de estudos para o pintor no início de sua carreira.

Depois da venda da série The migration of the negro [Migração do negro] em 1942, Lawrence alcançou os holofotes da cena artística nova-iorquina. No ano de 1946, ele já era um artista prestigiado por um público mais amplo do que a comunidade negra na qual cresceu. A despeito das resistências iniciais de Alfred Barr, Lawrence ganharia cada vez mais espaço no MoMA. Suas obras passaram a integrar itinerâncias internacionais e foram incluídas nos acervos dos principais museus e coleções de arte privada dos Estados Unidos. Em 1944, o MoMA realizou a exposição solo Paintings by Jacob Lawrence [Pinturas de Jacob Lawrence], a primeira dedicada a um artista negro norte-americano, incluindo todo o conjunto de 60 painéis da série de migrações. ${ }^{108}$

A obra no acervo do MAC, Lecture on architecture [Aula de arquitetura], faz parte de um rico período de produção de Jacob Lawrence, quando ele estava no auge de sua maturidade artística e no completo domínio da linguagem visual. Ela foi adquirida por US\$ 270 da galeria de

\footnotetext{
106 "Alfred Barr Jr., the diretor, was no big fan of Edith Halpert and was far more interested in spending his meager acquisition dollars on European art". POLLOCK, 2006, p.250.

107 "Edith periodically challenged Barr about his lack of support for her local talento, the Americans she has handpicked whose works hung just a few blocks away from the museum". POLLOCK, 2006, p.250.

108 As obras de Jacob Lawrence são continuamente retrabalhadas pela curadoria do museu. A exposição mais recente com toda a série The migration of the negro [Migração do negro] foi realizada no MoMA de abril a setembro de 2015, com o título One-way ticket: Jacob Lawrence's migration series and other works.
} 
Edith Halpert em novembro de 1946, segundo recibo de venda disponível dos Archives of American $\mathrm{Art}^{109}$. Lecture on architecture [Aula de arquitetura] foi produzida no verão de 1946, quando Lawrence foi convidado por Joseph Albers para dar aula no Black Mountain College, um reduto artístico progressista formado pelo ex-fundador da Bauhaus em uma pequena cidade do Estado da Carolina do Norte.

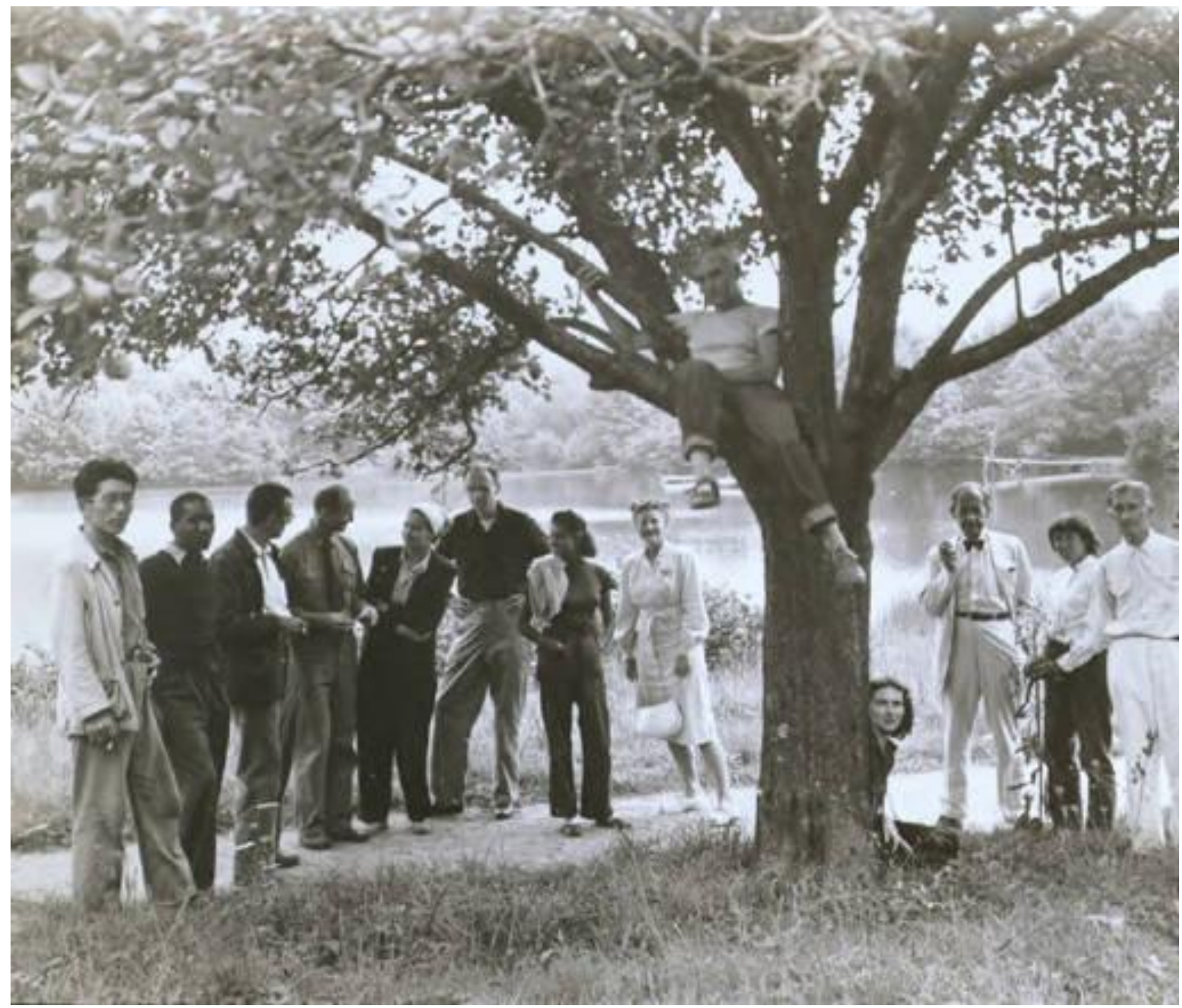

[Fig.31] Jacob e Gwen Knight Lawrence entre artistas do Black Mountain College.

${ }^{109}$ Downtown Gallery records, 1824-1974, pastas 1926-1969. Archives of American Art, Smithsonian Institution. 
A obra mostra um professor negro, muito provavelmente o próprio Lawrence, diante de uma sala de alunos de arte e uma lousa, em que se vêem arabescos, arcos e formas arquitetônicas simplificadas. Ele era o único professor negro da escola e, como era uma característica sua transpor elementos biográficos às telas, é possível que a experiência no Black Mountain College seja, em alguma medida, o pano de fundo desta obra.

Lecture on Architecture [Aula de arquitetura] contém cores vibrantes e primárias. O uso de tonalidades fortes está associado à estética pictórica das tradições da comunidade afrodescentes. E, assim como no caso de Morris Graves, o uso do papel como suporte se deu, em um primeiro momento, pelas restrições econômicas e a impossibilidade de praticar grandes composições em telas a óleo. Mas Lawrence acabou por dominar completamente a técnica tornando-se um artista virtuoso da têmpera sobre papel. O uso de obras em papel de tamanhos pequenos servia também ao seu propósito narrativo, permitindo a justaposição de cena após cena, em séries que chegavam a ter dezenas de composições.

No Brasil, Lawrence teve um reconhecimento tardio. Três pinturas de Lawrence estiveram presentes na I Bienal - Sedation [Sedação] (1950), Cortiço (1951) $)^{110}$ e Tombstones [Pedras Tumulares] (1942), mas ele só ganharia uma mostra individual no país em 1990, quando a historiadora norte-americana Samella Lewis, uma das grandes referências em arte negra moderna, organizou no MAC USP uma exposição com 15 desenhos e 11 serigrafias intitulada "Jacob Lawrence - Um americano do Harlem". ${ }^{111}$ Acompanhando a exposição, Lewis organizou um seminário sobre a expressão de artistas afro-brasileiros nas artes plásticas, em um intercâmbio entre as realidades sociais dos artistas negros do Brasil e dos Estados Unidos. Sobre o pintor, Lewis escreveu:

Lawrence representava com distinção a primeira geração de artistas reconhecidos que foram influenciados pela experiência afro-americana: sua comunidade e seus primeiros professores foram afro-descententes e seu primeiro encorajamento veio deles. Ele era um artista social de grande

\footnotetext{
${ }^{110}$ Não foi encontrado o título original da obra, apenas a tradução para o português no catálogo da I Bienal de São Paulo, Arquivo Wanda Svevo, Fundação Bienal de São Paulo, 1951.

111 A fúria negra, por um totem da vida norte-americana. O Estado de S. Paulo, 9 de agosto de 1990, p. 12.
} 
habilidade que falava em alto e bom som e com clareza sobre suas obras. Tão importante quanto o fato de Lawrence ser, provavelmente, o melhor, o mais publicado e influente artista afro-americano é o fato de que ele era um homem humilde de enorme estatura pessoal (LEWIS, 2003, p. 131). ${ }^{112}$

Jacob Lawrence foi reconhecido como um dos principais pintores negros da história da arte moderna norte-americana e sua obra é frequentemente interpretrada por meio da chave da questão racial e do movimento dos direitos civis nos Estados Unidos.

Tendo em vista as realidades sociais do Brasil, a inclusão dessa obra traz um forte subtexto político. Discursos sobre a raça estão presentes na doação Rockefeller. Se a obra de Gwathmey remete ao sistema de segregação, ao ambiente corrupto das leis Jim Crow e aos linchamentos, Lawrence registra uma sala de aula onde um professor negro fala de arte e arquitetura para uma plateia de estudantes negros. Se por um lado a pintura de Robert Gwathmey remete à opressão do homem branco no Sul dos Estados Unidos, o guache de Jacob Lawrence traz como tema o renascimento cultural da comunidade negra do Harlem.

112 "Lawrence represented with distinction the first generation of recognized artists nurtured by African American experience: his community and his early teachers were African American, and his first encouragement came from them. He was a social artist of great ability who spoke loudly and clearly through his works. As important as the fact that Lawrence was probably the best-known, the most published, and most influential African American artist is the fact that he was a humble man of great personal stature". LEWIS, 2003, p.131, tradução nossa. 


\section{Yellow plane, Alexander Calder}

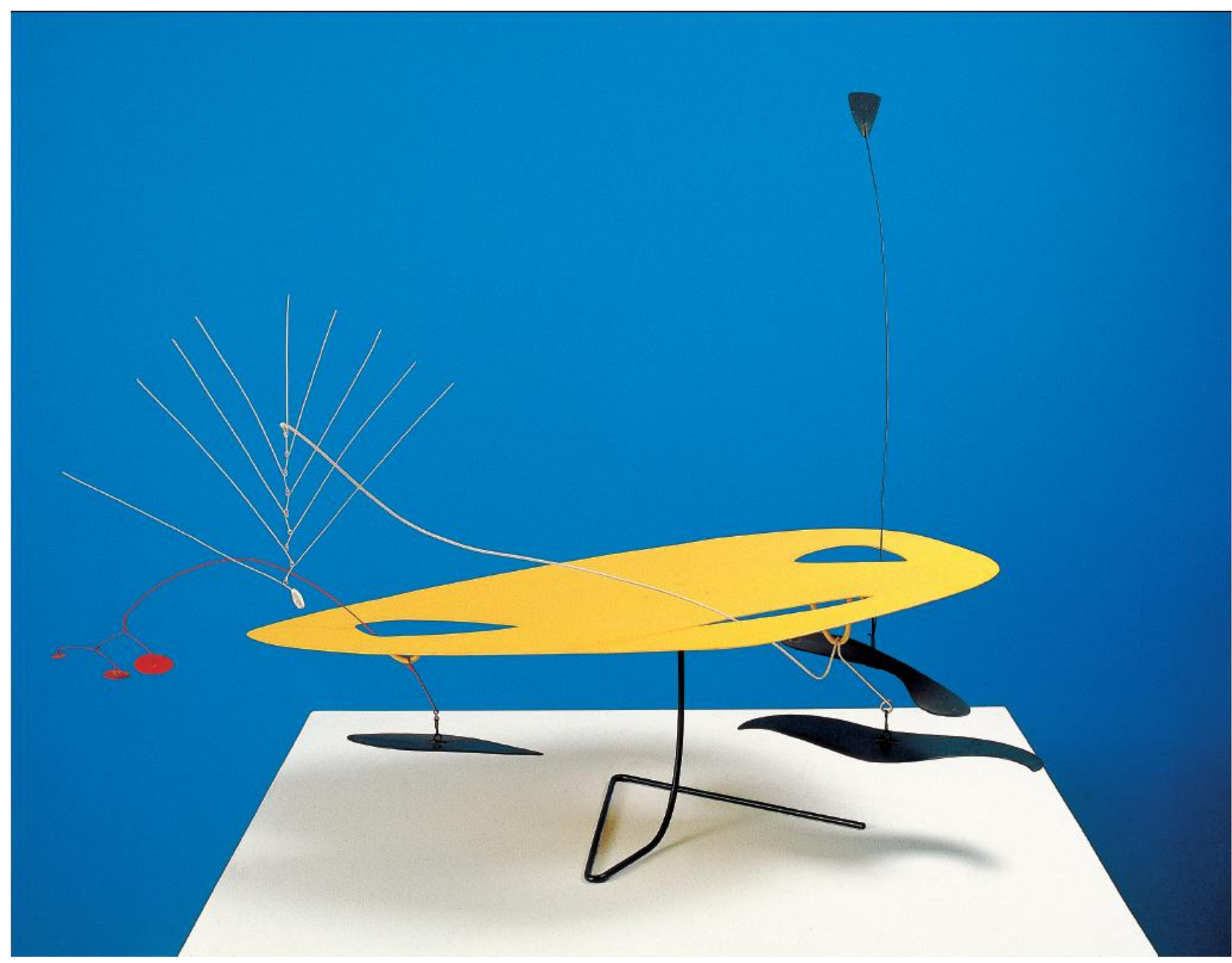

[Fig.32] Alexander Calder. Yellow plane [Plano amarelo ou Móbile amarelo, preto, vermelho e branco], sem data, metal pintado, $93 \times 130 \times 125 \mathrm{~cm}$.

Nascido em Lawnton, Pennsylvania, Alexander Calder é um gigante da escultura norteamericana. Mais conhecido por seus móbiles e estábiles do que propriamente por suas pinturas, ele é um dos expoentes da escultura cinética. Formado em engenharia pela Stevens Institute of Technology, de Hoboken, New Jersey, Calder começou os estudos em arte em Nova York. Teve aulas com Thomas Hart Benton e John Sloan na Art Students League e, em meados da década de 1920, passou uma temporada em Paris, onde teve contato com Marcel Duchamp, Joan Miró e Jean Arp. Nos Estados Unidos, Calder recebeu notoriedade em 1943, com uma 
exposição do MoMA inteiramente dedicada à sua arte. Com curadoria de James Johnson Sweeney, a exposição era uma retrospectiva da obra de Calder, que na época tinha 45 anos.

Escrevendo para The nation sobre a exposição do MoMA, Clement Greenberg diria que um dos "grandes trunfos de Calder é a felicidade". Essa ideia também ressoaria em outros críticos. Pedrosa chamaria os móbiles de Calder de "tlin-tlins de alegria" e Jean-Paul Sartre os caracterizou como "uma pequena festa local". O que nunca escapa à análise da arte de Calder é a atração pelo movimento e o engajamento da estrutura com o olhar do espectador. Os móbiles são pequenas orquestras de cores e formas que se agitam no ar e desenham trajetórias inesperadas no espaço. Os efeitos do movimento dos móbiles foram tratados por Giulio Carlo Argan como uma "grafia delicada" que "parece querer imitar o desenrolar da vida no sopro da respiração" (ARGAN, 2010, p.657).

Nelson Rockefeller era um grande colecionador de Calders e tinha várias esculturas espalhadas em suas propriedades. O MoMA realizou uma exposição das obras de destaque da coleção Rockefeller, em que cinco esculturas foram listadas, desde pequenas estruturas de arame, como The golfer [O jogador de golfe] (ca. 1927), feito em homenagem ao pai de Nelson, John D. Rockefeller Jr., como grandes estábiles de dimensão pública, como Large spiny (1966), que costumava decorar os jardins da casa de campo de Nelson. "Alexander Calder tem sido um amigo de Nelson Rockefeller por muitos anos. Nelson particularmente aprecia o humor despreocupado e sua tradução em objetos tridimensionais", disse o curador do MoMA William Lieberman (LIEBERMAN, 1969, p 32) ${ }^{113}$. Talvez uma das obras mais conhecidas da doação ao Brasil seja o móbile Yellow plane [Plano amarelo ou Móbile amarelo, preto, vermelho e branco]. Não se sabe se essa obra pertenceu a Nelson antes de ser enviada ao Brasil.

Calder teve ampla repercussão no Brasil nos anos 1940 e seus móbiles foram adquiridos por famílias proeminentes. Calder encontrou no Brasil um grande mercado para seus móbiles e no arquiteto Henrique Mindlin e Mário Pedrosa interlocutores próximos que ajudaram a criar um ambiente favorável para a recepção de suas obras na cena nacional. Em

\footnotetext{
113 "Alexander Calder has been a friend of Nelson Rockefeller's for many years [...] Nelson Rockefeller particularly appreciates light-hearted humor and its rendering in three-dimensional objects." LIEBERMAN, 1969, p 32, tradução nossa.
} 
1948, ele ganhou uma grande exposição solo no Ministério de Educação e Saúde do Rio de Janeiro, organizada com apoio de Mindlin.

O encantamento das obras de Calder reverberou com força em um dos críticos brasileiros mais importantes do período. Mário Pedrosa visitou a exposição do MoMA em 1943 e escreveu uma de suas primeiras peças críticas sobre as obras de Calder, que se tornaria um tema recorrente de seu itinerário crítico. Calder, o escultor de cata-ventos foi o primeiro texto de Pedrosa publicado sobre o artista no jornal Correio da Manhã, em dezembro de 1944.

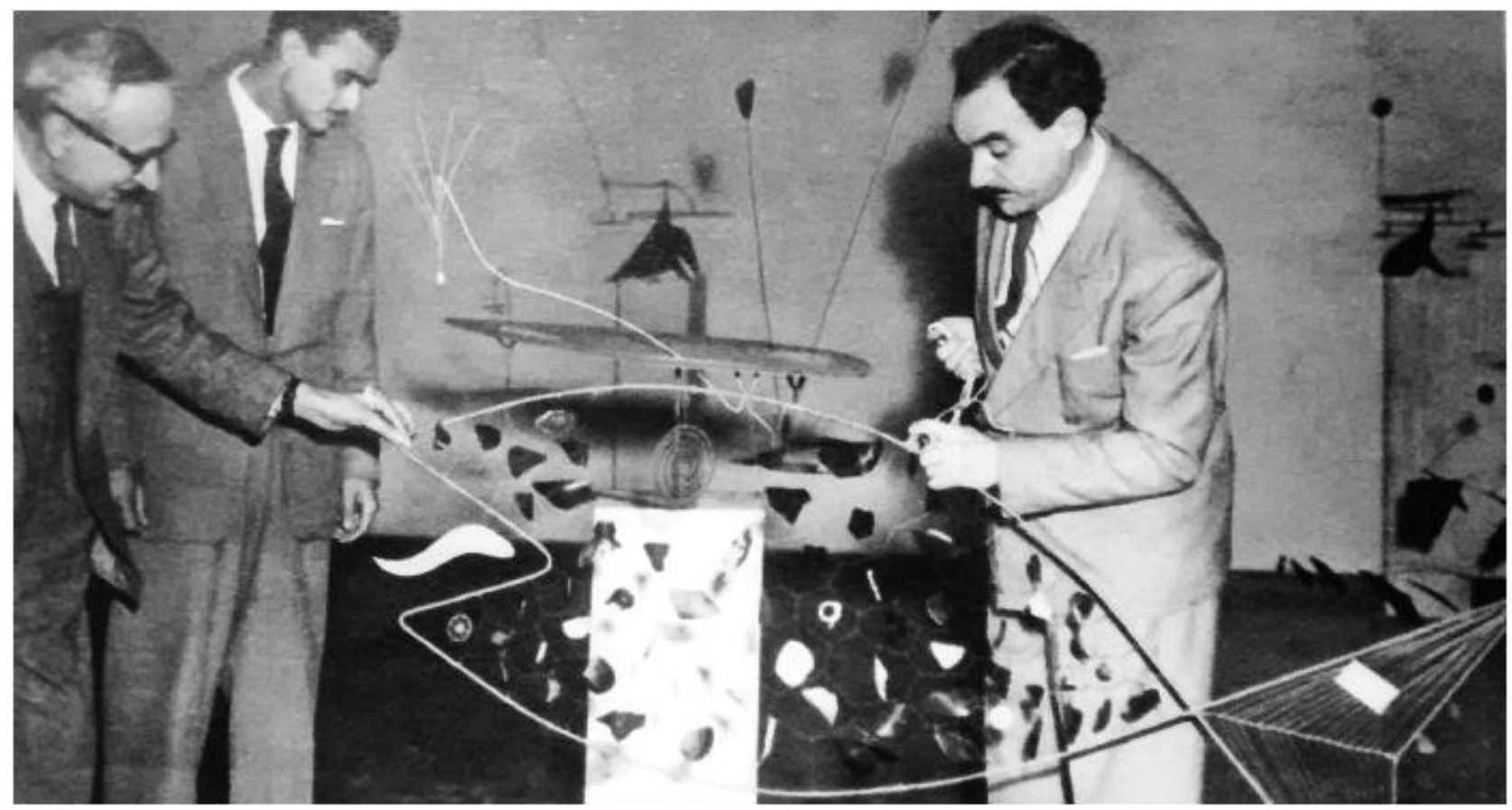

[Fig.33] Bardi exibe Brazilian fish [Peixe brasileiro] (1947) na exposição de Calder no Masp, em 1948. Ao fundo, está exposta a escultura Yellow Plane.

No ensaio, Pedrosa diz que as esculturas de Calder são resultado de um profundo conhecimento de mecânica somado a uma poderosa sensibilidade estética. Pedrosa credita a virada na obra de Calder ao seu contato com Mondrian. A partir deste encontro, o escultor passaria a se dedicar, não mais aos brinquedos articulados e temas circenses que vinham lhe ocupando a imaginação, mas à busca pela forma abstrata pura. "Sua obra pode-se então dividir em pré e pós-Mondrian", escreve Pedrosa. Ainda em Paris, Calder se engaja no grupo Abstraction-Création, formado por Arp, Jean Hélion e Theo van Doesburg. 
Abandonando de vez os problemas próprios à escultura, como os do aprofundamento do material, o tridimensionalismo, as massas compactas e seus contrastes de sombra e luz, ele toma por um caminho ainda não batido, por assim dizer fora do campo específico das artes plásticas. Fascina-o o problema da projeção das formas no espaço. A ideia the veio de projetar no espaço, de fazer girar aqueles painéis imaculados e estáticos, mas fortemente coloridos do ateliê de Mondrian. O mestre holandês horrorizou-se, naturalmente, com a ideia (PEDROSA, 2006, p. 45).

Dedicado à criação abstrata, Calder foi uma peça importante no debate que se estabeleceu no Brasil entre o Figurativismo e o Abstracionismo. O projeto sistematizado por Henrique Mindlin e amparado pela envergadura crítica de Mário Pedrosa de criar um espaço favorável para a divulgação de Calder na cena nacional já é bem documentado (SARAIVA, 2006). O interessante é perceber como esse processo se cruza com as doações Nelson Rockefeller e com o objetivo maior de popularizar a arte moderna norte-americana no Brasil. Certamente, Alfred Barr não estava alheio ao movimento de aproximação de Calder com o ambiente artístico brasileiro no momento em que escolhe seja o móbile Yellow plane [Plano amarelo ou Móbile amarelo, preto, vermelho e branco] para compor o conjunto de obras a doação Rockefeller de 1946.

A aproximação de Mindlin com Calder acontece em 1943, quando o arquiteto brasileiro viajou para os Estados Unidos para trabalhar no National Housing Agency. Naquele ano também acontecia a exposição Brazil builds, uma iniciativa do escritório de Nelson Rockefeller (CIAA) para criar um ponto de diálogo entre os Estados Unidos e o Brasil por meio do debate artístico. Mindlin e Calder se conhecem neste momento e ambos trabalhariam juntos para assegurar encomendas de seus móbiles para colecionadores brasileiros ao longo dos anos 1940 e 1950. De volta ao Brasil, Mindlin atuou como um marchard das obras de Calder e seu apartamento virou vitrine para as esculturas. "Dê-me apenas algum tempo e eu começarei uma febre de Calder no Rio", escreveu o arquiteto brasileiro em novembro de 1944 (SARAIVA, 2006, p. 35). 
Em um texto de Mindlin de 1945 para a Revista de arte da Escola Nacional de Belas Artes, ele associaria as esculturas do amigo à nova estética da arquitetura modernista nacional.

A obra de Calder oferece extraordinárias possibilidades para a integração da escultura na arquitetura de nossos dias. Basta imaginar um dos seus grandes móbiles suspenso no pórtico de um dos nossos edifícios novos, como por exemplo, o Ministério da Educação ou o Instituto de Resseguros, basta visualizá-lo tocado pela brisa, enchendo o espaço claro com seus ritmos sempre novos, para compreender não só a importância das contribuições que Calder traz à nova arquitetura, como especialmente aquela que poderia trazer para a arquitetura do sol e dos espaços abertos que se realiza no Brasil. ${ }^{114}$

Em setembro de 1948, o escultor veio ao Rio de Janeiro para trabalhar na montagem da exposição Alexander Calder no Ministério da Educação e Saúde. A escultura Yellow Plane foi enviada ao Rio para fazer parte da mostra inaugural e depois retornou a São Paulo em outubro, para integrar a versão paulista da exposição (SARAIVA, 2006, p.69). A montagem realizada no Masp foi idealizada por Lina Bo Bardi. Sua expografia caprichada incluiu painéis coloridos como pano de fundo para as esculturas, focos de luz para criar jogos de sombra e ventiladores para animar os móbiles.

Yellow plane [Plano amarelo ou Móbile amarelo, preto, vermelho e branco] aparece em uma fotografia da montagem da exposição no Masp, atrás de uma obra maior Brazilian fish [Peixe brasileiro] (1947) sendo manuseada por Pietro Maria Bardi. Esse é um dos únicos registros fotográficos que verifica a inserção da escultura na exposição inaugural de Calder no Brasil. Durante o tempo que permaneceu no país, Calder teria à sua disposição uma oficina no Rio de Janeiro para produzir obras para compradores brasileiros. "Além da boa acolhida crítica e pública, vendera a maior parte dos móbiles e doara algumas peças a instituições locais: um grande móbile, Black widow [Viúva Negra], para o Instituto de Arquitetos do Brasil" (SARAIVA,

114 MINDLIN, Henrique. Revista de Arte 3. Rio de Janeiro: Escola Nacional de Belas Artes, 1945. Reproduzido do livro Calder no Brasil organizado por Roberta Saraiva. 
2006, p. 84). Naquela época, o IAB ainda era o guardião oficial das obras doadas por Nelson Rockefeller e foi, muito provavelmente, o órgão que permitiu a inserção de Yellow plane nas exposições do Ministério da Educação e do Masp, uma vez que os projetos para a criação do antigo MAM ainda estavam sendo finalizados.

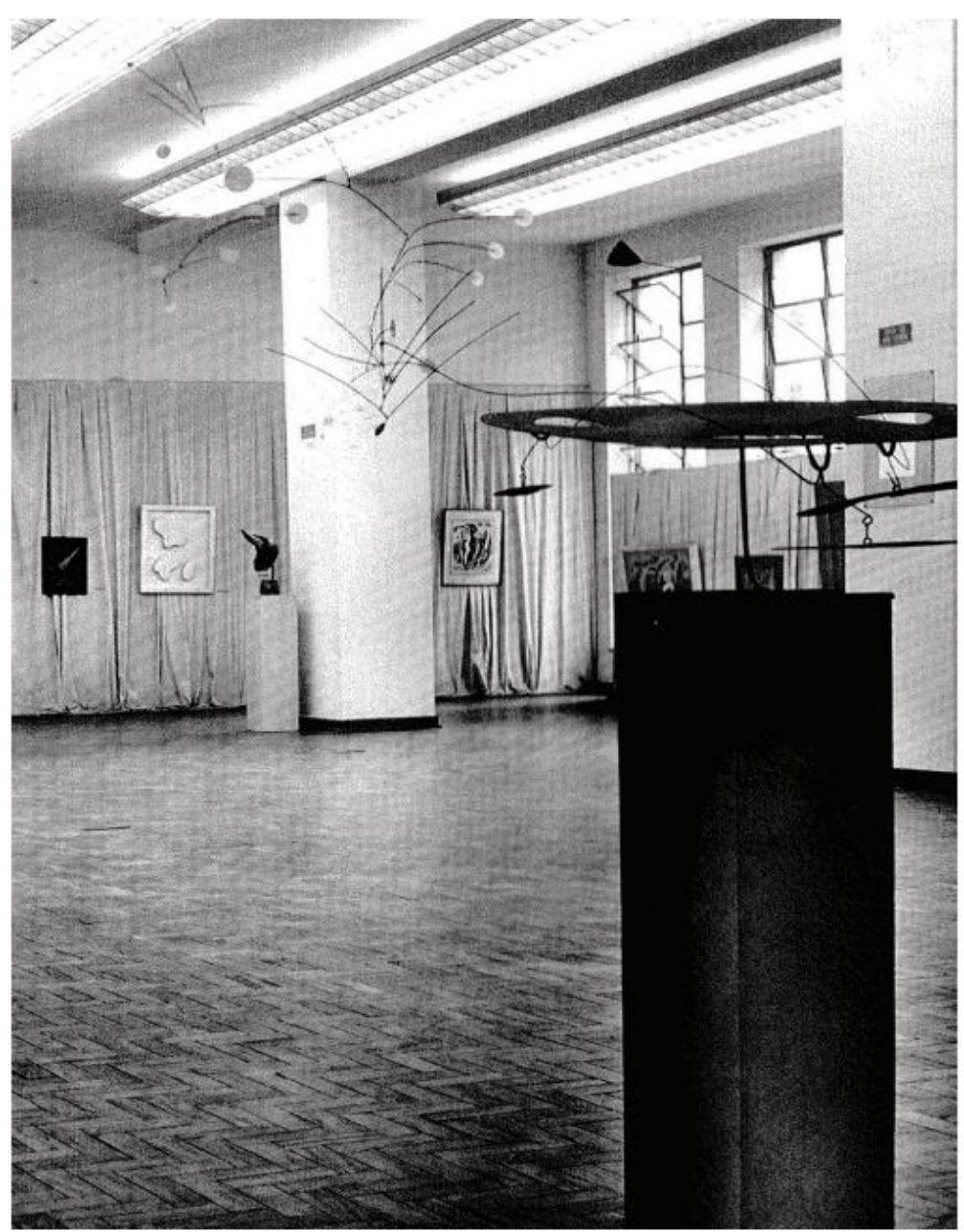

[Fig.34] Imagem de Yellow plane na exposição inaugural do MAM, Do figurativismo ao abstracionismo.

O móbile retornaria ao Museu de Arte Moderna na exposição inaugural Do figurativismo ao abstracionismo, organizada por Leon Degand em 1949. Yellow plane foi apresentada, com quatro outros móbiles, na exposição, além de ter sido incluída em sucessivas mostras 
posteriores organizadas pelo antigo MAM-SP e depois pelo MAC USP. ${ }^{115}$ Neste contexto, a única escultura da doação Rockefeller teve um papel relevante na discussão estética do modernismo no Brasil.

Léon Degand, apontado por Ciccillo Matarazzo para ser o primeiro diretor do antigo MAM-SP, organizou uma mostra inaugural que valorizava as expressões abstratas na arte. Degand reforçou o discurso em prol de uma "autonomia integral da plástica". E Alexander Calder seria introduzido neste contexto, ao lado de Pevsner, como um escultor abstrato que foi capaz de "renovações dos meios técnicos de expressão" e cujas esculturas representavam uma técnica tão "diferente da escultura tradicional que o termo construção Ihes convém mais" (DEGAND, 1949). Ao falar de escultura abstrata, Degand a compara com a arquitetura. Segundo ele, ambas teriam expressões próximas. "Como a arquitetura, a escultura abstrata é capaz de exteriorizar sentimentos e sensações de massa, de peso, de esmagamento ou de leveza, de força ascensional, de verticalidade ou de horizontalidade" (DEGAN, 1949). A escultura seria uma manifestação mais libertária destas expressões, pois não estaria associada a um "programa utilitário de construção". Assim como nos textos de Mindlin, Degand associa a escultura abstrata de Calder a uma relação com a arquitetura modernista em ascensão no Brasil. Esse discurso se provou bastante positivo para a fortuna crítica de Calder no contexto brasileiro e lucrativo para quem comercializava suas esculturas no país.

Quem viria a se opor frontalmente a essa visão foi Di Cavalcanti. Em uma conferência que proferiu no Museu de Arte sobre os "Mitos do Modernismo", ele rebateria vertente da abstração na arte, por entender que ela produto de um afastamento da realidade e um "mecanismo frio da inteligência". O discurso de Di Cavalcanti era eminentemente político e tinha como subsídio filosófico uma visão marxista da função social da arte. Ele chegaria a chamar a obra de Calder de uma "especialização estéril".

Esses artistas constróem um mundozinho ampliado, perdido em cada fragmento das coisas reais: são visões monstruosas de resíduos

115 Desde 1949, Yellow Plane foi inserida em 26 exposições do MAM-SP e do MAC USP. A mais recente foi em 2011, Escultura Aventura, Arte que (quase) se move!, na sede do MAC Cidade Universitária. Fonte: Relatório de Exposições de Yellow Plane, Alexander Calder, Arquivo do MAC USP. 
amebianos ou atômicos, revelados pelos microscópios de cérebros doentios (DI CAVALCANTI, 1948)

Essa discussão sobre as vertentes figurativas ou abstratas se arrastaria pelos próximos anos, marcando o panorama artístico brasileiro no Pós-Guerra. Neste contexto, obras da doação Nelson Rockefeller serviram como objeto direto para essa reflexão, sendo expostas em importantes mostras que foram pivô para o debate que se instalou a respeito dos caminhos da arte moderna no Brasil. Calder teve presença expressiva nas primeiras Bienais de São Paulo, vitrine através da qual se tornou mais conhecido do público e os colecionadores.

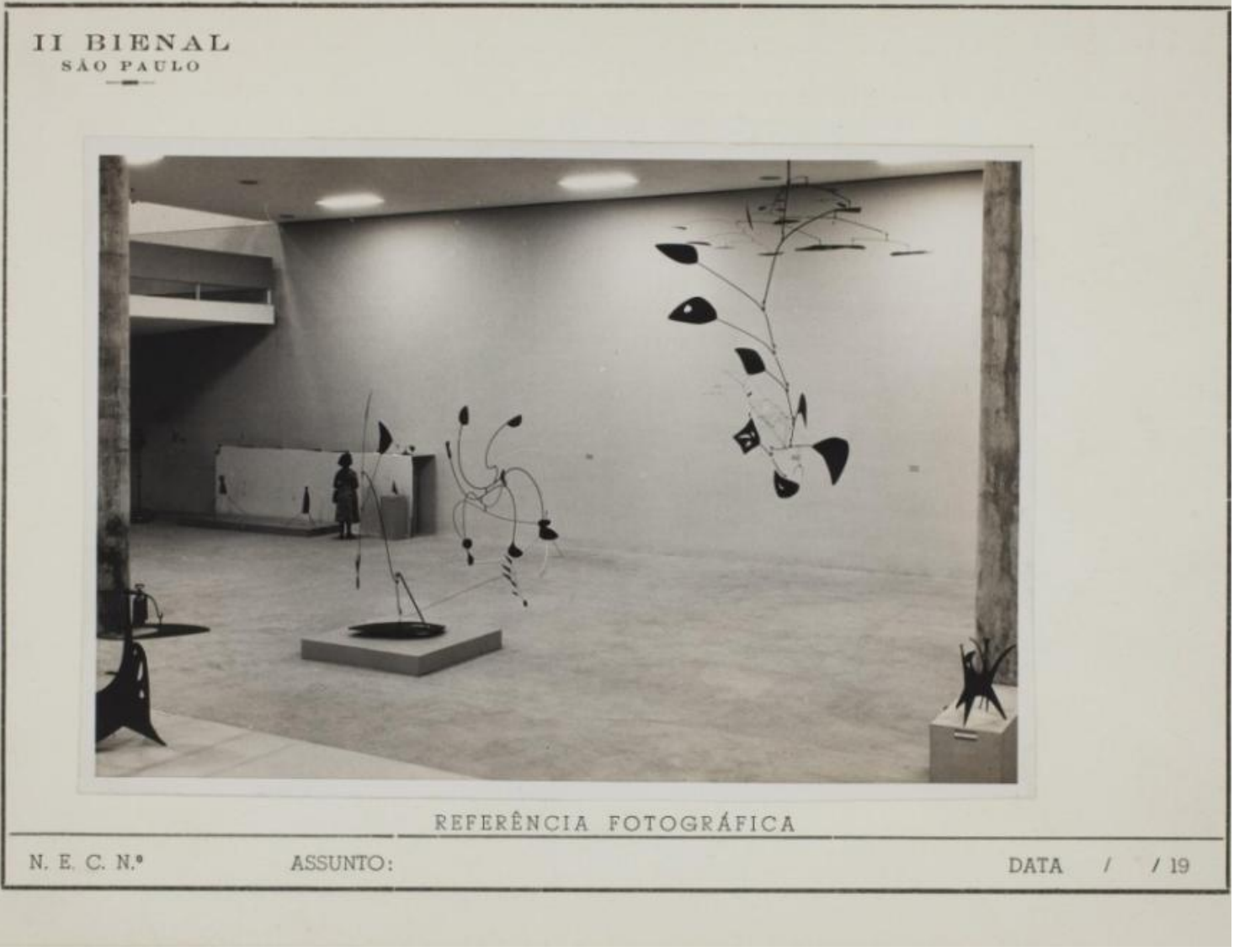

[Fig.35] Sala dedicada ao escultor Alexander Calder na II Bienal de São Paulo (1953).

Na I Bienal, Calder foi representado com apenas uma escultura, Ogunquit, contudo, na II Bienal sua visibilidade foi maior e ele figurou entre os 14 artistas escolhidos por René 
d'Harnoncourt, recebendo uma sala especial com 45 móbiles e estábiles na seção dos Estados Unidos. "De modo geral, a acolhida do grande público foi favorável, como atestam a documentação visual da exposição e os ecos na imprensa. Os seres de Calder excitavam a curiosidade geral, inclusive das crianças" (SARAIVA, 2006, p.167).

Há vários pontos de contato entre Calder e o Brasil que precisam de melhor investigação. Esse intercâmbio é evidente pela ampla divulgação de suas obras no país - desde a estreia em 1948, a exposição Do figurativismo ao abstracionismo de 1949 e a presença nas Bienais de São Paulo - e, sobretudo, pelo contato próximo com Mário Pedrosa, influente articulador cultural da vanguarda artística nacional. Para Roberta Saraiva, Calder foi, por intermédio de Pedrosa, também uma influência relevante para o grupo Frente de Ivan Serpa, Abraham Palatnik, Almir Mavignier e Ferreira Gullar. "A filiação de Pedrosa ao abstracionismo de Calder terá plausivelmente influenciado o rumo singular do grupo carioca" (SARAIVA, 2006, p. 158). Essa relação entre o escultor brasileiro e o movimento construtivo brasileiro permanece um rico campo para pesquisas futuras. 


\section{Forest of chimneys, Arthur Osver}

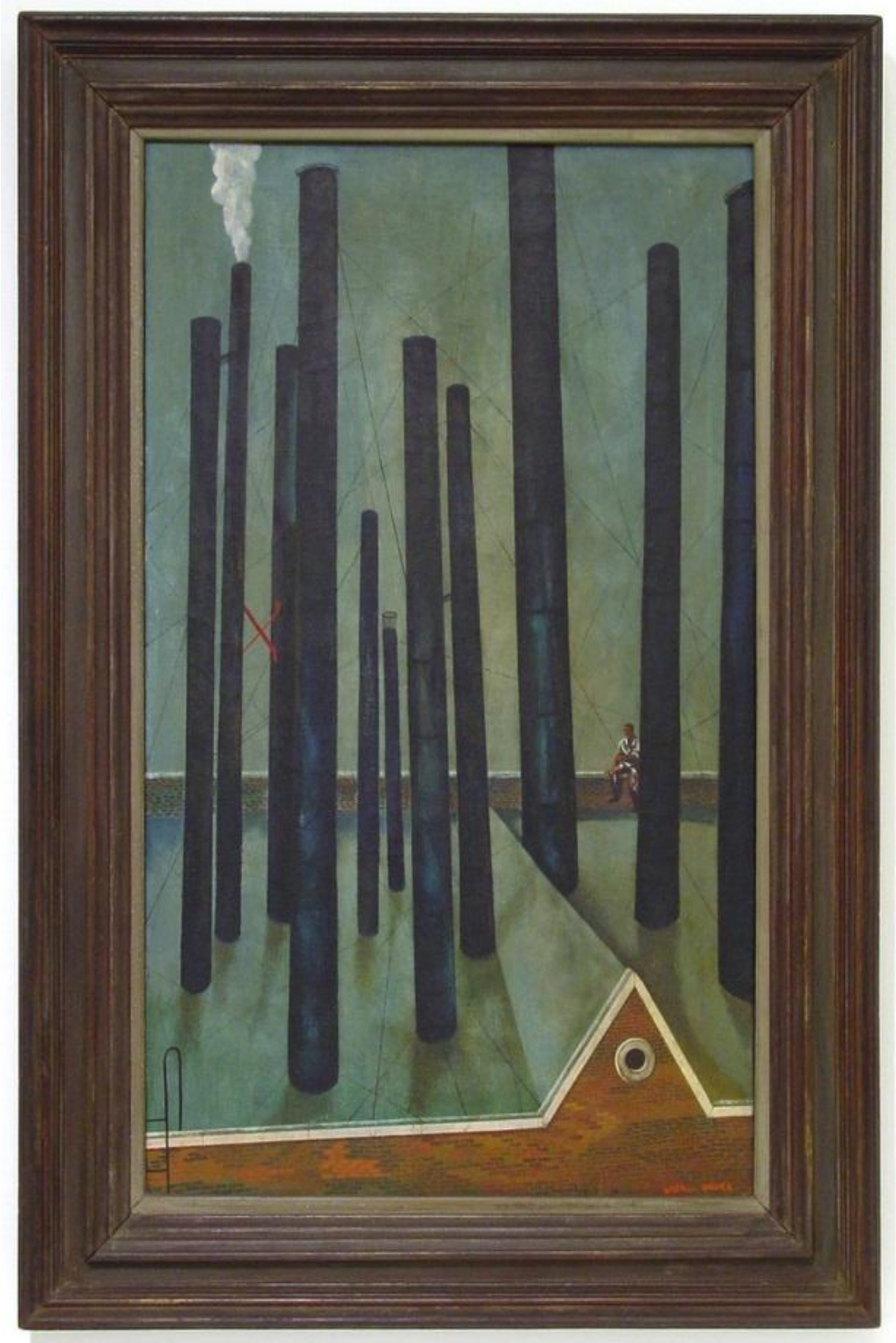

[Fig.36] Arthur Osver. Forest of chimneys [Floresta de chaminés] (1945), óleo sobre tela.

Arthur Osver foi um pintor de paisagens urbanas. Ficou conhecido sobretudo pelas cenas de telhados, chaminés e trilhos de trens de Nova York. Filho de russos, Osver iniciou a carreira artística em Chicago, mais tarde se mudando para Nova York no final dos anos 1930 
para dedicar-se totalmente à atividade de artista. Osver cresceu em uma família simples de imigrantes. Seu pai era judeu e tinha desertado o serviço militar devido aos maus tratos recebidos nos quartéis do exército russo. Ele fugiu com a mulher para Baltimore.

Nos Estados Unidos, o pai de Osver iniciou uma carreira bem-sucedida na encadernação de livros de luxo, mas com a queda da bolsa de Nova York, em 1929, ele foi levado à ruína. Abriu uma loja de secos e molhados no bairro de Melrose Park, o que garantiu a subsistência da família. O estabelecimento ficava em um subúrbio violento de Chicago habitado por imigrantes alemães, italianos e russos.

Acho que um dos primeiros trabalhos do meu pai foi de 'puxador'. Puxador, como o nome sugere, é alguém que, meio discretamente, ficava perto da entrada da porta de uma loja de roupas, por exemplo, e quando um homem passava por perto e olhava pela vitrine, o trabalho do meu pai era saltar e agarrar esse homem pelo braço e dizer, 'Olha, amigo, dá azar se a gente não realiza uma venda logo no início do dia para a primeira pessoa que entra'. E literalmente puxar esse homem, essa pobre vítima, para dentro da loja. E, é claro, uma vez que ele estivesse lá dentro, ele tinha que sair com alguma coisa. Valia sua vida, entende. Então, foi ali que eu nasci - na Maxwell Street. ${ }^{116}$

Arthur cresceu em Chicago neste ambiente de gueto imigrante e entre vizinhos da segunda geração de europeus que buscavam reinventar-se na América e conquistar melhores condições de vida, às vezes, custando o que custasse. "Meus primeiros amigos eram quase todos italianos. Mais tarde quando fui para a Itália senti que estava, de certo modo, voltando

\footnotetext{
116 "I think Dad's first job (...) was to be a puller. A puller, as the name implies, is someone who, not too obstrusively, hung near the entrance to a store, let's say, a clothing store, and as a man would come along and look in the window Dad's job was to sort of leap out, grab the man by the arm and say, ' Look, my friend, it's bad luck if we don't , make a sale right at the beginning of the day to the first person who comes in'. And literally pull this man, this poor victim, into the store. And of course once he was in there he was lost, he had to come out with something, it was worth his life, you see". Entrevista oral com Arthur Osver, 13-14 de janeiro de 1976, Archives of American Art, p. 10-11, tradução nossa.
} 
para casa" ${ }^{117}$ A mãe de Osver morreu quando ele tinha 15 anos. Depois dessa ruptura, a família se desestruturou. Arthur foi morar com um vizinho e seu irmão mais novo de 8 anos foi enviado para uma escola militar.

Um dos primeiros contatos com a arte se deu por intermédio de um pintor de vitrines que prestava serviço para sua família e que dava a ele acesso a um estoque de tintas e outros materiais de pintura. Nos anos de ensino médio, já demonstrava interesse por artes gráficas e dedicava-se à produção de quadrinhos para o folhetim da escola. Por um breve período, nutriu interesse de seguir carreira de jornalista, intento que logo abandonou depois de um ano de estudos na Medill School of Journalism da Northwestern University. Começou a frequentar o Art Institute de Chicago, em 1931, e a trabalhar em pequenos empregos como garçom, funcionário de limpeza e atendente de um museu universitário para se sustentar.

Arthur Osver se tornou conhecido nos círculos de Chicago, Filadélfia, Nova York e, finalmente, em St. Louis, Missouri, onde por muitos anos deu aulas na Universidade de Washington. Durante os anos 1930, foi agraciado com importantes prêmios de pintura que o proporcionaram reconhecimento e oportunidades de viajar para o exterior. Um dos primeiros prêmios que recebeu foi no quinto ano de estudos, quando o Art Institute de Chicago concedeu a ele uma bolsa de viagem, o prestigioso James Nelson Raymond Traveling Fellowship. “Acho que eles perceberam que eu ia continuar por lá até que eu ganhasse alguma coisa então, para se verem livres de mim, eles foram obrigados a me dar uma daquelas bolsas". ${ }^{118}$

Em outubro de 1936, Osver partiu para uma viagem de estudos na Europa, onde permaneceria pelos próximos dois anos, vivendo entre a França e a Itália. Sua esposa Ernestine Vetsburg, que também era artista do Art Institute of Chicago e ganhadora da mesma bolsa, se juntou a ele no ano seguinte. O casal passou novamente uma temporada na Europa quando Osver ganhou o Guggenheim Fellowship, em 1948. Em 1952, ele venceria o Prix de Rome, voltando a morar na Itália por mais dois anos.

\footnotetext{
117 "So my earliest friends were almost all Italians. Later on when I went to Italy I felt I was, in a sense, coming home". Entrevista oral com Arthur Osver, 13-14 de janeiro de 1976, Archives of American Art, p. 10, tradução nossa.

118 "I think they saw that I would just stay on until I got something and that in order to get rid of me they were obliged to give me one of these fellowships". Entrevista oral com Arthur Osver, 13-14 de janeiro de 1976, Archives of American Art, p. 7, tradução nossa.
} 
Uma das primeiras influências artísticas de Arthur Osver foi Vincent Van Gogh, segundo relata em entrevista concedida ao Archives of American Art. ${ }^{119}$ Osver conheceu seu trabalho através de uma exposição no Metropolitan Museum of Art e por meio da publicação das cartas de Van Gogh para seu irmão Theo. O estilo do mestre holandês seria um norte para Arthur no início de sua carreira, enquanto trabalhava para encontrar sua própria linguagem pictórica. Quando teve oportunidade de viajar, ele escolheria se estabelecer no sul da França, em Cagnessur-Mer, a poucas cidades de distância de Arles, onde Van Gogh estabeleceu um estúdio em 1888. "Eu fiz pinturas atrás de pinturas com esse estilo Van Gogh", declarou em uma entrevista $^{120}$. Quanto aos pintores da Cena Norte-americana, era admirador de Grant Wood, John Steuart Curry e Thomas Hart Benton, mas foram as referências da vanguarda europeia que tiveram maior impacto sobre ele.

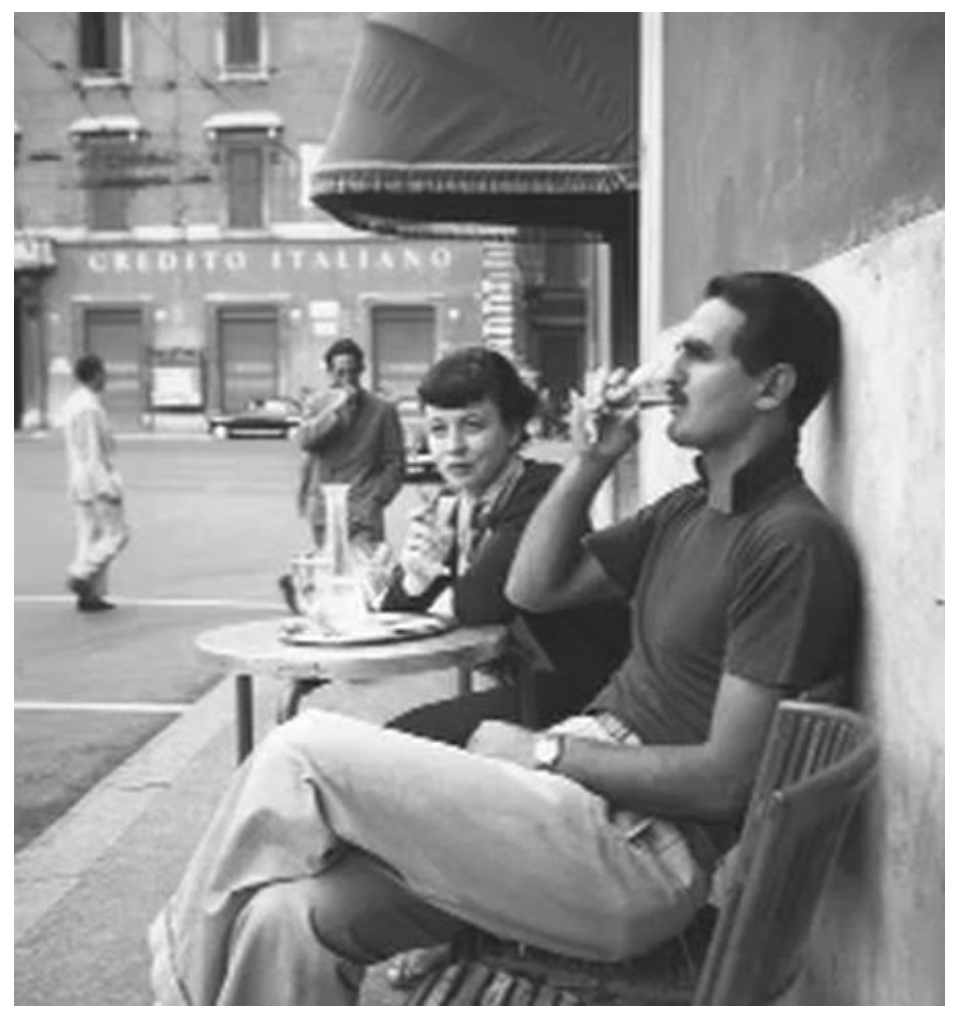

[Fig.37] Ernestine Vetsburg e Arthur Osver em viagem na Itália.

\footnotetext{
${ }^{119}$ Entrevista oral com Arthur Osver, 13-14 de janeiro de 1976, Archives of American Art.

${ }^{120}$ Entrevista oral com Arthur Osver, 13-14 de janeiro de 1976, Archives of American Art.
} 
Quando retornou para Chicago, depois do final de sua bolsa de estudos, Arthur Osver entrou no Federal Art Project e começou a desenvolver um estilo próprio com vistas aéreas de paisagens urbanas. Ele amadureceria esse tema quando se mudou para Nova York, no final dos anos 1930. Arthur e Ernestine moraram com dificuldades no Greenwich Village, fazendo de seus estúdios residência. Arthur foi liberado do serviço militar por um problema cardíaco e teve que acumular vários pequenos empregos - como leão de chácara do Y.M.C.A. e funcionário de uma indústria farmacêutica no bairro de Queens - para poderem sobreviver e encontrar algum tempo livre para pintar. Moravam mal, em apartamentos pequenos e com pouca luminosidade a muitos lances de escada acima, onde os aluguéis eram geralmente mais baratos.

“Nós sempre morávamos nos andares mais altos. No último andar você olha pela janela e vê um monte de coisas acontecendo que não se percebe no nível da rua. E estando no último andar, uma das coisas que me interessavam tremendamente eram os telhados"121. Em Queens, Osver encontraria muitas paisagens estimulantes. "Edifícios comerciais, pontes, estruturas estranhas me atraíam como artista. Era um material visual maravilhoso para mim". ${ }^{122}$

Os anos em que morou em Nova York foram alguns dos mais produtivos de sua carreira. Em 1942, o MoMA adquire uma obra sua Melancholy on a roof top [Melancolia no telhado] (1942), por meio do fundo de aquisições Mrs. Simon Guggenheim ${ }^{123}$ e, em 1943, a galeria Mortimer Brandt, em Nova York, promoveu uma exposição solo da sua obra. Osver esteve associado, durante mais de vinte anos, com a galeria Fairweather-Hardin, dedicada a apoiar artistas de Chicago, em Nova York, esteve alguns anos ligado a galeria Grand Central Moderns.

Na década de 1940, Arthur Osver compôs a série de cenas urbanas pela qual é mais reconhecido hoje. Ele tinha o costume de fotografar becos, terrenos baldios da cidade, ruas e pontes e, a partir desse registro, criava suas composições. Forest of chimneys [Floresta de chaminés], pintura do acervo do MAC USP, faz parte da série chamada Cityscapes [Paisagens urbanas], assim como High wind [Vento forte], High wind on the roof top [Vento forte no

\footnotetext{
121 "We always lived way up, usually on the top floor. On the top floor you look out the window and you see a lot of things going on that you don't see at street level. And being on the top floor, one of the things that interested me tremendously was roof tops". Entrevista oral com Arthur Osver, 13-14 de janeiro de 1976, Archives of American Art, p. 2, tradução nossa.

122 "Commercial buildings bridges, strange structures that turned me on as an artist". Entrevista oral com Arthur Osver, 13-14 de janeiro de 1976, Archives of American Art, p. 38, tradução nossa.

${ }^{123}$ Press release MoMA, 21 de agosto de 1942.
} 
telhado], Melancholy on a rooftop [Melancolia no telhado] e Pipes and chimneys [Canos e chaminés], algumas de suas obras mais importantes deste período.

A estética do urbano e o imaginário da cidade são componentes característicos da pintura de Osver e foi para ele um objeto de estudo durante longos anos. Ele se dedicou a investigar edificações, fábricas e pontes, estruturas que compõe a cena industrial da América. Forest of chimneys [Floresta de chaminés] (1945) é uma pintura bem característica desse conjunto de paisagens de telhados nova-iorquinos. A obra tem uma linguagem melancólica e onírica. As chaminés são imponentes e formam uma teia de altas estruturas envolventes. De uma abertura, escorre uma fumaça esbranquiçada, enquanto um homem senta no parapeito e observa, sozinho e apartado do resto do mundo, a vida urbana que corre andares abaixo. Um elemento marcante das Cityscapes [Paisagens urbanas] é que as paisagens não são horizontais, mas todas assumem um espaço vertical correspondente às linhas de força das chaminés e dos arranha-céus da cidade. Já no final da carreira, Osver retomaria o tema das chaminés, mas em uma abordagem pictórica mais abstrata e com uma paleta de cores mais claras.

Sobre esse conjunto de pinturas, Osver comenta:

Eu estava estimulado com essa verticalidade, esse objeto que sobe, a coisa que vai para cima e depois se ramifica. Isso tem sido algo bem temático ou muito obsessivo no meu trabalho. Eu me lembro de um homem chamado Ernest Smith que dirigia a Hilton Gallery. Ele escreveu um pouco sobre isso em um catálogo. Sendo um psicanalista ferrenho, ele começou a ponderar sobre o que essas estruturas poderiam significar. Ele pensou se isso era realmente chaminé e fumaça? Ou árvore e ramos? Ou seria um símbolo fálico e uma ejaculação? Eu não sei - mas o fato está aí e é verdade que essa forma ereta, essa forma vertical, é para mim uma forma muito significativa. ${ }^{124}$

\footnotetext{
124 "I was struck with this verticality, this soaring thing, the thing going up and then branching out. This has been something that's been very thematic, if you like; very obsessive in my work. I remember a man named Ernest Smith who ran the Hilton Gallery a number of years ago. He wrote a little bit in a catalogue. Being a curbstone psychologist, he began to cast about as to what this might mean. He thought is this really a chimney and smoke? Or a tree trunk and branches? Or is it a phallic symbol and and ejaculation and so on? I don't know - but the fact does remain and it's very true that this upright form, this vertical form, is to me a very meaningful form". Entrevista oral com Arthur Osver, 13-14 de janeiro de 1976, Archives of American Art. 56p., tradução nossa.
} 

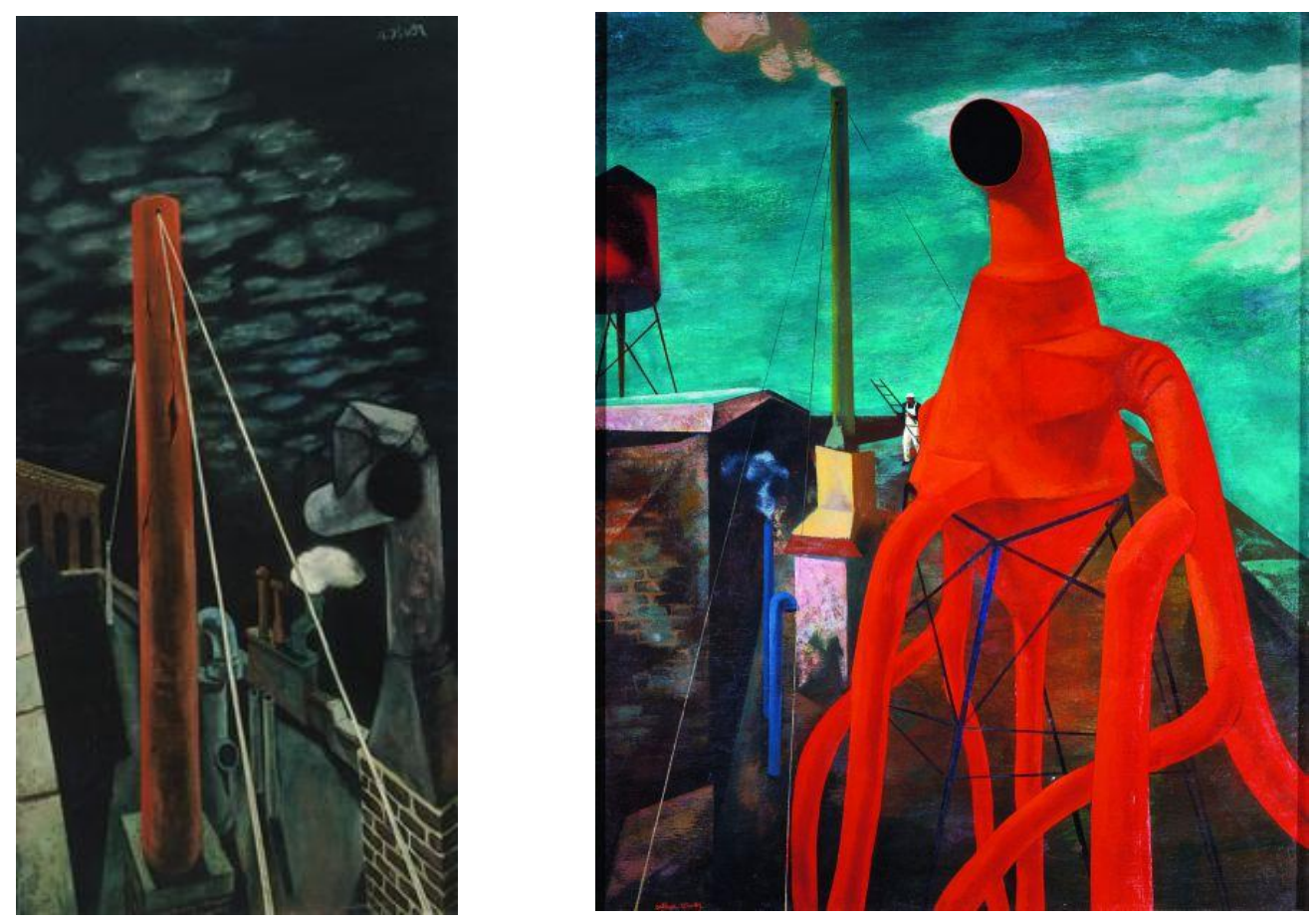

[Fig.38 e 39] Série de chaminés de Osver em 1940: Melancholy on a rooftop [Melancolia no telhado] (1942), oleo sobre tela, 121. 9 X $61 \mathrm{~cm}$, Coleção MoMA, e Red ventilator [Ventilador vermelho] (1945), óleo sobre compensado.
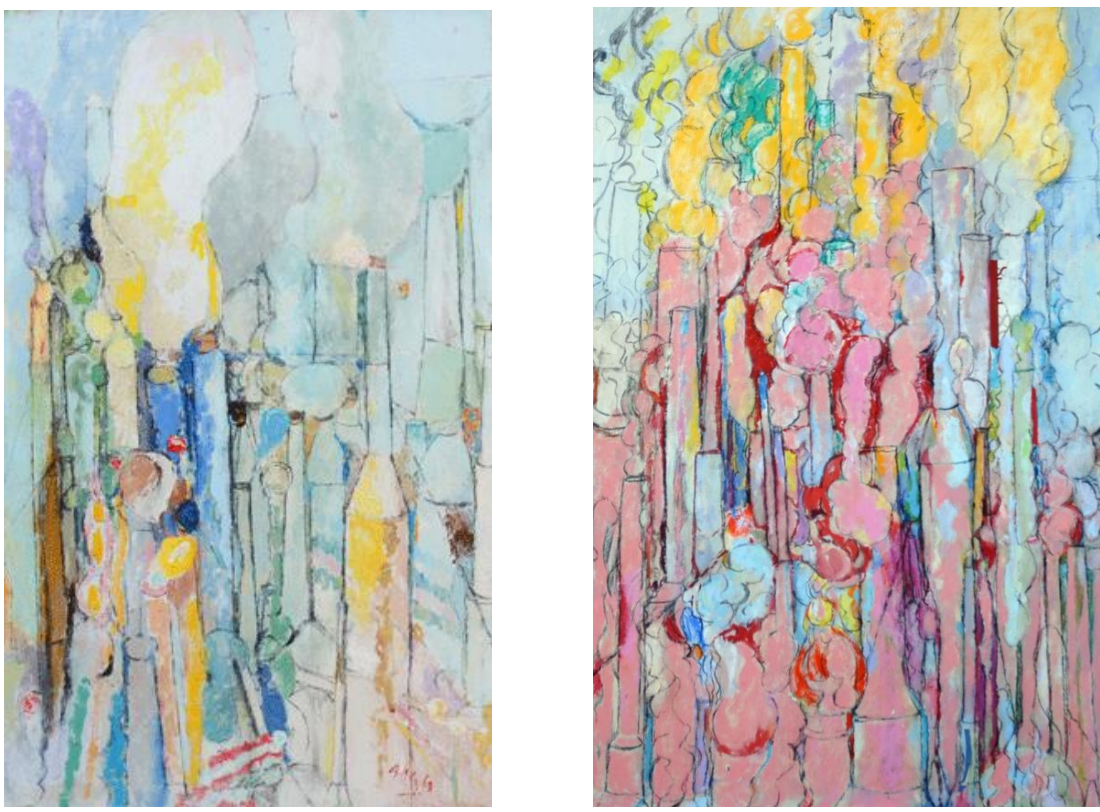

[Fig.40 a 41] Série de chaminés de Arthur Osver em 1990: Cumuli [Cúmulo] (1991), técnica mista sobre tela, 157,5 X $99 \mathrm{~cm}$, e Souvenir (1992), óleo sobre tela, 166,8 X $180 \mathrm{~cm}$. 
Em 1947, Osver foi convidado para substituir o pintor Rufino Tamayo nas aulas do Brooklyn Museum of Art. A partir de então, ele iniciou uma carreira no ensino da arte, que seria um suporte financeiro importante ao longo da vida. Osver deu aulas também na Universidade Columbia, de 1950 a 1951, e na Cooper Union, em 1955 e 1958. Nos anos 1960, o reitor da Universidade de Washington, Kenneth Hudson, realizou esforços para estruturar o programa de artes da instituição e atrair artistas renomados. Além de Arthur Osver, que manteve sua posição na universidade até sua aposentadoria em 1981, o reitor foi capaz de atrair também Max Beckmann e Philip Guston para St. Louis, fortalecendo, assim, a relevância da região no cenário da arte moderna norte--americana.

Sobre a mudança com Ernestine de Nova York para St. Louis, Arthur Osver comenta:

Em St. Louis conseguimos trabalhar. Nós tínhamos passado quase vinte anos da experiência de Nova York então sentimos que já tínhamos alguma idéia do tipo de artistas que éramos, não estávamos no processo de nos inventar tão ativamente quanto antes. E descobrimos que St. Louis nos permitiu trabalhar até mais (...) as condições eram melhores, o trabalho mais fácil... Nova York era uma terrível penúria econômica. ${ }^{125}$

Arthur Osver desfrutou, em vida, do reconhecimento de seus pares - seja por meio de prêmios, exposições ou aquisições de pinturas em museus - e do conforto material que permitiu que tivesse uma longa carreira dedicada à pintura. O Saint Louis Art Museum realizou uma retrospectiva de sua obra em 2000, seis anos antes de sua morte, homenageando sua trajetória artística. A presença de uma pintura de Osver na coleção Rockefeller de 1946 é um acontecimento singular e reflete a ascensão do artista em Nova York, em meados dos anos 1940, momento em que o próprio MoMA adquire uma de suas pinturas. Ainda assim, vê-se que a repercussão internacional do trabalho de Osver foi tímida e quase não há estudos

\footnotetext{
125 "(In St. Louis) We were able to work. We had gone through roughly twenty years of the New York experience so we felt we had that and we had a certain idea of who we were as artists, we weren't in the process of inventing ourselves as actively as we were earlier on. And we found that St. Louis enabled us to work even more (...) the conditions were easier, the job was easier... New York was a terrible scramble economically." Entrevista oral com Arthur Osver, 13-14 de janeiro de 1976, Archives of American Art , 48p., tradução nossa.
} 
aprofundados sobre ele. Mesmo nos Estados Unidos, Osver é tratado como um artista marginal na história da arte moderna norte-americana e suas obras são permanecem pouco conhecidas, o que torna a sua presença na doação Rockefeller ainda mais impressionante. 


\section{Europeus no exílio}

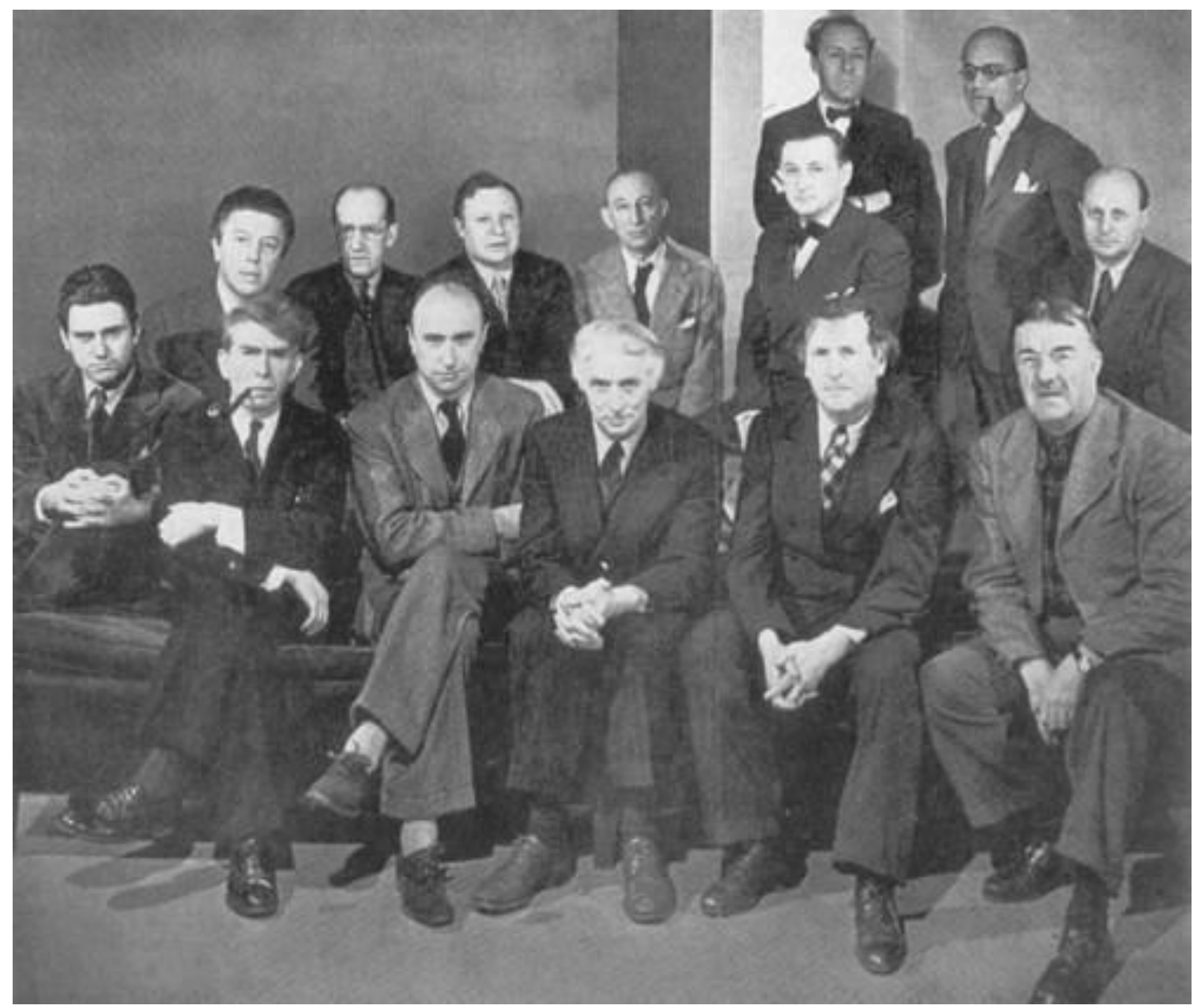

[Fig. 42] Foto de grupo da exposição Artists in exile [Artistas no exílio] da galeria Pierre Matisse (1942).

Em março de 1942, a galeria Pierre Matisse organizou a exposição Artists in exile [Artistas no exílio]. A mostra foi singular não apenas pelas obras apresentadas, mas, sobretudo, devido ao momento político e ao caráter simbólico da exposição. No auge do maior conflito armado do século XX, o relacionamento de Pierre Matisse - filho de ninguém menos do que Henri Matisse - com os principais artistas europeus foi capaz reunir, sob um mesmo teto, homens que se odiavam intelectual e pessoalmente.

Apesar de desenvolverem propostas artísticas divergentes - e por vezes diretamente conflitantes - os 14 pintores europeus foram apresentados ao público nova-iorquino como um 
conjunto coeso. Entre eles estavam Roberto Matta, Ossip Zadkine, Yves Tanguy, Max Ernst, Marc Chagall, Fernand Léger, André Breton, Piet Mondrian, André Masson, Amédée Ozenfant, Jacques Lipchitz, Pavel Tchelitchew, Kurt Seligmann e Eugene Berman. Eles eram os “exilados”.

Sobre a exposição, Pierre Matisse relembrou:

Eu reúno todas essas pessoas no estúdio para a exposição Artistas no exílio e, enquanto o fotógrafo arruma a câmera, essas pessoas que se odiavam estavam andando de um lado para o outro, tentando não se cumprimentar. Breton não gostava de Mondrian, Léger não gostava de Chagall, Chagall e Ernst não gostavam um do outro. Eles todos acabaram na fotografia do lado de quem menos gostavam (apud WELD, 1986, p.273). ${ }^{126}$

Como o relato de Pierre Matisse sugere, os artistas carimbados como "o grupo de exilados" não representavam, sob nenhum aspecto, uma escola ou movimento. Porém, na tentativa de construir um discurso sobre esta produção vinda da Europa, a exposição Artists in Exile [Artistas no exílio] buscava destacar o caráter "universal" da arte e a internacionalização da cultura ocidental. Para isso, esses artistas de temperamentos e humores estéticos tão diferentes foram apresentados como um corpo coletivo. Juntos, eles eram a perseguida arte moderna europeia que buscava uma nova casa na América do Norte.

A exposição foi acompanhada por um catálogo com dois artigos: Europa, assinado por James Thrall Soby, e América de Nicholas Calas. Ambos os manifestos procuravam ressaltar a universalização da arte, reforçando a ideia de que os Estados Unidos deveriam ser o bastião da liberdade cultural e intelectual do mundo. Contudo, a imagem de uma América aberta para todos os povos e culturas, e para todas as expressões artísticas, não passava de um constructo. A grande maioria do país não tinha contato nem interesse pela arte moderna. Sobre a recepção destes artistas, o estudo Victor Semerjian sobre a exposição Artists in exile [Artistas no exílio]

126 "I get all these people to the studio for the Artists in Exile show and while the photographer fired the camera, all these people who hated each other were walking around trying not to greet one another. Breton didn't like Mondrian, Leger didn't like Chagall, Chagall and Ernst didn't like each other. They all wound up in the picture next to the one they liked the least" apud WELD, 1986, p.273, tradução nossa. 
lembra que, ao passo que a Europa tinha denunciado a arte moderna como "degenerada", o público norte-americano também não estava de todo ambientado com a estética da vanguarda.

Quando o artista emigrado chegava à América, onde não havia nenhuma real tradição de arte de vanguarda, suas metodologias variadas foram novamente recebidas com ampla oposição (...) 0 sentimento anti-imigrante combinado à resistência nacional à arte moderna exigia um estratagema para conquistar os críticos e patronos necessários, a fim de assegurar a posição de Nova York como o novo centro mundial de prática internacional da vanguarda. A evidência de uma abordagem sistemática estava inequivocamente presente na exposição Artistas no exílio. Seu manifesto tentou superar a aversão à arte moderna europeia, elevando sua preservação a uma questão de importância política. Com os Estados Unidos agora em guerra contra a Alemanha, foi proposto que a continuação da arte moderna condenada e perseguida pelo próprio inimigo seria um ato de patriotismo e desafio coletivo (SEMERJIAN, 1990, p. 3). ${ }^{127}$

O auxílio e a receptividade que os artistas europeus tiveram quando desembarcaram nos Estados Unidos muito se deve ao esforço de uma restrita elite intelectual em Nova York. Em casos como o de Chagall, por exemplo, os custos de sua viagem para os Estados Unidos e da salvaguarda de suas obras foram arcados, em parte, por meio de uma rede de famílias judias proeminentes de Manhattan, que contribuíram financeiramente para garantir a passagem segura de Chagall e sua esposa Bella. Mas uma vez que atracavam na América, além de um núcleo de aliados, esses artistas e suas obras eram praticamente desconhecidos no país.

127 "Existing anti-alien sentiment combined with this native resistance to modern art required a stratagem to win over the needed critics and patrons in order to secure New York's position as the new world center of international avant-garde practice. Evidence of a systematic approach was unmistakably present in the Artists in Exile show. Its manifesto attempted to surmount an aversion to European modern art by elevating its preservation to an issue of considerable political importance. With America now at war with Germany, it was proposed that the continuance of modern art condemned and pursued by the enemy itself, would be an act of patriotism and collective defiance" SEMERJIAN, 1990, p. 3, tradução nossa. 
Vale notar que vários artistas contemplados na exposição Artists in exile [Artistas no exílio] obtiveram ajuda para sair da Europa por intermédio dos esforços do jornalista Varian Fry, quem liderava um esforço diplomático para trazer aos Estados Unidos milhares de refugiados ameaçados pela Gestapo. Em 1940, Varian Fry estabeleceu na Villa Air-Bel, em Marselha, o Comitê de Resgate de Emergência (Emergency Rescue Committee). Com a intervenção da primeira dama dos Estados Unidos, Eleanor Roosevelt, o Departamento de Estado dos EUA, concordou em fazer uma exceção a sua política restritiva de vistos e permitiu a emissão de 200 novos salvo-condutos. $\mathrm{O}$ comitê mais tarde ganharia respaldo oficial e seria ampliado. Varian Fry passou a servir, então, como consultor do War Refugee Board, órgão estabelecido pelo governo Roosevelt em 1944, para ajudar vítimas do regime nazista. Entre os artistas resgatados, estavam Marc Chagall, Max Ernst, André Masson e Bernard Reder, todos contemplados nas doações Rockefeller ${ }^{128}$.

Esse conjunto de artistas exilados da Europa foi amplamente representado na doação Rockefeller com não menos do que seis obras de Marc Chagall, Max Ernst, Fernand Léger, André Masson e Yves Tanguy - todos incluídos na foto de divulgação da exposição Artists in exile [Artistas no exílio]. A presença desses artistas exilados, assim como de George Grosz, que migrou para os Estados Unidos alguns anos antes dos demais, em 1938, - é reflexo do legado curatorial de Alfred Barr, que em todos os seus anos enquanto diretor do MoMA concentrou esforços na divulgação e apreciação das vanguardas modernas europeias. Se a presença de novos artistas norte-americanos pode ser mais associada ao trabalho de Dorothy Miller à frente de exposições como Americans [Americanos], o volume de obras da vanguarda europeia é sintomático de Alfred Barr.

\footnotetext{
${ }^{128}$ A história detalhada sobre a iniciativa governamental dos Estados Unidos para resgatar refugiados europeus está contemplada na obra Villa Air-Bel - o refúgio da intelectualidade europeia durante a segunda guerra mundial de Rosemary Sullivan.
} 


\section{Spring, Marc Chagall}

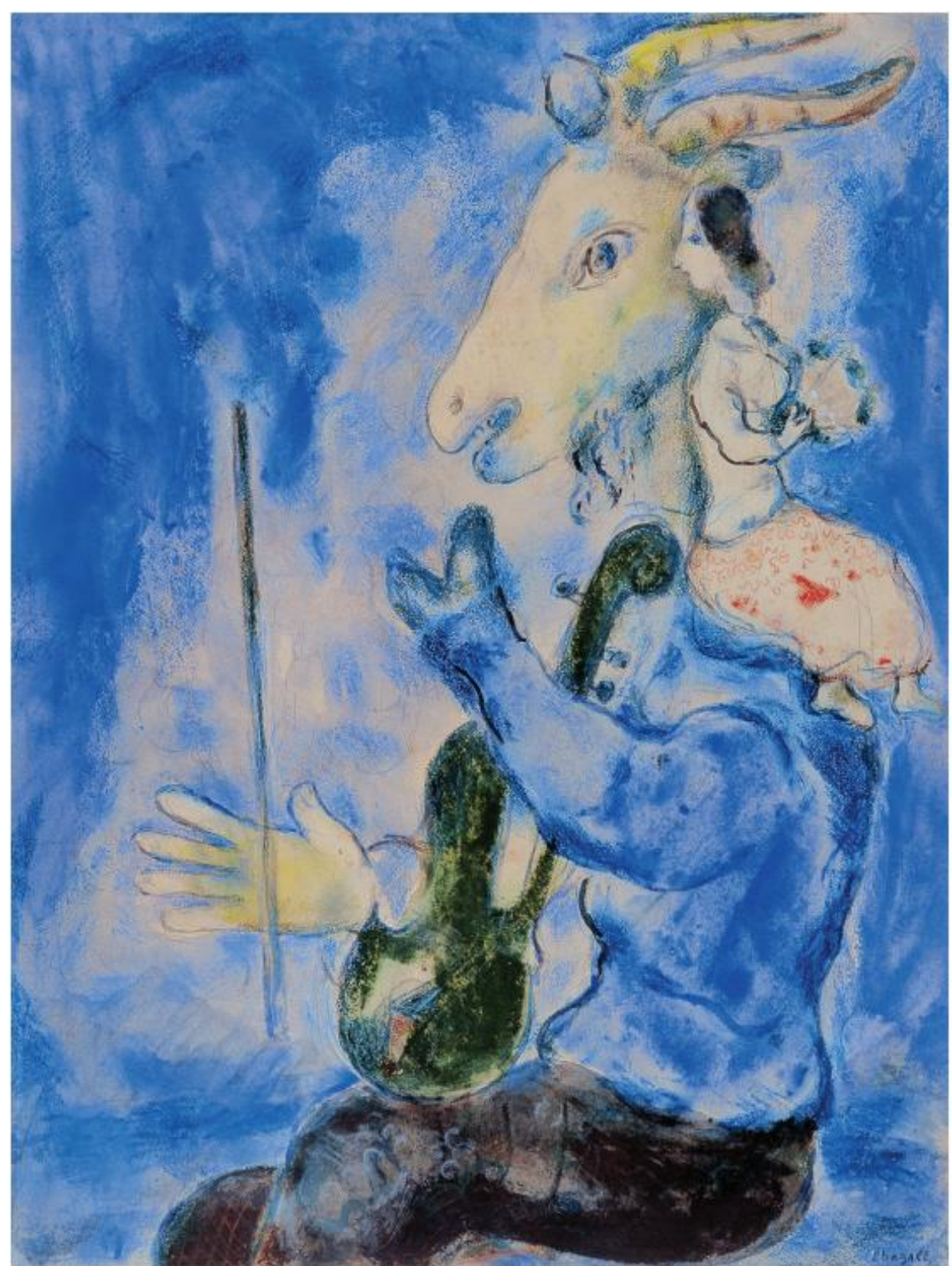

[Fig.43] Marc Chagall. Spring [Primavera] (1938), aquarela e pastel sobre cartolina e papelão, $64 X 48,3 \mathrm{~cm}$

Marc Chagall chegou em Nova York, em 21 de junho de 1941. Ele e sua mulher Bella foram recebidos por Pierre Matisse no porto de desembarque. Pierre ajudou o casal a encontrar seu primeiro alojamento em Manhathan, um hotel na rua 57th, bem ao lado de sua galeria. Ele seria o primeiro marchand a expor obras de Chagall nos Estados Unidos depois de 1941, e com quem o artista russo assinou um contrato de exclusividade pelo qual recebeu, 
inicialmente, US\$350. Uma soma suficiente para permitir certa estabilidade financeira e emocional para os recém-chegados. A parceria foi duradoura e a colaboração entre artista e galerista permaneceu ativa até 1948, quando Chagall retornou para a Europa. Matisse foi um ator importante para impulsionar a divulgação e circulação do trabalho de Chagall nos Estados Unidos. Ele foi crucial também na aproximação com os curadores do MoMA.

A primeira exposição de Chagall na galeria Pierre Matisse aconteceu em 25 de novembro a 13 de dezembro de 1941. Vinte e uma obras foram expostas, compondo uma pequena retrospectiva do período parisiense, com pinturas produzidas entre os anos de 1910 a 1914. Em março, Pierre Matisse o colocaria junto ao grupo de artistas da exposição Artists in exile [Artistas no exílio], entre os quais o pintor russo Ossip Zadkine, conterrâneo de Chagall na cidadezinha de Vitebsk. Aos poucos, Chagall ganhava notoriedade nos Estados Unidos e suas obras passavam a interessar grandes colecionadores e museus.

O momento de maior visibilidade para Chagall viria em abril 1946, quando o curador do MoMA James Johnson Sweeney organizou uma exposição individual. A mostra englobava 40 anos de carreira e consistia em 56 pinturas, além de gravuras, desenhos e 67 composições que o artista havia produzido para a montagem mexicana do ballet Aleko. A exposição Marc Chagall foi uma parceria do MoMA com o Art Institute of Chicago e ficou em cartaz até junho daquele ano. É importante lembrar que quando Barr e Miller realizam a seleção de obras enviadas ao Brasil, o nome de Chagall estava em evidência no museu. A seleção de uma obra menor do artista, no caso um guache como Spring [Primavera], seria uma escolha em sintonia com as atividades mais recentes do MoMA. Entre os principais doadores para a exposição, constam o próprio artista e Pierre Matisse, quem possivelmente intermediou a venda de Spring [Primavera] para Alfred Barr e Dorothy Miller, uma vez que o contrato de exclusividade entre Chagall e Pierre Matisse estava em pleno vigor em novembro de 1946.

A publicação de um catálogo do MoMA para acompanhar a exposição sobre Chagall também colaborou para aumentar sua visibilidade diante de um público norte-americano que, até então, tivera pouca ou nenhuma oportunidade para conhecer sua obra e assimilar sua linguagem. No catálogo, Sweeney, então diretor do Departamento de Pintura e Escultura do museu, o descreve como um artista da expressão, da cor e do sonho. Alguém que evitava a 
representação factual, mas que, por outro lado, não se contentava com a abstração nãofigurativa e cuja maior contribuição para a arte de vanguarda estava no "despertar de uma poética da representação" (SWEENEY, 1946, p. 7).

A obra de Chagall é mais conhecida pelas cenas fantásticas. São famosas as pinturas de bodes tocadores de violino e casais entrelaçados sobrevoando cidades europeias - muitas das quais inspiradas no retrato de sua esposa Bella. Em Chagall, o arranjo formal dos corpos não obedece a uma proporção naturalista; os elementos mais importantes ganham maiores dimensões, respeitando a lógica interna da composição. Um bom exemplo deste idioma pictórico é o guache Spring [Primavera]. Essa obra é uma representação do seu mundo onírico. Elementos recorrentes de sua pintura estão presentes. O bode, a noiva, o violino e o uso imponente do azul estão intimamente ligados à obra de Chagall, reaparecendo de maneira quase obsessiva em seus trabalhos.

Em Spring [Primavera], um bode de proporções exuberantes extrapola os limites da composição, enquanto uma mulher diminuta pousa levemente em seu ombro. O casal enamorado se deleita com os prazeres da primavera - a música, a natureza, o amor e a união. A figura dominante possui corpo de homem e cabeça de animal, e munido de mão e pata tenta administrar um violino. Os chifres atestam para a virilidade e robustez da figura central, em contraponto à leveza da noiva sentada sobre seu ombro esquerdo. O lirismo da cena é reforçado pelo azul chagalesco, que inunda toda a composição e mistura o corpo com o pano de fundo. Tons rosáceos compõem o buquê de flores, outra referência à chegada da primavera. O uso do guache proporciona transparência e luminosidade para as figuras. A obra tem uma qualidade de esboço e evidência de traços não desenvolvidos e movimentos abortados.

Spring [Primavera] foi composta em 1938, ano em que Marc Chagall e Bella se mudaram para uma casa no campo nas proximidades da cidade de Saint-Dye-Sur Loire na tentativa de se afastarem do epicentro da Segunda Guerra Mundial, e procurar alguma paz e concentração para continuar trabalhando. Naquele período, Chagall se dedicava à sua primeira tela de grande dimensão, The white cruxifiation [A cruxificação branca], em que a imagem de Cristo como um mártir judeu é uma alusão ao caos humanitário vivido pela Europa. Em 1938, situações explosivas se espalhavam pela Alemanha. Sinagogas de Munique e Nuremberg eram 
incendiadas, lojas de comerciantes judeus destruídas em Berlim e milhares começavam a ser enviados para campos de concentração.

No ano anterior, pinturas de Chagall tinham sido exibidas na exposição Entartete kunst [Arte degenerada] promovida pelo regime nazista com o intuito de condenar, desmerecer e ridicularizar a produção de artistas da vanguarda, tentando associar as obras à insanidade mental e deturpação moral de seus autores. A exposição teve um público de mais de quase três milhões de visitantes e ficou em tour durante três anos. Chagall, enquanto pintor judeu e expressionista, era um duplo alvo para a curadoria do Terceiro Reich.

Spring [Primavera] foi uma encomenda para Tériade, o editor da revista de arte Verve. A primeira edição da revista apareceu na França em dezembro de 1937. A publicação foi financiada pelo dono da Esquire nos Estados Unidos, David Smart, que tinha o desejo de criar nada menos do que "a mais bela revista do mundo" (ANTHONIOZ, 1988, p. 25). A linha editorial de Verve era administrada pelo grego Tériade, que tinha carta branca para contratar os mais renomados artistas e escritores. As cinco primeiras edições tiveram edições bilíngues, em francês e inglês, e a publicação desfrutou de amplo prestígio até sua última edição em 1960. Colaboradores ilustres de Verve incluem Paul Valéry, André Gide, Joan Miró, Pablo Picasso, Georges Braque, Henri Matisse e Marc Chagall.

Chagall forneceu desenhos e pinturas para reprodução de cinco edições, entre as quais duas capas. A primeira contribuição se deu em 1938, justamente com a publicação de Spring [Primavera] no terceiro volume da revista que circulou no verão daquele ano. A última edição de 1960 foi toda dedicada à Chagall e a suas ilustrações da Bíblia. Parte da proposta da revista consistia em reproduzir obras de arte por meio de gravuras que pudessem ser colecionadas por seus leitores. Toda reprodução implicava na perda de alguns elementos de tonalidade e nitidez de cores em relação à obra de arte original. Contudo, a dedicação de Tériade pela excelência e seu compromisso com os artistas resultou em uma publicação luxuosa e de alta qualidade gráfica. Mesmo durante a Segunda Guerra Mundial e o racionamento de papel, cinco edições da revista conseguiram circular entre os anos de 1940 e 1945, depois retornando para a periodicidade trimestral idealizada de início. 
Spring [Primavera] fazia parte de uma série de quatro gravuras tematizando as estações do ano. Além de Chagall, os artistas Joan Miró, Paul Klee e Abraham Rattner colaboraram com suas representações de Summer [Verão], Winter [Inverno] e Autumn [Outono], respectivamente. A capa da edição foi de autoria de Pierre Bonnard e o tema central tinha como foco o oriente. Textos de André Maulraux e Paul Valéry exploravam as peculiaridades da arte, literatura e filosofia orientais em oposição à tradição Ocidental. A revista foi ricamente ilustrada com desenhos de origem oriental, além de contar ainda obras de Henri Matisse e Rembrandt.

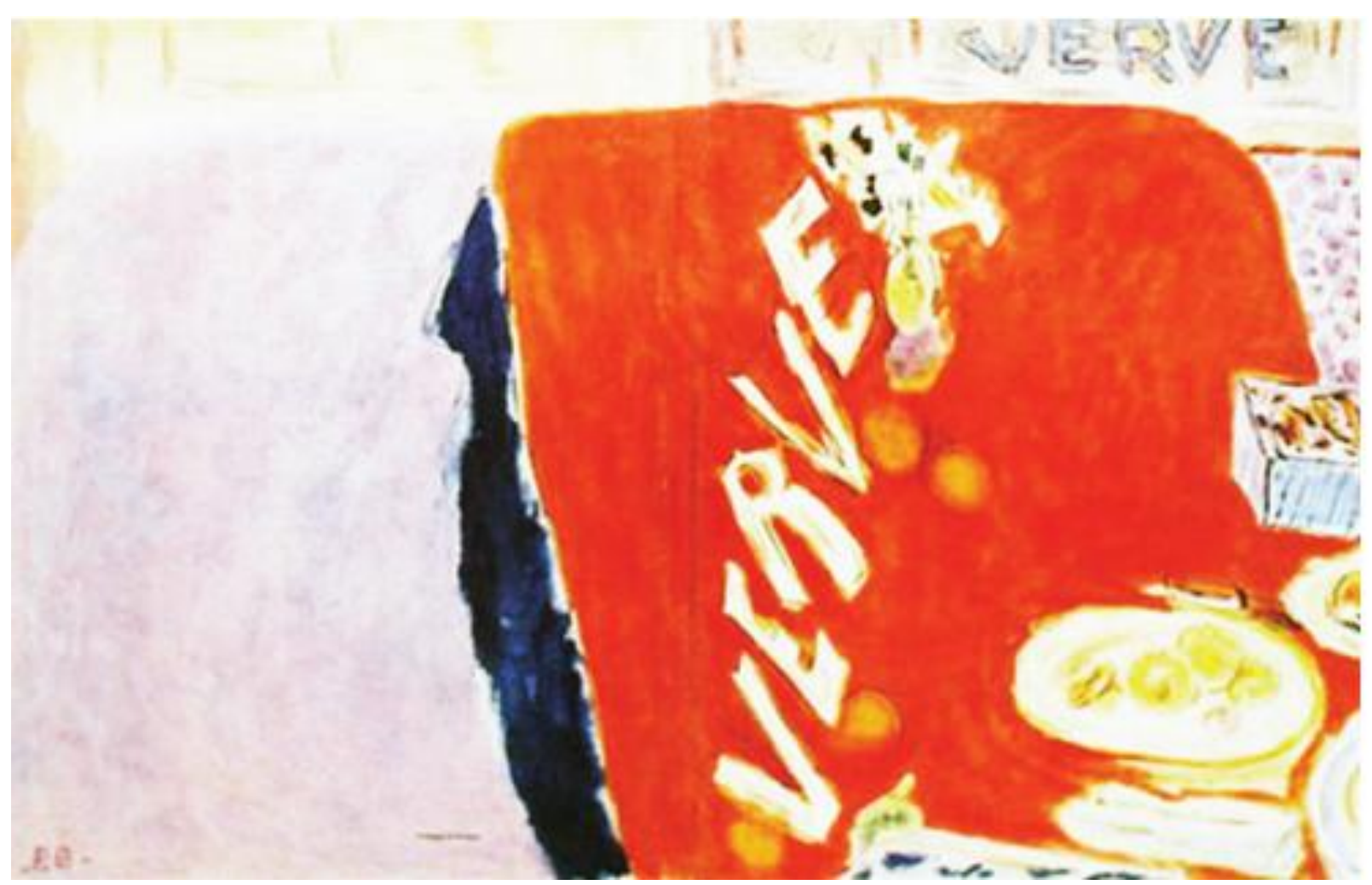

[Fig.44] Capa do terceiro volume da revista Verve, assinada por Pierre Bonnard. 


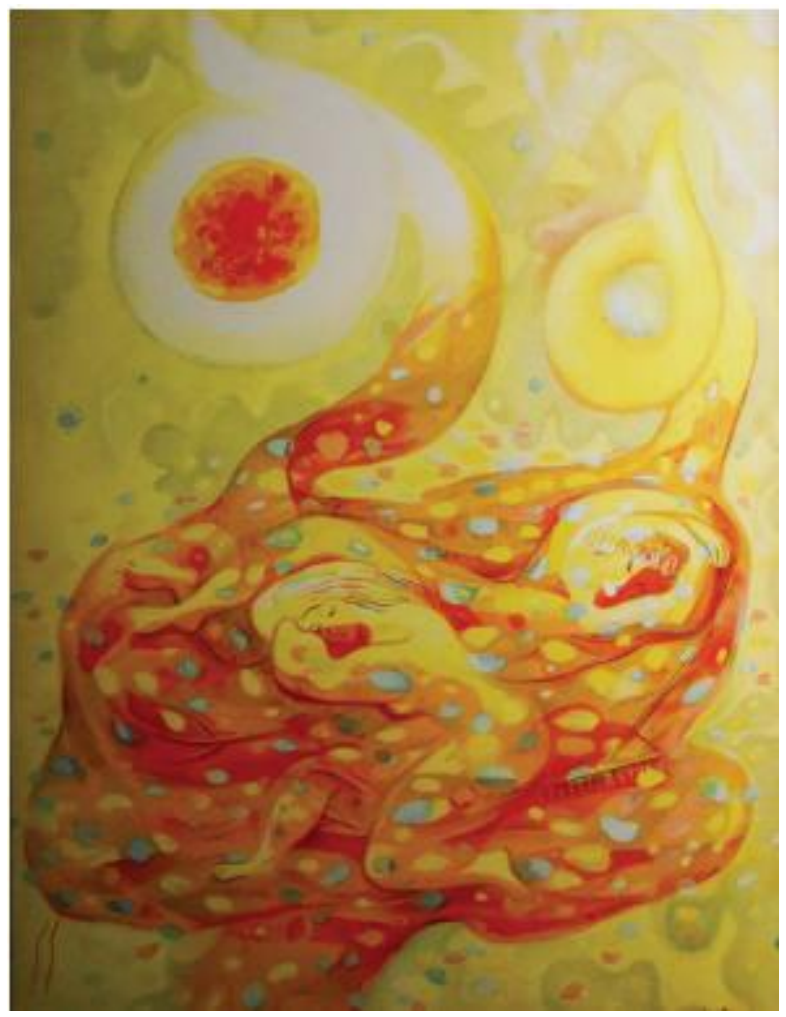

[Fig.45] Winter [Inverno] de Paul Klee, publicada na revista Verve.

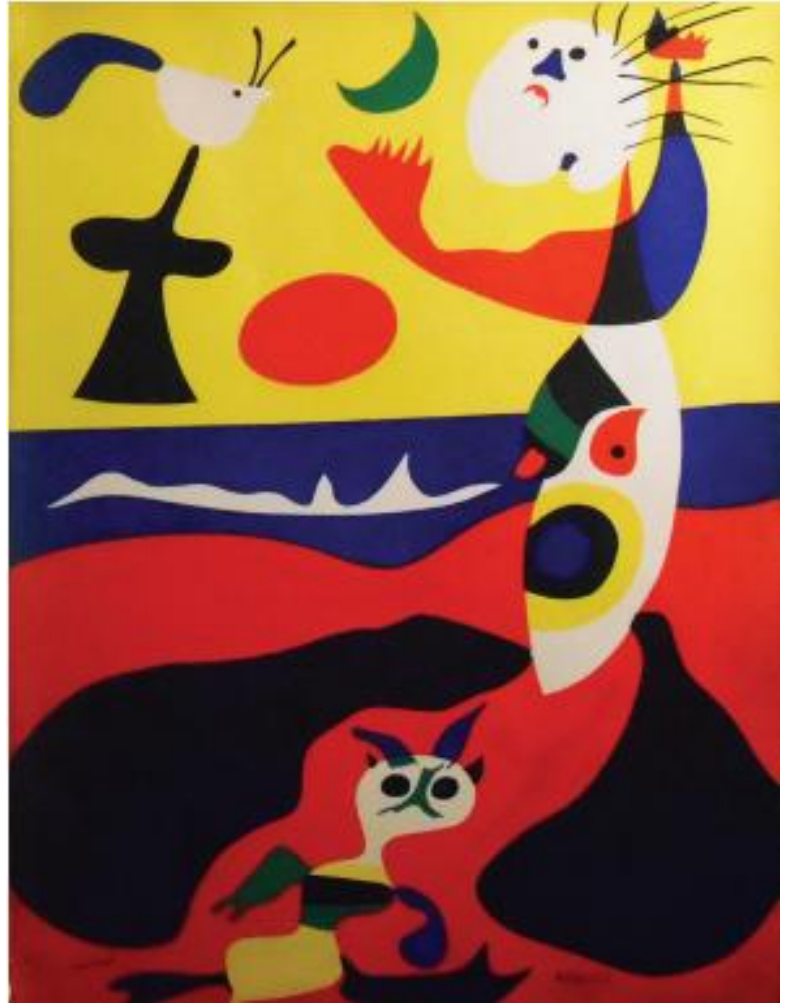

[Fig.46] Summer [Verão] de Joan Miró, publicada na revista Verve. 


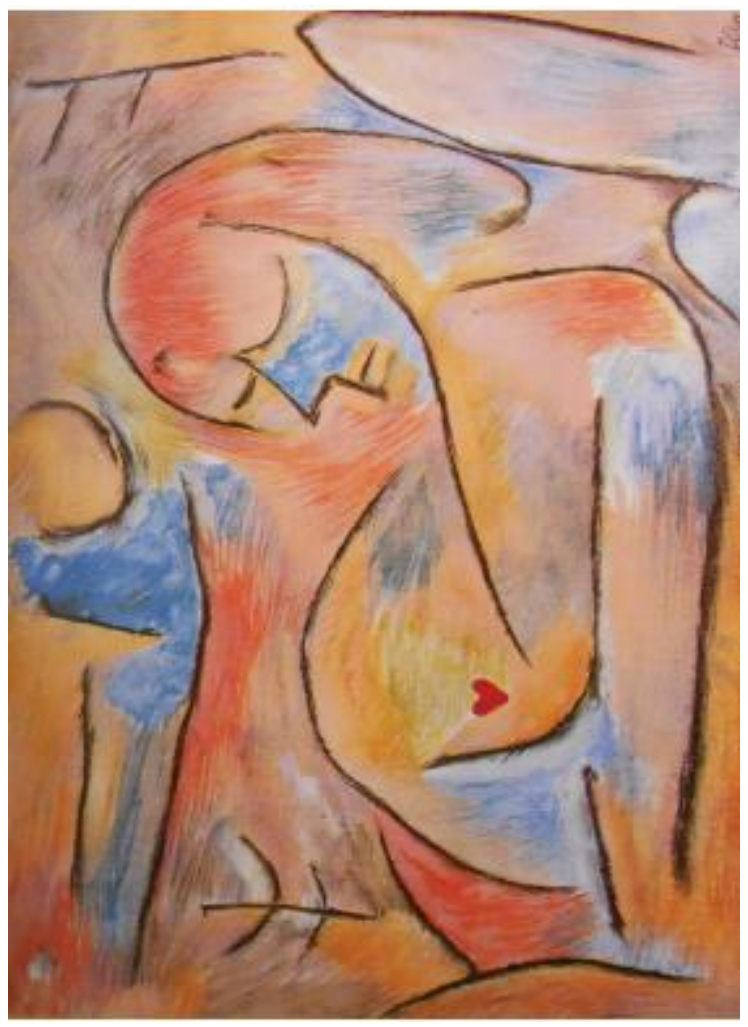

[Fig.47] Autumn [Outono] de Abraham Rattner, publicada na revista Verve.

As litografias em cor sobre as quatro estações estão inseridas em meio aos demais textos e ensaios fotográficos da revista e aparecem como pequenos presentes que o leitor poderia destacar e emoldurar. A contracapa de cada gravura é livre e conta com a assinatura dos pintores. A versão de Spring que se encontra atualmente no acervo do MAC USP é, possivelmente, um dos estudos preparatórios em guache que serviu de base para a reprodução da gravura publicada na Verve de 1938.

Sobre a trajetória da obra Spring [Primavera], da propriedade rural no sul da França, onde os Chagall moravam em 1938 e 1939, até a chegada à galeria Pierre Matisse em Nova York, e depois para as mãos de Dorothy Miller e Alfred Barr, a biografia de Chagall escrita por Jackie Wullschlanger oferece uma pista. Sabe-se que quando Chagall e Bella fugiram da Europa para os Estados Unidos em 1941, eles deixaram para trás todas as obras sob os cuidados da filha Ida, que seguiria com o marido em outro navio alguns meses depois. Notícias da Europa aumentavam o estresse e tensão de Chagall em Nova York. Os alemães marchavam para a Rússia e a tão amada cidade natal Vitebsk foi capturada em 10 de julho, quase um terço de sua 
população sendo aniquilada. Até o final da guerra, apenas 15 construções de Vitebsk permaneceriam em pé, enquanto o resto da cidade foi posta à ruína. Desde sua chegada aos Estados Unidos em junho até setembro, Chagall não tivera notícia sobre o paradeiro de sua filha. Ida havia conseguido embarcar em um navio espanhol chamado Navemare em direção a Cuba. Por meio do contato com um curador do Museu do Prado, ela foi capaz de liberar um caixote com obras, que estava detido na alfândega espanhola. Jackie Wullschlanger descreve a odisseia da filha de Chagall para garantir o deslocamento das pinturas até os Estados Unidos a bordo do Navemare, um navio cargueiro adaptado de maneira bastante rudimentar para o transporte de passageiros.

O superlotado, sujo, malcheiroso navio zarpou; no primeiro dia houve motins por garrafas de água e brigas pelas cadeiras no convés (o lugar mais limpo e seguro para dormir). Marinheiros estupraram passageiros e havia rumores de orgias em botes salva-vidas. Uma epidemia de febre tifóide foi deflagrada e dezesseis passageiros morreram - seus corpos foram lançados ao mar depois de uma leitura do Kaddish. Em meio a tudo isso, Michel e Ida se organizaram em um grupo com outros dois casais que protegiam uns aos outros e tentavam disciplinar as filas de comida e chá, mas era da ruiva e carismática Ida de quem muitos passageiros se lembravam, pois, por dias e noites, ela raramente se afastava de uma grande caixa sobre a qual se sentava, no alto como uma rainha, protegendo-a de qualquer um que chutasse ou tropeçasse contra ela. Ziguezagueando para evitar os submarinos alemães, o Navemare levou 40 dias para cruzar o Atlântico. No momento em que atingiu o Brooklyn, as condições eram atrozes, e Ida estava muito doente. Mas o caixote contendo as pinturas de Chagall estava seguro ao contrário da maioria das bagagens dos outros passageiros, que tinha viajado no compartimento inferior e ficou tão encharcada durante a 
longa jornada que foi considerada apodrecida e atirada ao mar por funcionários aduaneiros (WULLSCHLAGER, 2008, p. 398-399). ${ }^{129}$

Esta foi a última viagem do Navemare. O navio afundou no retorno à Europa ao ser atingido por uma unidade alemã. Não fosse o esforço e resiliência de Ida, talvez as obras de Chagall não tivessem chegado com segurança aos Estados Unidos, entre as quais estava, provavelmente, o guache Spring [Primavera], hoje parte da coleção do MAC USP.

No Brasil, essa obra teve uma longa vida de exposições e é uma peça já característica do núcleo histórico do MAC USP. Ela foi analisada por vários importantes curadores do museu ${ }^{130} \mathrm{e}$, segundo registros do acervo, fez parte de, ao menos, 47 mostras de 1949 até 2009. A obra também integrou a sala especial de Surrealismo e Arte Fantástica da VIII Bienal de São Paulo, em 1965. ${ }^{131}$ Já nos primeiros anos do antigo MAM-SP, Spring [Primavera] foi exibida como parte da mostra 1으 Seleção do Acervo MAM-SP e, desde então, recebe lugar de destaque nas exposições que buscam valorizar o acervo do museu.

129 "Eventually the overcrowded, filthy, foul-smelling ship sailed; riots over bottles of water and fights for chairs on deck (the safest, cleanest place to sleep) broke out on the first day. Sailors raped passengers, and there were rumours of orgies in the lifeboats. A typhoid epidemic erupted, and sixteen passengers died - their bodies were thrown into the sea after a recital of the Kaddish. Through it all Michel and Ida organised themselves into a group with two other couples who protected each other and tried to make sure lines for food and tea were disciplined, but it was red-haired, charismatic Ida whom many passengers remembered, for day and night she rarely moved from a large, high crate on which she sat, high up like a queen, protecting it from anyone who kicked or stumbled against it. Zigzagging to avoid German submarines, the Navemare took forty days to cross the Atlantic. By the time it reached Brooklyn conditions were atrocious, and Ida was very sick, had heart trouble, and had to stay in bed" WULLSCHLAGER, 2008, p. 398-399, tradução nossa.

130 Entre os historiadores brasileiros que escreveram sobre Spring, de Marc Chagall, incluem-se: Aracy Amaral (MAC USP: Perfil de um acervo, 1983), José Teixeira Coelho Netto (O Brasil no Século da Arte: Coleção MAC USP), Kátia Canton (O Trem da História: uma viagem pelo mundo da arte) e Elza Ajzenberg (MAC Virtual: prêmios bienais - acervo do MAC USP).

131 Marc Chagall foi homenageado na IV Bienal com uma sala especial no pavilhão francês. 


\section{Germination, André Masson}

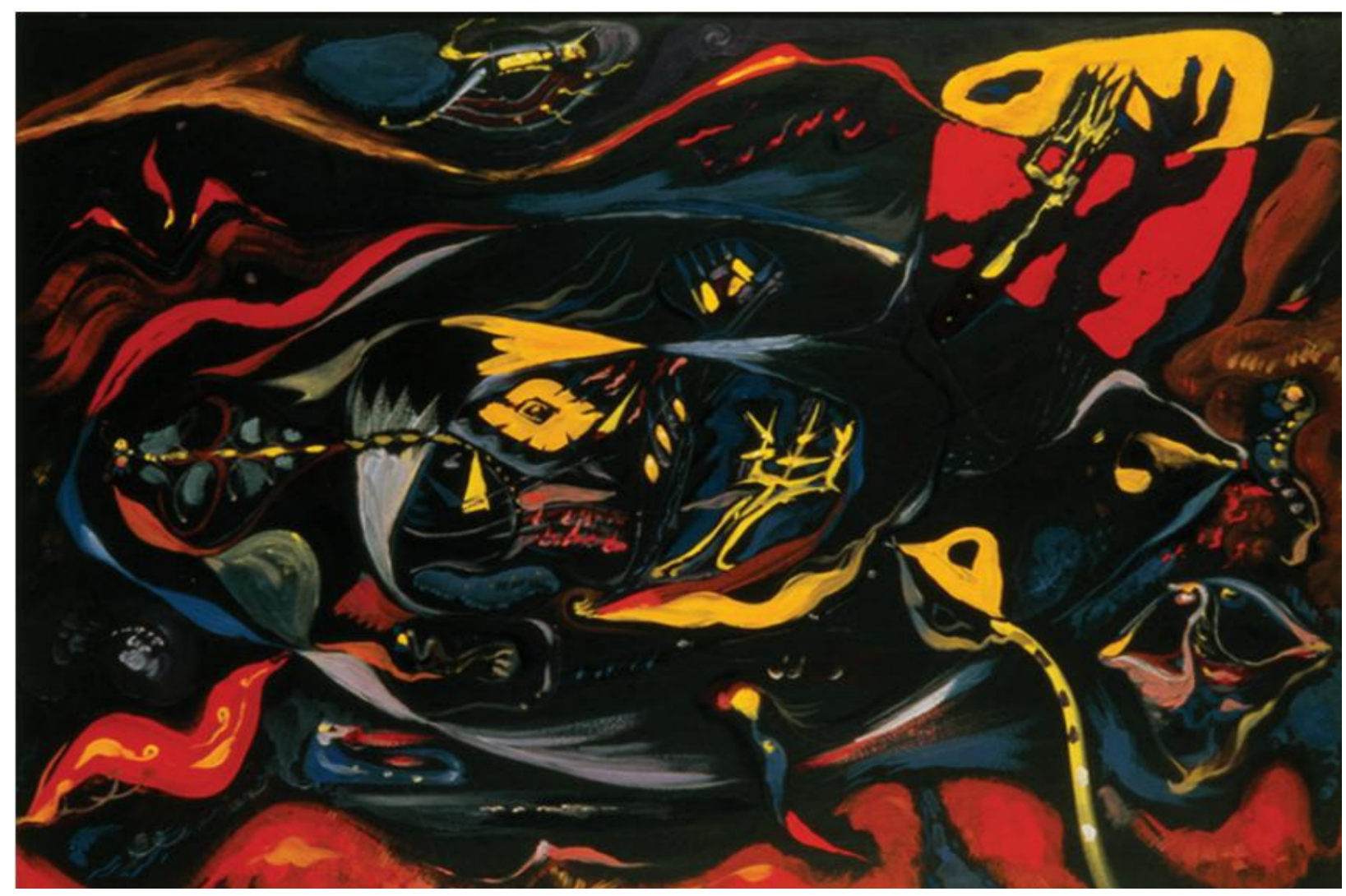

[Fig.48] André Masson. Germination [Germination] (1942), 51,3 X 66,5 cm.

André Masson fez parte do grupo de surrealistas forçados pela guerra a procurar exílio nos Estados Unidos, mas diferentemente de outros pintores emigrados, Masson evitou o burburinho urbano e intelectual de Nova York e buscou refúgio na zona rural de New Preston, cidade que compartilhava com os ateliês de Yves Tanguy e Alexander Calder - ambos presentes na doação Nelson Rockefeller.

Na remota colônia artística de New Preston, Connecticut, Masson encontrou inspiração na imponente natureza e geografia norte-americana, que se tornariam os temas mais férteis da arte produzida por ele no exílio. Masson realizou a série "pinturas telúricas", em que encontra na terra, na fauna e na vegetação, a fonte de sua linguagem surrealista.

Esse conjunto de pinturas está entre suas obras mais notáveis no exílio, que durou de 1941 a 1945. A pintura do MAC USP Germination [Germinação], de 1942, faz parte, justamente, 
desta fase. Outras obras que compõem esta série são Meditation upon an oak leaf [Meditação sobre uma folha de carvalho] (1942), Iroquois landscape [Paisagem de Iroquois] (1942), Indian spring [Primavera indígena] (1942), Pasiphäe (1945) e Le terrier (1946), que foi a última pintura do período telúrico. ${ }^{132}$

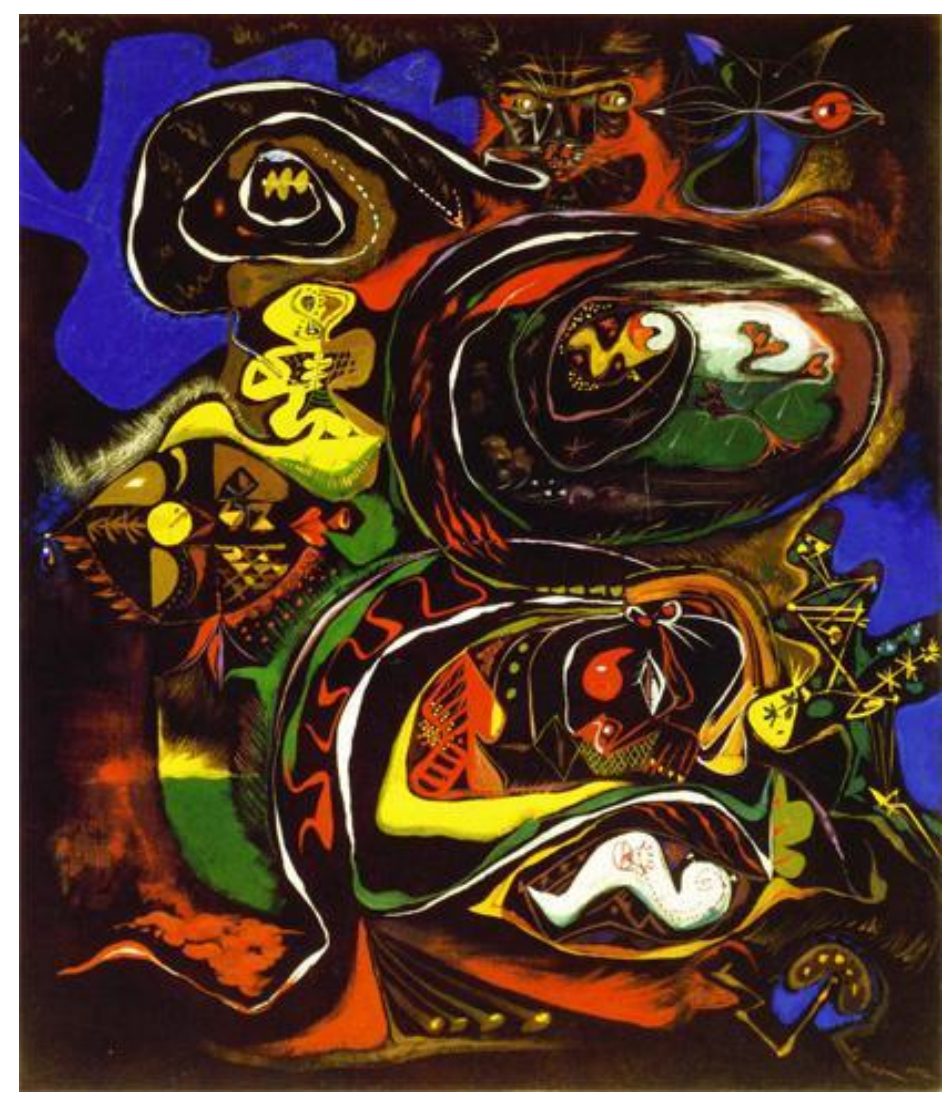

[Fig.49] Meditation upon an Oak Leaf (1942), André Masson. Coleção do MoMA.

Masson iniciou seu treinamento artístico aos 11 anos, na Academia Real de Belas Artes e Escola de Artes Decorativas de Bruxelas, depois seguindo a Paris para fazer parte do ambiente da vanguarda. A relação de André Masson com o grupo de surrealistas já é bem documentada. Masson foi uma figura importante para o desenvolvimento do Surrealismo e do Expressionismo

132 As pinturas telúricas de André Masson foram bem-recebidas pela diretoria de aquisições do MoMA e, atualmente, ao menos cinco obras desta fase do artista fazem parte da coleção permanente do museu: Meditation upon an oak leaf (1942), Meditation of a painter (1943), Pasiphae (1942), Pasiphäe (1945), Andromeda (1943). Isso pode sugerir que a seleção feita por Alfred Barr da obra Germination (1942) para a doação Rockefeller ao Brasil não tenha partido de um ato isolado, mas fazia parte de um processo mais amplo de aquisição de obras telúricas de Masson para o próprio acervo do MoMA. 
Abstrato. Próximo a André Breton de início, ele eventualmente seria expulso do grupo no segundo manifesto surrealista publicado em 1929. Segundo o ex-curador do MoMA William Rubin, o Surrealismo vivenciou um período muito produtivo nos Estados Unidos (1941-1945), comparável até aos anos pioneiros do movimento na França (1924-1929).

Masson, ainda que fizesse parte deste fenômeno, transitava às margens do grupo. "A maioria dos pintores surrealistas se deram bem em Nova York", escreve Rubin. "Ernst, Dali e Matta eram multilíngues, sofisticados e agregadores, e eles já tinham muitos amigos na América. Masson, que não conhecia e não aprendeu inglês, conduziu uma vida mais isolada que outros membros do grupo de exilados", indo para Nova York apenas para frequentar a abertura de exposições (RUBIN, 1976, p. 57).

Apesar de recluso, Masson foi bastante prestigiado pela cena artística nova-iorquina. Em quase todos os anos em que esteve no exílio, foi agraciado com uma mostra individual. Ele se associou à galeria de Curt Valentin, um dos principais atores do mercado artístico de Nova York nos anos 1940. "O desenraizamento de Masson para a América provou ser catalizador para uma enorme revitalização em sua arte", escreve Rubin (RUBIN, 1976, p. 76). Ao todo, 33 exposições com suas obras foram organizadas em galerias e museus americanos durante o seu período de exílio. Sua produção circulou intensamente nas paredes das galerias Pierre Matisse, Buchholz, Art of This Century, de Peggy Guggenheim, além do MoMA e do Whitney Museum de 1941 a 1945. Nos Estados Unidos, Masson encontrou um público ávido por suas obras e um ambiente fértil para a produção e discussão de novas propostas estéticas. Nestes anos, ele se aproximaria do Atelier 17 de Stanley Hayter, onde fez parte da inventiva revolução gráfica liderada pelo este gravurista inglês.

A primeira produção substancial de André Masson nos Estados Unidos será, precisamente, a série de pinturas telúricas da qual Germination faz parte. Esse conjunto de obras se caracteriza por uma investigação da morfologia de organismos rastejantes, folhagens e criações abstratas, resultando em um poderoso redemoinho de forma e cor. A presença de temas gerais como violência, caos, criação e morte, é uma retomada de uma obsessão que está presente na obra de Masson desde os primeiros anos surrealistas na década de 1920. A criação de um elaborado bestiário pessoal já pode ser identificada nas pinturas de areia de 1926 e1927 
- fase de experimentação em que fez uso de diferentes materiais em um processo de colagem. Para Rubin, as obras de areia, em que figuram peixes e criaturas primitivas lutando pela sobrevivência, adiantam o ambiente inóspito das pinturas telúricas feitas anos mais tarde. 0 sentido de violência será exarcebado por meio do uso do imaginário animal e, em especial, das pequenas criaturas e dos invertebrados. Este cenário é apresentado novamente nas pinturas dos anos 1940, mas desta vez em uma versão cromática mais rica, sofisticada e complexa.

Segundo Rubin, as pinturas telúricas só foram iniciadas depois do primeiro outono que Masson vivenciou nos Estados Unidos e os tons presentes em obras como Germination [Germinação] ou Meditation upon an oak leaf [Meditação sobre uma folha de carvalho] às cores do outono na região de New Preston, Connecticut. Ocres, marrons e vermelhos presentes no ambiente natural norte-americano são completados com um amarelo quase fosforescente, que serve como um ímã para o olhar. As cores mais vívidas eram inseridas com o uso de pastel sobre a base de tempera escura. Nuances de textura eram obtidas ao se misturar areia às tintas, assim como polvilhar o material sobre a tela final.

Ao tratar da série de pinturas telúricas, Rubin resgata uma entrevista de Masson em que ele descreve a troca das estações. "Em outubro, não há fim para a variedade de cores". As árvores maple, típicas do clima temperado, "variam de amarelo a violeta, de roxo a laranja e vermilhão, como se o céu derrubasse latas de tinta sobre a vegetação", disse o artista (apud RUBIN, 1976, p.164). ${ }^{133}$

Segundo Masson, em uma entrevista concedida para James Johnson Sweeney pouco antes de sua partida de volta para França, a exuberância da natureza norte-americana seria a imagem mais visualmente estimulante e que melhor explica a sua produção artística no exílio.

Aqui eu ficava imaginando uma floresta virgem em meu entorno. Isso teve uma influência psicológica na minha pintura na América. Não houve nenhuma influência das cidades. O que caracteriza a meu trabalho americano é sua maneira de expressar esse sentimento da

133 "In October, there's no end to the variety of colors. There are the maples under the sky of stained-glass blue; they range from yellow to violet, from purple to orange and vermilion as if the sky had poured cans of paint on the vegetation". apud RUBIN, 1976, p.164, tradução nossa. 
natureza. Aspectos noturnos, aspectos selvagens. Paisagens emblemáticas da minha vida no campo nos Estados Unidos. ${ }^{134}$

A morte e a criação são aspectos que se tornaram uma obsessão para Masson. A investigação do sentido de existência e passagem está posta em telas como Germination [Germinação]. Estas obras evocam o sentido de constante metamorfose e transformação do universo. As formas de casulos e larvas são projeções de Masson da alquimia do mundo natural. "Nestas pinturas, Masson alcança o seu objetivo de 'pintar o sexo da Natureza” (RUBIN, 1976, p. 164) $)^{135}$.

Em uma entrevista, Masson elabora seu entendimento poético sobre a gênese do mundo: "Encontro prazer nesta ideia de que em algum lugar na Terra existe um ponto central, onde uma abertura vulvar recebe um raio solar que, privilegiado, atinge um germe telúrico, germe de todas as germinações, e assim dá origem ao que chamamos de vida" (MASSON apud RUBIN, 1976, p. 172). ${ }^{136}$ A partir desta observação, é possível identificar em Germination [Germinação] a insinuação de uma forma uterina que abarca todas as figuras animalescas menores representadas na tela. Elas brotam de um ponto nevrálgico no centro da composição.

Do ponto de vista filosófico, é a investigação de uma mitologia pessoal sobre o nascimento do mundo que Masson transfere para a obra. E, como todo nascimento, há violência e ruptura. Elementos também expressos na obra por meio das tensões das formas que se agitam e confluem para o centro deste "útero do mundo". Do ponto de vista técnico e estético, Masson trabalha entre o abstracionismo orgânico e o desenho automático, procedimento que adota depois do contato com André Breton em Paris nos anos 1920.

134 "Here I kept imagining a virgin forest about me. This has had its psychological influence on my painting in America. There has been no influence of the cities. What characterizes my American work is rather its manner of expressing this feeling for nature. Nocturnal aspects, aspects of every (...) Emblematic Landscapes of my life in the countryside of the United States". SWEENEY, Eleven Europeans in America. The MoMA Art Bulletin v. 13, no 4-5, 1946, p. 3-6, tradução nossa.

135 "In these paintings Masson attains his ambition 'to paint the sex of Nature'." RUBIN, 1976, p. 164.

136 "I could find pleasure in this idea; somewhere on this earth is a central point where a vulvar opening receives a solar ray which, privileged, reaches a telluric germ (germ of all germinations) and so gives birth to what we call life". MASSON apud RUBIN, 1976, p. 172 
Nas pinturas telúricas, o automatismo de Masson se deixaria entrever pela espontaneidade com que ele relacionada cor, linha e forma. Para o crítico William Rubin, essas pinturas absorvem várias mudanças improvisadas durante a execução da obra, "o que representa um retorno de Masson a seu processo mais familiar de trabalhar de dentro para fora" da composição. As formas crescem a partir "de um pequeno núcleo de cor em paralelo com temas do crescimento orgânico imaginados na pintura" (RUBIN, 1976). O imbricamento das formas era uma qualidade essencial para Masson. As obras telúricas contam com uma sofisticada acomodação formal de modo que as áreas de cor e segmentos se interlacem de maneira ordenada sem perder a complexidade da composição.

A bibliografia sobre André Masson indica que uma obra intitulada Germination [Germinação] foi exposta na galeria Art of This Century, de Peggy Guggenheim, na mostra 15 early, 15 late paintings, que ficou em cartaz de 13 de março a 10 de abril de 1943. A exposição coletiva incluía uma obra recente de Masson, no caso Germination [Germinação] (1942), e uma pintura da fase inicial de sua carreira The Armor [A Armadura] (1925). Ainda que não tenha sido encontrada uma comprovação visual, o nome e data registrados no catálogo da exposição correspondem à obra presente no acervo do MAC USP, sugerindo se tratar da mesma pintura.

Nos primeiros anos de atividade de Art of this Century, Peggy era muito próxima dos surrelistas. A fase inicial da galeria seria muito associada ao renascimento do movimento nos Estados Unidos, entre os anos de 1942 e 1943. A exposição 15 early, 15 late paintings foi a quarta mostra organizada pela galeria e faz parte do período inicial das atividades de Art of this Century, o que, em parte, explica a lista de nomes contemplados na exposição e o uso da coleção particular de Peggy trazida da Europa para compor a mostra. Apenas nos anos seguintes, ela se afastaria do grupo - motivada também por questões pessoais, sobretudo o divórcio com Max Ernst - e buscaria calçar o futuro de sua galeria no trabalho dos novos norteamericanos do Expressionismo Abstrato, notoriamente apoiando o trabalho de Jackson Pollock.

A exposição foi uma proposta curatorial de Jimmy Ernst - filho de Max Ernst e secretário da galeria naquele momento - para traçar um comparativo sobre a produção artística inicial e recente de quinze pintores tidos pela Art of This Century como essenciais da vanguarda: Georges Braque, Marc Chagall, Salvador Dalí, Giorgio de Chirico, Marcel Duchamp, Max Ernst, 
Juan Gris, Wassily Kandinsky, Fernand Léger, André Masson, Joan Miró, Piet Mondrian, Pablo Picasso e Yves Tanguy. Novamente, vemos aqui se repetir alguns dos mesmos nomes contemplados na exposição dos exilados de Pierre Matisse e na doação Rockefeller de 1946. Havia em Nova York um mercado em ascensão para a circulação e recepção do modernismo europeu. Galerias como a de Curt Valentin, Peggy Guggenheim e Pierre Matisse formavam o núcleo deste posto avançado da vanguarda europeia na América.

A exposição não estava na programação original da galeria na temporada 1943. Ela teve que ser organizada às pressas para substituir uma exibição de ilustrações da revista surrealista VVV, organizada por Breton, Duchamp e Ernst, e cancelada por conta de um desentendimento entre Peggy e os editores. A Peggy havia sido prometido um anúncio grátis na revista. Quando Breton impediu a conclusão do acordo publicitário, os planos para a exposição de ilustrações foram desmantelados.

Todos os artistas foram representados com duas obras, exceto Duchamp, que só selecionou uma, e Dalí, que optou por três. A exposição tinha como objetivo mapear a mudança de estilos e temas destes artistas em períodos de tempo que variavam de 9 a 30 anos. Para contornar custos, Peggy tinha o hábito de organizar exposições a partir de sua coleção permanente. Oito pinturas de 15 early, 15 late eram do repositório pessoal da herdeira Guggenheim (LADER, 1981, p. 374), entre as quais The Armor [A Armadura] (1925), de André Masson, que havia sido reproduzida na quarta edição da revista La Révolution Surréaliste em Paris (RUBIN, 1976, p. 212). As demais obras da exposição foram cedidas por galerias parceiras de Nova York. A galeria Buchholz, de Curt Valentin, aparece com uma das apoiadoras da exposição e, devido ao contrato estabelecido com Masson, pode ter sido a intermediadora da venda de Germination [Germinação] para Nelson Rockefeller. 


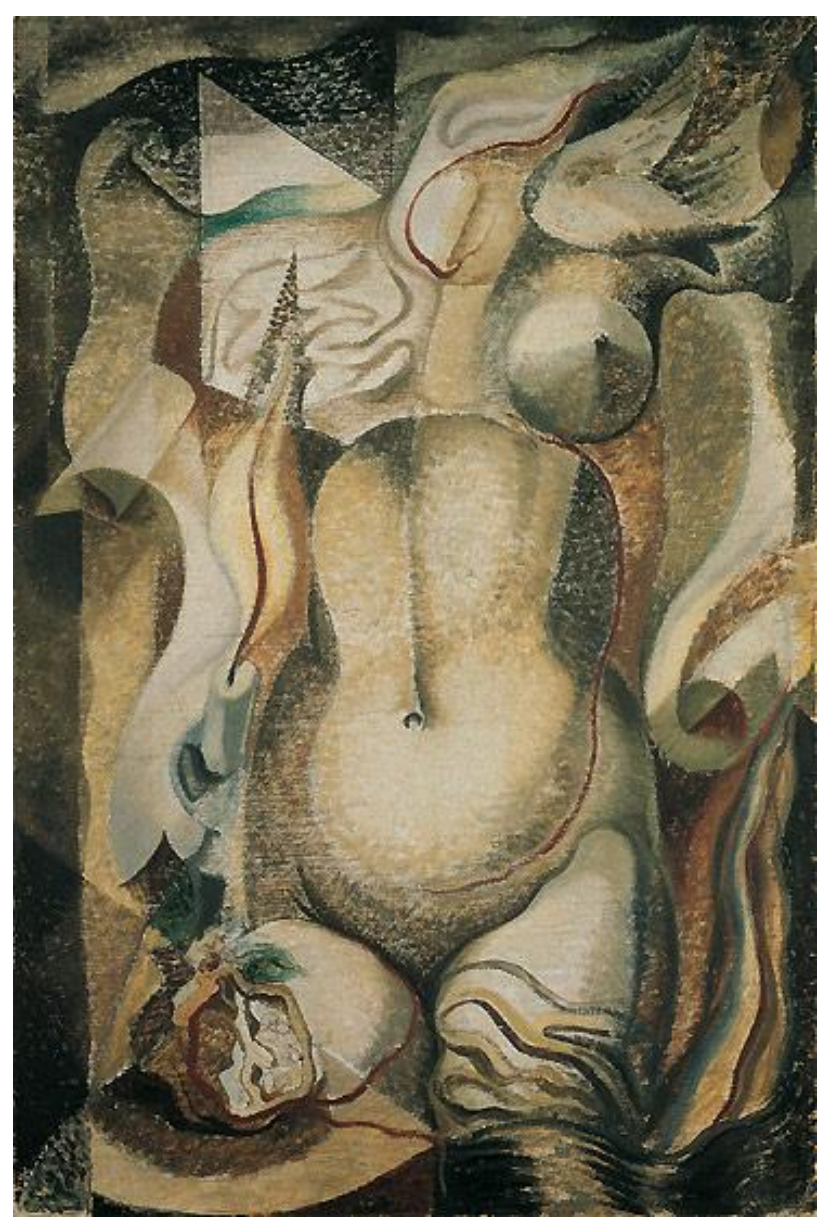

[Fig.50] The Armor [A Armadura] (1925), André Masson. Óleo sobre tela, 80.6 X $54 \mathrm{~cm}$. Coleção Peggy Guggenheim, Veneza.

A aproximação das duas pinturas fornece um comparativo de dois momentos bem distintos da carreira de Masson. Enquanto The Armor [A Armadura] é uma investigação da linguagem e composição cromática cubista, com a predominância dos tons pastel e uma valorização da geometrização do corpo feminino; Germination [Germinação], composta quase duas décadas depois, no momento em que o artista está convivendo intimamente com a paisagem natural de New Preston, apresenta uma explosão de cores e formas orgânicas e abstratas que carregam consigo um subtexto surrealista, assim como também The Armor [A Armadura]. A justaposição destas duas obras sugere uma pesquisa sobre os trajetos e experiências estéticas do artista ao longo de sua carreira. Estimular esse tipo de exercício visual parece ter sido, justamente, a finalidade da curadoria de 15 early, 15 late. Não há registros do 
caminho de Germination [Germinação] após sua primeira aparição pública nas paredes de Art of this Century, em março de 1943, até o envio ao Brasil no outono de 1946.

Assim como no caso de Chagall, a pintura de Masson integrou a sala especial "Do Surrealismo à Arte Fantástica", da 8 Bienal de São Paulo, além de outras 25 exposições do antigo MAM-SP e do MAC USP, sendo uma pintura recorrente em mostras do núclro histórico do acervo. 


\section{Picture for young people, Max Ernst}

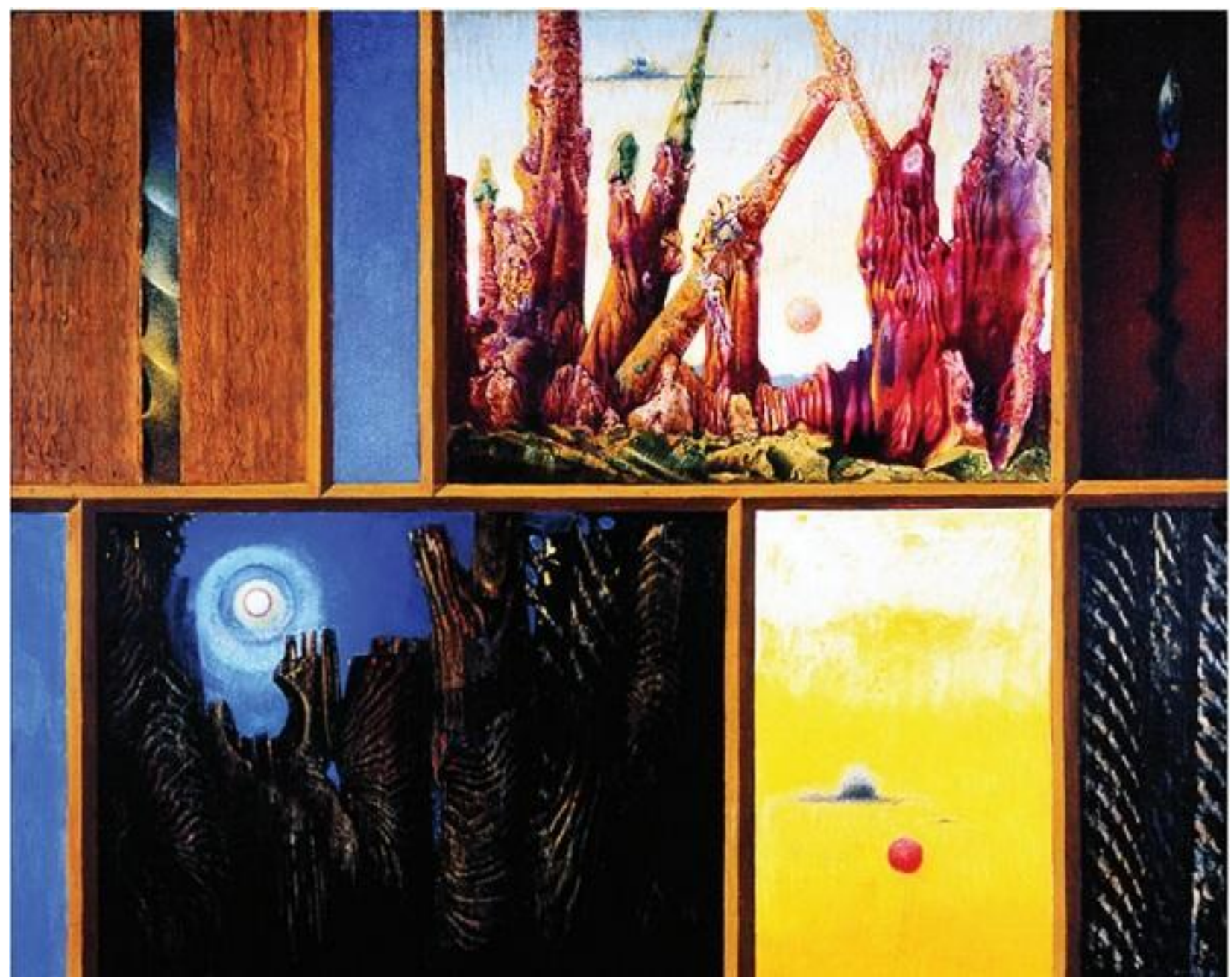

[Fig.51] Max Ernst. Picture for young people [Quadro para jovens] (1943), óleo sobre tela, 60,2 X 75,5 cm.

Aos 48 anos, Max Ernst foi pressionado a fugir para o exílio. Em 1937, ele havia sido rotulado como um "artista degenerado" pelos nazistas e suas obras inseridas na exposição Entartete kunst [Arte degenerada]. A pintura The creation of Eve or the fair gardener [A criação de Eva ou a bela jardineira] foi exibida sob o epitáfio "insulto à mulher alemã" e destruída pelo regime. Apreendido em 1939 como inimigo do Estado, Ernst foi enviado para a prisão francesa de Largentière, em Les Milles, por um período de enclausuramento de três meses. Assim como Chagall, Max Ernst foi forçado pela instabilidade política europeia a migrar para Nova York em 
1941, e tal qual Masson, encontrou na galeria de Peggy Guggenheim o primeiro lar para suas obras nos Estados Unidos. Contudo, diferentemente de outros artistas europeus exilados durante a Segunda Guerra Mundial, o trabalho de Ernst já era bastante conhecido nos Estados Unidos, especialmente por causa da inclusão de 48 de suas obras na exposição itinerante Fantastic art, dada and surrealismo [Arte fantástica, dadaísmo e surrealismo], organizada por Alfred Barr no MoMA em 1936.

As duas grandes guerras europeias impactaram intensamente a vida e obra de Max Ernst. A violência e o absurdo são temas reincidentes em sua arte, que reflete os acontecimentos turbulentos que marcaram sua vida adulta. Depois de seu alistamento no exército alemão, onde serviu de agosto de 1914 a novembro de 1918, Ernst se aliou ao grupo dos dadaístas. Foi nesta ocasião em que começou a realizar as primeiras experiências com a colagem. A desfiguração do corpo humano reaparece como uma obsessão da produção de Max Ernst e dialoga com o terror vivenciado por ele na Primeira Guerra Mundial. Para Ernst, diante do caos do mundo, a associação ao grupo dos Dada era mais do que uma experiência artística. Envolvia, antes de mais nada, um "estado da mente":

Contrário ao entendimento geral, Dada não queria chocar a burguesia. Ela já estava chocada o suficiente. Não, Dada era um levante rebelde de energia vital e raiva; resultante de todo o absurdo e imensa schweinerei [bagunça] daquela guerra imbecil. Nós jovens voltamos da guerra em um estado de estupefação e nossa raiva tinha que achar expressão de um jeito ou de outro. Isso ela fez quase naturalmente por meio dos ataques às fundações da civilização que tinha sido a reponsável pela guerra (...) Nosso entusiasmo exigia total revolução (ERNST apud SCHNEEDE, 1972, p. 16). ${ }^{137}$

137 "Dada was first and foremost an attitude of mind (...) Contrary to general belief, Dada did not want to shock the bourgeois. They were already shocked enough. No, Dada was a rebellious upsurge of vital energy and rage; it resulted from the absurdity, the whole immense Schweinerei of that imbecilic war. We young people came back from the war in a state of stupefaction, and our rage had to find expression somehow or other. This it did quite naturally through attacks on the foundations of the civilization responsible for the war... Our enthusiasm encompassed total revolution". ERNST apud SCHNEEDE, 1972, p. 16. 
Max Ernst foi um dos artistas centrais do Dadaísmo e um dos pivôs do movimento surrealista. No período marcado pelo lançamento dos dois manifestos do Surrealismo (1924 e 1930), Ernst experimentou com diferentes técnicas pictóricas em suportes diversos. Assim como Tanguy, Masson e Miró; Ernst trabalhou intensamente com o automatismo e, como Dalí e Magritte, pesquisou a potencialidade imagética do mundo dos sonhos e do subconsciente. Depois da publicação do manifesto de 1924, Ernst desenvolveu uma série de técnicas semiautomáticas, como a frottage, grattage, decalcomania e oscilação.

A frottage consiste em cobrir uma superfície com papel e esfregar a área com grafite ao ponto que os padrões e ranhuras sejam transpostas para a folha. A grattage é a aplicação da frottage na pintura, quando Ernst pressionava pedaços de madeira, vidro, folhas e gravetos contra o lado inferior da tela e adicionava camadas finas de tinta, depois raspadas com uma espátula, a fim de deixar aparecer os padrões dos objetos. A decalcomania é uma técnica de transferência de imagens, por meio da pressão de pedaços de vidro ou papel sobre tela, desenvolvida já no século XVIII e aperfeiçoada pelos surrealistas. Por fim, a oscilação foi uma técnica desenvolvida por Max Ernst nos Estados Unidos em 1942 e que consistia em amarrar uma corda a uma lata de tinta com um pequeno furo e circular o mecanismo sobre a tela, criando linhas e manchas de tinta correspondentes ao movimento do corpo do artista.

Sobre o método de Ernst, a historiadora Uwe M. Schneede diz que a característica deste artista foi continuamente mudar de estilos antes de ele ter conseguido aperfeiçoá-los. "Max Ernst não é um descobridor, mas um investigador", definiu (SCHNEEDE, 1972). Por isso também não é possível limitar Ernst a um estilo, técnica ou escola. Nenhuma obra ou série pode representar a amplitude e multiplicidade deste artista. "Nada dele é definitivo em caráter; cada trabalho individual reflete um dos variados traços do artista" (SCHNEEDE, 1972, p. 88). 


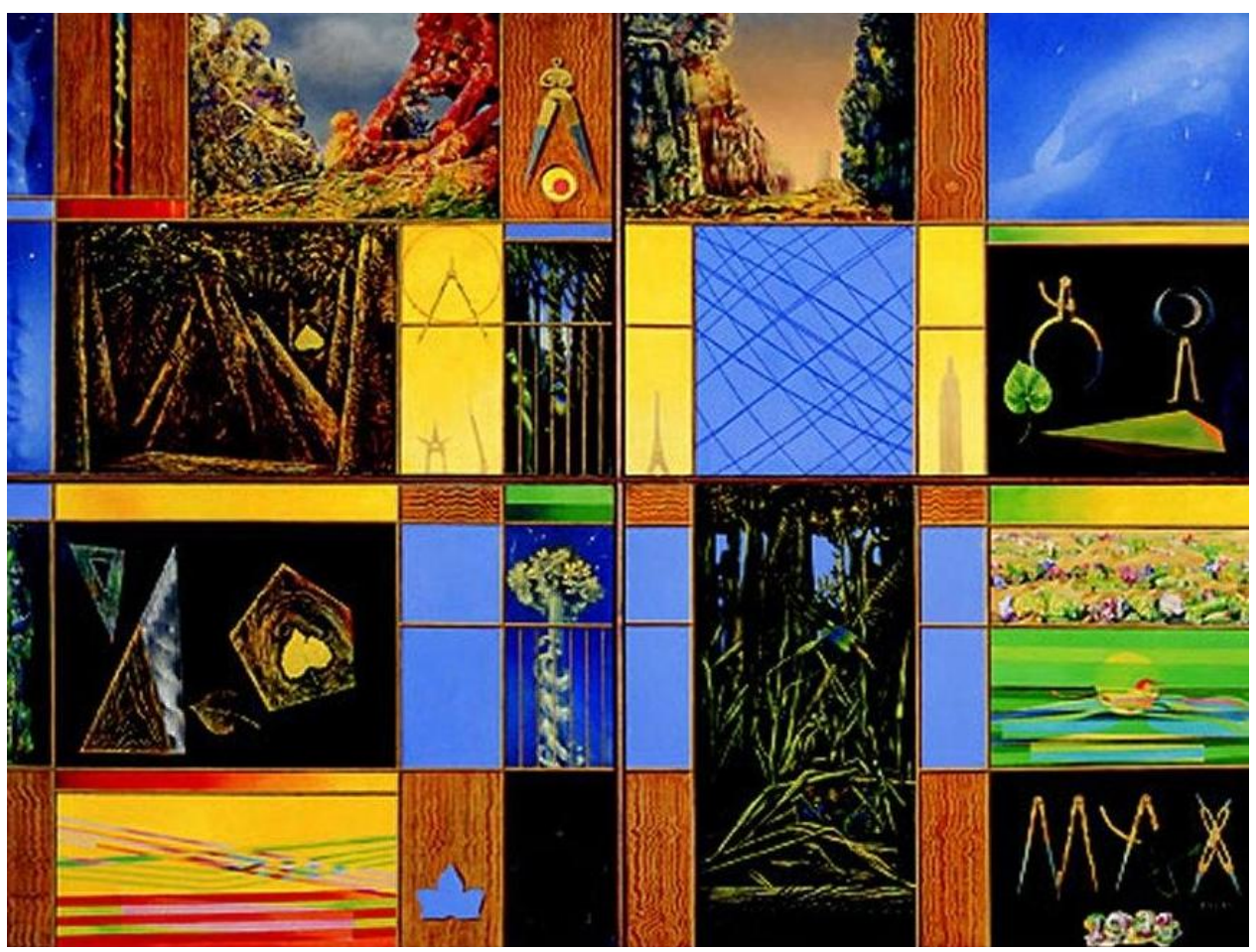

[Fig. 52] Max Ernst. Vox Angelica (1943), óleo sobre tela, 203 X 152, 4 cm. Coleção Particular

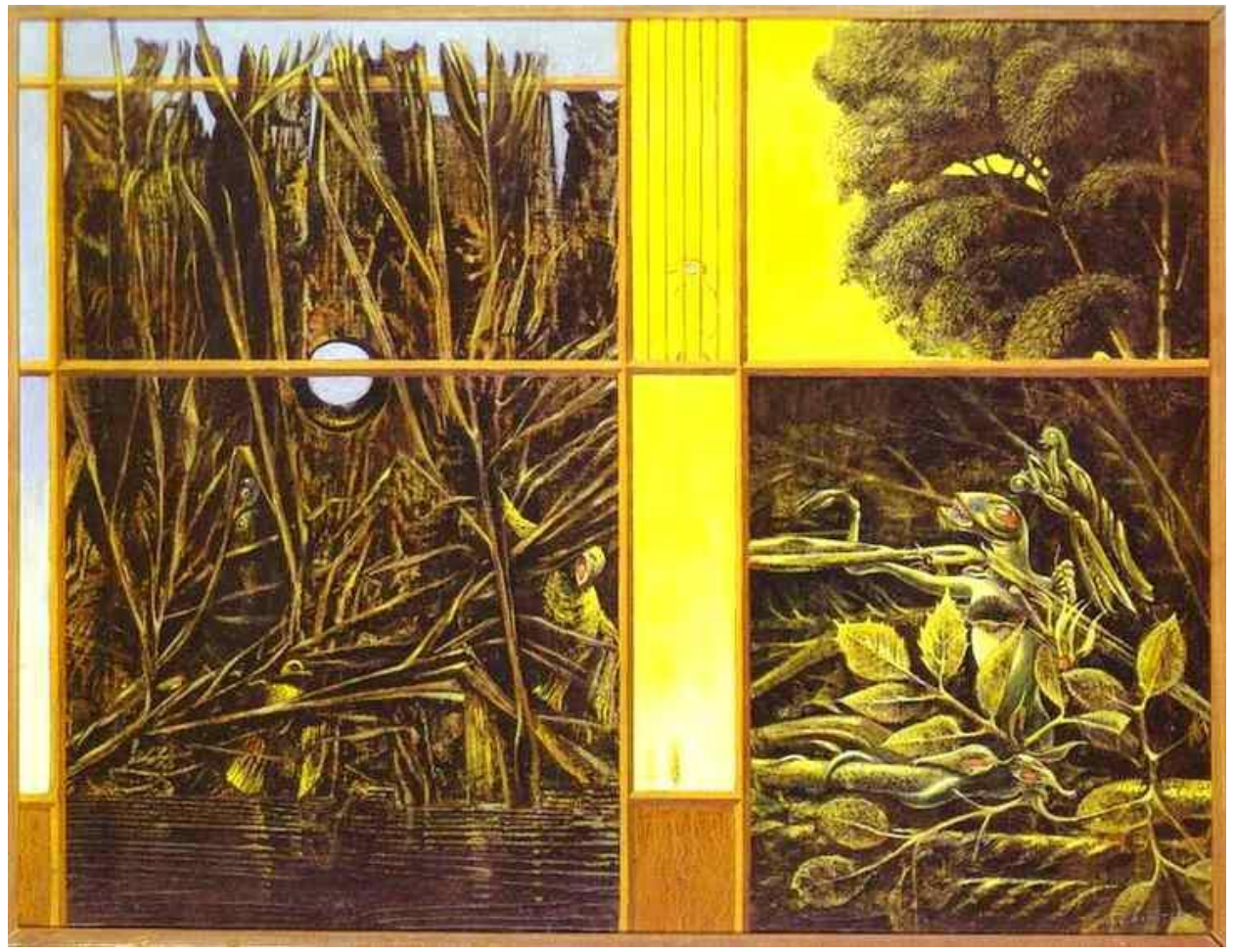

[Fig. 53] Max Ernst. Painting for young people [Quadro para jovens] (1943), óleo sobre tela, $60 \times 75 \mathrm{~cm}$. 


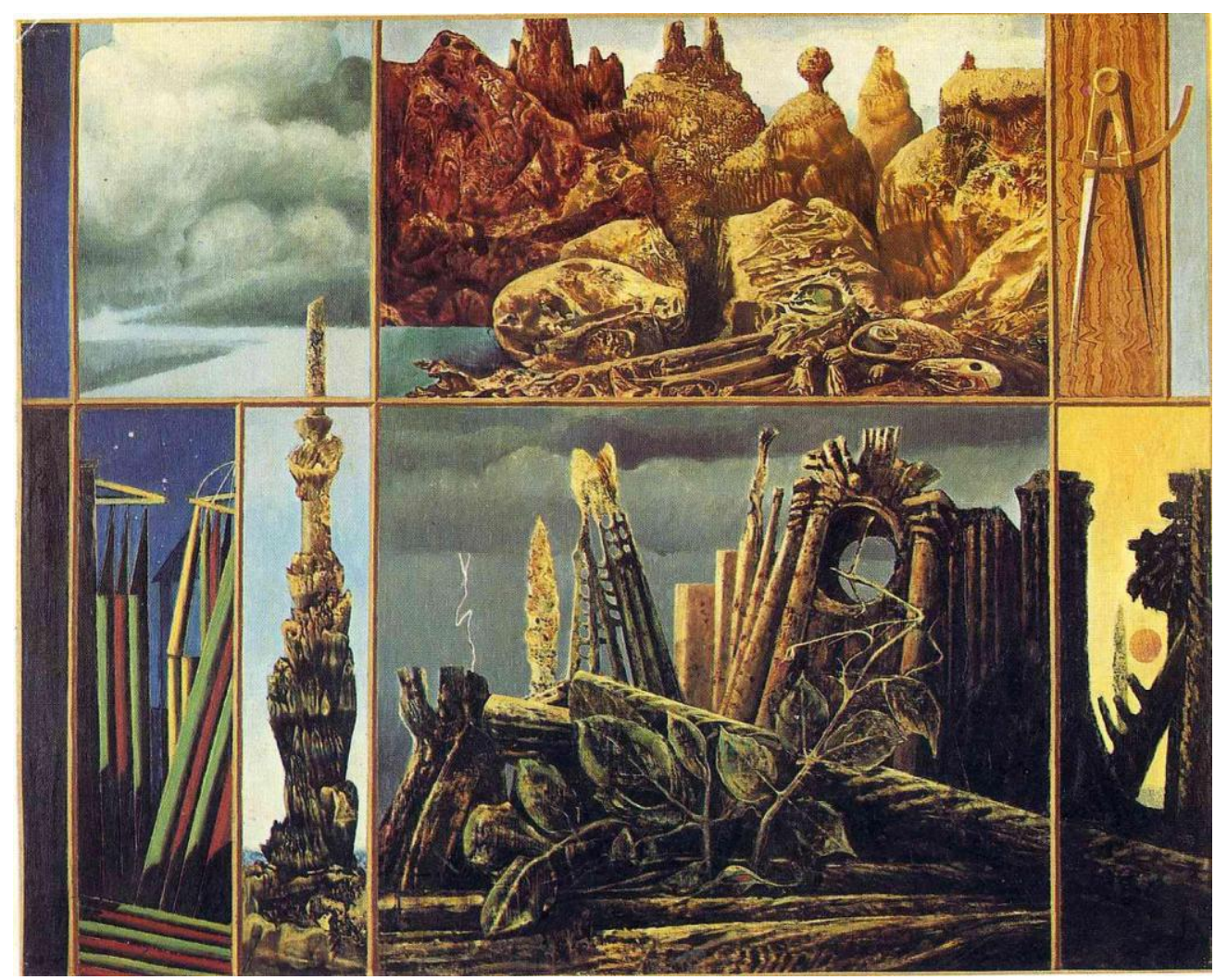

[Fig. 54] Max Ernst. Painting for young people [Quadro para jovens] (1943), óleo sobre tela, 60,5 X 76, $5 \mathrm{~cm}$. Coleção de Ulla e Heiner Pietzsch.

A colagem não era apenas um suporte para Ernst. Ela representava um método de trabalho e um modo de pensar. A justaposição, o rearranjo e a desarmonia eram mais importantes para o artista do que qualquer aspiração à consistência de estilo ou motivo. Segundo a análise da curadora Julia Drost, o amplo uso da colagem por vários artistas cubistas, futuristas e surrealistas após a Primeira Guerra tinha por objetivo evidenciar o absurdo de um mundo que parecia ter "perdido a sua coerência" (DROST. J; SPIES, 2009, p.52). Para Drost, a colagem foi a técnica que teve maior impacto no processo criativo de Ernst. Ele usaria o princípio não apenas em papel, mas também em pinturas, esculturas e escritos literários. Este é o fundamento da série de "pinturas-colagem" realizada no início dos anos 1940, que incluiu quadros como Day and night [Dia e noite] (1941-1942), Vox Angelica (1943) e Painting for the young [Quadro para jovens] (1943).

Em 1943, Max Ernst produziu três versões de Painting for young people [Quadro para jovens] e um Vox angelica, talvez a mais impressionante de suas "pinturas dentro de pinturas". 
Em todas essas obras, Ernst mistura estilos diferentes que remontam a fases anteriores de sua carreira. Os temas encapsulados nos diagramas retangulares são, em geral, formas orgânicas, paisagens sobrenaturais, e composições abstratas que se completam de maneira inusitada. 0 historiador da arte e maior especialista em Max Ernst, Werner Spies, sugere que os quadros compósitos refletem a influência das abstrações de Piet Mondrian, artista que morreu nos Estados Unidos em 1944 e que fazia parte do círculo de Ernst em Nova York (SPIES, 2009, p.160). Outra interpretação para essa série de telas é do pesquisador David Hopkins, da Universidade de Glasgow, para quem essas pinturas são uma espécie de autorretrato do artista, pois apresentam um compêndio dos principais estilos que marcaram sua trajetória.

"Max Ernst, agora no meio da carreira, reavalia e reapresenta a si mesmo" (HOPKINS, 1992, p. 720). Ernst fornece um resumo autobiográfico nas pinturas-colagem. Ele insere as florestas predatórias de suas obras dos anos 1930 e as paisagens inundadas pela chuva do início dos 1940. A isso, adiciona pequenos objetos, instrumentos como o compasso e o esquadro, assim como folhagens e formas animais. Essa série de obras foi associada à tradição dos Wunderkammer, os gabinetes de curiosidades, conhecidos também como as câmaras de maravilhas, do século XVI e XVII. Desta forma, as pinturas-colagens de Max Ernst seriam pequenas coleções de tesouros pictóricos. Cada compartimento, uma gaveta na qual o artista armazenava imagens que o estimulavam no presente e passado de sua carreira.

Hopkins associa o momento histórico da vida pessoal de Ernst e sua imigração forçada da França aos Estados Unidos com uma tentativa de o artista recompor nessas pinturas os pedaços de uma vida fragmentada pela guerra, formando um arquivo da própria obra.

Como inimigo estrangeiro, ele tinha sido forçado a deixar a França, seu lar adotivo, durante a guerra, e fugiu para os Estados Unidos em 1941. (...) A impressão dominante é de que o artista resgata fragmentos díspares de uma catástrofe pessoal e cultural. Simultaneamente, ele parece exercer um controle curatorial perverso sobre a sua obra, restabelecendo uma taxonomia particular (HOPKINS, 1992, p. 720). ${ }^{138}$

138 "As an enemy alien, he has been forced to leave France, his adopted home, during the war, and fled to the United States in 1941. (...) The overwhelming impression is of the artist salvaging disparate fragments from a 
Nessa série de pinturas-colagem, Ernst rearranjava temas que se repetem em outras obras suas do mesmo período. Um caso exemplar são as paisagens fantásticas da pintura Bryce canion translation, de 1946, parte do acervo do Masp. Há uma correspondência muito clara entre essa obra e um dos quadrantes a versão de Picture for young people [Quadro para jovens] do MAC USP. Da mesma forma, um tema que se sobrepõe nesta série de obras são as imagens de florestas. Ernst tinha começado a trabalhar com pinturas de florestas maravilhosas, ermas e soturnas, já no final dos anos 1920. Foi neste período que passou a experimentar a técnica da decalcomania, por meio da transferência de padrões e texturas de madeira e folhagens para compor florestas. Max Ernst era um grande admirador de Albrecht Altdorfer, artista renascentista alemão do século XV e XVI ligado à Escola de Danúbio, assim como de Caspar David Friedrich, grande paisagista romântico do século XIX. "Sem a tradição alemã da pintura de florestas sua própria teria sido impensável", afirma Schneede. "Nestas imagens florestais Max Ernst continua a tradição, que se origina com Caspar David Friedrich, imbuido uma paisagem com o conteúdo das experiências subjetivas" (SCHEEDE, 1972, p.105)

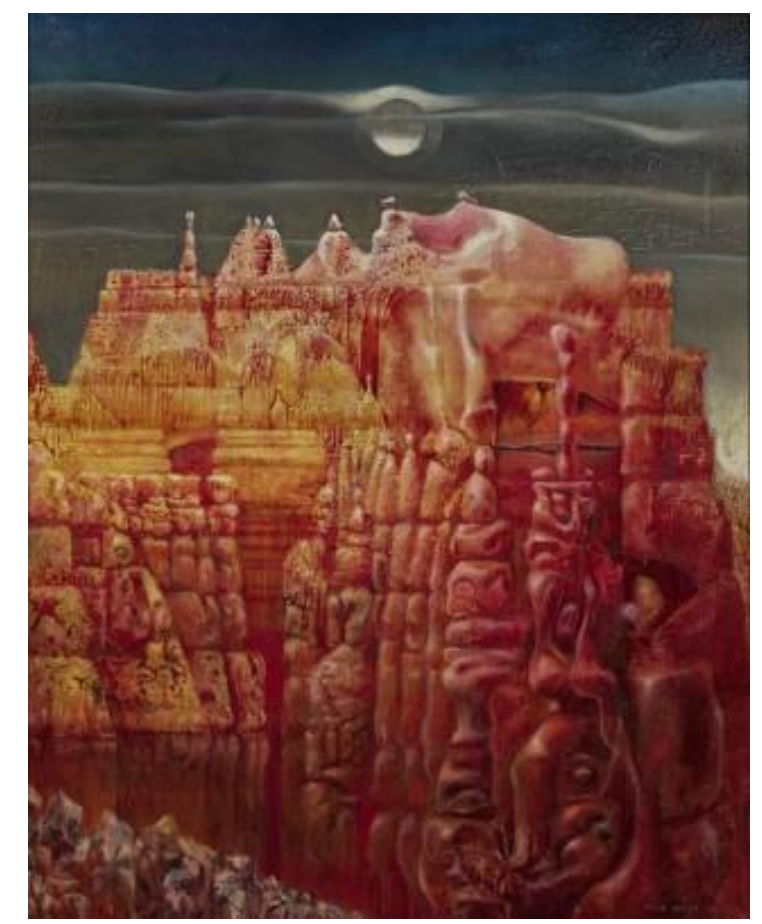

[Fig. 55] Max Ernst. Bryce Canion Translation (1946), óleo sobre tela, 51 X 41 cm. Coleção Masp.

personal; cultural catastrophe. Simultaneously he seems to be exercising a perverse curatorial control over his oeuvre, reestablishing a private taxonomy". HOPKINS, 1992, p. 720, tradução nossa. 


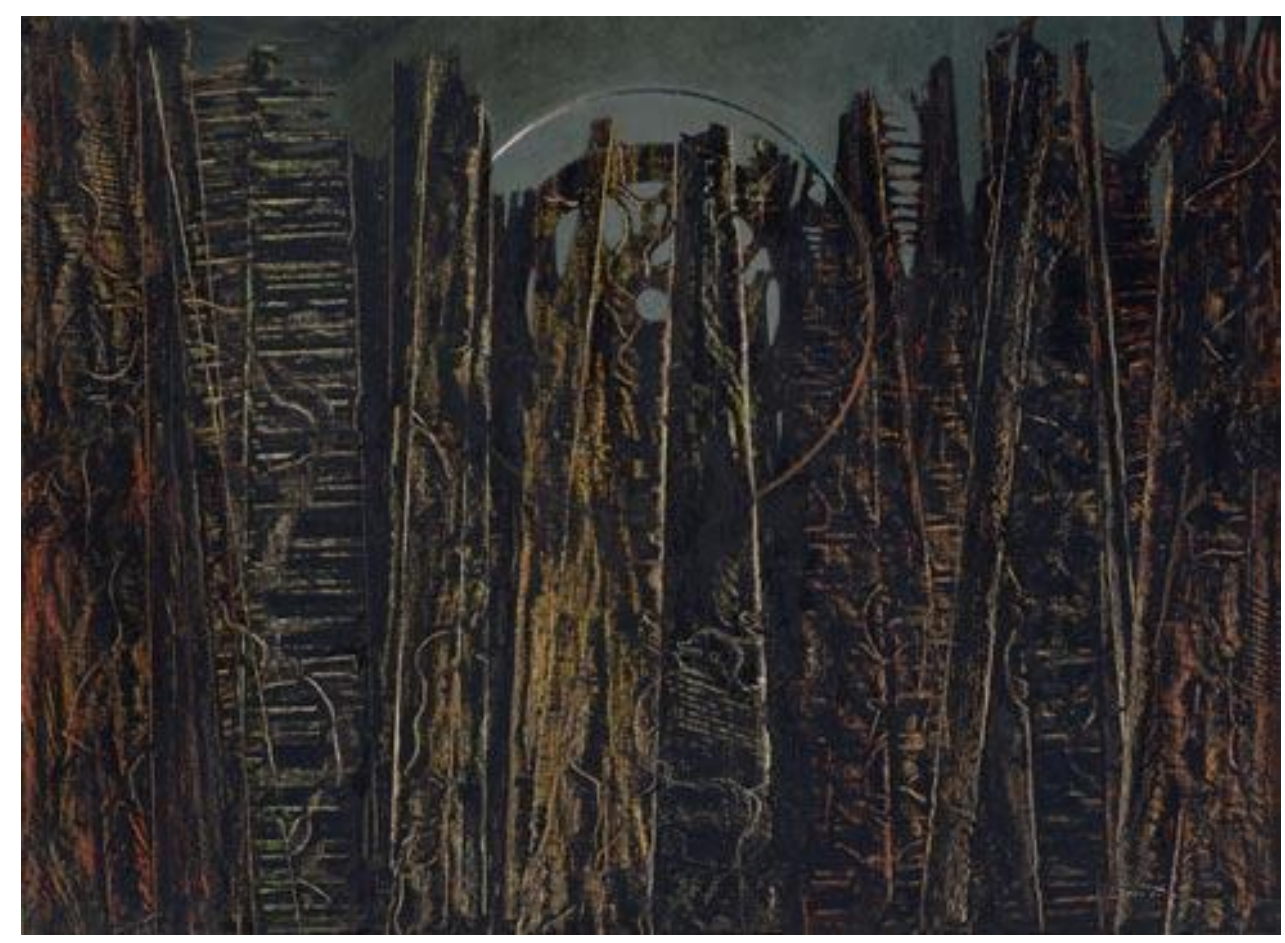

[Fig. 56] Max Ernst. The Forest [A Floresta] (1927-28), óleo sobre tela, 96.3 X $129.5 \mathrm{~cm}$. Fundação Solomon R. Guggenheim, Coleção Peggy Guggenheim, Veneza.

O Romantismo alemão - sua atração pela natureza, pelo mundo sobrenatural e o repúdio ao racionalismo iluminista, somado à investigação do inconsciente - são apontados como as principais influências para a produção das florestas sombrias de Max Ernst. Uma passagem bastante citada da biografia de Max Ernst envolve seu primeiro encontro com a natureza selvagem. Quando escreve sobre sua infância, Ernst lembra os sentimentos conflitantes de "prazer e opressão" na primeira vez em que entrou numa mata fechada. "A maravilhosa alegria de respirar livremente no espaço aberto, mas ao mesmo tempo a angústia de ser cercado por todos os lados por árvores hostis. Dentro e fora, livre e cativo, ao mesmo tempo" (ERNST apud SCHEEDE, 1972, p.36). ${ }^{139}$ As primeiras colagens dessa série foram Forest and sun [Floresta e sol] (1920) e The forest [A floresta] (1925), seguidas das pinturas noturnas, entre as quais Sun and forest [Sol e floresta] (1926) e The great forest [A grande floresta] (1927) e L'été imaginaire [Verão imaginário] (1927).

139 "The wonderful joy of breathing freely in open space, yet at the same time distress at being hemmed in on all sides by hostile trees. Inside and outside, free and captive, at one and the same time". apud SCHEEDE, 1972, p.36, tradução nossa. 
Em Painting for young people [Quadro para jovens], Max Ernst retoma temas e estilos que marcaram sua pintura na Europa e desenvolve uma pequena coleção de si mesmo, numa obra do período inicial de seu exílio nos Estados Unidos. Por sua ligação com Peggy Guggenheim neste período, com quem esteve casado e cuja galeria o representava, é muito possível que Alfred Barr tenha tomado conhecimento desta obra por meio de exposições ou visitas à Art of This Century. Painting for young people [Quadro para jovens] é uma obra de um pintor já maduro, que reflete sobre sua produção e a reapresenta. Essa pintura-colagem é um trabalho de autoreferência de Max Ernst, que deixa um testemunho de si mesmo para as próximas gerações de artistas e seguidores. Realizada em um momento-chave de sua carreira nos Estados Unidos, essa é uma obra importante de Max Ernst e, ao ser doada ao Brasil em 1946, fez parte do acervo cultural e do repertório imagético dos artistas brasileiros. ${ }^{140}$

140 A produção de Ernst terá um grande impacto no meio artístico brasileiro, entre os anos 1920 e 1940, e será um referencial para artistas e escritores como Flávio de Carvalho, Jorge de Lima e Murilo Mendes. Um estudo sobre como o movimento surrealista vai ser percebido pelos modernistas brasileiros foi desenvolvido por Tiago Gil de Oliveira na dissertação "Uma brecha para o surrealismo: percepções do movimento surrealista no Brasil entre as décadas de 1920 e 1940". 


\section{Composition, Fernand Léger}

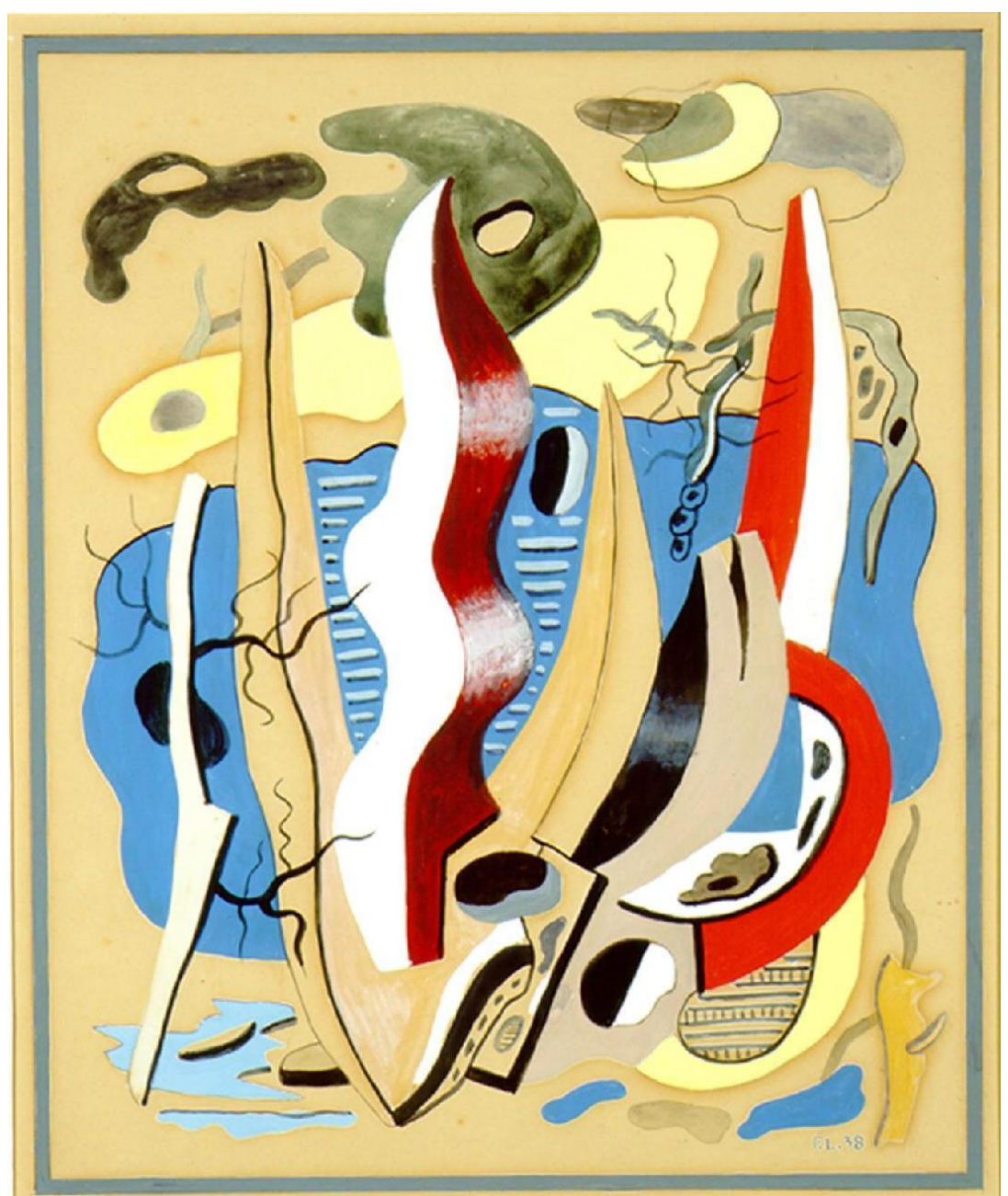

[Fig. 57] Fernand Léger, Composition [Composição] (1938), óleo sobre tela, 60,2 X 75,5 cm.

Durante a primeira visita aos Estados Unidos em 1931, Fernand Léger não conteve seu entusiasmo a respeito da arquitetura de Nova York. Em um artigo para o Cahier d'art de Paris, disse: “O mais belo espetáculo do mundo não é obra de um artista. Nova York tem uma beleza natural (...) É a sua força e sua variedade" (LÉGER, 1989, P.184). Para ele, Nova York era o "espetáculo mais colossal do mundo" (LÉGER, 1989, p. 184). Ali, ele encontraria um tema estimulante para sua arte.

As preocupações fundamentais de sua pintura muito se aproximariam do ambiente norte-americano de industrialização e modernização, que o artista encontraria no exílio nas 
décadas seguintes. A estética da máquina, por exemplo, foi um importante indutor para a abstração proposta por Léger já na Paris dos anos 1920. A máquina, segundo ele, "cria ornamentos" e muitas de suas pinturas procuram descobrir o belo encapsulado nos mais banais objetos cotidianos. ${ }^{141}$ "Todo artista possui uma arma ofensiva que lhe permite brutalizar a tradição (...) Servi-me da máquina, como outros costumam empregar o corpo nu ou a naturezamorta" (LÉGER, 1989, p.70). ${ }^{142}$

Léger morou nos Estados Unidos durante a Segunda Guerra Mundial e encontrou neste ambiente um público e um mercado receptivo para suas obras. A relação de Léger com os Estados Unidos começa em Paris, onde tinha contato com norte-americanos expatriados. Havia estabelecido conexões que Ihe seriam úteis anos mais tarde nos Estados Unidos, entre eles o artista e colecionador Gerald Murphy, o escritor John Dos Passos e a colecionadora Katherine Dreier. Katherine fundou, com Marcel Duchamp e Man Ray, a Société Anonyme, organização de arte sediada em Nova Jersey que promovia exibições, seminários e publicações sobre as novas tendências da arte moderna. A Société foi uma apoiadora importante da obra de Léger e, em 1925, elaborou uma das primeiras exposições solo na Galeria Anderson, de Nova York, contribuindo para torná-lo mais conhecido entre o público norte-americano de colecionadores e apreciadores de arte moderna.

Antes de seu exílio, Léger tinha viajado ao país em três temporadas anteriores. Em 1931, visitou os Estados Unidos pela primeira vez a convite do casal Sara e Gerald Murphy. Em 1935, James Johnson Sweeney organizou uma mostra retrospectiva com suas obras para o Renaissance Society em Chicago. A mostra foi pensada para ser itinerante e um dos primeiros museus a adquirir a exposição foi o MoMA, que ocupou dois andares com guaches, desenhos e pinturas de Léger. O privilégio de uma retrospectiva no MoMA havia sido concedido para apenas dois outros artistas europeus até o momento: Henri Matisse e Paul Klee. ${ }^{143}$ A exposição foi montada por um ex-aluno de Léger, George L. K. Morris. Foi nesta ocasião que o museu adquiriu para sua coleção as primeiras obras do artista (LANCHNER, 1998, p. 42).

141 A estética da máquina. O objeto fabricado, o artesão e o artista. In. LÉGER, Funções da Pintura. São Paulo: Nobel, 1989, 184p.

142 A estética da máquina. A ordem geométrica e o verdadeiro. In LÉGER, Op. cit.

143 Press release do MoMA: FOR RELEASE Saturday afternoon or Sunday morning, September 28 or 29, 5. Arquivo do MoMA. 
Em uma exposição anterior, Painting in Paris from American collections [Pinturas de Paris em coleções norte-americanas], Alfred Barr define Léger como o "mais importante artista vivo que tem usado constantemente a técnica cubista" (LANCHNER, 1998, p.35). Sua visibilidade nos Estados Unidos aumentava, principalmente tendo em vista que sua estreia no circuito norte-americano havia se dado discretamente no Armory show, em 1913, com uma participação marginal de apenas duas obras. Até 1920, não mais do que quatro obras de Léger tinham sido adquiridas para coleções norte-americanas (LANCHNER, 1998, p.21). Nos anos 1920, portanto, Léger era praticamente desconhecido na América. Iniciativas como a da Société Anonyme e a do MoMA contribuíram para lhe dar outra estatura no país.

Léger voltaria aos Estados Unidos em 1938 para proferir um ciclo de conferências na Universidade de Yale sobre o uso da cor na arquitetura. Nesta oportunidade, teve um contato mais próximo com o arquiteto Wally Harrison, envolvido no projeto do Rockefeller Center. Harrison e Rockefeller se tornaram grandes amigos e colaboradores. Ambos eram admiradores de Fernand Léger. O relacionamento do artista com esses dois homens resultaria em projetos de grande dimensão pública, assim como importantes encomendas de âmbito privado.

Em uma carta para Simone Herman, Léger escreveu com entusiasmo:

Há dez dias almocei com Harrison, o arquiteto da Radio City, e também Rockefeller (...) Deste projeto decorativo para o apartamento de Nelson Rockefeller, eu tenho a maquete e os planos -- 4,000 dólares, pode funcionar (...) O diretor de uma universidade norte-americana vai me visitar para falar de um curso de três meses sobre arquitetura e pintura de mural... o o o ! Ah! Ah! Então, uma viagem para Nova York por 3 meses com um estúdio à minha disposição. Ah! Ah! Ah! (LANCHNER, 1998, p.48). ${ }^{144}$

144 “Ten days ago I had lunch with Harrison, Radio City's architect and also Rockefeller's, with Mrs. Callery. From this, decorative project for Nelson Rockefeller's apartment, I have the maquette and the plans -- 4,000 dollars, it may work -- very supported by Callery... The director of an American university will visit to talk about a three month long course concerning architecture and mural painting.. o o o ! Ah! Ah! So, trip to New York stay 3 months with a studio at my disposition o o o ! Ah Ah Ah!". (LANCHNER, 1998, p.48. tradução nossa). 
Foi Harrison quem primeiro recomendou Léger a Nelson, que se tornaria um apreciador de longa data de sua obra e viria a ser um de seus grandes patrocinadores. Quando Léger teve problemas com a imigração durante a Segunda Guerra Mundial, Nelson estava listado como uma de suas referências pessoais. Em 1938, Rockefeller pediu a Léger que realizasse um mural para a sala de visitas de seu apartamento em Manhattan, onde a pintura estaria posicionada em frente a outro mural de Henri Matisse. Wally Harrison era o arquiteto responsável pelo projeto da reforma do apartamento e da casa de campo de Nelson em Pocantico Hills e ele também envolveu Léger nesta segunda encomenda. Além desses trabalhos para as residências de Rockefeller, Harrison contratou Léger para pintar sua própria sala de jantar em Long Island. Em um período financeiramente difícil para o artista, Harrison e Rockefeller serviram como importantes incentivadores e uma boa vitrine para tornar sua arte mais conhecida entre a elite de colecionadores norte-americanos.

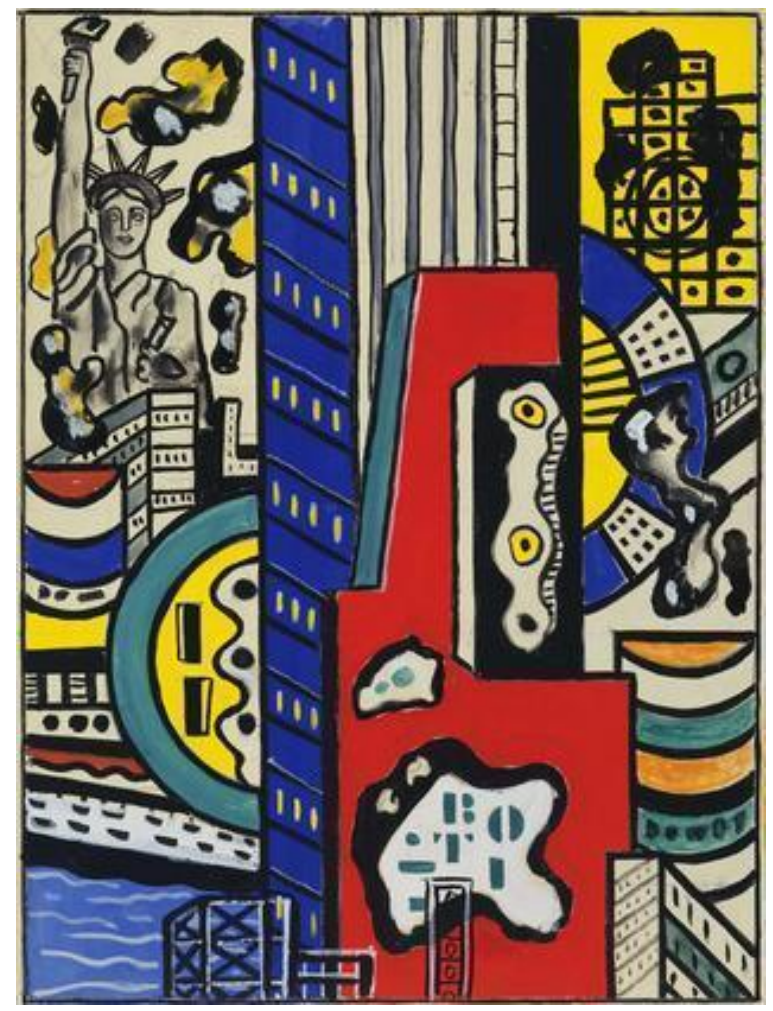

[Fig. 58] Fernand Léger. Study for cinematic mural, study III [Estudo para mural cinemático, estudo III] (1938-1939), guache e lápis sobre madeira, 50,7 X 37,8 cm. Coleção do MoMA. 
Além dos murais de âmbito particular, Harrison tentaria, sem sucesso, obter um "mural cinemático" de Léger para o Radio City. Contudo, a obra nunca foi instalada no prédio por ter sido rejeitada pelo Comitê de Arte do Rockefeller Center, dirigido na época por John D. Rockefeller, Jr., de gosto notoriamente mais conservador que seu filho Nelson. Sete estudos para o mural cinemático foram preservados e fazem parte hoje da coleção do MoMA. Para esse projeto, Léger preparava um grande painel sobre o legado norte-americano. A Estátua da Liberdade aparece como figura preponderante e inconfundível da composição, assim como as sugestões aos imensos arranha-céus de Nova York, as chaminés das indústrias, os navios, os portos e as polias das máquinas.

Harrison obteria maior sucesso em duas outras comissões, garantindo a instalação de um mural de Léger para a parede exterior do Edifício Consolidated Edison, em uma construção temporária para a Feira Mundial de Nova York, em 1939. A obra foi demolida depois da conclusão da feira. Novamente em 1952, Léger recebeu a comissão para duas pinturas de mural para o hall da Assembleia Geral das Nações Unidas. Essa foi uma das maiores encomendas de arte pública de Léger nos Estados Unidos e Harrison foi um ator central para o artista obter o trabalho.

Léger se filiou ao Partido Comunista em 1945 e a dimensão pública de sua arte passou a ser uma preocupação na obra do pintor. Havia um contínuo interesse de sua parte em obter mais encomendas de arte pública, mas diferentes tentativas neste sentido foram frustradas. Em 1952, ano que trabalhava no projeto da ONU, Léger escreve um breve texto Da pintura mural para a revista parisiense Derrière le miroir, em que elogia o advento do muralismo e sua relação complementar à arquitetura moderna. Para Léger, o quadro de cavalete era uma criação individual que "perde seu valor público e se absorve num apartamento particular (...) Mas há um acontecimento que assume uma importância cada vez maior -- a demanda da pintura mural" (LÉGER, 1989, p. 120). ${ }^{145}$ A respeito desse suporte, ele escreveu:

$\mathrm{O}$ quadro de cavalete consagrou a ruptura com o povo. Antes de todos esses quadros do Renascimento havia, apesar de tudo, grandes

145 Da Pintura Mural, 1952, In, LÉGER, Fernand. Funções da Pintura. São Paulo: Nobel, 1989, p. 120. 
pinturas murais, que o povo podia ver. A partir de então, só os ricos tiveram quadros, que encerraram cada vez mais em suas coleções privadas ou nos museus. Ora, como vocês sabem, os museus são lugares que fecham às seis horas, exatamente no momento em que os operários saem de suas fábricas (LÉGER, 1989, p. 177). ${ }^{146}$

Apesar de sua crítica, a arte de Léger seria mais associada a composições de cavalete e poucas foram as oportunidades nos Estados Unidos para a pintura mural. Os murais nas residências de Harrison e Rockefeller foram os dois únicos realizados por ele no âmbito privado no país (LANCHNER, 1998, p. 49). No ano seguinte à conclusão da pintura no seu apartamento, Nelson seria eleito diretor do MoMA e, em uma entrevista de rádio, ele definiria seu gosto por arte moderna remetendo a temas próximos da arte desenvolvida por Léger:

Interesso-me em arte que se relaciona com a vida de nossos dias, que expressa o espírito de nosso tempo -- arte que não é fechada e isolada, arte que inclui a casa e o carro motorizado (...) O verdadeiro prazer na arte é mais do que um respeito vago e obrigatório às tradições do passado. Em casa, quando colocamos um quadro na parede, não estou muito interessado por seu valor histórico. Estou mais interessado pelo prazer que ele me dá -- a contribuição que faz para um cômodo e para a casa. (LÉGER, 1969, p. 11) 147

Diferentemente de Matisse, que optou por realizar o mural de Nelson na França e enviálo por navio para ser instalado posteriormente no apartamento, Léger pode ter trabalhado no mural in loco, o que proporcionou uma relação mais pessoal entre colecionador e artista. ${ }^{148}$ Ao

146 A arte e o povo, 1945. In LÉGER, Fernand. Funções da Pintura. São Paulo: Nobel, 1989, p. 177

147 “I'm interested in art that relates to life in our own day that expresses the spirit of our time -- art that isn't cloistered and set apart, art that includes the house and the motor car... The true enjoyment of art is more than a vague and dutiful respect paid to traditions of the past. At home, when we put a painting on the wall, I'm not so much interested in its historical value. I'm more interested in the pleasure it gives -- the contribution it makes to a room and to the house..." Entrevista de rádio transcrita no catálogo da exposição Twentieth-Century art from the Nelson Aldrich Rockefeller collection. Greenwich: New York Graphic Society, 1969. p. 11, tradução nossa.

148 Relato de Simon Willmonth apud LANCHNER, 1998, p.49. 
longo de sua vida, Nelson adquiriu obras de milhares de artistas, mas a arte moderna teria um espaço especial na sua vida. A pintura cubista seria um dos eixos centrais de sua coleção ${ }^{149}$ e, neste sentido, nota-se um interesse particular pelo trabalho de Léger. Os meses que Léger passou em Nova York em 1938 são cruciais para entender a relação entre Nelson com o mestre francês. Não há indicativo de que Nelson tenha prestado muita atenção à arte de Léger antes deste período e foi apenas por intermédio de Harrison que passou a adquirir obras do pintor. Sobre o relacionamento estabelecido com Nelson e Harrison, Léger descreveu:

Em meus cinco meses em Nova York vim a apreciar dois norteamericanos, dois jovens homens... Nelson Rockefeller junior, o homem "responsável pelo Radio City", e seu arquiteto e amigo Wallace Harrison... Eu tive a oportunidade de vê-los se movimentando, atuando, trabalhando ao meu redor. Sua bondade, seu tato em meio a seus telefones tentaculares, que eles têm o sucesso de amenizar. De forma alguma eles são máquinas, ao contrário, são novos homens, limpos, claros, precisos, exatamente como "a atmosfera" que eles respiram (LÉGER apud LANCHNER, 1998, p. 50). ${ }^{150}$

Quando o MoMA organizou em 1969 uma exposição com destaques da coleção particular do então governador Nelson Rockefeller, duas obras de Léger fizeram parte do conjunto restrito de 100 peças selecionadas por Dorothy Miller a partir de um vasto repertório de 1,5 mil obras de arte. Uma das obras dessa exposição foi o retrato Women with a book [Mulher com livro] (1923), que costumava ficar pendurado ao lado do mural no apartamento em Manhattan. A outra pintura escolhida pela curadoria foi Armistice [Armistício] (1918), uma composição abstrata do período inicial da carreira. A exposição Twentieth-Century art from the

149 Ver introdução de William Lieberman para o catálogo da exposição Twentieth-Century art from the Nelson Aldrich Rockefeller Collection. Greenwich: New York Graphic Society, 1969.

150 "In my five months in New York, I came to appreciate two Americans, two young men... Nelson Rockefeller junior, the man 'responsible for Radio-City', and his architect and friend Wallace Harrison ... I was able to see them moving, acting, working around me. Their kindness, their tact in the middle of their tentacular telephones that they succeed in subduing. Just the right amount of time that they know how to give to worthwhile issues -- not more not less. In no way are they machines, on the contrary, new men, clean, clear, precise, exact like 'the atmosphere' they breathe". LANCHNER, 1998, p. 50, tradução nossa. 
Nelson Aldrich Rockefeller collection [Arte do século 21 na coleção Nelson Rockefeller] do MoMA procurava servir como síntese do perfil do colecionismo de Nelson e é interessante notar que os únicos artistas presentes nesta exposição e na doação de Rockefeller ao Brasil são Léger, Calder e Chagall, sendo que Léger é o único representado com duas obras na doação brasileira.

As composições de Léger doadas aos antigos MAM-RJ e MAM-SP são as únicas obras que pertenceram originalmente à coleção pessoal de Nelson. ${ }^{151}$ Todas as demais foram adquiridas em galerias nova-iorquinas com o propósito específico de serem enviadas aos museus brasileiros. As duas obras de Léger doadas ao Brasil foram realizadas no mesmo ano do mural no apartamento de Rockefeller e dos estudos para o mural cinemático para o Radio City. Há semelhanças entre Composition [Composição] (1938), obra do MAC USP, e o mural do apartamento de Nelson, sugerindo que talvez o primeiro fizesse parte de uma série de estudos preparatórios menores para o trabalho de parede. Nas duas obras, Léger se distancia de seu cubismo mais característico, associado à máquina, à indústria, às linhas de força da arquitetura moderna ou à forma humana.

Composition [Composição] é notável, pois investiga uma solução abstrata a partir de formar orgânicas e fluidas. Neste guache, Léger realiza arranjos de cores primárias, com um uso intenso do amarelo, verde, preto, azul e vermelho. As formas sugerem um ambiente marinho, em um padrão de algas e organismos microscópicos que florescem e se sobrepõem, por vezes extrapolando os limites da tela. O fundo da composição é deixado à mostra e as figuras assumem uma dimensão plana, sem sugestão de tridimensionalidade.

Ao escrever sobre a obra de Léger, o historiador Giulio Carlos Argan a classificaria como decorativa, uma interpretação talvez simplificada ao se pensar em toda a envergadura inventiva de Léger, mas uma leitura que se aplica ao contexto específico das composições do conjunto Rockefeller:

O espaço a que quer dar vida com figurações é o espaço mural da arquitetura racional; mesmo nos quadros de cavalete, o fundo é como uma parede dotada de espacialidade própria, à qual vêm se integrar

151 "Your two Légers, I think, were done here in 1938". Carta de Alfred Barr para Nelson Rockefeller, 13 Nov. 1946. Coleção NAR. Grupo: Museus. Série: II 4 L. Caixa: 148. Folder 1964, tradução nossa. 
formas plástico-volumétricas. O quadro adquire, pois, uma espessura e uma profundidade ou terceira dimensão, mas uma consistência plástica que é própria da superfície. No entanto, ainda que integrada, a decoração se mantém como decoração, conservando, dessa maneira, um fundo ideológico como representação de um mundo ideal (ARGAN, 1992, p. 458).

Para Argan, Léger era um "artesão apaixonado pelas máquinas", que tentava monumentalizar a modernidade, criando um mito de adoração da tecnologia. "A devoção quer suas imagens próprias; e são as rodas, os tubos, as engrenagens da máquina, regularmente comparadas, em igualdade de estilização decorativa, com formas naturais (folhas, flores, nuvens)" (ARGAN, 1992, p. 458).

Em certa medida, Argan dialoga com a intepretação do crítico brasileiro Mário Pedrosa. No texto A máquina, Calder, Léger e outros; o crítico compara a obra do escultor Alexander Calder com a de Léger. Ambos são, para Pedrosa, "da mesma família espiritual", mas desenvolveram leituras diferentes da abstração. Pedrosa diz que, diferentemente de Calder, Léger estava "tão dominado pela máquina que não consegue esquecê-la" e se tornou um "escravo da mecânica".

Para ele a máquina é bela mas estranha e inumana. Ao distribuir volumes, massas ou mesmo peças que, reunidas, recomporiam a unidade total da máquina, Léger o faz para expô-los, simultaneamente, num só plano. Traça-os sobre a tela ou papel com um fetichismo que lembra o do homem pré-histórico, ao gravar na pedra ou na parede das cavernas seus impulsos e obsessões transformados em signos exorcizantes da natureza impenetrável (PEDROSA, 2000, p. 85).

Interessante notar que Pedrosa escreveu esse texto para a publicação Política e Letras em 1948. Antes, portanto, da exposição inaugural do MAM-SP, Do Figurativismo ao Abstracionismo, que incluiria justamente o móbile de Calder doado por Rockefeller na mesma sala de Composition [Composição] (1938) de Léger, estabelecendo novo diálogo entre os dois 
artistas, assim como antecipara Pedrosa em sua crítica. Essa obra é especialmente importante por ter sido inserida na exposição inaugural do antigo MAM-SP e é hoje peça fundamental do núcleo histórico do MAC USP, tendo feito parte de 29 exposições do museu, entre 1966 e 2013. ${ }^{152}$ Outras quatro obras de Léger também constam na mostra organizada por Degand: Peinture murale [Pintura mural], Perfil e vaso (1930), Composição sobre fundo amarelo (1932) e Composição com aloés (1935).

Há registros de que Degand planejava montar em 1949 uma mostra restrospectiva de Léger no Brasil, e que tinha inclusive trocado inúmeras correspondências com o artista para organizar sua primeira visita ao país, mas desentendimentos com Ciccillo Matarazzo e seu eventual desligamento do museu resultariam no cancelamento do projeto (BARROS, 2009, p. 47).

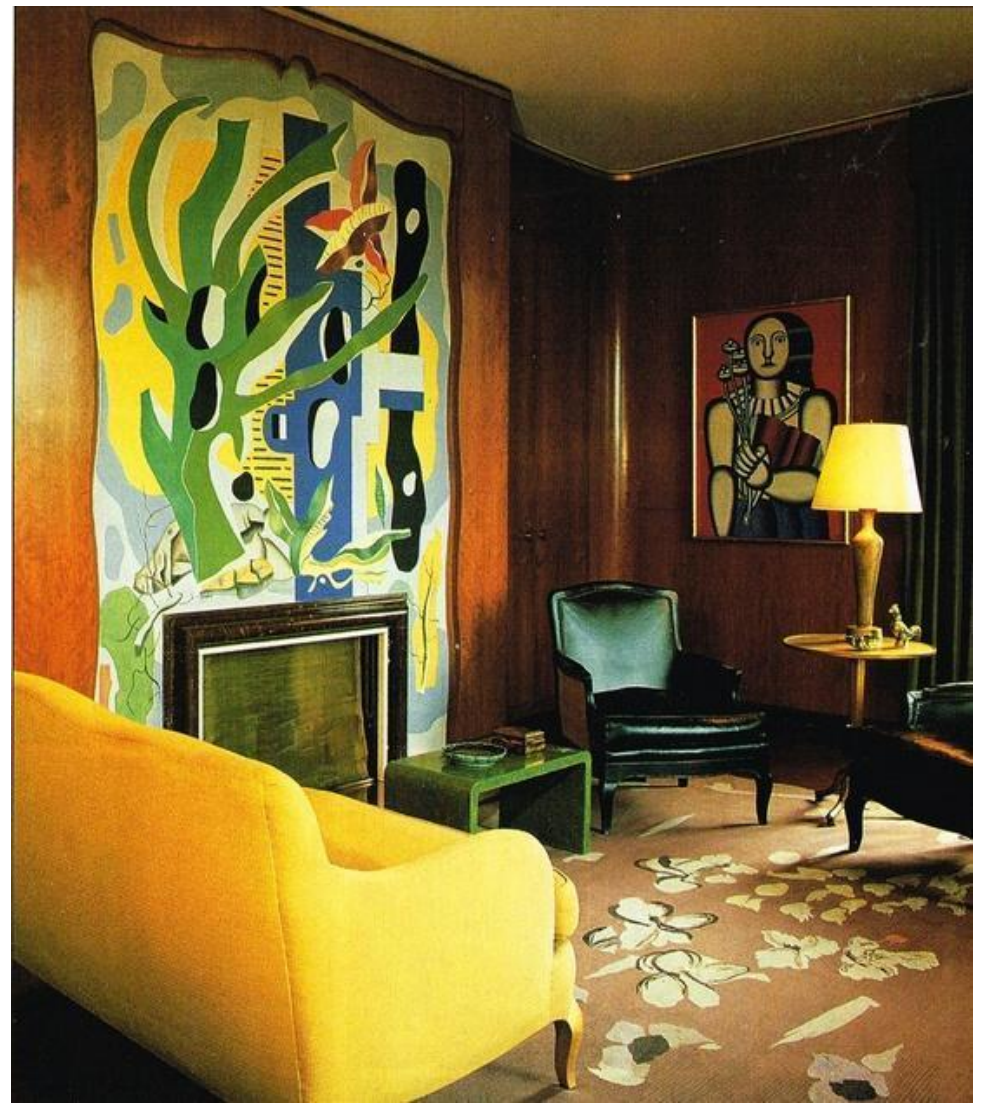

[Fig. 59] Fotografia do apartamento de Nelson Rockefeller com visão do mural de Léger realizado em 1938 e com o retrato de Women with a Book (1923).

152 Relatório do setor de catalogação e documentação do MAC USP, 2014. A exposição mais recente a incluir Composition (1938) foi O Artista como Autor, O Artista como Editor, de 2014, com curadoria de Tadeu Chiarelli. 


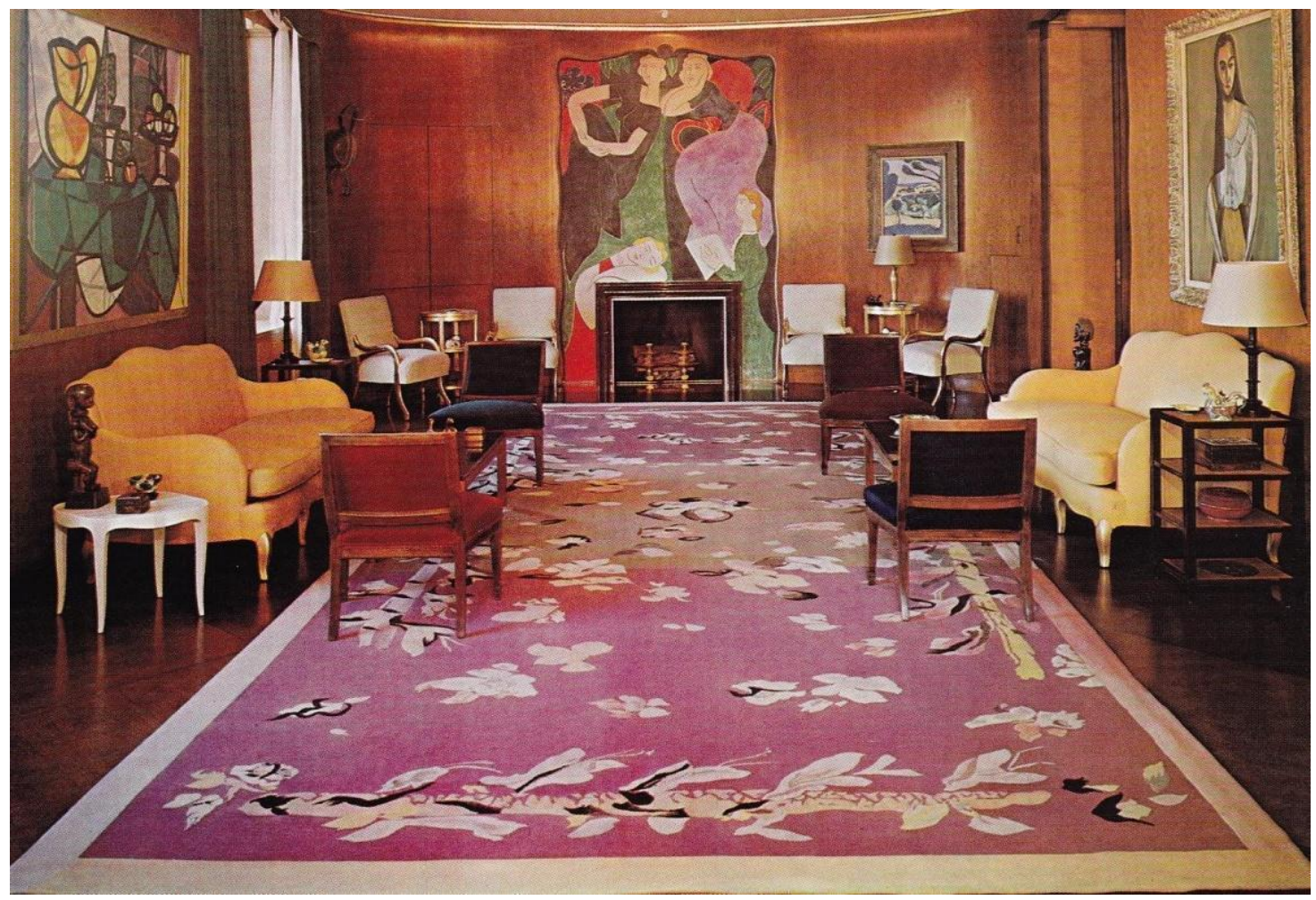

[Fig. 60] Vista oposta do apartamento de Nelson com mural pintado por Henri Matisse.

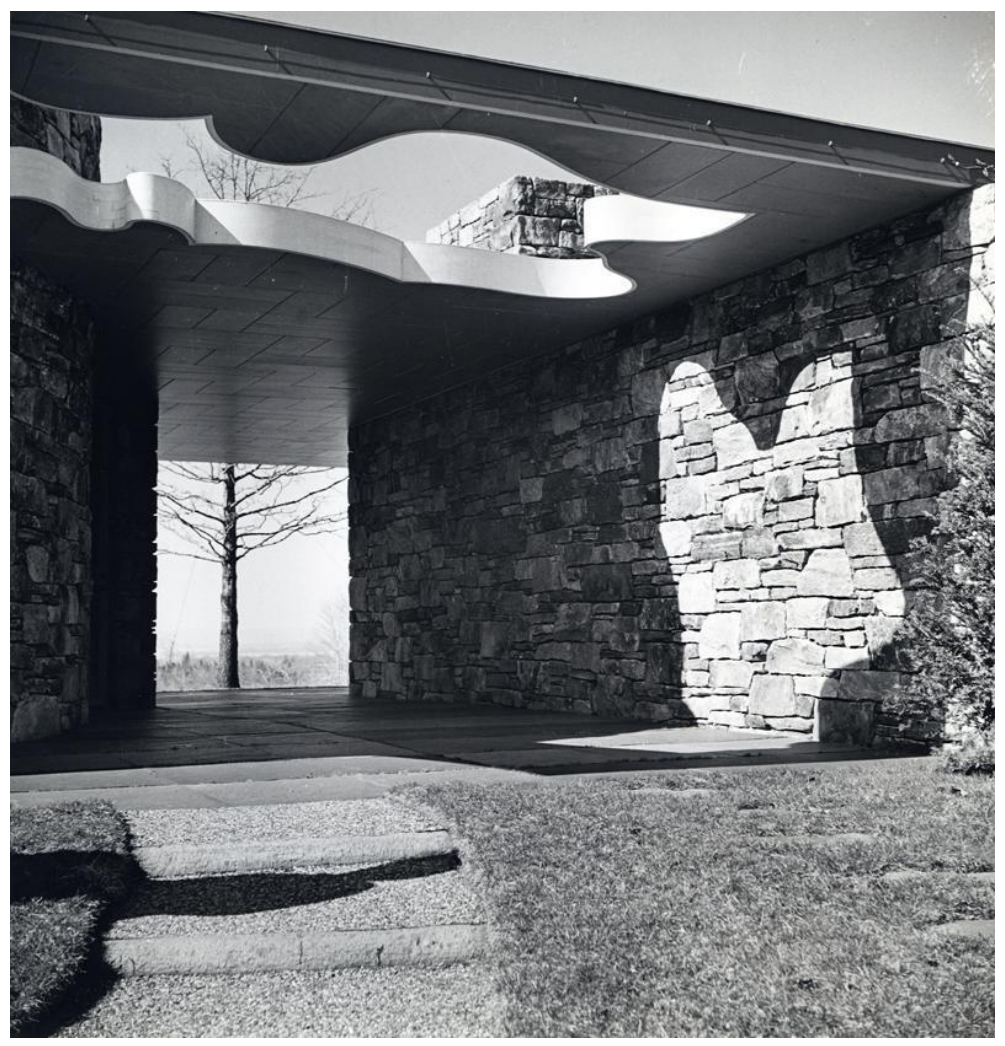

[Fig. 61] Casa de campo de Nelson Rockefeller projetada por Wally Harrison em Pocantico Hills. Léger desenhou o solário que marca a entrada da residência. 


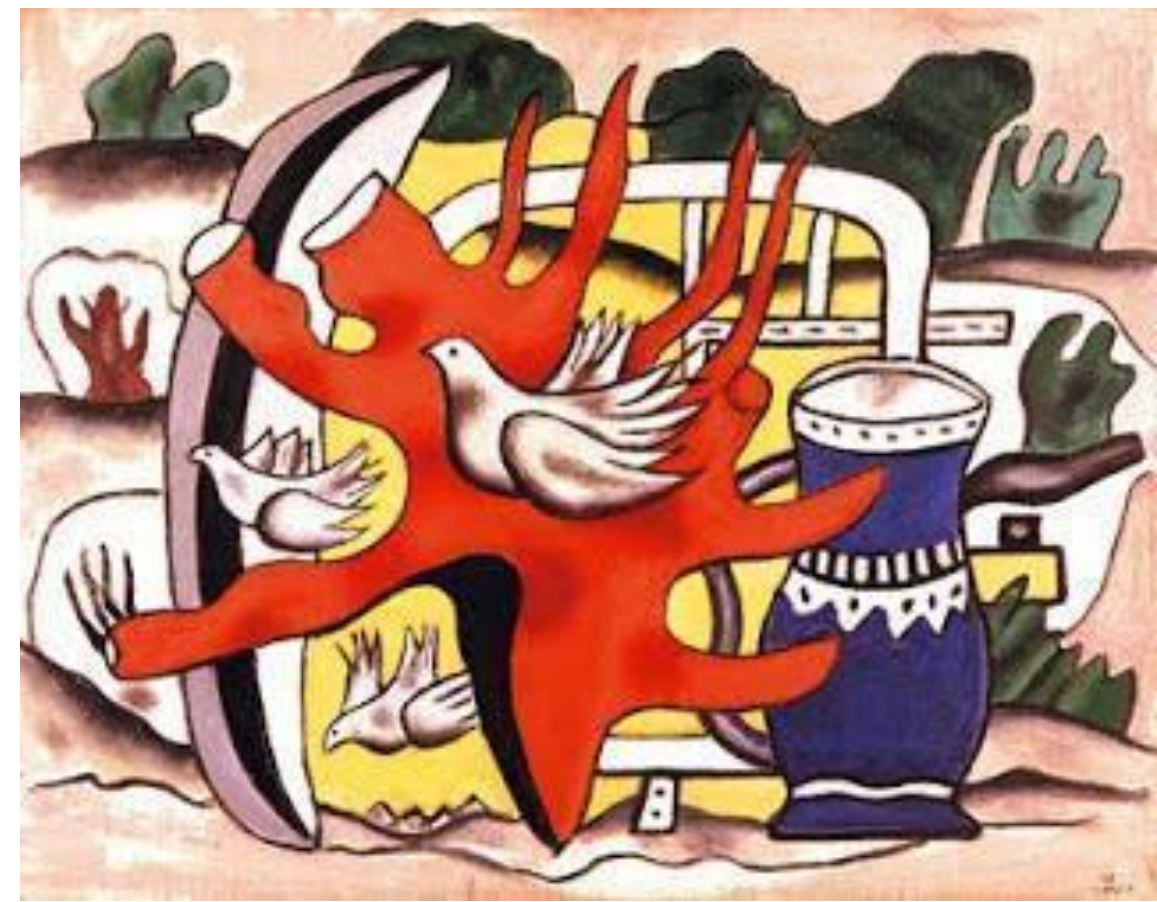

[Fig. 62] Fernand Léger. O Vaso Azul (1948), óleo sobre tela; 73,3 x 92,4 cm. Coleção MAC USP.

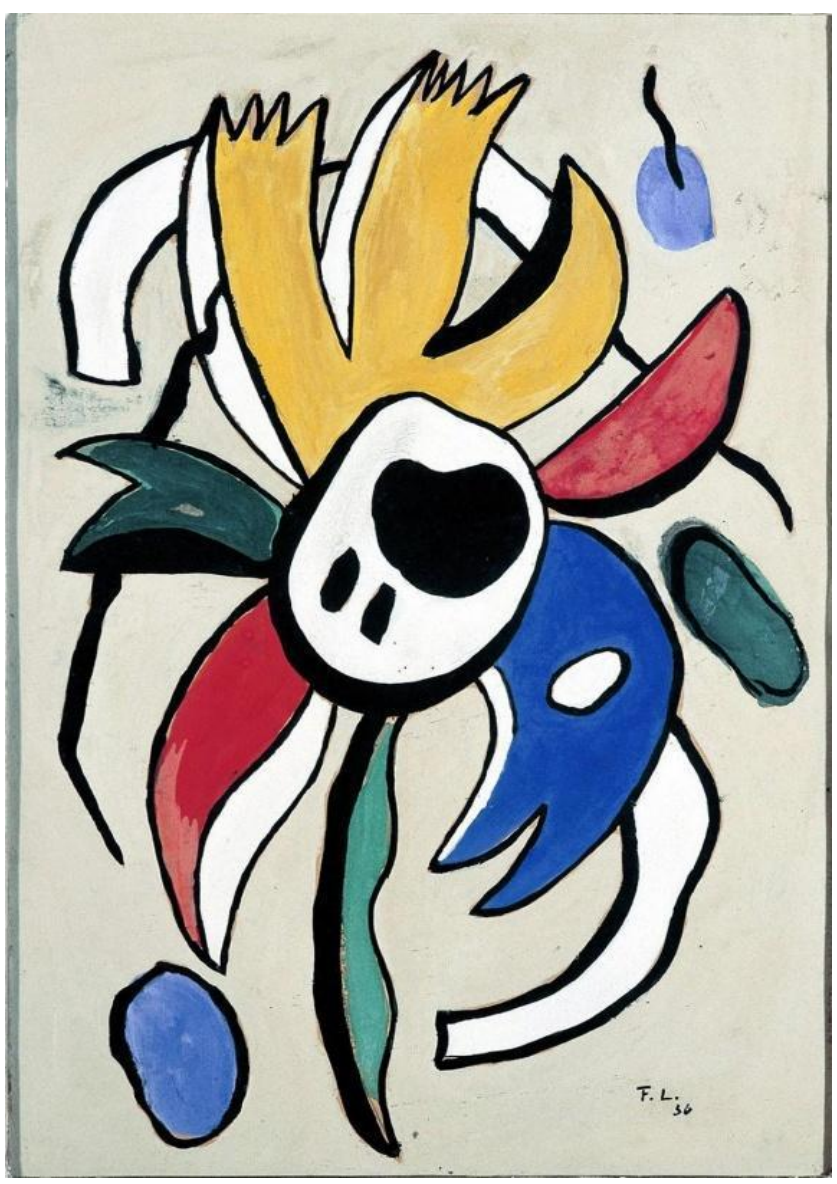

[Fig. 63] Fernand Léger. Composition [Composição] (1936), guache sobre papel, 49 X 33,3 cm. Coleção MAC USP. 
A segunda Composition doada por Rockefeller não fez parte da mostra, possivelmente porque já havia sido doada ao MAM-RJ, em janeiro de 1949, e não estava à disposição de Degand na montagem da exposição, que seria realizada em março daquele mesmo ano. A obra enviada ao Rio consta no catálogo do MAM-RJ de 1966, fez parte da primeira exposição do museu carioca e foi, provavelmente, destruída no incêncio de 1978.

As obras de Léger doadas por Rockefeller estiveram presentes na inauguração dos dois museus de arte moderna do Brasil, contribuindo para o debate artístico nacional. Contudo, a influência de Léger no Brasil é muito anterior às doações Rockefeller e à exposição Do Figurativismo ao Abstracionismo. A sua estatura precisa ser entendida de maneira mais ampla.

Fernand Léger era um dos artistas modernos mais conhecidos no Brasil entre os nomes inseridos nas doações Rockefeller. Inúmeros críticos e artistas brasileiros haviam tido contado com sua obra. Ele foi um interlocutor do modernismo nacional e sua obra foi adquirida por grandes colecionadores, além de ter sido exposta nos principais museus e eventos de arte no país. Ainda que nunca tenha viajado ao Brasil, os laços que Léger estabeleceu com Tarsila do Amaral, Oswald de Andrade, Maria Martins, Lygia Clark e os colecionadores Olívia Guedes Penteado e Francisco Assis Chateubriand são registros da magnitude de seu impacto no panorama artístico brasileiro.

A primeira vez que teve uma obra apresentada ao Brasil foi em 1924, por causa de uma exposição e conferência de Blaise Cendars, no Conservatório Dramático Municipal de São Paulo. Nesta ocasião, Tarsila do Amaral, Paulo Prado e Olívia Guedes Penteado cederam três obras de Léger para serem debatidas por Cendars (BARROS, 2009, p. 44). Tarsila do Amaral conheceu Léger por intermédio de Blaise Cendrars e foi sua aluna em 1923, durante a temporada em que se estabeleceu com Oswald de Andrade em Paris. Segundo Regina Teixeira de Barros, " todos os brasileiros que tiveram contato com Léger, Tarsila do Amaral é quem mais se contagiou por suas idéias estéticas" (BARROS, 2009). Nos anos 1940, Lygia Clark também visitaria o artista em seu ateliê. "Talvez o legado mais importante deixado pelo mestre francês para ambas tenha sido a liberdade para criar, a capacidade inventiva, que em Lygia despontou nos trabalhos neoconcretos e em Tarsila atingiu a maturidade nas pinturas e desenhos antopofágicos", conclui Regina Barros, no catálogo da exposição comemorativa Fernand Léger: 
relações e amizades brasileiras, realizada na Pinacoteca de São Paulo, em ocasião do ano da França no Brasil, em 2009 (BARROS, 2009, p.50).

Léger teve contatos pontuais com outros membros da elite brasileira. No início da década de 1950, por exemplo, Chateubriand encomendou a construção de uma aldeia de artistas na Côte d'Azur com o objetivo de acolher estudantes brasileiros em intercâmbio na Europa. O projeto jamais realizado foi uma colaboração entre Léger e o arquiteto André Bruyère, em que o pintor idealizaria a composição cromática das paredes e pisos do edifício de de Chateubriand. Um álbum com desenhos para o projeto da vila de artistas na Riviera Francesa foi doado ao MAC USP, em 1983, pelo filho de Chateubriand (BARROS, 2009).

Entre as principais obras de Léger a entrarem em coleções brasileiras, pode-se citar $A$ compoteira de peras (1923), adquirida por Olivia Guedes Penteado na galeria L'Effort Moderne, de Léonce Rosenberg, doado ao MASP em 1947; Composition [Composição] (1921) da coleção de Mário de Andrade hoje parte do Instituto de Estudos Brasileiros; La tasse de thé (1921) e Charlot cubiste (1924) que eram da coleção privada de Tarsila do Amaral; além de quatro obras adquiridas por Paulo Prado nos anos 1920, La fabrique (1922), Peinture murale [Pintura mural] (1924), Composition (1928) e L'homme au chien (1921). Foi na I Bienal de São Paulo que Ciccillo Matarazzo adquiriu O vaso azul (1948), uma das cinco obras do artista na primeira mostra internacional de São Paulo, e que atualmente integra o acervo do MAC USP. O museu possui ainda uma Composition [Composição] (1936) doada por Raul Bopp. Léger teve grande presença nas três primeiras bienais de São Paulo, sendo um destaque constante do pavilhão francês nessas edições do evento.

Léger teve, portanto, um grande público de admiradores e colecionadores do Brasil e, ainda que não tenha visitado o país nenhuma vez, muito contribuiu com ideias e obras para o fomento da discussão em torno do modernismo nacional e suas ligações com a vanguarda cubista europeia. Os museus mais importantes do país possuem obras suas e artistas centrais do modernismo tiveram contato próximo e estiveram sensíveis às suas visões. As doações Rockefeller são, portanto, um capítulo pontual de uma história muito mais ampla sobre o impacto e repercussão do cubismo de Léger no cenário artístico brasileiro. 


\section{Bestiality marches on, George Grosz}

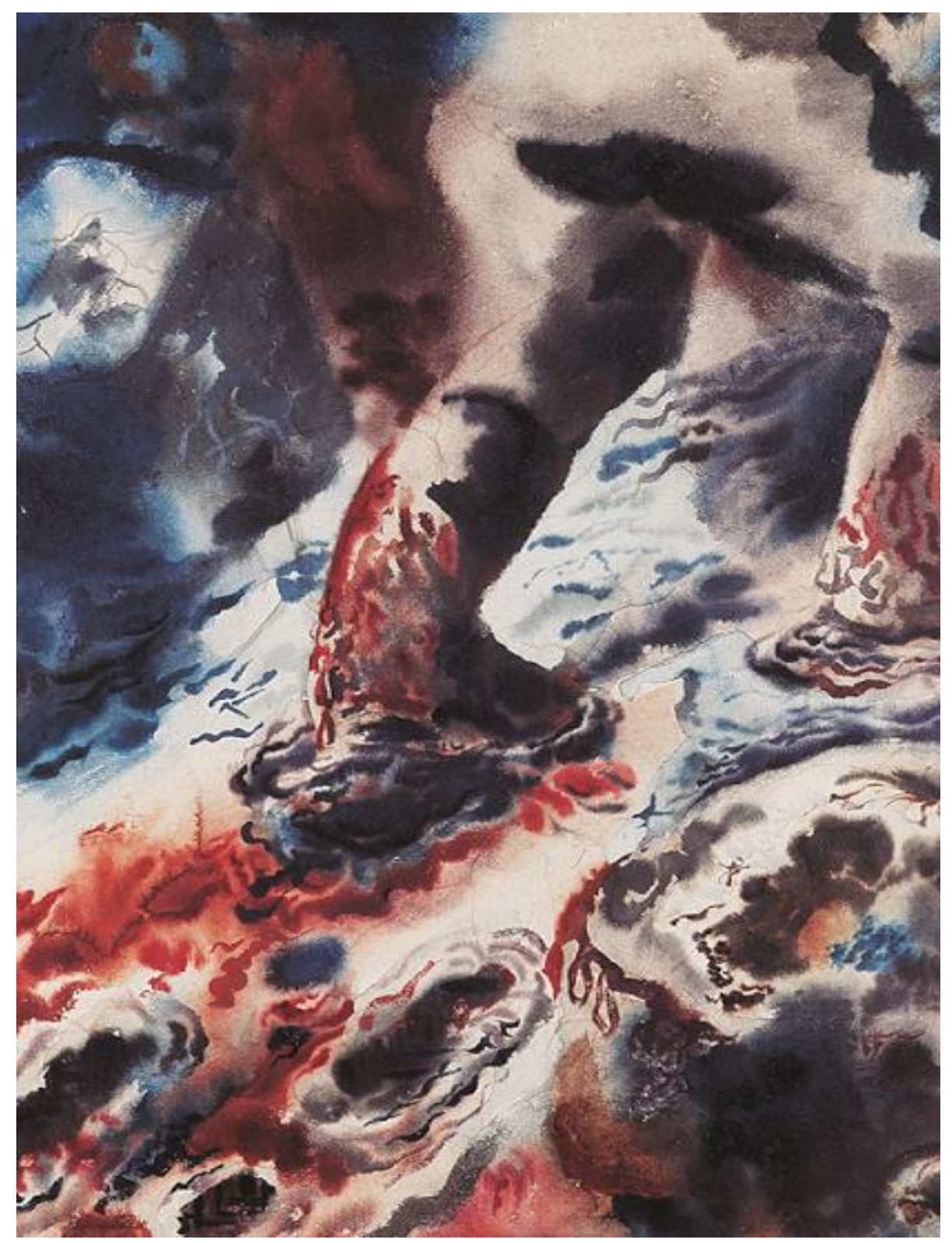

[Fig. 64] George Grosz. Bestiality marches on [Bestialidade avança] (1933), aquarela sobre papel, 66,5 X 48,3 cm.

Bestialidade avança é uma aquarela que faz parte da produção de George Grosz depois de ele se mudar aos Estados Unidos. Em junho de 1932, Grosz assumiu uma posição temporária de professor de desenho no Art Students League em Nova York. Ele se estabeleceu definitivamente com a família em 12 de janeiro 1933, quando a situação política em Berlim se provava impossível para um artista próximo à esquerda bolchevista e aos movimentos 
dadaístas. Grosz teve sua cidadania alemã revogada, seu apartamento em Berlim invadido pelos nazistas e suas contas bancárias saqueadas. Ele se tornaria um cidadão norte-americano, em 1938, e um artista de ascensão em Nova York. Grosz trabalhou 25 anos nos Estados Unidos e se destacou, principalmente, por seu trabalho gráfico. A adaptação ao novo ambiente não foi imediata. Vender obras não era sempre fácil e o salário na Art Students League não era suficiente para sustentar a família. Grosz passou a desenhar para revistas ilustradas como a Esquire e a Vanity Fair, tornando-se um ilustrador requisitado e conhecido por um público mais amplo. Grande parte do arcabouço crítico que se construiu em torno da obra de Grosz se concentra em desenhos e aquarelas expressionistas, cujo tema reflete sobre a condição do homem em uma sociedade disfuncional.

Grosz nasceu em 1893, em Berlim, e cresceu na cidade de Stolp, na região da Pomerânia. Ele foi um dos artistas centrais do movimento da Nova Objetividade alemã, surgido nos anos 1920, com o propósito de se contrapor aos temas abstratos, líricos e sentimentais do Expressionismo, e retormar um engajamento mais direto e pragmático com a vida urbana, política e espiritual da sociedade alemã. Este pensamento norteou a arte desenvolvida durante a República de Weimar (1919-1933), influenciando, além de Grosz, outros artistas como Max Beckmann e Otto Dix.

Grosz teve três desenhos incluídos na exposição Entartete Kunst [Arte degenerada] de 1937. Ele representava para os organizadores da mostra o declínio cultural da Alemanha. Seus desenhos ácidos retratavam o homem alemão sob uma ótica nada lisonjeira e expunham o ridículo da alta sociedade burguesa, seus momentos de devassidão, alcoolismo e crueldade, assim como toda sorte de fauna humana encontrada no submundo de Berlim nos anos difíceis após a derrota na Primeira Guerra Mundial. “A capital da nova República alemã parecia uma chaleira com água fervendo. Ninguém via a pessoa que tomava conta da chaleira, apenas que a água fervia de um jeito engraçado e que o calor aumentava cada vez mais (...) Cantos de ódio eram entoados pela cidade inteira", escreveu Grosz em sua autobiografia (GROSZ, 2001, p. 173). 
Em 1923, Grosz publicou um portfolio intitulado Ecce Homo, com cem litografias, em que retratava a vida decrépita da classe média de Berlim. A publicação do portfolio é lembrada como um dos primeiros grandes momentos da carreira do artista, quando Grosz, aos 30 anos, se posiciona diante do mundo decadente e surge como uma voz clara de oposição ao establishment alemão. Ecce Homo é uma série de gravuras de cenas de bar, casas noturnas e vistas urbanas. Prostitutas de meia idade e homens inchados são personagens recorrentes na obra, e crime e violência espreitam por entre as janelas da Berlim imaginadas por George Grosz. Com essa obra, o artista retratava o espírito da época da Alemanha como um momento de embriaguez coletiva e profunda depressão.

Sobre esse período, ele escreve:

Os estrangeiros que nos visitavam deixavam-se enganar por tanta felicidade, pela aparentemente despreocupada, engraçada e agitada vida superficial das casas noturnas e pela pretensa liberdade e pela arte de floração. Tudo isso era apenas uma espuma colorida e mais nada. Debaixo dessa animada superfície que parecia um esfuziante pântano, fervilhavam o ódio ao irmão, a desunião e a preparação das partes para o confronto definitivo (GROSZ, 2001, p. 174).

Grosz foi processado pelo governo por "ofender o senso de modéstia e moralidade" do povo. Ele "repudiou a noção de que o artista deveria conformar-se aos limites morais de sua sociedade (...) Ao retratar a natureza degradada da sociedade contemporânea em trabalhos que rompiam com as convenções pictóricas normais, ele poderia chocar sua audiência para reconhecer a necessidade de mudança" (FLAVELL, 1988, p.49). ${ }^{153}$ Vinte e quatro pranchas das litografias de Ecce Homo foram confiscadas, um grande número de desenhos destruídos e uma multa estabelecida na ordem de 6 mil marcos. Cópias de Ecce Homo foram destruídas na campanha de queima de livros promovidas por associações de estudantes em Berlim em 1933.

\footnotetext{
153 "He repudiated the notion that the artist must abide by the moral bounds of his society; he could wotk in the name of a higher morality. By depicting the degraded nature of contemporary society in works that broke with normal pictorial conventions, he could shock his audience into recognizing the need to change things". FLAVELL, 1988, p. 49, tradução nossa.
} 


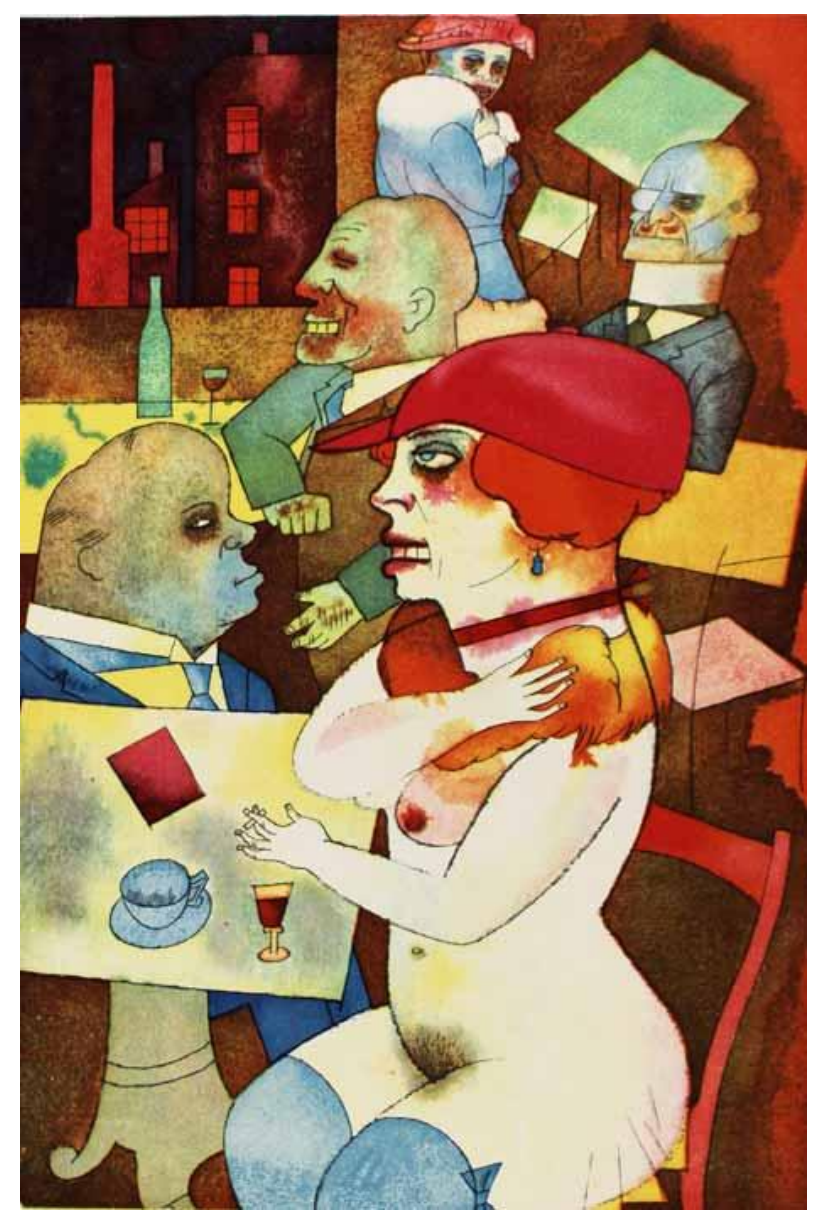

[Fig. 65] George Grosz. Schönheit, dich will ich preisen (1923) aquarela III de Ecce Homo.

Por causa de projetos ousados como Ecce Homo, realizados em um ambiente político difícil, a produção de Grosz na Alemanha antes da migração aos Estados Unidos é mais valorizada pela crítica de arte e considerada mais significativa de seu caráter combativo e pioneiro. Grosz foi renegado por amigos e críticos ao ter se voltado a temas menos políticos nos Estados Unidos, enquanto do outro lado do mundo se desenrolava um dos piores conflitos mundiais.

No início dos anos 1930, ele produziu um volume grande de pinturas de nus, retratos dos filhos e da esposa Eva, naturezas-mortas e vistas das dunas e praias de Cape Cod, cidade onde havia montado um estúdio. Em parte, essa crítica se deve a um olhar reducionista sobre arte de Grosz e também a um desconhecimento a respeito de toda uma produção realizada durante seu exílio que continuava a refletir sobre os absurdos do regime ditatorial alemão, na qual se pode incluir a aquarela do MAC USP, Bestiality marches on [Bestialidade avança]. 
Em trabalhos recentes, historiadores da arte têm buscado reanalisar a produção norteamericana de Grosz com novos olhos e reverter a interpretação de que o tempo nos Estados Unidos foram anos perdidos. (JUDIN, 2009, p.7). Segundo o historiador Ralph Jentsch, que administra o espólio de Grosz, ele tinha o desejeo de ser reconhecido como um artista norteamericano, mas "para fazer isso, ele teve que queimar algumas pontes com o passado" ${ }^{154}$.

Esse rompimento - que em situações extremas o levou a desacreditar e negar sua obra berlinense - muitas vezes resultaram em problemas e mal-entendidos quando se trata de avaliar o seu período norte-americano (...) Do outro lado do Atlântico, onde o mérito do artista era apenas medido pelos seus trabalhos famosos de Berlim, a falta de conhecimento sobre sua obra norte-americana deu peso aos rumores de que Grosz estava meramente pintando paisagens e nus nos Estados Unidos, que ele havia se tornado um bêbado, que seu trabalho tinha perdido o tempero dos seus primeiros anos, e que ele - o antigo revolucionário e combatente - tinha se tornado completamente apolítico (JENTSCH, 2009, p.23) $)^{155}$

Para a historiadora M. Kay Flavell, as obras de Grosz entre 1933 e 1936 podem se dividir em uma produção "norte-americana" e "alemã". Ainda que tente valorizar o período de Grosz nos Estados Unidos, Flavell define a obra norte-americana como menos complexa e subversiva, em contraposição às obras inspiradas por uma referência europeia.

Seus trabalhos americanos focam na observação cuidadosa e realista da superfície da vida em seu entorno: faces, vestimentas, cenas urbanas e rurais. Sua obra alemã, por contraste, tenta penetrar sob a superfície, empregando

\footnotetext{
154 "In order to do this, he had to burn some bridges with the past". JENTSCH, 2009, p.23, tradução nossa.

155 "This brake -- which in extreme situations even led him to disparage and disavow his Berlin oeuvre -- often resulted in trouble and misunderstanding when it came to evaluating his American period (...) On the other side of the Atlantic, where the artist's merit was usually only measured against the famous works of his Berlin period, a lack of knowledge about the American oeuvre gave weight to the rumors that Grosz was merely painting landscapes and nudes in the United States, that he turned to drink, that this work had simply lost the bite of his earlier years, and that he -- the former revolutionary and combatant -- had become completely apolitical". JENTSCH, 2009, p. 23, tradução nossa.
} 
múltiplos planos e integrando realismo e caricatura a fim de fazer a imagem carregar uma mensagem profética e moral (FLAVELL, 1988, p. 90). ${ }^{156}$

Bestiality marches on [Bestialidade avança] é uma obra singular, pois ainda que realizada nos Estados Unidos, remete aos temas europeus e retrata a preocupação de Grosz com a guerra que se instaurava do outro lado do oceano. Assim como outros artistas da vanguarda, Grosz teve uma relação íntima com a guerra. Ele havia ingressado no exército alemão em 1914 para lutar na Primeira Guerra Mundial e foi dispensado em 1916 por causa de uma internação médica. A experiência foi transformadora. Ele carregaria a memória do campo de batalha em grande parte de sua produção. "As cenas que presenciei me encheram de horror e desprezo pelo ser humano (...) Eu poderia escrever páginas e mais páginas sobre esse amplo tema, mas meus quadros expressam com precisão o que eu teria a dizer" (GROSZ, 2001, p.122).

Realizada em 1933, ano em que o partido nazista vence as eleições federais da Alemanha, Bestiality marches on [Bestialidade avança] faz parte de um vasto repertório de obras produzidas nos primeiros anos do exílio norte-americano em que o artista retrata cenas de conflito, como The burning world [O mundo em chamas] (1934) e Punishment [Punição] (1934). Sobre seu estilo, Grosz escreveu: “Na hora de pintar, principalmente aquarelas, sempre fica um pouco borrado. A cor ultrapassa os limites" (GROSZ, 2001, p. 288). Nessas obras, o uso da aquarela reforça os contornos indefinidos, as manchas de tinta viram manchas de sangue, destroços de explosões e fumaça. Ainda que o ápice da violência da Segunda Guerra Mundial estivesse mais de uma década à frente, Grosz já estava atento ao avanço de uma brutalidade avalassadora sobre a Europa e, de certa maneira, Bestiality marches on [Bestialidade avança] e outras obras deste período antecipam o conflito que viria a seguir.

Contudo, o que chama mais atenção na obra não é tanto o tema nem o estilo, mas o seu ponto de vista inusitado. O olhar do espectador está posicionado no chão, como a visão de um soldado na trincheira que vê seu compatriota, ou agressor, avançar em batalha. As botas do

156 "His American works focused on careful realistic observation of the surface of the life around him: faces, dress, urban and rural scenes. His German work, by contrast, tried to penetrate below the surface, employing multiple picture planes and integrating realism and caricature in order to make the picture carry a moral and prophetic message". FLAVELL, 1988, p. 90, tradução nossa. 
soldado estão sujas e ensanguentadas, sugerindo uma cena que se dá após um grande ato de violência. O ponto de vista é de alguém caído, submisso, desfalecendo, alguém de quem, talvez, a morte se aproxima.

Grosz retomou esse motivo em 1935, na obra After the questioning [Depois do interrogatório]. Essas duas aquarelas são similares no modo em que Grosz sujeita o ponto de vista do observador. Se em Bestiality marches on [Bestialidade avança] o espectador assume a posição de um combatente caído, em After the questioning [Depois do interrogatório] quem testemunha a cena é o prisioneiro político que acaba de ser torturado por um soldado -representado aqui também apenas por suas botas ensanguentadas. A bota do soldado assume para Grosz um caráter icônico. Nas duas aquarelas mencionadas, as botas são símbolo da força opressora de um regime que aplica violência e avança para a próxima vítima, uma crueldade sem rosto, sem identidade e, portanto, sem culpa individual. Se nas gravuras do portfolio Ecce Homo, Grosz se esforçou para retratar centenas de caras desfiguradas e ridículas de uma sociedade alemã decadente e cheia de ódios engarrafados, nessas duas obras posteriores a maldade não tem fisionomia, ela está institucionalizada e vai sempre em frente, deixando para trás um rastro de sofrimento.

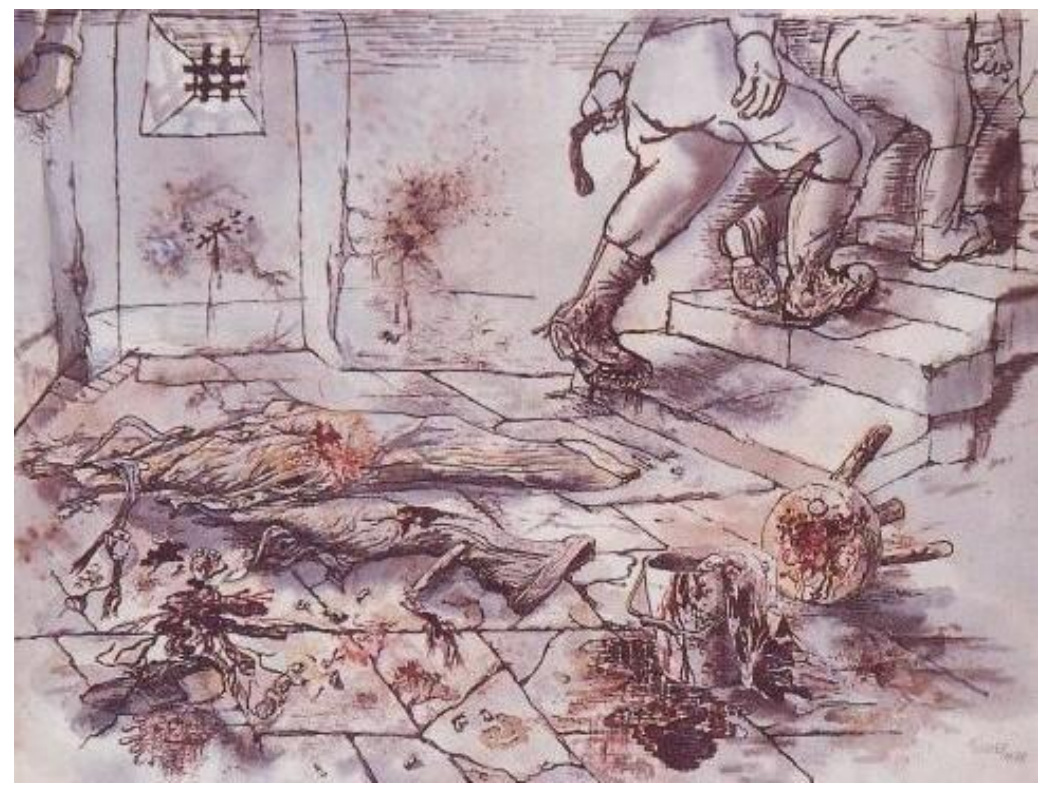

[Fig. 66] Grosz. After the questioning [Depois do interrogatório] (1935), aquarela sobre papel. 44.5 X 58,5 cm. 
After the questioning [Depois do interrogatório] (1935) faz parte de um conjunto de cenas de tortura que compõe seu terceiro portfolio, Interregnum, publicado nos Estados Unidos em 1936, com 64 desenhos de temas antifascistas. Grosz tinha esperança de que Interregnum fosse tão bem-sucedido quanto Ecce Homo havia sido treze anos antes na Alemanha. Contudo, das 280 cópias planejadas, apenas 40 foram publicadas. Uma maior repercussão de sua obra nos Estados Unidos viria através das encomendas de ilustrações para a revista Esquire.

Em círculos mais restritos, Grosz ganhou reconhecimento ao figurar em duas exposições do MoMA realizadas em 1936: Fantastic art, Dada and Surrealism [Arte fantástica, dadaísmo e surrealismo], com curadoria de Alfred Barr, e Modern painters and sculptors as illlustrators [Pintores e escultores modernos como ilustradores], de Monroe Wheeler. Apenas em 1937, sua situação financeira mudou de maneira significativa com a concessão da bolsa de apoio da Fundação Guggenheim aliada a um contrato com a Esquire, o que permitiu ao artista se dedicar inteiramente à sua produção, sem depender de dar aulas no Art Students League, atividade pela qual não tinha grande apreço. Neste ano, a notoriedade de Grosz cresceu também por ter sido um dos artistas incluídos na muito vista e comentada exposição de Entartete kunst [Arte degenerada] promovida por Hitler. Estima-se que, aproximadamente, 300 de suas obras foram destruídas pelo regime nazista durante a Segunda Guerra Mundial (JUDIN, 2009, p. 100).

Nos Estados Unidos, Grosz construiu uma nova vida e carreira, ainda que ele jamais tenha totalmente superado a perda de parte significativa de sua produção alemã. Desde sua chegada, ele foi contemplado em exposições individuais e coletivas, e nunca teve grande obstáculo em encontrar uma instituição com interesse de divulgar e comercializar suas obras, ainda que jamais tenha recuperado o mesmo prestígio que tinha na Alemanha pré-nazista.

Em 1941, a aproximação com o MoMA se intensificou e Grosz se tornou um dos primeiros artistas alemães a ter uma retrospectiva no museu. A mostra foi organizada por Lenore Browning, secretária do Departamento de Pinturas e Esculturas, e Elodie Courter, diretora do Departamento de Circulação de Exposições. No comunicado à imprensa escrito por Alfred Barr, Grosz é chamado de o "mais renomado caricaturista da Europa" que foi obrigado a 
deixar a Alemanha "porque os nazistas não puderam tolerar a força crescente de sua sátira" ${ }^{157}$. George Grosz foi o artista, entre os europeus exilados que fazem parte da doação Rockefeller, que mais vestiu a identidade norte-americana, tornando-se oficialmente um cidadão dos Estados Unidos.

Nas palavras do curador Alfred Barr: “Durante os anos recentes, Grosz ocupou seu espaço entre os mais brilhantes mestres norte-americanos de aquarela, e suas pinturas a óleo altamente originais chamam atenção nesta exposição" ${ }^{158}$. O comunicado vai um pouco longe ao declarar que "desde que chegou à América ele tem tentado esquecer a Alemanha"159. Quando Alfred Barr escreve para Rockefeller sobre as obras reunidas em 1946, ele já teria dificuldade em classificar Grosz como um artista europeu. "George Grosz, se você incluí-lo entre os norteamericanos, é o mais velho", escreveu o curador para Nelson. ${ }^{160}$ Porém, ainda que tivesse o interesse de ressaltar a preferência de Grosz pelo estilo de vida encontrado nos Estados Unidos, parte importante da arte desenvolvida por ele no exílio estava preocupada com a situação política da Europa. De toda forma, a mostra no MoMA foi importante para estreitar ainda mais os laços com a instituição, de maneira que é possível entender a presença de uma obra de Grosz na coleção que parte para o Brasil em 1946.

O ano de 1946 foi também um período de particular ascensão do artista, quando sua autobiografia Um pequeno sim e um grande não foi publicada pela Dial Press em Nova York. De 7 a 26 de outubro, a galeria Associated American Artists exibiu sua pintura a óleo $A$ piece of my world II (The last battalion) [Um pedaço do meu mundo II (o último batalhão)] (1938), uma das principais obras do período norte-americano, em uma exposição intitulada $A$ piece of my world

\footnotetext{
157 "Because the Nazis couls not endure the inscreasing force of his satire". Comunicado do MoMA à imprensa, 6 de outubro de 1941, tradução nossa. Disponível em: https://www.moma.org/momaorg/shared/pdfs/docs/press archives/740/releases/MOMA 19410077 1941-1006 411006-76.pdf?2010 Acessado em 21.06.2014.

158 "During recente years Grosz has taken his place among the most brilliant American másters of watercolor, and his highly original oils command attention in exhibitions throughout the country". Comunicado do MoMA à imprensa, 6 de outubro de 1941.

159 "Since coming to America he has tried to forget Germany". Comunicado do MoMA à imprensa, 6 de outubro de 1941, tradução nossa.

160 "George Grosz, if you include him among the Americans, is older". Carta para Nelson Rockefeller, 13 Nov. 1946. Coleção NAR. Grupo: Museus. Série: II 4L. Caixa: 148. Folder 1964, tradução nossa.
} 
in a world without peace [Um pedaço do meu mundo em um mundo sem paz]. A galeria promoveu ainda duas outras grandes exposições do artista em 1943 e 1945. A Associated American Artists era a galeria de Reeves Lewenthal e foi a intermediadora de Bestiality marches on [Bestialidade avança] para o MoMA no valor de US\$ 350, segundo consta em etiqueta colada no verso da obra encontrada nos arquivos do MAC USP ${ }^{161}$.

A Associated American Artists foi criada em 1934, com a missão de proporciar arte acessível para um público de classe média, se especializando, sobretudo, na venda por correio de gravuras de edições vendidas a poucos dólares. Contudo, vê-se também que a galeria operava de maneira mais tradicional, com exposições de pinturas, desenhos e aquarelas para um público mais circunscrito de clientes. Pouco se sabe sobre a relação de Grosz com Lewenthal ou a trajetória desta obra antes da doação Rockefeller. Contudo, uma relação entre a Associated American Artists e George Grosz tinha se iniciado em 1941, no mesmo ano em que o MoMA realiza a grande retrospectiva do artista. É interessante notar que todas as três obras de George Grosz presentes na I Bienal de São Paulo foram intermediadas pela Associated American Artists Galleries, estando inclusive a primeira edição da série A piece of my world I [Um pedaço do meu mundo] (1944), ao lado de The survivor [O sobrevivente] (1944) e The painter of the hole II [O pintor do buraco II] $(1948)^{162}$.

Bestiality marches on [Bestialidade avança] é a única obra de George Grosz no acervo do MAC USP. Desde sua doação em 1946, a obra participou de vinte exposições no Brasil, principalmente em mostras com destaques da coleção do museu e coletâneas sobre as vanguardas europeias. Contudo, só há registro de exposições que aconteceram a partir de 1982 e não se sabe quanto à circulação desta obra antes disso. Poucas são as mostras desta obra fora do MAC USP até os dias atuais. Em 2011, o Museu Lasar Segall exibiu a obra uma vez na mostra Verdade - Fraternidade - Arte, em uma reflexão sobre a arte da República de Weimar e, em particular ao grupo de artistas da Secessão de Dresden - Grupo 1919, do qual fazia parte Lasar Segall, Otto Dix, Peter August Böckstiegel, entre outros.

\footnotetext{
${ }^{161}$ A etiqueta pode ser encontrada na pasta dedicada à George Grosz no acervo do MAC USP.

${ }^{162}$ Catálogo da I Bienal de São Paulo, 1951. São Paulo: Fundação Bienal.
} 
Nesse período, Segall e Grosz estabeleceram uma amizade (BECCARI, 1984, p. 46). O relacionamento, pessoal, intelectual e artístico, entre Lasar Segall e George Grosz estava ligado ao contexto de Dresden após a Primeira Guerra Mundial e ao ambiente artístico da Nova Objetividade alemã. Ambos estavam submetidos ao mesmo ambiente político e tinham contato com os mesmos círculos de artistas e intelectuais.

Esse grupo, formado por antigos e atuais alunos da Academia de Dresden, não representava apenas um expressionismo tardio, mas uma forma muito original de expressionismo desenvolvido a partir das formas primordiais sob influência da Ponte, que se destacaram entre 1905 e 1910, e atingindo, nesses anos politicamente convulsionados, grande poder de denúncia das injustiças sociais. Desmascarando o mito do super-homem alemão, esses expressionistas mostravam um homem sempre débil, sofrido, e por esse motivo a arte expressionista não pôde ser tolerada pelo nacional socialismo que surgia pregando a força e a grandeza da raça alemã (BECCARI, 1984, p. 67-68).

Segall permanece na Alemanha de 1913 e 1923. Sobre o desenvolvimento de sua arte neste período, Vera D’Horta Beccari escreve:

No meio desse expressionismo jovem, panfletário, do Grupo 1919, a arte gráfica de Segall permaneceu sempre matizada liricamente (...) 0 temperamento de Segall ia encontrar mais afinidade com o movimento da Nova Objetividade, influenciado por um sentimento geral de resignação e de cinismo, de descrença que se seguia ao período de esperanças exuberantes de transformação. A Nova Objetividade propunha que se encarasse a realidade imediata, aceitando-a de modo objetivo, sem investi-la de um valor ideal. A guerra e a inflação que tomou conta da Alemanha mostraram aos expressionistas idealistas que suas esperanças eram bem magras, e que a desilusão conscientemente assumida pela nova tendência era, ao contrário, bastante realista e, portanto, sadia. Em 1920, a pintura e a arte gráfica 
de Segall já se modificavam, sob o impacto da nova tendência (BECCARI, 1984, p. 68-69).

É nesse período que Segall desenvolve quadros em que o aspecto social é predonderante, reflexo do ambiente ideológico ao que ele e Grosz estavam expostos. É nesta época também que Grosz preparava as gravuras e desenhos que comporiam Ecce Homo. Uma obra de Segall no acervo do Masp é particularmente interessante a título de comparação. No quadro Guerra (1942), Segall estava trabalhando no mesmo registro de Grosz, em Bestiality marches on [Bestialidade avança], e inclusive o mesmo elemento icônico da força repressora a bota do soldado - reaparece nas duas composições carregando uma mesma simbologia. 0 diálogo da obra de Segall é ainda mais evidente em comparação com pinturas como $A$ piece of my world II (The last battalion) [Um pedaço do meu mundo II (o último batalhão)] (1938) e The survivor [O sobrevivente] (1944). Ambos vão trabalhar com a guerra como objeto importante de sua pesquisa visual, além de compartilharem uma linguagem pictórica expressionista alemã.

Não é possível identificar trocas mais duradouras e profundas entre os dois, além do contexto da Nova Objetividade alemã dos anos 1920. Contudo, sabe-se que Lasar Segall e George Grosz enviaram correspondências pontuais em outra oportunidade, mesmo após a mudança de Grosz para os Estados Unidos. Quando Lasar Segall teve uma exposição em Nova York em 1948, ele a realiza justamente na galeria Associated American Art, com a qual Grosz ainda mantinha relação estreita. Nesta oportunidade, Grosz inclusive escreve para elogiar o trabalho de Segall exposto na AAA. ${ }^{163}$ Pontos de contato entre a fase inicial de Segall na Alemanha e o primeiro período artístico de Grosz antes de sua migração para os Estados Unidos ainda precisam ser melhor investigados.

163 Carta de George Grosz para Lasar Segall em 1948. Coleção Museu Lasar Segall, Num. tombo ALS 03828. Disponível: http://www.museus.gov.br/LasarSegall/Docs/als/c/1948/als03828c.pdf 


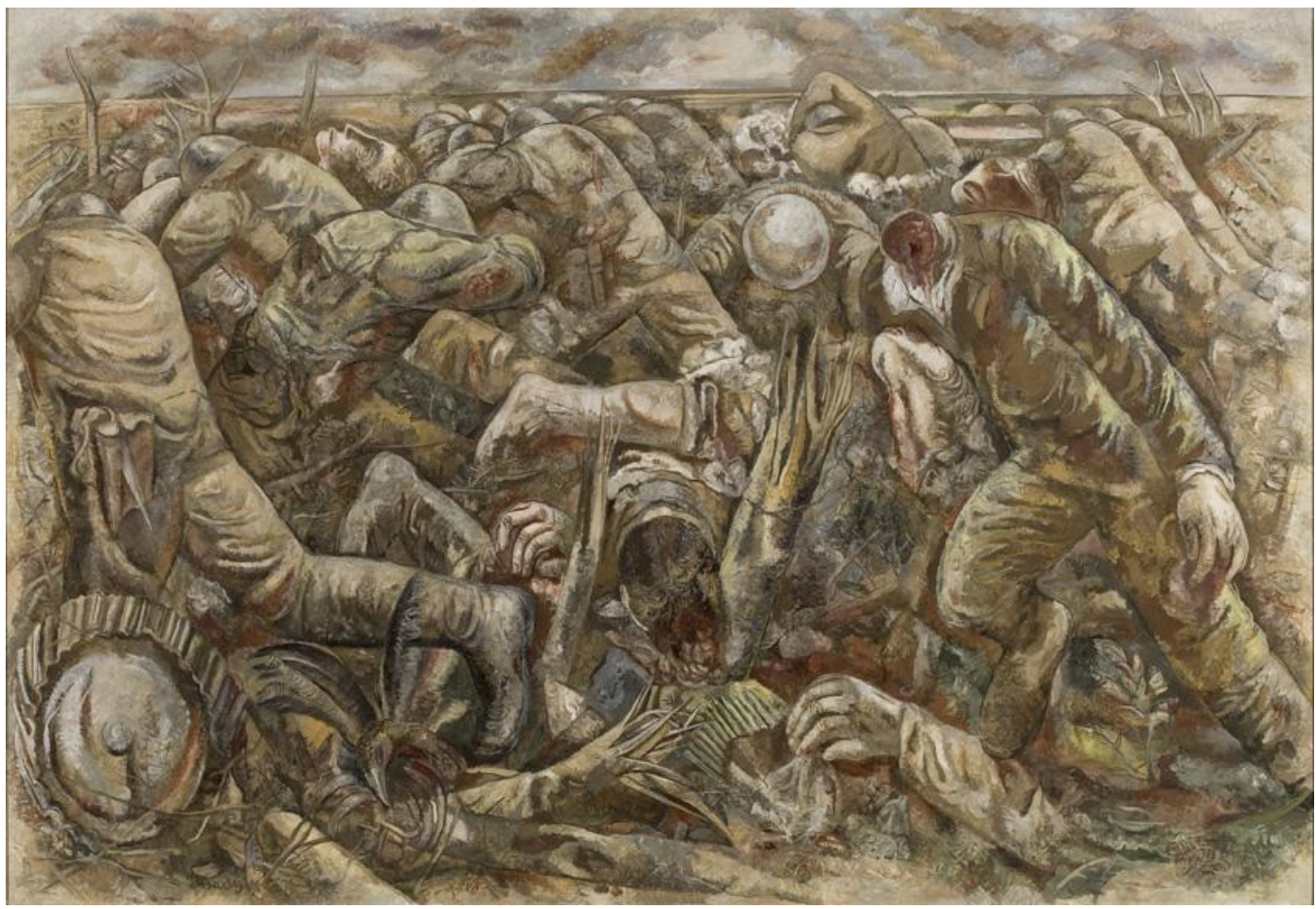

[Fig. 67] Lasar Segall. Guerra (1942), óleo sobre tela, 108 X 207 cm. Coleção do MASP.

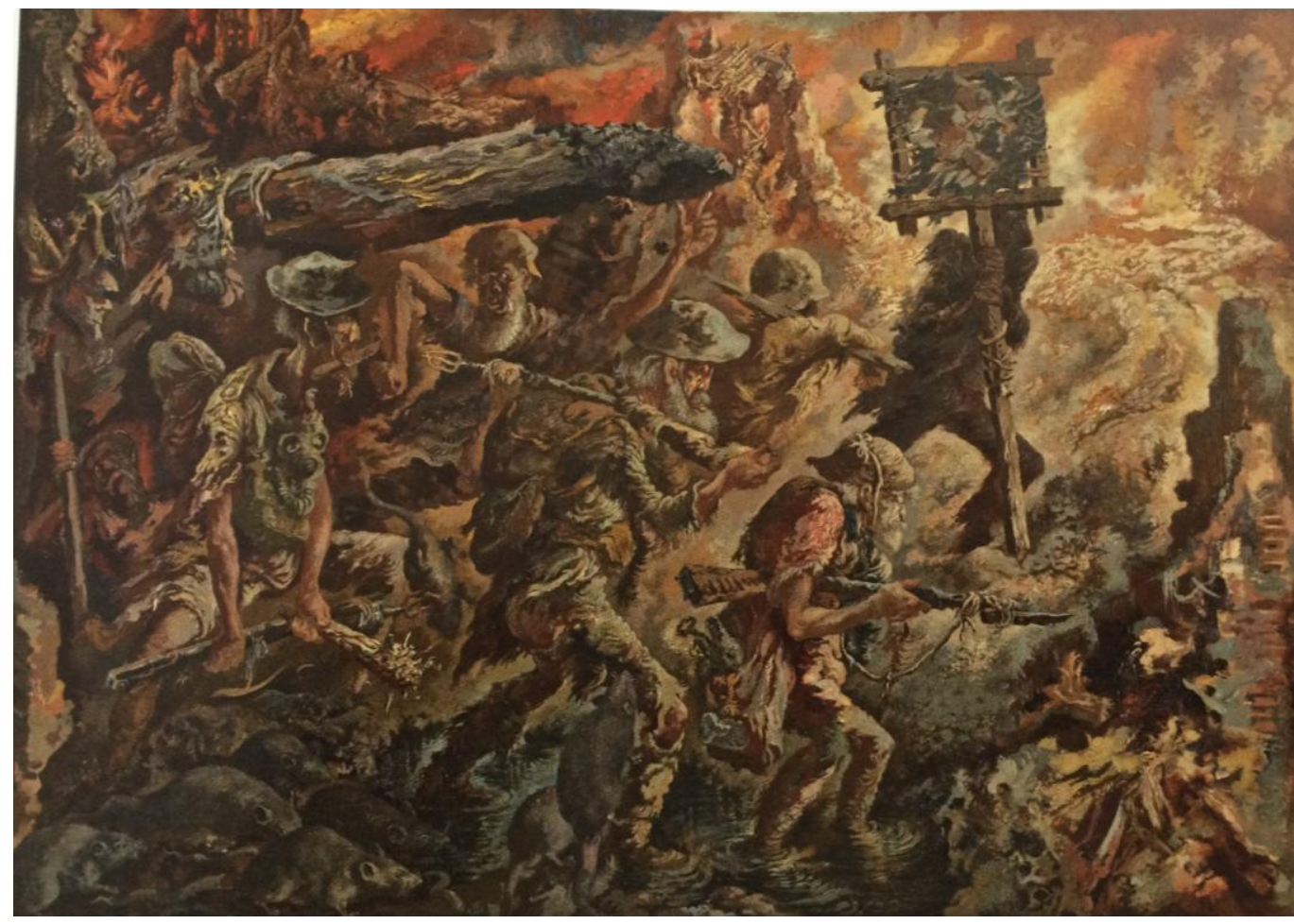

[Fig. 68] George Grosz. A piece of my world II (The last battalion) [Um pedaço do meu mundo II (o último batalhão)] (1938), óleo sobre tela, 100 X 140, $3 \mathrm{~cm}$. 
O conhecimento sobre a obra de Grosz chegaria ao Brasil, principalmente, por intermédio da comunidade de imigrantes alemãos. Na década de 1940, o exílio do escritor alemão Ulrich Becher no Brasil, entre os anos de 1941 e 1944, gerou uma maior discussão sobre a obra de Grosz no país. Becher foi seu aluno e grande admirador. Autor de Romanceiro Brasileiro, Becher é pouco conhecido pelos estudos literários germânicos e considerado um autor secundário. Contudo, seus escritos no jornal O Estado de S. Paulo sobre George Grosz são, possivelmente, os mais extensos realizados na imprensa nos anos que antecipam a doação Rockefeller. Por intermédio dos compatriotas germânicos, o diretor de teatro e jornalista Karl von Lustig-Prean e o antropólogo Herbert Baldus, Becher consegue publicar a tradução de uma série de quatro artigos sobre o Grosz que havia sido veiculada na revista antifascista em Buenos Aires chamada Das andere Deutschland [A outra Alemanha] (KESTLER, 2003, p. 78). Intitulada $O$ grande George Grosz e uma grande época, os textos foram veiculados de junho a agosto de 1944 e formam uma pequena biografia do pintor.

A partir de uma crônica pessoal, Becher descreve a relação estudante-professor que teve quando Grosz Ihe deu aulas de desenho, lembra episódios da tensão em Berlim no início dos anos 1930, o exílio para os Estados Unidos e as principais conquistas de sua carreira artística. Becher deixa transparecer certa decepção da obra mais recente do amigo, que segundo ele havia esquecido a Alemanha e abandonado alguns ideais políticos que o haviam diferenciado. Por meio dos textos de Becher, um público mais amplo no Brasil teve conhecimento de George Grosz em 1944.

A doação Nelson Rockefeller contribuiu para maior divulgação de seu nome na imprensa, assim como a inclusão de obras na I Bienal de São Paulo, mas poucas são as coleções públicas no Brasil que possuem obras de George Grosz. Casos pontuais incluem a Fundação José e Paulina Nemirovsky, que detém em seu acervo a obra Melancholy [Melancolia] (19201921), parte do portfolio Ecce homo, e o próprio acervo do MAC USP com Bestiality marches on [Bestialidade avança]. 


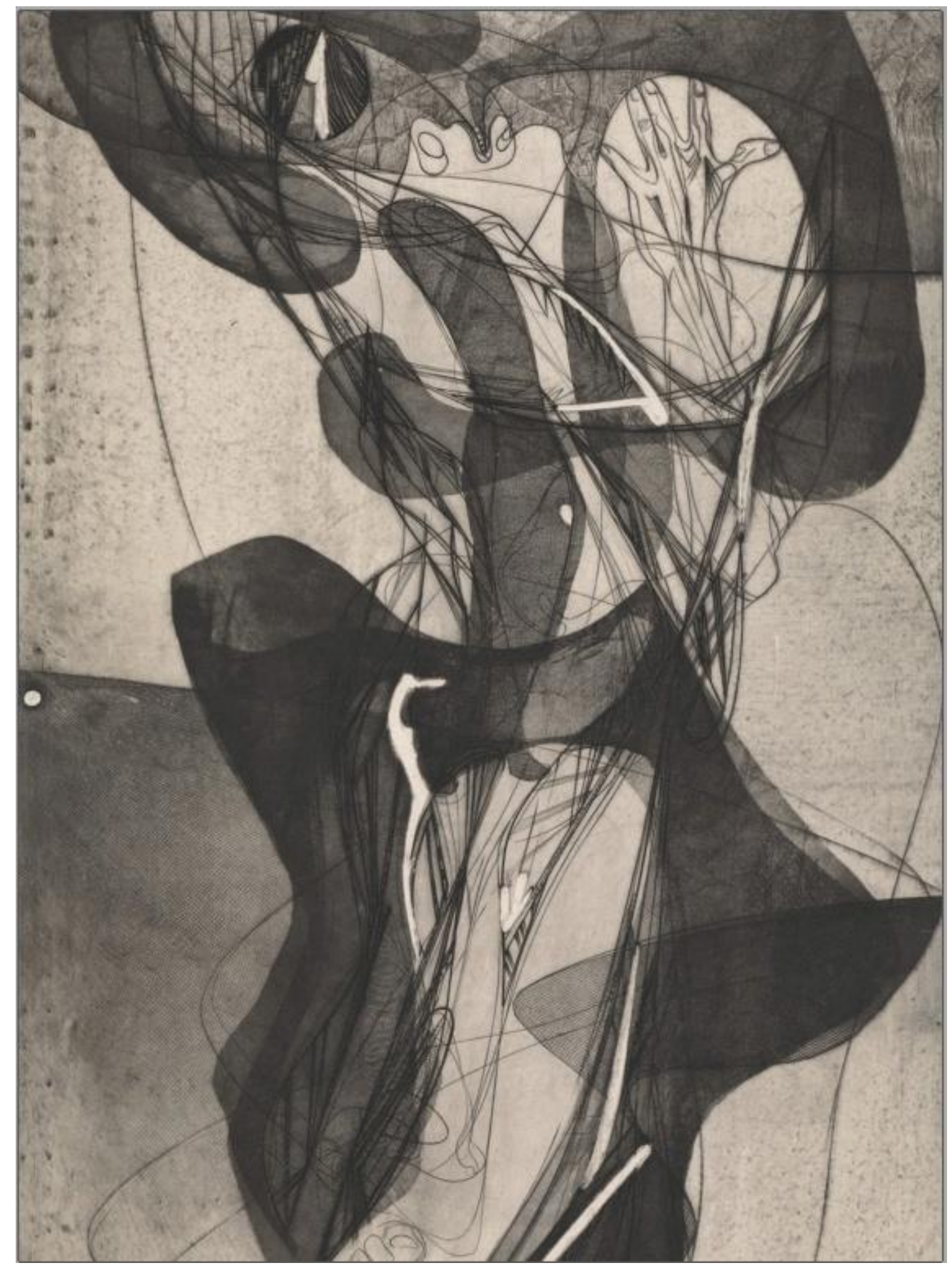




\section{Coleção de gravuras Nelson Rockefeller}

Poucos meses antes da I Bienal de São Paulo, o antigo MAM-SP inaugurou uma exposição chamada Gravadores norte-americanos, em 10 de abril de 1951. A coleção foi enviada por Nelson Rockefeller, por intermédio do MoMA, e reunia 27 obras produzidas com uma diversidade de técnicas, representando o que de mais avançado se fazia nos Estados Unidos em termos de arte gráfica naqueles anos. ${ }^{164}$ Destaque foi dado para o grupo de artistas próximos ao Atelier 17 de Stanley William Hayter, entre os quais Fred Becker, Gabor Peterdi, Seong Moy, Sue Fuller e Karl Schrag. As obras exibidas na sede do antigo MAM-SP foram transferidas ao MAC USP e fazem parte da segunda doação Rockefeller para a formação de acervos de arte moderna no Brasil. ${ }^{165}$

No catálogo da exposição, a curadoria descreve:

Ao nosso público, que começa a dar evidentes sinais de um interesse cada vez maior pela arte da gravura, os trabalhos expostos apresentarão muitas soluções originais e inovações técnicas, sem contarmos o fato de documentar a atividade que, num dos setores mais atraentes da arte, hoje se desenvolve nos

164 Ainda que a maioria das gravuras apresentadas na exposição Gravadores norte-americanos do MAM esteja hoje no acervo do MAC USP, duas obras não estão contabilizadas pelo museu e seu paradeiro é, até o momento, desconhecido. São elas: Worden Day (Runic traces, 1948) e Misch Kohn (Tiger, 1949).

165 A autoria da doação pode ser resgatada por um memorando que René d'Harnoncourt envia para Rockefeller em 16 de maio de 1951. "Caro Nelson/ Acabamos de receber essas fotos da exposição de artes gráficas dos EUA em São Paulo. Elas foram endereçadas a você no Museu e acredito que a mostra é realizada com a coleção que você deu para São Paulo" / "Dear Nelson / We just received these fotos of the exhibition of graphic arts from the USA in São Paulo. They were addressed to you at the Museum and I believe the show is made up of the collection you gave to São Paulo" A carta acompanhava uma série de fotos da exposição Gravadores Norte-Americanos e um catálogo da mostra. D’HARNONCOURT, [René]. (carta) 16 de maio de 1951, Nova York [para] ROCKEFELLER, [Nelson], Nova York. 1f, tradução nossa. Outro documento que confirma a doação como ato particular de Nelson Rockefeller (e não uma medida institucional do MoMA) é uma carta enviada por Dorothy Lytle, curadora do Departamento de Gravuras do MoMA, para Francis Jamieson, assistente de Rockefeller, oficializando a lista de gravuras "que o Sr. Nelson Rockefeller comprou por meio do Museu de Arte Moderna, Nova York, para apresentação aos museus no Brasil" / "that Mr. Nelson Rockefeller purchased through MoMA, New York, to be presented to the museums in Brazil". LYTLE, [Dorothy]. (carta) 29 de junho de 1950, Nova York [para] JAMIESON, [Francis], Nova York. 12f, tradução nossa. 
Estados Unidos. Para aqueles que, indo mais longe, desejam tornar-se gravadores, a exposição constituirá, por certo, proveitoso objeto de estudo. Mas, esses aspectos técnicos, por mais importantes que sejam, representam apenas os meios de realização postos a serviço de artistas desejosos, antes de mais nada, de transmitir sua visão estética de um novo mundo. ${ }^{166}$
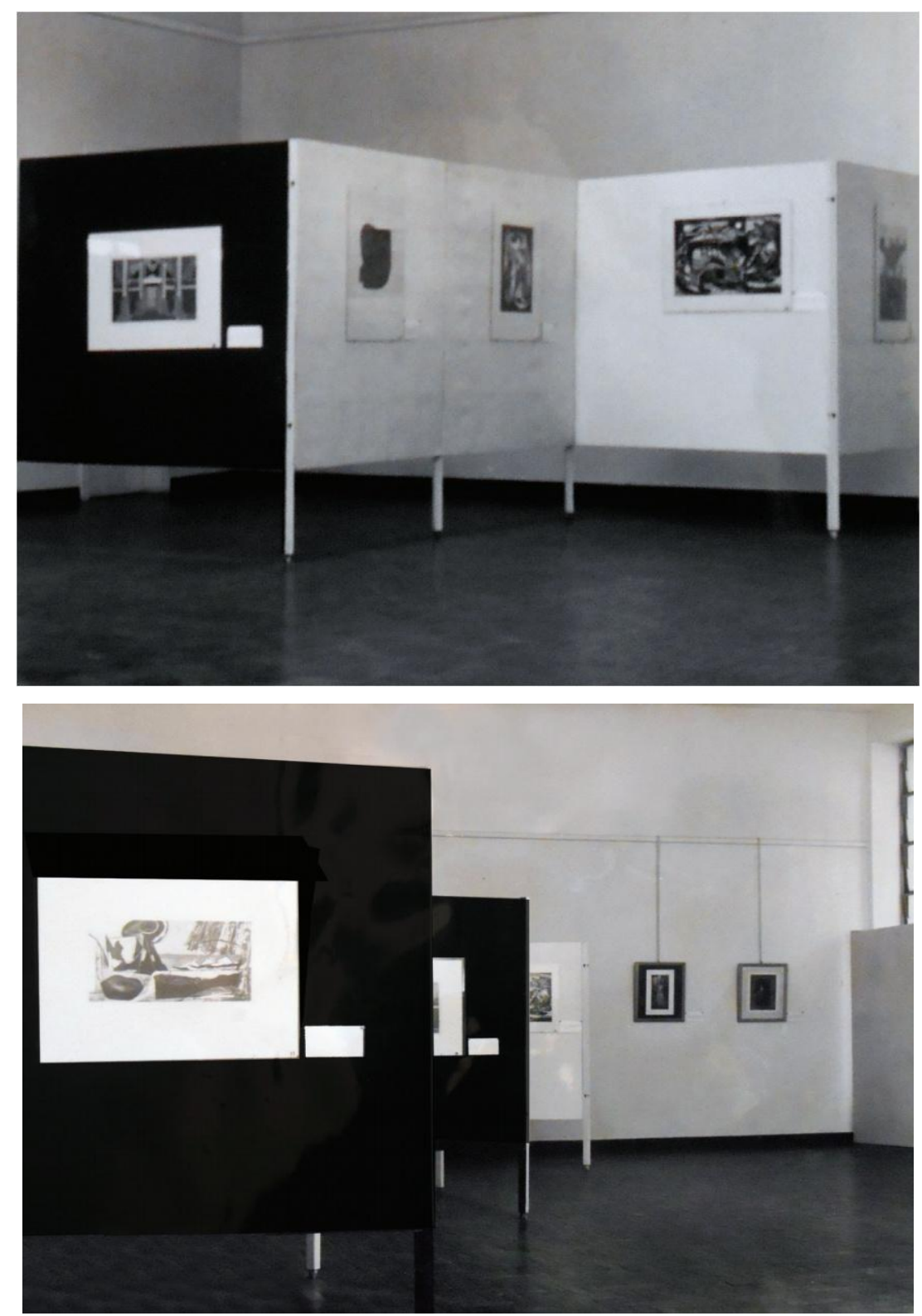

[Fig. 70 e 71] Imagens da exposição Gravadores Norte-Americanos, realizada na antiga sede do MAM-SP.

166 Catálogo da exposição Gravadores norte-americanos, Museu de Arte Moderna de São Paulo, 10 de abril a 06 de maio de 1951. 


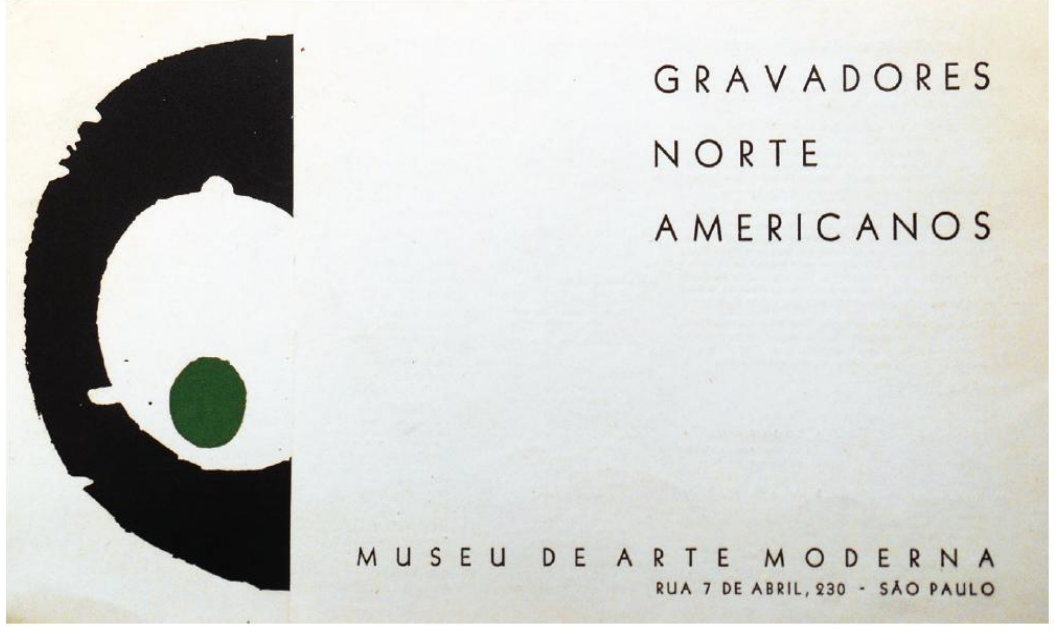

[Fig. 72] Catálogo da exposição Gravadores norte-americanos do MAM-SP, em 1951.

A gravura moderna norte-americana vivenciou um período de ascensão sem precedentes no mercado de arte na primeira metade do século XX. A valorização deste suporte passa pela popularização da prática da gravura nos Estados Unidos e o desenvolvimento de associações especializadas em várias regiões do país, entre as quais a tradicional Society of American Etchers, iniciada em 1913; a Painter-Gravers of America (1917), fundada por John Sloan, George Bellows e John Marin; a Provincetown Printers (1918), um dos primeiros grupos a encorajar o uso da cor na gravura até o desenvolvimento do Silk Screen Group (1940), com Edward Landon entre seus expoentes. Esses são apenas alguns exemplos de um universo muito maior de estúdios, entidades de premiação, revistas e clubes de colecionadores de gravuras que pipocaram nos Estados Unidos na virada do século. A transferência do Atelier 17 de Paris para Nova York em 1940 também foi um evento central para o desenvolvimento de novas fronteiras das artes gráficas. A presença cada vez maior de artistas da vanguarda europeia em Nova York foi um catalisador para a inovação.

Os artistas contemplados na exposição do antigo MAM-SP vieram deste ambiente em que a gravura, com a ajuda dos museus e grandes colecionadores, vinha ganhando maior status. Em 1947, o Brooklyn Museum passou a organizar exposições anuais de gravura, que foram cruciais para ampliar a visibilidade deste suporte. Várias das obras doadas ao antigo MAM-SP são, inclusive, prêmios de aquisição dessas mostras do Brooklyn Museum. O MoMA 
também tomou um passo importante neste sentido com a inauguração do Abby Rockefeller Print Room, em 1949, departamento que sistematizou o conhecimento e debate sobre as novas expressões da gravura moderna. Esses dois museus foram importantes atores na divulgação nacional e internacional dos artistas contemplados na coleção Rockefeller.

A doação Nelson Rockefeller oferece um panorama significativo do que se chamou de renascimento da gravura moderna nos Estados Unidos. Não há ênfase em um artista ou estilo e, sim, na amplitude de experimentações gráficas, passando pela litografia, a xilogravura, a serigrafia, água-tintas e monotipias. Assim como a primeira doação Rockefeller de 1946, reaparece a preocupação curatorial de enviar ao Brasil obras de artistas norte-americanos e europeus imigrados, cujo trabalho era prestigiado e chancelado pelas principais instituções de arte dos Estados Unidos, especialmente em Nova York. Muitas das gravuras que chegam ao antigo MAM-SP em 1950 tinham sido premiadas nas exposições do MoMA e do Brooklyn Museum. As mesmas gravuras hoje presentes do MAC USP fazem parte dos acervos permanentes do Metropolitan Museum of Art, MoMA, Art Institute of Chicago e de museus universitários importantes como o Fogg Art Museum de Harvard, e são continuamente retrabalhadas em exposições contemporâneas, assumindo novos contextos e leituras.

Do ponto de vista histórico, o conjunto de 27 gravuras da segunda doação é uma importante amostra da produção gráfica mais prestigiada do circuito de arte moderna do final dos anos 1940. O uso da gravura como um suporte preferido por iniciativas culturais de caráter oficial - devido ao seu baixo custo e facilidade de transporte - também ajuda a entender o contexto desta doação, que chega a São Paulo poucos meses antes da I Bienal. Se traçarmos linhas de contato entre os artistas, os grupos dos quais faziam parte, os estúdios onde trabalhavam, as galerias que comercializavam suas obras, os interesses políticos e econômicos dos colecionadores envolvidos, e os curadores que expunham seus trabalhos, veremos surgir um imbricado jogo de relações e um vigoroso sistema de arte que explica o florescimento de tantos expoentes da gravura moderna nos anos 1940. Um fragmento desta história faz parte do legado do acervo do MAC USP. 


\section{O departamento de gravuras do MoMA e o legado de Abby Rockefeller}

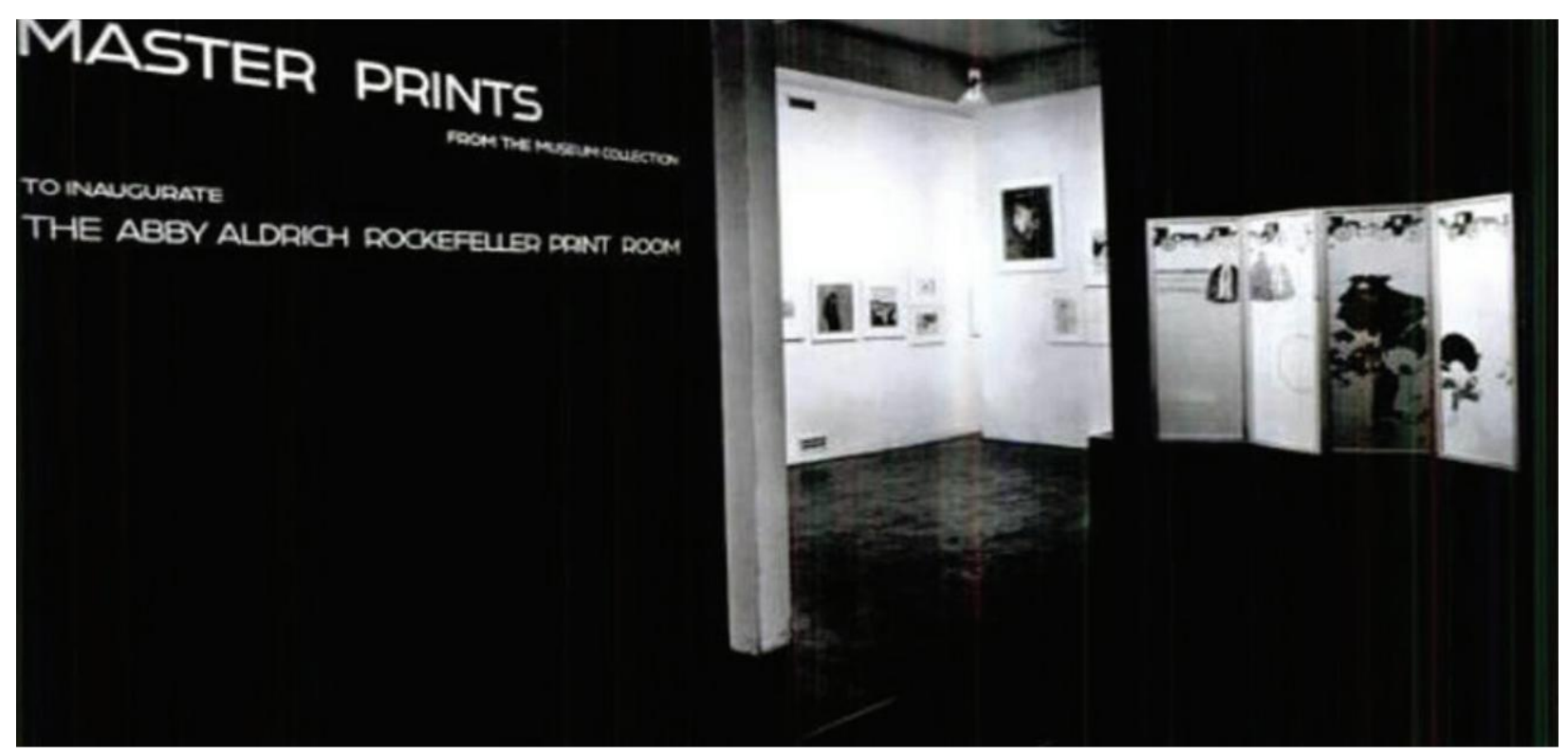

[Fig. 73] Exposição Master prints que marcou a inauguração do Abby Aldrich Rockefeller Print Room em 1949.

Abby Aldrich Rockefeller faleceu em abril de 1948. Vítima de um ataque cardíaco fulminante aos 73 anos, a socialite nova-iorquina não sobreviveu para testemunhar a inauguração da sala de gravuras do MoMA que levaria seu nome. Abby Rockefeller mantinha uma impressionante coleção de arte gráfica com obras de mestres europeus e norteamericanos, cuja aquisição começou no final da década de 1920, a partir do interesse despertado por colegas intelectuais do calibre de Paul Sachs, prestigiado curador do Fogg Art Museum de Harvard, e do artista Arthur Bowen Davies.

Em 1940, Abby doou ao MoMA 1.600 gravuras. Entre os destaques, estão litografias de Degas, Cézanne, Renoir, xilogravuras de Gauguin, trabalhos de Chagall, Braque, Matisse, Rouault, Nolde, Kandinsky, Moholy-Nagy, a única água-forte de Van Gogh, a maior coleção de gravuras do mundo de Paul Klee, com 60 obras; além de 200 composições de Picasso. Os esforços de catalogação, seleção e curadoria desse conjunto custou à equipe do museu o trabalho de quase uma década. Foi apenas um ano depois da morte de Abby Rockefeller, que o MoMA organizou a primeira grande exposição com 230 de suas melhores peças. Entre maio e 
julho de 1949, a mostra Master prints apresentou ao público um amplo panorama da gravura moderna dos últimos 65 anos. A exposição teve curadoria de William Lieberman, em colaboração com Alfred Barr.

A mostra procurou situar a coleção inédita de Abby Rockefeller em perspectiva histórica, oferecendo ao visitante uma visão didática a respeito das várias técnicas de produção de gravuras. Seguindo uma sequência linear, as salas iniciais de Master prints eram dedicadas a obras impressionistas, abrindo caminho para as vanguardas históricas europeias. As paredes finais continham exemplares da vigorosa produção norte-americana, que constituía metade de toda a coleção. ${ }^{167} \mathrm{Um}$ volume grande de obras de artistas contemporâneos, ligados em sua maioria ao Atelier 17 de Stanley William Hayter, foi acomodado na última galeria da exposição.

No dia 12 de maio de 1949, foi oficializado o lançamento do Abby Rockefeller Print Room. Um ano depois, Nelson Rockefeller faria a segunda doação ao antigo MAM-SP. A seleção das 27 gravuras enviadas ao Brasil precisa ser compreendida a partir do trabalho desempenhado por Lieberman à frente da seção de gravuras do MoMA e do colecionismo de Abby Rockefeller.

William Lieberman se tornaria um dos mais importantes e influentes especialistas em gravura dos Estados Unidos. À frente do departamento do MoMA para gravuras e desenhos, separado em duas áreas específicas somente nos anos 1970, ele seria responsável pela aquisição de obras importantes para o museu. Ao longo de uma carreira de três décadas no MoMA, onde começou como estagiário do setor de publicações, ele assumiu vários papéis na instituição. Associando-se inicialmente a Alfred Barr, de quem foi assistente pessoal de 1945 a 1949, Lieberman foi, aos poucos, adquirindo autonomia. Em 1967, foi apontado curador do Departamento de Pintura e Escultura e, de 1971 a 1979, diretor do Departamento de Desenhos. Teve também papel importante na concepção e montagem das exposições itinerantes do Departamento de Circulação de Exposições e do Conselho Internacional do MoMA.

Deborah Wye, curadora do Abby Rockefeller Print Room em 2004, descreveu a evolução do departamento sob a gestão Lieberman:

167 Press release: Master Prints, an exhibition of 230 American and European prints, to commemorate opening of Abby Aldrich Rockefeller Print Room at Museum, 06 de maio de 1949, Arquivo do MoMA. 
O curador William S. Lieberman merece o maior elogio e reconhecimento por seu papel seminal na formação (da coleção) mais proeminente do mundo. A representação esplêndida de gravuras de grandes mestres, Picasso e Matisse entre eles, se deve a sua aquisição astuta e aos vários presentes doados durante os seus anos de administração (WYE, 2004, p.8). ${ }^{168}$

Foi na gestão Lieberman que a coleção de Abby Rockefeller ganhou corpo e contexto. Ele lembra que o acervo de gravuras e desenhos não era uma das prioridades da direção artística durante as primeiras décadas do museu. Segundo Lieberman, foi apenas por causa da insistência de Abby que o Print Room se concretizou. "Tornou-se aparente, quase imediatamente após minha chegada (ao museu), que algo precisava ser feito com a coleção de gravuras, então comecei a colocar aquilo em ordem", relata Lieberman ${ }^{169}$. "Miss Abby estava martelando para que isso fosse realizado. Certamente não era uma das prioridades de Alfred. Então, com base nas aquisições dela, eu transformei aquela coleção na melhor coleção de gravuras modernas em existência". ${ }^{170}$

O conjunto de Abby Rockefeller, que posteriormente se tornaria o núcleo do acervo de artes gráficas do mais importante museu de arte moderna do mundo, nasce, antes de mais nada, de um projeto pessoal de aquisição, só possível devido à curiosidade estética implacável de Abby pela nova arte e aos seus recursos financeiros ilimitados. Abby usufruiu da consultoria de grandes curadores e galeristas para construir seu acervo. Ainda assim, a escolha final era

168 "Curator William S. Lieberman, who came to the Museum in 1945 and assumed responsibility for the print collection in 1949, deserves the greatest praise and recognition for the seminal role he played in shaping it into the foremost of its kind in the world. The Museum's superb representation of prints by the major masters of printmakers, Picasso and Matisse among them, are due to his astute acquisitions and to the many gifts donated during his years of stewardship". WYE, 2004, p.8, tradução nossa.

169 It became apparent, which began almost immediately when I arrived, something had to be done with the print collection, and so I began putting that in order. LIEBERMAN, William. Entrevista com o curador realizada pelo Oral MoMA em 18 de dezembro de 1990, MoMA Archives, p. 43.

170 Miss Abby was hammering away that it be done. I don't think it would have been on Alfred's...it certainly would have been a priority but not a top one for Alfred. Then, based on her holdings, I turned that collection into the greatest collection of modern prints in existence. LIEBERMAN, William. Entrevista com o curador realizada pelo Oral MoMA em 18 de dezembro de 1990, MoMA Archives, p. 43. 
sua, fazendo do Print Room do MoMA um reflexo do seu perfil enquanto consumidora e apreciadora de objetos artísticos.

Ela começou a colecionar gravuras em 1927, antes mesmo da fundação do museu. Mas segundo Alfred Barr, a partir de 1931, todos seus movimentos já tinham em mente a construção de um acervo para o MoMA. Neste ano, Abby concedeu ao museu um fundo para a aquisição de gravuras, que Barr usou para comprar obras na Europa, entre as quais The vase [O vaso] (1926) de Léger e Three friends [Três amigos] (1927) de Pablo Picasso. Mais do que os artistas europeus, Abby gostava do trabalho de seus contemporâneos norte-americanos e adquiriu obras importantes de John Sloan, Stuart Davis, Yashuo Kuniyoshi, Arthur B. Davies, que veio a ser inclusive seu professor de história da arte. Abby também colecionava trabalhos que não apreciava ciente de que, apesar de suas preferências estéticas pessoais, eram obras importantes para o museu.

O gosto dela era definido, mas, às vezes, ela poderia ser convencida a comprar obras que não admirava. Entre essas estava o formidável Minotauromachy de Picasso que, com bom humor característico e graça, ela sugeriu listar como parte do 'Fundo de Gravuras que Mrs. Rockefeller Não Gosta' (BARR, 1949, p.7-8). ${ }^{171}$

Apesar de seus infinitos recursos, não era costume de Abby Rockefeller gastar mais de \$1000 em uma obra de arte (LOEBL, 2000, p. 2361). Talvez a maior contradição da família Rockefeller fosse ser absurdamente rica e, ao mesmo tempo, exageradamente controlada nas finanças. Era comum que todas as aquisições maiores fossem justificadas por escrito com argumentos racionais em longas cartas endereçadas aos membros da família. Assim, exceto em casos especiais, Abby preferia dispor de suas próprias economias na compra de um volume maior de obras de menor porte. Como o marido John D. Rockefeller Jr. notoriamente não era um apreciador da arte moderna, preferindo investir na compra de porcelanas chinesas e

171 "Her tastes were definite, but occasionally she would be persuaded to purchase works which she herself did not admire. Among these was Picasso's formidable Minotauromachy, which, with characteristic humor and good grace, she suggested might be listed as among the 'Fund for Prints which Mrs. Rockefeller Doesn't Like'." BARR, 1949, p.7-8, tradução nossa. 
tapeçarias medievais, Abby usava o dinheiro dos Aldrich para financiar aquisições de artistas contemporâneos. Suas compras privilegiavam gravuras nacionais a pinturas de mestres europeus. Ela tinha ainda uma grande coleção de folk art (objetos de arte decorativa produzidos por colonos ou comunidades indígenas). Agindo desta forma, Abby foi capaz de usar seu dinheiro para financiar uma legião de artistas jovens dos Estados Unidos e manter um punhado de galerias em contínuo crescimento.

Ela sentia que essa abordagem lhe rendia os melhores trabalhos de artistas desconhecidos e trabalhos de segunda categoria de homens com reputações mais estabelecidas. O sistema resultou em uma coleção altamente particular, cuja diversidade é um testemunho de seu gosto excelente. Eventualmente, (a coleção) iria formar o núcleo do Abby Aldrich Rockefeller Print Room, do MoMA (LOEBL, 2000, p. 2361) $)^{172}$.

Comovido pela crescente paixão e estudo de Abby pelas novas manifestações em arte, John D. Rockefeller Jr. concedeu à esposa uma mesada anual de US\$25,000 para completar seu orçamento para gastos em obras de arte no ano de 1927. Apesar de cultivar um gosto mais conservador, ele era conivente com as escolhas estéticas de Abby e permitia que ela inundasse a mansão dos Rockefellers com objetos de arte moderna.

Em 1930, com os filhos já crescidos, Abby transformou o quarto de jogos da casa da Rua 54 em uma galeria particular, onde pudesse contemplar sua crescente coleção e entreter visitas. O projeto foi elaborado pelo arquiteto Duncan Candler e o decorador Donald Deskey, depois empregado para trabalhar nos interiores do Radio City Music Hall no maior empreendimento imobiliário da família, o Rockefeller Center. Candler e Deskey desenharam molduras móveis de alumínio, em que se pudesse alternar a exposição das gravuras. Na montagem, Abby contou com a ajuda e conselho de Edith Halpert, dona da Downtown Gallery. As duas senhoras passavam tardes inteiras escolhendo a disposição das obras na saleta de

172 "She felt that this approach yielded the best work of unknown artists and the second-rate work of men with established reputation. The system resulted in a highly personal collection whose diversity is a testimonial to her excellent taste. Eventually, it also would form the nucleus of MoMA's Abby Aldrich Rockefeller Print Room”. LOEBL, 2000, p. 2361, tradução nossa. 
Abby. Alfred Barr, por vezes, também desempenhava esse papel de amigo e curador pessoal. Em 1999, as salas do MoMA foram configuradas para espelhar a mesma concepção expográfica do gabinete particular de Abby, em uma exposição comemorativa intitulada Print collecting: an early mission for MoMA [Colecionando gravuras: uma antiga missão do MoMA].

A ideia de batizar um departamento com o nome de Mrs. Rockefeller foi sugestão de Alfred Barr. Em carta a Nelson, Barr explicou que, devido à grande modéstia de Abby e a sua vontade em vida de não ter o nome associado a obras doadas ao MoMA, a melhor forma de homenagear a imensa contribuição desta mulher não era por meio de uma exposição, como havia sido feito depois da morte de outra fundadora, Lillie Bliss, mas ao atrelar o nome de Abby a um de seus "maiores interesses": a gravura moderna.

No catálogo do lançamento do Abby Aldrich Rockefeller Print Room, Barr escreveu:

Mrs. Rockefeller, com gentil insistência, argumentou pela inclusão da sala de gravura, lembrando seus colegas que gravuras, porque têm preços baixos o suficiente para estarem disponíveis em uma escala democrática, deveriam ter um lugar especialmente importante em um museu preocupado em encorajar o amplo colecionismo de obras originais de artistas vivos (BARR, 1949, p.7). ${ }^{173}$

Abby Rockefeller teve papel central no incentivo e financiamento das novas expressões estéticas da arte do início do século XX e na consolidação de um poderoso modelo institucional para a arte moderna. Ao todo, ela doaria mais de quatro mil obras para o museu. Esse conjunto seria adquirido ao longo da sua vida e também depois de sua morte, com os recursos gerados pelo fundo de aquisição que deixou ao museu. Sua paixão e contínuo investimento em obras sobre papel estão na raiz da fundação de um departamento específico para a curadoria de gravuras e desenhos no MoMA.

173 “Mrs. Rockefeller, with gentle insistence, argued for the inclusion of a print room, reminding her colleagues that prints, because they were low priced enough to be available on a democratic scale, should hold a place of special importance in a museum concerned with encouraging the widespread collecting of original works by living artists". BARR, 1949, p.7, tradução nossa. 
As primeiras obras a integrar o acervo do museu foram oito gravuras e um desenho expressionista alemão doados pelo professor da Universidade de Harvard e curador do Fogg Art Museum, Paul Sachs. Por causa da generosa contribuição intelectual às atividades do museu, as salas de exposição de desenhos e gravuras do MoMA foram batizadas em sua homenagem. Ávido colecionador desde os tempos de estudante, Sachs usava obras de sua coleção particular, obtidas em sucessivas viagens a galerias europeias, como ferramenta de trabalho para o seu curso de história da arte e museologia em Harvard. O método de connoisseurship promovido por ele requeria um contato diário com obras originais para um exercício contínuo do olhar. As características de reprodutibilidade e baixo custo das obras em papel tornavam possível essa dinâmica de trabalho no âmbito privado. O colecionismo de gravuras e desenhos como instrumento da formação do historiador da arte seria um hábito adquirido por vários estudantes de Sachs ao longo de suas vidas profissionais, entre os quais se destacam os curadores Alfred Barr e William Lieberman.

Paul Joseph Sachs começou a dar aulas na Universidade Harvard em 1917. Seu envolvimento com a instituição iniciara três anos antes, quando foi apontado diretor assistente do Fogg Art Museum. Naquele momento, abandonava uma carreira insatisfatória no mercado financeiro, na qual tinha passado a última década trabalhando para o banco de investimentos da família, o Goldman Sachs. Aos 38 anos, deu início a uma trajetória no ensino de história de arte, aceitando um cargo de professor assistente, sendo reconhecido por formar uma geração de profissionais de museu. Alfred Barr foi um de seus alunos prediletos e quem Sachs indicou para assumir a direção do recém-criado Museu de Arte Moderna em Nova York. Sachs permaneceu ligado ao MoMA como membro do conselho de 1929 a 1938.

Em novembro de 1929, na intenção de auxiliar a montagem do acervo do MoMA, Sachs doou ao museu uma litografia de George Grosz Christmas eve [Noite de Natal] (1921) e uma xilogravura de Max Pechstein Dialogue [Diálogo] (1920), ambas inseridas na exposição Master prints organizada por William Lieberman vinte anos mais tarde. É possível identificar muitos pontos de contato entre o trabalho de curadoria de William Lieberman e a visão de Paul Sachs sobre a história da gravura. 
Em 1954, Sachs empreendeu esforços na edição de um amplo panorama sobre a arte gráfica. O livro Modern prints \& drawings - a guide to a better understanding of modern draughtsmanship reflete um ponto de vista sobre a história e o desenvolvimento da gravura muito semelhante àquela encenada nas paredes do MoMA. Documentos encontrados nos arquivos do MoMA mostram que Sachs teve, inclusive, apoio de Barr e Lieberman na edição do livro ${ }^{174}$. Na introdução, Sachs comenta o trabalho desenvolvido pelo museu: "Com a coleção de Mrs. John D. Rockefeller, Jr., como fundação, Lieberman formou, em poucos anos, a melhor coleção no Ocidente de gravuras moderna"175.

A narrativa proposta por Lieberman e Sachs se inicia na França do final do século XIX com as litografias impressionistas de Degas e Renoir, passando pela produção de Cézanne, Gauguin, Van Gogh e Toulouse-Lautrec. A preocupação acadêmica de Sachs fez com que ele recuperasse as pedras fundamentais da gravura em Goya, David e Ingres, fazendo as correspondências necessárias com o trabalho dos primeiros impressionistas da geração de Manet - retrospecto histórico que Lieberman, curador de um acervo do MoMA que tem início em 1885, não desenvolve. Na sequência, ambos dão grande destaque para a produção da Escola de Paris e providenciam uma revisão semelhante do Cubismo, com a citação de obras de Picasso, Braque e Léger, e incluem, na mesma medida, o Expressionismo e Abstracionismo do Norte da Europa, com Chagall, Klee, Nolde e Kokoschka. Depois de uma breve passagem pela produção mexicana de Orozco e Siqueiros e as litografias norte-americanas da Ashcan School, desembocam no mesmo ponto exato: a produção contemporânea dos Estados Unidos encapsulada pelo Atelier 17.

Ao optar por exibir Stanley William Hayter no capítulo final, Sachs argumenta:

Hayter deve ser incluído mesmo em um breve relato da arte gráfica do século XX porque ele é um influente professor, um artista original e criativo, um mestre e profissional apreciado por suas inovações

174 BARR [Alfred]. (carta) 23 de fevereiro de 1954, Nova York [para] LIEBERMAN [William], Nova York. 1f. Documento pertencente ao Arquivo do MoMA. Coleção William Lieberman. Série II. A. Pasta 112.

175 "With the collection of Mr. John D. Rockefeller, Jr., as a foundation, Lieberman has, in a few years, built for the Museum of Modern Art the finest collection in the Western world of modern prints. SACHS, 1954, p.2. 
técnicas. O seu Atelier 17 em Paris abriu em 1924. Ele era visitado por artistas da estatura de Picasso, Miró, Kandinsky, Chagall e Calder. Hayter, um inglês, influenciou de sobremaneira artistas de Nova York dos anos 1940 (SACHS, 1954, p. 251). ${ }^{176}$

Sachs elegeu a Tarantelle [Tarantelta], de Hayter, como a última obra reproduzida no livro e, assim, ponto de chegada de sua jornada intelectual. Um exemplar dessa gravura faz parte da coleção MAC USP. Cinco anos antes, William Lieberman parecia antecipar a leitura de Sachs. A última galeria da exposição do MoMA Master prints dava destaque justamente para os trabalhos do Atelier 17. Sue Fuller, Raymond Jordan, Gabor Peterdi, Minna Citron, Kenneth Kilstrom, Adja Yunkers, Boris Margo - todos frequentadores do estúdio de Hayter - foram exibidos como os exemplos da proclamada renascença da gravura norte-americana. O núcleo artístico do Atelier 17 tinha posição de destaque na exposição do MoMA e, não por acaso, esse grupo compõe 17 das 27 obras Rockefeller doadas ao Brasil no ano seguinte.

Sobre o atelier, Lieberman escreve:

Uma repentina renascença começou em 1940 quando o inglês Stanley William Hayter transferiu seu estúdio, Atelier 17, de Paris para Nova York. Novos experimentos inspirados pelo ensinamento de Hayter, sua insistência no buril e engenhosa aplicação de texturas na gravura com verniz mole, em larga medida mudou a direção da produção da gravura norte-americana. Em comparação ao período de 1915 a 1935, essas realizações estão menos representadas. O museu possui, contudo, 10 gravuras e uma chapa de cobre de Hayter, e várias gravuras de seus associados e estudantes incluindo Sue Fuller, lan Hugo, Raymond

176 "Hayter must be included in even a short account of Twentieth Century graphic art because he is an influential teacher, an original creative artist, master practitioner, appreciated for his technical innovations. His Atelier 17 in Paris opened in 1924. It was visited by artists of such stature as Picasso, Miró, Kandinsky, Chagall, and Calder. Hayter, an Englishman, greatly influenced New York artists in the 1940's". SACHS, 1954, p. 251, tradução nossa. 
Jordan, Mauricio Lassansky, Gabor Peterdi, André Racz e Yves Tanguy (LIEBERMAN, 1949, p. 14-15). ${ }^{177}$

A proximidade com o grupo de Hayter seria tanta que Lieberman chegou a estudar a técnica de produção de gráfica em seu atelier. Em entrevista concedida ao Oral MoMA em 1993, ele lembra como vários curadores de sua geração, apesar de saberem em profundidade os mais diversos tipos de gravura, eram ignorantes quanto aos conceitos fundamentais das técnicas de produção. Por isso, decidiu participar das oficinas de Hayter, que na época assumia um papel de artista-curador e ajudou a delinear algumas exposições do museu. ${ }^{178}$

O contexto da doação a São Paulo está atrelado, portanto, ao crescente prestígio que esse suporte usufruía em Nova York no final da década de 1940. Foi um momento particularmente produtivo em que novas técnicas de produção estavam sendo desenvolvidas por coletivos de artistas plásticos, em especial aqueles ligados ao Atelier 17. Algumas das inovações desse grupo incluíram o maior refinamento e amplitude dos traços obtidos com o buril, a possibilidade de usar várias cores a partir de uma mesma prancha e a retomada de métodos tradicionais, como a xilogravura, por artistas abstratos. Novas experiências foram incentivadas por donos de galerias, críticos e curadores, e legitimadas em grandes exposições montadas pelo MoMA e pelo Brooklyn Museum.

Apesar da inquestionável proeminência do conjunto de obras de papel do MoMA, não longe dali estava se formando outra coleção de mesma estatura e importância: a seção de gravuras do Brooklyn Museum. Constituída em 1937, antes mesmo do Print Room do MoMA, a

177 "A sudden renaissance began in 1940 when the Englishmen Stanley William Hayter transferred his studio, Atelier 17, from Paris to New York. New experiments in engraving inspired by Hayter's teaching, his insistence on the burin and ingenious appliance of textures to soft ground etching, to a large extent changed the direction of American printmaking. In comparison with the period 1915 to 1935, these recent achievements are less thoroughly represented. The Museum owns, however, ten engravings and a copperplate by Hayter, and many prints by his associates and students including Sue Fuller, lan Hugo, Raymond Jordan, Mauricio Lasansky, Gabor Peterdi, André Racz and Yves Tanguy". LIEBERMAN, 1949, p. 14-15, tradução nossa.

178 LIEBERMAN, William. Entrevista com o curador realizada pelo Oral MoMA em 18 de dezembro de 1990, MoMA Archives. 
partir da divisão das obras sobre papel do acervo da biblioteca, a coleção do Brooklyn se transformou em um rico repositório das expressões mais inovadoras da gravura moderna. Una Johnson, assim como William Lieberman, teve um papel decisivo no patrocínio e estímulo de gravuristas modernos atuando em Nova York nos anos 1940. Johnson se tornaria uma das figuras mais influentes da arte gráfica nos Estados Unidos.

Em 1947, ela fundou a exposição anual de gravura moderna, evento que consagraria o Brooklyn Museum no cenário artístico nacional. Johnson assumiu a direção do setor de gravuras e desenhos do Brooklyn Museum em 1941. Ela havia sido assistente de Carl Schniewind, curador do Brooklyn e especialista em gravura medieval. Dois anos depois da publicação do livro de Paul Sachs, Una Johnson também lançou uma retrospectiva sobre gravura: Ten years of American prints - 1947-1956. No livro, ela foca na explicação das mais diversas técnicas de gravura. Com riqueza de detalhes, explora as inovações nos campos da xilogravura e da litografia, descreve os novos tipos de solventes e suportes - que variavam de metais, celulóide ou madeira - e aponta os trabalhos que tiveram resultados mais atraentes e inventivos. Artistas relevantes para seu comentário são os mesmos incorporados na doação Rockefeller ao Brasil, entre os quais Seong Moy, Anne Ryan, Louis Schanker, Gabor Peterdi, Stanley William Hayter, Armin Landeck, Boris Margo e Fred Becker.

Para a curadora:

Hoje, nos Estados Unidos, alguns dos discursos mais originais e criativos no campo da arte estão sendo encontrados no meio da gravura. Ainda que artistas tenham trabalhado com métodos de gravura nos últimos seis séculos, as técnicas básicas mudaram pouco. Nos Estados Unidos durante as últimas gerações, o artista tem tido liberdade e relativa segurança com a qual pode redescobrir e aplicar novos e, cada vez mais amplos, meios de expressão gráfica (JOHNSON, 1956, p. 14). ${ }^{179}$

179 "Today, in the United States, some of the most original and creative statements in the field of art are to be found in the medium of fine printmaking. Although artists have worked with printing methods for the past six centuries, the basic techniques have changed little. In the United States during the past several generations, the artist has had freedom and comparative security in which to rediscover and to apply a new and ever-widening means of graphic expressionism". JOHNSON, 1956, p. 14, tradução nossa. 
O que norteou o trabalho de Johnson durante mais de duas décadas à frente do departamento foi a sua intenção de apresentar essa produção gráfica. Respaldada por uma instituição de peso, sua dedicação ao tema foi crucial para o sucesso de alguns artistas. As exposições anuais de gravura do Brooklyn, que contavam com cerca de 200 obras por edição, eram importantes espaços de divulgação e discussão das experiências realizadas neste campo.

Vemos que as exposições do Brooklyn Museum também apresentam várias semelhanças com a doação Rockefeller. De 1947 a 1950, 8 das 27 obras doadas ao Brasil estiveram presente nos National Print Annuals do Brooklyn Museum, tendo sido quatro delas vencedoras do prêmio de aquisição: Cat walk [Passeio do gato] (1949) de Max Kahn, Rain and sea [Chuva e o mar] (1946) de Karl Schrag, Heavy bird [Pássaro pesado] (1950) de Marjean Kettunen, e Self-analysis [Autoanálise] (1947) de James Louis Steg. Além dessas, outras obras integraram as mostras anuais, como Dead bird [Pássaro morto] de Adja Yunkers, Alleyway [Passagem no beco] (1948) de Armin Landeck, Eternal wanderer [Eterno errante] de Henry Mark e The sea [O mar] (1950) de Boris Margo. O Brooklyn adquiriu ainda a gravura Carnival [Carnaval] de Louis Schanker e Hen [Galinha] de Sue Fuller, obras que também estiveram presentes em Master prints, do MoMA.

Há, portanto, pontos de contato importantes entre o trabalho desenvolvido nos departamentos de gravura do MoMA e do Brooklyn. O processo de seleção que norteava a curadoria dessas instituições está refletido em larga medida no conjunto de obras sobre papel doado ao Brasil em 1950. Uma primeira leitura a respeito do valor da doação de Rockefeller sugere que as 27 gravuras formam uma coleção bastante atualizada, composta de artistas prestigiados, aceitos pela crítica modernista, cobiçados pelo mercado de gravuras, vendidos nas principais galerias de arte moderna de Nova York, e cujas obras, no final dos anos 1940, já se faziam presentes nos acervos dos principais museus de arte moderna dos Estados Unidos. 
Tab 1 - Gravuras da doação Rockefeller expostas em mostras do MoMA e do Brooklyn Museum

\begin{tabular}{|c|c|c|}
\hline Artista & Obra & Exposição \\
\hline Minna Citron & Marine & Master Prints, MoMA, 1949. \\
\hline Sue Fuller & Hen (1945) & Master Prints, MoMA, 1949. \\
\hline Stanley W. Hayter & Tarantelle (1943) & Master Prints, MoMA, 1949. \\
\hline Raymond Jordan & Synthesis (1948) & Master Prints, MoMA, 1949. \\
\hline Kenneth Kilstrom & $\begin{array}{l}\text { Attack on Marshall Gilbert } \\
\text { (1948) }\end{array}$ & Master Prints, MoMA, 1949. \\
\hline Armin Landeck & Alleyway (1948) & $\begin{array}{c}\text { Master Prints, MoMA, } 1949 . \\
\text { National Print Annual, Brooklyn Museum, } 1949\end{array}$ \\
\hline Boris Margo & The Sea (1949) & Master Prints, MoMA, 1949. \\
\hline Alton Pickens & Pastorale (1947) & Master Prints, MoMA, 1949. \\
\hline Adja Yunkers & Dead bird (1947) & $\begin{array}{c}\text { Master Prints, MoMA, } 1949 . \\
\text { Recent American Woodcuts, MoMA, } 1952 \\
\end{array}$ \\
\hline Max Kahn & Cat walk (1949)* & National Print Annual, Brooklyn Museum, 1949 \\
\hline Karl Schrag & Rain and sea (1946)* & National Print Annual, Brooklyn Museum, 1947 \\
\hline Marjean Kettunen & Heavy bird $(1950)^{*}$ & National Print Annual, Brooklyn Museum, 1950 \\
\hline James Louis Steg & Self-analysis $(1947)^{*}$ & National Print Annual, Brooklyn Museum, 1947 \\
\hline Henry Mark & Eternal wanderer (1947) & National Print Annual, Brooklyn Museum, 1947 \\
\hline Louise Krueger & The Boaters (1948) & Recent American Woodcuts, MoMA, 1952 \\
\hline Anne Ryan & The Captive (1946) & Recent American Woodcuts, MoMA, 1952 \\
\hline Louis Schanker & Carnival (1945) & Recent American Woodcuts, MoMA, 1952 \\
\hline Frank Wallace & Pompei I (1949) & Recent American Woodcuts, MoMA, 1952 \\
\hline
\end{tabular}

* Prêmios de aquisição das exposições anuais do Brooklyn Museum. 


\section{O papel da gravura na democratização da arte moderna}

A ascensão da gravura moderna em meados dos anos 1940 é um fenômeno artístico melhor compreendido se levado em conta dois outros aspectos, um de âmbito econômico e outro político. Depois da Segunda Guerra Mundial, a economia norte-americana estava a todo vapor e passava por um período de crescimento. Em 1945, a estrutura política do mundo se alterava. Novas alianças eram formadas e, ao longo do século XX, a presença diplomática, a influência cultural e o poderio econômico se tornariam instrumentos importantes da Guerra Fria. É neste cenário em que gravura moderna norte-americana se prolifera. É sob essa ótica que a doação Rockefeller ao antigo MAM de São Paulo deve ser interpretada.

Diante de uma Europa estraçalhada, o eixo econômico do mundo se movia para os Estados Unidos. A fuga de intelectuais e artistas europeus fazia com que, gradativamente, Paris perdesse sua proeminência no cenário cultural. A classe média, fortalecida por programas de fomento do governo Roosevelt, chegava à década de 1940 com uma nova musculatura econômica. Insuflados por um período de recuperação, os norte-americanos se transformaram nos principais compradores de objetos de arte do Ocidente.

Levantamento de Serge Guilbaut demostra o crescimento exponencial do mercado de arte em Nova York:

O "boom da arte" seguiu o "boom da economia". De repente o país parecia ter desenvolvido um apetite insaciável pelas artes. (...) 0 número de galerias em Nova York cresceu de 40 no começo da guerra para 150 em 1946 (...) A arte se tornava uma commodity e a galeria um supermercado (GUILBAUT, 1983, p. 91-92). ${ }^{180}$

180 "The 'art boom' followed the 'economic boom'. All of a sudden the country seemed to have developed an insatiable appetite for the arts (...) The numbers of art galleries in New York grew from 40 at the beginning of the war to 150 by 1946 (...) Art became a commodity and the gallery a supermarket". GUILBAUT, 1983, p. 91-92, tradução nossa. 
Nesse hipermercado da arte, a gravura, a fotografia e as reproduções ganharam cada vez mais espaço. O mercado de arte estava aquecido e as obras em papel, por terem um preço acessível, eram um produto cultural atraente para um público crescente. O perfil do colecionador se ampliava. Para atender a nova demanda, galerias se adaptaram, criando diferentes maneiras de expor e comercializar. Publicações especializadas com o objetivo de informar o novo colecionador se tornavam mais numerosas. Catálogos enviados pelo correio, anúncios em jornais e vendas por telefone passaram a ser métodos incorporados por algumas galerias voltadas para um público ampliado de apreciadores. A gravura encontra o seu lugar neste cenário por suas qualidades materiais. A arte gráfica é um suporte de baixo custo, de rápida produção, voltada para a reprodutibilidade em série, assim ampliando a capacidade de divulgação da arte moderna.

Em 1945, era possível comprar uma gravura premiada de Stanley William Hayter, como Tarantelle [Tarantela], por US\$45, ${ }^{181}$ ou uma xilogravura de Anne Ryan, The captive [O cativo] por US\$40. ${ }^{182}$ Obras de menor calibre ou de artistas menos conhecidos saídam por até um terço do preço. A obra Composition in oval [Composição em oval], de Jim Forsberg, por exemplo, foi adquirida por US\$ 15 da galeria Jacques Seligman \& Co. A acessibilidade da arte moderna talvez nunca tenha sido tão ampla quanto no ambiente criado pela profusão e concorrência de galerias nova-iorquinas nos anos de recuperação econômica do pós-guerra. ${ }^{183}$ A lista de aquisição enviada para o Brasil aponta oito galerias que venderam as 27 obras por US\$ 1,154 no total. $^{184}$

A principal fonte foi a Weyhe Gallery da Av. Lexington, fundada em 1914 pelo imigrante alemão Erhard Weyhe, por intermédio do qual foram adquiridas as xilogravuras de Louise

\footnotetext{
${ }^{181}$ Catálogo da exposição American Printmakers, Galeria Buchholz, 1945. Archives of American Art, Smithsonian Institution, Washington D.C.

182 Documento com lista de preços de obras de Anne Ryan da Galeria Betty Parsons (sem data), Archives of American Art. Ainda que a galeria tenha vendido um exemplar da gravura Captive de Anne Ryan, a obra que chega ao Brasil foi intermediada diretamente pela artista no mesmo valor de US\$ 40, segundo indica o documento encontrado nos arquivos do MoMA. LYTLE, [Dorohy L.] (carta) 28 de junho de 1950, Nova York [para] BOYER, Nova York. 2f.

${ }^{183}$ O salário mínimo de um trabalhor americano em 24 de outubro de 1945 era no valor de US\$ 64, valores da época, para uma jornada mensal de trabalho de 160 horas, segundo registro do Departamento de Trabalho dos Estados Unidos. Disponível em: http://www.dol.gov/whd/minwage/chart.htm 184 LYTLE, [Dorohy L.] (carta) 28 de junho de 1950, Nova York [para] BOYER, Nova York. $2 f$.
} 
Krueger The boaters [Os barqueiros] (1949), Bernard Reder Fighting cocks [Galos de briga] (1949), Frank Wallace Pompei I [Pompéia I] (1949) e Misch Kohn Tiger [Tigre] (1950) ${ }^{185}$; a águatinta e verniz mole de Minna Citron Marine [Marinha] (1948); a litografia de Eleonor Coen Baby in the high chair [Bebê na cadeira de pés altos] (1950); e as duas gravuras premiadas nas exposições anuais do Brookyn Museum Self-analysis [Autoanálise] (1947) de James Steg e Heavy bird [Pássaro pesado] (1950) de Marjean Kettunen.

Uma galeria que tinha como objetivo específico de expandir a comercialização de obras de arte para a classe média era a Associated American Artists, de Reeves Lewenthal, fundada em 1934. "Ninguém é pobre demais para comprar uma obra-prima"186, descreveu um jornalista ao escrever uma reportagem sobre AAA, que foi bem-sucedida em sua estratégia comercial até 1958, ano em que fechou as portas. Lewenthal se associou ao Society of American Etchers, grupo ligado a Thomas Benton na Art Student League, garantindo assim uma produção contínua de gravuras que pudessem ser vendidas a US\$ 5, com um adicional de US\$ 2 pela moldura.

"Lewenthal acreditava em processos modernos de negócio que ligavam a cultura do consumo à indústria da cultura por meio de um sistema de produção e distribuição eficiente e lucrativa" (DOSS, 1991, p. 145) ${ }^{187}$. Ele fazia contratos com os artistas acertando pagamentos mensais no valor de US\$ 200 e estabelecia acordos com lojas de departamentos de cidades grandes e médias em vários pontos do território americano para garantir a venda em massa.

"O sistema de galeria está arruinado", diria Lewenthal. "A classe do colecionador rico está morrendo (...) Arte norte-americana deve ser tratada como qualquer outro negócio" (apud DOSS, 1991, p. 145) ${ }^{188}$. Até 1937, estima-se que a AAA já tinha vendido 70 mil gravuras. Por uma questão de gosto e popularidade, a AAA passaria a promover, em certa altura, artistas

\footnotetext{
${ }^{185}$ A obra Tiger não faz parte da coleção do MAC USP.

186 "Now 'nobody', one article on the AAA stated, was 'too poor to buy a masterpiece". DOSS, 1991, p. 151.

187 "Lewenthal believed in modern business procedures that linked consumer culture with the culture industry through an efficient, profit-oriented system of production and distribution". DOSS, 1991, p. 145

188 “'The gallery system', Lewenthal observed, 'is doomed. The rich collector class is dying out (...) American art ought to be handled like any other American business". apud DOSS, 1991, p.145)
} 
abstratos, decisão que resultou em cisão com os regionalistas vinculados a Thomas Benton. ${ }^{189}$ A Associated American Artists trabalhou, por exemplo, com Adja Yunkers e Gabor Peterdi, cujas obras Dead bird [Pássaro morto] (1947) e Sign of the lobster [Sinal da lagosta] (1947-48) integram a doação Rockefeller de 1950 e as exposições do MoMA. Ao longo dos anos 1940, a AAA perdeu sua reputação entre a classe artística, principalmente por começar a fazer artigos de decoração de interiores, como tapetes, cinzeiros, abajures e padrões de tecidos. "Se tornou quase degradante comprar da AAA", declarou o galerista Sylvian Cole, funcionário da empresa desde $1946^{190}$.

Para a historiadora da arte Erica Doss, a galeria de Lewenthal serviu como um atenuador ao estresse econômico de artistas trabalhando durante o período de Depressão, mas seu prestígio e posição durante o reaquecimento do mercado da arte foi continuamente diminuído ao longo dos anos 1940.

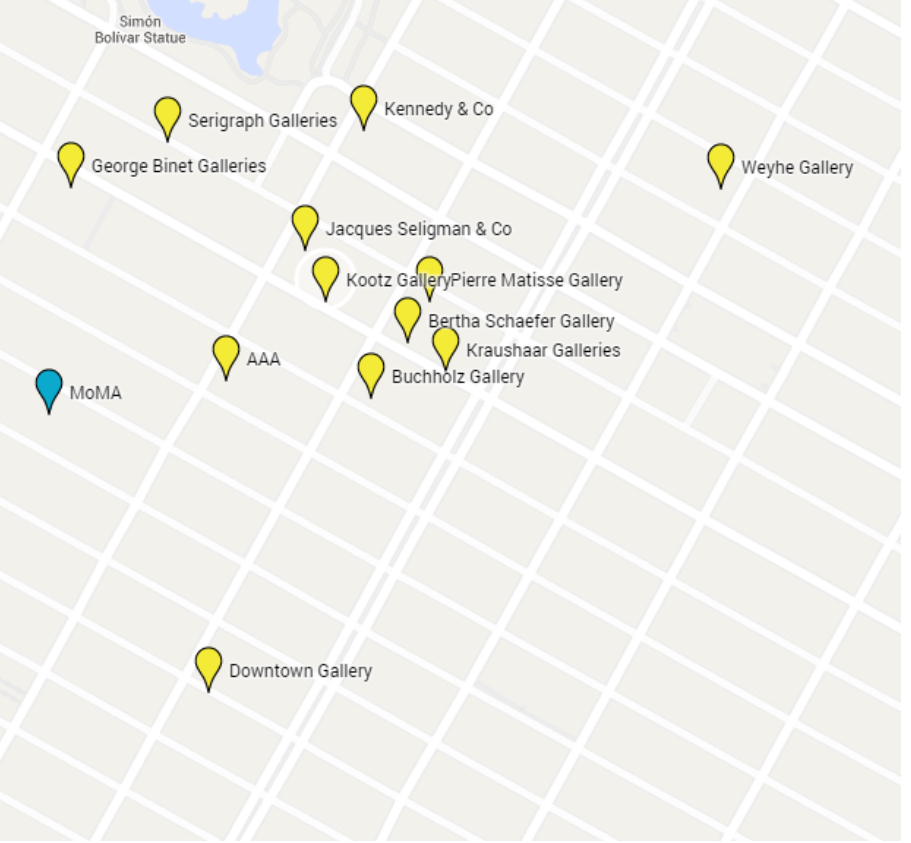

[Map. 1] Localização das galerias de Nova York que intermediaram a venda das obras da doação Rockefeller.

189 Ainda que o foco principal de Rewenthal tenha sido promover a arte norte-americana a preços módicos, a AAA funcionava também como uma galeria tradicional e vendia obras por preços menos populares para a época. $A$ aquarela de George Grosz, hoje presente no MAC USP, foi comercializada pela AAA e vendida a Alfred Barr por US\$ 250, segundo recibo encontrado no verso da obra.

190 "It became almost degrading to buy from AAA" apud DOSS, 1991, p.166. 
[Tab. 2] - Galerias de Nova York que intermediaram a venda das obras da doação Rockefeller.

\begin{tabular}{|c|c|c|}
\hline Doação 1946 & Artistas & $\begin{array}{l}\text { Valor } \\
\text { (US\$, 1946) }\end{array}$ \\
\hline Downtown Gallery & Jacob Lawrence & 270 \\
\hline American Artists Association & George Grosz & 225 \\
\hline Art of This Century & André Masson & 500 \\
\hline Pierre Matisse & Marc Chagall & 900 \\
\hline Kootz Gallery & Byron Browne & 800 \\
\hline Galerias não identificadas & $\begin{array}{l}\text { Everett Spruce, Alexander Calder, } \\
\text { Fernand Léger, Yves Tanguy, Max } \\
\text { Ernst, Morris Graves, Robert } \\
\text { Gwathmey, Arthur Osver }\end{array}$ & 4.728 \\
\hline Total & & 7.423 \\
\hline Doação 1950 & Artistas & $\begin{array}{l}\text { Valor } \\
\text { (US\$, 1950) }\end{array}$ \\
\hline George Binet Galleries & Max Kahn & 45 \\
\hline Buchholz Gallery & Stantley W. Hayter, Alton Pickens & 80 \\
\hline Kennedy \& Co & Armin Landeck & 24 \\
\hline Kraushaar Galleries & Karl Schrag & 25 \\
\hline Bertha Schaefer Gallery & Worden Day, Sue Fuller & 75 \\
\hline Jacques Seligman \& Co & $\begin{array}{l}\text { Jim Forsberg, Boris Margo, Seong } \\
\text { Moy, Louis Schanker }\end{array}$ & 135 \\
\hline Serigraph Galleries & Edward Landon, Henry Mark & 35 \\
\hline Weyhe Gallery & $\begin{array}{l}\text { Minna Citron, Eleanor Coen, } \\
\text { Marjean Kettunen, Misch Kohn, } \\
\text { Louise Krueger, Bernard Reder, } \\
\text { Louis Steg, Frank Wallace }\end{array}$ & 385 \\
\hline Venda pelo próprio artista & $\begin{array}{l}\text { Raymon Jordan, Kenneth Kilstrom, } \\
\text { Guy Mayer (Fred Becker), Gabor } \\
\text { Peterdi, Anne Ryan, Adja Yunkers }\end{array}$ & 350 \\
\hline Total & & 1.154 \\
\hline
\end{tabular}


Os museus também desempenharam um papel importante na tentativa de aumentar a aquisição de arte pela classe média. O MoMA, voltado desde sua inauguração ao ensino e formação de um público para a arte, promoveu ao menos 10 exposições de gravuras e objetos de design com valores iniciais de US\$ 5 a US\$ 10 na década de $1940 .{ }^{191}$ As primeiras exposições deste tipo estavam diretamente ligadas à produção saída das oficinas do Federal Art Project.

Criado em 1935 pelo governo Roosevelt para ser o New Deal da arte, o FAP era um braço do Work Projects Administration, o principal órgão federal responsável pelo estímulo à produção cultural nos Estados Unidos de 1935 a1943. Neste período, 32 mil artistas foram empregados pelo Works Project Administration, 11.285 gravuras originais e 250 mil reproduções foram realizadas (DOSS, 1991, p. 145). O custo estimado do programa foi de US\$ 35 milhões. A Seção de Artes Gráficas do FAP foi criada em 1936 e o primeiro estúdio de gravura foi fundado em Nova York. Artistas tinham que cumprir cotas de produção e recebiam um salário de \$23.86 por semana. As gravuras produzidas tinham tiragens de 25 a 30 exemplares, sendo que três ficavam para o artista. As obras eram enviadas para decorar prédios públicos, hospitais e escolas.

Em novembro de 1940, o MoMA promoveu duas pequenas exposições simultâneas ao Art Week, evento anual do WPA para divulgar a produção artística do programa. O objetivo era estimular a compra de obras de artistas nacionais nas semanas próximas ao feriado natalino. Color prints under ten dollars [Gravuras coloridas a menos de dez dólares] disponibilizou 79 serigrafias de artistas americanos, muitos dos quais vinculados ao programa do WPA. ${ }^{192}$ O slogan "buy american", reforçado no comunicado à imprensa, mostra como a preocupação protecionista naquele momento se estendia não só à indústria, mas também à produção artística. Alfred Barr e Nelson Rockefeller apoiaram publicamente o programa governamental de fomento às artes.

Alfred Barr declarou que estava "muito encorajado pela qualidade (das obras) do WPA e acredito que seria um sério choque para a cultura norte-americana caso ele seja

191 Lista de exposições realizadas pelo MoMA (1940-1949). Arquivo do MoMA.

192 Quanto a essa exposição de 1940 vale destacar a presença de Edward Landon, um gravurista inserido no círculo social do Art Students League de Nova York e interlocutor de Arthur Dove. Uma serigrafia de Landon That which we mourn [Aquele a quem pranteamos] (1945), faz parte da doação Rockefeller de 1950. 
descontinuado" (BARR apud HARRIS, 1995, p. 134). Barr tinha sido eleito presidente do Conselho de Nova York para o Art Week em 1940. Para ele, o objetivo da semana de arte era "chamar atenção das pessoas em todos os lugares para os trabalhos de artistas nacionais de forma a encorajar a aquisição de arte norte-americana em todos os lares" (BARR apud HARRIS, 1995, p. 152).

Em março de 1942, o Works Projects Administration Art Program foi descontinuado. Parte da administração do programa foi transformada na Seção Gráfica do War Services Program. As encomendas para os artistas passaram a ser de natureza militar: design de uniformes de camuflagem, produção de mapas, pôsteres com mensagens de guerra, ilustrações para manuais, etc. O Federal Art Project foi oficialmente desarticulado em 1943 e criticado por ter sido um instrumento castrador do Estado de forma a canalizar a produção cultural em direção a determinadas representações ideológicas de nacionalidade e da narrativa do American way of life. Ainda assim, o Federal Art Project foi um importante viabilizador do fazer artístico durante a Depressão. Artistas saídos do programa ganhariam espaço no mercado privado e alguns passariam a ser estrelas do circuito crescente de galerias em Nova York nos anos 1940 e 1950. Um grupo grande de artistas outrora vinculados ao programa federal entraria para o acervo do MoMA e para as coleções privadas da família Rockefeller, como Seong Moy, Eleanor Coen, Max Kahn, Jacob Lawrence e Byron Browne.

Outro vetor importante para a popularização da gravura norte-americana em escala internacional foi o trabalho desenvolvido pelo Departamento de Circulação de Exposições do MoMA. Desde seu início, a missão do museu era formar público e ser a plataforma de divulgação de conhecimento sobre a arte moderna. A vocação didática do MoMA se fez sentir já nos seus primeiros anos de funcionamento, com programas voltados a escolas e exposições itinerantes. Em 1952, o museu recebeu financiamento da fundação dos irmãos Rockefeller para implementar um robusto programa internacional de divulgação artística, sob coordenação de Elodie Courtier e depois de Porter A. McGray. Se em 1938 a primeira exposição internacional do museu tinha sido pensada apenas para circular em Paris, ao longo da década seguinte a presença institucional do MoMA ganharia maior fôlego e seria sentida na América Latina, Ásia e 
Austrália. Ao todo, o museu montou exposições de seu acervo em 37 nações. ${ }^{193}$ Uma dessas exposições incluiu, por exemplo, a delegação norte-americana na II Bienal de São Paulo.

Neste contexto, a gravura foi ferramenta importante. Com financiamentos módicos, foi possível montar sucessivas exposições itinerantes de gravuristas modernos em várias cidades da América Latina. Em 1944, o departamento realizou a exposição Silk screen prints [Serigrafias] e, no ano seguinte, New directions in gravure [Novas direção na gravura], sobre o trabalho desenvolvido pelo Atelier 17. Apenas no ano de 1954, foram organizadas cinco exposições de gravura moderna: The American woodcut today [Xilogravuras norte-americanas hoje], Contemporary printmaking in U.S.A [Gravura contemporânea nos EUA], Thirty American printmakers [Trinta gravadores norte-americanos], Twenty five American prints [Vinte e cinco gravuras norte-americanas] e Young American printmakers [Jovens gravadores norteamericanos]. Essas mostras eram facilitadoras de uma aproximação política e cultural com os países pelos quais passavam.

O trabalho do departamento internacional do MoMA é importante para se entender a segunda doação Rockefeller ao Brasil, pois grande parte da coleção surge justamente de uma dessas exposições itinerantes. O Atelier 17 em Nova York teve o seu período de ascensão na primeira metade da década de 1940. Em agosto de 1944, o MoMA coroou a produção do grupo com uma exposição Hayter and Studio 17: new directions in gravure [Hayter e Atelier 17: novas direções na gravura]. O curador da mostra, James Johnson Sweeney, descreveu o trabalho desse núcleo como "uma das mais vitais pesquisas em arte gráfica do século XX". Para ele, Hayter e seus associados "recuperaram a dignidade da gravura em buril como um meio de expressão original" ${ }^{194}$. Havia um interesse por parte dos apoiadores do atelier e da curadoria do MoMA de equiparar a gravura a outros meios de desenvolvimento artístico da vanguarda, como a pintura e a escultura, e reafirmá-la enquanto suporte necessário de ser tomado em consideração pelo mercado e crítica.

Por causa da proximidade curatorial com essas exposições itinerantes, a doação Rockefeller precisa ser entendida como parte de um projeto maior de divulgação cultural e

193 The Bulletin of the Museum of Modern Art - Circulating Exhibitions 1931-1954. Vol. 21, No. 3/4.

194 "The revival of engraving as a medium for original expression" SWEENEY, 1944, p.3, tradução nossa. The Bulletin of the Museum of Modern Art. Vol. 12, No. 1, Aug., 1944. 
promoção da arte moderna norte-americana nos países de interesse estratégico para os EUA durante a Guerra Fria - um projeto que estava em diálogo com as tendências do mercado artístico da Nova York, que fazia parte do colecionismo desempenhado por Abby Rockefeller e do trabalho da primeira geração de curadores do MoMA.

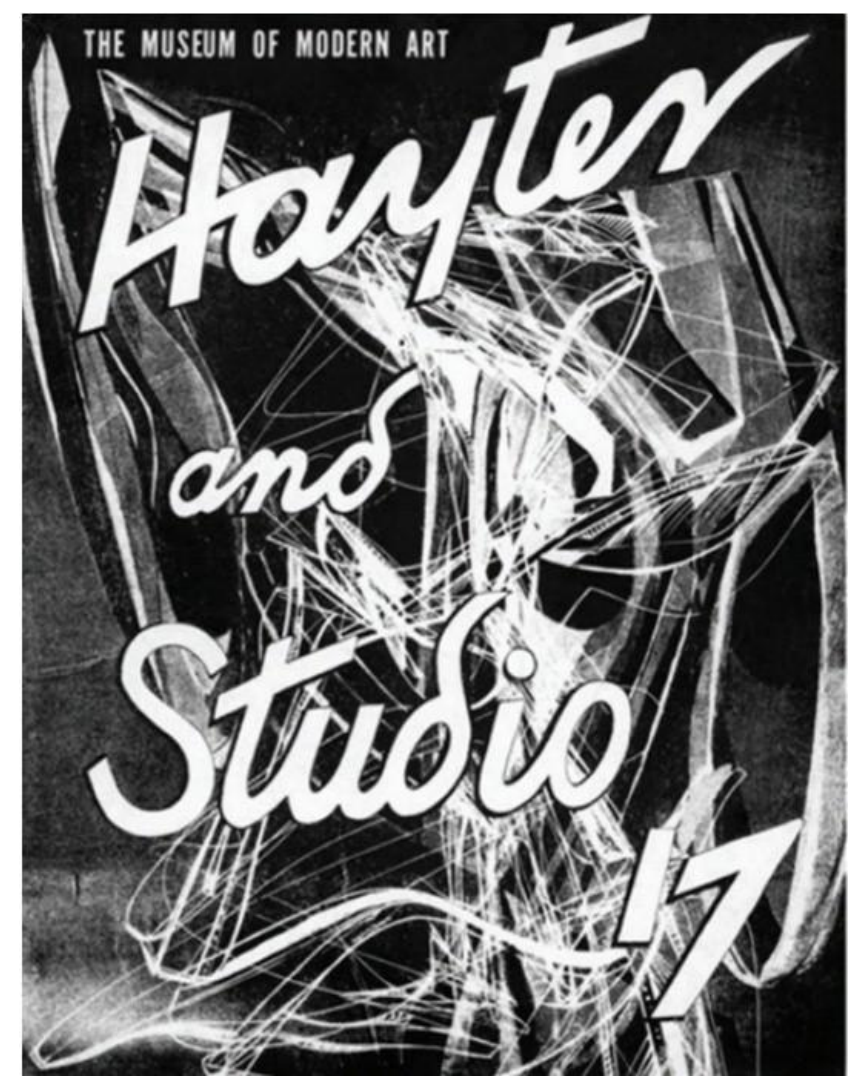

[Fig. 74] Capa da revista do MoMA sobre a exposição Hayter and Studio 17 (1944) 


\section{Atelier 17: um centro de inovação}

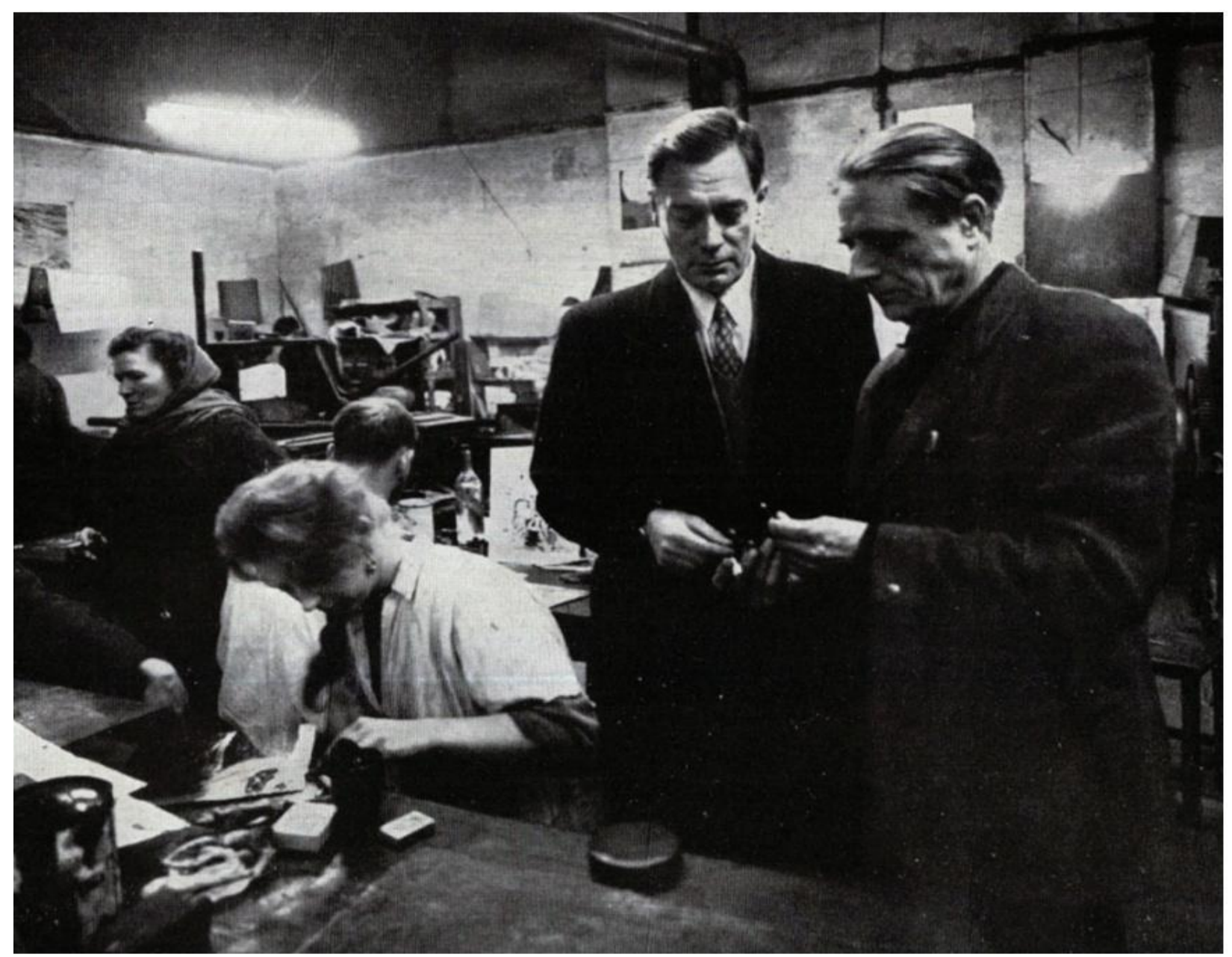

[Fig. 75] Stanley William Hayter trabalhando no Atelier 17 em Nova York.

Um dia típico no Atelier 17 começava com o fluxo errático de entrada e saída de seus frequentadores e o barulho do buril contra madeira e chapas de metal. Artistas iam e vinham livremente. Sentavam-se nas ilhas de trabalhos, dedicando-se por longas horas a suas composições. O Atelier 17 não era uma escola. Não havia aulas, turmas ou horários. De acordo com a visão de Hayter, aquele deveria ser um espaço de convívio social e dedicação total à arte da gravura. Todos os materiais necessários para a produção das obras eram fornecidos pelo próprio estúdio. Todas as mesas e prensas eram comunitárias. O ambiente não era muito sofisticado, pois Hayter preferia investir os rendimentos obtidos na compra de materiais e na subsistência de estudantes promissores, e não na aquisição de novos equipamentos. Enquanto 
os artistas esculpiam, Hayter sobrevoava os postos de trabalho com olhar certeiro de um observador experiente, tecendo comentários e críticas individualizadas. Ele atuava mais como um orientador do que propriamente um professor. Raramente trabalhava em suas próprias gravuras durante o tempo que passava no atelier. Naquele espaço, dedicava-se ao desenvolvimento dos outros e a discussões conceituais sobre propostas estéticas e filosóficas das vanguardas. O Atelier 17 era um espaço para o fazer técnico, mas também um centro para o debate artístico.

Em About prints, Stanley William Hayter descreve:

Algumas grandes mesas dão espaço e luz suficiente para trabalhar nas placas (...) um canto contém os ácidos e uma pia; no outro, papel e gravuras secando são empilhados. Há três prensas e todo o equipamento, apesar de muito caro, é rudimentar em comparação com outros estabelecimentos educacionais privados fundados por exmembros do grupo. Embora tenha sido confundido como tal, o Atelier 17 não é uma escola, exceto na medida em que todo o grupo e aqueles que trabalharam nele, agora espalhados em uma dúzia de países, constituem uma 'Escola' no sentido histórico. A qualquer momento, artistas maduros de reputação internacional podem estar trabalhando ao lado de artistas menos conhecidos de gerações diferentes e até mesmo alguns poucos estudantes de arte (HAYTER, 1960, p.62). ${ }^{195}$

Nascido em 1901, Hayter formou-se em química e geologia no Kings College de Londres. Depois da graduação, trabalhou três anos para a companhia Anglo-Iranian Oil, ocasião em que foi alocado para a cidade de Abadan. Mesmo neste emprego, investia grande parte de seu

195 "A number of large tables give space and sufficient light for work on plates, and for the glass plates on which colors are rolled out; a corner contains the acids and a sink; in another, paper and drying prints are stacked. There are three presses and all the equipment, although very expensive, is rudimental compared with other educational establishments funded by ex-members of the group. Although it has been mistaken for such by innocent people, the Atelier 17 is not a school, except in so far as the whole group and those who have worked in it, now in a dozen countries, could be said to constitute a 'School' in the historical sense. At any time, mature artists of worldwide reputation may be working in it alongside lesser-known artists of different ages". HAYTER, 1960, p.92, tradução nossa. 
tempo e energia no desenvolvimento de suas habilidades artísticas, que veio a aprofundar quando retornou à Europa. Em 1926, mudou-se para Paris e passou a frequentar os círculos da vanguarda. Entre os seus principais interlocutores naquele período, constam Alexander Calder, Antony Gross, Joan Miró e Alberto Giacometti.

Em Paris, o atelier começou com um grupo de quatro artistas, depois aumentando para dez. Eles trabalhavam, lado a lado, no apartamento de Hayter na Rua Campagne-Première, n. 17. No estúdio, artistas iniciantes conviviam com Max Ernst, Joan Miró, Alberto Giacometti, Jean Hélion, Yves Tanguy, Pablo Picasso e Vassily Kandinsky (LÉVY, 2003, p.154). Quando Hayter migrou para os Estados Unidos, grandes nomes da vanguarda norte-americana também frequentaram o seu estúdio; Frank Kline, Robert Motherwell, Willem de Kooning e Jackson Pollock entre eles.

Hayter se mudou para os Estados Unidos em 1937. Com ele, vieram suas ideias sobre o papel do subconsciente e da abstração na arte. Ligado ao movimento surrealista francês, a chegada de Hayter a Nova York ventilou a cena da arte gráfica norte-americana com propostas estéticas inovadoras. Para a historiadora da arte Joann Moser, curadora de gravura no Smithsonian Institution, artistas no Atelier 17 estavam expostos a muito mais do que informação técnica. "As ideias de Hayter sobre arte estavam de acordo com o pensamento mais avançado da arte moderna e ajudou a gerar nova vitalidade na produção da gravura moderna norte-americana que, com raras exceções, era relativamente conservadora" (MOSER, 1978, p.2). ${ }^{196}$ Em 1940, Hayter transferiu o atelier para uma sala do New School for Social Research em Nova York, uma escola de atmosfera liberal e personalidade progressista. A partir de 1945, procurando maior independência institucional, ele mudaria o estúdio para um espaço maior em Greenwich Village. Aos poucos, o atelier se popularizou e o número de frequentadores escalonou.

O artista cantonês radicado em Minnesota, Seong Moy, descreveu a experiência:

\footnotetext{
196 "Hayter's ideas on art (...) were in accord with some of the most advanced thinking in modern art and helped generate a new vitalizy in American printmaking which, with a few exceptions, was relatively conservative". MOSER, 1978, p.2.
} 
Era uma situação muito diferente. Acho que foi, provavelmente, a situação mais ideal para qualquer artista que tem algum conhecimento prévio. Não é o lugar onde se ensina algo muito rudimentar. Você tem que ter alguma experiência quando você vai lá, porque o que é feito não é ensino, é uma troca de pontos de vista, intercâmbio de ideias, a procura por alguma novidade em inovações técnicas. ${ }^{197}$

Para Karl Schrag, outro artista do Atelier 17, e quem Hayter escolheria para continuar a administrar o estúdio depois de seu retorno para Paris, relatou:

O Atelier era um ponto de encontro onde se discutiam problemas muito além da gravura. Não era nada parecido com uma escola de artesanato. (Ali era discutido) todo o contexto do que a arte gráfica poderia ser, e também os elementos que compunham a gravura, como a linha, os valores e a cor. Toda complexidade do problema tornava-se visível e você podia fazer sua própria escolha. Para mim, foi um lugar útil. Primeiro, há algo inspirador no ar quando você está trabalhando em conjunto com pessoas extremamente criativas. Mas, além disso, havia a enorme ampliação do alcance das possibilidades gráficas, que nos dava não tanto a possibilidade de utilizar todos esses suportes, mas entender quais técnicas realmente atendiam sua própria necessidade. ${ }^{198}$

197 "Yes, it was a very different kind of situation. I think it was probably the most ideal situation for any artist who has some background. I think an artist must have some background and be able to feel that he has a certain command of technique. It isn't the kind of place where one teaches the very rudimentary kind of thing. You have to have some kind of background when you go there because what is done there is not teaching; it's an exchange of points of view, exchange of ideas, what one is trying to do and searching for some newness in technical innovations to fit in with a situation". Entrevista oral com Seong Moy, 1971 Jan. 18-28, Archives of American Art, Smithsonian Institution, tradução nossa.

198 "The Atelier was in a sense a meeting place where problems far beyond printmaking were discussed. It was not at all like a crafts school or anything like that. The whole complex of what graphics could be and also the elements that makes up graphics, like line, and values, and, to a degree, color. The whole problem became visible and you could make your own choice as to what you would accept. To me it was helpful in a peculiar way. First of all, there is something in the atmosphere when you are working together with such enormously creative people which is inspiring. But also beyond that the enormous widening of your grasp of the possibilities of graphics in general gives you not so much the possibility of using all of them but of understanding what would really fit your own needs". Entrevista oral com Karl Schrag, 14-20 de outubro de 1970, Archives of American Art, Smithsonian Institution, tradução nossa. 
Ao ingressar no atelier pela primeira vez, o artista novato seria convidado a participar de uma experiência. Reconhecido pela sua habilidade no processo do intaglio, Hayter fornecia uma placa de metal a ser trabalhada livre e intuitivamente pelo artista. A recomendação era não ter medo de estragar o suporte. Quanto mais automático o traço, melhor. O objetivo desta primeira aproximação com o trabalho do estúdio visava encorajar novatos a explorarem a natureza do material.

Uma placa de zinco era preparada com uma camada suave na qual o recém-chegado era convidado a fazer um 'desenho automático' que utilizasse todo o espaço disponível, mas que não sugerisse contornos, objetos, texturas, ou luz e sombra. Esse procedimento introduzia o artista na prática de trabalhar diretamente com a placa ao invés de copiar um desenho preparatório. Ele também eliminava a noção de que um desenho deveria descrever algo ou sugerir uma imagem reconhecível. Porém, mais importante, Hayter tinha a intenção de que essa ação fosse tão diferente dos procedimentos tradicionais do desenho que provocaria uma situação nada familiar em que uma descoberta era mais provável de acontecer (MOSER, 1978, p. 3). ${ }^{199}$

A porta de entrada para o grupo do Atelier 17 exigia, portanto, um processo de estranhamento. O artista deveria se despir de seus maneirismos e sair da zona de conforto. Hayter promovia o abstracionismo por meio do método de desenho automático empregado por surrealistas ligados a André Breton nos anos 1920. No Atelier 17, esse método procurava criar um constrangimento inicial para o artista e chamar atenção para as qualidades intrínsecas do suporte. Segundo Joann Moser, Hayter estimulava esse procedimento, pois ele permitiria

199 "A zinc plate was prepared with a soft ground onto which the newcomer was invited to make an "automatic drawing" that utilized all the available space, but did not suggest outlines, objects, textures, or light and shade. This procedure introduced the artist to the practice of working directly on the plate instead of copying a preparatory sketch. It also eliminated the notion that a drawing should describe something or suggest a recognizable image. But more important, Hayter intended this action to be so unlike traditional drawing procedures that it would provoke an unfamiliar situation in which discovery would be more likely to occur". MOSER, 1978, p.3, tradução nossa. 
perceber que a gravura não era apenas uma extensão do desenho ou da pintura, mas era dotada de características e possibilidades singulares. "Assim como havia inspirado os surrealistas, essa investida ao desconhecido, ao não premeditado, ao incerto, excitava as imaginações de muitos artistas que buscavam uma nova fonte de inspiração" (MOSER, 1978). O passo seguinte era trabalhar a placa de zinco cingida e mergulhá-la em ácido:

Em cada etapa sucessiva no desenvolvimento da placa, uma prova era realizada para revelar imediatamente para o artista qual o resultado de sua ação anterior e registrar a transformação gradual do desenho em imagem. Ainda que a placa fosse trabalhada repetidas vezes ao ponto que precisava ser abandonada, a experiência familiarizava o artista com as técnicas básicas do intaglio e servia de ponto de partida para o próximo esforço (HAYTER, 1978, p.4). ${ }^{200}$

O estúdio de Hayter era, acima de tudo, um laboratório experimental. Acidentes de percurso eram incentivados. A formação em química dava a Hayter conforto para testar diferentes solventes, ácidos e metais. Os efeitos inesperados desses desvios eram explorados e inseridos nas composições. Os artistas recebiam instruções básicas sobre as técnicas tradicionais da gravura e todo novo passo era uma descoberta. O objetivo era que, com apenas a mínima orientação, pudessem descobrir todos os processos por meio da manipulação prática. Um dos pontos de investigação central era o desenvolvimento da gravura de múltiplas cores realizada em uma mesma placa de metal.

O método tradicional de inserir cor às gravuras consistia no uso de várias pranchas tingidas com cores diferentes. Hayter orquestrou uma maneira que lhe permitia a exposição simultânea das cores sobre a mesma placa, obtendo uma delicada transparência cromática e maior economia de materiais. Hayter trabalhava da seguinte forma: cobria uma placa de metal com uma fina camada de plástico adesivo. Com o buril, revelava o desenho na superfície. Uma

200 "At each successive stage in the development of the plate, a proof was pulled to reveal immediately to the artist what the result of his previous action was and to record the gradual transformation of the design or image. Although the plate was worked again and again to such a degree that it had to be abandoned, the experience familiarized the artist with the basic techniques of intaglio printmaking and served as a basis for his next effort". HAYTER, 1978, p. 4, tradução nossa. 
moeda era colada na parte inferior da placa, permitindo movimentar o suporte com liberdade. A mão que segura o buril quase não se movimenta. É placa que gira a fim de permitir o deslizar do buril. Uma vez que o artista esteja satisfeito com a composição, ele retira o plástico de algumas seções do desenho. A placa toda é mergulhada em ácido. Caso haja a intenção de criar diferentes tonalidades e texturas, uma nova série de seções do desenho tem o plástico retirado e a placa toda é exposta ao ácido novamente. Isso criava gradações de profundidade com que o ácido ataca o metal. Com uma série de rolos de diferentes pesos, Hayter aplicava camadas finas de tintas de cores e assim obtinha diferentes intensidades de cor na impressão final. Artistas do Atelier 17 também realizaram a combinação deste método com serigrafia e xilogravura.

Aquele era um espaço para a vivência de artistas dispostos a arriscar. Para Una Johnson, "os críticos e artistas mais conservadores que se opunham ao Surrealismo também refutaram a filosofia e os métodos do Atelier 17. Um número de gravurtistas mais tradicionais se sentia ameaçado pelas novas tendências e, sempre que possível, excluíam esse trabalho das exposições nacionais" (JOHNSON, 1980, p.77). ${ }^{201}$

Hayter teve um papel relevante na formação da vanguarda norte-americana do PósGuerra. Motherwell, Rothko e William Baziotes frequentaram seu atelier, mas quem teve uma experiência mais significativa da convivência com Hayter foi Jackson Pollock. O pintor norteamericano conhecia o trabalho do mestre inglês desde os anos 1930 e, por meio de um amigo em comum, John Graham, passou a frequentar o estúdio no outono de 1944.

Ambos os artistas tinham um interesse em automatismo e livre expressionismo abstrato, mas, mais importante, compartilhavam a tendência da expressão dinâmica e linear. (...) A ênfase de Hayter no desenho automático e o estranhamento de trabalhar com uma nova ferramenta parece ter libertado a linha de Pollock da função descritiva e simbólica (MOSER, 1978, p. 6). ${ }^{202}$

\footnotetext{
201 "Critics and more conservative artists who opposed Surrealism also refuted the philosophy and methods of the Atelier 17. A number of more traditional engravers felt threatened by new trends and, when possible, excluded the work of national exhibitions". JOHNSON, 1980, p.77, tradução nossa.

202 "Both artists had an interest in automatism and free, expressionistic abstraction, but, more important, they shared a tendency toward dynamic, linear expression (...) Hayter's emphasis on automatic drawing and the
} 
Pollock trabalhou com Hayter no período exatamente anterior ao desenvolvimento de sua fase madura. Enquanto permaneceu no atelier, produziu entre 10 e 11 pranchas, nenhuma das quais fez tiragens comerciais. Esse fato reforça a tese de que seu mergulho na gravura foi pontual e se devia mais ao interesse em adquirir disciplina e maior liberdade do traço, não por querer se dedicar, necessariamente, à gravura enquanto meio de expressão.

"A ênsafe constante do Atelier 17 na linha reforçou a tendência de Pollock de usá-la como sua fonte primeira de expressão" (MOSER, 1978, p.7). ${ }^{203}$ A historiadora Joann Moser sugere ainda que a transição de Pollock da pintura de cavalete para a tela estendida no chão se deve à experiência adquirida na gravura, uma vez que o gravurista também trabalha com essa mesma mobilidade de ponto de vista e constantemente altera a orientação de sua prancha. Não era incomum, por exemplo, um gravurista trabalhar na composição de ponta cabeça, girando a placa de metal mediante necessidade, decidindo apenas nos movimentos finais qual deveria ser a orientação da obra. "A inspiração de Pollock ao trabalhar com a tela no chão e se mover entorno de seus quatro lados pode, em parte, ter como origem sua breve experiência como gravurista no Atelier 17 (MOSER, 1978, p.8). ${ }^{204}$

É grande o legado do Atelier 17 para a arte norte-americana moderna, não só por Pollock e outros nomes da vanguarda que frequentaram o espaço, mas também pela sua influência na sistematização do ensino de gravura no país. Antigos membros do atelier viriam a montar seus próprios estúdios e assumiram posições em departamentos de artes plásticas nas universidades norte-americanas, divulgando os princípios de Hayter para uma nova geração. Gabor Peterdi, por exemplo, inaugurou um estúdio no porão do Brooklyn Museum e assumiu um cargo no Hunter College e na Universidade de Yale. Da mesma forma, Fred Becker foi o fundador de uma oficina na Universidade de Washington em St. Louis em 1948.

Segundo o historiador Stephen Coppel, um aspecto importante do impacto de Hayter foi ter feito emergir linhas de pesquisas dentro de instituições acadêmicas com ênfase em

strangeness of working with a new tool seem to have freed Pollock's line from any descriptive or symbolic function". MOSER, 1978, p. 6, tradução nossa.

203 "The constant emphasis on line at Atelier 17 reinforced Pollock's tendency to use it as his primary means of expression". (MOSER, 1978, p.7, tradução nossa).

204 "Pollock's inspiration to work on a canvas placed on the floor and to move around all four sides of it may stem in part from his brief experience as a printmaker at Atelier 17". (MOSER, 1978, p. 8, tradução nossa). 
procedimentos e avanços técnicos. "Seus ensinamentos no ambiente acadêmico asseguraram a continuação dos preceitos de Hayter como a nova ortodoxia, que veio a dominar a prática da gravura na América durante os anos 1950" (COPPEL, 2008, p.33-34). ${ }^{205}$

205 Their teaching within an academic environment ensured the continuation of Hayter's precepts as the new orthodoxy; it came to dominate the practice of printmaking in America during the 1950's". COPPEL, 2008, p.33-34, tradução nossa. 
Gravuras da doação Nelson Rockefeller (1950) 


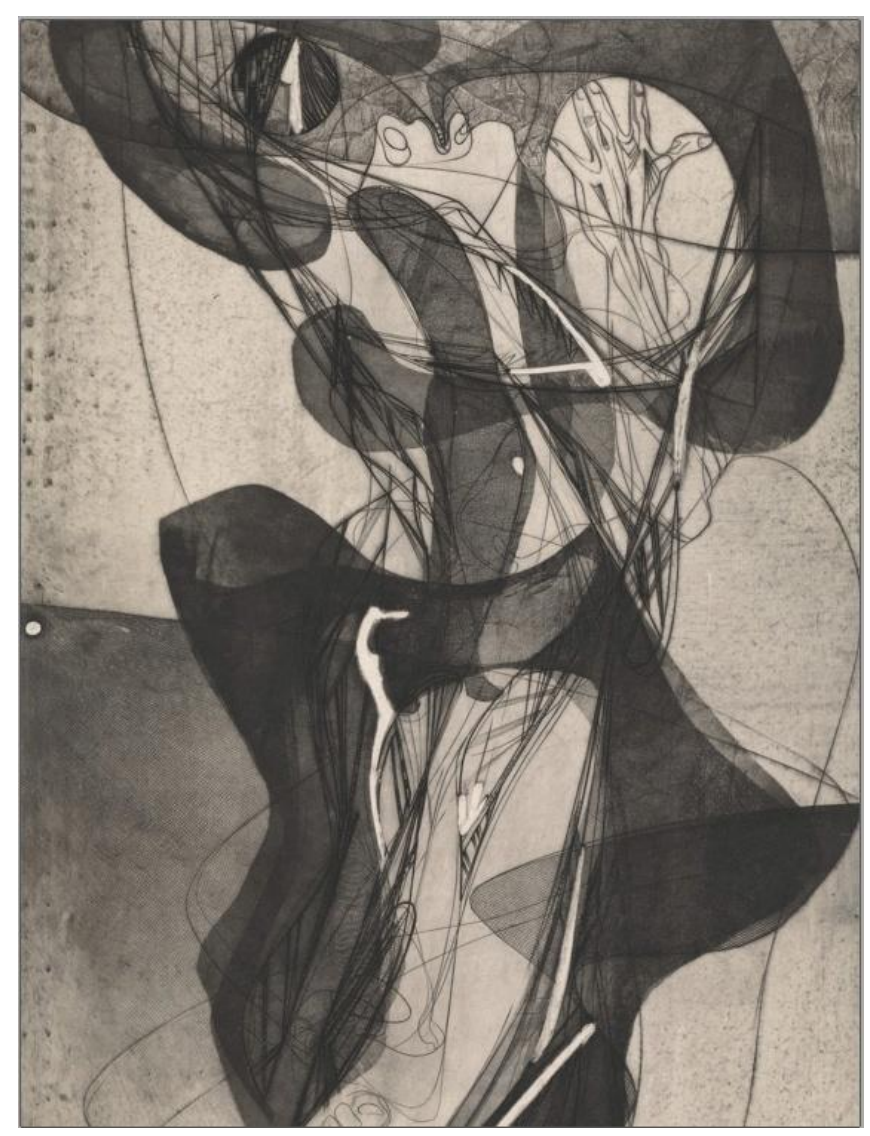

[Fig. 76] Tarantelle [Tarantela] (1943)

Stanley William Hayter (Reino Unido - 1909-1988)

Verniz mole e buril em cores sobre papel; $55,2 \times 33 \mathrm{~cm}$.

Essa composição é batizada com o nome da dança camponesa típica do sul da Itália. A origem da tarantela é também associada à picada de aranhas venenosas, que segundo crenças populares induziria uma dança frenética e convulsiva. O artista usa desse repertório para compor sua Tarantelle. Ele adota dois métodos diferentes para retratar os corpos do casal de dançarinos, cujos braços e pernas se entrelaçam em um ritmo sedutor. Essa obra foi apresentada pela primeira vez na exposição itinerante New ways of gravure, do MoMA, em 1944, assim como na mostra Master prints, de 1949, que marcou a abertura oficial do Abby Rockeffeller Print Room. 


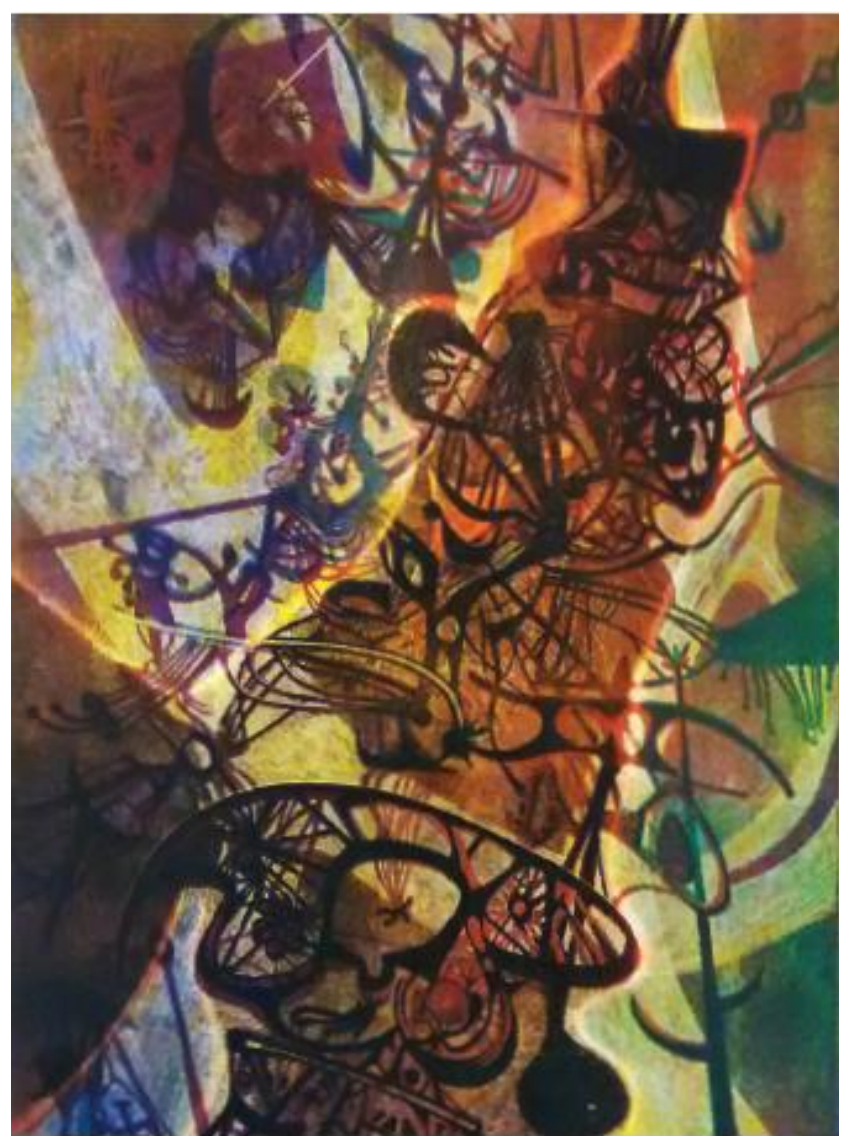

[Fig. 77] Aerial jungle IV [Floresta imaginária] (1948)

Fred Becker (Estados Unidos - 1913-2004)

Água-tinta e ponta seca em cores sobre papel; $44,8 \times 30,3 \mathrm{~cm}$

Essa obra é um exemplo do tipo de exercício livre e aproximação imediata com o suporte da gravura que era incentivada no Atelier 17. Becker substituiu uma composição premeditada por uma gestualidade expansiva e intuitiva, atitute que pautou seu trabalho mais abstrato dos anos 1950. Becker nasceu em Oakland, Califórnia, e se emancipou em 1933, mudando-se para Nova York para estudar arquitetura. Aprendeu sozinho a técnica da xilogravura, pela qual se apaixonou e fez carreira. Foi convocado para servir na Segunda Guerra Mundial e teve que suspender a prática artística até 1946. Becker era próximo de Hayter e, com o mestre, experimentou várias técnicas de gravura, em uma atitude destemida e revolucionária para a época. Suas obras fazem parte hoje dos acervos de museus como o Metropolitan Museum of Art, MoMA e Whitney, e ele é considerado um dos principais expoentes do período de "renascimento da gravura moderna norte-americana" dos anos 1940 e 1950. Sua influência no panorama norte-americano muito se deve também a uma longa carreira como professor da Universidade de St. Louis e Universidade de Massachusetts, onde instalou departamentos de artes gráficas que deram continuidade ao espírito inovador e experimental do Atelier 17. 


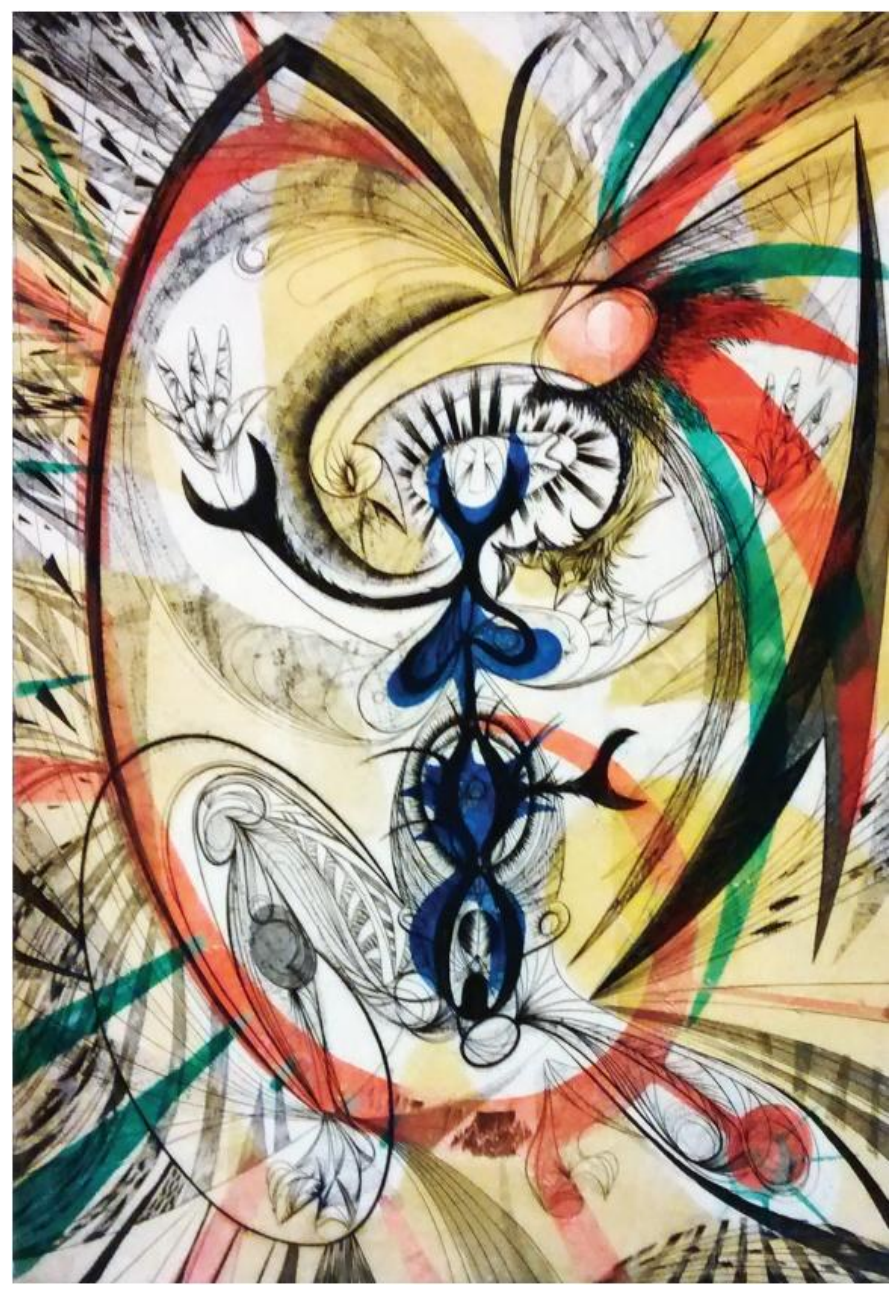

[Fig. 78] Sign of the lobster [Sinal da lagosta] (1947-48)

Gabor Peterdi (Hungria -1915-2001)

Verniz mole e água-tinta em cores sobre papel, $50,4 \times 37,7 \mathrm{~cm}$

Nascido em Budapeste, Hungria, ganhou o prestigiado Prix de Rome e estudou na conceituada Academie Julian, em Paris. Era um prodígio. Aos 14 anos, já tinha organizado duas exposições solo. Peterdi era um gravurista excepcional e um professor influente, tendo dado aulas na Universidade de Yale, no Brooklyn Art School e no Hunter College. Essa foi a primeira gravura a cores de Gabor Peterdi e é uma obra marcante de sua carreira. Entre 1947 e 1948, realizou um portifólio de gravuras com o tema da lagosta, entre os quais Sign of the lobster [Sinal da lagosta], The dreamy lobster [A lagosta adormecida] e Nervous lobster [Lagosta nervosa]. Peterdi começou a frequentar o Atelier 17 ainda em Paris, entre 1933 e 1939, e veio a se reencontrar com Hayter em Nova York depois da guerra. 


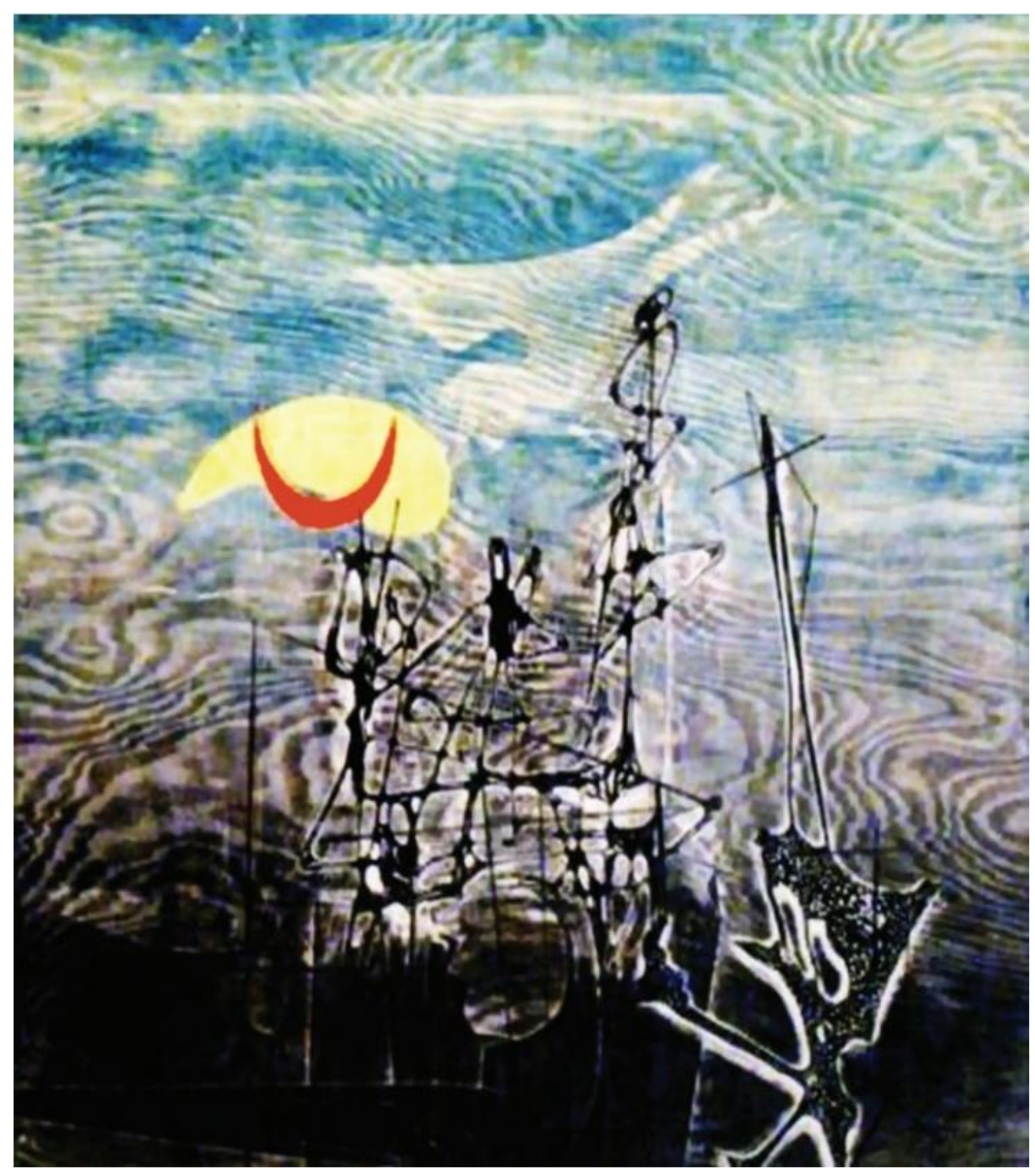

[Fig. 79] The Sea [O mar] (1949)

Boris Margo (Ucrânia - $1902-1995)$

Cellocut em cores sobre papel; $42,1 \times 42,2 \mathrm{~cm}$

Boris Margo foi o inventor de uma técnica completamente nova de gravura, a cellocut. A história da invenção do cellocut foi acidental. Margo vinha desenvolvendo gravuras em madeira por muito tempo, quando um dia deparou com uma folha de celulóide caída no chão e questionou se com aquilo era possível criar algo novo. Ele começou a trabalhar o material e percebeu que celulóide era fácil de manusear com um buril e reagia a solventes, permitindo que o material fosse usado na produção de gravuras no lugar das tradicionais chapas de zinco ou cobre. Margo dissolvia a folha de celulóide em ácido até o ponto em que criava uma textura de pasta, este verniz era depositado sobre uma prancha de madeira e quando o material estivesse seco criava-se uma camada plástica sobre a qual era possível incisar. A gravura The sea [O mar] é um exemplo desse método. As rugosidades que formam o efeito das águas do oceano e de nuvens no céu são registros do meio líquido do celuloide. Essa obra ganharia repercussão internacional ao integrar a exposição Master prints do MoMA e a Exposição anual de gravura do Brooklyn Museum em 1949. 


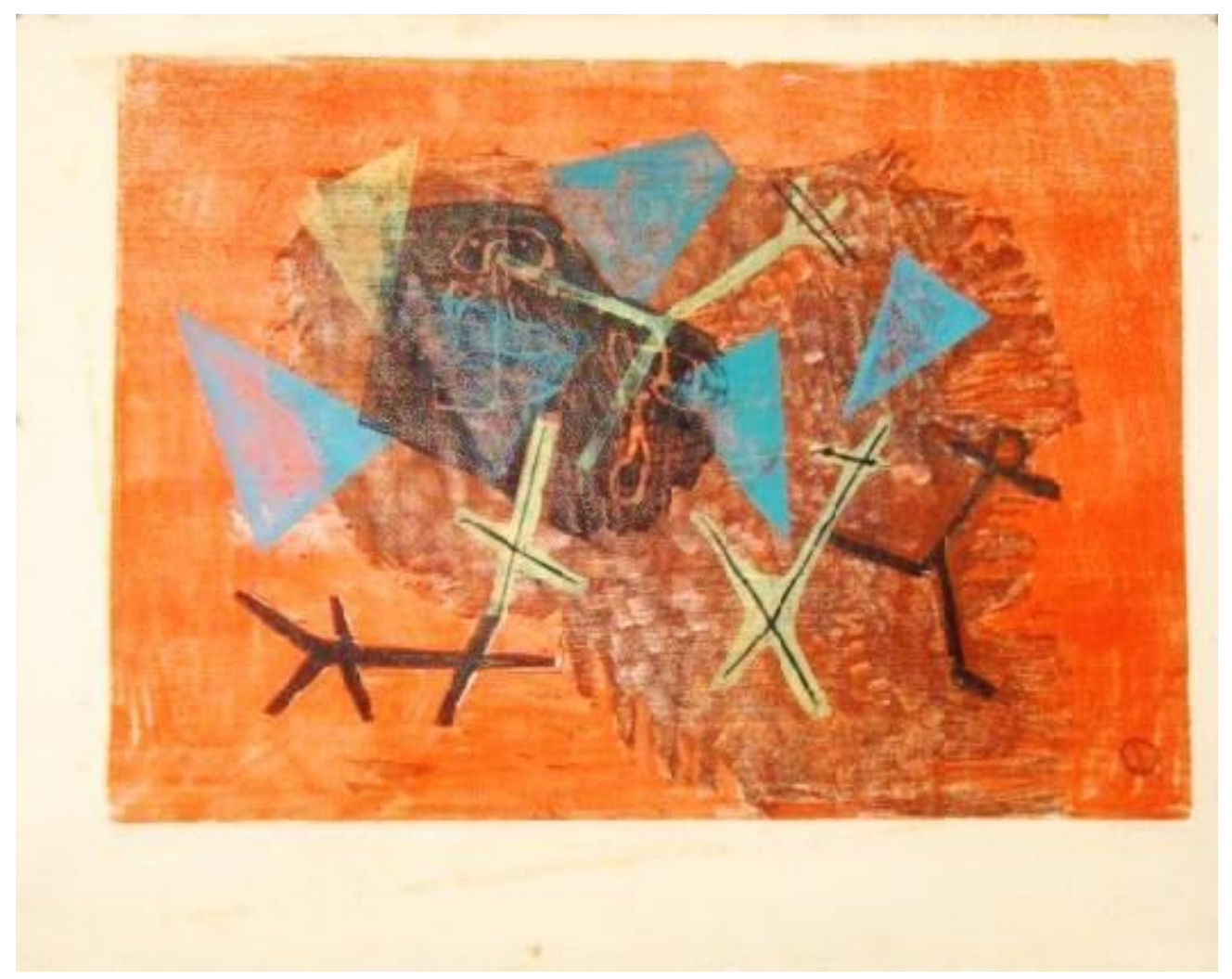

[Fig. 80] Carnival [Carnaval] (1945)

Louis Schanker (Estados Unidos - 1903-1981)

Xilogravura em cores sobre papel; $36,5 \times 53, \mathrm{~cm}$.

Louis Schanker é um artista do Bronx, filho de judeus ortodoxos de descendência romena. Quando criança, fugiu de casa e se juntou ao circo, e na adolescência, viajou pelo país pegando caronas e morando nas ruas. Sua formação artística se deu na Art Students League e na igualmente progressista Cooper Union de Nova York, assim como em viagens pela França, Espanha e Itália. Foi um dos artistas que fez parte do programa de fomento às artes durante a Grande Depressão - o Federal Art Project - e ao longo de toda a carreira foi um defensor tenaz da abstração. Ele integrou o grupo "Os Dez", ao lado de Mark Rothko, para boicotar a exposição anual do Whitney Museum em 1938 devido à falta de artistas abstratos na seleção. Schanker se tornou uma referência na produção de xilogravuras de composições abstratas e festivas, como em Carnival [Carnaval], em que trabalhou com formas geométricas simplificadas de maneira quase lúdica, sobrepondo finas camadas de tinta que deixam entrever a cor dos planos inferiores favorecendo a transparência da composição. Schanker dava aulas de gravura no currículo regular da New School for Social Research, quando entrou em contato pela primeira vez com o Atelier 17. Logo ele se aproximaria de Stanley William Hayter, com quem manteve uma longa relação de amizade e admiração profissional. 


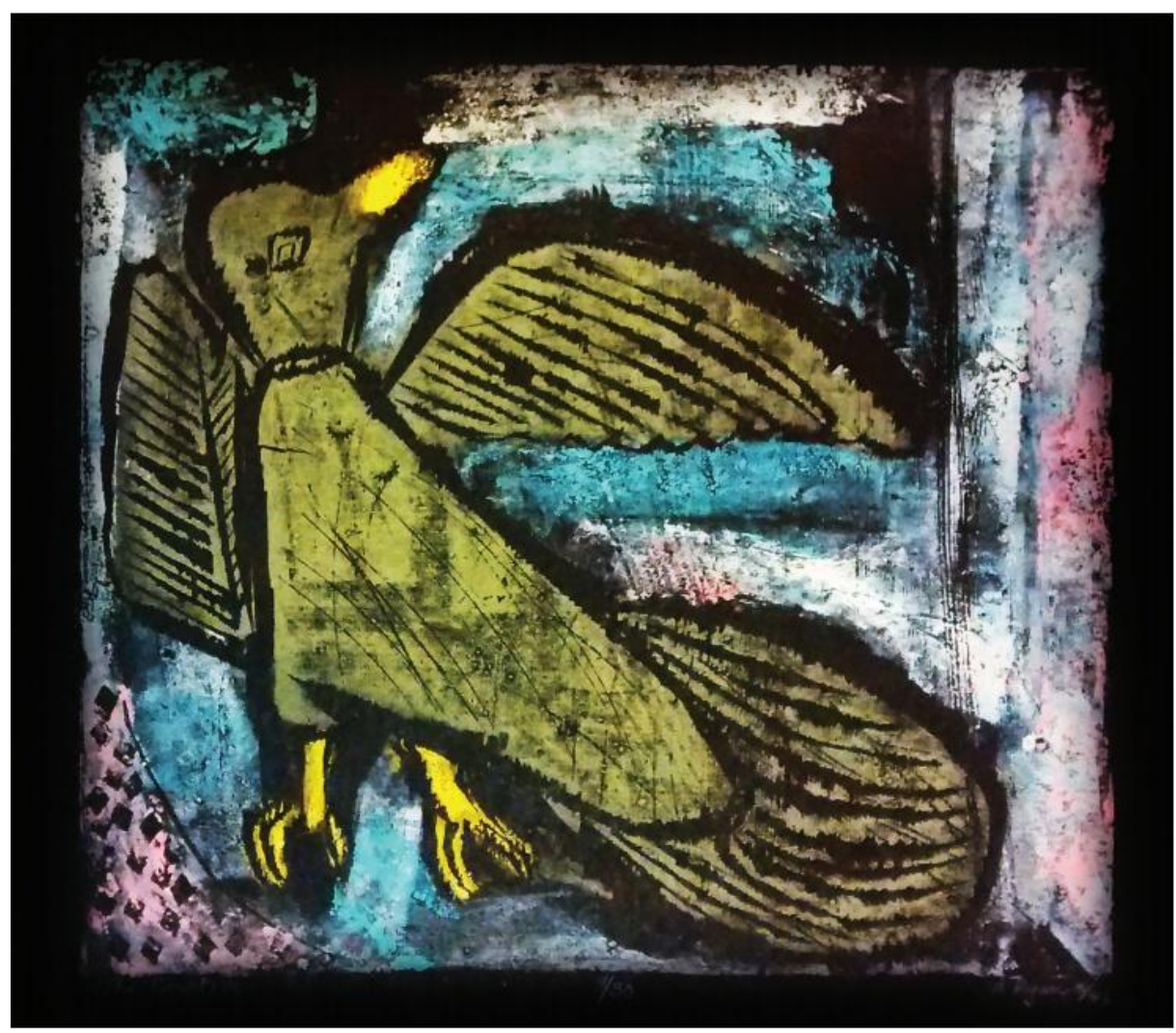

[Fig. 81] The captive [O cativo] (1946)

Anne Ryan (Estados Unidos - 1889-1954)

Xilogravura em cores sobre papel; $35,7 \times 39,7 \mathrm{~cm}$

Anne Ryan ingressou tarde na prática artística. Tinha quase 60 anos quando começou a fazer as primeiras gravuras. Nascida em Hoboken e filha de um banqueiro, ela era poeta e sua incursão nas artes plásticas se deveu ao estímulo do amigo Hans Hofmann, figura central do Expressionismo Abstrato. Anne trabalhou amplamente com a xilogravura em cores, técnica que aprendeu nos cursos de Louis Schanker na New School for Social Research, mas diferentemente de Schanker - que preferia usar vários blocos para aplicar cores - Anne passou a adotar um método próprio, em que reutilizava um único pedaço de madeira tingindo áreas do bloco com cores diferentes ao mesmo tempo e sem se misturar. Essa técnica havia sido aprimorada por artistas de Provincetown, Massachusetts, a partir de influências da gravura chinesa, e foi chamada de gravura da linha branca (white-line print). Esse método exigia desenhos simplificados e às vezes Anne aplicava a tinta com as próprias mãos, sem usar rolos, de modo a criar efeitos de borrão, como vemos em The captive [O cativo]. Essa obra faz parte de uma série de gravuras noturnas realizada com embalagens de filmes fotográficos, que ela prensava e reutilizava. Ryan trabalhou com gravuras por um curto período (1945 a 1949), passando depois para a intensa produção de colagens pela qual é mais conhecida hoje. 


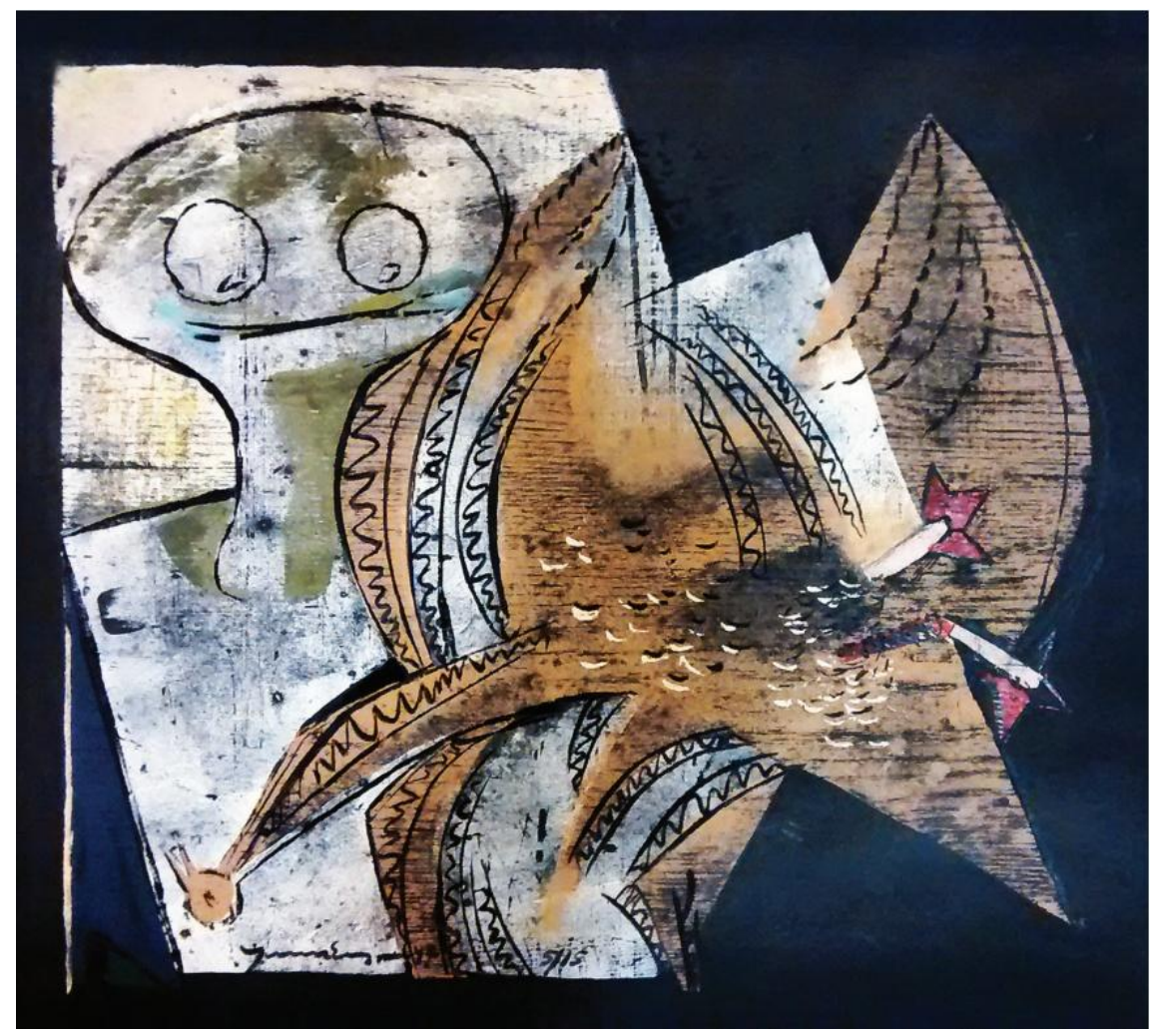

[Fig. 82] Dead bird [Pássaro morto] (1947)

Adja Yunkers (Letônia - 1900-1983)

Xilogravura em cores sobre papel; 43, 2 X 50,6 cm

A obra gráfica de Adja Yunkers fez parte da retomada da xilogravura por artistas modernos, movimento que marcou o panorama da gravura nos anos 1940 e 1950. Seu objetivo era refutar "a concepção de que a xilogravura é uma forma inferior de arte, e provar que ela é hoje uma forma artística autônoma", escreveu Yunkers, em 1949 (BARTELIK, 2000, p. 43). ${ }^{206}$ Ligado ao grupo de surrealistas da Suécia, Yunkers era natural da cidade de Riga, capital da Letônia, e se mudou para Nova York depois de um incêndio catastrófico no seu atelier em Estocolmo, que liquidou toda a sua produção de gravuras e pinturas. Desde 1942, desenvolvia uma obra singular, que ele ampliou em sua fase norte-americana, quando começou a trabalhar com o grupo de xilogravuristas da New School for Social Research, onde teve contato com Hayter. A obra Dead bird é uma das primeiras composições realizadas neste momento de retomada da produção de gravuras em Nova York. Nos Estados Unidos, Yunkers foi bem recebido, museus rapidamente adquiriram suas obras e ele angariou um público para sua produção, permanecendo ativo na cena artística e acadêmica até sua morte em 1983. Dead bird integrou a exposição inaugural do Abby Rockefeller Print Room no MoMA em 1949.

206 "To end the general conception of the woodcut being an inferior form of art, and to prove that woodblock printing today is an automatic form of art with its own well defined rights". BARTELIK, 2000, p.43. 


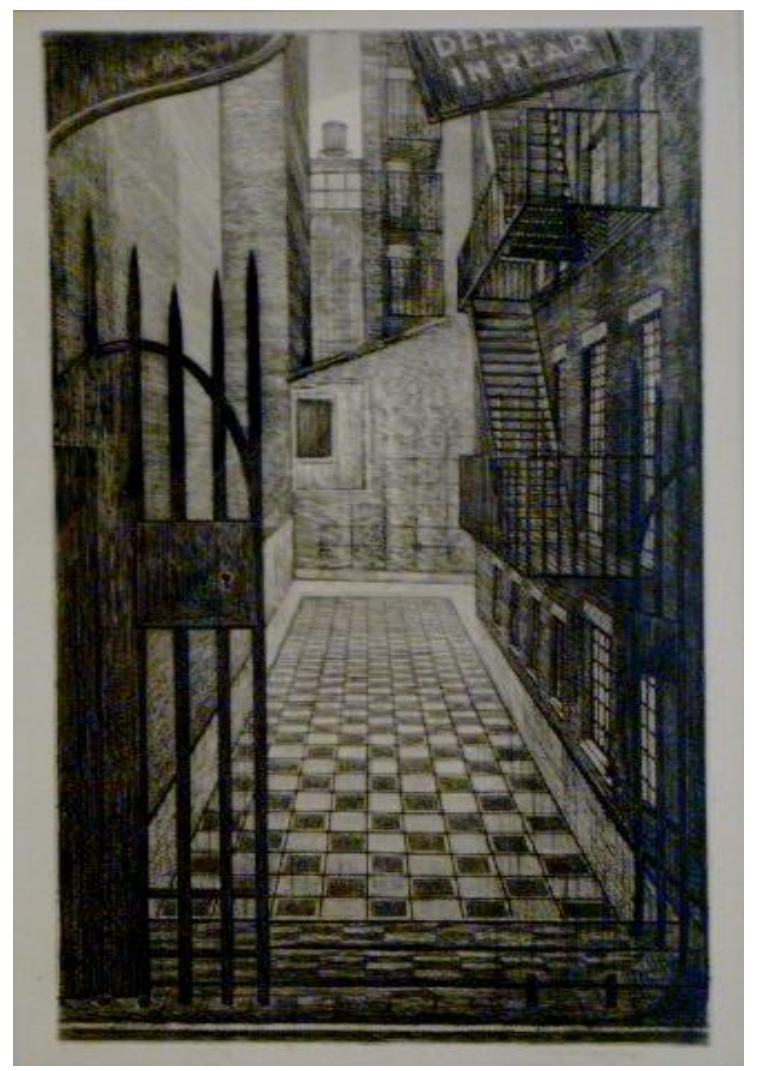

[Fig. 83] Alleyway [Passagem no beco] (1948)

Armin Landeck (Estados Unidos - 1905-1984)

Buril e ponta seca sobre papel; $34,9 \times 17,7 \mathrm{~cm}$

Landeck fez parte do Atelier 17 por um breve período em 1941. Graduado em arquitetura pela Universidade de Columbia, ele nunca usou cor na sua gravura e tinha como tema central as vistas de cidades europeias. Seu trabalho era distante do substrato surrealista e abstrato de Hayter, ainda assim foi ele que mostrou a Landeck o uso do buril de ponta seca e as qualidades da placa de cobre. Esse trabalho é uma demonstração de maestria nesta técnica e faz parte de uma sequência de becos novaiorquinos. Alleyway [Passagem no beco] marca uma passagem do ponto de vista de Landeck, que até então vinha trabalhando paisagens dos telhados. A cidade passa a ser desvendada a partir do chão. Os prédios não são os monumentos da arquitetura de outrora. As fachadas passam a ser entrecortadas, anguladas. A cidade não é mais um horizonte aberto dos telhados, mas um labirinto misterioso e claustrofóbico de cimento, saídas de incêndio e entradas de serviço. Landeck foi um artista prestigiado em vida e premiado por alguns dos grupos mais tradicionais de gravura, como a Society of American Etchers. Essa gravura teve uma tiragem de 100 exemplares, o número máximo que o artista permitia antes de anular a placa original, e foi comercializada pela tradicional galeria Kennedy \& Co por US\$ 24. Essa obra também faz parte da coleção permanente do MoMA. 


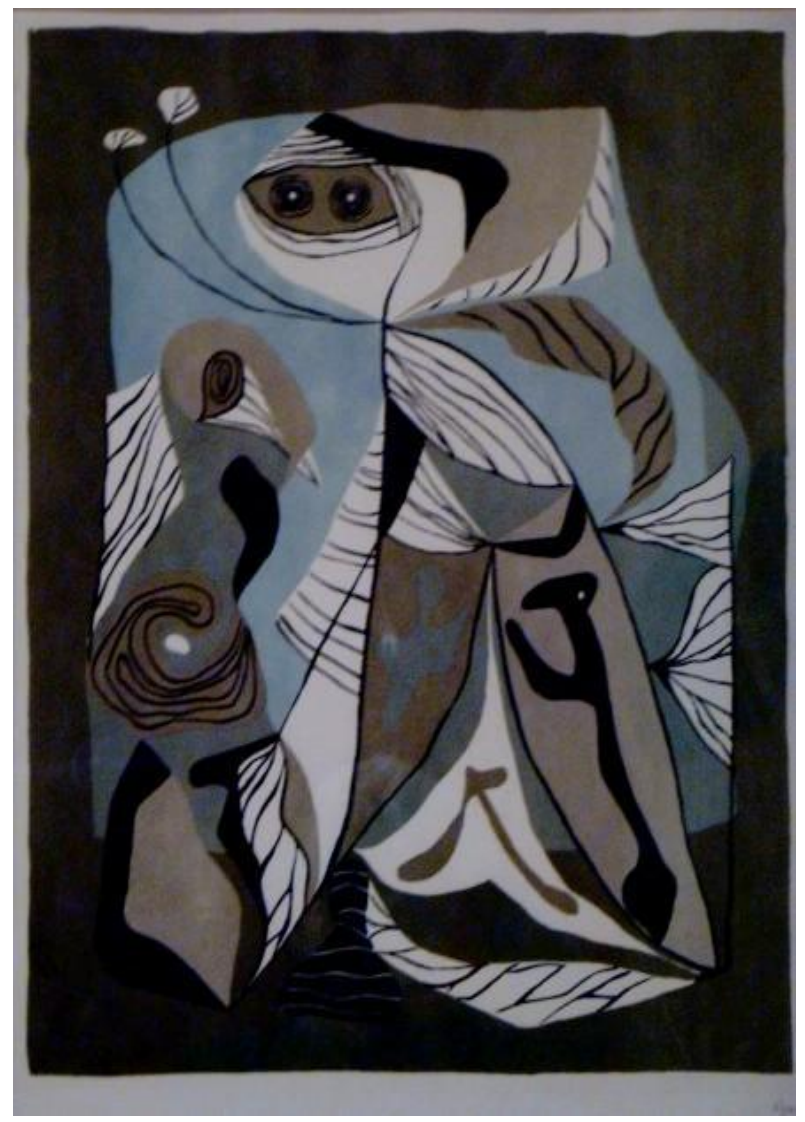

[Fig. 84] That which we mourn [Aquele a quem pranteamos] (1945)

Edward Landon (Estados Unidos - 1911-1984)

Serigrafia em cores sobre papel; $46,7 \times 36,7 \mathrm{~cm}$.

Edward Landon foi um dos pioneiros da serigrafia e um dos primeiros artistas a testar esse suporte nas oficinas do Federal Art Project de Nova York, em 1938. Quem cunhou o termo serigrafia ou silk-screen (no sentido de "seda") foi o crítico Carl Zigrosser, na tentativa de separá-la da produção de estêncil usada pela indústria publicitária. Na época de Landon, muitas galerias e museus não aceitavam serigrafias, pois consideravam uma forma de impressão rudimentar e comercial. Landon foi um agente importante para reverter essa imagem. Ele organizou a primeira exposição de serigrafia dos Estados Unidos, no Springfield Museum of Fine Arts em Massachusetts, e fundou a National Serigraph Society, em 1944, ao lado de Robert Gwathmey, outro artista contemplado na primeira doação Rockefeller. Essa obra é deste período inicial de estruturação de uma prática profissional de silk-screen. Landon seria também encarregado de organizar itinerâncias internacionais através da agência de Serviços de Informação do governo norte-americano, com o objetivo de promover essa técnica no exterior e valorizar a inovação gráfica norte-americana. Seu trabalho pavimentou o caminho para os expoentes da Pop Art, como Andy Warhol e Roy Lichtenstein. 


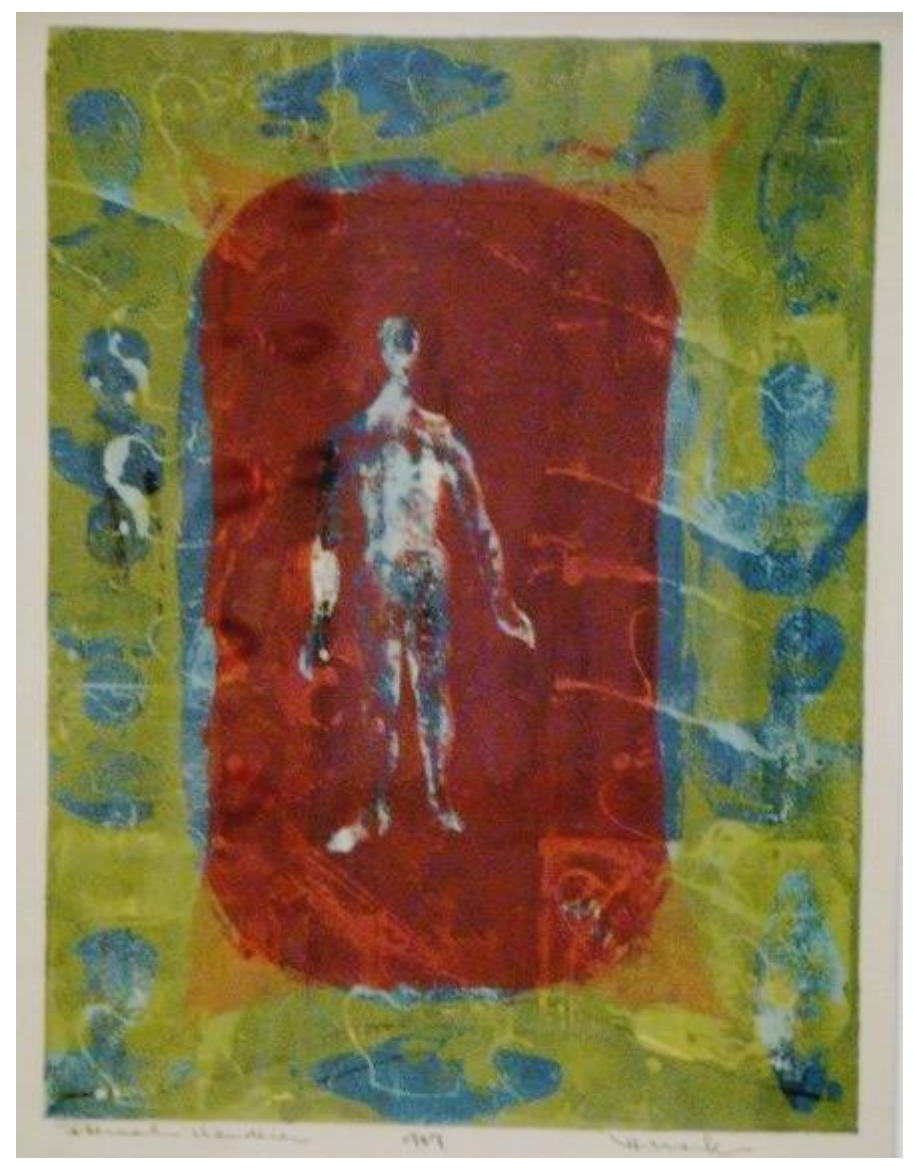

[Fig. 85] Eternal wanderer [Eterno errante] (1947)

Henry Mark (Estados Unidos - 1915- ?)

Serigrafia em cores sobre papel; $36,8 \times 26,8 \mathrm{~cm}$.

Nascido no Brooklyn, New York, Henry Mark foi um artista autodidata. Começou a trabalhar com a serigrafia no momento em que a técnica era considerada um suporte comercial e não era respeitado no meio artístico. A gravura Eternal wanderer [Eterno errante] foi prêmio de aquisição da National Serigraph Society, associação fundada por Edward Landon e Robert Gwathmey para a divulgação da serigrafia. Ela foi exibida na mostra do MoMA, Some American prints: 1945-50 [Algumas gravuras norteamericanas: 1945-50], organizada por William Lieberman em 1951, como uma continuidade do trabalho do Departamento de Gravuras e Desenhos, inaugurado dois anos antes a partir da coleção de Abby Rockefeller, em adquirir e exibir as novas expressões gráficas desenvolvidas nos Estados Unidos. 


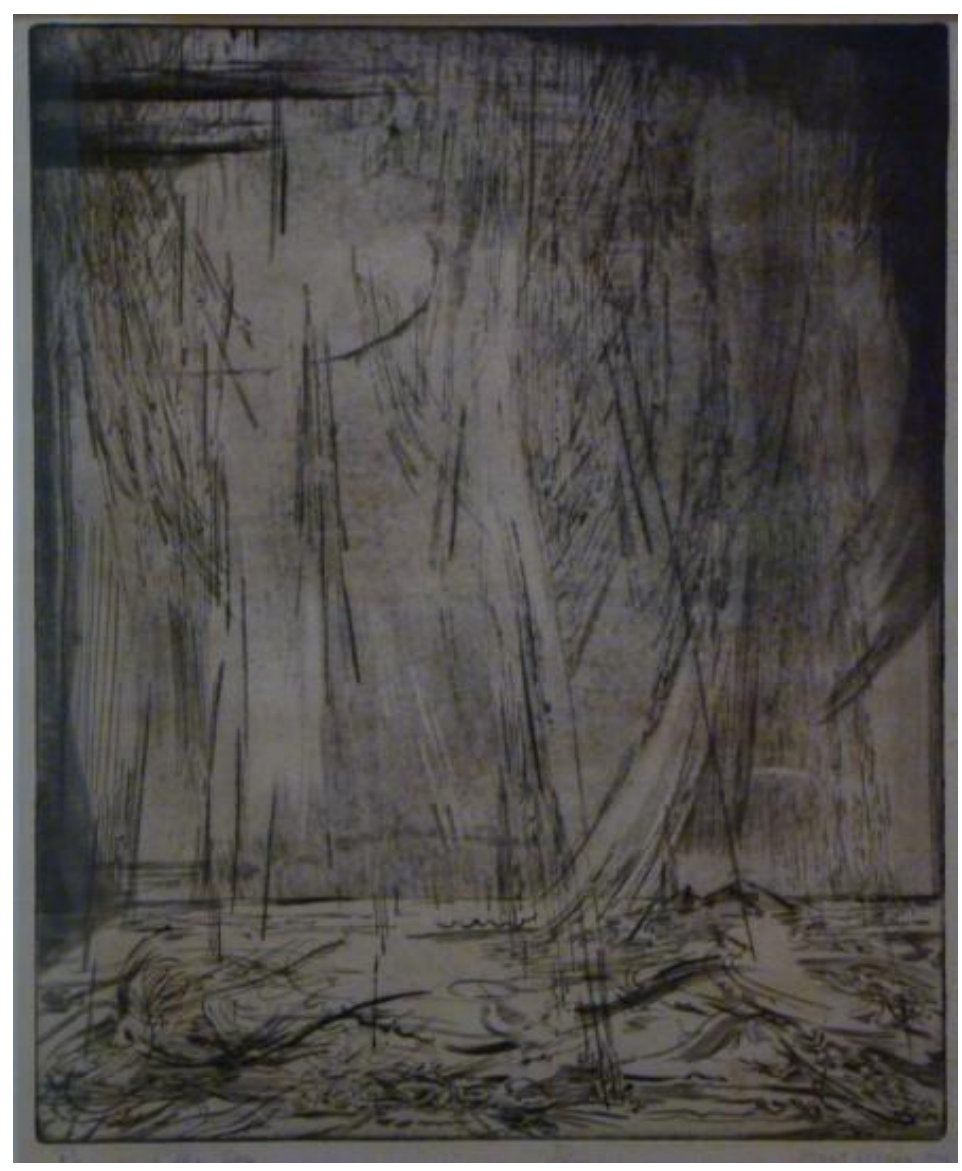

[Fig. 86] Rain and sea [Chuva e o mar] (1946)

Karl Schrag (Alemanha - 1912-1995)

Buril, verniz mole e água-tinta sobre papel; $37,9 \times 27,8 \mathrm{~cm}$

Essa obra foi prêmio de aquisição da primeira exposição anual de gravuras do Brooklyn Museum em 1947. Ela foi realizada em Nova York, depois de Schrag começar a frequentar o Atelier 17 e experimentar novas possibilidades gráficas com o buril. Sob a influência de Hayter, sua arte sofre uma virada e começa a adotar uma linguagem mais abstrata e investigar novos alcances expressivos da linha, como vemos em Rain and sea [Chuva e mar]. "O buril é um instrumento do movimento porque todas as mais delicadas voltas e mudanças de direção da sua mão e mesmo todas as pressões que você aplica são imediatamente traduzidas na linha", descreve Schrag. ${ }^{207}$ Nascido na pequena cidade alemã de Karlsruhe, ele nunca tinha realizado uma gravura até se mudar para Nova York em 1938 e começar a frequentar o Art Students League, uma escola de vanguarda que era administrada pelos próprios alunos. Nessa época

\footnotetext{
207 "The burin is almost (...) an instrument of movement because all your finest twists and changes in the direction of your hand and even all the pressures that you apply are immediately translated into that line". Entrevista oral com Karl Schrag, 14-20 de outubro de 1970, Archives of American Art, Smithsonian Institution.
} 
conhece Hayter, que Ihe confiaria a direção do Atelier 17, quando Hayter retornou para Paris depois da guerra. Em 1947, Schrag se vinculou à galeria Kraushaar e fez sua primeira exposição individual nos Estados Unidos. Neste ano foi premiado pela exposição do Brooklyn Museum. Essa galeria representaria o artista por toda a vida e foi quem intermediou a venda de Rain and sea [Chuva e o mar] para Nelson Rockefeller. 


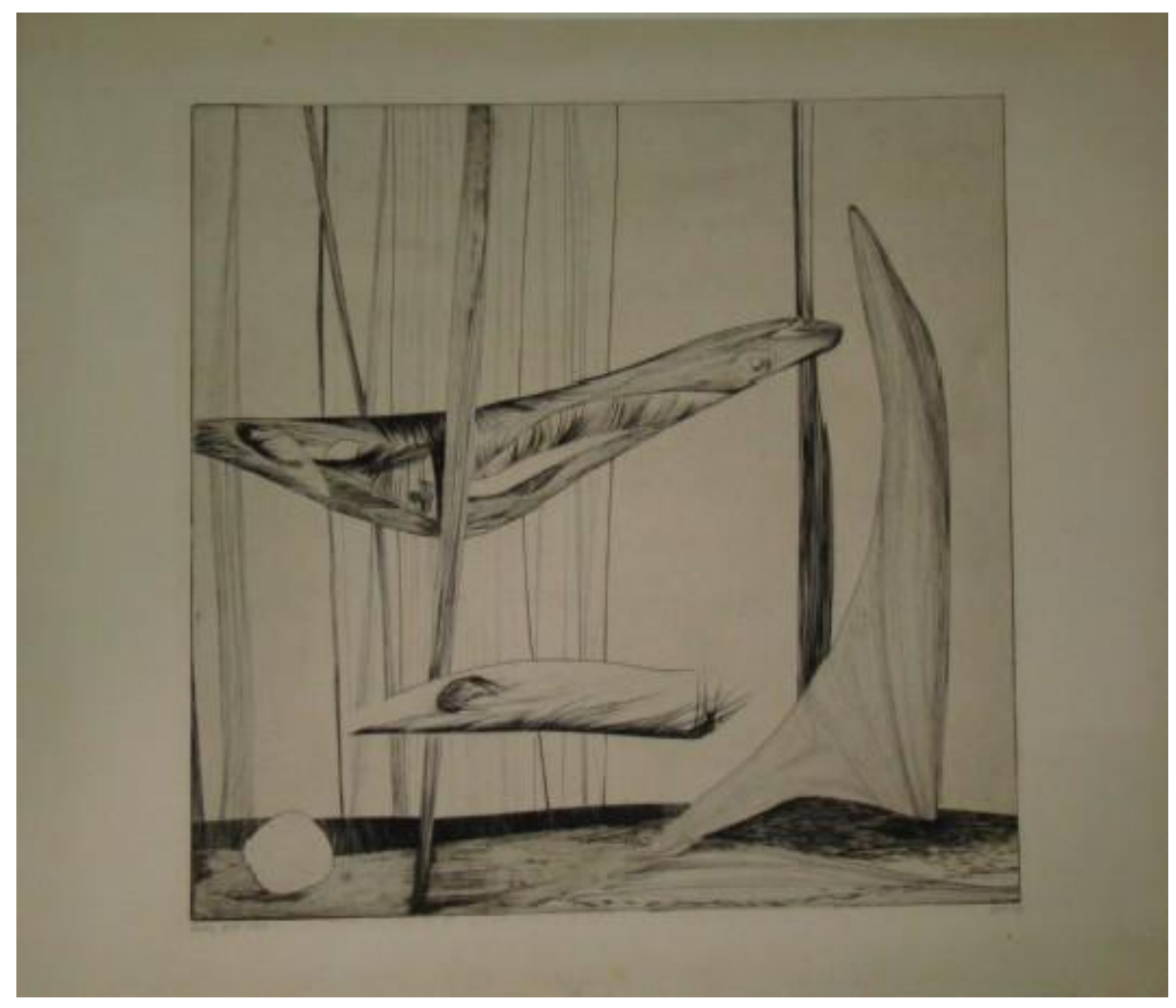

[Fig. 87] Heavy bird [Pássaro pesado] (1950)

Marjean Kettunen (Estados Unidos - 1922-?)

Buril e ponta seca sobre papel; 45,3 X 49,2 cm.

Uma das poucas mulheres da coleção Rockefeller, Marjean Kettunen, também conhecida como Kett, foi uma das artistas vinculadas ao Atelier 17 de Hayter, em Nova York. Ainda que minoria, um grupo de artistas mulheres teve sucesso na produção gráfica dos Estados Unidos em meados do século XX, impulsionadas pela rede de contatos do Atelier 17, além de galerias e museus que promoviam seu trabalho. Marjean fazia parte de um grupo maior de gravuristas modernas que também incluía Minna Citron, Eleanor Coen, Sue Fuller e Anne Ryan. A curadora Una Johnson, do Brooklyn Museum, teve um papel importante na promoção dessas artistas. Heavy bird [Pássaro pesado], de Marjean, faz parte do acervo permanente do museu, tendo sido prêmio de aquisição da exposição anual de gravura do Brooklyn em 1950. Nascida em East Lansing, Michigan, ela fez a Cranbook Academy e imigrou para Nova York para estudar na New School for Social Research. Obras suas fizeram parte de exposições do MoMA, como Young American printmakers [Jovens gravadores norte-americanos] (1954), organizada pelo Junior Council para popularizar a gravura no mercado de arte nacional e internacional. 


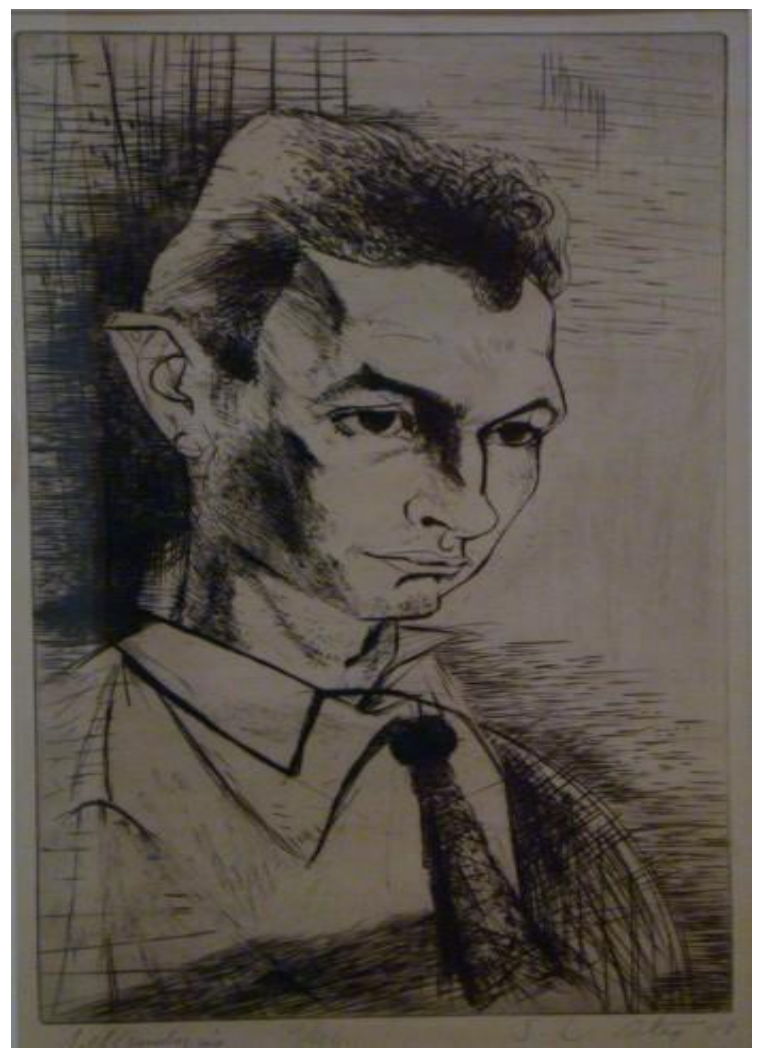

[Fig. 88] Self-analysis [Autoanálise] (1947)

James Louis Steg (Estados Unidos - 1922-2001)

Buril sobre papel; $60,6 \times 33,9 \mathrm{~cm}$

Essa obra de James Steg é um autorretrato realizado com a técnica tradicional do buril. Foi prêmio de aquisição da segunda exposição anual de gravuras organizada pelo Brooklyn Museum, em 1948. Muitas das obras presentes na doação Rockefeller vieram dessas mostras do Brooklyn, que serviram como uma plataforma para a divulgação de novos talentos da gravura. O MoMA também adquiriu Self-analysis [Autoanálise] por meio do fundo Abby Rockefeller. Nascido em Alexandria, Virgínia, Steg foi aluno do argentino Mauricio Lasansky, fundador do lowa Print Group, nos anos 1940, período em que se formaram vários coletivos e associações de colecionadores para divulgar a prática da gravura. Era um momento em que a gravura, até então desvalorizada, estava em ascensão no cenário artístico. Steg deu continuidade à disseminação deste suporte como professor da Universidade de Tulane, New Orleans. Ele seria um dos primeiros artistas norte-americanos a misturar a gravura com a colagem, na produção das chamadas collagraphs (que consistia em inserir materiais como recortes de jornal, pedaços de metal, folhas, tecido, areia na placa onde seria impressa a imagem). Apesar de sua inventidade e importância na promoção de novas experiências artísticas, Steg foi pouco estudado pela história da arte e permanece hoje quase desconhecido. 


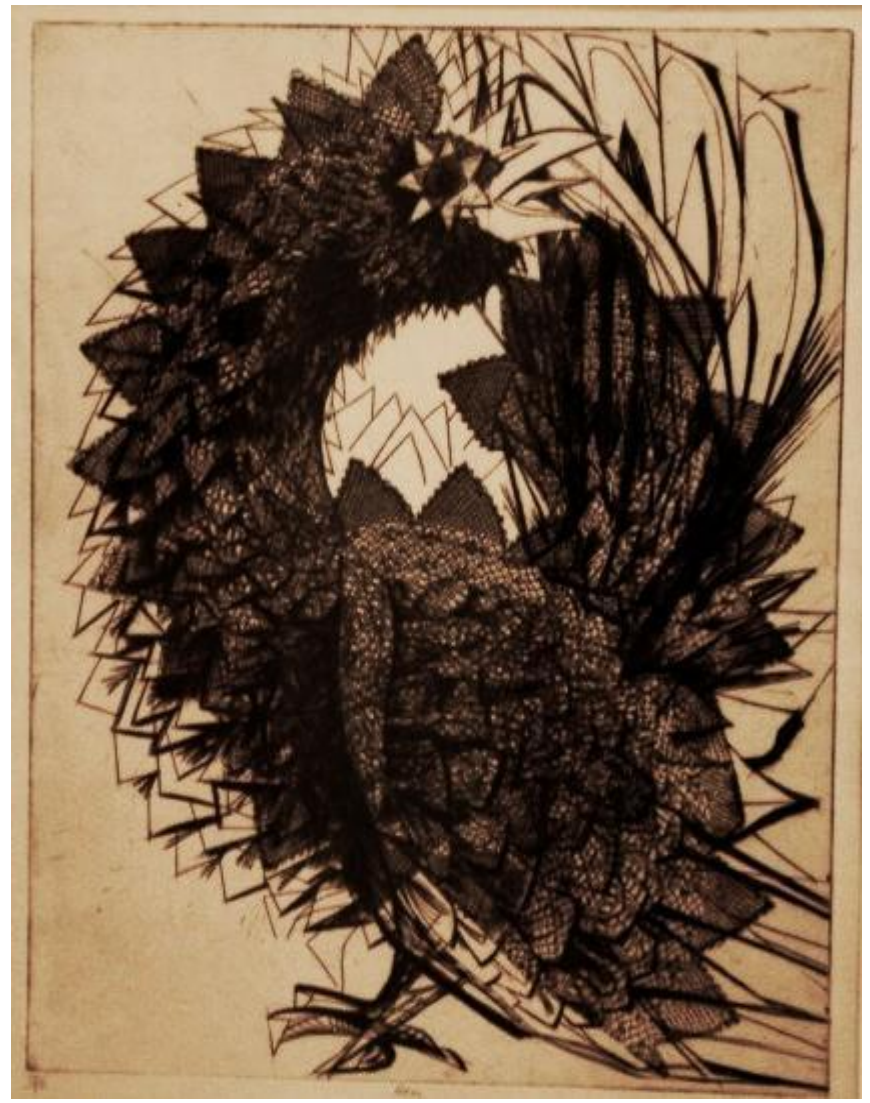

[Fig. 89] Hen [Galinha] (1945)

Sue Fuller (Estados Unidos - 1914-2006)

Verniz mole e água-forte sobre papel; $37,4 \times 30,3 \mathrm{~cm}$

Sue Fuller começou a experimentar com verniz mole no Atelier 17, em 1943. Aos poucos, ela aperfeiçoou essa técnica e introduziu o uso de tecidos nas suas composições. Uma colagem que pertence hoje ao Metropolitan Museum of Art revela que, ao compor Hen [Galinha], ela recortou pedaços de renda vitoriana da coleção de sua mãe para formar o corpo da galinha. Esse tecido era pressionado contra um meio de verniz mole, criando o padrão estrutural da galinha, depois finalizada com o desenho da cabeça, pé e penas do animal. Sue era uma das poucas gravuristas mulheres com uma linguagem moderna circulando na vanguarda. Em vários trabalhos, ela usaria elementos do repertório doméstico feminino, principalmente corte e costura, tear e crochê. Sue Fuller nasceu em Pittsburg, Pennsylvania, e teve uma edução privilegiada. Estudou no Carnegie Institute of Technology e na Universidade de Columbia. Teve aulas com Stanley Hayter e também com o mestre da Bauhaus, Joseph Albers. Foi professora do programa de educação infantil do MoMA e, entre os vários prêmios que recebeu, foi contemplada com o Guggenheim Fellowship em 1949. Suas obras fizeram parte da exposição itinerante New directions of gravure: Hayter and studio 17 [Novas direções da gravura: Hayter e Atelier 17], que circulou na América Latina em 1944. 


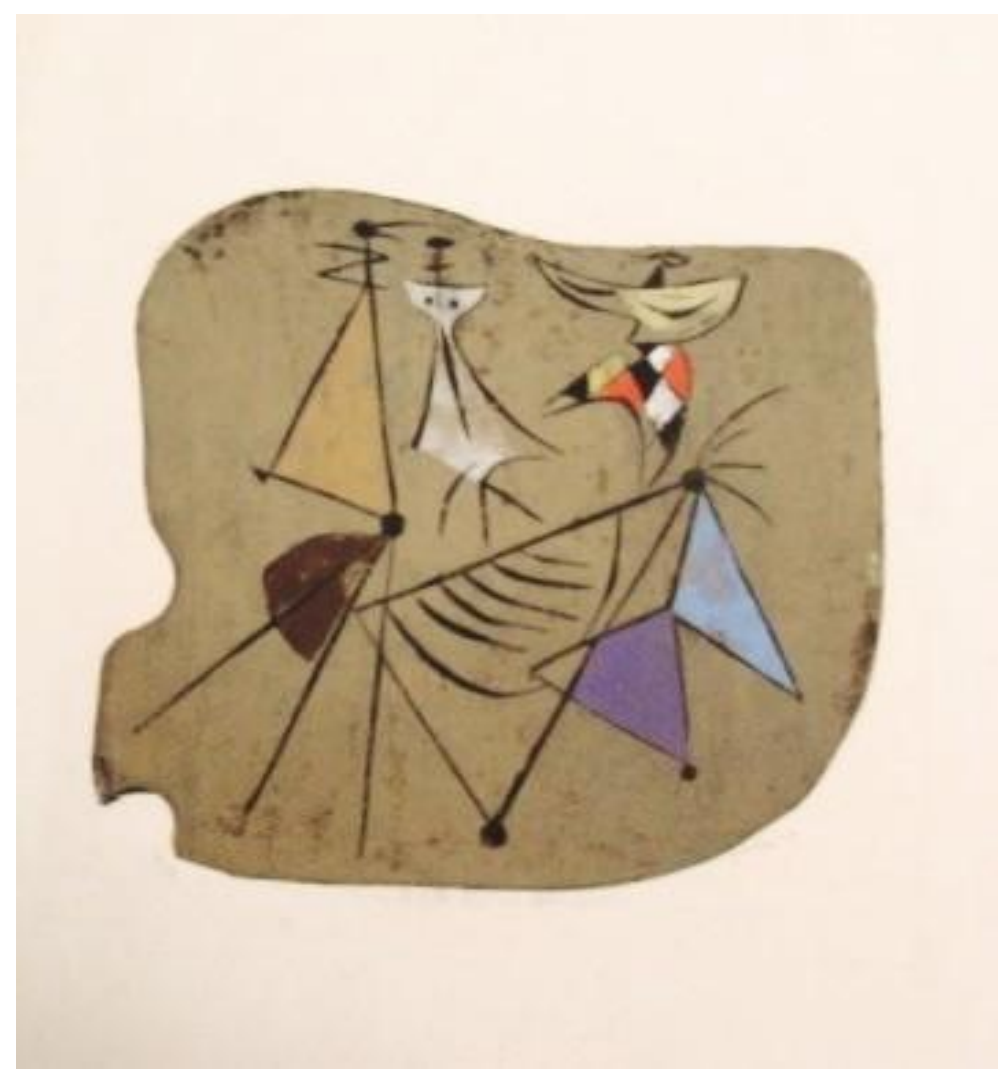

[Fig. 90] The little act on horseback [Pequeno ato a cavalo] (1949) Seong Moy (China - 1921-2013)

Xilogravura em cores sobre papel; $31,5 \times 32 \mathrm{~cm}$

Seong Moy é o único artista asiático da coleção. Nascido em uma vila nos arredores da cidade de Cantão, em 1921, sua primeira aproximação com a arte se deu por meio da caligrafia chinesa -elemento que estaria presente em toda sua carreira. Moy foi enviado pelos pais a St. Paul, Minnesota, aos 10 anos, para que pudesse receber boa educação. Seus guardiões queriam que ele parasse os estudos no nível fundamental para trabalhar no restaurante da família. Moy brigou para continuar sua formação e, por meio da amizade com um ajudante de pratos do restaurante, conheceu a oficina de artes do Federal Art Project. Ele iniciou a produção de gravuras no WPA Graphic Workshop no Walker Art Center em Minneapolis, em 1940, tendo a xilogravura em cores como sua técnica mais bemsucedida, a exemplo de The little act on horseback [Pequeno ato a cavalo]. Em 1941, Moy se inscreveu para uma bolsa no Art Students League de Nova York e partiu rumo ao centro das artes. Ali, seu trabalho alcançou outro patamar e conheceu os artistas do Atelier 17, espaço que frequentou por dois anos. Gravuras de Moy fizeram parte das mostras do MoMA e seu trabalho ganhou repercussão internacional. Ele foi um dos 16 artistas selecionados na seção norte-americana da II Bienal de São Paulo, onde foi apresentado ao público brasileiro com duas xilogravuras em cor, que misturavam componentes da caligrafia chinesa com o uso de formas abstratas, um componente característico da sua obra gráfica. 


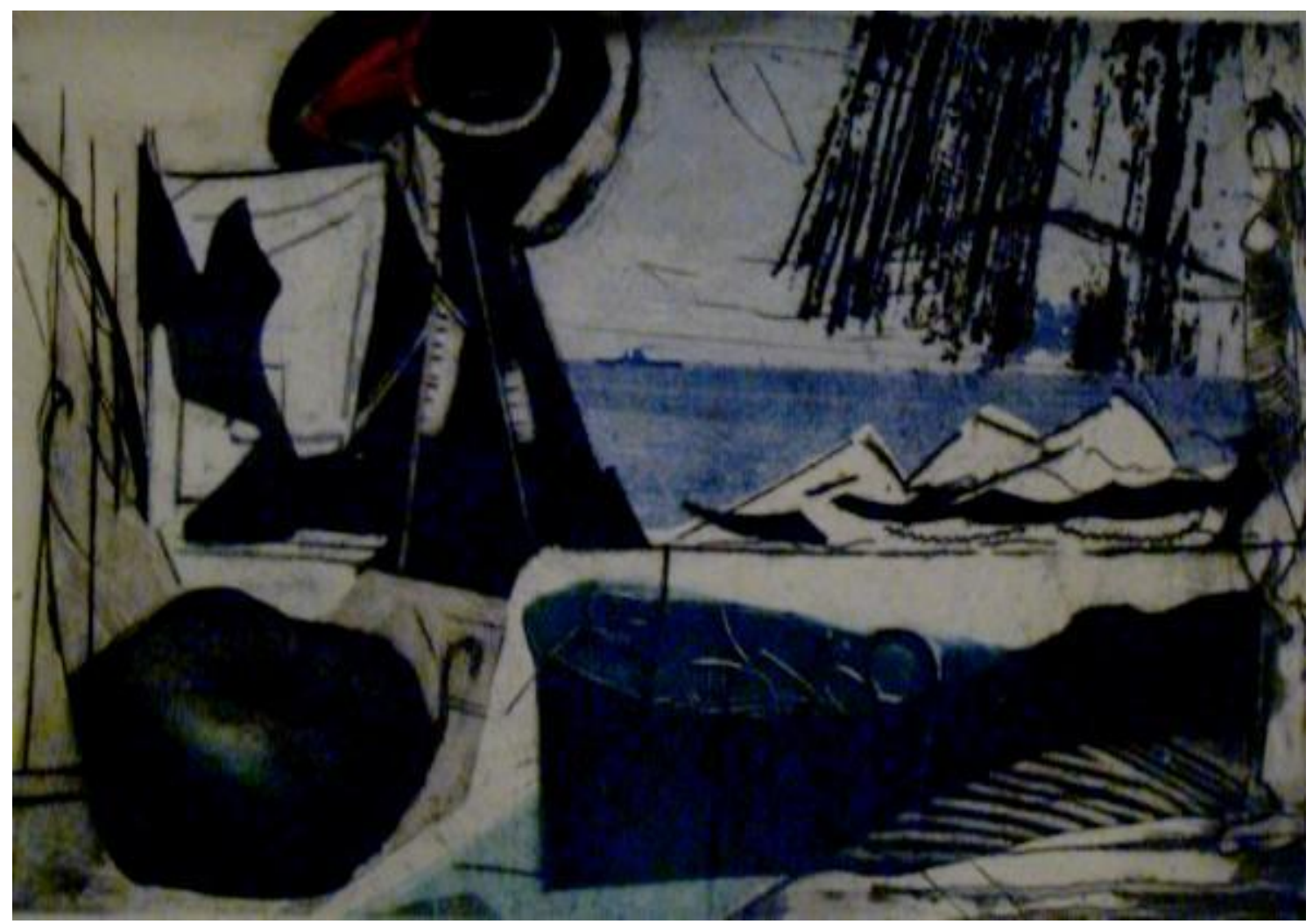

[Fig. 91] Attack on Marshall Gilbert [O ataque a Marshall Gilbert] (1948)

Kenneth Kilstrom (Estados Unidos - 1922-1995)

Verniz mole, buril, água-tinta sobre papel e offset; $25,4 \times 45,2 \mathrm{~cm}$

Essa é a gravura mais conhecida de Kenneth Kilstrom e remete aos ataques aéreos e navais da força militar norte-americana contra as ilhas japonesas de Marshall e Gilbert, em 10 de fevereiro de 1942, pouco tempo depois do Pearl Harbor. A obra é conhecida por ser a primeira vez em que um artista usou a transferência de fotografias para o suporte da gravura a buril como um elemento de composição (WARD, 2008, p. 208). Há apenas 15 exemplares dessa gravura no mundo, alguns estão no Fogg Art Museum de Harvard e na Biblioteca do Congresso Americano. Kenneth Kilstrom é um artista de Chicago, conhecido por integrar o grupo de Expressionistas Abstratos. Estudou em instituições progressistas como a Cooper Union e o Art Students League de Nova York. Sua obra teria uma influência de temas e técnicas asiáticas, reflexo do convívio com seu professor Isamu Noguchi, artista, arquiteto e designer japonês radicado em Nova York. Kilstrom passou a frequentar o Atelier 17 em 1947, oportunidade em que teve maior liberdade de testar novas técnicas artísticas. Pouco tempo depois do contato com Hayter, produziria Attack on Marshall Gilbert [O ataque a Marshall Gilbert], sua obra mais icônica. A carreira de Kilstrom foi desacelerada por uma grave doença psiquiátrica que resultou em sua internação por grande parte dos anos 1950 e 1960. Artista premiado, suas obras integram as principais instituições de arte moderna dos Estados Unidos. 


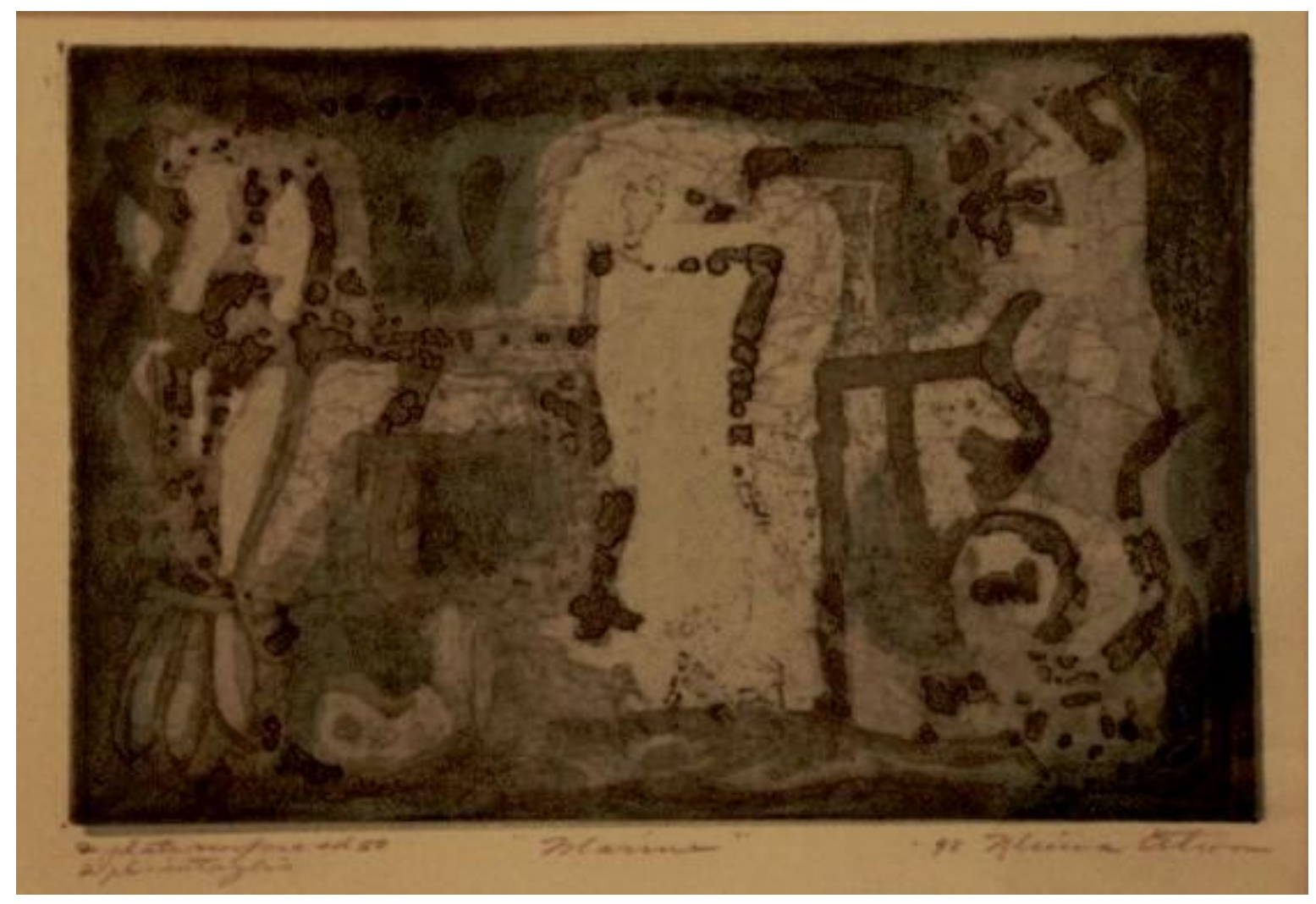

[Fig. 92] Marine [Marinha] (1948)

Minna Citron (Estados Unidos - 1896-1991)

Água-tinta e verniz mole sobre papel; $15,8 \times 22,7 \mathrm{~cm}$.

Minna Citron frequentou o Atelier 17 nos anos 1940 e fez parte do renascimento da gravura norteamericana. Divorciada e mãe de dois filhos, o papel da mulher na sociedade e as novas relações de gênero foram temas centrais de investigação para sua arte. Minna foi uma das pioneiras do movimento feminista e sua primeira exposição individual, intitulada "Feminilidades", tratava da condição da mulher dona de casa em uma sociedade repressora. Nascida em Newark, Nova Jersey, Minna estudou no Brooklyn Institute of Arts and Sciences, seguido de três anos na New York School of Applied Design for Women. Em 1928, começou a ter aulas na Art Students League, um dos ambientes mais progressistas de Nova York. O início da carreira de Minna é marcada por composições figurativas e obras realizadas sob a estética do New Deal para o Federal Art Project. A partir das décadas de 1940 e 1950, sua arte se tornaria mais abstrata e, nesse momento, a psicanálise aparece como um indutor para sua reflexão sobre o papel do inconsciente na arte. Essa gravura fazia parte da coleção Abby Rockefeller e foi inserida na exposição Master prints do MoMA, em 1949. Marine [Marinha] também foi destaque da I Bienal de São Paulo, em 1951. 


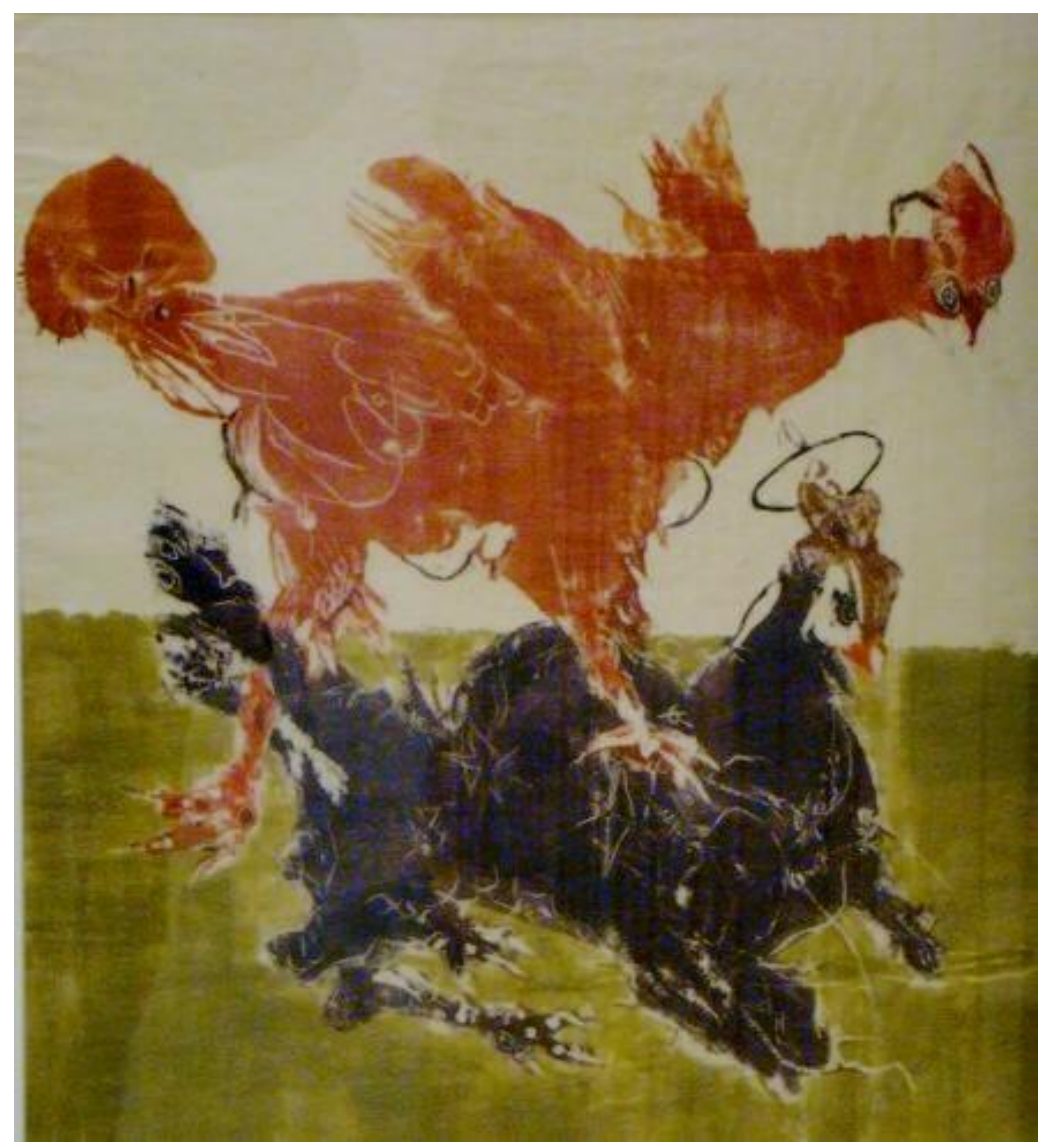

[Fig. 93] Fighting cocks [Galos de briga] (1949)

Bernard Reder (Ucrânia - 1897-1963)

Monotipia em cores sobre papel; 51,4 X45,8 cm

Mais conhecido como escultor, Bernard Reder foi um artista judeu de grande sucesso em Praga e Paris, onde se tornou amigo de Aristide Maillol. Na década de 1920, ainda jovem, sobreviveu como artesão de lápides dos cemitérios de sua cidade natal Czernowitz, Ucrânia, tornando-se prestigiado por sua escultura apenas a partir nos anos 1940 e 1950. Perseguido na Segunda Guerra Mundial, imigrou para os Estados Unidos em 1943, com auxílio do jornalista norte-americano Varian Fry, que havia organizado um comitê de resgate para artistas procurados pelo regime nazista. Em 1948, Reder obteve cidadania norteamericana. Nos Estados Unidos, ficou por um tempo doente e impossibilitado de continuar o trabalho de escultura, passando para a prática menos extenuante da gravura sobre madeira. Foi assim que ele desenvolveu essa técnica com primor e passou a se tornar conhecido neste campo artístico, tendo feito parte da exposição do MoMA Master prints, de 1949, mostra organizada a partir da coleção de Abby Rockefeller e que inaugurou o departamento de gravuras do museu. Muitas de suas obras tinham temas bíblicos ou eram ilustrações de provérbios judaicos. Durante um período curto, dedicou-se a temas de bestiários e animais, fase da qual faz parte a obra Fighting cocks [Galos de briga]. 


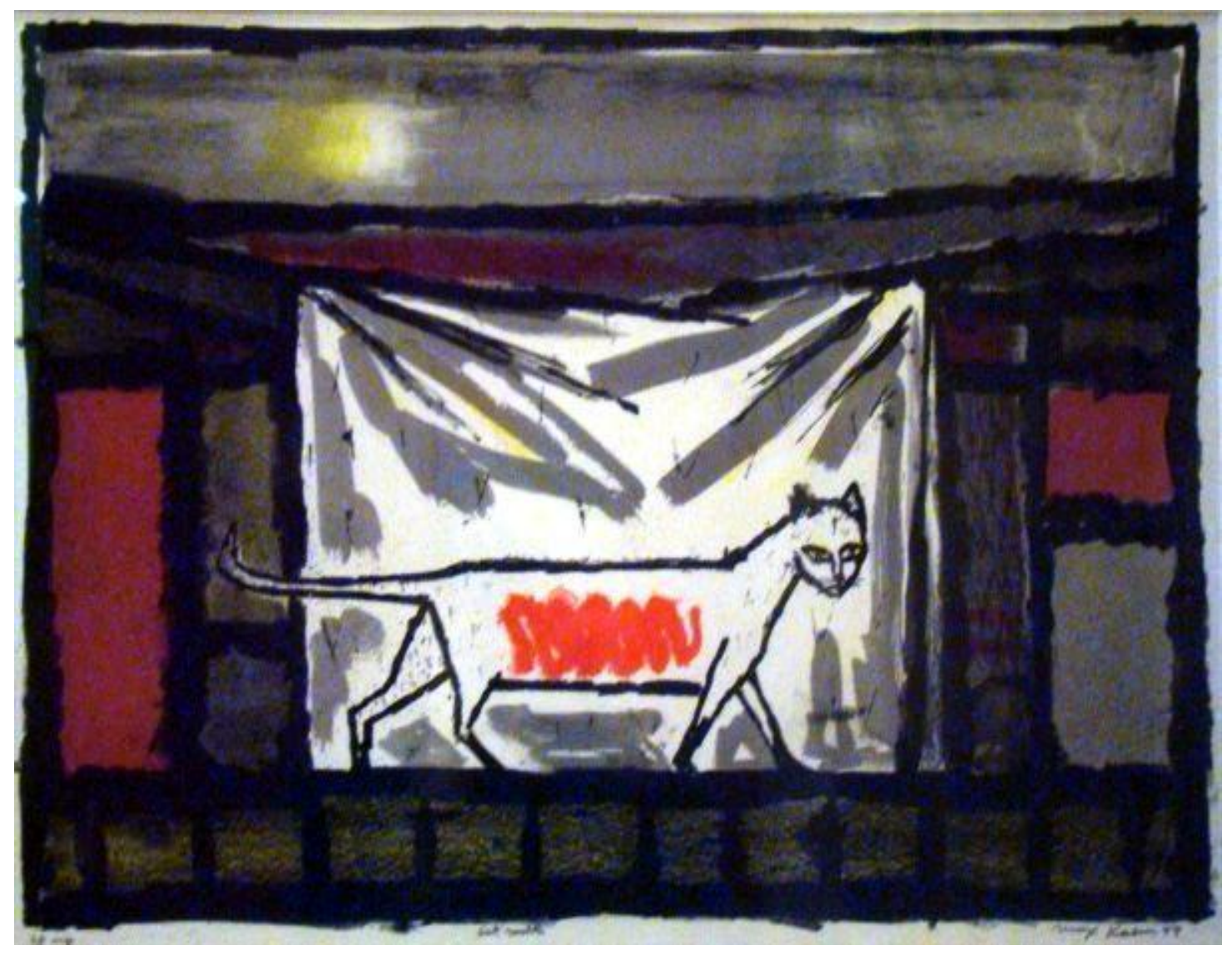

[Fig. 94] Cat walk [Passeio deo gato] (1949)

Max Kahn (Bielorrússia - 1902-2005)

Litografia em cores sobre papel; 34, 6 X 50,3 cm

Max Kahn nasceu na pequena cidade de Slonim, Bielorrússia. Sua família, de origem humilde, imigrou para Peoria, Illinois, quando ele tinha três anos, na tentativa de construir uma vida melhor na América. Com incentivo do pai, Kahn ingressou na carreira artística com um treinamento clássico na tradicional Academy Suede West em Paris, sob ensino do escultor Émile Antoine Bourdelle, discípulo de Rodin. De volta aos Estados Unidos passou a ter aulas com o gravurista Francis Chapin, no Art Institute of Chicago, ambiente central da vanguarda modernista. Seu trabalho seria influenciado pela temporada no Taller de Gráfica Popular, na Cidade do México, em 1941, um coletivo de gravuristas de esquerda que defendia uma arte socialmente engajada. A obra Cat walk foi prêmio de aquisição da exposição anual do Brooklyn Museum, em 1949, momento em que Max Kahn teve sua produção reconhecida e prestigiada internacionalmente. A inclusão de seu nome na doação Rockefeller faz parte de um fenômeno maior de valorização crítica do núcleo de gravuristas de Chicago, entre os quais se incluem Eleanor Coen, sua esposa, e Misch Kohn - ambos inseridos na doação Rockefeller. 


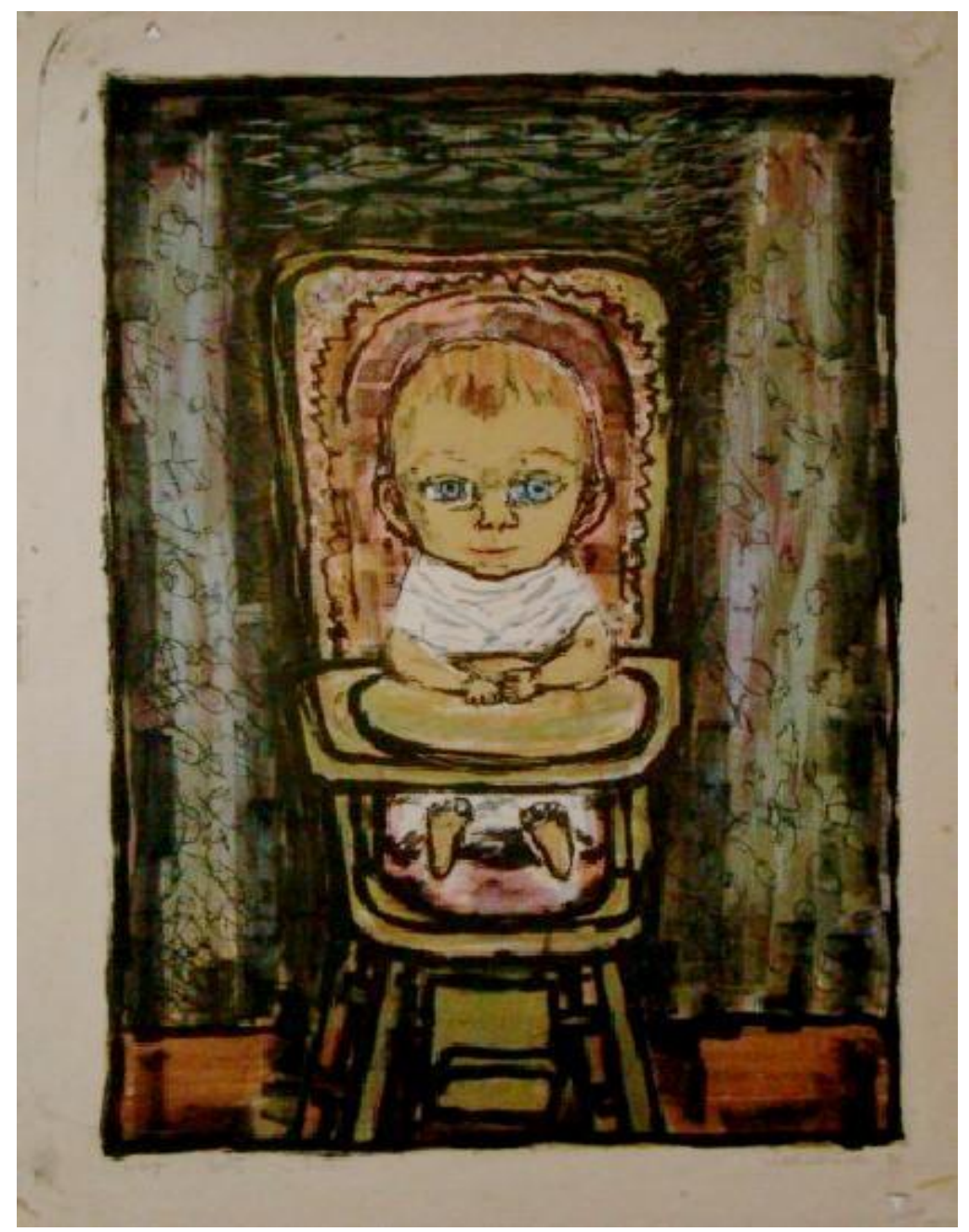

[Fig. 95] Baby in the high chair [Bebê na cadeira de pés altos] (1950)

Eleanor Coen (Estados Unidos - 1916-1910)

Litografia em cores sobre papel; 40,3 X 45,8 cm

Eleanor Coen fazia parte do grupo de gravuristas expoentes de Chicago. Trabalhou como garçonete para pagar as aulas no Art Institute de Chicago, onde foi aluna Francis Chapin e Max Kahn, com quem casouse em 1942. Durante anos 1930, participou das gráficas do Works Progress Administration e ficou conhecida, sobretudo, pelo uso de litografias de crianças, como é o caso de Baby in the high chair [Bebê na cadeira de pés altos]. Muitas vezes usava seus próprios filhos como modelo, mas a fonte dessa gravura parece ter sido uma obra de mesmo nome e composição semelhante de Francis Chapin, que muito influenciou sua carreira. Eleanor foi a primeira mulher a ganhar o James Nelson Raymond Travelling Fellowship e, ao invés de usar o dinheiro para uma temporada em Paris, como era praxe, ela optou por investir o prêmio em um tour pela Taller Gráfica Popular, na Cidade do México, em 1942, ambiente profundamente transformador. Ela deu aula na Escuela Universitária de Bellas Artes, em San 
Miguel de Allende, cidade onde também praticou, por algum tempo, a pintura mural, sob influência do tradicional arcabouço de artistas mexicanos consagrados neste suporte. Uma gravura de Eleanor, também uma litografia sobre uma criança - Child in a tree [Criança na árvore]-, foi prêmio de aquisição da III Exposição Anual de Gravura do Brooklyn Museum, em 1949. Suas obras foram premiadas também pela American Color Print Society (1953) e pela Philadelphia Print Club (1952).

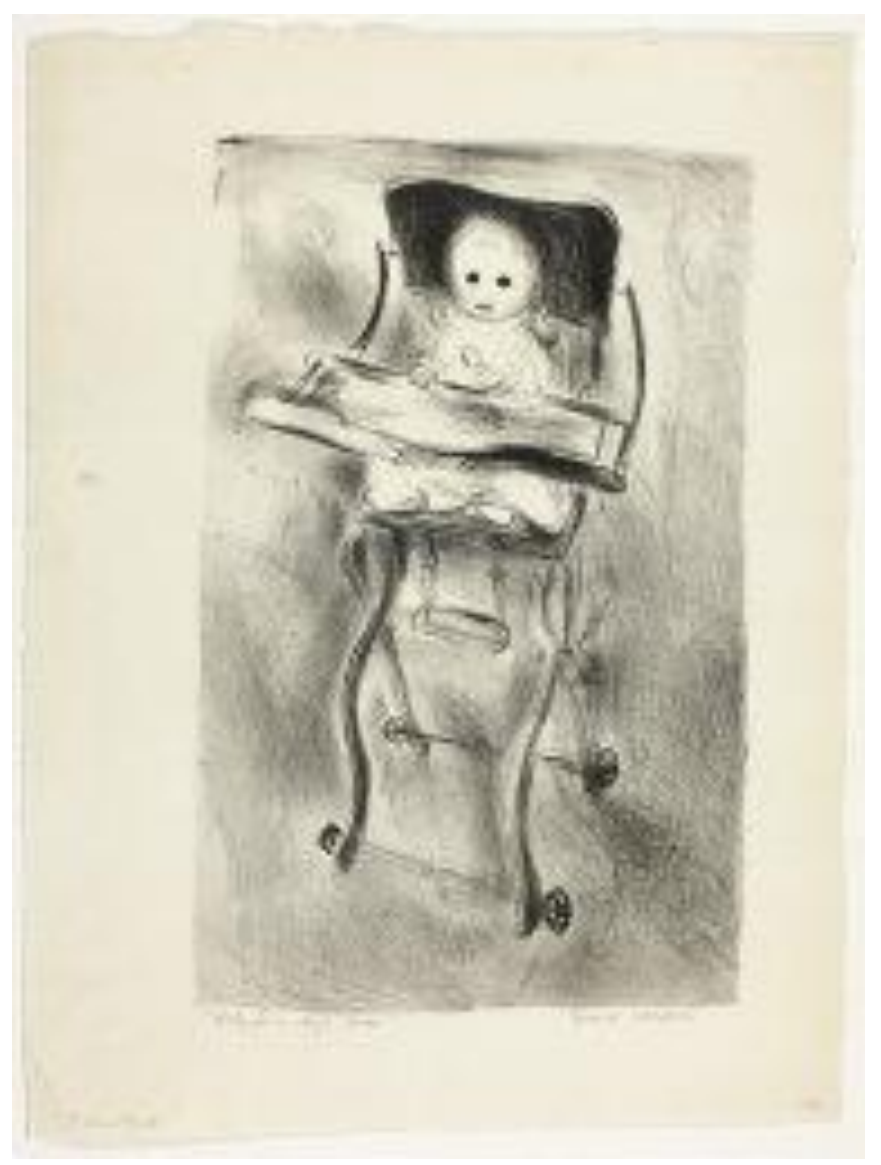

[Fig. 96] Baby in a high chair [Bebê na cadeira de pés altos], s.d, Francis Chapin. Litogravura sobre papel. 


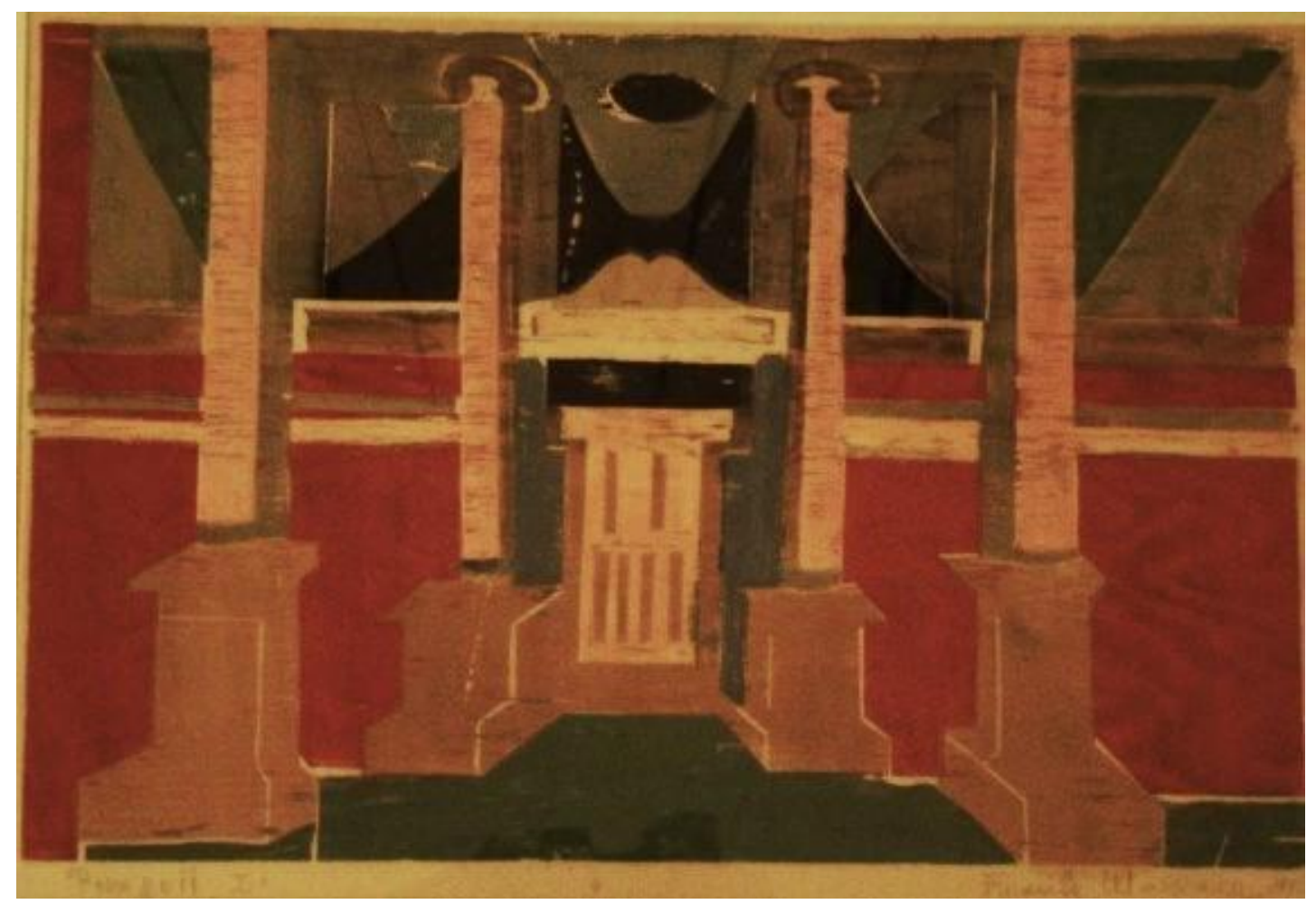

[Fig. 97] Pompei I [Pompéia I] (1949)

Frank Wallace (Estados Unidos - 1915- ?)

Xilogravura em cores sobre papel; 30,2 X45,6 cm.

Frank Wallace nasceu em Toledo, Ohio, estudou na Academia de Belas Artes da Pennsylvania e na Art Students League de Nova York. Ele foi um artista ativo na região de Vermont, onde fundou uma escola de arte particular. Wallace se dedicou, principalmente, a pinturas a óleo e aquarelas, e teve uma carreira curta como gravurista. Documentos biográficos reunidos pela equipe do MoMA para a segunda doação Rockefeller indicam que, em 1951, Frank Wallace estava praticando a xilogravura há apenas um ano, portanto era um novato nesse suporte. Seu nome tinha acabado de aparecer entre os artistas presentes na Exposição Anual de Gravuras do Brooklyn Museum, em 1950, o que pode explicar sua presença na coleção enviada ao Brasil. Em 1952, o MoMA incluiu essa mesma gravura Pompei I [Pompéia I] na exposição Recent American woodcuts [Xilogravuras recentes de norte-americanos] mostra que também contemplou Composition in oval [Composição em oval], de Jim Forsberg, The boaters [Os barqueiros], de Louise Krueger, The captive [O cativo], de Anne Ryan, Carnival [Carnaval], de Louis Schanker, e Dead bird [Pássaro morto], de Adja Yunkers (as mesmas gravuras da doação Rockefeller ao Brasil). Essa correspondência entre coleções de gravuras enviadas ao exterior e as mostras pensadas para o público doméstico mostram como a curadoria dessa coleção se deu, de fato, no "calor da hora" e reflete o que era de mais contemporâneo no cenário artístico da época. 


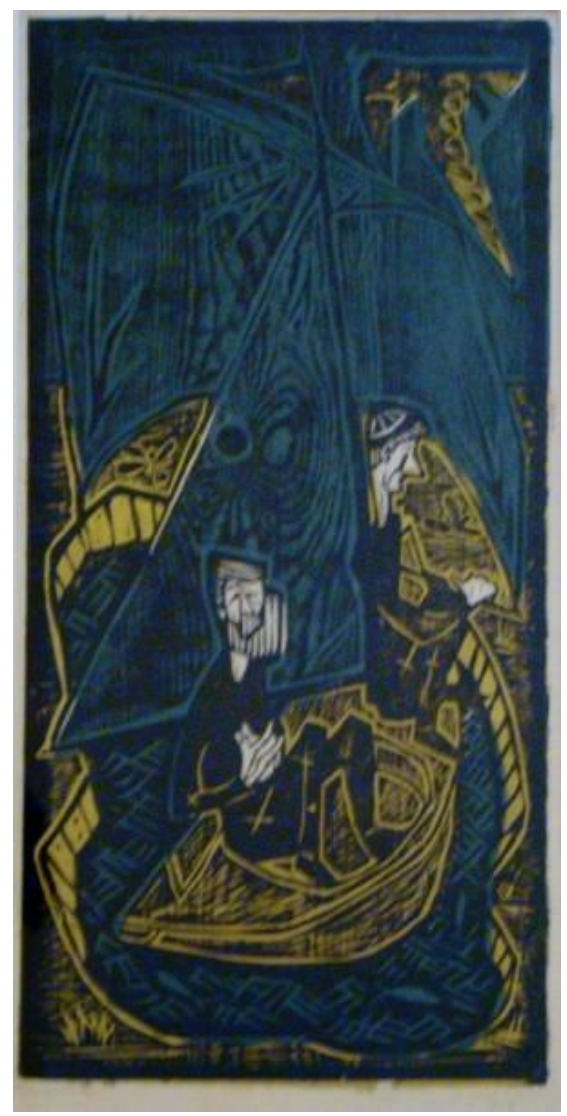

[Fig. 98] The Boaters [Os barqueiros] (1949) Louise Krueger (Estados Unidos - 1924)

Xilogravura em cores sobre papel; $58,7 \times 29,3 \mathrm{~cm}$

Krueger pertence ao grupo de artistas trabalhando de maneira inovadora com a xilogravura em cores no final da década de 1940. Ela fazia parte de um movimento maior que buscava revalorizar essa prática e usar o tradicional método da gravura sobre madeira com uma linguagem moderna. Artistas que também atuavam neste registro incluem Anne Ryan, Seong Moy e Misch Kohn. A gravura The boaters [Os barqueiros] foi adquirida pelo MoMA para sua coleção permanente e exposta na mostra Some American prints: 1945-1950 [Algumas gravuras norte-americanas: 1945-50], de curadoria de William Lieberman. Também fizeram parte dessa exposição as mesmas obras de Henry Mark, Gabor Peterdi, Anne Ryan e Louis Schanker presentes da doação Rockefeller. Isso é importante pois evidencia que esse grupo particular fazia parte de uma coletânea que já circulava no MoMA e buscava mostrar ao público a amplitude de técnicas e temas da gravura norte-americana. Com a doação Rockefeller, essa narrativa ganhava o cenário internacional. A repercussão de Louise Krueger precisa ser entendida neste contexto específico de valorização das artes gráficas e, além da sua participação em algumas exposições do MoMA, há poucos registros sobre sua vida e obra. 


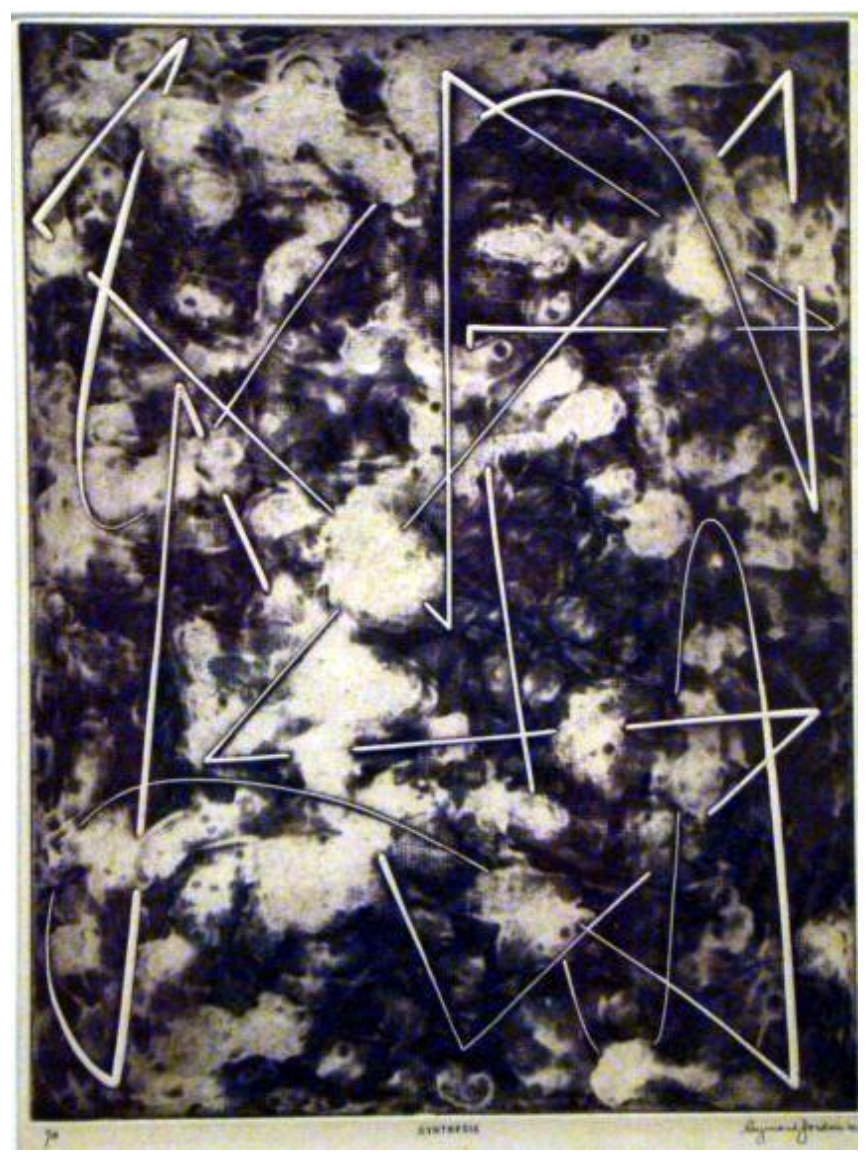

[Fig. 99] Synthesis [Síntese] (1948)

Raymond Jordan (Estados Unidos - 1898-?)

Verniz mole e buril sobre papel; $45,4 \times 35,2 \mathrm{~cm}$.

Formado em arquitetura, Raymond Jordan foi atuante em Chicago e Nova York. Uma viagem à Europa despertou seu interesse pela gravura em cores, suporte que desenvolveria ao longo da carreira. Ele atuou no Atelier 17 de Hayter em Nova York e seria exposto como um dos discípulos da revolução gráfica incentivada neste ambiente. Suas obras foram exibidas nos Estados Unidos e no exterior. Synthesis [Síntese] é um exemplo da experimentação com o abstracionismo que era incentivada no estúdio de Hayter. Essa gravura foi apresentada na exposição Master prints, do MoMA, em 1949, como um dos exemplos da vanguarda gráfica dos Estados Unidos. 


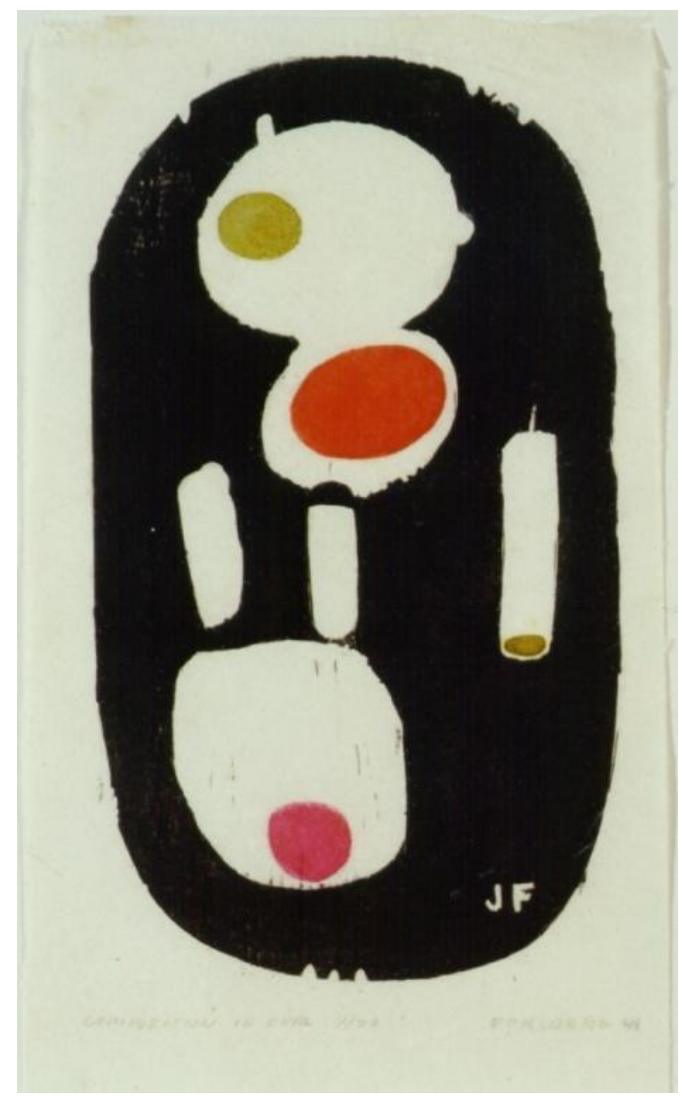

[Fig. 100] Composition in oval [Composição em oval](1948)

Jim Forsberg (Estados Unidos - 1919-1991)

Xilogravura em cores sobre papel; 27,6 X 14,8 cm

Nascido em Provincentown, cidade que era centro da produção de xilogravuras desde 1920, James Forsberg começou seu treinamento artístico Escola de Arte de Minneapolis. Serviu o exército norteOamericano durante a Segunda Guerra Mundial e se mudou para Nova York em 1946, quando passou a frequentar o Art Students League. Na década de 1950, ele estudou com o pintor Hans Hofmann e integrou o núcleo do Expressionismo Abstrato. Forsberg fez parte de um coletivo artístico chamado "The Printmakers" ou "os gravadores", que se reunia para testar novas possibilidades no campo das artes gráficas. Por meio do coletivo, começou a exibir seus trabalhos na prestigiada Jacques Seligman \& Co, galeria importante na divulgação da gravura moderna norte-americana e que intermediou a venda de Composition in oval [Composição em oval] para a segunda doação Rockefeller. Nessa obra, Forsberg utiliza-se de um dos métodos mais antigos à base de madeira, usando uma linguagem abstrata e moderna. Ele realizaria uma série de gravuras com o tema de pedras e rochas, trabalhando com a simplificação das formas orgânicas em objetos abstratos. Essa gravura fez parte da exposição Recent American prints [Gravuras norte-americanas recentes], do MoMA, em 1952. 


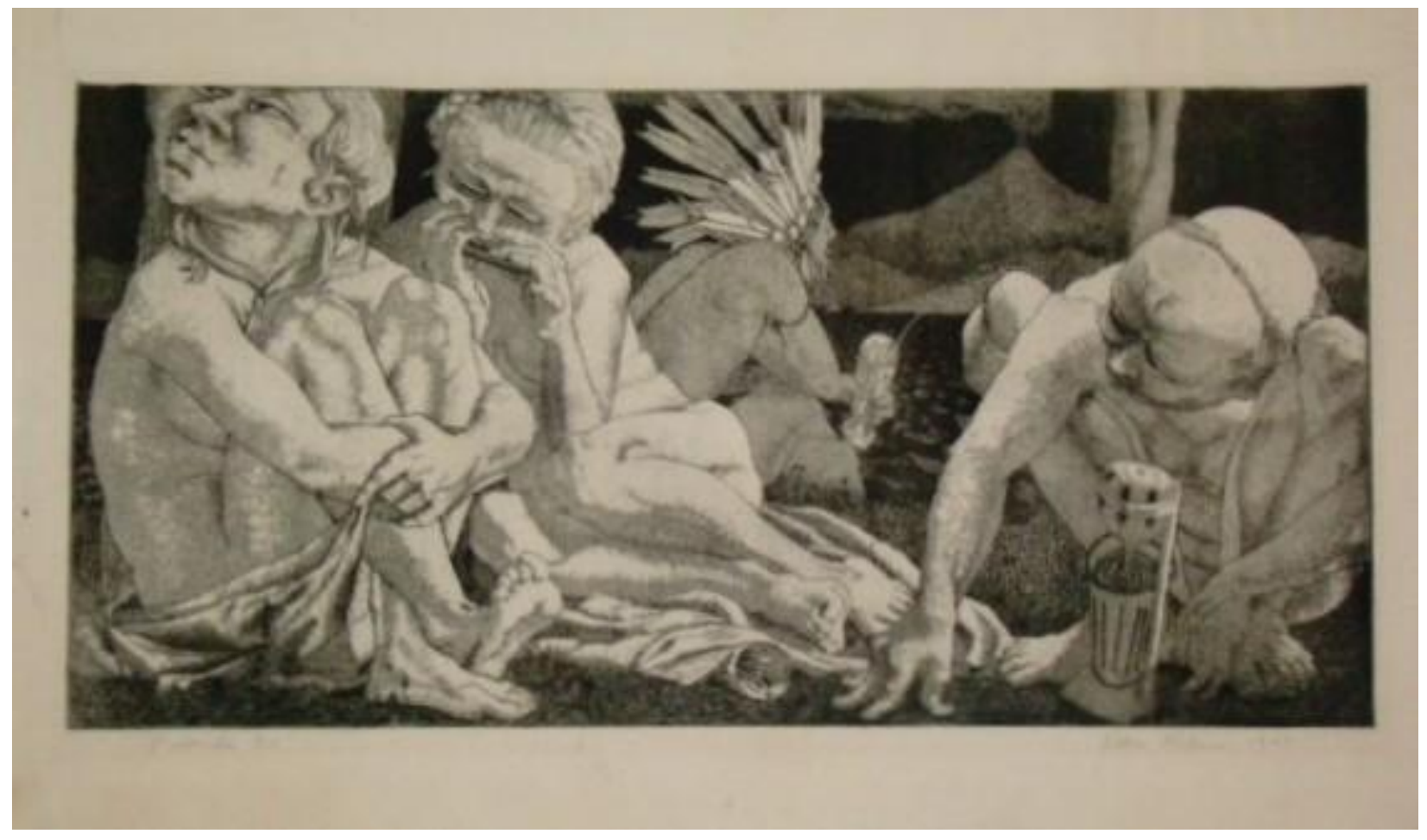

[Fig. 101] Pastorale [Pastoral] (1947)

Alton Pickens (Estados Unidos - 1917-1991)

Água-forte e água-tinta sobre papel; 30,2 X 59,9 cm

Essa gravura participou da seção norte-americana na I Bienal de São Paulo e também fez parte da exposição inaugural do departamento de gravuras do MoMA, em 1949. A obra de Pickens estava distante das manifestações estéticas do Atelier 17 e dos artistas abstratos, mas em vida ele foi muito prestigiado como um dos expoentes da arte figurativa norte-americana. Em 1946, a curadora Dorothy Miller, responsável pela seleção da primeira doação Rockefeller, incluiu o nome de Pickens na exposição 14 Americans [Americanos], que tinha o objetivo de lançar novos nomes da vanguarda. No catálogo, Pickens define sua arte como essencialmente social. "Uma cidade de pessoas é a fonte para minha pintura (...) existe a incrível crueldade dos homens contra homens, sua resiliência miraculosa e trágica subserviência, que tem como resultado uma fantasia distorcida. É mais fácil, talvez, visualizar a tragédia dos guetos da Europa do que ver o desperdício dos corpos humanos ao nosso redor. E como olhar essas coisa sem um pouquinho de humor incrédulo?" ${ }^{208}$ Nascido em Seattle, ele se formou na Portland Art Museum School e na New School of Social Research em Nova York e deu aulas de arte na Universidade

208 "A city of people is the source from which I make I make a picture (...) there is the incredible cruelty of man towards man, his miraculous endurance and tragic subservience, the outcome of which is a fantasy of distortion. It is easier perhaps to visualize the tragedy of the ghettos of Europe than to see the wasting of human bodies all about us. And then how could one see these things without a modicum of incredulous humor?". Catálogo de 14 Americans. Nova York: Museum of Modern Art, 1946, tradução nossa. 
de Vassar e da Universidade da Indiana.Em 1950, a revista LIFE selecionou Pickens como um dos 19 melhores jovens artistas do país. A arte de Pickens se destacava pelo uso da figuração e com frequência, a cenas fantásticas, doses de simbolismo e crítica social, como se vê em Pastorale [Pastoral] -- que remete ao ambiente de marginalização e alcoolismo das comunidades indígenas norte-americanas. 


\section{Considerações finais}

As doações Rockefeller foram catalizadoras da aproximação entre agentes culturais brasileiros e norte-americanos no pós-guerra. Seu legado extrapola o momento da outorga do conjunto e se insere em um contexto mais amplo da formação dos primeiros museus de arte moderna do Brasil. As obras fazem parte do núcleo histórico do MAC USP e algumas se tornaram verdadeiros destaques do museu, ao passo que outras foram pouco investigadas pelos curadores da instituição, e são, atualmente, desconhecidas pelos historiadores da arte no Brasil e público em geral. Com o aniversário de 50 anos do MAC USP e o advento da nova sede, o museu estabeleceu um compromisso com sua memória, incentivando um olhar renovado sobre seu acervo. Essa pesquisa faz parte dessa revisão da história do MAC USP e, mais do que isso, propõe outra perspectiva sobre a coleção Rockefeller, prestes a completar 70 anos.

Há muitas obras no MAC USP que, a um primeiro olhar, parecem deslocadas, mas que um esforço recente de pesquisa tem demonstrado se tratar de uma coleção única, montada "no calor da hora"209. O acervo inicial foi reunido por intermédio do colecionismo de Ciccillo Matarazzo e Yolanda Penteado, dos prêmios de aquisição da Bienal de São Paulo ou por meio de doações particulares, entre as quais se insere a de Nelson Rockefeller. Essa pesquisa tenta entender a coleção do MAC USP não a partir de suas aparentes lacunas, mas justamente pelas particularidades e idiossincrasias que compõem a originalidade deste acervo, em sintonia com o trabalho desenvolvido pela curadora Ana Gonçalves Magalhães sobre as origens do antigo MAM-SP.

Foi a partir da busca por um maior entendimento de uma coleção tão peculiar como a do antigo MAM-SP que se propôs novos horizontes de pesquisa em arte; estudos que fogem de discussões centradas puramente nas qualidades estéticas e nos mecanismos internos de uma obra de arte, mas que levam em conta o papel das instituições, dos atores históricos e das

\footnotetext{
${ }^{209}$ MAGALHÃES, Ana. Pintura italiana do entreguerras nas Coleções Matarazzo e as origens do acervo do antigo MAM - Arte e crítica de arte entre Itália e Brasil. São Paulo: MAC USP, 2014, p.42.
} 
externalidades político-culturais para a melhor compreensão de um determinado fenômeno artístico.

Foi a convivência com um acervo de arte moderna formado em um país periférico, como o Brasil ainda é dentro da historiografia da arte ocidental, que nos proveu de outro olhar sobre acervos já cristalizados. Isto é, as novas práticas da história da arte, que envolvem hoje o estudo da recepção dos objetos artísticos, a história das exposições, a ideia da biografia dos objetos e sua relação com as instituições artísticas, têm produzido excelentes frutos entre nós e nos instrumentalizou a propor novos problemas para temas aparentemente esgotados - neste caso, a história da arte moderna, que deixa cada vez mais a esfera das questões formais e ganha novos contornos ao ser reinterpretada à luz dos processos de institucionalização, divulgação e tradução/transposição de práticas artísticas em outros territórios (MAGALHÃES, 2014, p. 131).

Uma das primeiras conclusões desta pesquisa é que as doações Rockefeller não foram um ato espontâneo de um benfeitor descompromissado. Ainda que a aquisição das obras tenha sido acelerada, e Alfred Barr e Dorothy Miller pouco tempo tiveram para planejar a coleção; a ideia de doar objetos de arte para o Brasil estava posta desde o memorando de René d'Harnoncourt de 1945. A doação deveria representar um marco na aproximação com o Brasil e fazia parte de uma estratégia mais ampla de articulação política por meio da cultura que Nelson já vinha realizando desde seus anos como diretor do CIAA no governo Roosevelt. O envio de obras de arte para países latino-americanos era um dos procedimentos descritos no plano de ação do CIAA, mas os custos elevados e a dificuldade de navegação internacional durante a Segunda Guerra Mundial impossibilitaram a continuidade de iniciativas como a exposição itinerantes Pintura contemporânea norte-americana, de 1941.

A documentação encontrada mostra que Nelson Rockefeller tinha um pensamento holístico das suas ações na América Latina. Seja no âmbito privado, nos negócios da família ou nas atividades de governo, não agia de maneira gratuita. Ele reconheceu cedo as oportunidades que a região oferecia e coordenou seus objetivos pessoais, filantrópicos, políticos e econômicos. A articulação de interesses foi evidente na viagem realizada em novembro de 
1946. Nelson veio ao Brasil em um momento geopolítico delicado e, ainda que estivesse afastado da administração Roosevelt, ele continuava a ser uma figura pública de grande visibilidade, agindo como um embaixador dos ideais norte-americanos de modernidade, democracia e progresso. Nelson aqui chegou para deslanchar uma instituição filantrópica de fomento à agricultura e ao bem-estar social na América Latina, e nesse processo estabeleceu alianças com industrialistas, políticos e líderes do agronegócio, com os quais eventualmente se tornaria sócio em fazendas de gado no Brasil. Com o objetivo claro de expandir sua influência em outras esferas da sociedade brasileira, ele realizou a doação de 14 obras para o estímulo das artes no país. Com esse gesto, inscreveu seu nome da historiografia brasileira, atuando de maneira significativa na formação do primeiro museu moderno do país.

Outro ponto importante é identificar se a doação foi um gesto particular ou institucional. Seria essa uma coleção de Rockefeller ou do MoMA? De que maneira era extensão de sua atividade política? Os limites entre o privado e o público são muito tênues na história de Nelson Rockefeller e, continuamente, essas esferas iriam se sobrepor na sua vida. No caso específico das doações para o Brasil, havia um conhecimento de América Latina adquirido na vida pública somado a um interesse privado, só viabilizado com o trabalho de uma equipe vinculada à estrutura institucional do MoMA. Portanto, as três esferas estão presentes. O dinheiro que financiou as doações parece ter vindo dos bolsos do próprio magnata, ainda que uma comprovação exata seja impossível. Sabe-se que ele recebeu de Alfred Barr uma lista detalhada, identificando os gastos com cada obra de maneira a prestar contas das aquisições.

Além disso, as duas composições de Fernand Léger seguramente fizeram parte de sua coleção particular. A repercussão na imprensa da época também é um indicativo do caráter pessoal da doação. As reportagens veiculadas nos jornais cariocas e paulistas noticiaram a doação como uma empreitada individual de Nelson, não do MoMA. A doação é descrita como uma iniciativa privada de um generoso Rockefeller, ainda que sua vinculação anterior à diretoria do MoMA e ao CIAA não seja omitida pelos jornalistas. Da mesma forma, em 1950, o MoMA levantou uma lista das gravuras adquiridas referentes à segunda doação -- com título, 
galeria de proveniência e preço -- e uma conta foi enviada ao escritório de Nelson localizado no edifício do Rockefeller Center para fatura.

O perfil da equipe envolvida nas doações também demonstra o quanto elas foram uma mistura entre o campo institucional e a vida pública de Nelson Rockefeller. Se os curadores responsáveis pela seleção eram parte do corpo técnico do MoMA, os demais assessores envolvidos nas doações vinham da equipe que Nelson cultivara no Escritório do Coordenador de Assuntos Interamericanos (CIAA). René d'Harnoncourt, por exemplo, havia servido como diretor da seção de arte do departamento e estava encarregado de providenciar um programa de relacionamento proativo com a América Latina por meio da arte. Foi d'Harnoncourt que mapeou os possíveis interlocutores brasileiros no campo da cultura. Nas correspondências entre ele e Nelson aparecem as primeiras referências a uma doação de obras de arte ao Brasil.

Outro funcionário de Nelson Rockefeller do período governamental é Francis Jamienson, jornalista vencedor do Prêmio Pulitzer de 1933 e o ex-diretor do Escritório de Informação Pública do CIAA. Jamieson havia sido responsável pela estratégia de comunicação do CIAA na América Latina e foi um importante assessor de Nelson para iniciativas de relações públicas. Em 1950, Jamieson estava trabalhando novamente para Rockefeller e é ele quem recebe no escritório do Rockefeller Center, na sua sala particular 5600, a correspondência do departamento de gravuras do MoMA, com a lista de obras adquiridas para envio ao Brasil. Pelo calibre dos profissionais envolvidos nessa doação e seus papeis anteriores em cargos estratégicos na administração federal, é impossível ignorar o significado político e diplomático dessas doações.

O financiamento das doações de 1946 e de 1950 foi, muito possivelmente, patrocinado pela fortuna pessoal de Nelson. Contudo, todo o trabalho intelectual investido na seleção está diretamente vinculado à estrutura do MoMA. Nelson não esteve envolvido na escolha dos artistas e de maneira alguma as doações representam uma extensão de seu colecionismo particular. Exceto pelos dois Légers, todas as obras de 1946 foram adquiridas em galerias novaiorquinas com o propósito específico de formar a pedra fundamental dos futuros museus de arte moderna no Brasil. Já as gravuras de 1950, sim, surgem do colecionismo de Abby 
Rockefeller, que resultou na estruturação do departamento de artes gráficas no MoMA, e no uso posterior dessa coleção em mostras itinerantes que davam visibilidade à arte moderna norte-americana por meio do suporte reprodutível da gravura.

Os dois conjuntos refletem nitidamente as visões de arte moderna que estavam sendo praticadas em exposições do museu, seja pela visão de Alfred Barr das vanguardas europeias, pela a investigação de Dorothy Miller de novos nomes da arte moderna norte-americana, ou pelo trabalho de William Lieberman no acervo de gravuras modernas. A única instrução de Nelson para Alfred Barr parece ter sido de ordem geracional e geográfica. O curador deveria, segundo o magnata, se preocupar em formar o conjunto com obras artistas jovens, vivos e atuantes no cenário artístico norte-americano. Todo o trabalho de escolher quais os artistas, obras e tendências de arte moderna que deveriam ser apresentados ao público brasileiro foi realizado pela curadoria do MoMA, com total autonomia. Na doação de 1950, não há indicativo de qualquer direcionamento de Nelson para curadoria. Essa segunda coleção surge como parte de um trabalho já sedimentado do departamento de gravuras em promover novas técnicas e tendências da arte gráfica, primeiro para um público nacional e depois internacional.

Se à primeira vista alguns dos artistas presentes nestes conjuntos parecem deslocados, ignorados pela história da arte tradicional e praticamente desconhecidos pela crítica brasileira; sua presença das doações Rockefeller precisa ser entendida em relação direta com o panorama artístico daquele período. O conjunto é datado, no sentido que reflete nitidamente a temperatura do cenário artístico norte-americano de 1946 e 1950, tendo Nova York como o seu centro difusor. Da mesma maneira, a segunda doação é evidência da divulgação internacional de um grupo especifico de gravuristas modernos atuando em Nova York e que tinham tido seu trabalho validado por importantes colecionadores, como Abby Rockefeller, e por grandes exposições de arte gráfica no MoMA e no Brooklyn Museum.

Quanto ao perfil da coleção de 1946, é possível notar a tentativa de um resgate das vanguardas europeias, com a representação dos três mais importantes movimentos da arte moderna na Europa na primeira metade do século $X X$, o Cubismo - Fernand Léger -, o Expressionismo - Marc Chagall e George Grosz - e o Surrealismo - André Masson, Max Ernst e 
Yves Tanguy. Esse é o lado da doação Rockefeller que corresponde às narrativas tradicionais da história da arte universal. É importante notar, contudo, que as obras enviadas ao Brasil não fazem parte do período mais característico da atuação desses pintores nos movimentos artísticos europeus. A maioria das obras foram produzidas no contexto norte-americano e, em alguns casos, em períodos de exílio.

Por outro lado, a seção dos Estados Unidos nitidamente demonstrava um enigma. Nomes como Arthur Osver, Byron Browne e Everett Spruce foram praticamente eliminados dos estudos de história da arte, e Robert Gwathmey e Morris Graves permanecem circunscritos a uma bibliografia limitada e a narrativas da arte regional. Mesmo nas instituições culturais dos Estados Unidos, suas obras ficaram em segundo plano e, exceto casos pontuais, seus nomes não estimularam pesquisas. A presença destes artistas na doação está diretamente associada a um trabalho pioneiro de Dorothy Miller na descoberta e divulgação de artistas jovens ainda desconhecidos pelos críticos, na década de 1940. A síntese do trabalho de Miller foi o conjunto de exposições Americans [Americanos] no MoMA, que teve sua primeira edição em 1942, e já destacava os trabalhos de Spruce e Graves. Dois nomes que tiveram maior expressão foram o escultor Alexander Calder e o pintor Jacob Lawrence. Calder encontraria no Brasil uma elite ávida por adquirir seus móbiles, que até hoje são objetos recorrentes nas principais feiras de arte no país. Por sua vez, Lawrence é figura central dos livros de história da arte afroamericana e a sua série Migrações do negro é continuamente exposta com destaque pelo MoMA e coleção Philips.

Já a coleção de gravuras é centrada em artistas vinculados ao Atelier 17 de Stanley William Hayter, que tinham uma atitude experimental e inovadora no suporte gráfico, com tendências de abstração e surrealismo. Além disso, a coleção inclui nomes não vinculados a Hayter e que eram identificados com a excelência em técnicas gráficas, como Armin Landeck na litografia, e Edward Landon na serigrafia. Esse conjunto refletia o que a historiografia chama de período de "renascimento da gravura moderna norte-americana", que se deu principalmente nos anos 1940, a partir do trabalho pioneiro de imigrantes europeus da vanguarda em contato com artistas norte-americanos. A é composta de artistas prestigiados, aceitos pela crítica 
modernista e pelo mercado, e cujas obras faziam parte dos acervos dos principais museus de arte moderna dos Estados Unidos.

A respeito da recepção dos objetos de arte e sua relação com a história das exposições, as doações Rockefeller tem uma grande simbiose com as primeiras Bienais de São Paulo. Em alguma medida, elas antecipam as visões da curadoria do pavilhão dos Estados Unidos nas duas primeiras edições. Essa relação parece ter sido ignorada pela literatura sobre a Bienal de São Paulo. Um olhar mais detido mostra como o júri de curadores envolvidos na seleção de obras para a sala norte-americana na I Bienal é composto, justamente, pelos mesmos personagens gravitando entorno de Rockefeller. A delegação norte-americana foi organizada pelo MoMA e trazida ao Brasil por René d'Harnoncourt, então diretor do museu e um dos primeiros interlocutores de Nelson sobre a doação. Outros curadores envolvidos na I Bienal são Dorothy Miller, na época conservadora de coleções do MoMA e o braço direito de Alfred Barr na seleção das obras enviadas ao Brasil.

No texto para o catálogo da Bienal, René agradece também a colaboração de Dorothy Lytle, da seção de gravuras do MoMA. Isso é interessante pois Lytle aparece nas correspondências da doação de 1950 como a assistente do MoMA que organizou, embalou, listou e enviou para Rockefeller as 27 gravuras. Vale notar também a presença de Una Johnson, do Brooklyn Museum, e Carl Zigrosser, conservador do Philadelphia Museum of Art. Ambos os curadores foram figuras essenciais para a divulgação e promoção das novas técnicas de gravura moderna dos Estados Unidos, sendo responsáveis pelo sucesso de muitos artistas presentes na doação de 1950 e nas seções de artes gráficas da I e II Bienal de São Paulo. O fato de que as mesmas pessoas envolvidas na operação das doações Rockefeller e na I Bienal de São Paulo explica por que tantos artistas reaparecem nas duas ocasiões.

A seção norte-americana da I Bienal buscava contemplar diversos movimentos artísticos atuantes nos Estados Unidos, com a presença de 58 pintores, escultores e gravuristas. Seguindo uma linha de raciocínio semelhante ao que guiou as doações Rockefeller, René d'Harnoncourt explicava no catálogo da I Bienal que "a representação é composta tanto de artistas nascidos nos Estados Unidos como daqueles que nasceram no exterior, mas aqui fixaram sua residência 
e produziram uma parte considerável de sua obra" ${ }^{210}$. Desta forma, tanto a delegação da I Bienal quanto as doações Rockefeller incluíram obras de Max Ernst, Morris Graves, George Grosz, Jacob Lawrence, Alton Pickens, Yves Tanguy, Alexander Calder, Sue Fuller, Robert Gwathmey, Max Kahn, Misch Kohn, Armin Landeck, Boris Margo e Louis Schanker. Vemos que reaparecem os nomes de jovens artistas atuantes no cenário norte-americano naquele momento, com especial atenção para a gravura.

[Tab.3 ] - Presença dos artistas das doações Rockefeller nas bienais de São Paulo (1951-1959).

\begin{tabular}{|c|c|c|c|c|c|}
\hline Artistas/Bienais & $\begin{array}{l}\text { I Bienal } \\
\text { (1951) }\end{array}$ & II Bienal (1953) & III Bienal (1955) & IV Bienal (1957) & V Bienal (1959) \\
\hline Alexander Calder & $\mathbf{x}$ & $x$ & & & \\
\hline Alton Pickens & $\mathbf{x}$ & $\mathbf{x}$ & & & \\
\hline André Masson & $\mathrm{x}$ & & & & \\
\hline Armin Landeck & $x$ & & & & \\
\hline Boris Margo & $\mathbf{x}$ & & & & \\
\hline Fernand Léger & $\mathbf{x}$ & $x$ & $x$ & & \\
\hline Gabor Peterdi & & $x$ & & & \\
\hline George Grosz & $\mathbf{x}$ & & & & \\
\hline Jacob Lawrence & $\mathbf{x}$ & & & & \\
\hline Louis Schanker & $\mathbf{x}$ & & & & \\
\hline Marc Chagall & & & & $x$ & \\
\hline Max Ernst & $x$ & & & & \\
\hline Max Kahn & $\mathbf{x}$ & & & & \\
\hline Minna Citron & & $x$ & & & \\
\hline Misch Kohn & $\mathbf{x}$ & & & & \\
\hline Morris Graves & $\mathbf{x}$ & & $x$ & & \\
\hline Robert Gwathmey & $\mathbf{x}$ & & & & \\
\hline Seong Moy & & $x$ & & & \\
\hline Stanley W. Hayter & & & & & $x$ \\
\hline Sue Fuller & $\mathbf{x}$ & & & & \\
\hline Yves Tanguy & $\mathbf{x}$ & & & & \\
\hline
\end{tabular}

x Artistas presentes na Bienal em seções não organizadas pela delegação dos EUA

${ }^{210}$ Catálogo a I Bienal de São Paulo, Fundação Bienal: São Paulo, 1951, p. 112. Fundação Bienal de São Paulo. 
Na II Bienal de São Paulo, a seção dos Estados Unidos teve apenas 16 artistas e um quarto da exposição foi formada por nomes contemplados nas doações Rockefeller: o escultor Alexander Calder -- que teve uma sala especial -- e os gravuristas Seong Moy, Gabor Peterdi e Alton Pickens -- este último representado na II Bienal com a mesma obra Pastoral inserida na doação Rockefeller de 1950. Havia, portanto, uma clara proposta de apresentar algumas tendências artísticas e movimentos pictóricos que, para a visão dos organizadores desses dois conjuntos, refletiam o que havia de mais significativo na arte norte-americana naquele período. Até aquele momento, nomes como Gwathmey, Lawrence, Landeck e Pickens despontavam como os grandes destaques da nova arte dos Estados Unidos com a mesma presença de Pollock, Rothko, Baziotes e de Kooning, artistas também presentes nas primeiras bienais paulistas e quem a história da arte coroou de maneira exemplar e bastante desigual em relação aos demais.

Ainda que o termo Expressionismo Abstrato tenha sido cunhado pelo crítico de arte Robert Coates em 1946, ano da primeira doação Rockefeller, seria apenas no início de 1950 que o movimento surgiria com toda força, ganhando maior visibilidade e espaço no mainstream da arte. Isso explica, em parte, porque as doações Rockefeller ignoram totalmente esse movimento, privilegiando artistas trabalhando com a figuração, o expressionismo em suas várias modalidades, o surrealismo e mesmo com a pintura sócio-realista.

Neste ponto, é necessária uma ressalva à tese apresentada por Antonio Pedro Tota no seu estudo O amigo americano - Nelson Rockefeller e o Brasil (2014). O historiador propõe que as ações culturais de Nelson Rockefeller no Brasil tinham como objetivo a disseminação da abstração na arte de modo a valorizar os ideais norte-americanos de liberdade e democracia, em contraposição a um realismo apoiado pelo regime soviético. "Para Nelson a estética do abstracionismo era um indicativo de liberdade artística e, portanto, individual, só possível numa sociedade democrática, capitalista e saudável" (TOTA, 2014, p. 342). Essa é uma visão bastante repetida, mas que não leva em conta as características formais das obras efetivamente trazidas por Rockefeller ao Brasil. Em outro trecho, Tota afirma que "a difusão da pintura expressionista-abstrata, preferência da vanguarda norte-americana, era feita e subsidiada mais 
pela atuação de particulares do que pelo governo. Era 'tarefa' dos Whitney, dos Guggenheim, dos Rockefeller, ou daquilo que os russos chamavam de conspiradores de 'uoll estrit'." (TOTA, 2014, p 360). Citando um discurso de Nelson na inauguração de uma nova ala no Masp em 1950, Tota associa a imagem do americano a alguém que privilegia a arte abstrata por seus valores humanísticos. "Rejeitamos a presunção que a arte esteticamente inovadora possa de alguma maneira ser social e politicamente subversiva e, portanto, não norte-americana"211, disse Nelson na cerimônia do Masp.

Porém, o discurso político, por vezes, precisa ser colocado em perspectiva com os fatos. Ao contrário do que diz Tota, essa pesquisa mostrou que o Expressionismo Abstrato não era uma preferência absoluta do establishment no momento em que Nelson começou a atuar no Brasil. As doações de 1946 e 1950 não contém um exemplar sequer dos grandes nomes do Expressionismo Abstrato, e tampouco as exposições anteriores promovidas pelo Escritório do Coordenador de Assuntos Interamericanos (CIAA) destacam essa linha estética. Há, sim, exemplos de uma pintura figurativa de Everett Spruce, do surrealismo de Max Ernst, do expressionismo lírico de Marc Chagall e do sócio-realismo de cunho político como em Jacob Lawrence e Robert Gwathmey; contrapondo, portanto, a tese de que as ações culturais de Nelson Rockefeller no Brasil tinham o objetivo claro de divulgar a arte abstrata por meio da promoção de seus grandes ícones.

Nelson Rockefeller doaria obras do Expressionismo Abstrato para o Brasil apenas em uma circunstância, quando em 1952 dá ao MAM do Rio de Janeiro uma Composição de Robert Motherwell e uma pintura № 16 de Jackson Pollock para formar seu acervo inicial. Se as bienais de São Paulo incluem, de fato, "as grandes vedetes do expressionismo abstrato" -- entenda-se Pollock e Rothko -- como destaca Antonio Tota, as exposições terão também muitos exemplares de um tipo de arte norte-americana menos prestigiada pelos anais da história da arte e que deixam transparecer uma visão muito mais complexa e rica sobre o que era considerado vanguarda dos Estados Unidos em meados dos anos 1940 e início dos 1950.

\footnotetext{
${ }^{211}$ Nelson Rockefeller apud TOTA, 2014, p. 353.
} 
Outro ponto que permaneceu ignorado pela historiografia da arte é a relação entre as doações Rockefeller e o colecionismo brasileiro. Como as doações dialogam com o acervo do antigo MAM? De maneira geral, percebe-se que a maioria dos artistas contemplados na doação Rockefeller eram inusitados para o antigo MAM-SP e permaneceriam excluídos do acervo não fosse por essas doações. Os interesses de Ciccillo Matarazzo e Yolanda Penteado enquanto colecionadores não correspondiam, ao que parece, ao conjunto de artistas de Rockefeller. O museu não viria a ter outras obras desses artistas, exceto em casos muito específicos. O foco de Matarazzo e Yolanda seria, sobretudo, pelo Novecento italiano e por artistas franceses. As doações Rockefeller atuam, portanto, de maneira a complementar o acervo do antigo MAM-SP, com importantes nomes das vanguardas europeias que de outra forma estariam excluídos do museu -- Max Ernst, George Grosz e André Masson --, mas principalmente ao introduzir novos nomes da arte moderna norte-americana, com destaque para os gravuristas. Vale notar que, diferentemente da coleção montada por Matarazzo que se propunha a ser, verdadeiramente, um amplo panorama da arte italiana de meados do século $X X$; essa mesma intenção não se mostra evidente no processo de seleção das doações Rockefeller, que, até pelo seu porte diminuto, atuam mais como uma amostra pontual da arte moderna dos Estados Unidos.

Há algumas semelhanças pontuais entre as coleções Matarazzo e a Rockefeller que merecem atenção. Do total de 37 artistas das doações Rockefeller ${ }^{212}$, apenas cinco estão contemplados na coleção do MAC USP com mais de uma obra: Marc Chagall, Alexander Calder, Fernand Léger, Stanley William Hayter e Minna Citron. Em todos os casos em que isso ocorre, Ciccillo Matarazzo aparece como o outro doador. É pouco provável, contudo, que Matarazzo tenha sido sensibilizado a adquirir obras desses artistas em virtude de Rockefeller, uma vez que outros fenômenos do circuito da arte também justificariam essas aquisições. Por exemplo, ao passo que Rockefeller doa Yellow Plane [Plano amarelo ou Móbile amarelo, preto, vermelho e branco], de Alexander Calder, em 1946; Ciccillo adquire o ainda mais imponente Snow Flurry [Grande móbile branco] de 1948, ano em que o escultor teve sua primeira grande mostra no

${ }^{212}$ Foram contabilizados apenas os artistas cujas obras foram efetivamente doadas ao MAC USP, excluindo, portanto, obras enviadas ao MAM-RJ e perdidas no incêndio de 1978, assim como as duas gravuras de Worden Day e Misch Kohn, cujo paradeiro é desconhecido. 
Brasil e momento em que ganha notoriedade entre os principais colecionadores brasileiros. Snow Flurry [Grande móbile branco] foi exposto no MAM-SP em 1948 e provavelmente foi adquirido por Matarazzo neste contexto logo após sua grande estreia no Brasil. Da mesma forma, as duas águas-fortes de Stanley William Hayter -- Merou (1958) e Varèche (1958) -foram adquiridas por Ciccillo durante a V Bienal de São Paulo, quando o pavilhão britânico dedicou uma sala especial ao gravurista.

Quanto aos demais, sabe-se que o Autorretrato de Marc Chagall (1914) foi comprado por Ciccillo antes mesmo das primeiras correspondências com Rockefeller e O vaso azul (1948) de Fernand Léger foi um presente para Yolanda Penteado, fazendo parte do conjunto de 19 obras que ficaram como usufruto dela após o divórcio, tendo sido doadas ao MAC USP em 1963. É pouco provável, portanto, que as doações Rockefeller tenham estimulado o colecionismo dos artistas representados nas doações, especialmente dos artistas norteamericanos menos conhecidos na época e dos gravuristas vinculados ao Atelier 17. Ao menos, a relação com o núcleo histórico do antigo MAM-SP sugere pouco ou nenhum impacto das doações Rockefeller na política de colecionismo de Matarazzo e Yolanda.

Essa pesquisa não identificou oportunidades diretas para a entrada de certos artistas e galerias no mercado brasileiro em virtude das doações Rockefeller. Possivelmente, porque este não era o propósito das doações, tendo em vista o tamanho secundário do mercado de arte no Brasil naquele momento. Porém, isso não quer dizer que não havia um interesse dos atores norte-americanos em intermediar a venda de obras de arte para o Brasil, ainda que nenhuma documentação neste sentido seja associada às doações. As doações Rockefeller serviram muito mais como elementos de aproximação cultural com a elite brasileira, que possibilitaram a abertura de diálogo e as parcerias institucionais entre museus norte-americanos e brasileiros do que como estímulos para a instalação de galerias norte-americanas no Brasil.

O maior legado das doações parece ter sido de ordem política e institucional, pavimentando o caminho para a parceria entre o MAM-SP e o MoMA, assinada em 1948, com a presença de Nelson Rockefeller e de René d'Harnoncourt em São Paulo. Os estatutos da Fundação de Arte Moderna seriam modelados a partir da documentação enviada pelo MoMA, 
seguindo inclusive as sugestões de composição do conselho administrativo enviadas por Carleton Sprague Smith (BARROS, 2002), o que contribuiu para a realização de um dos objetivos da equipe de Nelson Rockefeller, que era tentar replicar o modelo institucional do museu de arte moderna nos países da América Latina.

As doações Rockefeller criaram laços políticos, culturais e institucionais que extrapolaram em muito o gesto da outorga das obras de arte. As obras trazidas aos Brasil ofereceram ao público -- de ontem e de hoje -- uma outra visão de arte moderna que foge das narrativas ortodoxas da história da arte. Só a partir de um acervo peculiar como o do MAC USP é possível propor uma revisão dessa história, mostrando uma série de nuances e complexidades esquecidas e ignoradas por um discurso já engessado sobre a formação dos museus brasileiros e as relações culturais entre o Brasil e o Estados Unidos no pós-guerra.

Há ainda muito espaço para novas pesquisas sobre as doações Nelson Rockefeller. De maneira alguma o tema se esgota com esse estudo. Novas documentações podem sempre vir a alterar e corrigir algumas das conclusões apresentadas aqui, como é inescapável em toda pesquisa. Um estudo ainda precisa ser realizado com uma visão mais ampla, que associe as doações realizadas ao Brasil às demais atividades de Nelson Rockefeller e do MoMA na América Latina. Ainda que o foco desta pesquisa tenha sido as doações brasileiras, sabe-se que Nelson Rockefeller olhava para os países latinoamericanos de uma maneira igualmente estratégica. Será que ele teria realizado outras doações semelhantes para países como Venezuela, para onde viajava com uma frequência muito maior do que o Brasil? Há Jacob Lawrences, Alexander Calders, Robert Gwathmeys e Minna Citrons espalhados em museus latinoamericanos com um contexto de doação semelhante ao do MAM-SP e MAM-RJ? Terá sido a doação ao Brasil um ato isolado ou uma ação repetida em outros locais? Uma pesquisa neste sentido, que pudesse contextualizar as ações culturais de Nelson Rockefeller no Brasil com atividades semelhantes na América Latina, poderia dar uma nova perspectiva para o conjunto do MAC USP, mostrando correspondências deste museu com outras instituições da América Latina, de modo a ajudar a melhor entender o perfil da nossa própria coleção. 
Quanto à coleção de gravuras, resta saber o impacto -- se houve -- da prática do Atelier 17 no circuito brasileiro? Havia intercâmbio ou correspondência entre os artistas gravitando entorno de Stanley William Hayter e os ateliês coletivos de gravura moderna que se instalaram no Rio de Janeiro, São Paulo e Belo Horizonte nos anos $1950 ?^{213}$ Compartilhavam da mesma filosofia de ensino e prática coletiva instaurada no Atelier 17? A investigação das novas fronteiras gráficas encabeçada por Hayter teve reverberação na prática nacional da gravura? A doação Rockefeller de 1950, e a posterior exposição no conjunto na sede do antigo MAM-SP em 1951, tiveram algum impacto nessa história? Uma evidência dessa aproximação é, por exemplo, a viagem de estudos Livio Abramo, que passou uma temporada no Atelier 17 em Paris em 1951 para aperfeiçoar a técnica da gravura em metal, em ocasião de ter vencido o prêmio de viagem ao exterior do Salão Nacional de Belas Artes. Outros artistas brasileiros que estudaram com Hayter incluem Geraldo de Barros e Tuni Murtinho ${ }^{214}$, nome artístico de Maria Antonieta Prado Uchôa, que vem a ser sobrinha do historiador Caio Prado Júnior e do pintor Carlos Prado.

Há, portanto, linhas de pesquisa que permanecem abertas e sugerem a necessidade de estudos adicionais a partir das doações Nelson Rockefeller no MAC USP, podendo vir a revelar uma nova visão sobre o lugar do Brasil no sistema internacional da arte moderna de meados do século XX.

\footnotetext{
${ }^{213}$ TÁVORA, Maria Luisa. A crítica e a gravura artística - Anos 50-60: entendimentos da experiência informal. Arte \& Ensaios. Revista do PPGAV-EBA-UFRJ. n.27. Dezembro 2013, e O Ateliê livre de gravura do MAM-Rio - 1959/ 1969. A pesquisa da professora Maria Luisa Tavora envolve a análise do ambiente da gravura moderna brasileira, sobretudo o processo de formação do Ateliê livre do MAM-Rio, à luz do intercâmbio da prática gráfica nacional com o ambiente artístico internacional, por meio do contato de artistas brasileiros e mestres da gravura na Europa, como, por exemplo, Johnny Friedlaender em Paris, personagem central na formação do estúdio de gravuras do museu carioca. Nessa mesma linha, é possível imaginar uma pesquisa que situe as trocas de experiências entre o grupo de Stanley William Hayter contemplado nas doações Rockefeller e gravuristas brasileiros que tiveram passagem pelo Atelier 17.

${ }^{214}$ Folha da Manhã. Entre todas as modalidades artísticas, é a gravura a que mais se assemelha à experiência científica (Entrevista com Livio Abramo), 19 de abril de 1953, p.7.
} 


\section{Bibliografia}

\section{Artigos de jornal}

Hóspede oficial do Brasil o Sr. Nelson Rockefeller.

O Globo, Rio de Janeiro, p. 3, 9 nov. 1946.

Retificação de uma incoerência.

O Globo, Rio de Janeiro, p. 3, 12 nov. 1946.

Seis séculos de pintura italiana numa exposição.

O Globo, Rio de Janeiro, p.1, 13 de nov. 1946.

Os Estados Unidos prosseguirão na política da Boa Vizinhança.

O Estado de s. Paulo, São Paulo, p. 14, 14 nov. 1946.

Amanhã, no Rio, o sr. Nelson Rockefeller.

O Globo, Rio de Janeiro, p. 4, 14 nov. 1946.

Chegou ao Rio o sr. Nelson Rockefeller.

Folha da noite, São Paulo, p. 1, 16 nov. 1946.

A missão do sr. Nelson Rockefeller.

O Globo, Rio de Janeiro, p. 2, 16 nov. 1946.

Declaração do sr. Nelson Rockefeller.

O Estado de s. Paulo, São Paulo, p. 48, 17 nov. 1946.

Cooperação entre norte-americanos e brasileiros para o fomento agrícola.

Folha da Manhã, São Paulo, p. 3, 19 nov. 1946. 
Uma sabatina com o ministro da Viação.

O Globo, Rio de Janeiro, p. 3, 19 nov. 1946.

Homenagem ao sr. Nelson Rockefeller.

O Globo, Rio de Janeiro, p. 4, 19 nov. 1946.

Solicitada a visita do sr. Nelson Rockefeller a Campinas.

Folha da noite, São Paulo, p. 3, 20 nov. 1946.

Visita do gen. Juin e do sr. Nelson Rockefeller às Casas do Congresso.

Folha da Manhã, São Paulo, p. 1, 20 nov. 1946.

Várias entidades convidarão o sr. Nelson Rockefeller a visitar Campinas.

Folha da Manhã, São Paulo, p. 6, 20 nov. 1946.

Para o primeiro Museu de Artes Modernas no Brasil.

O Globo, Rio de Janeiro, p. 3, 20 nov. 1946.

Honrando um grande amigo do Brasil.

O Globo, Rio de Janeiro, p. 5, 20 nov. 1946.

Apoio dos EUA aos planos agrícolas de nosso país.

Folha da Manhã, São Paulo, p. 1, 21 nov. 1946.

Chegará hoje às 11.30 o sr. Nelson Rockefeller.

Folha da noite, São Paulo, p. 2, 21 nov. 1946.

Chega hoje a São Paulo o sr. Nelson Rockefeller.

Folha da Manhã, São Paulo, p. 1, 21 nov. 1946.

Condecorado o sr. Nelson Rockefeller. 
Folha da Manhã, São Paulo, p. 2, 21 nov. 1946.

Sugestões para o início da mecanização dos serviços da lavoura.

O Estado de s. Paulo, São Paulo, 21 nov. 1946.

Visita do sr. Nelson Rockefeller ao Ministério da Educação.

O Globo, Rio de Janeiro, p. 9, 21 nov. 1946.

Rockefeller panamericanista.

O Estado de s. Paulo, São Paulo, p. 14, 22 nov. 1946.

Elevar o padrão de vida do povo é produzir gêneros a preços baixos.

Folha da noite, São Paulo, p. 1, 22 nov. 1946.

Plano a completar.

O Globo, Rio de Janeiro, p. 9, 22 nov. 1946.

Rockefeller, o republicano.

O Estado de s. Paulo, São Paulo, p. 18, 23 nov. 1946.

Bases para plano de organização de pequenas empresas agrícolas.

Folha da Manhã, São Paulo, p. 5, 23 nov. 1946.

Cogita-se da organização do museu de arte moderna em nossa capital.

Folha da Manhã, São Paulo, p. 5, 23 nov. 1946.

A estada do sr. Nelson Rockefeller em São Paulo.

O Estado de s. Paulo, São Paulo, p. 8, 23 nov. 1946.

Coquetel em homenagem ao casal Rockefeller.

Folha da Manhã, São Paulo, p. 6, 24 nov. 1946. 
Homenagem do cônsul Cecil Cross ao casal Rockefeller.

Folha da noite, São Paulo, p. 4, 25 nov. 1946.

Visitou a Escola de Enfermagem o sr. Nelson Rockefeller.

Folha da noite, São Paulo, p. 6, 26 nov. 1946.

Esteve em visita à cidade de Campinas o sr. Nelson Rockefeller.

Folha da noite, São Paulo, p. 2, 26 nov. 1946.

Repercussão nos Estados Unidos da viagem do sr. Nelson Rockefeller.

Folha da noite, São Paulo, p. 2, 26 nov. 1946.

Por via aérea regressou ao Rio o sr. Nelson Rockefeller.

Folha da Manhã, São Paulo, p. 4, 26 nov. 1946.

Contando o tempo de serviço dos que trabalham na Fundação Rockefeller.

O Globo, Rio de Janeiro, p. 7, 27 nov. 1946.

Instalação de Santos de grande fábrica de adubo azotado.

Folha da noite, São Paulo, p. X, 27 nov. 1946.

Grande obra social para os brasileiros.

O Globo, Rio de Janeiro, p. 2, 27 nov. 1946

A missão Rockefeller instalará no município de Campinas um posto de reprodutor.

Folha da Manhã, São Paulo, p. 4, 28 nov. 1946.

Duas mentalidades em relação ao Brasil.

O Globo, Rio de Janeiro, p. 3, 28 nov. 1946.

"Vim ao Brasil com a esperança de contribuir para o bem-estar deste país". 
Folha da Manhã, São Paulo, p. 3, 28 nov. 1946.

Não serão criados mais novos ministérios.

O Globo, Rio de Janeiro, p. 2, 279 nov. 1946.

Gravadores Norte-Americanos.

O Estado de s. Paulo, São Paulo, 6 mai. 1951. Caderno de Artes e Artistas, p.10.

O Museu de Arte Moderna.

O Estado de s. Paulo, p.6, 4 de mar. 1948.

Valiosa doação do Sr. Nelson Rockefeller.

O Estado de s. Paulo, p. 6, 24 dez. 1949.

Entrevistas

LANDON, Edward. Oral history interview with Edward Landon, 1975 Apr. 17-May 28, Archives of American Art, Smithsonian Institution.

LIEBERMAN, William. Entrevista com o curador realizada pelo Oral MoMA em 18 de dezembro de 1990, MoMA Archives.

MOY, Seong. Oral history interview with Seong Moy, 1971 Jan. 18-28, Archives of American Art, Smithsonian Institution.

OSVER, Arthur. Oral history interview with Karl Schrag. 1976, Jan 13-14, Archives of American Art, Smithsonian Institution.

SCHRAG, Karl. Oral history interview with Karl Schrag. 1970 Out. 14-20, Archives of American Art, Smithsonian Institution.

YUNKERS, Adja. Oral history interview with Adja Yunkers, 1969 Dec. 9, Archives of American Art, Smithsonian Institution. 


\section{Filmes}

Brazil at War. Um filme do Office of War Information produzido pelo Coordenador de Assuntos Inter-Americanos. Disponível: https://archive.org/details/Brazilat1943

\section{Artigos, catálogos de exposição, livros e teses}

ALMEIDA, Fernando de Azevedo de. O franciscano Ciccillo. São Paulo: Pioneira, 1976. AMARAL, Aracy (org.). Museu de Arte Contemporânea de São Paulo, perfil de um acervo. São Paulo: Technit, 1998.

Arte Para Que? A Preocupação Social na Arte Brasileira 1930- 1970. São Paulo:

Studio Nobel, 1984.

MAC - Uma seleção do acervo da cidade universitária. São Paulo: Museu de Arte da Universidade de São Paulo, 1983. 69p.

AMARANTE, Leonor. As Bienais de São Paulo, 1951-1987. São Paulo: Projeto, 1989. 408p. il.

ANTHONIOZ, Michel. Verve - The ultimate review of art and literature (1937-1960). Nova York: Harry N. Abrams, Inc., Publishers, 1988.

ARGAN, Giulio Carlo. Arte Moderna: Do Iluminismo aos movimentos contemporâneos. Tradução Denise Bottmann e Federico Carotti. São Paulo: Companhia das Letras, 1992.

AUSFELD, M.. L.; MECKLENBURG, V. Advancing American art: politics and aesthetic in the State Department Exhibition 1946-48. Montgomery: Montgomery Museum of Fine Arts, 1984. 108p. BATISTA, Marta Rossetti. Os Artistas Brasileiros na Escola de Paris - Anos 20. São Paulo: USP, 1987. Tese (Doutorado) Departamento de Artes Plásticas da Escola de Comunicações e Artes da Universidade de São Paulo, 1987.

BARR, Alfred. Fantastic Art, Dada, Surrealism. Washington: Arno Press. 1968. Modern Prints and the Museum em The Abby Rockefeller Print Room, Master Prints from the Collection, Museum of Modern Art Bulletin 16, no.4 (1949).

BARRON, Stephanie. Degenerate art: the fate of the Avante-Garde in Nazi Germany. Los Angeles and New York: Los Angeles County Museum of Art (LACMA) and Abrams, 1991. 
BARROS, Regina T. Revisão de uma história: a criação do Museu de Arte Moderna de São Paulo 1946-1949. Dissertação (Mestrado) - Departamento de Artes Plásticas da Escola de Comunicação e Artes da Universidade de São Paulo - ECA/USP. São Paulo, 2002.

(Org.) Fernand Léger: relações e amizades brasileiras. São Paulo: Pinacoteca do Estado de São Paulo: Imprensa Oficial do Estado de São Paulo, 2009. 108 p.

BARTELIK, Marek. To invent a garden: the life and art of Adja Yunkers. Nova York: Hudson Hills Press, 2000. 144p.

BECCARI, Vera D’Horta. Lasar Segall e o modernismo paulista. São Paulo: Editora Brasiliense, 1984.

BIVAR, Antonio. Yolanda. São Paulo: A Girafa Editora, 2004.

BURGRESS, Lana. Advancing American Art and its afterlife: from the State Department to the University Museum. Dissertação de doutorado no Departamento de História da Arte da Universidade da Flórida, 2010.

BLACK, P.;MOORHEAD, D. The prints of Stanley William Hayter: a complete catalogue. Londres: Phaidon Press, 2009. 400p.

CAHILL, Holger (Org,.) New Horizons in American Art. New York, Museum of Modem Art, 1936. http://www.artic.edu/sites/default/files/libraries/pubs/1937/AIC1937NewHrznAmArt comb.p df

CATÁLOGO I Bienal de São Paulo, Fundação Bienal: São Paulo, 1951.

CATÁLOGO III Bienal de São Paulo, Fundação Bienal: São Paulo, 1955.

CAUQUELIN, Anne. Arte contemporânea: uma introdução. São Paulo: Martins Fontes, 2005. (Coleção Todas as Artes).

. Teorias da Arte. São Paulo: Martins, 2005.

CAVALCANTI, Di. Realismo e Abstracionismo. Fundamentos, no 3. São Paulo, agosto de 1948.

CINCO EXPOSIÇÕES NORTE-AMERICANAS. São Paulo: Museu de Arte Contemporânea de São Paulo, 3 mar. 1977.

CIRCULATING EXHIBITIONS 1931-1954. The Bulletin of the Museum of Modern Art. Vol. 21, No. 3/4, Verão, 1954, pp. 3-30. Disponvível em: http://www.jstor.org/stable/4058235 
CHIARELLI, Tadeu (org.). MAM inventário: catálogo geral do acervo do Museu de Arte Moderna de São Paulo. São Paulo: Lemos, 2002. 338 p., il. p\&b.

CHAGALL, Marc. My life. Cambridge: Da Capo Press, 1994. 190p.

COHAN, William D. MoMA's Problematic Provenances em Art News, 17 nov. 2011. Disponível: http://www.artnews.com/2011/11/17/momasproblematic-provenances/

COCKFROFT, Eva. Abstract Expressionism, Weapon of the Cold War, Artforum, vo. 15, no.10, June 1974, pp.39-41.

COLE, S.; GOLDMAN, J. One hundred prints by 100 artists of the Art Students League of New York, 1875-1975. New York: The Art Students League of New York, 1975.

CONTEMPORARY PAINTING IN THE UNITED STATES. New York: Metropolitan Museum of Art, 19 a 17 de abril, 1941. Disponível:

://libmma.contentdm.oclc.org/cdm/singleitem/collection/p15324coll10/id/1156/rec/19

CONTRERAS, Belisario R. Tradition and innovation in the New Deal Art. Lewisburg: Bucknell University Press, 1984. 253 p.

COPPEL, Stephen. American prints: from Hopper to Pollock. Burlington: Lund Humphries, 2008. $272 p$.

COSTA, Helouise. A exposição como múltiplo: lições de uma mostra norte-americana em São

Paulo, 1947. Anais do Museu Paulista. São Paulo. N. sér. V. 22. N. 1. P.107-132. Jan-jun. 2014.

DEGAND, Léon. Do Figurativismo ao Abstracionismo, 1949.

DOSS, Erica. Catering to consumerism: Associated American Artists and the Marketing of Modern Art, 1934-1958. In Winterthur Portfolio, 1991, Inc. Vol 26, p. 145

EICHENBERG, Fritz. The art of the print: masterpieces, history, techniques. Nova York: Harry N. Adams, Inc., Publishers, 1976. 612p.

ERMAKOFF, George; NAYLOR, Genevieve, Genevieve Naylor: uma fotógrafa americana no Brasil - 1940-42. Editora Ermakoff, Rio de Janeiro, 2013.

FABRIS, Annateresa. “Um 'Fogo de palha aceso': considerações sobre o primeiro momento do Museu de Arte Moderna de São Paulo" In: cat. exp.

MAM 60. São Paulo: Museu de Arte Moderna de São Paulo, 2008, pp. 14-89.

FIRST PRINT ANNUAL EXHIBITION. Nova York: The Brooklyn Brooklyn Museum, 1947. 
FLAVEL, M.K. George Grosz: a biography. New Haven \& London: Yale University Press, 1998. $355 p$.

FRASER, VALERIE. Encounters in New York, Printmaking in Chile. In American Art, Vol. 26, No. 2 (Summer 2012), pp.28-33. Disponível em: http://www.jstor.org/stable/10.1086/667948 Acesso em: 06.10.2013.

GONÇALVES, Lisbeth R. Sérgio Milliet, crítico de arte. São Paulo: Perspectiva; Edusp, 1992.

GUILBAUT, Serge. How New York stole the idea of modern art abstract expressionism, freedom, and the cold war. Chicago; London; The University of Chicago, 1983.

Respingos na parada modernista: a invasão fracassada da arte abstrata no

Brasil, 1947-1948 em ARS Vol.9 (2011), n.18, pp. 148-173. Disponível: http://dx.doi.org/10.1590/S1678-53202011000200010

GREENBERG, Clement. Clement Greenberg: the collected essays and criticism. Volume I: perceptions and judgments 1939-1944. Ed. John O'Brian. Chicago and London: University of Chicago Press, 1986. 250p.

Clement Greenberg: the collected essays and criticism. Volume II: arrogant purpose 1945-1949. Ed. John O’Brian. Chicago and London: University of Chicago Press, 1986.

GRIEVE, Victoria. The Federal Art Project and the creation of middlebrow culture. Urbana and Chicago: University of Illinois, 2009. 230p.

HACKER, P. M. S. ed.: The Renaissance of Gravure: The Art of S. W. Hayter. Oxford: Oxford University Press, 1988. Disponível:

http://www.stanleywilliamhayter.com/anglais/biography.htm

HALLMARK, Kara Kelley. Encyclopedia of Asian American Artists - Artists of the American mosaic. Wesport: Greenwood Press, 2007.

HAYTER, S.W. New Ways of Gravure. Londres: Oxford University Press, 1966.

About Prints, 1962. London: Oxford University Press, 1962. 176p.

HARRIS, Jonathan. Federal Art And National Culture - The Politics of Identity in New Deal America. New York: Cambrigde University Press, 1995.

HARSHAV, B.; CHAGALL, M. Marc Chagall and his times: a documentary narrative. Stanford: Stanford University Press, 2004. 1035p. 
HOPKINS, David. Hermetical and Philosophical Themes in Max Ernst's Vox Angelica and Related Works em The Burlington Magazine. Vol. 134, No 1076 (Nov.,1992), pp. 716-723. Disponível em: http://www.jstor.org/discover/10.2307/885382

HOROWITZ, F.A.; DANILOWITZ, B. Joseph Albers: to open eyes: the Bauhaus, Black Mountain College, and Yale. New York: Phaidon Press, 2006. 288p.

JENTSCH, Ralph. George Grosz: the Berlin years. Milan: Electa, 1997. 216p. George Grosz: Berlin - New York. Milan: Skira Editore S.p.A, 2008. 287p. Reception of the American Grosz in JUDIN, Juerg (ed). George Grosz, The Years in America 1933-1958. Ostfildern: Hatje Cantz, 2009.

JOHNSON, Una. American prints and printmakers: a chronicle of over 400 artists and their prints from 1900 to the present. Nova York: Doubleday \& Company, Inc, Garden City, 1980. 266p.

Ten years of American prints, 1947-1956. New York: Brooklyn Museum, 1956. Disponível: http://hdl.handle.net/2027/uc1.32106001489126 - Acessado em 20.01.2014. Adja Yunkers: Prints, 1927-1967. New York: Brooklyn Museum, 1969. Louis Schaker prints, 1924-1971. New York: Brooklyn Museum, 1974. 58p. JUDIN, Juerg (ed). George Grosz, The Years in America 1933-1958. Ostfildern: Hatje Cantz, 2009. KANTOR, Sybil Gordon. Alfred H. Barr, Jr. and the Intellectual Origins of the Museum of Modern Art. Cambridge: The MIT Press, 2001.

KASS, Ray. Morris Graves: vision of the inner eye. Nova York: George Braziller, Inc., 1983. 176p. KENNEDY, R.G.; LARKIN D. When art worked: the New Deal, art, and democracy. New York: Rizolli, 2009. 368p.

KESTLER, Izabela Maria Furtado. Exílio e literatura: escritores brasileiros de fala alemã durante a época do nazismo. São Paulo: Edusp, 2003.

KOOTZ, Samuel New frontiers in American painting. Nova York: Hasting House Publishers, 1943. $65 p$.

Modern American painters. Nova York: Brewer \& Warren Inc., 1930. 124p.

KRAEFT, J.; KRAEFT, N. Armin Landeck - The Catalog Raisonée of His Prints. Bethlehem: June 1 Gallery, 1977. 115p. 
KRENN, Michael. Fall-out Shelters for the Human Spirit: American Art and the Cold War. The University of North Carolina Press: Chapell Hill, 2005.

LADER, MELVIN P. Peggy Guggenheim's Art of this Century: the Surrealist milieu and the American Avant-Garde, 1942-1947. Tese (Tese de doutorado em Filosofia em Historia da Arte Universidade de Delaware), 1981. 506p.

LANCHNER, Carolyn. Fernand Léger at The Museum of Modern Art. Nova York: The Museum of Modern Art, 1998.

LANDON, Edward. Serigraphy. Art Education , Vol. 17, No. 4 (Apr., 1964), pp. 18-20. Disponível em: http://www.jstor.org/stable/3190459 - Acesso em: 06. out. 2013.

LÉGER, Fernand. Nova York. in Funções da Pintura. São Paulo: Nobel, 1989.

LEVINE, Robert. The Brazilian Photographs of Genevieve Naylor, 1940-1942. Durham: Duke University Press, 1998, 144 p.

LÉVY, Sophie e DEROUET, Christian (ed). A Transatlantic Avant-Garde: American Artists in Paris, 1918-1939. Terra Foundation for the Arts, 2003.

LEWIS, Samella. African American Art and Artists. Berkeley California Press: Berkeley e Los Angeles, 2003.

LIEBERMAN, William. The Print Collection em The Bulletin of the Museum of Modern Art. Vol. 16, No. 4, The Abby Aldrich Rockefeller Print Room: Master Prints from the Museum Collection (1949), pp. 9-13. Disponível: http://www.jstor.org/stable/4058197

Twentieth-Century Art from the Nelson Aldrich Rockefeller Collection. Museum of Modern Art of New York: Nova York, 1969.

LIMA, Zueler. R. M. A. Nelson A. Rockefeller and Art Patronage in Brazil after World War II: Assis Chateaubriand, the Museu de Arte de São Paulo (MASP) and the Museu de Arte Moderna (MAM). Rockefeller Archive Center Research Reports Online. 2010.

LOURENÇO, Maria C. F. Museus acolhem moderno. São Paulo: Edusp, 1999. 293 p.

MAGALHÃES, Ana Gonçalves. Classicismo, Realismo, Vanguarda: Pintura Italiana no Entreguerras. São Paulo: MAC USP, 2013, p.11.

MALCOM, Gee. Art Criticism since 1900. Nova York: Manchester University Press, 1993. 245 p. 
MAUAD, Ana Maria. Genevieve Naylor, fotógrafa: impressões de viagem (Brasil, 1941- 1942) in Revista Brasileira de História. Vol. 25 no. 49, São Paulo jan-jun 2005. Disponível em: http://www.scielo.br/scielo.php?pid=S0102-01882005000100004\&script=sci arttext- Acessado em 07.11.2013.

MILLER, Dorothy C. Americans 1942: 18 artists from 9 states. Nova York: The Museum of Modern Art, 1942. 128p.

Fourteen americans. Nova York: The Museum of Modern Art, 1946. 80p.

MElOT, M.; GRIfFITHS, A.; FIELD, R.S.; BEgUIN, A. Prints. Nova York: Rizzoli International Publications, Inc., 1981. 280p.

MEYER, Richard. What was contemporary art? Cambridge and London: MIT Press, 2013. 376p. MOSER, Joann. The Impact of Stanley William Hayter on Post-War American Art: Archives of American Art Journal, Washington, v. 18, n. 1, pp. 2-11. 1978. Disponível em http://www.jstor.org/stable/1557211 - Acesso em: 04 ago. 2013.

MOTHERWELL, R.; REINHARDT, A. Modern art in America. New York: Wittenborn, Schultz, Inc., 1951. 200p.

NASCIMENTO, Ana Paula. MAM: Um museu para a metrópole. São Paulo: USP, 2003. Tese (Mestrado) Faculdade de Arquitetura e Urbanismo da Universidade de São Paulo, 2003. Disponível em: http://www.teses.usp.br/teses/disponiveis/16/16131/tde-12012005122318/pt-br.php - Acesso em: 11 abr. 2014.

NESBETT, P.; DUBOIS,M. Jacob Lawrence: paintings, drawings and murals (1935-1999): a catalogue raisonné. Seattle: University of Washington Press, 2000.

Over the line: the art and life of Jacob Lawrence. Seattle: University of Washington Press, 2000. 286p.

PAUL, April J. Byron Browne in the Thirties: The Battle for Abstract Art em Archives of American Art Journal, Vol. 19, No. 4. (1970), pp.9-24.

PEDROSA, Mário. Modernidade Cá e Lá: textos escolhidos IV Mário Pedrosa; Otília Arantes (Org.) - São Paulo: Edusp, 2000.

PETERDI, Gabor. Great prints of the world. New York: Macmillan, 1969. 277p. 
PIEHL, Charles. The Southern Social Art of Robert Gwathmey in Wisconsin Academy of Sciences, Art and Letters, Vol. 73. Disponível:

http://images.library.wisc.edu/WI/EFacs/transactions/WT1985/reference/wi.wt1985.ckpiehl.p df - Acesso em: 03. Jan. 2014.

POLLOCK, Lindsay. The girl with the gallery. Public Affairs, 2007. 504p.

RAND, Harry. Byron Browne: paintings \& drawings from the 30's, 40's and 50's. Roslyn: Nassau County Museum of Fine Art, 1987. 40p.

REICH, Cary. The Life of Nelson A. Rockefeller: worlds to conquer, 1909-1958. Doubleday: New York, 1996.

RELATÓRIO DO INTER-AMERICAN OFFICE - Jan.1944 - Maio 1946. National Gallery of Art. Disponível em: http://babel.hathitrust.org/cgi/pt?id=mdp.39015073812987;view=1up;seq=1

RUBIN, W. LANCHER, C. Andre Masson. Nova York: The Museum of Modern Art, 1976. 232p.

RUSSELL, John. Matisse: father and son. Harry N. Abrams, 2001. 415p.

$\mathrm{SAAB}$, Joan. For the millions: American art and culture between the wars. University of Pennsylvania Press, 2009. 240p.

SACHS, PAUL. Modern Prints \& Drawings. A guide to a better understanding of modern draughtsmanship. Nova York: Alfred A. Knopf, 1954, p. 209. Disponível: http://archive.org/stream/modernprintsdraw007948mbp/modernprintsdraw007948mbp djvu. txt - Acessado em 21. 01. 2014.

SARAIVA, Roberta (Org.) Calder no Brasil: crônica de uma amizade. São Paulo: Cosac Naify, 2006. 288 p.

SAPHIRE, Lawrence. Andre Masson the complete graphic work. Vol I: Surrealism, 1924-49. Nova York: Blue Moon Press, 1990. 519p.

SAUNDERS, Frances S. The Cultural Cold War: The CIA and the World of Arts and Letters. New Press: New York, 2000.

SCHMECKEBIER, Laurance. Boris Margo - Graphic Work (1932-1968). Syracuse: Syracuse University, 1968.

SECOND PRINT ANNUAL EXHIBITION. Nova York: The Brooklyn Brooklyn Museum, 1948. 
SEMERJIAN, Victor. Artists in Exile: The great flight of culture. Dissertação apresentada para o título de Mestre em Artes no Departamento de Belas-Artes da Universidade de York. The University of British Columbia, Set, 1990.

SHEPARD, John. The legacy of Carleton Sprague Smith: Pan-American Holding in the Music Division of the New York Public Library for the Performing Arts. New York: Music Library Association, Notes, Second Series, Vol. 62, No. 3 (Mar., 2006), pp. 621-662.

SIWI, Márcio. U.S- Brazil Relations during the Cold War: The Making of Modern Art Museums in São Paulo. Latin American Network Information Center, 2007.

SMITH, Richard Norton. On his own terms - a life of Nelson Rockefeller. Random House, 2014. 880 p.

SCHNEEDE, Uwe. The essential Max Ernst. Thames and Hudson, 1972. 216 p.

SOBY, J. T.; MILLER, D. Romantic painting in America. Nova York: The Museum of Modern Art, 1943. 144p.

STUBBE, Wolf. History of modern graphic art. Londres: Thames and Hudson, 1963. 318p.

SPINELLI, João. Sérgio Milliet, o idealizador de museus de arte moderna em Sérgio Milliet -100 anos: Trajetória, Crítica de Arte e Ação Cultural (org. Lisbeth Rebollo Gonçalves). São Paulo: Imprensa Oficial: ABCA, 2004. 248p.

SPIES, W.; MULLER-WESTERMANN, I.; DEGEL, K. Max Ernst: dream and revolution. Paris: Hatje Cantz, 2009. 256p.

SWEENEY, JAMES J. Marc Chagall. Nova York: Museu of Modern Art, 1946. 102p.

Eleven Europeans in America. he MoMA Art Bulletin v. 13, no 4-5, 1946, p.

3-6. Disponível:

http://www.jstor.org/discover/10.2307/4058114?uid=3737664\&uid=2134\&uid=4579975247\& $\underline{\text { uid }=4579975237 \& \text { uid }=2 \& \text { uid }=70 \& \text { uid }=3 \& \text { uid }=60 \& \text { sid }=21103393913777}$

TÁVORA, Maria Luisa. A crítica e a gravura artística - Anos 50-60: entendimentos da experiência informal. Arte \& Ensaios. Revista do PPGAV-EBA-UFRJ. n.27. Dezembro 2013.

THE FEDERAL ART PROJECT: American prints from the 1930's in the collection of the University of Michigan Museum of Art. Ann Arbor: The University of Michigan Museum of Art, 1985. 220p. THIRD PRINT ANNUAL EXHIBITION. Nova York: The Brooklyn Brooklyn Museum, 1949. 
TOTA, Antônio P. O imperialismo sedutor a americanização do Brasil na época da Segunda Guerra. São Paulo: Companhia das Letras, 2000.

WARD, Gerald (Ed.) The Grove Encyclopedia of Materials and Techniques in Art. New York: Oxford University Press, 2008.

WATERHOUSE, Max (ed.) George Grosz. Ecce Homo - Catalogue. Uppingham, Goldmark Gallery, 2013).

WELD, Jacqueline. Peggy: The Wayward Guggenheim. Nova York: E.P. Dutton, 1986.

WERNER, Alfred. Chagall: watercolors and gouaches. Nova York: Watson-Guptill Publications, 1970. 87p.

WECHSLER, James. Fred Becker and experimental printmaking. Print Quarterly, Vol. 10, No. 4 (Dezembro 1993), pp.373-384. Disponível em:http://www.jstor.org/stable/41825158 - Acesso em: 06. out. 2013.

WIGHT, F. S.; BAUR, J.I.H.; PHILLIPS, D. Morris Graves. Berkeley and Los Angeles: University California Press, 1956. 64p.

WEYL, Christina. Networks of Abstraction: Postwar printmaking and women artists of Atelier 17. Archives of American Art, 2014.

WYE, Deborah (org.). Artists \& Prints: Masterworks from the Museum of Modern Art. Nova York: The Museum of Modern Art, 2004. 288p

WOLF, Theodore. Morris Graves: An Appreciation in Morris Graves: vision of the inner eye. Nova York: George Braziller, Inc., 1983. 176p.

WULLSCHLAGER, Jackie. Chagall: a biography. Nova York: Alfred A. Knopf, 2008. 608p.

ZIGROSSER, Carl. The book of fie prints: an anthology of printed pictures and introduction to the study of graphic art in the West and the East. Nova York: Crown Publishers Inc., 1956. 499p. Six centuries of fie prints. New York: Garden City Publishing Co., Inc., 1939. Misch Kohn. New York: The American Federation of Arts, 1961. 53p. Introduction to Adja Yunkers: color woodcuts, monotypes. Philadelphia: Philadelphia Art Alliance, 1948. 


\section{Comunicados do MoMA à imprensa}

Artist exiled by nazis in 1932 given retrospective exhibition at Museum of Modern Art, 6 oct. 1941, Nova York. Disponível:

http://www.moma.org/momaorg/shared/pdfs/docs/press archives/740/releases/MOMA 194 $10077 \quad 1941-10-06 \quad 411006-76 . p d f ? 2010$

Brazilian Architecture heads new exhibition schedule for Museum of Modern Art, 4 jan. 1943, Nova York. Disponível:

http://www.moma.org/pdfs/docs/press archives/849/releases/MOMA 19430001 1943-0104 43104-1.pdf?2010 - Acessado em 07. 11.2013.

Brazilian government leads Western Hemisphere in encouraging modern architecture.

Exhibition of Brazilian Architecture opens at Museum of Modern Art, 12 jan. 1943. Nova York.

Disponível:

http://www.moma.org/pdfs/docs/press archives/850/releases/MOMA 19430002 1943-01-

12 43112-2.pdf?2010 - Acessado em 07. 11.2013.

For release Saturday afternoon or Sunday morning, September 28 or 29, 5 Disponível:

http://www.moma.org/momaorg/shared/pdfs/docs/press archives/255/releases/MOMA 193 4-35 0070 1935-09-23 35923-31.pdf?2010

Museum of Modern Art opens photography exhibition of Faces and Places in Brazil, 20 jan.

1943, Nova York. Disponível:

http://www.moma.org/pdfs/docs/press archives/854/releases/MOMA 19430006 1943-01-

25 43125-7.pdf?2010 - Acessado em 07. 11.2013.

Reorganization at Museum of Modern Art. Alfred H. Barr retires as director, 28 out. 1943.

Disponível:

http://www.moma.org/pdfs/docs/press archives/906/releases/MOMA 19430058 1943-10-

27 431027-55.pdf?2010 - Acessado em 07. 11.2013. 
224 new acquisitions make Museum of Modern Art Collection of Modern Latin American Art most important in world, 16 fev. 1943. Disponível:

http://www.moma.org/pdfs/docs/press archives/868/releases/MOMA 19430020 1940-0209 40029-20.pdf?2010 - Acessado em 08. 11.2013.

Modern Painters of Brazil, 1943. Coleção Circulating Exhibitions Records, Series II, Folder, I. 90.8.1. MoMA Archives.

Museum of Modern Art announces new exhibition schedule and continuation of Latin American exhibition to June 6, 21 abr. 1943. Disponível:

http://www.moma.org/pdfs/docs/press archives/870/releases/MOMA 19430022 1943-0421 43421-22.pdf?2010 -Acessado em 08. 11.2013.

Museum of Modern Art to open exhibition of gravure tecniques. 16 jun. 1944. Disponível : http://www.moma.org/pdfs/docs/press archives/949/releases/MOMA 19440035 1944-0616 44616-27.pdf?2010 - Acessado em 24.01.2014.

Museum of Modern Art opens retrospective exhibition of works of Marc Chagall. 08 abr. 1946. Disponível: http://www.moma.org/pdfs/docs/press archives/1047/releases/MOMA 194619470030 1946-04-08 46408-18.pdf?2010 - Acessado em 24.01.2014.

Master Prints, an exhibition of 230 American and European prints, to commemorate opening of Abby Aldrich Rockefeller Print room at museum. 06 mai. 1949. Disponível:

http://www.moma.org/pdfs/docs/press archives/1324/releases/MOMA 19490038 1949-0506 490506-36.pdf?2010 - Acessado em 24. 01.2014.

Comunicado à imprensa sobre exposição Modern Painters of Brazil. Coleção Circulating Exhibition. Série II, Folder I. 82. 2. Arquivo MoMA.

Press-release Museum of Modern Art, New York, sep. 1946. 
Press-release Museum of Modern Art, New York, 20 nov. 1940.

40 recent prints from 30 American artists acquired and shown by the Museum for the first time.

Press-release Museum of Modern Art, New York, 1951.

The Abby Rockefeller Print Room 1949-1958. Museum of Modern Art Bulletin. New York, 1958. Hayter and Atelier 17. Museum of Modern Art Bulletin. New York, v. 12, n.1. 1944.

\section{Documentação}

Documentação referente às obras doadas por Nelson Rockefeller em 1946 e 1950 para o antigo MAM - Coleções Nelson Rockefeller.

\section{> CARTAS E TELEGRAMAS}

ALVES, [Carlos Pinto]. (carta) 02 de fevereiro de 1948, São Paulo [para] SMITH, [Carleton Sprague], Nova York. 1f. Documento pertencente ao Arquivo Histórico Wanda Svevo da Fundação Bienal de São Paulo.

ALVES, [Carlos Pinto]. (carta) 02 de fevereiro de 1948, São Paulo [para] ROCKEFELLER, [Nelson], Nova York. 1f. Documento pertencente ao Arquivo Histórico Wanda Svevo da Fundação Bienal de São Paulo.

ANDRADE, [Rodrigo]. (carta) 04 de janeiro de 1947, Rio de Janeiro [para] SMITH, [Carleton Sprague], Nova York. 2f. Documento pertencente ao Rockefeller Archive Center. Coleção Nelson A. Rockefeller, Grupo: Museus, Série III 4 L, Caixa 148, Pasta 1467. 
Carta do MAM-SP, 23 de setembro de 1949, São Paulo [para] diretor da Biblioteca Municipal de São Paulo, São Paulo. 1f. Documento pertencente ao Arquivo do Museu de Arte Contemporânea da Universidade de São Paulo, pasta Doações Nelson Rockefeller.

Carta não assinada, 13 de novembro de 1946, Nova York [para] ROCKEFELLER, [Nelson], Nova York. 15f. Documento pertencente ao Rockefeller Archive Center. Coleção Nelson A. Rockefeller. Grupo: Museus, Série III 4 L, Caixa 148, Pasta 1964.

CLARK, [Stephen]. (carta) 15 de outubro de 1943, Nova York [para] BARR, [Alfred], Nova York. 3f. Documento pertencente ao Rockefeller Archive Center. Coleção Abby Aldrich Rockefeller. Grupo 2, Série I, Caixa 9, Pasta 118.

D'HARNONCOURT, [René]. (carta) 2 de abril de 1945, Nova York [para] CLARK, [Stephen], Nova York. 1f. Documento pertencente ao Arquivo do MoMA. Coleção René d’Harnoncourt, Série II, Pasta 28.

D'HARNONCOURT, [René]. (carta) 16 de maio de 1951, Nova York [para] ROCKEFELLER, [Nelson], Nova York. 1f. Documento pertencente ao Rockefeller Archive Center. Coleção Nelson A. Rockefeller. Grupo: Museus, Série III 4L, Caixa 148, Pasta 1470.

LEVI, [Rino] (carta) 16 de maio de 1949, São Paulo [para] SMITH, [Carleton Sprague]. Cópia de documento pertencente ao Acervo do Museu de Arte Contemporânea da Universidade de São Paulo. Pasta Doações Rockefeller.

LYTLE, [Dorohy L.] (carta) 28 de junho de 1950, Nova York [para] BOYER, Nova York. 2 f. Documento pertencente ao Rockefeller Archive Center. Coleção Nelson A. Rockefeller. Grupo: Museus, Série III 4L, Caixa 148, Pasta 1470. 
LYTLE, [Dorohy L.]. (carta) 29 de junho de 1950, Nova York [para] JAMIESON, [Francis A.], Nova York. 12f. Documento pertencente ao Rockefeller Archive Center. Coleção Nelson A. Rockefeller. Grupo: Museus, Série III 4L, Caixa 148, Pasta 1470.

MELLO, [Eduardo Kneese]. (carta) 26 de dezembro de 1946, São Paulo [para] SMITH, [Carleton Sprague], Nova York. 1f. Documento pertencente ao Rockefeller Archive Center. Coleção Nelson A. Rockefeller. Grupo: Museus, Série III 4L, Caixa 148, Pasta 1467.

MELLO, [Eduardo Kneese]. (carta) 26 de dezembro de 1949, São Paulo [para] ROCKEFELLER, [Nelson], Nova York. 1f. Documento pertencente ao Rockefeller Archive Center. Coleção Nelson A. Rockefeller. Grupo: Museus, Série III 4L, Caixa 148, Pasta 1470.

MUSEU DE ARTE MODERNA DE SÃO PAULO. (Carta) 23 de setembro de 1949, São Paulo [para] BIBLIOTECA MUNICIPAL DE SÃO PAULO, São Paulo. Documento pertencente ao Acervo do Museu de Arte Contemporânea da Universidade de São Paulo.

MINDLIN, [Henrique]. (carta) 15 de março de 1945, Rio de Janeiro [para] D'HARNONCOURT, [Renée], Nova York. 1f. Documento pertencente ao Arquivo do MoMA. Coleção René D’Harnoncourt. Séries II. Folder 7.

ROCKEFELLER, [Abby]. (carta) 17 de novembro de 1943, Nova York [para] CLARK, [Stephen], Nova York. 1f. Documento pertencente ao Rockefeller Archive Center. Grupo 2, Series I, Caixa 9, Pasta 118. Coleção Abby Aldrich Rockefeller Papers.

ROCKEFELLER, [Nelson A.]. (carta) 24 de dezembro de 1945, Nova York [para] VARGAS, [Getúlio], Rio de Janeiro. 1f. Documento pertencente ao Rockefeller Archive Center. Coleção Nelson A. Rockefeller. 
ROCKEFELLER, [Nelson A.]. (carta) 11 de novembro de 1946, Nova York [para] BEALS, [Ralph], Nova York. 1f. Documento pertencente ao Rockefeller Archive Center. Coleção Nelson A. Rockefeller. Grupo: Museus. Série III 4L, Box 148, Folder 1964.

ROCKEFELLER, [Nelson A.]. (telegrama) 23 de novembro de 1946, São Paulo [para] BARR, [Alfred], Nova York. 1f. Documento pertencente ao Arquivo do MoMA. Coleção Alfred H. Barr, Jr. Papers. Correspondence - Nelson Rockefeller. Série de microfilmes: AHB [AAA: 1.192: 1594].

ROCKEFELLER, [Nelson].. (carta) 25 de novembro de 1946, São Paulo [para] MILLIET, [Sérgio], Nova York. 1f. Apud AMARAL (1990, p. 13).

ROCKEFELLER, [Nelson A.]. (esboço de carta) 2 de junho de 1949, Nova York [para] MILLIET, [Sérgio], São Paulo. 1f.Documento pertencente ao Rockefeller Archive Center. Coleção Nelson A. Rockefeller. Grupo: Museus. Série III 4L, Box 148, Folder 1970.

ROCKEFELLER, [Nelson A.]. (carta) 23 de junho de 1949, Nova York [para] SOBRINHO, [Francisco Matarazzo], São Paulo. 1f. Documento pertencente ao Rockefeller Archive Center. Coleção Nelson A. Rockefeller. Grupo: Museus. Série III 4L, Box 148, Folder 1967.

ROCKEFELLER, [Nelson A.]. (carta) 23 de junho de 1949, Nova York [para] MELLO, [Eduardo Kneese], São Paulo. 1f. Documento pertencente ao Rockefeller Archive Center. Coleção Nelson A. Rockefeller. Grupo: Museus. Série III 4L, Box 148, Folder 1970.

ROCKEFELLER, [Nelson A.]. (carta) 23 de junho de 1949, Nova York [para] MILLIET, [Sérgio], São Paulo. 1f. Documento pertencente ao Rockefeller Archive Center. Coleção Nelson A. Rockefeller. Grupo: Museus. Série III 4L, Box 148, Folder 1970.

ROCKEFELLER, [Nelson A.]. (carta) 21 de dezembro de 1949, Nova York [para] SOBRINHO, [Francisco Matarazzo], São Paulo. 1f. Documento pertencente ao Rockefeller Archive Center. Coleção Nelson A. Rockefeller. Grupo: Museus. Série III 4L, Box 148, Folder 1970. 
SMITH, [Carleton Sprague]. (carta) 28 de novembro de 1946, São Paulo [para] MELLO, [Eduardo Kneese], São Paulo. 2f. Documento pertencente ao Arquivo do Museu de Arte Contemporânea da Universidade de São Paulo. Pasta Doações Nelson Rockefeller.

SMITH, [Carleton Sprague]. (carta) 30 de novembro de 1946, São Paulo [para] MILLIET, [Sérgio], São Paulo. 1f. Documento pertencente ao Arquivo Histórico da Biblioteca Mário de Andrade SMC/PMSP

SMITH, [Carleton Sprague]. (carta) 26 de dezembro de 1946, Nova York [para] MELLO, [Eduardo Kneese], São Paulo. 1f. Documento pertencente ao Rockefeller Archive Center. Coleção Nelson A. Rockefeller. Grupo: Museus. Série III 4L, Box 148, Folder 1467.

SMITH, [Carleton Sprague]. (carta) 30 de janeiro de 1947, São Paulo [para] ALVES, [Carlos Pinto], São Paulo. 1f. Documento pertencente ao arquivo da Biblioteca Paulo Mendes de Almeida/Centro de Estudos Luis Martins do MAM.

SMITH, [Carleton Sprague]. (carta) 23 de julho de 1947, São Paulo [para] ALVES, [Carlos Pinto], São Paulo. 1f. Documento pertencente ao Arquivo Histórico Wanda Svevo da Fundação Bienal de São Paulo.

SMITH, [Carleton Sprague]. (carta) 06 de novembro de 1947, Nova York [para] ROCKEFELLER, [Nelson], Nova York. 1f. Documento pertencente ao Rockefeller Archive Center. Coleção Nelson A. Rockefeller. Grupo: Museus. Série III 4L, Box 148, Folder 1467.

SMITH, [Carleton Sprague]. (carta) 01 de março de 1948, São Paulo [para] ROCKEFELLER, [Nelson], Nova York. 1f. Documento pertencente ao Rockefeller Archive Center. Folder 1464, Box 148, RG 4, NAR Personal Documents, Museums, Rockefeller Family Archives. 
SMITH, [Carleton Sprague]. (carta) 07 de fevereiro de 1949, Nova York [para] ROCKEFELLER, [Nelson], Nova York. 1f. Documento pertencente ao Rockefeller Archive Center. Coleção Nelson A. Rockefeller. Grupo: Museus. Série III 4L, Box 148, Folder 1465.

SMITH, [Carleton Sprague]. (carta) 3 de junho de 1949, Nova York [para] LEVI [Rino], São Paulo. 1f. Documento pertencente ao Acervo do Museu de Arte Contemporânea da Universidade de São Paulo.

SOBRINHO, [Francisco Matarazzo]. (carta) 30 de janeiro de 1948, São Paulo [para] ROCKEFELLER, [Nelson], Nova York. 1f. Documento pertencente ao Arquivo Histórico Wanda Svevo da Fundação Bienal de São Paulo.

SOBRINHO, [Francisco Matarazzo]. (carta) 16 de novembro de 1948, São Paulo [para] ROCKEFELLER, [Nelson], Nova York. 1f. Documento pertencente ao Rockefeller Archive Center. Coleção Nelson A. Rockefeller. Grupo: Museus. Série III 4L, Box 148, Folder 1467.

SOBRINHO, [Francisco Matarazzo]. (carta) 16 de maio de 1949, São Paulo [para] ROCKEFELLER, [Nelson], Nova York. 1f. Documento pertencente ao Rockefeller Archive Center. Coleção Nelson A. Rockefeller. Grupo: Museus. Série III 4L, Box 148, Folder 1467.

SOBRINHO, [Francisco Matarazzo]. (carta) 07 de dezembro 1949, São Paulo [para] ROCKEFELER, [Nelson], Nova York. 1f. Documento pertencente ao Rockefeller Archive Center. Coleção Nelson A. Rockefeller. Grupo: Museus. Série III 4L, Box 148, Folder 1470.

SOBRINHO, [Francisco Matarazzo]. (carta) 08 de dezembro 1949, São Paulo [para] MELLO, [Eduardo Kneese], São Paulo. 1f. Documento pertencente ao Rockefeller Archive Center. Coleção Nelson A. Rockefeller. Grupo: Museus. Série III 4L, Box 148, Folder 1470. 
SOBRINHO, [Francisco Matarazzo]. (carta) 9 de abril de 1951, São Paulo [para] ROCKEFELLER, [Nelson], Nova York. 1f. Documento pertencente ao Acervo do Museu de Arte Contemporânea da Universidade de São Paulo.

> RELATÓRIOS, FOTOS E DOCUMENTOS DO ARQUIVO DO MUSEU DE ARTE MODERNA DE NOVA YORK E DO ROCKEFELLER ARCHIVE CENTER

Catálogo da exposição Gravadores Norte-Americanos, Museu de Arte Moderna de São Paulo, 10 de abril a 06 de maio de 1951. [documento impresso em cores]

Documento pertencente ao Rockefeller Archive Center. Coleção Nelson A. Rockefeller. Grupo: Museus. Série III 4L, Box 148, Folder 1470.

FOTOGRAFIA E CATÁLOGO DA EXPOSIÇÃO GRAVADORES NORTEAMERICANOS no MAM. Documentação pertencente ao Rockefeller Archive Center. Grupo: Museus, Série III 4L, Caixa 148, Pasta 1470.

Relatório sobre a Exposição de Pintura Norte-americana, 1941. 4f. [documento datilografado] Documento pertencente ao Arquivo do MoMA. Coleção Departamento de Circulação de Exposições, Série II. Pasta I. 56.6.

Lista de compra das 14 obras intitulada "Paintings for Brasil". 1f. [documento datilografado] Documento pertencente ao Arquivo do MoMA. Coleção Alfred H. Barr, Jr. Papers. Série de microfilmes: AHB. 2176 F-60.

Lista de Pinturas de 10 Repúblicas Latino-americanas,1943-1944. [documento datilografado] Documento pertencente ao Arquivo do MoMA. Coleção Departamento de Circulação de Exposições. Series II, Pasta, I. 90.8.1 - I. 90.8.2. 
D'HARNONCOURT, [René]. (relatório da viagem para a América Latina Dec. 27, 1944 a 23 de Mar, 1945), (inserir data), Nova York [para] BOARD OF TRUSTEES, Nova York. $3 f$.

[documento datilografado] Documento pertencente ao Arquivo do MoMA. Coleção René d’Harnoncourt. Série II. Pasta 28.

Possible outline of things to do in Brazil for The Museum of Modern Art, 1944. [documento datilografado] Documento pertencente ao Arquivo do MoMA. Coleção René d'Harnoncourt, Série II, Pasta 28.

MoMA's Attendance Report for September, 1943. [documento datilografado] Documento pertencente ao Rockefeller Archive Center. Coleção Aldrich Rockefeller. Grupo 2, Série I, Caixa 9, Pasta 118.

Relatório do Programa das Artes do CIAA, 1943. [documento datilografado] Documento pertencente ao Arquivo do MoMA. Coleção RDH. Series II. Folder 26. 